\title{
Surfactant Based Enhanced Oil Recovery and Foam Mobility Control
}

\author{
Semi Annual Technical Report \\ Reporting Period Start Date: July 2004 \\ Reporting Period End Date: June 2005 \\ Principal Authors: \\ George J. Hirasaki, Rice University \\ Clarence A. Miller, Rice University \\ Gary A. Pope, The University of Texas \\ Date Report was Issued: July 2005
}

\section{DE-FC26-03NT15406}

Rice University Department of Chemical Engineering, MS-362 6100 Main Street Houston, TX 77005-1892

The University of Texas Department of Petroleum Engineering P.O. Box 7726 Austin, TX 78713-7726

INTERA, Inc. 9111A Research Blvd. Austin, TX 78758 


\section{DISCLAIMER}

This report was prepared as an account of work sponsored by an agency of the United States Government. Neither the United States Government nor any agency thereof, nor any of their employees, make any warranty, expressed or implied, or assumes any legal liability or responsibility for the accuracy, completeness, or usefulness of any information, apparatus, product, or process disclosed, or represents that its use would not infringe privately owned rights. References herein to any specific commercial product, process, or service by trade name, trademark, manufacturer, or otherwise does not necessarily constitute or imply its endorsement, recommendation, or favoring by the United States Government or any agency thereof. The views and opinions of authors expressed herein do not necessarily state or reflect those of the United States Government or and agency thereof. 


\section{ABSTRACT}

Surfactant flooding has the potential to significantly increase recovery over that of conventional waterflooding. The availability of a large number of surfactant structures makes it possible to conduct a systematic study of the relation between surfactant structure and its efficacy for oil recovery. A combination of two surfactants was found to be particularly effective for application in carbonate formations at low temperature. A formulation has been designed for a particular field application.

The addition of an alkali such as sodium carbonate makes possible in situ generation of surfactant and significant reduction of surfactant adsorption. In addition to reduction of interfacial tension to ultra-low values, surfactants and alkali can be designed to alter wettability to enhance oil recovery. The design of the process to maximize the region of ultra-low IFT is more challenging since the ratio of soap to synthetic surfactant is a parameter in the conditions for optimal salinity. Compositional simulation of the displacement process demonstrates the interdependence of the various components for oil recovery.

An alkaline surfactant process is designed to enhance spontaneous imbibition in fractured, oil-wet, carbonate formations. It is able to recover oil from dolomite core samples from which there was no oil recovery when placed in formation brine.

Mobility control is essential for surfactant EOR. Foam is evaluated to improve the sweep efficiency of surfactant injected into fractured reservoirs.

UTCHEM is a reservoir simulator specially designed for surfactant EOR. It has been modified to represent the effects of a change in wettability. Simulated case studies demonstrate the effects of wettability. 


\section{TABLE OF CONTENTS}

ABSTRACT

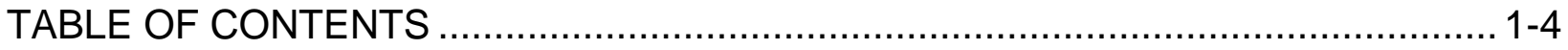

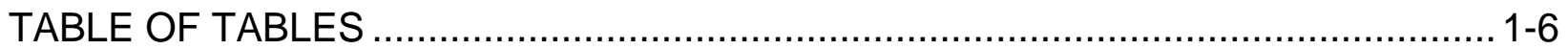

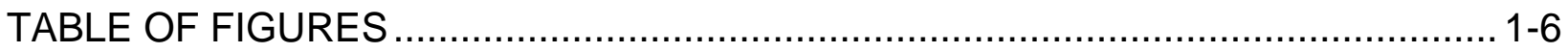

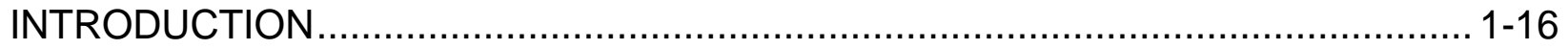

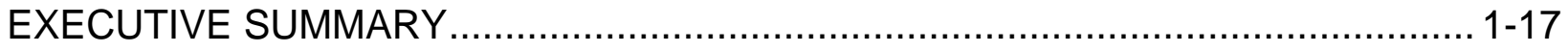

Task 1 Improved surfactants and formulations................................................ 1-19

Subtask 1.1 Identifying and synthesizing improved, cost-effective surfactants1-19

1.1.1 Surfactant Screening using Phase Behavior Experiments .......... 1-21

1.1.2 Results and Discussion for Subtask 1.1.............................. 1-21

Subtask 1.2. Surfactant Tailoring for Crude Oils and Phase Behavior ........... 1-24

1.2.1 Results of Phase Behavior Experiments ................................ 1-25

Effects of Electrolyte Concentration ………….................... 1-28

Effects of Sodium Carbonate ............................................ 1-30

Effects of sec-Butyl Alcohol (SBA) ..................................... 1-32

1.2.2 Results of Polymer Testing ................................................ 1-33

1.2.3 Results of Experiments to Characterize Rock Cores ................. 1-36

Berea core preparation ................................................ 1-36

Dolomite core testing and preparation ............................... 1-36

Air permeability tests ...................................................... 1-36

High Resolution X-ray Computed Tomography (HRXCT) scans 1-37

Conservative tracer tests ................................................. 1-39

Polymer retention and degradation ...................................... 1-40

Surfactant adsorption .................................................... 1-42

1.2.4 Results of Core Flood Experiments to Evaluate Oil Recovery ... 1-42

Midland Farms Core Flood \#1 …....................................... 1-45

Midland Farms Core Flood \#2 ........................................... 1-46

Task 2 Phase behavior, adsorption, and composition changes during displacement .. 2-1

Subtask 2.1 Surfactant Adsorption ....................................................... 2-1

Surfactant propagation velocity with adsorption.................................. 2-1

Alkali consumption on carbonate formation ..................................... 2-3

Potential determining ions for surfactant adsorption ............................ 2-4

Surfactant aggregates' size ....................................................... 2-5

Surfactant adsorption on porous media with different surface area ........ 2-6

Adsorption isotherms for NEODOL-67-7PO:IOS (4:1) and threshold of

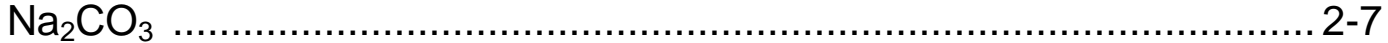

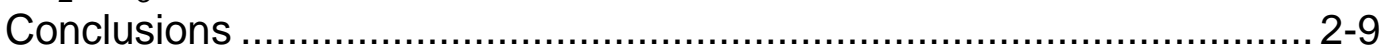

Subtask 2.2 Composition route for alkali-surfactant flooding ......................... 2-9

Assumptions and Models ........................................................ 2-10 


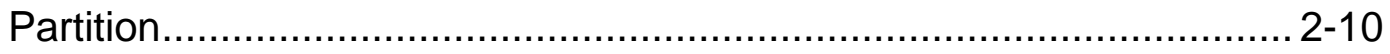

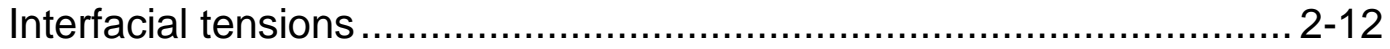

Aqueous Phase Viscosity ......................................................... 2-14

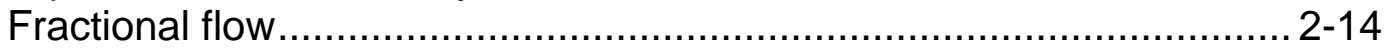

Surfactant Adsorption ............................................................. 2-15

Equations and calculation procedure ........................................ 2-16

Calculation example .................................................................. 2-17

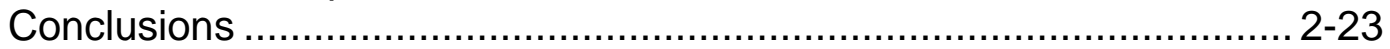

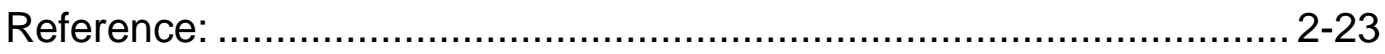

Subtask 2.5 Surfactant-enhanced spontaneous imbibition experiments ......... 2-24

Surfactant Identification .......................................................... 2-24

Problems with the TC Blend .................................................... 2-25

N67-3PO S and Blends............................................................ 2-26

N67-7PO Sulfate and Blends.................................................. 2-28

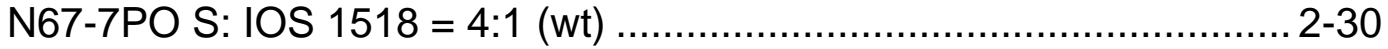

Adsorption................................................................................. 2-31

Phase Behavior and IFT ....................................................... 2-31

Oil recovery by centrifuge imbibition ............................................. 2-33

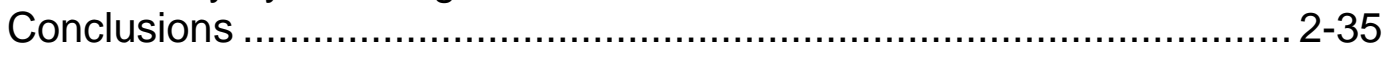

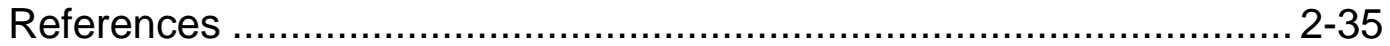

Task 3 Foam for Mobility Control ...................................................................... 3-1

3.1 Foam diversion in fracture network model ........................................... 3-1

Experimental technique ............................................................. 3-1

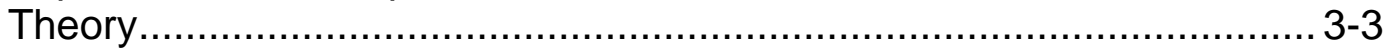

Apparent viscosity ..................................................................... 3-3

Experimental results ............................................................. 3-5

Conclusions ........................................................................... 3-11

3.2 Test of surfactant's ability in generating foam ..................................... 3-12

Task 4: Simulation of Field-Scale Processes .......................................................... 4-1

Subtask 4.2: Wettability alterations in naturally fractured reservoirs............... 4-1

Effect of Wettability on Residual Oil Saturation, Relative Permeability, and

Capillary Desaturation Curves ....................................................... 4-1

Simulations with Differing Wettability ........................................... 4-2

Case \#1: Strongly water-wet....................................................... 4-3

Case \#2: Neutral-wet ...................................................................... 4-4

Case \#3: Neutral-wet with a different CDC ..................................... 4-5

Case \#4: Oil-wet .................................................................. 4-6

Discussion ............................................................................. 4-6

Computing the Relative Permeability Curves as a Function of Wettability4-8

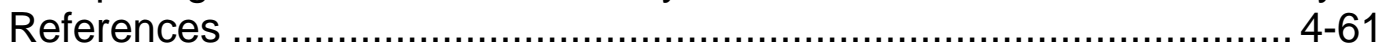




\section{TABLE OF TABLES}

Table 1.1-1. Surfactants Tested in Year 2 ..................................................... 1-20

Table 1.2-1. Formulations Screened with Midland Farms Crude Oil at $38^{\circ} \mathrm{C}$............ 1-26

Table 1.2-2. Formulations Screened with Elk Hills Crude Oil, $100^{\circ} \mathrm{C}$....................... 1-27

Table 1.2-3. Effects of SBA and Sodium Carbonate on Phase Behavior .................. 1-33

Table 1.2-4. Summary of MF Core Permeability ................................................ 1-37

Table 1.2-5. Summary of Outcrop Dolomite Rock Permeability ............................. 1-37

Table 1.2-6. Sulfate Measured in Produced Formation Brine.................................... 1-47

Table 1.2-7. Summary of Core Floods ............................................................ 1-50

Table 2.2-1 Operating Parameters for the example ........................................... 2-17

Table 2.2-2 Other major parameters for the example ........................................ 2-17

Table 2.5-1 Surfactant and co-surfactant identification ........................................... 2-24

Table 2.5-2 Bond number at 6,000 RPM, Perm=6 md ...................................... 2-33

Table 2.5-3 Core properties, experimental conditions and results .......................... 2-35

Table 4.2.1a. Reservoir Properties and Simulated Well Conditions ......................... 4-11

Table 4.2.1b. Fluid Properties ...................................................................... 4-11

Table 4.2.2. Input Parameters for Each Test Case ........................................... 4-11

Table 4.2.3. Summary of Literature Search to Obtain Trapping Parameter Data....... 4-12

\section{TABLE OF FIGURES}

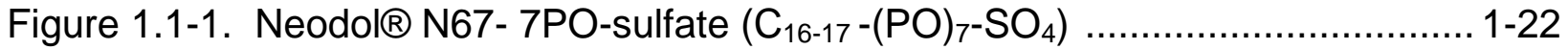

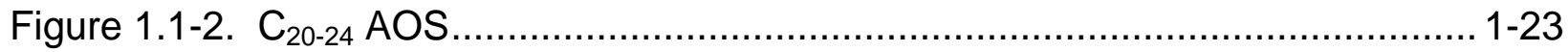

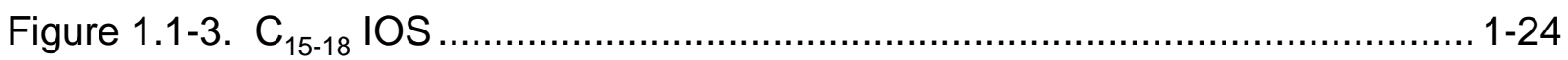

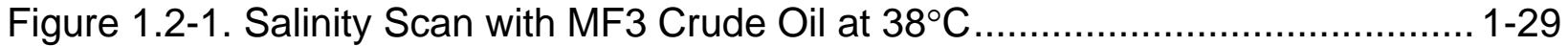

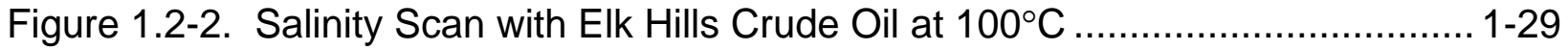

Figure 1.2-3. Effect of Sodium Carbonate on MF3 Crude Oil at a WOR $1: 1$ and $38^{\circ} \mathrm{C}$ using a mixture of $0.75 \%$ N67-(PO) $)_{7}-\mathrm{SO}_{4}, 0.25 \% \mathrm{C}_{15-18} \mathrm{IOS}, 2 \% \mathrm{SBA} \ldots \ldots \ldots \ldots .1-30$

Figure 1.2-4. Effect of Sodium Carbonate on Optimal Salinity with ELK Crude, WOR 1:1

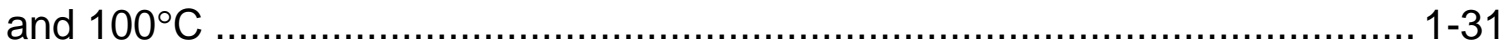

Figure 1.2-5. Effect of Sodium Carbonate on Equilibration Time with Elk Hills Crude, WOR 1:1, $100^{\circ} \mathrm{C}, 2 \% \mathrm{C}_{20-24} \mathrm{AOS}, 4 \%$ SBA ……................................... 1-32

Figure 1.2-6. Viscosity of HPAM Polymer (Flopaam 3330S) in Brine ....................... 1-34

Figure 1.2-7. Viscosity for HPAM Polymer (Flopaam 3330S) in Brine....................... 1-35

Figure 1.2-8. Viscosity for HPAM Polymer (Flopaam 3330S) in Brine...................... 1-35 
Figure 1.2-9. CT Scans of MF54 Dolomite Core ................................................. 1-38

Figure 1.2-10. CT Scans of MF11 Dolomite Core ............................................. 1-39

Figure 1.2-11. IPA Tracer Breakthrough Curve ............................................. 1-40

Figure 1.2-12. Viscosity for HPAM polymer Injectate and Effluent ......................... 1-41

Figure 1.2-13. Pressure Drop for HPAM Injection Test ...................................... 1-41

Figure 1.2-14. Surfactant Recovery and Concentration Curves ............................ 1-42

Figure 1.2-15. Pressure Drop for Berea Core \#3 with MF2 Crude .......................... 1-44

Figure 1.2-16. Oil Recovery in Berea Core \#3 with MF2 Crude ............................. 1-45

Figure 1.2-17. XRD Data from Crushed MFU Well \#629 Rock Sample .................... 1-47

Figure 1.2-18. Oil Recovery for MF Core \#2 with MF3 Crude Oil ........................... 1-48

Figure 1.2-19. Pressure Drop Data for MF Core \#2 ….................................... 1-49

Figure 2.1-1 Relationships between effluent retardation and Langmuir parameters .... 2-2

Figure 2.1-2 Relationships between retardation and $\mathrm{CaSO}_{4}$ fraction in porous medium

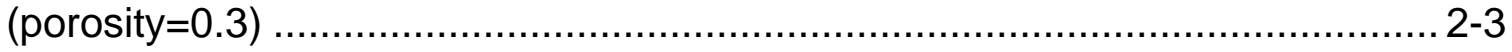

Figure 2.1-3 Adsorption on powdered dolomite of blended surfactant with different potential determining ion ............................................................................ 2-4

Figure 2.1-4 Particle size distribution of Stepan TDA-4PO ...................................... 2-5

Figure 2.1-5 Relationship between appearance of scatter beam and dominant peak

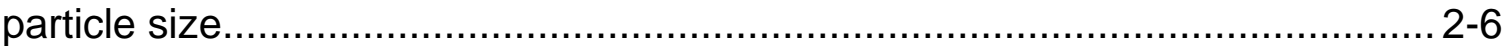

Figure 2.1-6 Adsorption of CS330: TDA-4PO (1:1) on dolomite with different surface

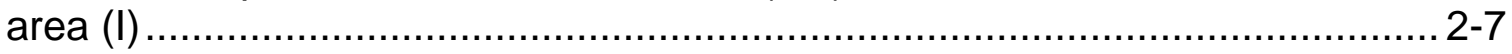

Figure 2.1-7 Adsorption of CS330: TDA-4PO (1:1) on dolomite with different surface

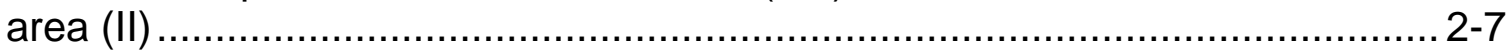

Figure 2.1-8 Adsorption on powdered calcite of N67:IOS (1:1) with different $\mathrm{Na}_{2} \mathrm{CO}_{3}$

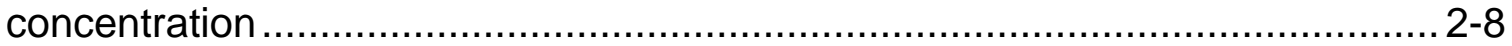

Figure 2.1-9 Test of threshold concentration of $\mathrm{Na}_{2} \mathrm{CO}_{3}$ for the adsorption ................ 2-9

Figure 2.2-1 Optimal Salinity vs. Soap-Synthetic Surfactant Ratio Curve for N67:IOS

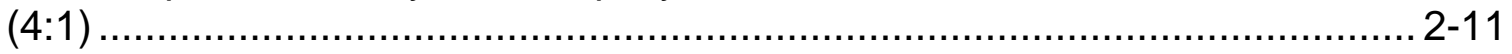

Figure 2.2-2 Contour of Average Partition Coefficient $\left(\log _{10}\left(K_{\text {aver }}\right)\right) \ldots \ldots \ldots \ldots \ldots \ldots \ldots \ldots . . . . . . .12$

Figure 2.2-3 Contour of interfacial tension $\left(\log _{10}(\mathrm{IFT})\right)($ IFT: dyne $/ \mathrm{cm}) \ldots \ldots \ldots \ldots \ldots \ldots \ldots . . . . .13$

Figure 2.2-4 IFT (dyne/cm) vs Salinity for Soap Surfactant Ratio $=1 \ldots \ldots \ldots \ldots \ldots \ldots \ldots . . . .2-13$

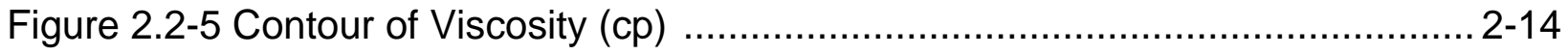

Figure 2.2-6 fractional flow changes with saturation at different IFT

(Aqueous phase viscosity = Oleic phase viscosity) .................................... 2-15

Figure 2.2-7 Profiles of surfactant and soap at 0.5PV ........................................ 2-18 
Figure 2.2-8 Profiles of IFT and soap-synthetic surfactant ratio at 0.5PV 2-18

Figure2.2-9 Profile of oil saturation at 0.5PV

Figure 2.2-10 Effluent History of Synthetic surfactant and Soap ............................. 2-19

Figure 2.2-11 Effluent History of Oil .......................................................... 2-20

Figure 2.2-12 Oil recoveries vs. injecting brine salinities (no soap, 1800ppm polymer)2-21

Figure 2.2-13 Oil recoveries vs. injecting brine salinities (with soap, 1800ppm polymer)2-21

Figure 2.2-14 Oil recoveries vs. injecting brine salinities (no soap, 2500ppm polymer)2-22

Figure 2.2-15 Oil recoveries vs. injecting brine salinities (with soap, 2500ppm polymer)2-22

Fig 2.5-1 Dependence of optimal salinity on soap/synthetic surfactant ratio ............. 2-25

Fig 2.5-2 TC Blend surfactant forms viscous emulsions.................................... 2-25

Fig. 2.5-3 Optimal salinity of N67-3PO S / 1\% $\mathrm{Na}_{2} \mathrm{CO}_{3} / \quad \mathrm{x} \% \mathrm{NaCl} \ldots \ldots \ldots \ldots \ldots \ldots . . . . . . . . .2-26$

Fig 2.5-4 IFT and viscosity of 3\% N67-3PO S / 1\%AOS C2024 / 8\%SBA / 1\% $\mathrm{Na}_{2} \mathrm{CO}_{3}$

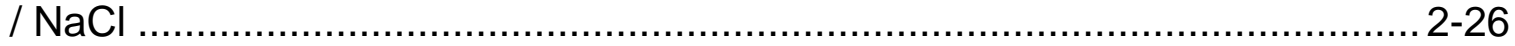

Fig 2.5-5 Solubility parameters of 3\% N67-3PO S and N67-7PO S, with n-C10 at

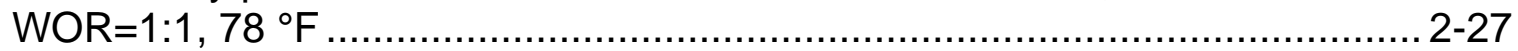

Fig 2.5-6 Phase behavior of 3\% N67-7PO S with $1 \% \mathrm{Na}_{2} \mathrm{CO}_{3}$ as a function of $\mathrm{NaCl}$ concentration.

Fig 2.5-7 Phase behavior of 3\% N67-7PO S / 8\% secondary butyl alcohol, with 1\% $\mathrm{Na}_{2} \mathrm{CO}_{3}$ as a function of $\mathrm{NaCl}$ concentration.

2-28

Fig 2.5-8 Salinity of phase separation increases when N67-7PO S and IOS 1518 are blended compared with used alone.

Fig 2.5-9 Optimal salinity of 3\% total surfactant at different N67-7PO S and IOS 1518 ratio. 2-29

Fig 2.5-10 Phase behavior of 2.4\% N67-7PO S / 0.6\% IOS 1518 with $1 \% \mathrm{Na}_{2} \mathrm{CO}_{3}$ as a function of $\mathrm{NaCl}$ concentration..... 2-30

Fig 2.5-11 Soap/Synthetic Surfactant Mole Ratio Correlation ............................... 2-30

Fig 2.5-12 Adsorption of NI Blend on calcite powder .......................................... 2-31

Fig 2.5-13 Phase Behavior of 0.05\% NI Blend / 1\% $\mathrm{Na}_{2} \mathrm{CO}_{3} / \mathrm{x} \% \mathrm{NaCl}$................. 2-32

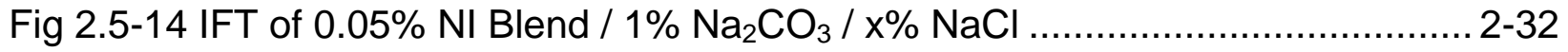

Fig 2.5-15 Schematic set-up of centrifuge imbibition with formation brine of surfactant solution. 2-33

Fig 2.5-16 Correlation between residual oil saturation and Bond number. 2-34

Fig 2.5-17 Phase behavior of $0.2 \% \mathrm{NI}$ Blend $/ 1 \% \mathrm{Na}_{2} \mathrm{CO}_{3} / \mathrm{x} \% \mathrm{NaCl}$ at WOR $=1$ and 32-34

Fig 2.5-18 Oil Recovery by centrifuge imbibition in either formation brine (water flooding) or $0.2 \% \mathrm{NI}$ Blend / $1 \% \mathrm{Na}_{2} \mathrm{CO}_{3} / \mathrm{x} \% \mathrm{NaCl}$. 2-35 
Fig. 3.1-1. Detailed diagram of heterogeneous fracture model 3-1

Fig. 3.1-2. Set -up diagram for foam mobility control experiment in fracture model..... 3-2

Fig. 3.1-3. Mechanism of affecting apparent viscosity in fracture system 3-3

Fig. 3.1-4. Apparent viscosity for fracture ratio of $0.05 \mathrm{~mm} / 0.15 \mathrm{~mm}$, bubble size $=0.4$

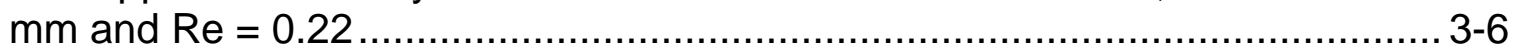

Fig. 3.1-5. Apparent viscosity for fracture ratio of $0.1 \mathrm{~mm} / 0.2 \mathrm{~mm}$, bubble size $=0.4 \mathrm{~mm}$

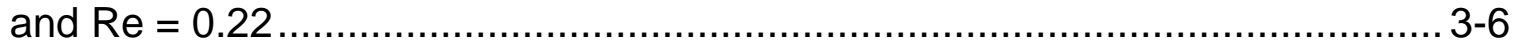

Fig. 3.1-6. Apparent viscosity for fracture ratio of $0.1 \mathrm{~mm} / 0.2 \mathrm{~mm}$, bubble size $=0.4 \mathrm{~mm}$ and $\mathrm{Re}=0.44$

Fig. 3.1-7. Apparent viscosity for fracture ratio of $0.1 \mathrm{~mm} / 0.2 \mathrm{~mm}$, bubble size $=0.6 \mathrm{~mm}$ and $\mathrm{Re}=0.22 \mathrm{Fig}$. 3.1-8. Surfactant solution sweeping heterogeneous fracture,

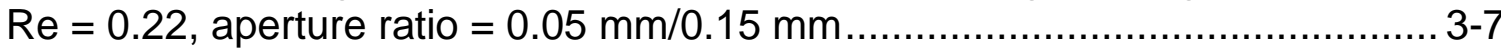

Fig. 3.1-8. Surfactant solution sweeping heterogeneous fracture, $\operatorname{Re}=0.22$, aperture

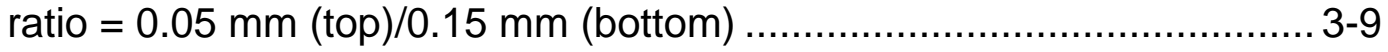

Fig. 3.1-9. Foam/surfactant solution sweeping heterogeneous fracture, $R e=0.22, f_{g}=$

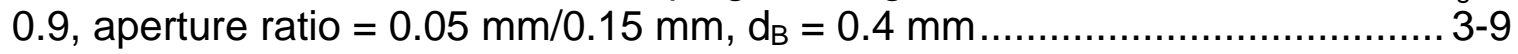

Fig. 3.1-10. Comparison between the calculation and the experiment results for foam/surfactant sweep in heterogeneous fractures with 1:3 aperture ratio ..... 3-11

Fig. 3.2-1. Set -up diagram for foam strength test ........................................... 3-12

Fig. 3.2-2 Foam strength at different surfactant composition ................................ 3-13

Fig. 3.2-3 Foam strength at different surfactant composition and salinity ................. 3-13

Figure 4.2.1. Effect of Amott-Harvey Wettability Index on Residual Oil Saturation in Berea Sandstone .............................................................................. 4-13

Figure 4.2.2. Effect of Wettability on Oil/Water Relative Permeability Curves (Morrow et. al. 1973)

Figure 4.2.3. Example Water/Oil CDC for a Water Wet Berea Sandstone (Amaefule, 1982)

Figure 4.2.4. Effect of Wettability on the CDC for a Berea Sandstone (Mohanty, 1983)

Figure 4.2.5. Effect of Wettability on the CDC for Three Weakly Oil-Wet to Neutral-Wet Carbonate Rocks 4-15

Figure 4.2.6. Permeability Field (md) Used in All Test Simulations .......................... 4-16

Figure 4.2.7. Relative Permeability Curves used in the Test Simulations ................. 4-16

Figure 4.2.8. Water and Oil CDC for Case \#1 .................................................. 4-17

Figure 4.2.9. Water and Oil CDC for Case \#2 ................................................ 4-17 
Figure 4.2.10. Water and Oil CDC for Case \#3 ............................................ 4-18

Figure 4.2.11. Water and Oil CDC for Case \#4 .............................................. 4-18

Figure 4.2.12. Capillary Pressure Curves for Each Test Simulation......................... 4-19

Figure 4.2.13. Waterflood - Cumulative Oil Recovery for Each Test Simulation........ 4-19

Figure 4.2.14. Waterflood - Average Reservoir Pressure for Each Test Simulation .. 4-20

Figure 4.2.15. - Waterflood - Water Production Rate for Each Test Simulation ........ 4-20

Figure 4.2.16. Waterflood - Oil Production Rate for Each Test Simulation ............... 4-21

Figure 4.2.17. Hypothetical 1-D Fractional Flow Curves for Case \#1....................... 4-21

Figure 4.2.18. Hypothetical 1-D Fractional Flow Curves for Cases \#2 and \#3 ........... 4-22

Figure 4.2.19. Hypothetical 1-D Fractional Flow Curves for Case \#4 ....................... 4-22

Figure 4.2.20. S/P Flood - Incremental Waterflood Oil Recovery for Each Test

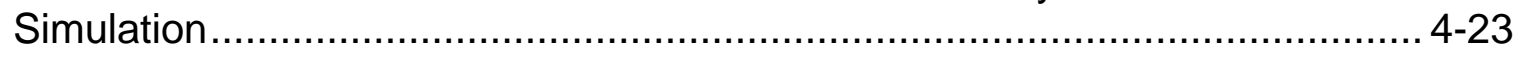

Figure 4.2.21. S/P Flood - Average Reservoir Pressure for Each Test Simulation .... 4-24

Figure 4.2.22. S/P Flood - Water Production Rate for Each Test Simulation ............. 4-24

Figure 4.2.23. S/P Flood - Oil Production Rate for Each Test Simulation .................. 4-25

Figure 4.2.24. Oil Saturation at 0.2 PV of Waterflood (Case \#1) ............................. 4-26

Figure 4.2.25. Oil Saturation at 0.9 PV of Waterflood (Case \#1) ............................. 4-26

Figure 4.2.26. Pressure at 0.2 PV of Waterflood (Case \#1) ..................................... 4-26

Figure 4.2.27. Pressure at 0.9 PV of Waterflood (Case \#1) ................................... 4-26

Figure 4.2.28. Oil Sat. in Layer 3 at 0.2 PV of Waterflood (Case \#1) ....................... 4-27

Figure 4.2.29. Oil Sat. in Layer 3 at $0.9 \mathrm{PV}$ of Waterflood (Case \#1) ....................... 4-27

Figure 4.2.30. Pressure in Layer 3 at $0.2 \mathrm{PV}$ of Waterflood (Case \#1) ..................... 4-27

Figure 4.2.31. Pressure in Layer 3 at $0.9 \mathrm{PV}$ of Waterflood (Case \#1) ..................... 4-27

Figure 4.2.32. Oil Sat. at 0.25 PV of Chemical Flood (Case \#1) .............................. 4-28

Figure 4.2.33. Oil Sat. at 0.75 PV of Chemical Flood (Case \#1) ............................ 4-28

Figure 4.2.34. Oil Sat. at 2.25 PV of Chemical Flood (Case \#1) ............................ 4-28

Figure 4.2.35. Pressure at $0.25 \mathrm{PV}$ of Chemical Flood (Case \#1) ............................ 4-28

Figure 4.2.36. Pressure at $0.75 \mathrm{PV}$ of Chemical Flood (Case \#1) ........................... 4-28

Figure 4.2.37. Pressure at $2.25 \mathrm{PV}$ of Chemical Flood (Case \#1) ........................... 4-28

Figure 4.2.38. Oil Sat. at 0.25 PV of Chemical Flood (Case \#1) .............................. 4-29

Figure 4.2.39. Oil Sat. at 0.75 PV of Chemical Flood (Case \#1) ............................. 4-29

Figure 4.2.40. Oil Sat. at 2.25 PV of Chemical Flood (Case \#1) ............................ 4-29

Figure 4.2.41. Pressure at 0.25 PV of Chemical Flood (Case \#1) .......................... 4-29 
Figure 4.2.42. Pressure at 0.75 PV of Chemical Flood (Case \#1) .......................... 4-29

Figure 4.2.43. Pressure at 2.25 PV of Chemical Flood (Case \#1) ........................... 4-29

Figure 4.2.44. ME Sat. at 0.25 PV of Chem. Flood (Case \#1 ................................ 4-30

Figure 4.2.45. ME Sat. at 0.75 PV of Chem. Flood (Case \#1) ............................... 4-30

Figure 4.2.46. ME Sat. at 2.25 PV of Chem. Flood (Case \#1) ............................... 4-30

Figure 4.2.47. Poly Conc. (wt.\%) at 0.25 PV of Chemical Flood (Case \#1)............... 4-30

Figure 4.2.48. Poly Conc. (wt.\%) at 0.75 PV of Chemical Flood (Case \#1)............... 4-30

Figure 4.2.49. Poly Conc. (wt.\%) at 2.25 PV of Chemical Flood (Case \#1)............... 4-30

Figure 4.2.50. ME Sat. at 0.25 PV of Chem. Flood (Case \#1) ............................... 4-31

Figure 4.2.51. ME Sat. at $0.75 \mathrm{PV}$ of Chem. Flood (Case \#1) ............................... 4-31

Figure 4.2.52. ME Sat. at 2.25 PV of Chem. Flood (Case \#1) ............................... 4-31

Figure 4.2.53. Poly Conc. (wt.\%) at 0.25 PV of Chemical Flood (Case \#1)............... 4-31

Figure 4.2.54. Poly Conc. (wt.\%) at 0.75 PV of Chemical Flood (Case \#1)............... 4-31

Figure 4.2.55. Poly Conc. (wt.\%) at 2.25 PV of Chemical Flood (Case \#1)............... 4-31

Figure 4.2.56. Surf. Conc. (vol. frac.) at 0.25 PV of Chem. Flood (Case \#1) ............. 4-32

Figure 4.2.57. Surf. Conc. (vol. frac.) at 0.75 PV of Chem. Flood (Case \#1) ............. 4-32

Figure 4.2.58. Surf. Conc. (vol. frac.) at 2.25 PV of Chem. Flood (Case \#1) ............. 4-32

Figure 4.2.59. IFT $(\log ($ dynes $/ \mathrm{cm}))$ at $0.25 \mathrm{PV}$ of Chem. Flood (Case \#1) ................ 4-32

Figure 4.2.60. IFT (log(dynes/cm)) at 0.75 PV of Chem. Flood (Case \#1) ................ 4-32

Figure 4.2.61. IFT $(\log ($ dynes $/ \mathrm{cm}))$ at $2.25 \mathrm{PV}$ of Chem. Flood (Case \#1) ................ 4-32

Figure 4.2.62. Surf. Conc. (vol. frac.) at $0.25 \mathrm{PV}$ of Chem. Flood (Case \#1)............. 4-33

Figure 4.2.63. Surf. Conc. (vol. frac.) at $0.75 \mathrm{PV}$ of Chem. Flood (Case \#1) ............. 4-33

Figure 4.2.64. Surf. Conc. (vol. frac.) at 2.25 PV of Chem. Flood (Case \#1) ............. 4-33

Figure 4.2.65. IFT $(\log ($ dynes $/ \mathrm{cm}))$ at $0.25 \mathrm{PV}$ of Chem. Flood (Case \#1) ................ 4-33

Figure 4.2.66. IFT (log(dynes/cm)) at $0.75 \mathrm{PV}$ of Chem. Flood (Case \#1) ................ 4-33

Figure 4.2.67. IFT $(\log ($ dynes/cm) $)$ at $2.25 \mathrm{PV}$ of Chem. Flood (Case \#1) ................ 4-33

Figure 4.2.68. Oil Saturation at 1.0 PV of Waterflood (Cases \#2,3) ........................ 4-34

Figure 4.2.69. Oil Saturation at 3.5 PV of Waterflood (Cases \#2,3) ........................ 4-34

Figure 4.2.70. Pressure at 1.0 PV of Waterflood (Cases \#2,3) .............................. 4-34

Figure 4.2.71. Pressure at 3.5 PV of Waterflood (Cases \#2,3) ................................ 4-34

Figure 4.2.72. Oil Sat. in Layer 3 at 1.0 PV of Waterflood (Cases \#2,3) .................. 4-35

Figure 4.2.73. Oil Sat. in Layer 3 at 3.5 PV of Waterflood (Cases \#2,3) .................. 4-35

Figure 4.2.74. Pressure in Layer 3 at 1.0 PV of Waterflood (Cases \#2,3) ................. 4-35 
Figure 4.2.75. Pressure in Layer 3 at 3.5 PV of Waterflood (Cases \#2,3) ................ 4-35

Figure 4.2.76. Oil Sat. at 0.25 PV of Chemical Flood (Case \#2) ............................ 4-36

Figure 4.2.77. Oil Sat. at 0.75 PV of Chemical Flood (Case \#2) ............................ 4-36

Figure 4.2.78. Oil Sat. at 2.25 PV of Chemical Flood (Case \#2) ............................. 4-36

Figure 4.2.79. Pressure at 0.25 PV of Chemical Flood (Case \#2)............................ 4-36

Figure 4.2.80. Pressure at 0.75 PV of Chemical Flood (Case \#2)........................... 4-36

Figure 4.2.81. Pressure at 2.25 PV of Chemical Flood (Case \#2)........................... 4-36

Figure 4.2.82. Oil Sat. at 0.25 PV of Chemical Flood (Case \#2) ............................ 4-37

Figure 4.2.83. Oil Sat. at 0.75 PV of Chemical Flood (Case \#2) ............................. 4-37

Figure 4.2.84. Oil Sat. at 2.25 PV of Chemical Flood (Case \#2) ............................ 4-37

Figure 4.2.85. Pressure at 0.25 PV of Chemical Flood (Case \#2) ........................... 4-37

Figure 4.2.86. Pressure at 0.75 PV of Chemical Flood (Case \#2)............................ 4-37

Figure 4.2.87. Pressure at 2.25 PV of Chemical Flood (Case \# 2)........................... 4-37

Figure 4.2.88. ME Sat. at 0.25 PV of Chem. Flood (Case \#2) ............................. 4-38

Figure 4.2.89. ME Sat. at $0.75 \mathrm{PV}$ of Chem. Flood (Case \#2) ............................... 4-38

Figure 4.2.90. ME Sat. at 2.25 PV of Chem. Flood (Case \#2) .............................. 4-38

Figure 4.2.91. Poly Conc. (wt.\%) at 0.25 PV of Chemical Flood (Case \#2)............... 4-38

Figure 4.2.92. Poly Conc. (wt.\%) at 0.75 PV of Chemical Flood (Case \#2)............... 4-38

Figure 4.2.93. Poly Conc. (wt.\%) at 2.25 PV of Chemical Flood (Case \#2)............... 4-38

Figure 4.2.94. ME Sat. at 0.25 PV of Chem. Flood (Case \#2) ............................... 4-39

Figure 4.2.95. ME Sat. at $0.75 \mathrm{PV}$ of Chem. Flood (Case \#2) ............................... 4-39

Figure 4.2.96. ME Sat. at 2.25 PV of Chem. Flood (Case \#2) ............................... 4-39

Figure 4.2.97. Poly Conc. (wt.\%) at 0.25 PV of Chemical Flood (Case \#2)............... 4-39

Figure 4.2.98. Poly Conc. (wt.\%) at 0.75 PV of Chemical Flood (Case \#2)............... 4-39

Figure 4.2.99. Poly Conc. (wt.\%) at 2.25 PV of Chemical Flood (Case \#2)............... 4-39

Figure 4.2.100. Surf. Conc. (vol. frac.) at 0.25 PV of Chem Flood (Case \#2) ............ 4-40

Figure 4.2.101. Surf. Conc. (vol. frac.) at 0.75 PV of Chem Flood (Case \#2) ............ 4-40

Figure 4.2.102. Surf. Conc. (vol. frac.) at 2.25 PV of Chem Flood (Case \#2) ............ 4-40

Figure 4.2.103. IFT $(\log ($ dynes/cm) $)$ at 0.25 PV of Chem Flood (Case \#2) ............... 4-40

Figure 4.2.104. IFT $(\log ($ dynes/cm) $)$ at 0.75 PV of Chem Flood (Case \#2) ............... 4-40

Figure 4.2.105. IFT (log(dynes/cm)) at 2.25 PV of Cheml Flood (Case \#2) ............... 4-40

Figure 4.2.106. Surf. Conc. (vol. frac.) at $0.25 \mathrm{PV}$ of Chem Flood (Case \#2) ............ 4-41

Figure 4.2.107. Surf. Conc. (vol. frac.) at 0.75 PV of Chem Flood (Case \#2) ............ 4-41 
Figure 4.2.108. Surf. Conc. (vol. frac.) at 2.25 PV of Chem Flood (Case \#2) ............ 4-41

Figure 4.2.109. IFT $(\log ($ dynes $/ \mathrm{cm}))$ at $0.25 \mathrm{PV}$ of Chem Flood (Case \#2) ................ 4-41

Figure 4.2.110. IFT $(\log ($ dynes $/ \mathrm{cm}))$ at 0.75 PV of Chem Flood (Case \#2) ................ 4-41

Figure 4.2.111. IFT $(\log ($ dynes $/ \mathrm{cm}))$ at 2.25 PV of Chem Flood (Case \#2) ................ 4-41

Figure 4.2.112. Oil Sat. at 0.25 PV of Chemical Flood (Case \#3) .......................... 4-42

Figure 4.2.113. Oil Sat. at 0.75 PV of Chemical Flood (Case \#3) ........................... 4-42

Figure 4.2.114. Oil Sat. at 2.25 PV of Chemical Flood (Case \#3) ........................... 4-42

Figure 4.2.115. Pressure at 0.25 PV of Chemical Flood (Case \#3)......................... 4-42

Figure 4.2.116. Pressure at 0.75 PV of Chemical Flood (Case \#3)......................... 4-42

Figure 4.2.117. Pressure at 2.25 PV of Chemical Flood (Case \#3).......................... 4-42

Figure 4.2.118. Oil Sat. at 0.25 PV of Chemical Flood (Case \#3) ........................... 4-43

Figure 4.2.119. Oil Sat. at 0.75 PV of Chemical Flood (Case \#3) ........................... 4-43

Figure 4.2.120. Oil Sat. at 2.25 PV of Chemical Flood (Case \#3) ........................... 4-43

Figure 4.2.121. Pressure at $0.25 \mathrm{PV}$ of Chemical Flood (Case \#3) .......................... 4-43

Figure 4.2.122. Pressure at $0.75 \mathrm{PV}$ of Chemical Flood (Case \#3).......................... 4-43

Figure 4.2.123. Pressure at $2.25 \mathrm{PV}$ of Chemical Flood (Case \#3)........................... 4-43

Figure 4.2.124. ME Sat. at 0.25 PV of Chem. Flood (Case \#3) .............................. 4-44

Figure 4.2.125. ME Sat. at 0.75 PV of Chem. Flood (Case \#3) ............................... 4-44

Figure 4.2.126. ME Sat. at 2.25 PV of Chem. Flood (Case \#3) .............................. 4-44

Figure 4.2.127. Poly Conc. (wt.\%) at 0.25 PV of Chemical Flood (Case \#3).............. 4-44

Figure 4.2.128. Poly Conc. (wt.\%) at 0.75 PV of Chemical Flood (Case \#3)............. 4-44

Figure 4.2.129. Poly Conc. (wt.\%) at 2.25 PV of Chemical Flood (Case \#3)............. 4-44

Figure 4.2.130. ME Sat. at 0.25 PV of Chem. Flood (Case \#3) ............................. 4-45

Figure 4.2.131. ME Sat. at 0.75 PV of Chem. Flood (Case \#3) ............................. 4-45

Figure 4.2.132. ME Sat. at 2.25 PV of Chem. Flood (Case \#3) ............................. 4-45

Figure 4.2.133. Poly Conc. (wt.\%) at 0.25 PV of Chem Flood (Case \#3) .................. 4-45

Figure 4.2.134. Poly Conc. (wt.\%) at 0.75 PV of Chem Flood (Case \#3) .................. 4-45

Figure 4.2.135. Poly Conc. (wt.\%) at 2.25 PV of Chem Flood (Case \#3) .................. 4-45

Figure 4.2.136. Surf. Conc. (vol. frac.) at 0.25 PV of Chem Flood (Case \#3) ............ 4-46

Figure 4.2.137. Surf. Conc. (vol. frac.) at 0.75 PV of Chem Flood (Case \#3) ............ 4-46

Figure 4.2.138. Surf. Conc. (vol. frac.) at 2.25 PV of Chem Flood (Case \#3) ............ 4-46

Figure 4.2.139. IFT $(\log ($ dynes/cm) ) at 0.25 PV of Chem Flood (Case \#3) ............... 4-46

Figure 4.2.140. IFT $(\log ($ dynes/cm)) at 0.75 PV of Chem Flood (Case \#3) ................ 4-46 
Figure 4.2.141. IFT $(\log ($ dynes $/ \mathrm{cm}))$ at 2.25 PV of Chem Flood (Case \#3) ............... 4-46

Figure 4.2.142. Surf. Conc. (vol. frac.) at $0.25 \mathrm{PV}$ of Chem Flood (Case \#3)............ 4-47

Figure 4.2.143. Surf. Conc. (vol. frac.) at 0.75 PV of Chem Flood (Case \#3)............. 4-47

Figure 4.2.144. Surf. Conc. (vol. frac.) at 2.25 PV of Chem Flood (Case \#3) ............ 4-47

Figure 4.2.145. IFT $(\log ($ dynes $/ \mathrm{cm}))$ at $0.25 \mathrm{PV}$ of Chem Flood (Case \#3) ................ 4-47

Figure 4.2.146. IFT (log(dynes/cm)) at 0.75 PV of Chem Flood (Case \#3) ............... 4-47

Figure 4.2.147. IFT $(\log ($ dynes $/ \mathrm{cm}))$ at 2.25 PV of Chem Flood (Case \#3) ............... 4-47

Figure 4.2.148. Oil Saturation at 0.3 PV of Waterflood (Case \#4) ........................... 4-48

Figure 4.2.149. Oil Saturation at 1.9 PV of Waterflood (Case \#4) ........................... 4-48

Figure 4.2.150. Pressure at 0.3 PV of Waterflood (Case \#4) .................................. 4-48

Figure 4.2.151. Pressure at 1.9 PV of Waterflood (Case \#4) ................................. 4-48

Figure 4.2.152. Oil Sat in Layer 3 at $0.3 \mathrm{PV}$ of Waterflood (Case \#4) ...................... 4-49

Figure 4.2.153. Oil Sat in Layer 3 at 1.9 PV of Waterflood (Case \#4) ...................... 4-49

Figure 4.2.154. Pressure in Layer 3 at 0.3 PV of Waterflood (Case \#4).................... 4-49

Figure 4.2.155. Pressure in Layer 3 at 1.9 PV of Waterflood (Case \#4).................... 4-49

Figure 4.2.156. Oil Sat. at 0.25 PV of Chemical Flood (Case \#4) .......................... 4-50

Figure 4.2.157. Oil Sat. at 0.75 PV of Chemical Flood (Case \#4) ........................... 4-50

Figure 4.2.158. Oil Sat. at 2.25 PV of Chemical Flood (Case \#4) ........................... 4-50

Figure 4.2.159. Pressure at $0.25 \mathrm{PV}$ of Chemical Flood (Case \#4).......................... 4-50

Figure 4.2.160. Pressure at 0.75 PV of Chemical Flood (Case \#4).......................... 4-50

Figure 4.2.161. Pressure at 2.25 PV of Chemical Flood (Case \#4).......................... 4-50

Figure 4.2.162. Oil Sat. at 0.25 PV of Chemical Flood (Case \#4) ........................... 4-51

Figure 4.2.163. Oil Sat. at 0.75 PV of Chemical Flood (Case \#4) ........................... 4-51

Figure 4.2.164. Oil Sat. at 2.25 PV of Chemical Flood (Case \#4) ........................... 4-51

Figure 4.2.165. Pressure at 0.25 PV of Chemical Flood (Case \#4) ......................... 4-51

Figure 4.2.166. Pressure at $0.75 \mathrm{PV}$ of Chemical Flood (Case \#4).......................... 4-51

Figure 4.2.167. Pressure at 2.25 PV of Chemical Flood (Case \#4)......................... 4-51

Figure 4.2.168. ME Sat. at 0.25 PV of Chem. Flood (Case \#4) ............................. 4-52

Figure 4.2.169. ME Sat. at 0.75 PV of Chem. Flood (Case \#4) .............................. 4-52

Figure 4.2.170. ME Sat. at 2.25 PV of Chem. Flood (Case \#4) ............................... 4-52

Figure 4.2.171. Poly Conc. (wt.\%) at 0.25 PV of Chemical Flood (Case \#4)............. 4-52

Figure 4.2.172. Poly Conc. (wt.\%) at 0.75 PV of Chemical Flood (Case \#4).............. 4-52

Figure 4.2.173. Poly Conc. (wt.\%) at 2.25 PV of Chemical Flood (Case \#4)............. 4-52 
Figure 4.2.174. ME Sat. at 0.25 PV of Chem. Flood (Case \#4 $4-53$

Figure 4.2.175. ME Sat. at 0.75 PV of Chem. Flood (Case \#4) 4-53

Figure 4.2.176. ME Sat. at 2.25 PV of Chem. Flood (Case \#4) 4-53

Figure 4.2.178. Poly Conc. (wt.\%) at 0.25 PV of Chemical Flood (Case \#4) 4-53

Figure 4.2.179. Poly Conc. (wt.\%) at 0.75 PV of Chemical Flood (Case \#4) 4-53

Figure 4.2.180. Poly Conc. (wt.\%) at 2.25 PV of Chemical Flood (Case \#4). 4-53

Figure 4.2.181. Surf. Conc. (vol. frac.) at $0.25 \mathrm{PV}$ of Chem Flood (Case \#4) 4-54

Figure 4.2.182. Surf. Conc. (vol. frac.) at $0.75 \mathrm{PV}$ of Chem Flood (Case \#4) 4-54

Figure 4.2.183. Surf. Conc. (vol. frac.) at $2.25 \mathrm{PV}$ of Chem. Flood (Case \#4) 4-54

Figure 4.2.184. IFT (log(dynes/cm)) at 0.25 PV of Chem Flood (Case \#4) 4-54

Figure 4.2.185. IFT (log(dynes/cm)) at 0.75 PV of Chem Flood (Case \#4) 4-54

Figure 4.2.186. IFT (log(dynes/cm)) at 2.25 PV of Chem Flood (Case \#4) 4-54

Figure 4.2.187. Surf. Conc. (vol. frac.) at $0.25 \mathrm{PV}$ of Chem Flood (Case \#4) 4-55

Figure 4.2.188. Surf. Conc. (vol. frac.) at 0.75 PV of Chem Flood (Case \#4) 4-55

Figure 4.2.189. Surf. Conc. (vol. frac.) at $2.25 \mathrm{PV}$ of Chem. Flood (Case \#4) 4-55

Figure 4.2.190. IFT (log(dynes/cm)) at 0.25 PV of Chem Flood (Case \#4) 4-55

Figure 4.2.191. IFT (log(dynes/cm)) at 0.75 PV of Chem Flood (Case \#4) 4-55

Figure 4.2.192. IFT (log(dynes/cm)) at 2.25 PV of Chem Flood (Case \#4) 4-55 


\section{INTRODUCTION}

Oil recovery by primary depletion and waterflooding recovers only about one third of the original in place, on the average. The remaining oil can be categorized into: (1) the residual oil in the regions swept by water and (2) the movable oil in the regions unswept or poorly swept by water. This project uses surfactants to reduce the residual oil saturation by both interfacial tension reduction and wettability alteration, the latter in cases where wettability is responsible for retaining oil in the matrix. A factor in the sweep efficiency of a reservoir is the mobility ratio between the resident fluids and the injected fluids. Polymer solution is the traditional method for mobility control in surfactant flooding. This project will evaluate foam as an alternate or supplement to polymer for mobility control. Our objective is to economically increase the recovery efficiency beyond that achieved by waterflooding.

Both unfractured and fractured formations will be addressed in this project. The driving force for displacement of oil in unfractured systems is primarily the pressure gradient developed by displacing fluids from the injection well to the production well. This pressure gradient may be only a small contributor in fractured formations. In this case, spontaneous imbibition is needed to exchange the injected fluid and oil between the fracture and matrix. The driving force for spontaneous imbibition includes capillary pressure gradients and buoyancy, or gravity drainage. The contribution due to capillary pressure gradients may be diminished because of low interfacial tension.

Both sandstone and carbonate formations will be considered. Carbonate formation usually tend to be more oil-wet and fractured compared to sandstone formations. In either case, surfactant adsorption on the mineral surfaces must be minimized. Sodium carbonate is used with anionic surfactants in carbonate formations to reduce adsorption. The alkalinity of the sodium carbonate also generates surfactants in situ by reacting with the naphthenic acids in the crude oil.

Scale-up from the laboratory to the field is a necessary part of developing an enhanced oil recovery process. The tool for this scale-up in the reservoir simulator, UTCHEM. 


\section{EXECUTIVE SUMMARY}

Twenty four surfactants are compared for their efficacy for oil recovery by surfactant flooding. Surfactant structure - performance relationships are needed for applications with a specified crude oil composition, brine salinity, reservoir temperature, formation mineralogy, and recovery mechanism. The surfactants are characterized by the optimal salinity for different pure hydrocarbon oils, the solubilization ratio, which is an estimator of the level of interfacial tension at optimal conditions, and whether it forms viscous gel or liquid crystalline phases that cause slow emulsion coalescence. A combination of two surfactants, N677PO-S and IOS 15-18, was found to be particularly effective. N67-7PO-S has a moderately branched hydrophobe with 16-17 carbons, an average of $7 \mathrm{PO}$ (propylene oxide) groups, and is sulfated. IOS $15-18$ is an internal olefin sulfonate with 15-18 carbons. The location of the sulfonate in the IOS is distributed along the carbon chain and thus the result is a twin-tailed or branched hydrophobe. The branching reduces the tendency to form gels and viscous emulsions at low temperatures. EO and PO groups impart tolerance to divalent ions. PO is more lipophlic than the hydrophilic EO group and results in a lower optimal salinity requirement. The sulfate has an ester linkage and is subject to hydrolysis at high temperatures and low $\mathrm{pH}$. Thermally stable sulfonates are evaluated for high temperature applications.

A surfactant-polymer formulation is being developed for a West Texas carbonate reservoir that has a pressure too low for $\mathrm{CO}_{2}$ flooding. The formulation has recovered up to $95 \%$ of the oil remaining after waterflooding in reservoir formation core material. The project team has met with the operator and partners to plan for a field test.

An alkaline surfactant process is being developed for enhanced spontaneous imbibition in a fractured, oil-wet, carbonate formation. The carbonate ion of sodium carbonate is a potential determining ion in carbonate formations such as calcite and dolomite. Alteration of the mineral surface to a negative charge aids in the wettability alteration and makes a dramatic reduction in the adsorption of anionic surfactants. Calcium ion concentration is sequestered because of the low solubility product of calcium carbonate. Also the alkali raises the $\mathrm{pH}$, which results in sponification of naphthenic acids to naphthenic soap, a natural surfactant. The naphthenic soap is usually too lipophilic by itself and addition of a synthetic surfactant is needed. Ultra-low interfacial tensions are possible at synthetic surfactant concentrations as low as $0.05 \%$. However, the system is complex because it is a mixture of two surfactants with very different properties. This results in the optimal salinity that depends on the water/oil ratio and surfactant concentration. However, these dependencies can be correlated by the ratio of natural surfactant/synthetic surfactant.

Surfactant retention by adsorption and phase trapping determine the amount of surfactant required for a surfactant enhanced oil recovery process. We show that the adsorption of anionic surfactants on calcite and dolomite can be reduced by an order of magnitude by addition of sodium carbonate. 
Mobility control is recognized as an essential element of surfactant EOR. Surfactant injection into fractured formations imposes a severe challenge for reservoir conformance or sweep efficiency. Foam has the potential to improve the liquid distribution in fractured systems. The volumetric flow rate of a Newtonian liquid into a set of parallel fractures is proportional to the third power of the fracture width. This will result in large fractures acting as "thief zones" and small fractures being bypassed. For bubbles of the same size, the apparent viscosity is higher in larger fractures compared to smaller fractures. We have verified that the model developed for foam in capillaries can be extended to flow between parallel plates. We demonstrated that better sweep efficiency is possible with the use of foam.

The reservoir simulator, UTCHEM will be used as the tool to scale-up from laboratory experiments to field design. 3-D simulations with UTCHEM demonstrate the effect of changing wettability on oil recovery. 
The following series of steps were taken to identify promising surfactants and surfactant EOR formulations:

- Use knowledge of surfactant chemistry and commercial surfactant production capabilities to identify prospective surfactant test candidates (Subtask 1.1)

- Acquire samples from surfactant companies and screen surfactants using phase behavior experiments with alkanes (Subtask 1.1)

- Use phase behavior experiments to optimize formulations of surfactants, co-surfactants and co-solvents with crude oils (Subtask 1.2)

- Conduct laboratory core flood experiments using the best surfactant formulations from the phase behavior screening data (Subtask 1.2)

Based upon the surfactant selection and phase behavior screening procedure discussed in this report, a core flood was performed using a very heterogeneous dolomite field core and crude oil from the Midland Farms reservoir. The oil recovery was $95 \%$ and the final oil saturation only 0.01 . The results of this core flood experiment indicate that the surfactant selection procedure used in this research is based upon sound scientific principles and leads to excellent performance as well as being very efficient.

\subsection{Subtask 1.1. Identifying and Synthesizing Improved, Cost-effective Surfactants}

The research in Year 1 identified several families of propoxylated sulfate surfactants that were suitable for enhanced oil recovery both from standpoints of both performance and the ability to be commercially manufactured. Specifically, branched alcohol propoxy sulfate surfactants were synthesized for screening with both pure hydrocarbons and crude oils. The isotridecanol $\left(\mathrm{C}_{13}\right.$ Exxal ${ }^{\circledR}$ TDA) was considered to be most suitable hydrophobe in terms of phase behavior for pure hydrocarbons ranging between hexane and decane. Additionally, the TDA is a low-cost commodity alcohol that would minimize total surfactant cost.

Formulations with this $\mathrm{C}_{13} \mathrm{PO}$-sulfate exhibited high optimal salinities and thus would work well in high salinity environments. Another property inherent to surfactants with sulfate ester hydrophilic groups is their susceptibility to hydrolysis at elevated temperatures. Therefore, additional surfactant development and screening were undertaken to find candidates for hightemperature and low-salinity reservoirs. This involved the testing of alcohol propoxy sulfate surfactants with larger hydrophobic groups (to lower the optimal salinities) and the screening of temperature-stable sulfonate surfactants containing desirable branched hydrophobes. This follow-on screening for surfactants with lower optimal salinities plus resistance to high temperature degradation utilized surfactants identified in Year 1 in addition to ones that were 
specially designed in Year 2. Table 1.1-1 below lists the surfactants used in Year 2 screening.

Table 1.1-1 Surfactants Tested in Year 2

\begin{tabular}{|c|c|}
\hline $\begin{array}{l}\text { Descriptive or Trade Name } \\
\text { (supplier) }\end{array}$ & $\begin{array}{l}\text { Abbreviated Chemical Formula } \\
\text { (b= branching in the carbon chain) }\end{array}$ \\
\hline $\begin{array}{l}\text { Amphosol 810-B (octyl\&decyl- } \\
\text { amidopropyl betaine) (Stepan) }\end{array}$ & $\mathrm{C}_{7-9} \mathrm{CO}-\mathrm{NH}-\left(\mathrm{CH}_{2}\right)_{3}-\mathrm{N}^{+}\left(\mathrm{CH}_{3}\right)_{2}-\mathrm{CH}_{2} \mathrm{COO}^{-}$ \\
\hline $\begin{array}{l}\text { Amphosol HCG (coco-amidopropyl } \\
\text { betaine) (Stepan) }\end{array}$ & $\mathrm{C}_{7-11} \mathrm{CO}-\mathrm{NH}-\left(\mathrm{CH}_{2}\right)_{3}-\mathrm{N}^{+}\left(\mathrm{CH}_{3}\right)_{2}-\mathrm{CH}_{2} \mathrm{COO}^{-}$ \\
\hline $\begin{array}{l}\mathrm{C}_{14} \text { Alpha Olefin Sulfonate (AOS) } \\
\text { (Stepan) }\end{array}$ & 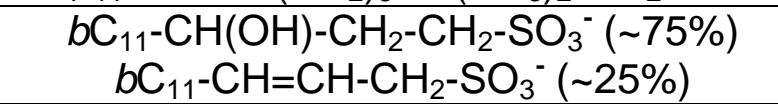 \\
\hline $\mathrm{C}_{16}$ o-Xylene Sulfonate (Shell) & $\begin{array}{c}\mathrm{C}_{16}-\left(\mathrm{C}_{8} \mathrm{H}_{12}\right)-\mathrm{SO}_{3}^{-} \\
\text {where } \mathrm{C}_{8} \mathrm{H}_{12}=\text { o-xylene }\end{array}$ \\
\hline $\begin{array}{l}\mathrm{C}_{16-18} \text { Alpha Olefin Sulfonate (AOS) } \\
\text { (Stepan) }\end{array}$ & $\begin{array}{c}\left.b \mathrm{C}_{13-15-\mathrm{CH}} \mathrm{COH}\right)-\mathrm{CH}_{2}-\mathrm{CH}_{2}-\mathrm{SO}_{3}^{-}(-75 \%) \\
b \mathrm{C}_{13-15}-\mathrm{CH}=\mathrm{CH}-\mathrm{CH}_{2}-\mathrm{SO}_{3}^{-}(-25 \%)\end{array}$ \\
\hline $\begin{array}{l}\mathrm{C}_{20-24} \text { Alpha Olefin Sulfonate (AOS) } \\
\text { (Stepan) }\end{array}$ & $\begin{array}{c}b \mathrm{C}_{17-21}-\mathrm{CH}(\mathrm{OH})-\mathrm{CH}_{2}-\mathrm{CH}_{2}-\mathrm{SO}_{3}^{-}(\sim 75 \%) \\
b \mathrm{C}_{17-21}^{-} \mathrm{CH}=\mathrm{CH}-\mathrm{CH}_{2}-\mathrm{SO}_{3}^{-}(-25 \%)\end{array}$ \\
\hline $\begin{array}{l}\mathrm{C}_{16-18} \text { Alcohol Propoxy Sulfate } \\
\text { (HN1618-5.7POS) (Harcros) }\end{array}$ & $\mathrm{C}_{16-18}\left(\mathrm{CH}_{3}-\mathrm{CH}-\mathrm{CH}_{2}-\mathrm{O}-\right)_{5.7}-\mathrm{SO}_{3}^{-}$ \\
\hline $\begin{array}{l}\text { Hostapur Secondary Alkane } \\
\text { Sulfonate (SAS-60) (Clariant) }\end{array}$ & $\begin{array}{c}\mathrm{R}-\mathrm{CH}\left(\mathrm{SO}_{3}^{-}\right)^{-\mathrm{R}^{\prime}} \\
\text { where } \mathrm{R}+\mathrm{R}^{\prime}=\mathrm{C}_{14}-\mathrm{C}_{17}\end{array}$ \\
\hline $\begin{array}{c}\mathrm{C}_{15-18} \text { Internal Olefin Sulfonate (IOS) } \\
\text { (Shell) }\end{array}$ & $\begin{array}{c}\mathrm{R}-\mathrm{CH}(\mathrm{OH})-\mathrm{CH}_{2}-\mathrm{CH}\left(\mathrm{SO}_{3}^{-}\right)-\mathrm{R}^{\prime}(\sim 75 \%) \\
\mathrm{R}-\mathrm{CH}=\mathrm{CH}-\mathrm{CH}\left(\mathrm{SO}_{3}^{-}\right)-\mathrm{R}^{\prime}(\sim 25 \%) \\
\text { where } \mathrm{R}+\mathrm{R}^{\prime}=\mathrm{C}_{12-15}\end{array}$ \\
\hline $\begin{array}{c}\text { Neodol@ N67-3POS }\left(\mathrm{C}_{16-17}(\mathrm{PO})_{3}\right. \\
\text { APS) Alcohol Propoxy Sulfate } \\
\text { (Stepan) }\end{array}$ & $b \mathrm{C}_{16-17}\left(\mathrm{CH}_{3}-\mathrm{CH}-\mathrm{CH}_{2}-\mathrm{O}\right)_{3}-\mathrm{SO}_{3}^{-}$ \\
\hline $\begin{array}{c}\text { Neodol@ N67-5POS }\left(\mathrm{C}_{16-17}(\mathrm{PO})_{5}\right. \\
\text { APS) Alcohol Propoxy Sulfate } \\
\text { (Stepan) }\end{array}$ & $b \mathrm{C}_{16-17}\left(\mathrm{CH}_{3}-\mathrm{CH}-\mathrm{CH}_{2}-\mathrm{O}\right)_{5}-\mathrm{SO}_{3}^{-}$ \\
\hline $\begin{array}{l}\text { Neodol@ N67-7POS }\left(\mathrm{C}_{16-17}(\mathrm{PO})_{7}\right. \\
\text { APS) Alcohol Propoxy Sulfate } \\
\text { (Stepan) }\end{array}$ & $b \mathrm{C}_{16-17}\left(\mathrm{CH}_{3}-\mathrm{CH}-\mathrm{CH}_{2}-\mathrm{O}\right)_{7}-\mathrm{SO}_{3}^{-}$ \\
\hline ORS-62HF (Oil Chem Tech.) & Unknown (not provided) \\
\hline ORS-66HF (Oil Chem Tech.) & Unknown (not provided) \\
\hline $\begin{array}{l}\text { Petrostep } ® \text { SB (coco amidopropyl } \\
\text { hydroxyl sultaine (Stepan) }\end{array}$ & $\begin{array}{c}\mathrm{C}_{7-11} \mathrm{CO}-\mathrm{NH}-\left(\mathrm{CH}_{2}\right)_{3}-\mathrm{N}^{+}\left(\mathrm{CH}_{3}\right)_{2-}^{-} \\
\mathrm{CH}_{2} \mathrm{CH}(\mathrm{OH})-\mathrm{CH}_{2}-\mathrm{SO}_{3}^{-}\end{array}$ \\
\hline $\begin{array}{l}\text { Polystep } \circledast \text { A-16-22 (Branched Alkyl } \\
\text { Benzene Sulfonate) (Stepan) }\end{array}$ & $b \mathrm{C}_{11-13}\left(\mathrm{C}_{6} \mathrm{H}_{5}\right)-\mathrm{SO}_{3}^{-}$ \\
\hline XSA 1416 (Oil Chem Tech.) & Unknown (not provided) \\
\hline XSA 2024 (Oil Chem Tech.) & Unknown (not provided) \\
\hline
\end{tabular}




\subsubsection{Surfactant Screening using Phase Behavior Experiments}

Surfactant screening in Year 2 followed the same process of phase behavior testing as in Year 1 and involved the quantification of the low IFT microemulsions formed from test oils and the surfactants (either individually or in combinations). Promising surfactant formulations were tested with pure alkane hydrocarbons as a first step, followed by a more detailed study of the better-performing surfactants with selected crude oils. The surfactant screening tests for Year 2 can be divided into two groups; one for surfactant formulation testing below $50^{\circ} \mathrm{C}$ and the second set for testing above $50^{\circ} \mathrm{C}$. The temperature of the phase behavior testing reflected the actual temperatures of the reservoirs from which the crude oils were obtained. Another issue that was addressed in the Year 2 testing was the requirement for low viscosity phases, particularly at low temperatures. This requirement pointed to the need for highly branched hydrophobes or the mixture of hydrophobic structures such that the tendency to form liquid crystals and gels was minimized.

\subsubsection{Results and Discussion for Subtask 1.1}

In order to reduce optimum salinity the size of the hydrophobic group needed to be larger than the $\mathrm{C}_{13}$ TDA used in previous alcohol propoxylate sulfate surfactants. A new Shell alcohol, Neodol ${ }^{8} 67$, (slightly branched $\mathrm{C}_{16}-\mathrm{C}_{17}$ primary alcohol) was identified, and a set of $\mathrm{N} 67-(\mathrm{PO})_{n}-\mathrm{SO}_{4}$ (where $\mathrm{n}=3,5$, or 7 ) surfactants were prepared by Stepan Company. These three new surfactants were designated N67-3POS, N67-5POS and N67-7POS or generically as $\mathrm{C}_{16-17^{-}}$ $(\mathrm{PO})_{3}-\mathrm{SO}_{4}, \mathrm{C}_{16-17-}(\mathrm{PO})_{5}-\mathrm{SO}_{4}$ and $\mathrm{C}_{16-17}-(\mathrm{PO})_{7}-\mathrm{SO}_{4}$ in this report. A space-filling, molecular model of $\mathrm{C}_{16-17}-(\mathrm{PO})_{7}-\mathrm{SO}_{4}$ without its hydrogen atoms is shown in figure 1.1-1. 


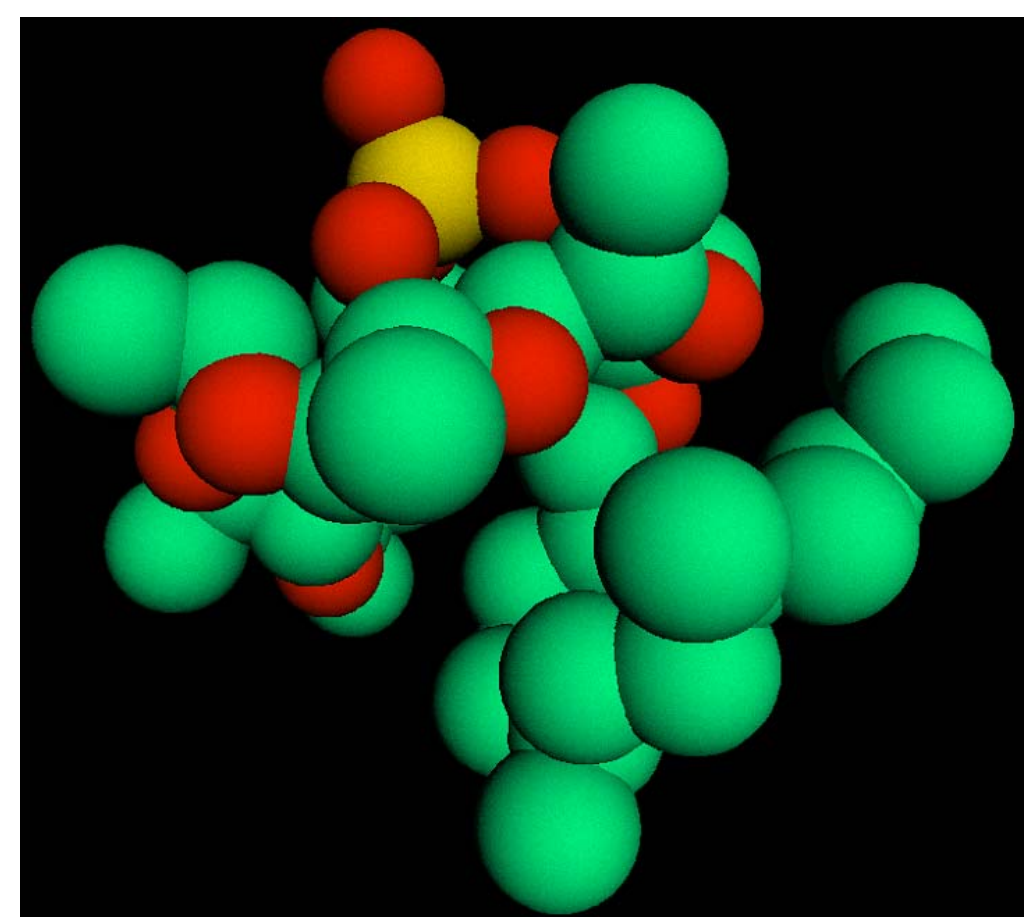

Figure 1.1-1. Neodol ${ }^{\circledR}$ N67-7PO-sulfate $\left(\mathrm{C}_{16-17}-(\mathrm{PO})_{7}-\mathrm{SO}_{4}\right)$

The minimal energy image shows that the molecule is very compact because the large propylene oxide (PO) part of the molecule folds into a spiral. The hydrophobe here is shown with 16 carbon atoms and 3 methyl branches. Both the $\mathrm{PO}$ and the branching result in a molecule that is very different from the chemically similar, linear alcohol ethoxy sulfate surfactants used as laundry detergents. Linear hydrophobes tend to form ordered structures that lead to undesirable liquid crystals and gels. Also, POs, in contrast to EOs, are larger and more balanced at the interface between the water and oil. This leads to lower IFT. Changing the number of POs alters optimum salinity and thus can be used to tailor the surfactant's performance. Phase behavior testing with pure hydrocarbons predictably has shown that the optimum salinity is lower than those with the $\mathrm{C}_{13}$ TDA hydrophobe. Finally, the presence of propoxyl groups in the surfactant molecule enhances calcium tolerance. The only negative aspect of this molecule is the sulfate hydrophilic group, which is susceptible to hydrolysis at the elevated temperatures of many reservoirs. This surfactant is expected to cost approximately $\$ 2 / \mathrm{lb}(100 \%$ active), which is very reasonable for a high performance surfactant.

The Year 2 work also examined sulfonate surfactants for higher temperature reservoirs. Three custom-made alpha-olefin sulfonate (AOS) surfactants were screened: (1) $\mathrm{C}_{14-16}$ AOS, (2) $\mathrm{C}_{16-18}$ AOS and (3) $\mathrm{C}_{20-24}$ AOS. A model of the $\mathrm{C}_{20-}$ ${ }_{24} \mathrm{AOS}$ is shown below. 


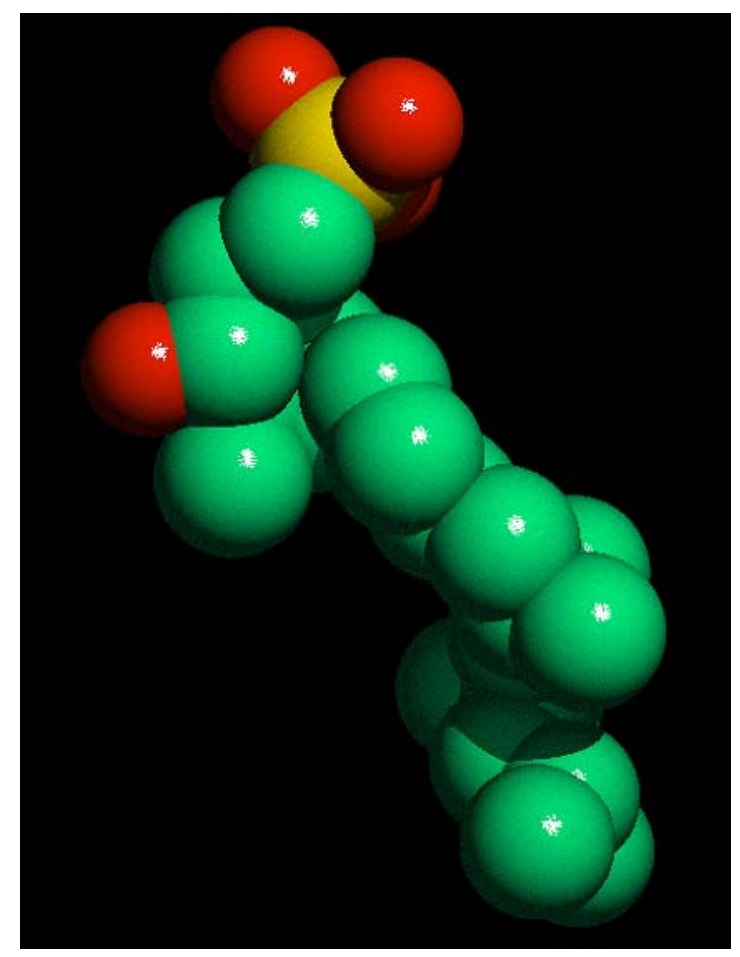

Figure 1.1-2. $\mathrm{C}_{20-24} \mathrm{AOS}$

The image shows a 22-carbon alpha olefin sulfonate with some typical methyl branching. The actual surfactant has 20 to 24 carbon atoms and a variable number and positioning of methyl branches and either a double bond or a hydroxyl group (as shown in figure 1.1-2) at a position located two carbon atoms from where the sulfonate group is located. If linear, it would make a poor surfactant for EOR.

Additionally, a $\mathrm{C}_{15-18}$ internal-olefin sulfonate $\left(\mathrm{C}_{15-18} \mathrm{IOS}\right)$ surfactant made by Shell was identified as a potential co-surfactant for use with both high temperature AOS surfactants and low temperature alcohol propoxylate sulfate surfactants. A model of the hydroxyl form of the molecule is shown in figure 1.13. This IOS tends not to form liquid crystals and gels, thereby reducing the need for alcohol (co-solvent) addition. The figure below depicts a structure with "twin hydrophobe tails". However, this is just one of the many sulfonate positional isomers that can exist depending on the location of the internal double bond of the starting internal olefin feedstock. This has the same overall effect as with the branched alcohol-PO sulfate surfactants by negating the orderly alignment among molecules to form liquid crystals and gels. 


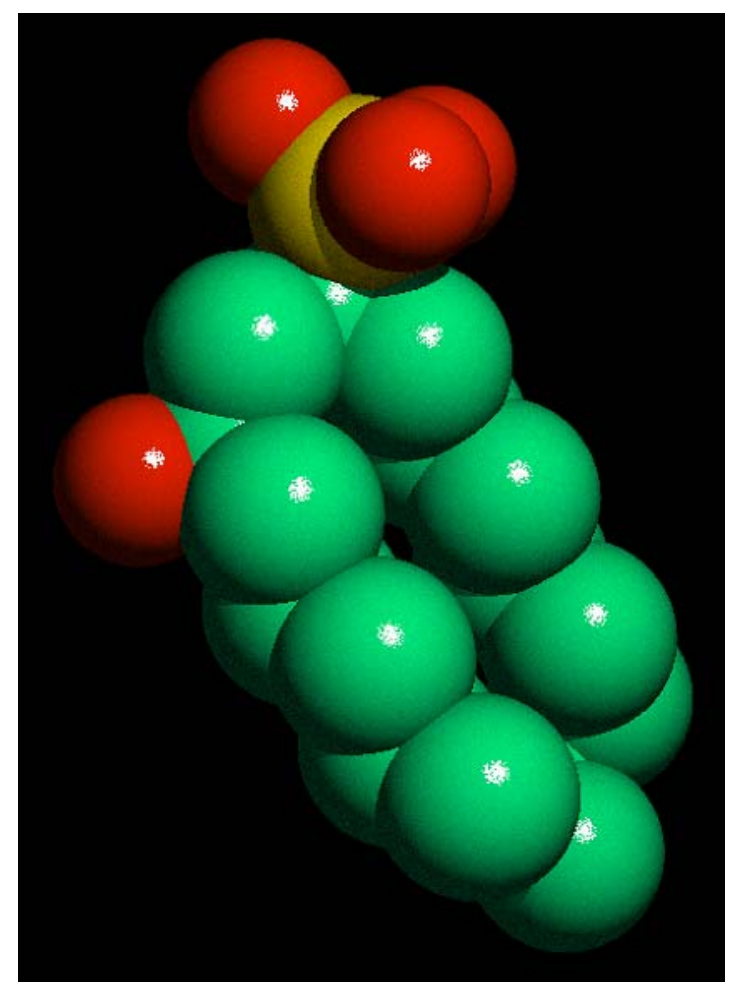

Figure 1.1-3. $\mathrm{C}_{15-18} 10 \mathrm{~S}$

Both the AOS and IOS surfactants are inexpensive in part because they are made in a one step synthesis. Both surfactants are estimated to cost only about $\$ 1$ per lb (100\% active), which is very low for a high performance EOR surfactant.

Surfactants or surfactant blends also have been provided by Oil Chem Technologies (OCT) for laboratory testing (see Table 1.1-1). These are custom surfactants manufactured for EOR projects. No detailed surfactant-structure information was provided by OCT other than that shown in Table 1.1-1.

Progress for Year 2 can be summarized as focused efforts to find surfactants with the desired phase behavior. The synthesis and testing of a group of alcohol propoxy sulfates with the larger Neodol ${ }^{\circledR} 67$ alcohol resulted in the desired behavior for low-temperature EOR applications. The synthesis and testing of novel AOS and IOS surfactants resulted in the desired behavior for high temperature EOR applications.

\section{2 Behavior \\ Subtask 1.2. Surfactant Tailoring for Crude Oils and Phase}

Surfactant tailoring for crude oils in Year 2 was conducted in a series of steps. First, the phase behavior experiments were used to narrow possible surfactant candidates in an efficient and effective manner. Second, polymers and mixtures 
of surfactants and polymers were tested to select suitable polymers for core flooding tests. Next, experiments were conducted to characterize reservoir rock cores prior to core flood experiments. Finally, these processes were integrated into core flood experiments to evaluate the best surfactants for oil recovery for the particular crude oils provided by oil companies.

\subsubsection{Results of Phase Behavior Experiments}

One crude oil was from the Midland Farms (MF) reservoir in Andrews County TX and was provided by Oxy Permian, the operator of the reservoir. Surfactants were evaluated by measuring their aqueous solubility, solubilization parameters, coalescence time and the viscosity of the aqueous and microemulsion phases. This process includes determining how much alcohol co-solvent is needed for acceptable phase behavior and compatibility with polymers. Suitable formulations were then evaluated in core floods to assess oil recovery and surfactant adsorption on the rock. Importantly, pressure was monitored in the core flood experiments since high pressure gradients are not practical in reservoirs and would indicate problems with the use of the surfactant or polymer.

Surfactant formulations were screened at the actual $38^{\circ} \mathrm{C}$ reservoir temperature. Table 1.2-1 lists the various formulations evaluated with the MF crude oil. A formulation that showed excellent middle phase microemulsions in phase behavior experiments with octane and decane was tested with the MF crude oil. This formulation contained $2 \mathrm{wt} \%$ isotridecyl-3PO-sulfate, $2 \mathrm{wt} \%$ branched$\mathrm{C} 12$ (Guerbet)-3PO-sulfate and $1 \mathrm{wt} \%$ sodium dihexyl-sulfosuccinate (Aerosol® MA-80). However, a high electrolyte concentration on the order of $12 \mathrm{wt} \%$ brine was required to induce middle phase microemulsions. Such a high optimum salinity necessitated the switch to the hydrophobic $\mathrm{C}_{20-24}$ alpha olefin sulfonates and the Neodol ${ }^{\circledR} \mathrm{N} 67$ propoxylate sulfate surfactants. 
Table 1.2-1. Formulations Screened with Midland Farms Crude Oil at $38^{\circ} \mathrm{C}$

\begin{tabular}{|c|c|c|c|}
\hline Surfactant Formulation & $\begin{array}{l}\text { Optimum Salinity } \\
\mathrm{S}^{*}(\mathrm{wt} \% \mathrm{NaCl})\end{array}$ & $\begin{array}{c}\text { Optimum } \\
\text { Sol. Ratio, } \\
\sigma \text { (cc/cc) }\end{array}$ & $\begin{array}{c}\text { Equilibration } \\
\text { Time at } \mathbf{S}^{*} \\
\text { (days) }\end{array}$ \\
\hline $\begin{array}{c}2 \% \boldsymbol{b C}_{12}-(\mathrm{PO})_{3}-\mathrm{SO}_{4}, 2 \% \text { TDA- }(\mathrm{PO})_{3}-\mathrm{SO}_{4} \\
1 \% \text { dihexyl-sulfosuccinate }\end{array}$ & 7.5 & 3.5 & $<2$ \\
\hline $4 \% \mathrm{C}_{20-24} \mathrm{AOS}, 8 \% \mathrm{SBA}$ & 2.5 & 6 & 5 \\
\hline $4 \% \mathrm{~N} 67-(\mathrm{PO})_{3}-\mathrm{SO}_{4}\left(\mathrm{NH}_{4}\right), 8 \% \mathrm{SBA}$ & $>3$ & 5 & 9 \\
\hline $4 \% \mathrm{~N} 67-(\mathrm{PO})_{5}-\mathrm{SO}_{4}\left(\mathrm{NH}_{4}\right), 8 \% \mathrm{SBA}$ & 1.9 & 7 & 2 \\
\hline $4 \% \mathrm{~N} 67-(\mathrm{PO})_{7}-\mathrm{SO}_{4}\left(\mathrm{NH}_{4}\right), 8 \% \mathrm{SBA}$ & 1.75 & 7 & 2 \\
\hline $\begin{array}{c}0.75 \% \mathrm{~N}^{0} 7-(\mathrm{PO})_{7}-\mathrm{SO}_{4}, 0.25 \% \mathrm{C}_{20-24} \\
\text { AOS, } 2 \% \mathrm{SBA}\end{array}$ & $>2$ & 5 & 5 \\
\hline $\begin{array}{c}1.5 \% \mathrm{~N} 67-(\mathrm{PO})_{7}-\mathrm{SO}_{4}, 0.5 \% \mathrm{C}_{15-18} \mathrm{IOS} \\
1 \% \mathrm{SBA}, 1 \% \mathrm{Na}_{2} \mathrm{CO}_{3}\end{array}$ & 3.8 & 6 & 1 \\
\hline $\begin{array}{c}1.5 \% \mathrm{~N} 67-(\mathrm{PO})_{7}-\mathrm{SO}_{4}, 0.5 \% \mathrm{C}_{15-18} \mathrm{IOS} \\
1 \% \mathrm{Na}_{2} \mathrm{CO}_{3}\end{array}$ & 3.5 & 12 & 2 \\
\hline $\begin{array}{c}1.5 \% \mathrm{~N} 67-(\mathrm{PO})_{7}-\mathrm{SO}_{4}, 0.5 \% \mathrm{C}_{20-24} \mathrm{AOS} \\
4 \% \mathrm{SBA}, 1 \% \mathrm{Na}_{2} \mathrm{CO}_{3}\end{array}$ & 1.6 & 6.1 & 1 \\
\hline $1.5 \%$ N67-(PO) $)_{7}-\mathrm{SO}_{4}, 0.5 \% \mathrm{C}_{15-18} \mathrm{IOS}$ & gels & gels & gels \\
\hline $\begin{array}{c}0.325 \% \mathrm{~N} 67-(\mathrm{PO})_{7}-\mathrm{SO}_{4}, 0.125 \% \mathrm{C}_{15-18} \\
\text { IOS, } 0.5 \% \text { SBA }\end{array}$ & Did not equilibrate & $\begin{array}{l}\text { Did not } \\
\text { equilibrate }\end{array}$ & $\begin{array}{l}\text { Did not } \\
\text { equilibrate }\end{array}$ \\
\hline $\begin{array}{c}1.5 \% \mathrm{~N} 67-(\mathrm{PO})_{7}-\mathrm{SO}_{4}, 0.5 \% \mathrm{C}_{20-24} \mathrm{AOS} \\
4 \% \mathrm{SBA}, 1 \% \mathrm{Na}_{2} \mathrm{CO}_{3}, 0.125 \% \mathrm{HPAM}\end{array}$ & 1.7 & 11 & 1 \\
\hline $\begin{array}{c}0.75 \% \mathrm{~N} 67-(\mathrm{PO})_{7}-\mathrm{SO}_{4}, 0.25 \% \mathrm{C}_{15-18} \mathrm{IOS} \\
2 \% \mathrm{SBA}\end{array}$ & 4.5 & 9 & 7 \\
\hline $\begin{array}{c}0.75 \% \mathrm{~N} 67-(\mathrm{PO})_{7}-\mathrm{SO}_{4}, 0.25 \% \mathrm{C}_{15-18} \mathrm{IOS} \\
2 \% \mathrm{SBA}, 1 \% \mathrm{Na}_{2} \mathrm{CO}_{3}\end{array}$ & 3.4 & 12 & 16 \\
\hline
\end{tabular}

The most favorable phase behavior was created with the Neodol ${ }^{\circledR}$ N67 propoxylated sulfate surfactants containing 7 moles PO. These experiments showed that increasing the number of POs results in higher solubilization and a lower optimum salinity. Gels were observed when SBA was greatly reduced or eliminated from the formulation. The addition of the $\mathrm{C}_{15-18}$ internal olefin sulfonate co-surfactant allowed for the reduction in SBA. Also, the $\mathrm{C}_{15-18}$ IOS performed better than the $\mathrm{C}_{20-24}$ AOS when diluted to $1 \mathrm{wt} \%$ total surfactant.

The best phase behavior in terms of coalescence and high solubilization ratio at optimum salinity (an indicator of low IFT) was observed with formulations containing the N67-7PO- $\mathrm{SO}_{4}, \mathrm{C}_{15-18}$ IOS and SBA. These experiments demonstrated that the formulation containing $0.75 \%$ Neodol67-7PO- $\mathrm{SO}_{4}, 0.25 \%$ $\mathrm{C}_{15-18} \mathrm{IOS}$ and $2 \%$ SBA produced rapid coalescence and high solubilization 
ratios. This surfactant formulation was chosen for flooding of using Midland Farms reservoir core and is presented in the "Results of Core Flood Experiments" section below.

Surfactants were also evaluated with crude oil from the Elk Hills (ELK) reservoir in California, which is operated by OXY Elk Hills. Surfactant formulations were screened at the $100^{\circ} \mathrm{C}$ reservoir temperature, and the results are presented in Table 1.2-2. Candidate surfactant formulations were tested in the same way as with MF crude by measuring aqueous solubility, solubilization parameters, coalescence times and viscosities of the aqueous and microemulsion phases.

Table 1.2-2. Formulations Screened with Elk Hills Crude Oil, $100^{\circ} \mathrm{C}$

\begin{tabular}{|c|c|c|c|}
\hline Surfactant Formulation & $\begin{array}{c}\text { Optimum } \\
\text { Salinity S* } \\
\text { (wt\% } \\
\text { NaCl) }\end{array}$ & $\begin{array}{c}\text { Optimum } \\
\text { Sol. Ratio, } \\
\sigma(c c / c c)\end{array}$ & $\begin{array}{c}\text { Equilibration } \\
\text { Time at } \mathbf{S}^{*} \\
\text { (days) }\end{array}$ \\
\hline $1.5 \% \mathrm{C}_{15-18} \mathrm{IOS}, 0.5 \% \mathrm{C}_{20-24} \mathrm{AOS}, 2 \% \mathrm{SBA}$ & $6-9$ & 4 & 1 \\
\hline $0.75 \% \mathrm{C}_{15-18} \mathrm{IOS}, 0.25 \% \mathrm{C}_{20-24}$ AOS & $9-11$ & 4 & 4 \\
\hline $1.5 \%$ SAS- $60,0.5 \% \mathrm{C}_{20-24}$ AOS & $5-7$ & 3 & 3 , until gel \\
\hline $2 \% \mathrm{C}_{20-24} \mathrm{AOS}, 4 \% \mathrm{SBA}$ & 2.1 & 8.5 & 1 \\
\hline $1 \% \mathrm{C}_{20-24}$ AOS, $1 \% \mathrm{C}_{15-18} \mathrm{IOS}$ & $6-8$ & 3 & 5 \\
\hline $1.5 \% \mathrm{C}_{16} \mathrm{o}-\mathrm{Xylene}$ sulfonate, $0.5 \% \mathrm{C}_{20-24} \mathrm{AOS}$ & $\begin{array}{c}\text { Did not } \\
\text { equilibrate }\end{array}$ & $\begin{array}{l}\text { Did not } \\
\text { equilibrate }\end{array}$ & $\begin{array}{l}\text { Did not } \\
\text { equilibrate }\end{array}$ \\
\hline $0.5 \% \mathrm{C}_{20-24}$ AOS, $1 \% \mathrm{SBA}$ & 2.1 & 9 & 1 \\
\hline $0.5 \% \mathrm{C}_{20-24} \mathrm{AOS}, 1 \% \mathrm{SBA}, 1 \% \mathrm{Na}_{2} \mathrm{CO}_{3}$ & 1.2 & 14 & 1 \\
\hline $0.05 \% \mathrm{C}_{20-24}$ AOS, $0.05 \% \mathrm{C}_{15-18} \mathrm{IOS}, 0.2 \%$ SBA & $\begin{array}{c}\text { Did not } \\
\text { equilibrate }\end{array}$ & $\begin{array}{l}\text { Did not } \\
\text { equilibrate }\end{array}$ & $\begin{array}{l}\text { Did not } \\
\text { equilibrate }\end{array}$ \\
\hline $2 \% \mathrm{C}_{20-24} \mathrm{AOS}, 4 \% \mathrm{SBA}, 1 \% \mathrm{Na}_{2} \mathrm{CO}_{3}$ & 1.4 & 12 & 1 \\
\hline
\end{tabular}

The sulfate surfactants are not stable at $100^{\circ} \mathrm{C}$, so sulfonate surfactants were used for the Elk Hills study. Alcohol was added to decrease the equilibration time and microemulsion viscosity. The experiments using only $\mathrm{C}_{20-24} \mathrm{AOS}$ and SBA were the most promising because they showed the highest solubilization without gelling after short equilibration times and with sharp and distinct interfaces between the microemulsion and the excess water and excess oil. 
Effects of Electrolyte Concentration. Phase behavior testing seeks to establish the salinity where the Winsor Type III middle phase microemulsions are largest (i.e. maximum volume oil solubilized per volume surfactant). If $\mathrm{V}_{\mathrm{o}}$ is the volume of solubilized oil in the middle phase, $V_{w}$ the volume of solubilized water and $V_{s}$ the volume of neat surfactant, then the solubilization ratios $V_{0} / V_{s}$ and $V_{w} / V_{s}$ are the volume of oil and water per unit volume of surfactant in the microemulsion phase. The ratio $V_{0} / V_{s}$ increases and the ratio $V_{w} / V_{s}$ decreases with salinity. When these ratios are plotted, the intersection point within the Type III salinity range is the optimum solubilization ratio at the optimum salinity as shown in Tables1.2-1 and 1.2-2. This optimum solubilization ratio corresponds to the lowest IFT, which is the desired condition for mobilizing oil in EOR. Thus, phase behavior testing also indicates the electrolyte concentrations needed to produce the lowest IFT and maximum oil recovery for EOR. Optimum solubilization ratios for specified oils will vary for different surfactants and their mixtures. High values are noteworthy because they denote surfactants and conditions that produce ultralow IFT. However, as pointed out earlier in this report, a high optimum solubilization ratio is not sufficient for acceptable behavior and high oil recovery. The absence of viscous phases such as gels, liquid crystals and macroemulsions and short equilibration times are equally important. The behavior of neighboring Type I and II regions also are evaluated for viscosity of the aqueous and microemulsion phases. This information is particularly important in developing the salinity gradient used for core flood experiments and later application in the field.

Figure 1.2-1 shows the salinity scan for a mixture containing N67-7PO-SO $\mathrm{SO}_{4}, \mathrm{C}_{15}$ ${ }_{18} \mathrm{IOS}$ and SBA with MF crude at $38^{\circ} \mathrm{C}$. The surfactant mixture included 0.02 wt $\%$ sodium carbonate as a buffer to keep the stock solution at about $\mathrm{pH}=9$. The optimum salinity recorded 21 days after mixing occurred at $1.65 \mathrm{wt} \% \mathrm{Na}^{+}$ concentration in the water with a solubilization ratio of 12 . Figure 1.2-2 shows the optimum solubilization ratio for the $\mathrm{C}_{20-24}$ AOS $(2 \%)$ at $100^{\circ} \mathrm{C}$ with Elk Hills crude oil was 9 at $0.85 \% \mathrm{Na}^{+}$concentration in the water. Generally speaking, optimum solubilization ratios that are $\sim 10$ or higher indicate the preferred surfactant(s) and chemical conditions for use in core floods. These figures show just some of hundreds of phase behavior experiments that have been conducted to screen surfactants and to establish electrolyte conditions for the core flood experiments. 


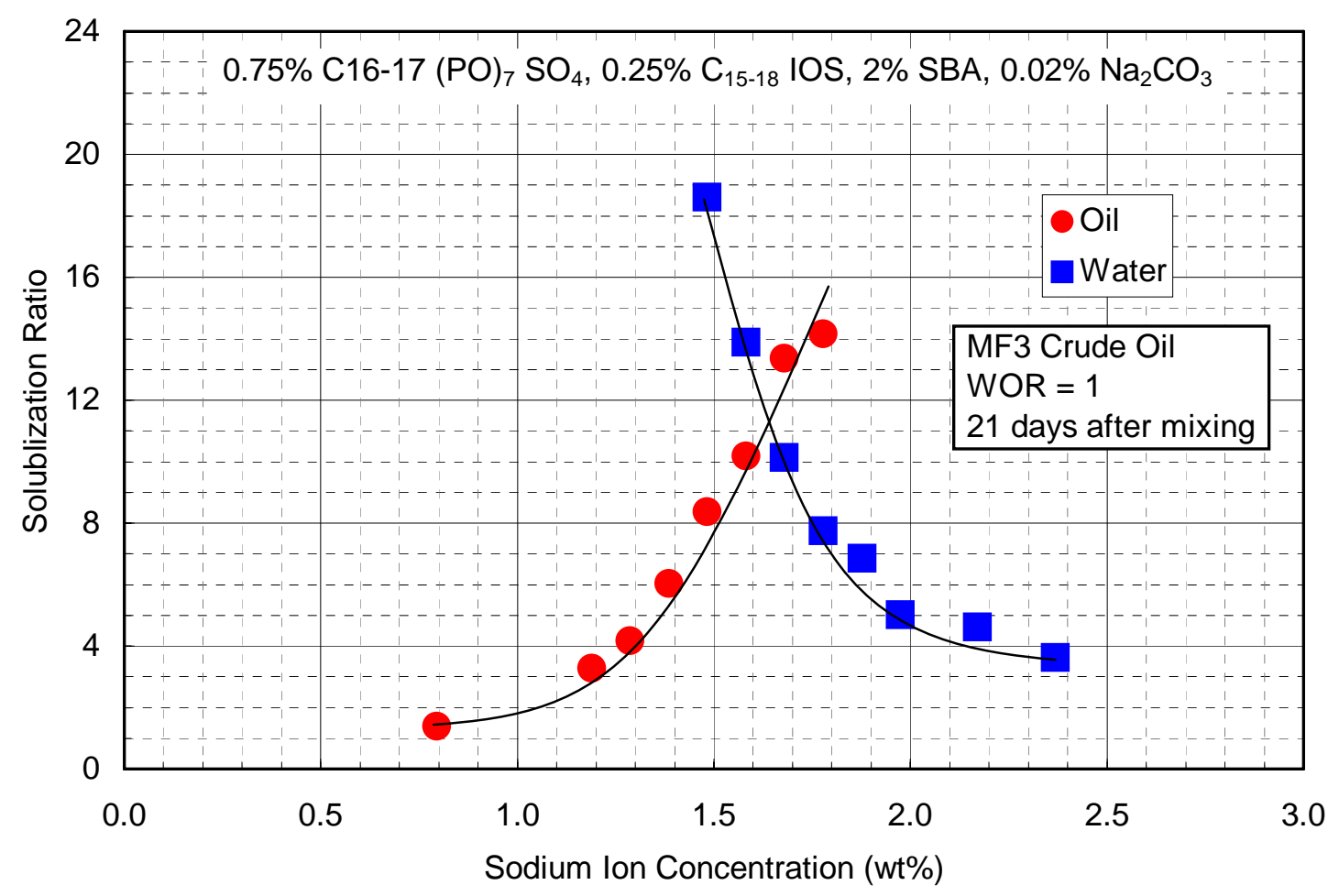

Figure 1.2-1. Salinity Scan with MF3 Crude Oil at $38^{\circ} \mathrm{C}$

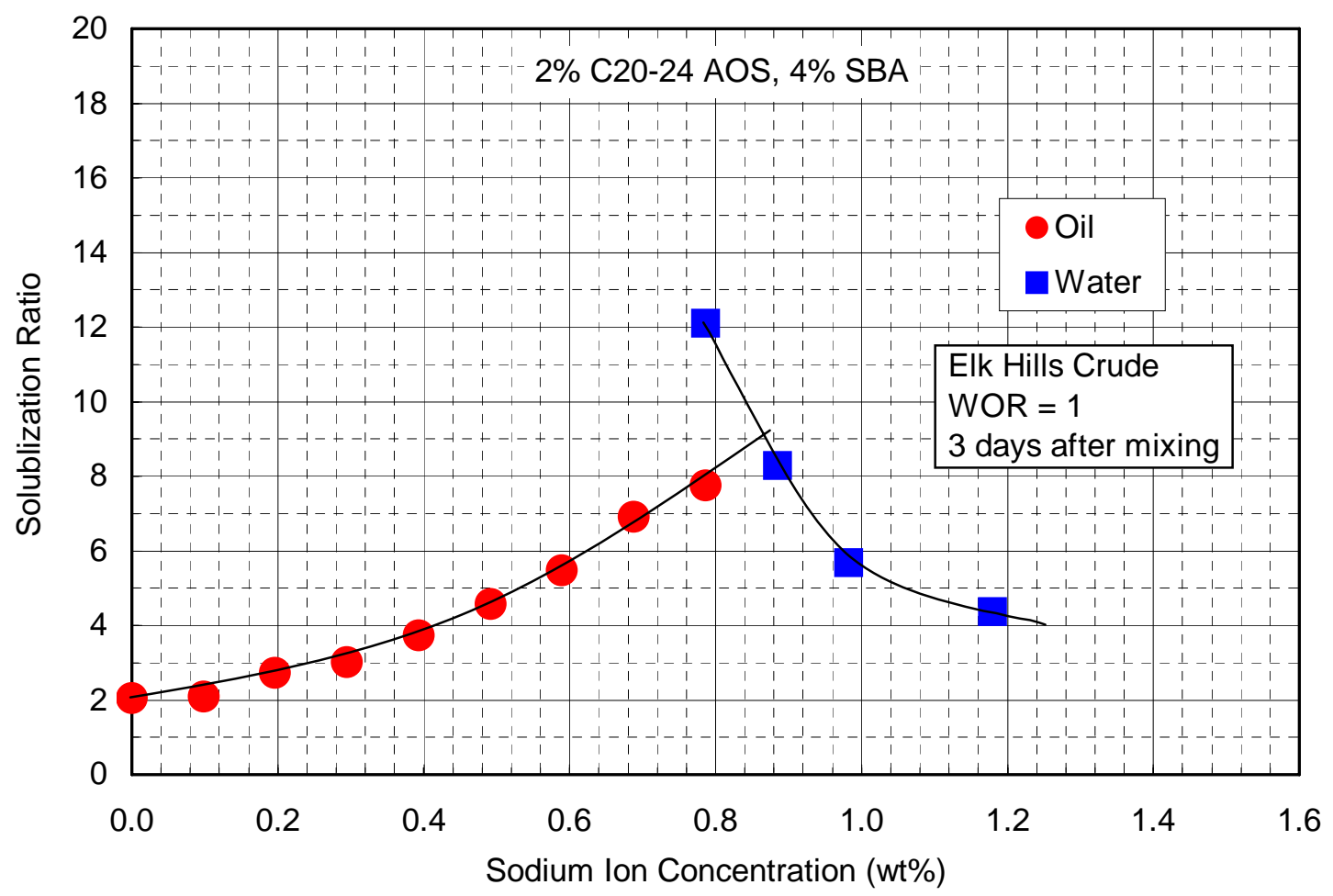

Figure 1.2-2. Salinity Scan with Elk Hills Crude Oil at $100^{\circ} \mathrm{C}$ 
Effects of Sodium Carbonate. Crude oils contain napthenic acids that may saponify upon the addition of sodium carbonate and generate an in-situ soap (surfactant) and is the basis for the so called ASP process. The addition of sodium carbonate is also desirable because it reduces anionic surfactant adsorption in reservoir rocks, allowing a smaller mass of surfactant to be injected. Additionally, the higher $\mathrm{pH}$ resulting from the addition of sodium carbonate helps maintain the stability of some of the surfactants being used. However, the interaction between each crude oil and sodium carbonate is unique and must be tested. Some crude oils have a low acid number and may not form a significant amount of soap, but the other effects may still be significant. However, even if the sodium carbonate has a beneficial effect on the phase behavior, it must still be tested with the reservoir core because of chemical reactions with the minerals in the rock.

A formulation using N67-(PO) $\mathrm{SO}_{4}, \mathrm{C}_{15-18} \mathrm{IOS}$ and SBA with MF3 crude oil was evaluated by testing with $0.02 \%, 1.0 \%$ and $2.0 \%$ sodium carbonate. The measurements of oil and water solubilization with respect to time are shown in figure 1.2-3.

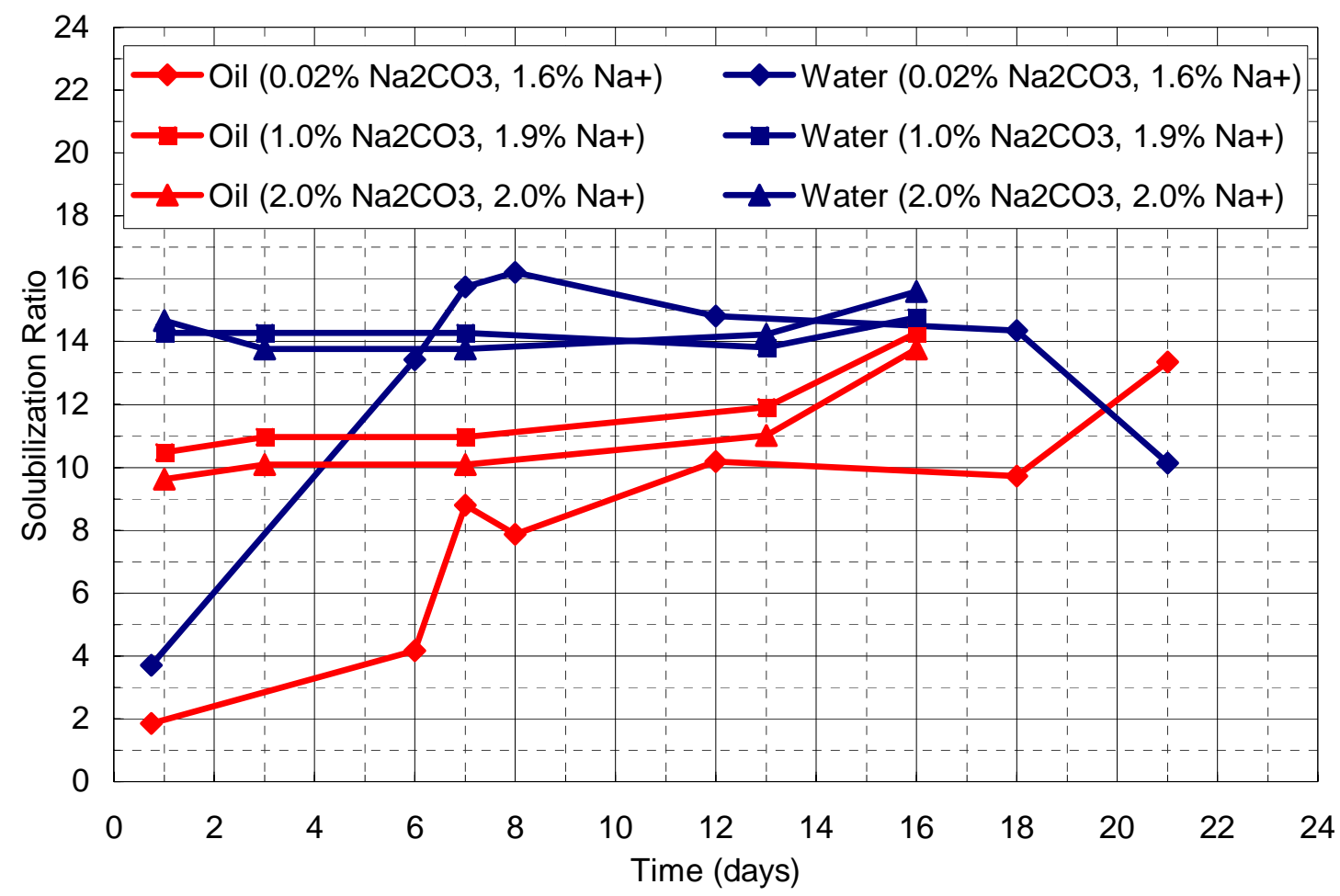

Figure 1.2-3. Effect of Sodium Carbonate on MF3 Crude Oil at a WOR 1:1 and $38^{\circ} \mathrm{C}$ using a mixture of $0.75 \% \mathrm{~N} 67-(\mathrm{PO})_{7}-\mathrm{SO}_{4}, 0.25 \% \mathrm{C}_{15-18} \mathrm{IOS}, 2 \% \mathrm{SBA}$

All the phase behavior tubes were observed just below optimum salinity. A comparison of the three experiments near optimum shows that the optimum 
solubilization ratio remains about 12 for all three cases. This means the addition of more than $0.02 \%$ sodium carbonate is unnecessary for the MF3 crude oil. The figure does show a quicker equilibration for the samples at $1 \%$ and $2 \%$ sodium carbonate, indicating that the phase behavior equilibration time is reduced at higher carbonate concentrations. Overall, the sodium carbonate has no substantial effect on the solubilization of Midland Farms crude, but may be used to help lower surfactant adsorption and speed up equilibration times.

A formulation using $\mathrm{C}_{20-24}$ AOS and SBA with Elk Hills (ELK) crude oil was evaluated at both $0.02 \%$ and $1.02 \%$ sodium carbonate. The observed effect was a change in the optimum salinity, solubilization ratio and equilibration time. Figure 1.2-4 shows the salinity scan for a $\mathrm{C}_{20-24}$ AOS and SBA formulation with ELK crude at $100^{\circ} \mathrm{C}$ and the shift resulting from adding sodium carbonate.

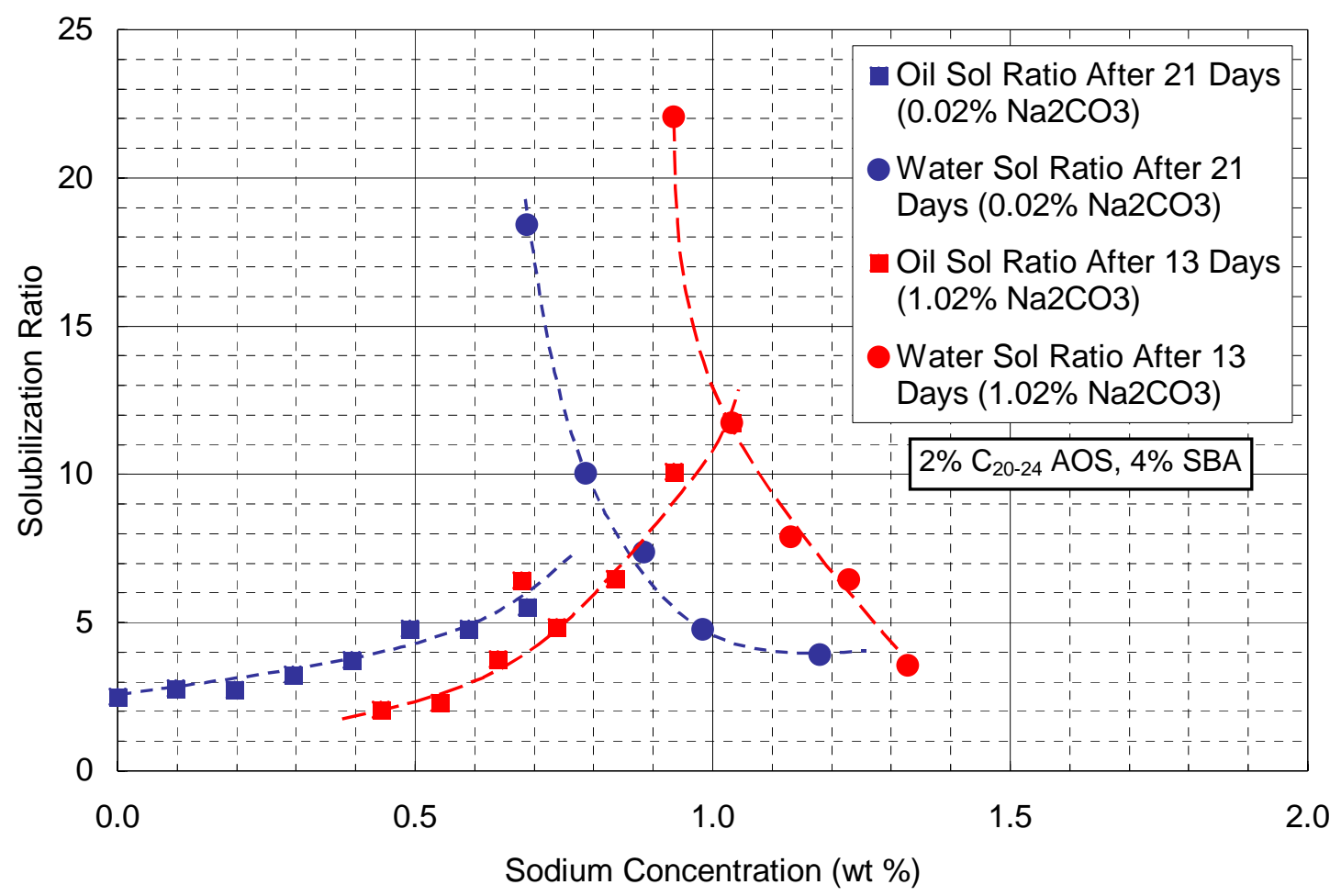

Figure 1.2-4. Effect of Sodium Carbonate on Optimal Salinity with ELK Crude, WOR 1:1 and $100^{\circ} \mathrm{C}$

These phase behavior tests were measured at their optimum salinities. The recorded measurements of oil and water solubilization ratios with respect to time are shown in Figure 1.2-5. A comparison of the two results shows that the solubilization ratio increases from about 9 to 12 with the addition of $1.02 \%$ sodium carbonate. The addition of sodium carbonate also helps reduce the equilibration time of the sample from about 90 days to about 12 days. These results show that the addition of sodium carbonate to the ELK crude oil could lead to a higher oil solubilization ratio and lower interfacial tension and quicker 
equilibration times. It would very likely also result in decreased surfactant adsorption on the reservoir rock, but adsorption tests have not been done.

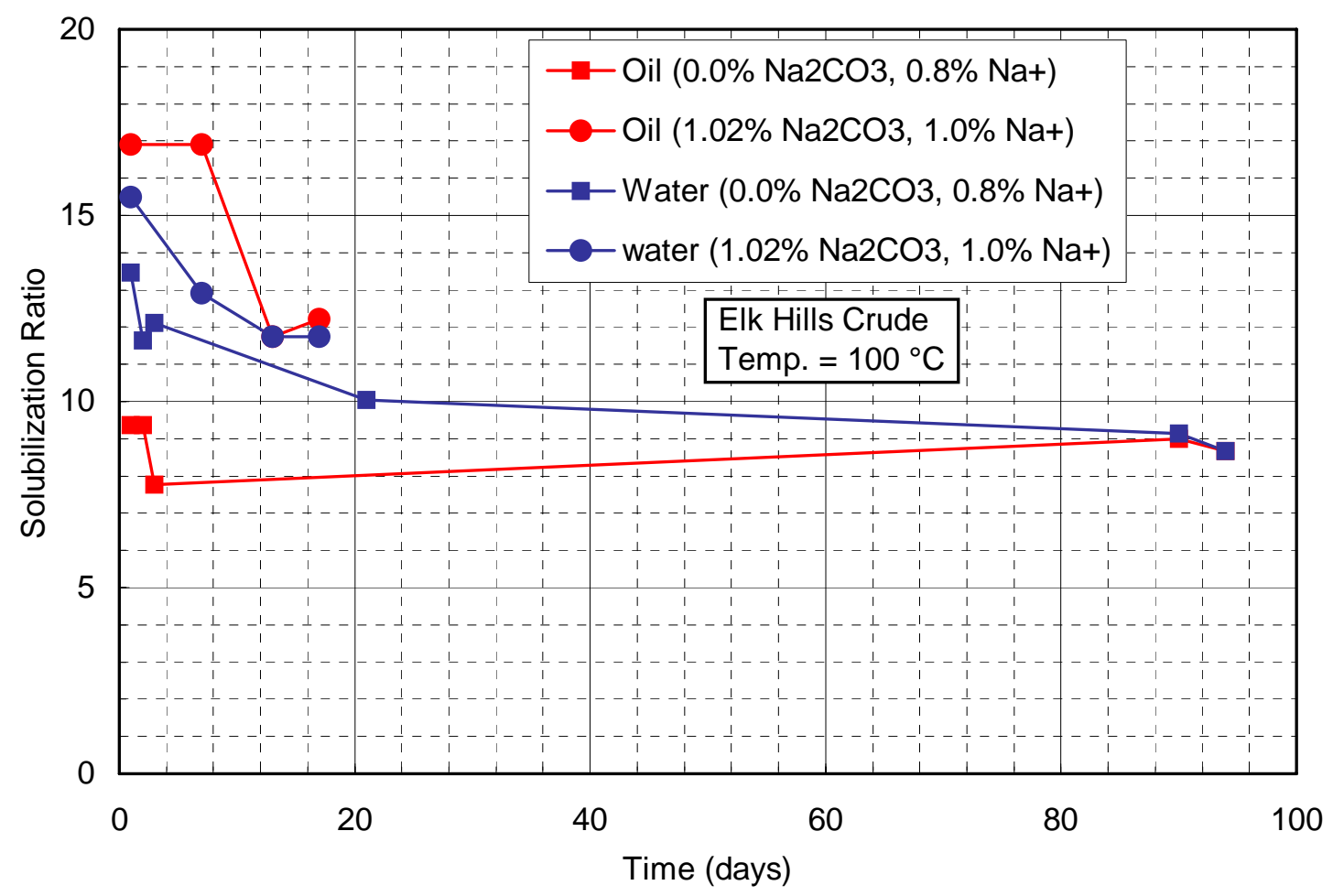

Figure 1.2-5. Effect of Sodium Carbonate on Equilibration Time with Elk Hills Crude, WOR $1: 1,100^{\circ} \mathrm{C}, 2 \% \mathrm{C}_{20-24}$ AOS, $4 \%$ SBA

Effects of sec-Butyl Alcohol (SBA). Phase behavior experiments done with varying concentrations of sec-butyl alcohol (SBA) in order to observe its effects on separation time, optimal salinity and optimum solubilization ratio. The results are presented below in Table 1.2-3. N67-7PO- $\mathrm{SO}_{4}$ and $\mathrm{C}_{15-18}$ IOS were selected as surfactant and co-surfactant respectively based on good results from previous phase behavior experiments with Midland Farms crude oil batch \#3 at $38^{\circ} \mathrm{C}$. 
Table 1.2-3. Effects of SBA and Sodium Carbonate on Phase Behavior

\begin{tabular}{|c|c|c|c|c|c|c|}
\hline $\begin{array}{c}\text { Surf } \\
(w t \%)\end{array}$ & $\begin{array}{c}\text { Co-surf } \\
\text { (wt \%) }\end{array}$ & $\begin{array}{c}\text { SBA } \\
(w t \%)\end{array}$ & $\begin{array}{c}\mathrm{Na}_{2} \mathrm{CO}_{3} \\
\text { (wt\%) }\end{array}$ & $\begin{array}{l}\text { Separation } \\
\text { Time (days) }\end{array}$ & $\begin{array}{l}\text { Optimum } \\
\text { Salinity, S* } \\
\text { (wt\% Na+) }\end{array}$ & $\begin{array}{l}\text { Optimum } \\
\text { Sol. Ratio } \\
\sigma^{*}(c c / c c)\end{array}$ \\
\hline 1.50 & 0.50 & 0 & 0 & gel & d.n.e. & d.n.e. \\
\hline 1.50 & 0.50 & 2 & 0 & 1 & 1.6 & 12 \\
\hline 0.75 & 0.25 & 2 & 0 & 2 & 1.7 & 12 \\
\hline 1.50 & 0.50 & 0 & 1 & 4 & 1.8 & 13 \\
\hline 0.75 & 0.25 & 2 & 1 & 2 & 1.7 & 13 \\
\hline 1.50 & 0.50 & 4 & 1 & 1 & 1.9 & 5 \\
\hline 0.75 & 0.25 & 2 & 2 & 2 & 2.0 & 13 \\
\hline
\end{tabular}

d.n.e. = Did not equilibrate;

WOR $=1: 1$

The phase behavior results in this table illustrate the trade-offs between phase separation time and optimum solubilization ratio when alcohol is added to the formulation. The addition of alcohol prevented gel formation and shortened separation times to 1 or 2 days. As SBA concentration increased to 4\%, optimum solubilization ratios dropped significantly from 12 to 5 . These and other results show that adding SBA reduces equilibration time and viscosity but at the expense of reducing the solubilization ratio at optimum salinity. The addition of up $2 \%$ SBA to the surfactant mixture with N67-7PO-SO ${ }_{4}$ and $\mathrm{C}_{15-18}$ IOS produced reasonable equilibration times while maintaining a sufficiently high solubilization ratio of about 12. Also, alcohols such as SBA can make the formulation more robust by giving low IFT across a wider range of electrolyte concentrations and is sometimes needed as well to prevent incompatibility between the polymer and surfactant.

\subsubsection{Results of Polymer Testing}

Mobility control is needed for an efficient surfactant flood to prevent fingering, reduce the effects of channeling caused by permeability layering and also to improve displacement sweep efficiency and lower surfactant retention. Either polymer must be added to the surfactant solution or foam must be used for mobility control. Both approaches are being investigated as part of this research. In this section, the results of polymer tests are presented. The only two commercially available, low-cost water-soluble polymers currently being used in EOR are xanthan gum and partially hydrolyzed polyacrylamide (HPAM). Each of these polymers has well known advantages and limitations. We report both a core flood experiment using xanthan gum polymer in Berea sandstone and a core flood experiment using HPAM in a dolomite core from the MF reservoir.

Preliminary experiments were conducted to verify performance of HPAM for use with a surfactant formulation consisting of $0.75 \%$ N67-7PO- $\mathrm{SO}_{4}, 0.25 \% \mathrm{C}_{15-18}$ IOS and 2\% SBA. There was no substantial effect on the microemulsion phase behavior at $2000 \mathrm{mg} / \mathrm{L}$ HPAM. Next, it was necessary to evaluate viscosity as a 
function of salinity. Figure 1.2-6 shows the relationship between viscosity and HPAM concentration at $4 \% \mathrm{NaCl}, 69.5 \mathrm{sec}^{-1}$ shear rate and $38 \mathrm{C}$. Figure 1.2-7 shows the relationship between viscosity of the HPAM polymer and salinity. Increasing salinity causes the viscosity to decrease rapidly until about $3 \% \mathrm{NaCl}$ after which it decreases only slowly. The range of interest for Midland Farms is 3 to $5 \mathrm{wt} \% \mathrm{NaCl}$ and the viscosity change was small in this range of salinity. At $1500 \mathrm{ppm}$ polymer concentration, the viscosity of an aqueous solution in this range of salinity is about $5 \mathrm{cp}$, which was deemed adequate for the purposes of testing the candidate surfactant formulation in MF cores since some permeability reduction was also expected and observed. The viscosity is also a function of shear rate. Figure 1.2-8 shows that this polymer under these conditions is only mildly shear thinning and taking a typical reservoir or core flooding shear rate of $69.5 \mathrm{sec}^{-1}$ as a benchmark value is more than adequate to characterize it for core flooding.

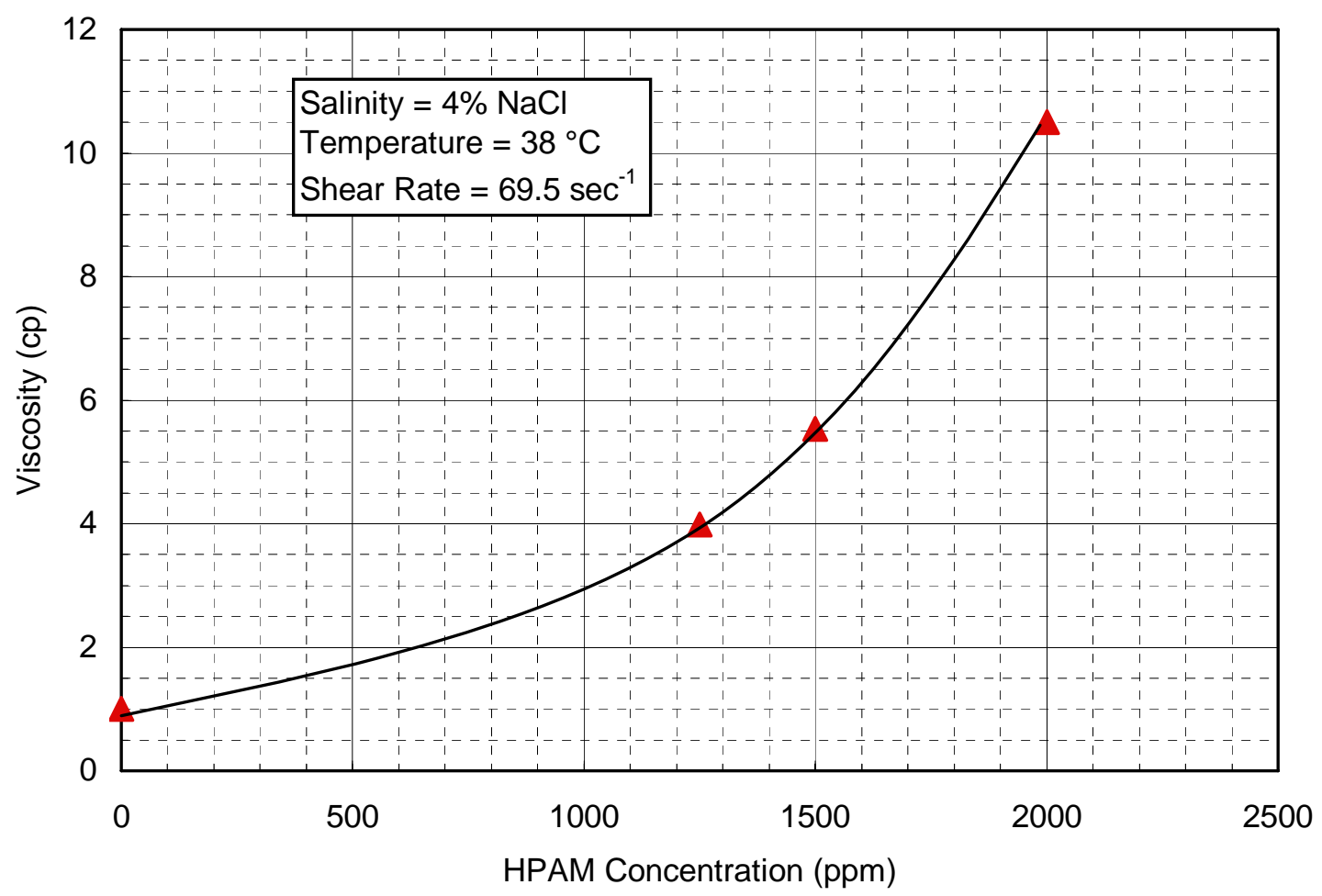

Figure 1.2-6. Viscosity of HPAM Polymer (Flopaam 3330S) in Brine 


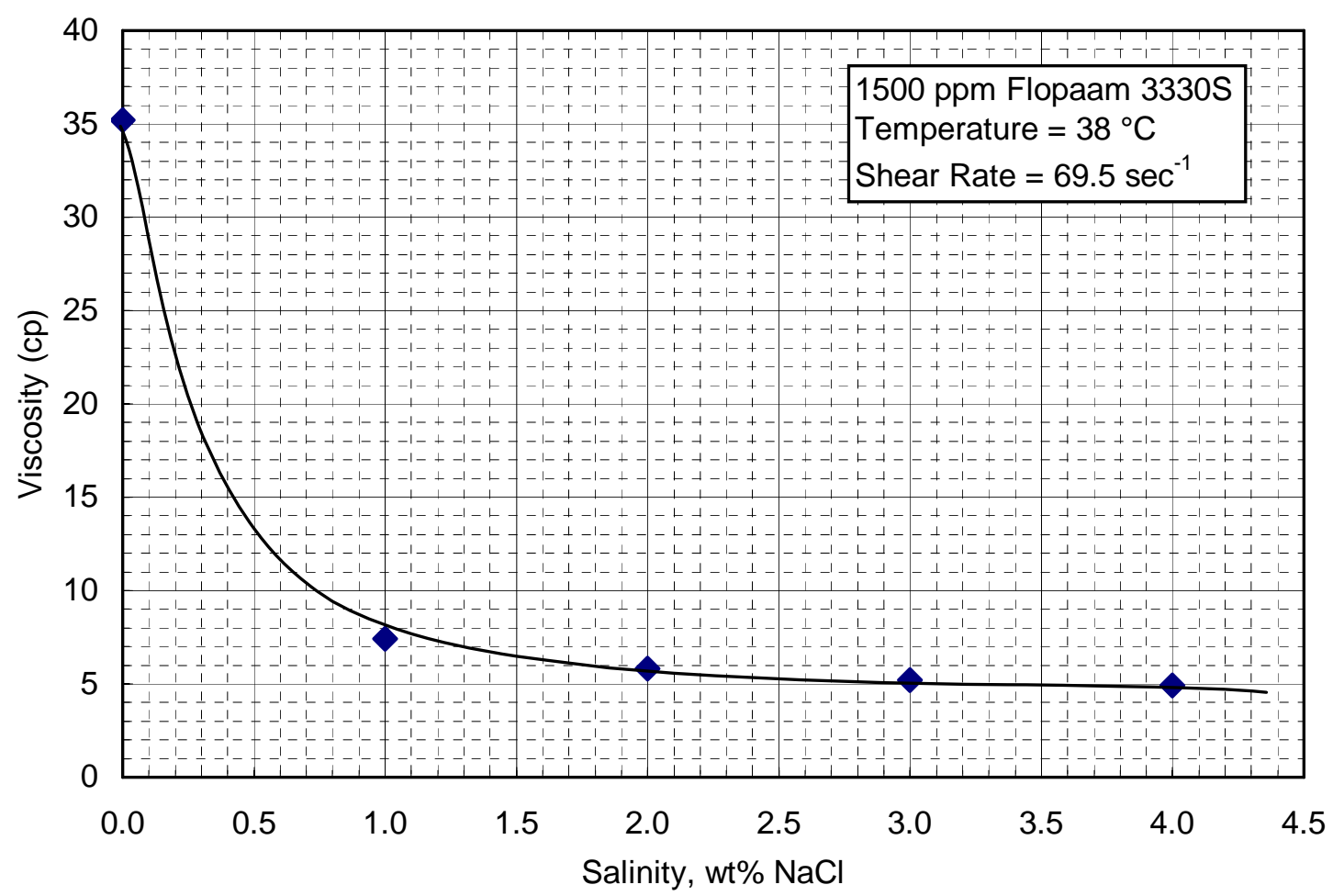

Figure 1.2-7. Viscosity for HPAM Polymer (Flopaam 3330S) in Brine

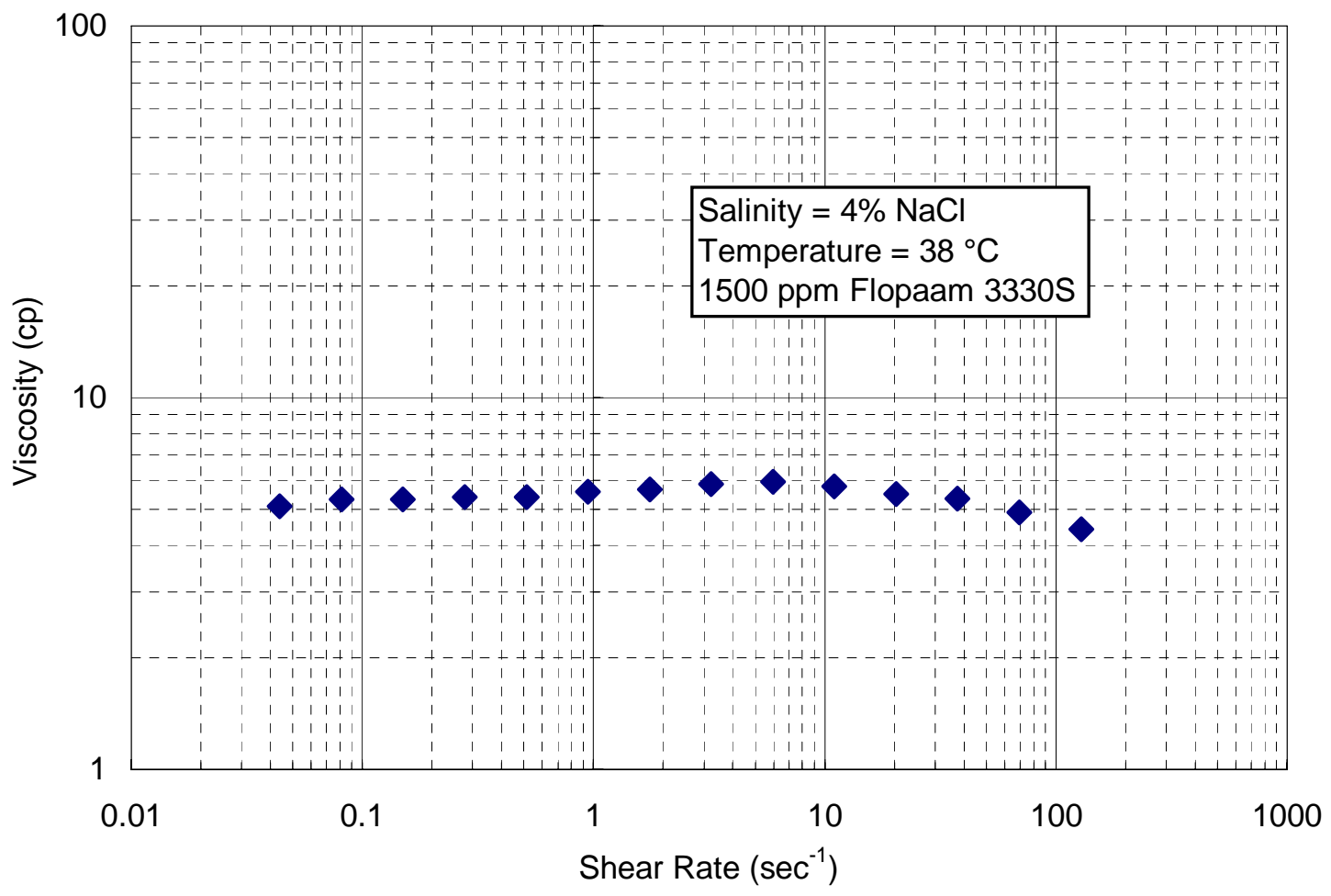

Figure 1.2-8. Viscosity for HPAM Polymer (Flopaam 3330S) in Brine 


\subsubsection{Results of Experiments to Characterize Rock Cores}

Berea rock is an outcrop sandstone commonly used for EOR core flooding and serves both as a useful benchmark because of the extensive amount of experimental data available for it, including previous studies by this team, and because it is serves as a surrogate for medium permeability sandstone reservoir rock. Furthermore, it can be easily obtained in large quantities and longer samples can be used for testing than with reservoir cores. For these and other reasons, it was used to evaluate one of the more promising surfactant formulations as a first step before reservoir cores were used.

OXY Permian provided core samples from the Midland Farms reservoir for us to evaluate surfactants in core floods. The MF reservoir is a dolomite formation with characteristics very different from Berea sandstone so considerable characterization measurements were needed before it could be used in surfactant core flooding. Using dolomite cores was much more difficult and complicated than testing in sandstones. Very little surfactant EOR data have been reported for carbonate or dolomite reservoir rocks, so this study also represented a more significant innovation. Also, the cooperation of OXY geologists and engineers was needed and very significant in this study.

Berea core preparation. Uniform Berea blocks were drilled to make two-inch diameter cylindrical cores and typically one foot in length. Due to previous experience with our stock of Berea blocks no further characterization tests were performed to examine heterogeneity. Each core was fitted with specially machined, plastic end pieces with 1/32 in. headspaces and then potted in epoxy contained within a Lexan outer sleeve. Each core was saturated with brine under vacuum and then flooded with synthetic formation brine. The pressure drop across the core was measured to obtain a baseline value, and pressure drop readings vs flow rate were used to calculate the brine permeability for the core.

Dolomite core testing and preparation. MF core samples were potted in epoxy resin by the same procedures as for Berea sandstone cores. Carbonate and dolomite rocks often have local, small-scale irregularities such as vugs, fractures and highly cemented, low permeability nodules that affect flow. These features do not significantly impact large-scale processes where fluids can move around them, but in a core plug any of these features potentially can result in failed experiments. It was therefore important to screen the rocks for properties affecting their permeability and pore volume.

Air permeability tests. The MF core samples received from OXY were tested with a mini air permeameter as a first step in a core selection process. Cores with verifiable and consistent air permeability values were selected for further testing. A summary of selected data are presented in Table 1.2-4. 
Table 1.2-4. Summary of MF Core Permeability

\begin{tabular}{|c|c|c|}
\hline \multirow{2}{*}{$\begin{array}{c}\text { Location } \\
\text { (Sample I.D.) }\end{array}$} & \multicolumn{2}{|c|}{ Air Permeability } \\
\cline { 2 - 3 } & Average (md) & Standard Deviation (md) \\
\hline MFU629/4823A & 41 & 33 \\
\hline MFU629/4824A & 195 & 109 \\
\hline MFU637/4834D & 224 & 120 \\
\hline MFU637/4838B & 61 & 23 \\
\hline MFU637/4831A & 15 & 10 \\
\hline
\end{tabular}

The core flood experiments were originally intended to use outcrop dolomite samples provided by OXY so that larger samples could be used. When air permeability measurements were performed on these outcrop samples, very low permeability values that were not representative of the oil reservoir were observed (see Table 1.2-5). Therefore, subsequent core flood experiments used actual field cores rather than outcrop samples.

Table 1.2-5. Summary of Outcrop Dolomite Rock Permeability

\begin{tabular}{|c|c|c|}
\hline \multirow{2}{*}{$\begin{array}{c}\text { Location } \\
\text { (Sample I.D.) }\end{array}$} & \multicolumn{2}{|c|}{ Air Permeability } \\
\cline { 2 - 3 } & Average (md) & Standard Deviation (md) \\
\hline Boulder 1 & 3.7 & 0.7 \\
\hline Stone Canyon 2 & 3.2 & 1.3 \\
\hline Stone Canyon 3 & 1.2 & 0.2 \\
\hline
\end{tabular}

High Resolution X-ray Computed Tomography (HRXCT) scans. CT scans were conducted on MF core plugs that passed the screening for sufficiently high air permeability. HRXCT scans were performed by Dr. Richard Ketchum at the UT CT laboratory. Heterogeneity created from vugs, fractures and low permeability nodules were noted in several cores. The CT data was used to select reservoir core plugs to use in core flooding experiments. Figure 1.2-9 displays a few of the many images of a $6 \mathrm{~cm}$ long $\times 3.8 \mathrm{~cm}$ diameter core plug. In these images, lighter areas indicate denser materials with less porosity whereas vugs and high porosity appear as dark spots or darkened areas. Generally permeability and porosity are correlated although in a very complicated way that varies significantly from one rock type to another. Nevertheless, these images were very useful in understanding the rock and selecting samples for core flooding. 

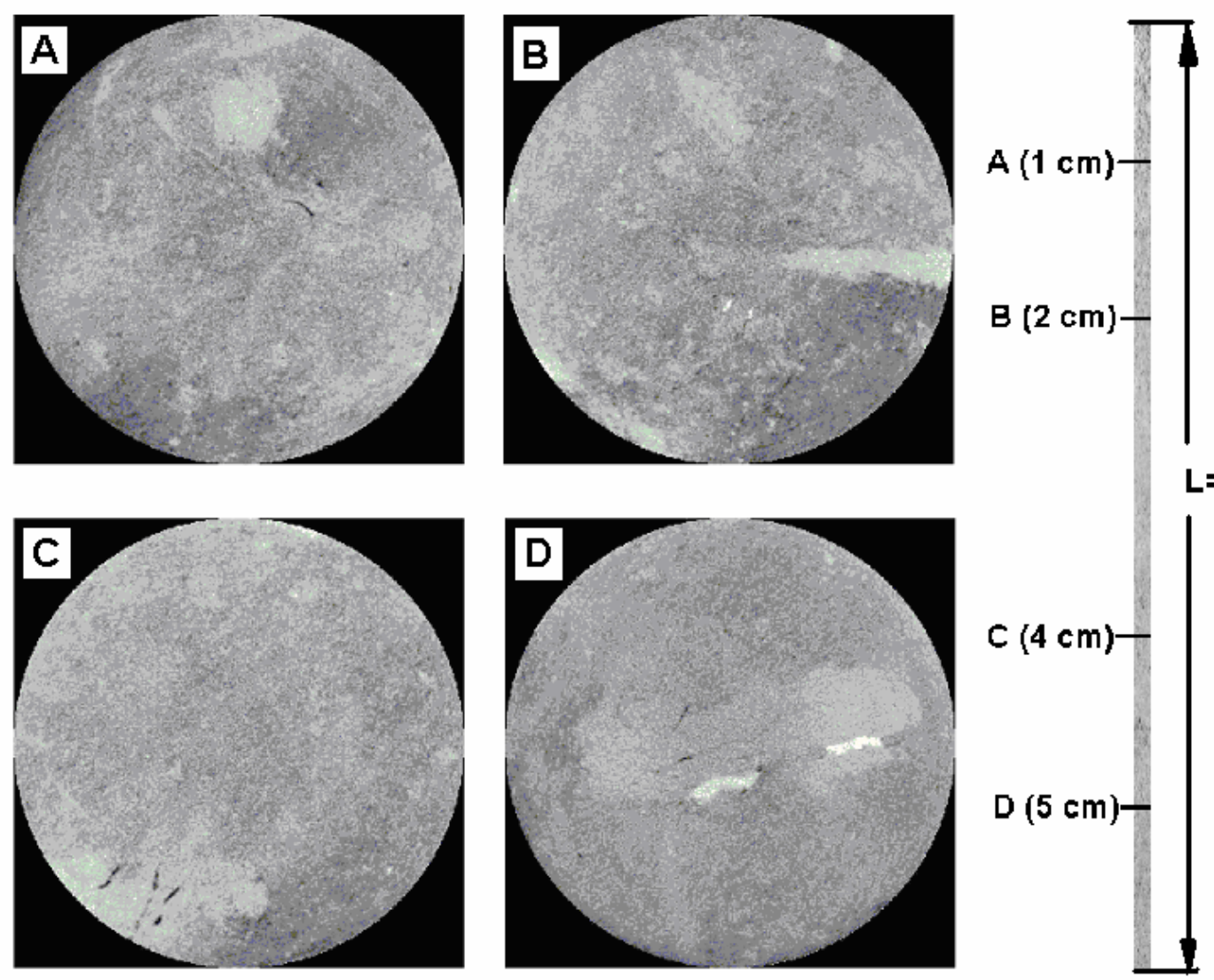

low density $\rightarrow \square \square \square \square \rightarrow$ high density

Figure 1.2-9. CT Scans of MF54 Dolomite Core

Low permeability nodules can be seen in images $A, B$, and $D$, but these are isolated and do not propagate through the entire length of the core. The overall cross-sectional area of these nodules is not large and probably would not greatly affect core permeability.

Images from a CT scan for a second core are shown in Figure 1.2-10. This core was scanned both vertically and horizontally allowing us to see changes along the entire length of the core. The images show this core to have more permeable ends and a less permeable middle. The top of the core (Image A) also appears to have lots of vugs. Core plugs with less extreme heterogeneities were marked for use in further tests leading up to a surfactant core flood. 

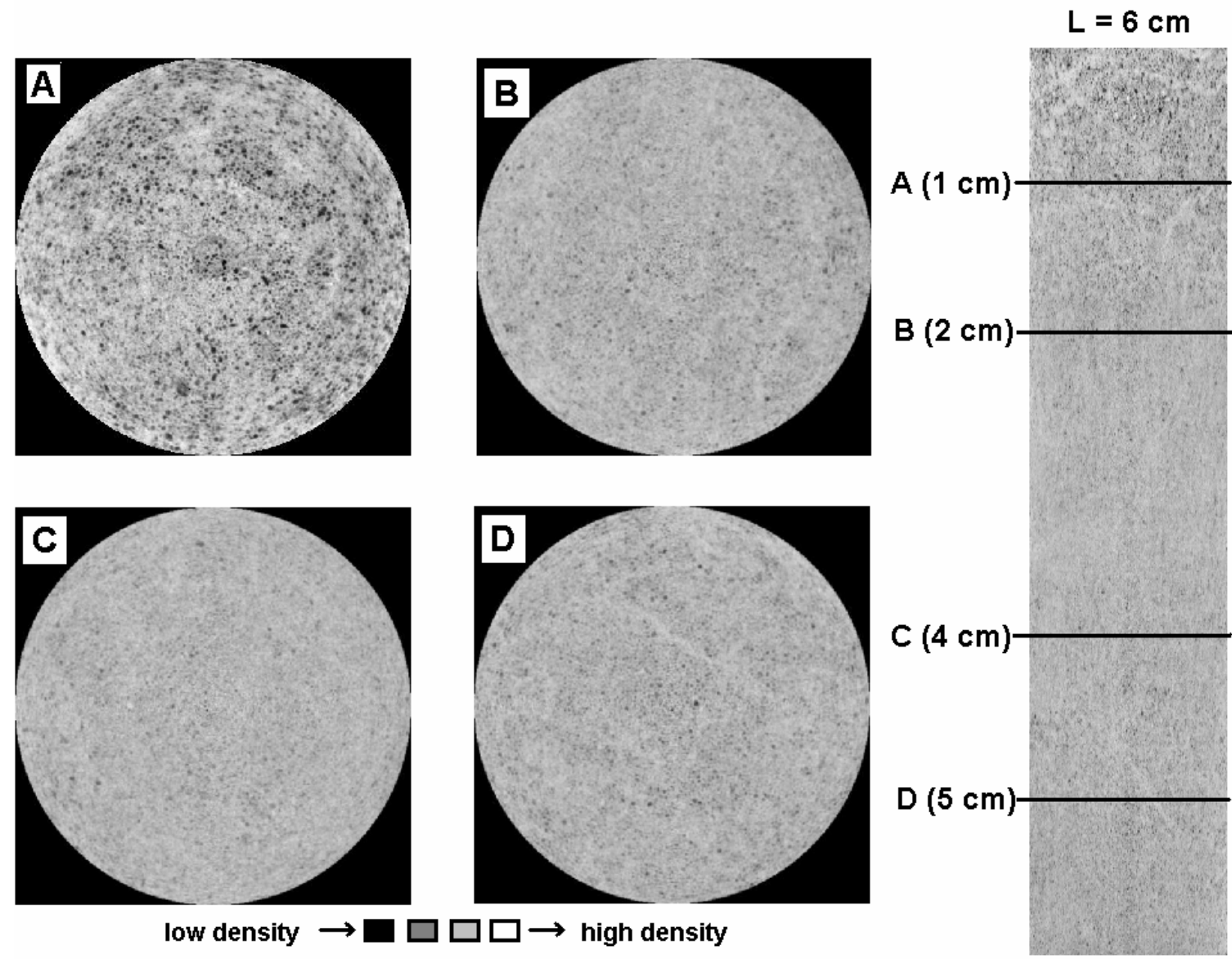

low density $\rightarrow \square \square \square \square \rightarrow$ high density

Figure 1.2-10. CT Scans of MF11 Dolomite Core

Conservative tracer tests. Core plugs were saturated with a synthetic reservoir brine and baseline pressure drop and brine permeability were measured. A conservative tracer, isopropyl alcohol (IPA), was added to the water and injected into the core. Tracer data are a useful indication of heterogeneity such as secondary porosity or dead end pores among other features. Figure 1.2-11 shows the tracer breakthrough data for one of the core plugs tested. The pore volume was estimated based upon the first temporal moment of the tracer data. 


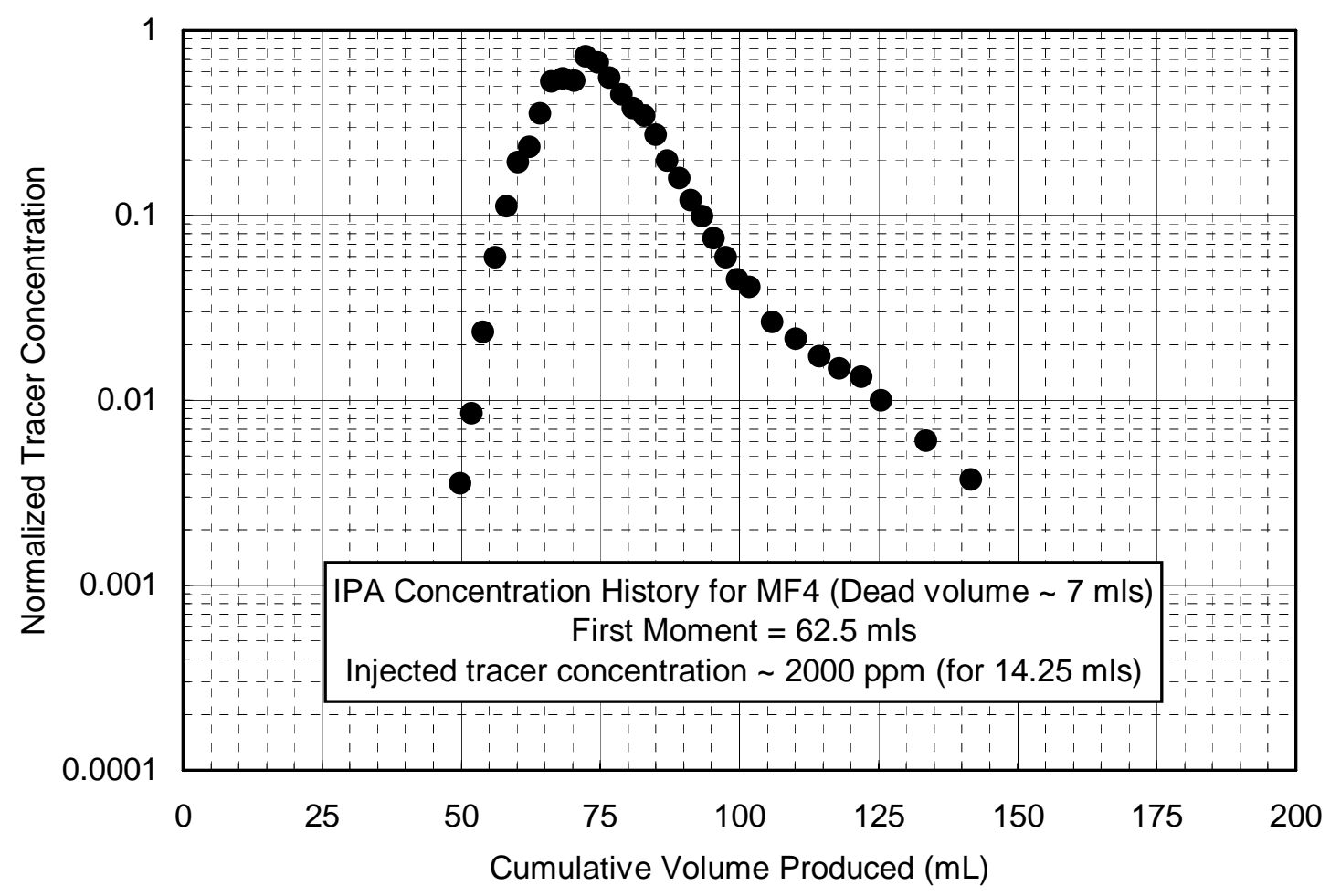

Figure 1.2-11. IPA Tracer Breakthrough Curve

Polymer retention and degradation. An 18 md core plug from well MFU\#623 was prepared to study the polymer transport and specifically to verify that the polymer did not plug the core. The core was flooded with more than 4 pore volumes of $1000 \mathrm{ppm}$ HPAM (Alcomer 60RD) containing $1.0 \% \mathrm{Na}^{+}, 0.88 \% \mathrm{Cl}^{-}$, and $0.56 \%$ $\mathrm{CO}_{3}{ }^{-2}$. The effluent from the core was collected and its viscosity tested. Figure 1.2-12 presents viscosity data at varying shear rates and shows that there was no measurable difference in viscosity between the injected polymer solution and produced polymer effluent. The viscosity data indicate the polymer transport is acceptable and that there were no problems with polymer degradation or excessive retention in this low permeability core. The pressure drop data for the polymer flood are presented in figure 1.2-13. 


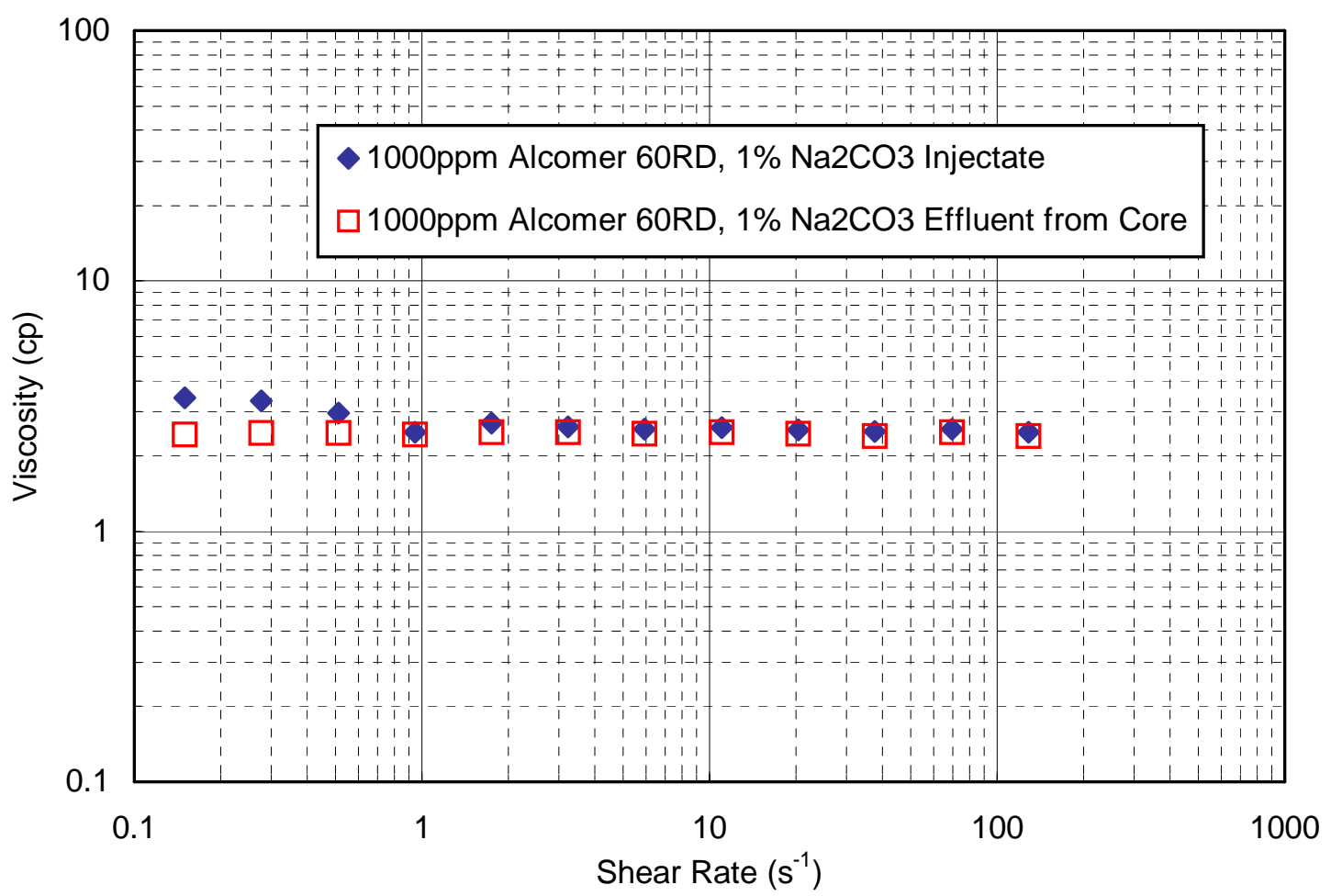

Figure 1.2-12. Viscosity for HPAM polymer Injectate and Effluent

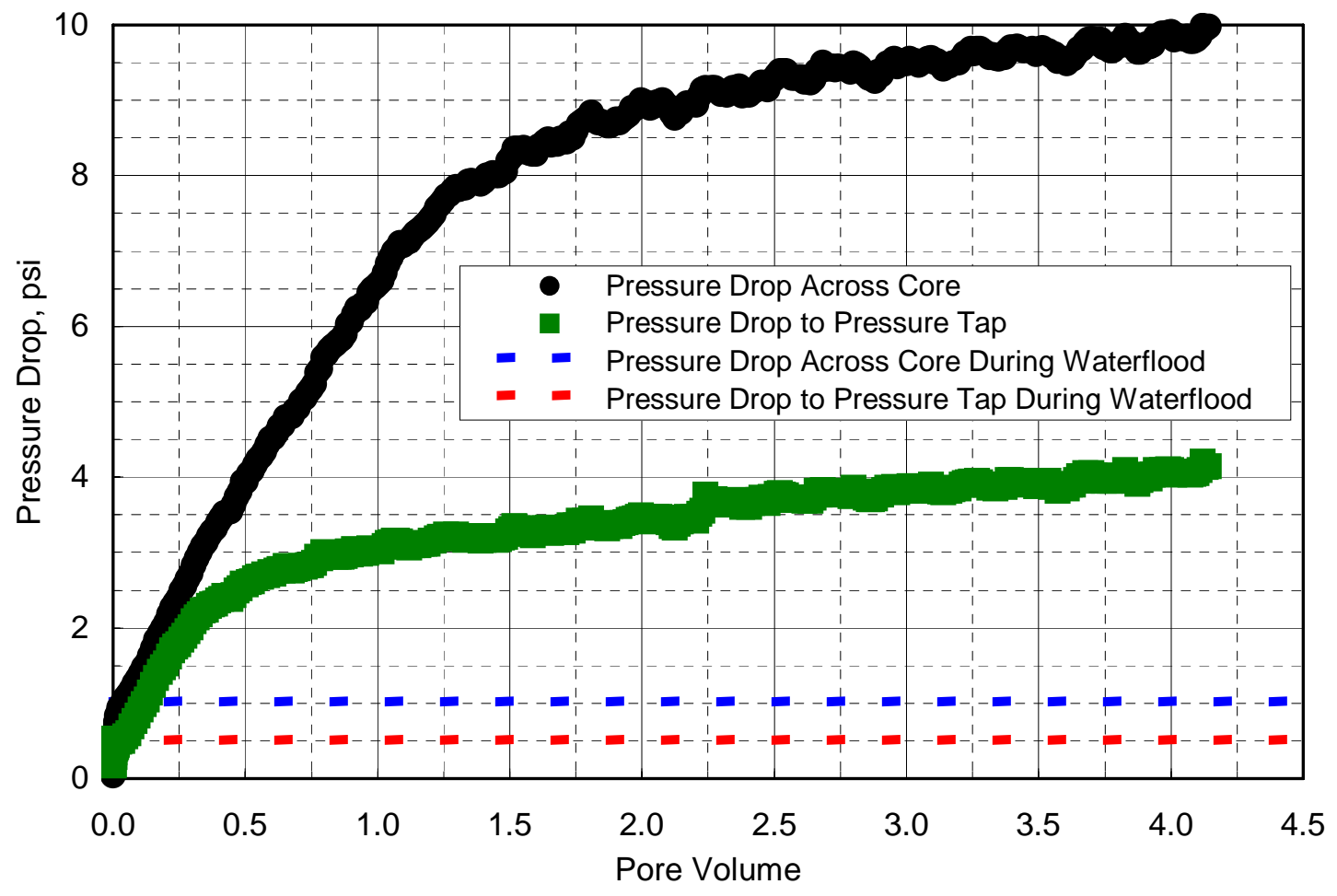

Figure 1.2-13. Pressure Drop for HPAM Injection Test 
Surfactant adsorption. The adsorption of surfactant in the dolomite rock was expected to be high. Concurrent experiments by team members at Rice University had shown that the addition of sodium carbonate could minimize surfactant adsorption. An experiment was devised to quantify the level of adsorption in a MF core. An $18 \mathrm{md}$ MF core was prepared and injected with a $0.6 \mathrm{PV}$ slug of surfactant-polymer solution consisting of $1.5 \% \mathrm{~N} 67-(\mathrm{PO})_{7}-\mathrm{SO}_{4}$, $0.5 \% \mathrm{C}_{20-24} \mathrm{AOS}, 4 \% \mathrm{SBA}$ and $2000 \mathrm{ppm}$ Alcomer 60 RD HPAM polymer with $1 \% \mathrm{Na}_{2} \mathrm{CO}_{3}$. The surfactant slug was followed by a polymer drive solution with a lower electrolyte concentration to create a salinity gradient across the core. The effluent samples produced during the core flood were collected and analyzed for surfactant concentration using an anionic surfactant-specific electrode and Hyamine $^{\mathrm{TM}}$ titration assays. The surfactant breakthrough and recovery curves are shown in figure 1.2-14.

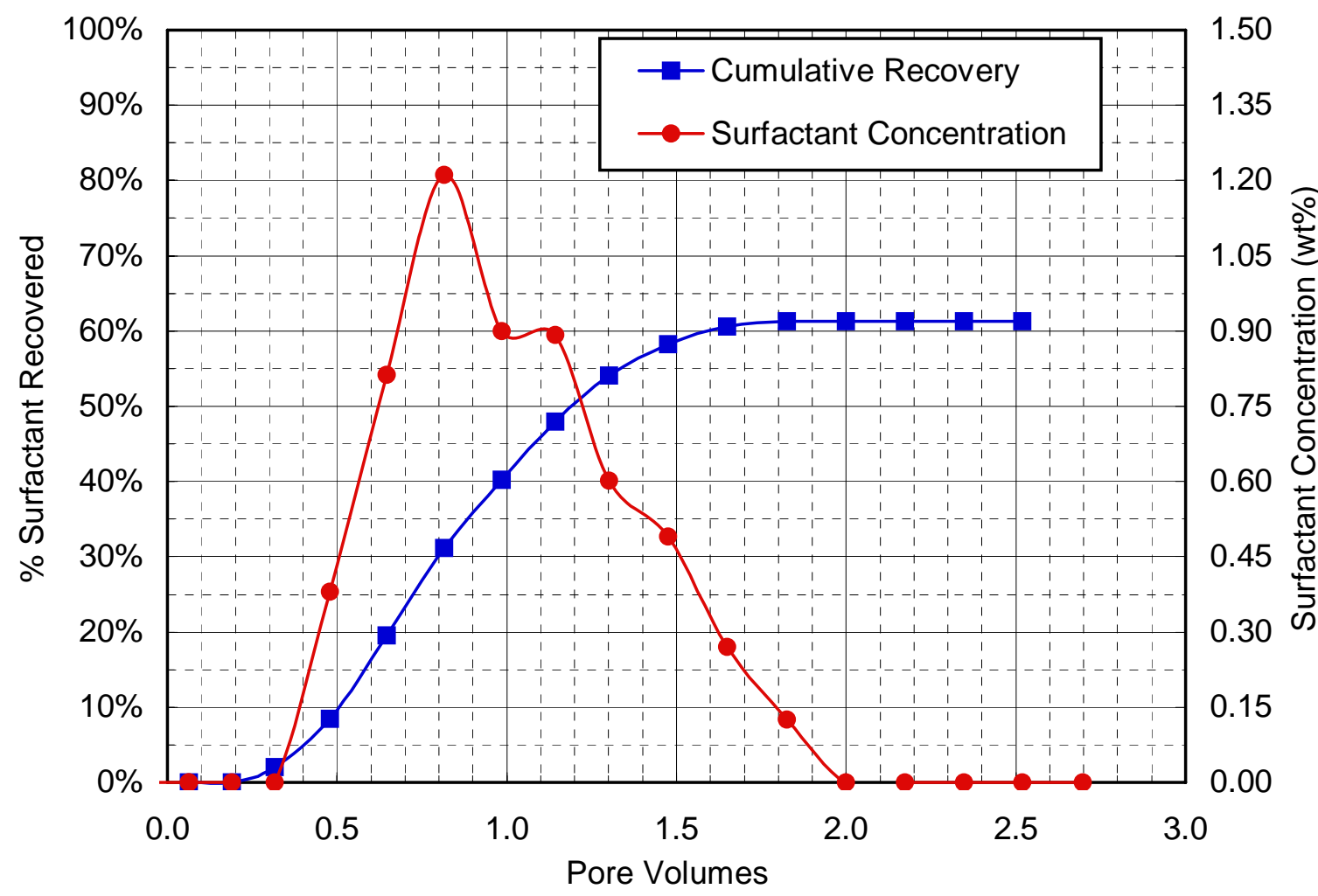

Figure 1.2-14. Surfactant Recovery and Concentration Curves

The surfactant recovery data show that $88 \mathrm{mg}$ of the injected surfactant were retained by the core during the flood. This correlates to a surfactant adsorption value of $0.54 \mathrm{mg}$ of surfactant per gram of rock.

\subsubsection{Results of Core Flood Experiments to Evaluate Oil Recovery}

Core flooding experiments in this project required an approach to minimize the use of valuable and scarce field cores. Each experiment is considered a building 
block for subsequent work. The results and lessons learned from each experiment were incorporated into subsequent tests in a fine-tuning process.

Once suitable surfactant formulations had been identified and tested in the phase behavior tests, a limited number of core floods were done. As described in the previous section, the rock properties of sandstone and dolomite cores were evaluated before conducting any core floods. The first two core flooding experiments were conducted in Berea sandstone cores with octane as the surrogate oil. These experiments were performed at $60^{\circ} \mathrm{C}$ as they were not reservoir specific.

The first core flood was performed in a $448 \mathrm{md}$ Berea core (\#1) with a waterflood residual oil saturation of 0.38 . A $0.10 \mathrm{PV}$ slug of $4 \%$ surfactant/8\% SBA solution was injected into the core followed by a $1.9 \mathrm{PV}$ polymer drive. The oil recovery from this core flood was about $68 \%$ with a final oil saturation of $11 \%$. Due to surfactant retention, no surfactant was recovered in the effluent. A surfactant retention value of $0.39 \mathrm{mg} / \mathrm{g}$ of rock was measured. The data collected during this experiment indicated the need for a larger surfactant slug and for the use of sodium carbonate in both the slug and the polymer drive to help minimize surfactant retention in the core. The results also showed the need for tighter control on the salinity of the injected fluids.

A second core flood was performed in a 400 md Berea core (\#2) with a waterflood residual oil saturation of 0.31 . A larger surfactant slug of $0.20 \mathrm{PV}$ containing $4 \%$ surfactant $/ 8 \%$ SBA solution was injected into the core. The salinity of the surfactant slug and the polymer drive solution was maintained closer to optimum design parameters throughout the injection period. This core flood resulted in a final oil saturation of 0.05 with an oil recovery of $83 \%$. Surfactant adsorption was decreased to $0.36 \mathrm{mg} / \mathrm{g}$ of rock due to the addition of sodium carbonate. The lower surfactant retention and larger surfactant slug size and the better salinity control helped increase oil recovery.

These two experiments were followed by a Berea sandstone core flood (\#3) containing MF2 crude oil with a waterflood residual oil saturation was 0.35 . This experiment introduced additional difficulties to the process by reducing the temperature to $38^{\circ} \mathrm{C}$ (the actual MF reservoir temperature) and by using a synthetic reservoir brine to saturate the core. A salinity gradient was used in this core flood to improve its performance. The initial brine permeability $(100 \%$ water saturation) was $338 \mathrm{md}$ and the brine permeability at residual oil saturation was $28 \mathrm{md}$. The initial brine salinity was $6.1 \mathrm{wt} \%$ total dissolved solids (TDS), which is the same as the reservoir brine. Figure 1.2-15 shows the pressure gradient across the Berea core approximately one foot in length.

A 0.20 PV surfactant slug with $3 \%$ N67-(PO) $7-\mathrm{SO}_{4}, 1 \% \mathrm{C}_{20-24} \mathrm{AOS}, 8 \%$ SBA with $0.02 \%$ sodium carbonate and $1000 \mathrm{ppm}$ xanthan gum polymer was injected into the core. This was followed by a 2.7 PV polymer drive with sodium carbonate 
added to the polymer solution. The surfactant retention was $0.41 \mathrm{mg}$ of surfactant per gram of rock. This core flood recovered $92 \%$ of the oil in the core, reducing the oil to a final saturation of 0.027 . The cumulative oil recovery and the fractional flow of oil are shown on figure 1.2-16. The pressure gradient during the surfactant/polymer slug and the polymer drive was about the same as the water flood pressure gradient of $2.3 \mathrm{psi} / \mathrm{ft}$ (as shown in figure 1.2-15). The low pressure gradient indicates there were no problems with plugging or surfactant/polymer transport during this core flood.

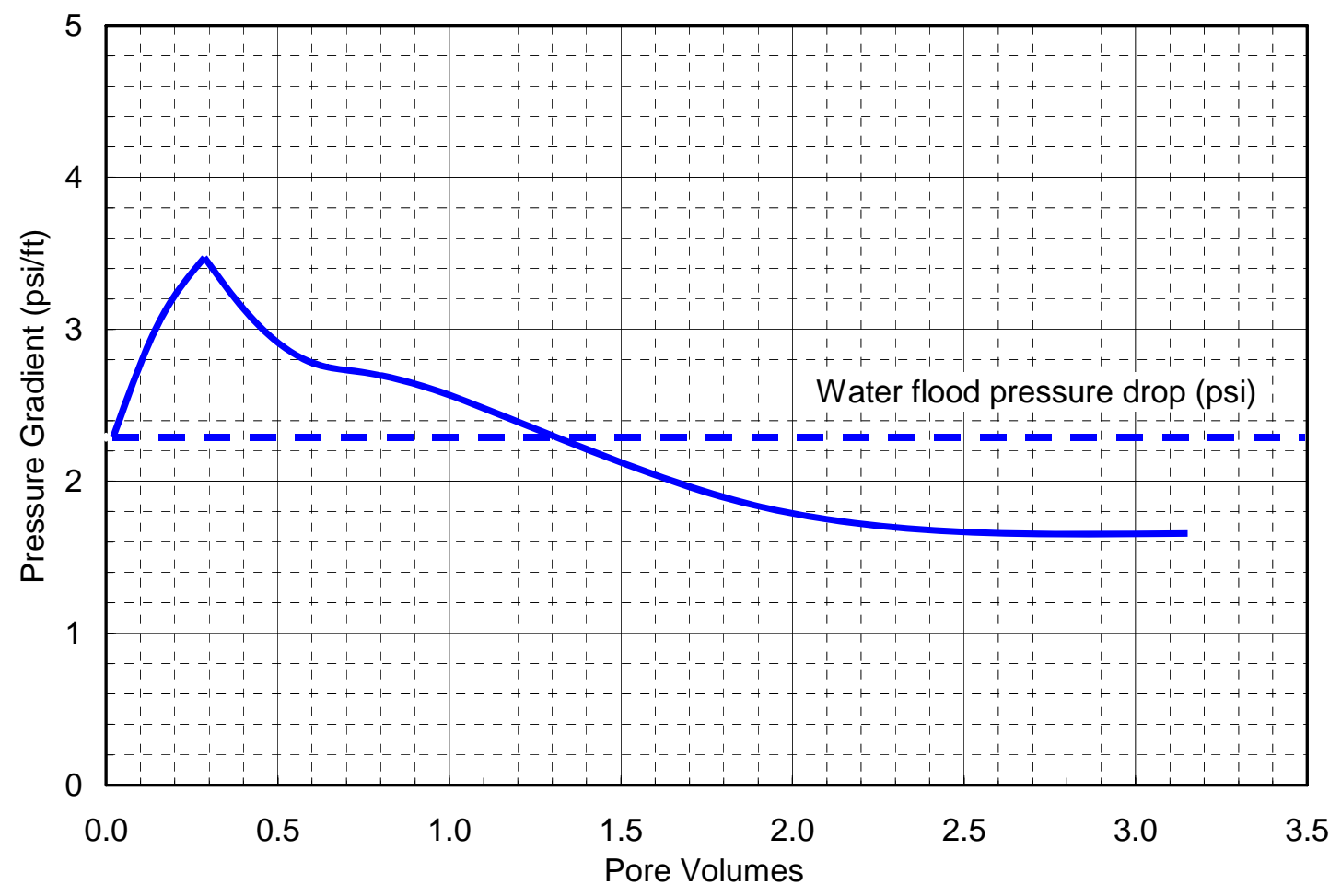

Figure 1.2-15. Pressure Drop for Berea Core \#3 with MF2 Crude 


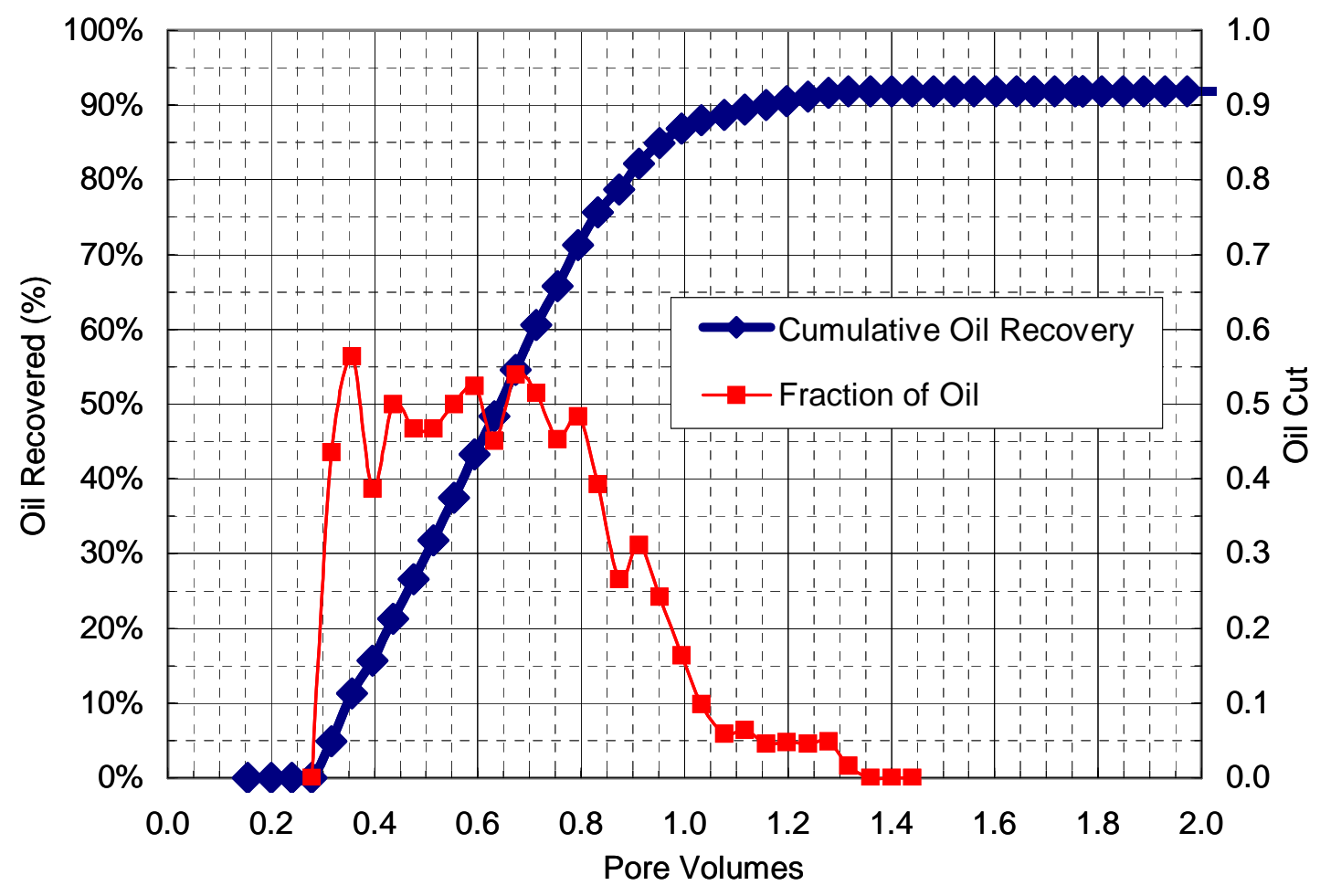

Figure 1.2-16. Oil Recovery in Berea Core \#3 with MF2 Crude

The results of this set of experiments indicated that the selected surfactant formulation worked well in the Berea sandstone cores with both surrogate oil and field crude oil. These results also confirm the value and validity of the phase behavior screening approach to core flooding as the research team was able to achieve greater than $90 \%$ oil recovery with just a few core flooding experiments.

Midland Farms Core Flood \#1. After successfully demonstrating a sandstone core flood using a field crude oil, a dolomite reservoir core from the MF reservoir was selected for the next core flood. The dolomite core (\#1) was saturated with a synthetic formation brine and brine flooded to a residual oil saturation of 0.23 . The core had an initial brine permeability of $92 \mathrm{md}$ and a brine permeability of 8 $\mathrm{md}$ at residual oil saturation.

Due to additional phase behavior observations, the surfactant formulation from the last Berea sandstone core flood was modified. The surfactant formulation substituted $\mathrm{C}_{15-18}$ IOS for $\mathrm{C}_{20-24}$ AOS to help reduce the need for SBA and improve the behavior at low surfactant concentrations. The change in the cosurfactant increased the optimum salinity of the slug making it closer to the formation salinity of $6.1 \mathrm{wt} \%$. The surfactant slug contained $2000 \mathrm{ppm}$ of a hydrolyzed polyacrylamide (HPAM) polymer for mobility control. A 0.40 PV slug of $2 \%$ surfactant $/ 4 \%$ SBA solution was used in this test. This was followed by a 2000 ppm Alcomer 60RD polymer drive solution. The surfactant slug and the 
polymer drive both contained $1 \%$ sodium carbonate to reduce the amount of surfactant adsorption.

This core flood yielded an oil recovery of approximately $70 \%$ leaving a chemical residual oil saturation of $6.9 \%$. Most of this oil was recovered as free oil, with approximately $15 \%$ of it in an emulsion. The oil in the emulsion was separated via centrifugation so it could be measured. Approximately $0.10 \mathrm{PV}$ of emulsion remained after centrifugation. This volume of oil was not included in the oil recovery results, so the actual oil recovery is slightly higher than $70 \%$. Surfactant breakthrough occurred at $0.12 \mathrm{PV}$, which was earlier than expected and is likely due mostly to inadequate mobility control in this core flood and the adverse effects of channeling and fingering. $68 \%$ of the injected surfactant was recovered, which gives a surfactant retention of $0.21 \mathrm{mg} / \mathrm{g}$ of rock. This is significantly lower than retention values measured in previous experiments. Lower than expected pressure gradients indicated that mobility control was unfavorable. This may explain the early surfactant breakthrough, low surfactant retention, and lower than expected oil recovery. As a result a higher polymer resistance factor was targeted for the next flood by using a higher molecular weight HPAM polymer.

Midland Farms Core Flood \#2. A second carbonate core flood (\#2) was designed to address the problems identified in the previous one. Core material was crushed and analyzed for anhydrite using X-ray Diffraction as shown figure 1.2-17. The magnitude of the peak corresponding to anhydrite indicated this sample of rock had roughly $1.2 \%$ anhydrite in it. Sulfate was measured in the produced brine from the core to test for dissolved anhydrite. Results reported in Table 1.2-6 show that sulfate is present in quantities consistent with anhydrite dissolution. These levels of sulfate correspond to high concentrations of dissolved calcium and this was verified by some qualitative measurements of $\mathrm{Ca}^{++}$in the produced brine on the order of $1200 \mathrm{ppm}$. Therefore, sodium carbonate was not used due to concerns about precipitation of calcium carbonate. It is unlikely that sodium carbonate could be used in a rock with anhydrite present, but some further investigation is needed to better understand the aqueous chemistry and verify this conclusion. 


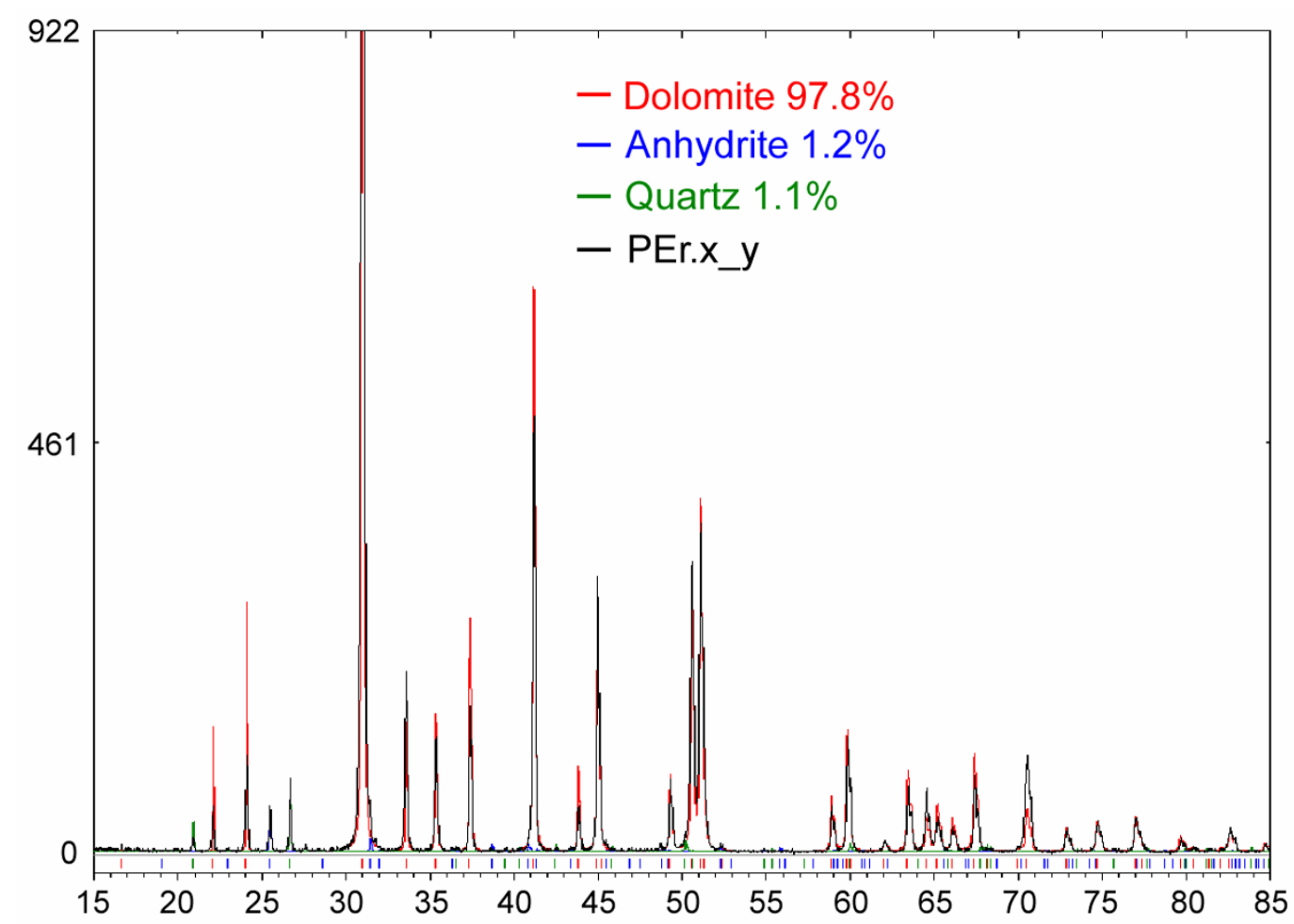

Figure 1.2-17. XRD Data from Crushed MFU Well \#629 Rock Sample Courtesy of Dr. Steve Swinnea, University of Texas at Austin Materials Engineering Department.

Table 1.2-6. Sulfate Measured in Produced Formation Brine

\begin{tabular}{|c|c|}
\hline Effluent Sample & Sulfate Concentration [mg/L] \\
\hline Tube \#8 - analysis \#1 & 1238 \\
\hline Tube \#8 - analysis \# 2 & 1686 \\
\hline Tube \#9 - analysis \# 1 & 2094 \\
\hline Tube \#9- analysis \# 2 & 2615 \\
\hline
\end{tabular}

The MF core used for core flood \#2 was saturated with the synthetic formation brine containing about 2400 ppm Ca++ and oil flooded with MF3 crude oil. The initial brine permeability was $166 \mathrm{md}$ and the brine permeability at a residual oil saturation of 0.39 was $5 \mathrm{md}$. A surfactant slug of $0.8 \mathrm{PV}$ consisting of $0.75 \%$ N67-(PO) $)_{7}-\mathrm{SO}_{4}, 0.25 \% \mathrm{C}_{15-18}$ IOS, 2\% SBA, and 1500 ppm Flopaam $3330 \mathrm{~S}$ polymer was injected into the core. This was followed by a polymer drive of 2.5 PV of 1200 ppm Flopaam 3330S solution. No surfactant breakthrough was observed prior to the start of the polymer drive injection.

Surfactant breakthrough occurred at $1.3 \mathrm{PV}$ and the peak concentration was reached at $1.5 \mathrm{PV}$. The injected surfactant mass was $640 \mathrm{mg}$ and $322 \mathrm{mg}$ of surfactant was retained by the core or $0.43 \mathrm{mg}$ surfactant per gram of rock. The cumulative oil recovery and the oil cut for the core is presented in figure 1.2-18. 
The flood recovered $95 \%$ of the oil in the core. Approximately $90 \%$ of the oil was recovered in a clean oil bank and $5 \%$ in the form of an emulsion.

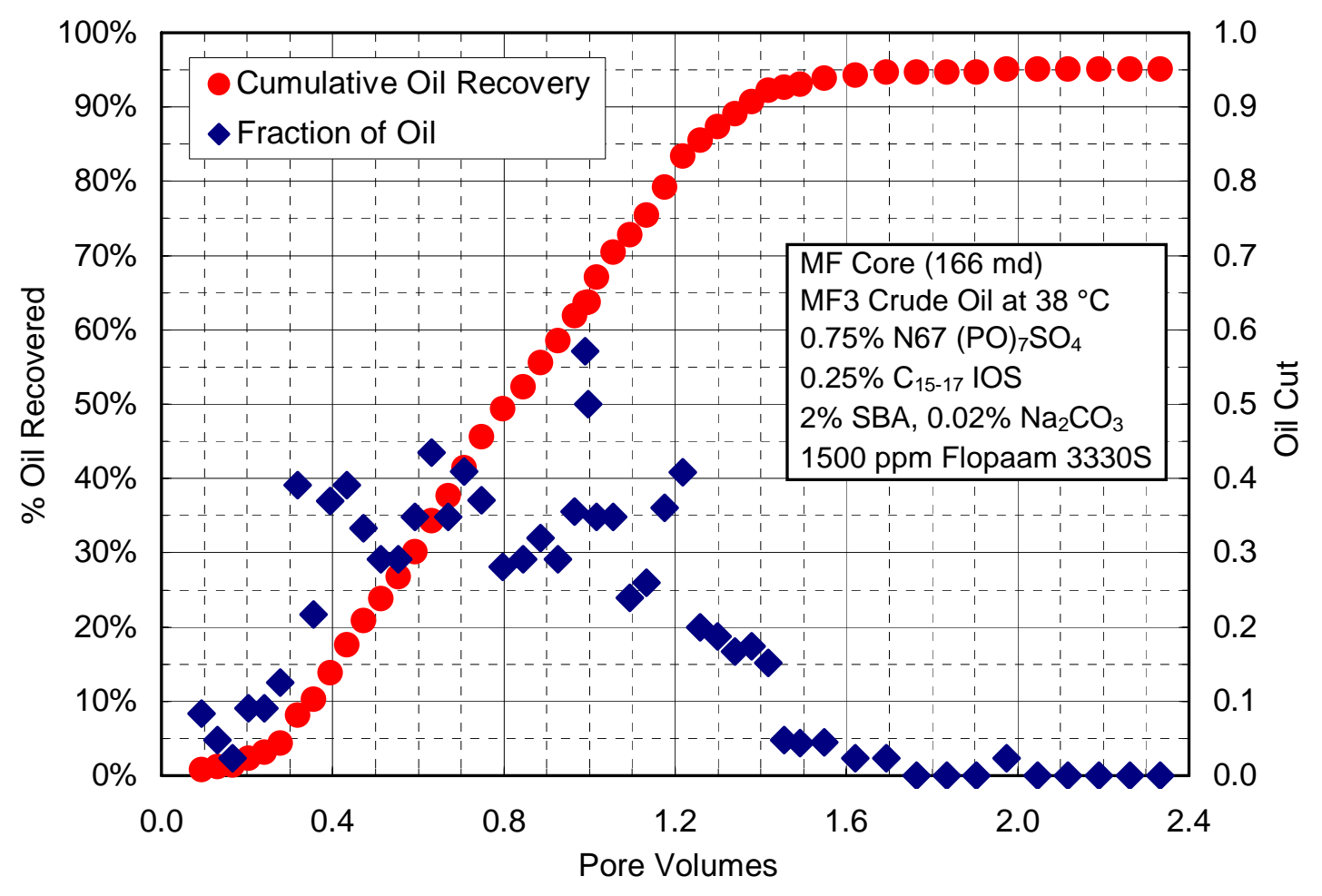

Figure 1.2-18. Oil Recovery for MF Core \#2 with MF3 Crude Oil

The pressure drop data are shown in figure 1.2-19. The pressure drop increased during the flood but there were no indications of plugging. 


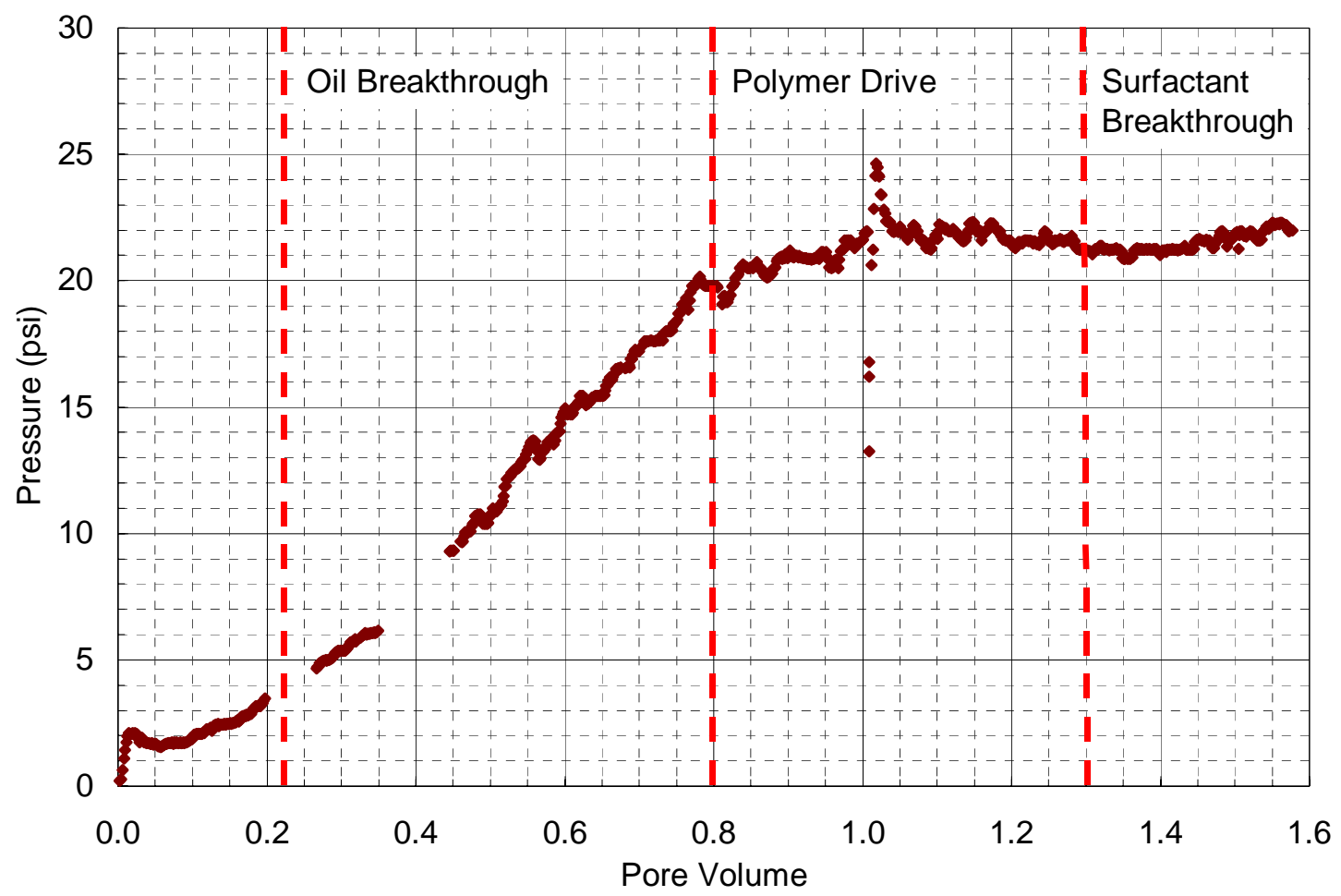

Figure 1.2-19. Pressure Drop Data for MF Core \#2

The mobility reduction caused by the polymer was good from the point of view of mobility control and stability, but it was larger than expected and higher than desirable for a field process. The viscosity of the polymer solution was reasonable and known in advance, but the permeability reduction factor of about 7 was higher than expected for a core of this permeability. Subsequent core floods will be done with a polymer of lower molecular weight to reduce the pressure gradient to values closer to field values.

In summary:

- $95 \%$ of the waterflood residual oil saturation was recovered.

- Final chemical flood residual oil saturation was 0.01 .

- Surfactant retention was $0.43 \mathrm{mg} / \mathrm{g}$.

- No plugging occurred.

- Sulfate in produced brine before the surfactant was injected showed the presence of anhydrite; therefore no sodium carbonate was used in the slug or drive in this experiment.

- Mobility control with polymer was good, but the polymer resistance factor was higher than needed. 
The results of this core flood experiment indicate that the surfactant selection procedure used in this research is based upon sound scientific principles and leads to excellent performance as well as being very efficient.

Table 1.2-7. Summary of Core Floods

\begin{tabular}{|c|c|c|c|c|c|}
\hline Rock Type & Berea \#1 & Berea \#2 & Berea \#3 & Carbonate \#1 & Carbonate \#2 \\
\hline Temperature, ${ }^{\circ} \mathrm{C}$ & 60 & 60 & 38 & 38 & 38 \\
\hline Pore Volume, $\mathrm{cm}^{3}$ & 148 & 157 & 157.4 & 37.2 & 59.7 \\
\hline \begin{tabular}{|c|} 
Initial Permeability, \\
md
\end{tabular} & 448.7 & 404.4 & 338.4 & 91.9 & 166 \\
\hline Oil & Octane & Octane & $\begin{array}{l}\text { Midland Farms } \\
2 \text { Crude }\end{array}$ & $\begin{array}{l}\text { Midland Farms } \\
2 \text { Crude }\end{array}$ & $\begin{array}{c}\text { Midland Farms } 3 \\
\text { Crude }\end{array}$ \\
\hline $\begin{array}{c}\text { Residual Oil } \\
\text { Saturation, \% }\end{array}$ & $38.0 \%$ & $31.5 \%$ & $34.9 \%$ & $23.0 \%$ & $39.0 \%$ \\
\hline $\begin{array}{c}\text { Permeability at } \\
\text { Sorw }_{\text {ord }} \text { md }\end{array}$ & 41.7 & 52.0 & 27.5 & 7.6 & 5 \\
\hline$\underset{\%}{\text { Formation Brine, wt }}$ & $\begin{array}{c}1.6 \%(9: 1 \\
\left.\mathrm{NaCl} / \mathrm{CaCl}_{2}\right)\end{array}$ & $\begin{array}{c}2.5 \%(9: 1 \\
\left.\mathrm{NaCl} / \mathrm{CaCl}_{2}\right)\end{array}$ & $\begin{array}{c}6.1 \%(8: 1 \\
\left.\mathrm{NaCl} / \mathrm{CaCl}_{2}\right)\end{array}$ & $\begin{array}{c}6.1 \%(8: 1 \\
\left.\mathrm{NaCl} / \mathrm{CaCl}_{2}\right)\end{array}$ & $\begin{array}{c}6.1 \%(8: 1 \\
\left.\mathrm{NaCl} / \mathrm{CaCl}_{2}\right)\end{array}$ \\
\hline $\begin{array}{c}\text { Surfactant/Solvent } \\
\text { concentrations, } \\
\text { wt } \%\end{array}$ & $\begin{array}{c}4 \% \mathrm{C}_{16-17}(\mathrm{PO})_{7} \\
\mathrm{SO}_{4}, 8 \% \mathrm{SBA}\end{array}$ & $\begin{array}{c}4 \% \mathrm{C}_{16-17}(\mathrm{PO})_{3} \\
\mathrm{SO}_{4}, 8 \% \mathrm{SBA}\end{array}$ & $\begin{array}{l}3 \% \mathrm{C}_{16-17}(\mathrm{PO})_{7} \\
\mathrm{SO}_{4}, 1 \% \mathrm{C}_{20-24} \\
\mathrm{AOS}, 8 \% \mathrm{SBA}\end{array}$ & $\begin{array}{c}1.5 \% \mathrm{C}_{16-17} \\
(\mathrm{PO})_{7} \mathrm{SO}_{4}, \\
0.5 \% \mathrm{C}_{15-18} \text { IOS, } \\
4 \% \mathrm{SBA}\end{array}$ & \begin{tabular}{|c|}
$0.75 \% \mathrm{C}_{16-17}$ \\
$(\mathrm{PO})_{7} \mathrm{SO}_{4,}$ \\
$0.25 \% \mathrm{C}_{15-18} \mathrm{IOS}$ \\
$2 \% \mathrm{SBA}$ \\
\end{tabular} \\
\hline Slug Salinity, wt \% & $\begin{array}{c}1.2 \%(9: 1 \\
\left.\mathrm{NaCl} / \mathrm{CaCl}_{2}\right)\end{array}$ & $\begin{array}{c}1.7 \%(9: 1 \\
\left.\mathrm{NaCl} / \mathrm{CaCl}_{2}\right)\end{array}$ & $\begin{array}{c}1.7 \%(9: 1 \\
\left.\mathrm{NaCl} / \mathrm{CaCl}_{2}\right)\end{array}$ & $3.8 \% \mathrm{NaCl}$ & $4.45 \% \mathrm{NaCl}$ \\
\hline $\begin{array}{c}\text { Polymer } \\
\text { Concentration in } \\
\text { slug }\end{array}$ & $\begin{array}{c}1000 \text { ppm } \\
\text { xanthan gum }\end{array}$ & $\begin{array}{c}1000 \mathrm{ppm} \\
\text { xanthan gum }\end{array}$ & $\begin{array}{c}1000 \mathrm{ppm} \\
\text { xanthan gum }\end{array}$ & $\begin{array}{c}2000 \mathrm{ppm} \\
\text { Alcomer 60RD }\end{array}$ & $\begin{array}{c}1500 \text { ppm } \\
\text { Flopaam 3330s }\end{array}$ \\
\hline $\begin{array}{c}\mathrm{Na}_{2} \mathrm{CO}_{3} \\
\text { concentration in } \\
\text { slug, wt } \%\end{array}$ & none & $0.02 \%$ & $0.02 \%$ & $1.00 \%$ & $0.02 \%$ \\
\hline $\begin{array}{l}\text { Surfactant Slug } \\
\text { size, PV: }\end{array}$ & 0.107 & 0.2 & 0.2 & 0.4 & 0.8 \\
\hline $\begin{array}{c}\text { Polymer } \\
\text { concentration in } \\
\text { polymer drive }\end{array}$ & $\begin{array}{c}1000 \text { ppm } \\
\text { xanthan gum }\end{array}$ & $\begin{array}{l}1000 \mathrm{ppm} \\
\text { xanthan gum }\end{array}$ & $\begin{array}{c}1000 \text { ppm } \\
\text { xanthan gum }\end{array}$ & $\begin{array}{c}2000 \mathrm{ppm} \\
\text { Alcomer 60RD }\end{array}$ & $\begin{array}{c}1200 \mathrm{ppm} \\
\text { Flopaam 3330s }\end{array}$ \\
\hline $\begin{array}{l}\text { Polymer drive } \\
\text { salinity, wt \% }\end{array}$ & $\begin{array}{l}\text { 1.1\% TDS }(9: 1 \\
\left.\mathrm{NaCl} / \mathrm{CaCl}_{2}\right)\end{array}$ & $1.0 \% \mathrm{NaCl}$ & $1.0 \% \mathrm{NaCl}$ & $1.6 \% \mathrm{NaCl}$ & $1.93 \% \mathrm{NaCl}$ \\
\hline \begin{tabular}{|c|}
$\mathrm{Na}_{2} \mathrm{CO}_{3}$ \\
Concentration in \\
polymer drive, wt \%
\end{tabular} & none & $0.02 \%$ & $0.02 \%$ & $1.00 \%$ & $0.01 \%$ \\
\hline Polymer Drive, PV & 1.9 & 2.0 & 2.7 & 1.0 & 2.5 \\
\hline Oil Recovery & $67.7 \%$ & $83.2 \%$ & $92.4 \%$ & $70.0 \%$ & $95.0 \%$ \\
\hline Final Oil Saturation & $10.9 \%$ & $5.3 \%$ & $2.7 \%$ & $6.9 \%$ & $1.0 \%$ \\
\hline \begin{tabular}{|c|} 
Oil Breakthrough, \\
PV \\
\end{tabular} & 0.2 & 0.2 & 0.3 & 0.1 & 0.3 \\
\hline $\begin{array}{c}\text { Surfactant } \\
\text { Breakthrough, PV }\end{array}$ & NA & 0.7 & 0.8 & 0.12 & 1.3 \\
\hline $\begin{array}{c}\text { Oil Production } \\
\text { ceases, PV }\end{array}$ & 1.1 & 1.1 & 1.4 & 1.4 & 1.7 \\
\hline $\begin{array}{c}\text { Surfactant } \\
\text { Retention, } \mathrm{mg} / \mathrm{g}\end{array}$ & 0.39 & 0.36 & 0.41 & 0.21 & 0.43 \\
\hline
\end{tabular}


Task 2 Phase behavior, adsorption, and composition changes during displacement

\section{Subtask 2.1 Surfactant Adsorption}

The surfactant adsorption and alkali consumption are crucial for the alkaline-surfactant process. By using the solubility calculation, alkali consumptions were calculated for carbonate formations when $\mathrm{CaSO}_{4}$ exists. Substantial retardation of $\mathrm{Na}_{2} \mathrm{CO}_{3}$ was found due to precipitation of $\mathrm{CaCO}_{3}$. Two other potential determining ions, hydroxyl ion and sulfate ion were tested to see whether they could reduce the surfactant adsorption as found previously for carbonate ion. Light scattering could easily determine the sizes of surfactant aggregates that can also significantly influence the propagation velocity of the injected surfactant solution in a porous medium. By using porous media with different surface area, we found it was the surface area, not the weight, of the porous media that determine the adsorption amount. The threshold concentration of potential determining ion $\left(\mathrm{CO}_{3}{ }^{2-}\right)$ required to achieve significant reductions in surfactant adsorption was investigated.

\section{Surfactant propagation velocity with adsorption}

The adsorption of surfactant can alter the propagation velocity. For one-phase flow, we have

$$
\frac{\partial\left(c+c_{s}\right)}{\partial t}+v \frac{\partial c}{\partial x}=0
$$

where $c_{s}$ is the adsorbed concentration of surfactant. And $c_{s}$ is a function of local concentration c, i.e., $c_{s}=f(c) . v$ is the interstitial velocity.

We assume Langmuir-type isotherm, where $c_{\max }$ is the maximum adsorption value

$$
\begin{aligned}
& c_{s}=\frac{c_{\max } c}{k+c} \\
& \frac{d c_{s}}{d c}=\frac{c_{\max } k}{(k+c)^{2}}=\frac{c_{\max } / k}{(1+c / k)^{2}}
\end{aligned}
$$

After some manipulations, we can obtain that the surfactant velocity $v_{s}$ is

$$
v_{s}=v \frac{1}{1+\frac{d c_{s}}{d c}}
$$

Since the isotherms of surfactant are Langmuir-type, $\mathrm{d} c_{s} / d c$ will decrease as $c$ increases from (3) and hence $v_{s}$ will increase from (4). From the rule of 
wave theory, waves originating from the same point must have non-decreasing velocities in the direction of flow. If slower waves from compositions close to the initial conditions originate ahead of faster waves as is the case here, a shock will form as the faster waves overtake the slower waves. To determine the shock velocity, we must apply a mass balance across the shock and gain the result given by equation (5)

$$
\left(\frac{d x}{d t}\right)_{\Delta c}=v \frac{c_{2}-c_{1}}{c_{2}-c_{1}+c_{s 2}-c_{s 1}}=v \frac{\Delta c}{\Delta c+\Delta c_{s}}=v \frac{1}{1+\frac{\Delta c_{s}}{\Delta c}}
$$

where $\Delta c_{s} / \Delta c$ is the chord slope of the isotherm between the concentrations at each side of the shock.

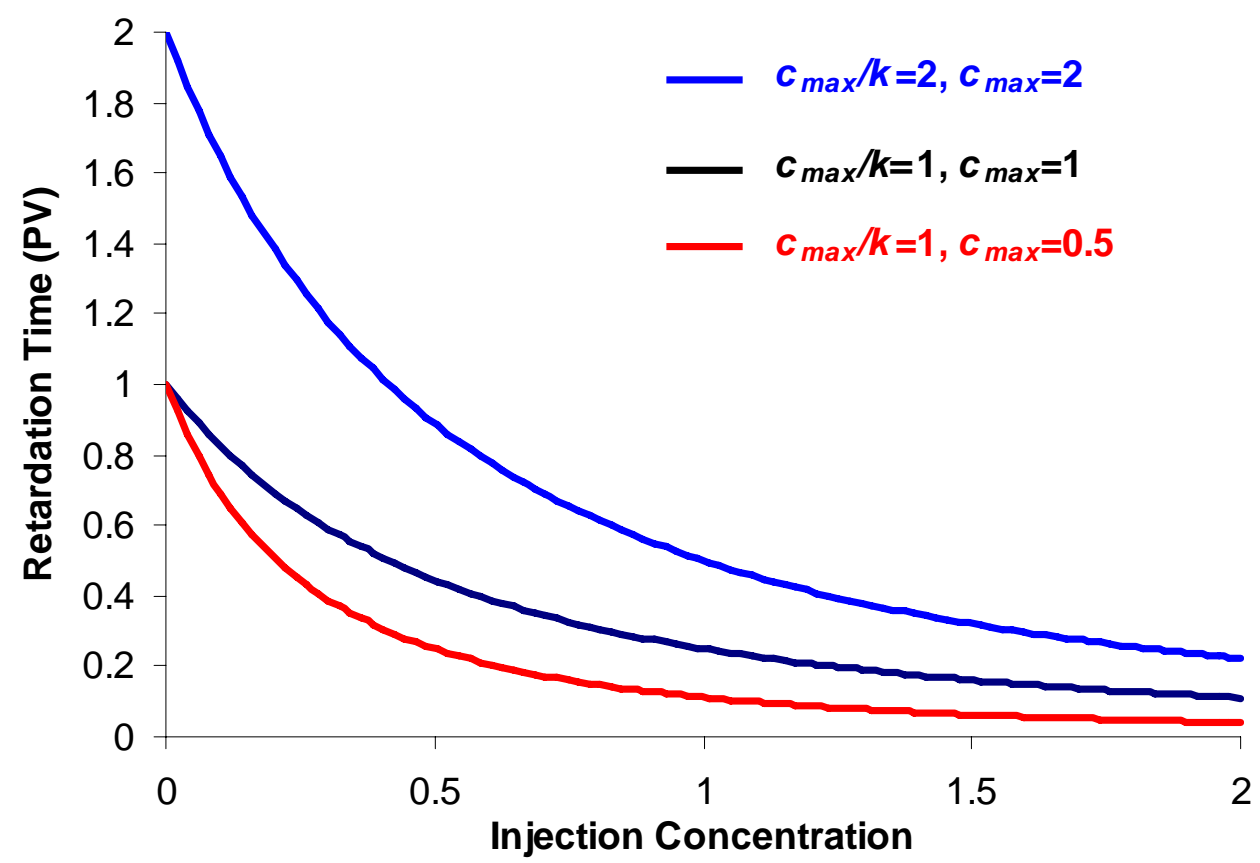

Figure 2.1-1 Relationships between effluent retardation and Langmuir parameters

Figure 2.1-1 shows the relationship between break-through retardation time and Langmuir parameters. The break-through retardation time is defined as the difference between the required injection pore volume $(P V)$ to see the surfactant break-through and unit pore volume. Zero retardation time implies unit propagation velocity and no adsorption. Larger retardation means slower propagation velocity. From this plot, we can generalize that increasing the injection concentration reduces the retardation, i.e., increases the propagation velocity. Furthermore, the Langmuir parameters can significantly change the retardation degree, i.e. the propagation velocity. At very low concentration, the initial slope of Langmuir isotherm $\left(c_{\max } / k\right)$ determines the velocity. And lower propagation velocity or larger surfactant retardation occurs at lower injection concentration. At higher concentration, the surfactant propagation velocities depend on the maximum adsorption amount $c_{\max }$ only. In our process, the 
surfactant concentrations we apply are above the $\mathrm{CMC}$ so that the adsorption isotherms already reach the plateau. Thus, the maximum adsorption amount is the determining factor for the surfactant propagation.

\section{Alkali consumption on carbonate formation}

Pure calcite does not consume much alkali. However, the consumption of alkali in carbonate reservoir may be a crucial problem because of the precipitation reaction of alkali with gypsum and anhydrite impurities. Because the solubility products of $\mathrm{CaCO}_{3}$ and $\mathrm{CaSO}_{4}$ are $4.96^{\star} 10^{-9}$ and $7.10^{\star} 10^{-5}$ respectively (CRC Handbook $68^{\text {th }}$ Edition), it is a serious problem to apply $\mathrm{Na}_{2} \mathrm{CO}_{3}$ as our alkali candidate because of the precipitation reaction shown as equation (6).

$$
\mathrm{CO}_{3}{ }^{2-}+\mathrm{CaSO}_{4} \rightarrow \mathrm{CaCO}_{3} \downarrow+\mathrm{SO}_{4}{ }^{2-}
$$

Figure 2.1-2 shows the retardation for a porous medium with porosity 0.3 . It illustrates that the retardation is significant. For a $0.1 \mathrm{M}(\sim 1 \%) \mathrm{Na}_{2} \mathrm{CO}_{3}$, the concentration usually being considered for oil recovery processes, the retardation is around $0.7 \mathrm{PV}$ for the condition that $0.1 \%$ of the porous medium is $\mathrm{CaSO}_{4}$. Although we still can reduce the retardation or enhance the propagation velocity by increasing the injection alkali concentration, the total amount of alkali consumption will not change. It is impractical to solve this problem by increasing the sulfate ion concentration through adding $\mathrm{Na}_{2} \mathrm{SO}_{4}$ because of the tremendous difference between the two solubility products.

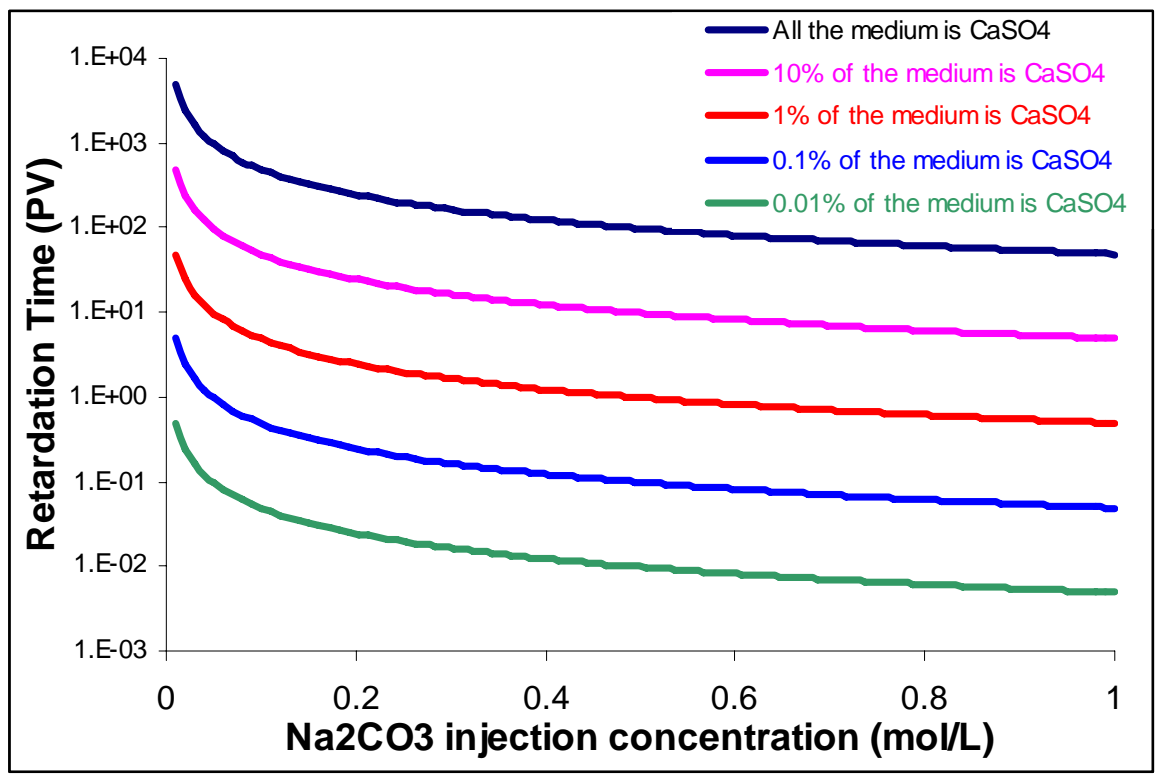

Figure 2.1-2 Relationships between retardation and $\mathrm{CaSO}_{4}$ fraction in porous medium (porosity $=\mathbf{0 . 3}$ )

$\mathrm{NaHCO}_{3}$ with $\mathrm{Na}_{2} \mathrm{SO}_{4}$ may be a potential choice for the situation with $\mathrm{CaSO}_{4} \cdot \mathrm{NaHCO}_{3}$ has much lower carbonate ion concentration and additional sulfate ions can decrease calcium ion concentration in the solution. However, 
this method is not applicable again. The concentration of $\mathrm{CO}_{3}{ }^{2-}$ is around the one hundredth the concentration of $\mathrm{NaHCO}_{3}$ for a $\mathrm{NaHCO}_{3}$ solution so that we still need large amount $\mathrm{Na}_{2} \mathrm{SO}_{4}$ to avoid precipitation of $\mathrm{CaCO}_{3}$. For a $0.1 \mathrm{M}$ $\mathrm{NaHCO}_{3}$ solution, the carbonate ion concentration is around $1.0^{*} 10^{-3} \mathrm{M}$, and we need $14 \mathrm{M} \mathrm{Na}_{2} \mathrm{SO}_{4}$ to restrain the precipitation of $\mathrm{CaCO}_{3}$.

The other alkali candidate is $\mathrm{NaOH}$ with $\mathrm{Na}_{2} \mathrm{SO}_{4}$ since the solubility product of $\mathrm{Ca}(\mathrm{OH})_{2}$ is $4.68^{\star} 10^{-6}$. The reaction between $\mathrm{NaOH}$ with $\mathrm{Na}_{2} \mathrm{SO}_{4}$ is shown as equation (7). The minimum $\mathrm{Na}_{2} \mathrm{SO}_{4}$ concentration that restrains the $\mathrm{Ca}(\mathrm{OH})_{2}$ precipitation can be calculated by equation (8). For a $0.1 \mathrm{M} \mathrm{NaOH}$ solution, $0.15 \mathrm{M} \mathrm{Na}_{2} \mathrm{SO}_{4}$ is needed to suppress the calcium ion concentration so that no $\mathrm{Ca}(\mathrm{OH})_{2}$ will precipitate. And higher $\mathrm{Na}_{2} \mathrm{SO}_{4}$ is necessary with higher $\mathrm{NaOH}$ concentration. Also, the surfactant adsorption isotherm will change at this condition and we need to measure it.

$$
\begin{aligned}
& 2 \mathrm{NaOH}+\mathrm{CaSO}_{4} \Leftrightarrow \mathrm{Ca}(\mathrm{OH})_{2}+\mathrm{Na}_{2} \mathrm{SO}_{4} \\
& {\left[\mathrm{SO}_{4}{ }^{2-}\right]=\left[\mathrm{OH}^{-}\right]^{2} \frac{K_{\text {spCaSO}}}{K_{\text {spCa(OH })_{2}}}=15 *\left[\mathrm{OH}^{-}\right]^{2}}
\end{aligned}
$$

Therefore, $\mathrm{Na}_{2} \mathrm{CO}_{3}$ is our first choice for the carbonate formation reservoir if minimal $\mathrm{CaSO}_{4}$ exists. Otherwise, $\mathrm{NaOH}$ with $\mathrm{Na}_{2} \mathrm{SO}_{4}$ will be our next candidate.

\section{Potential determining ions for surfactant adsorption}

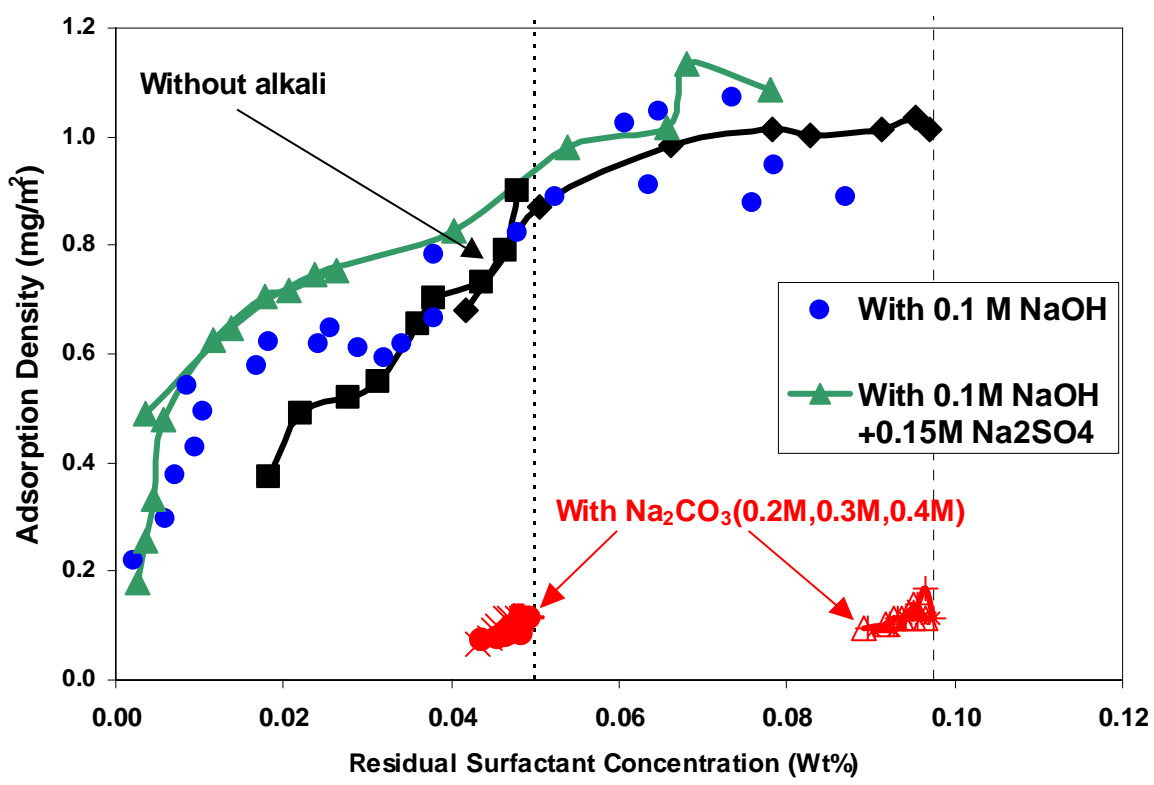

Figure 2.1-3 Adsorption on powdered dolomite of TDA-4PO:CS330(1:1) with different potential determining ion

As discussed in previous part, we can suppress the alkali consumption by using $\mathrm{NaOH}$ with $\mathrm{Na}_{2} \mathrm{SO}_{4}$. However, we do not know whether this alkali 
formulation could restrain the surfactant adsorption as well as $\mathrm{Na}_{2} \mathrm{CO}_{3}$ does. Several experiments were performed and we found that this approach could not decrease the surfactant adsorption. As figure 2.1-3 shows, the adsorption amount on dolomite surface with these ions is the same as that without any potential determining ion. Thus, we need to use other surfactant and alkali when there is a large amount of $\mathrm{CaSO}_{4}$ in the reservoir.

\section{Surfactant aggregates' size}

The sizes of surfactant aggregates can also significantly influence the propagation velocity of the injected surfactant solution in a porous medium. Small micelles are equilibrium aggregates and cause no problems. However, phase separation occurs if aggregates' sizes become large enough or the shape and interaction between aggregates change. In this situation, the surfactant may be trapped in the pores and not flow with the aqueous phase. We found that the surfactant type and the alkali concentration determined the aggregates' sizes by using light scattering experiments for different surfactants with same concentration $(0.05 \% \mathrm{Wt})$. For the samples where bulk phase separation occurred yielding a thin layer of surfactant-rich liquid at the air/water interface (phase separation in figure 2.1-5), we measured the clear bulk phase in the light scattering experiments.

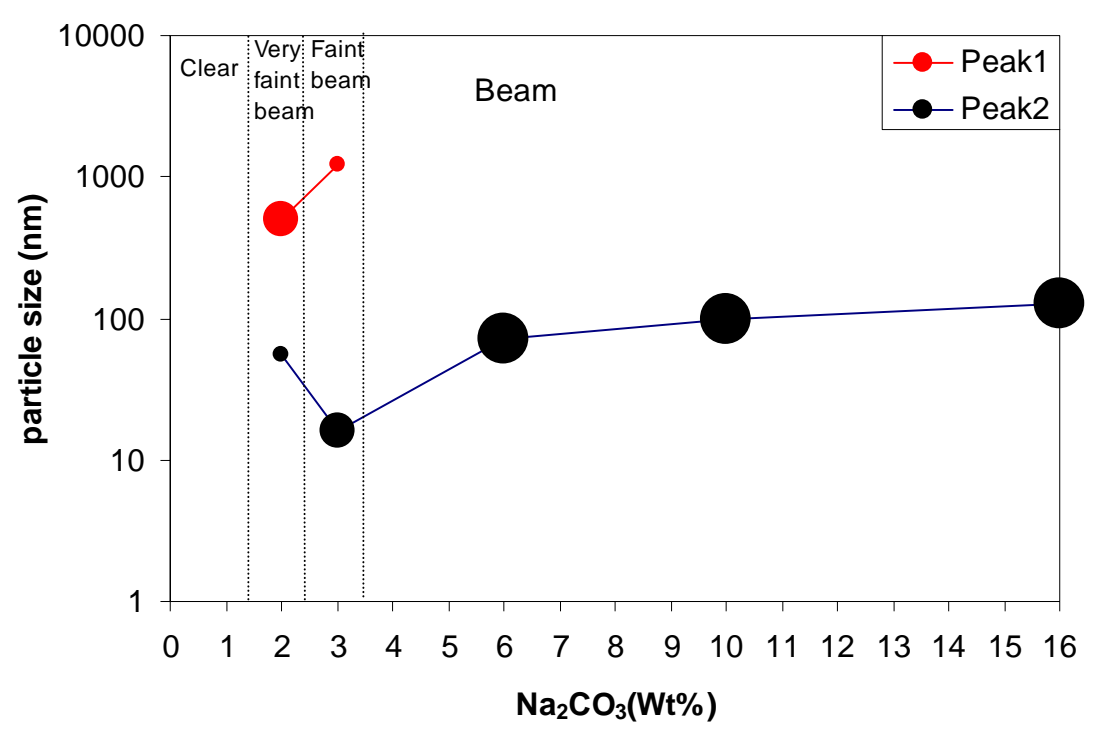

Figure 2.1-4 Particle size distribution of Stepan TDA-4PO

Figure 2.1-4 is an example of particle size distribution for different surfactants. In this plot, the area of each point indicates the intensity of that particle size. And the total area of peaks for each sample is fixed. Thus, we can know how many peaks the sample has and which peak of the sample is the dominant one. It seems that the drop size distributions are different with different surfactant. However, the size of the dominant peak increases with the sodium carbonate concentration for all the surfactant solutions. Also, we found an easy method to estimate the dominant particle size instead of the complex 
light scatter experiments. Before the light scattering experiments, we record the appearance of scattered light. Light from optical fiber and laser pointer light will give us the same appearance. Figure 2.1-5 indicates this relationship. For a very faint beam the dominant particle size is in $11 \pm 5 \mathrm{~nm}$. Faint beam implies the dominant particle size is in $30 \pm 17 \mathrm{~nm}$. When we see strong beam, the drop size of the primary peak should be $69 \pm 37 \mathrm{~nm}$. The beam strength is increased with the dominant particle size. When we see phase separation, we may conclude that the dominant particle size must be larger than $180 \mathrm{~nm}$. We can use this feature to estimate the dominant particle size in our future samples.

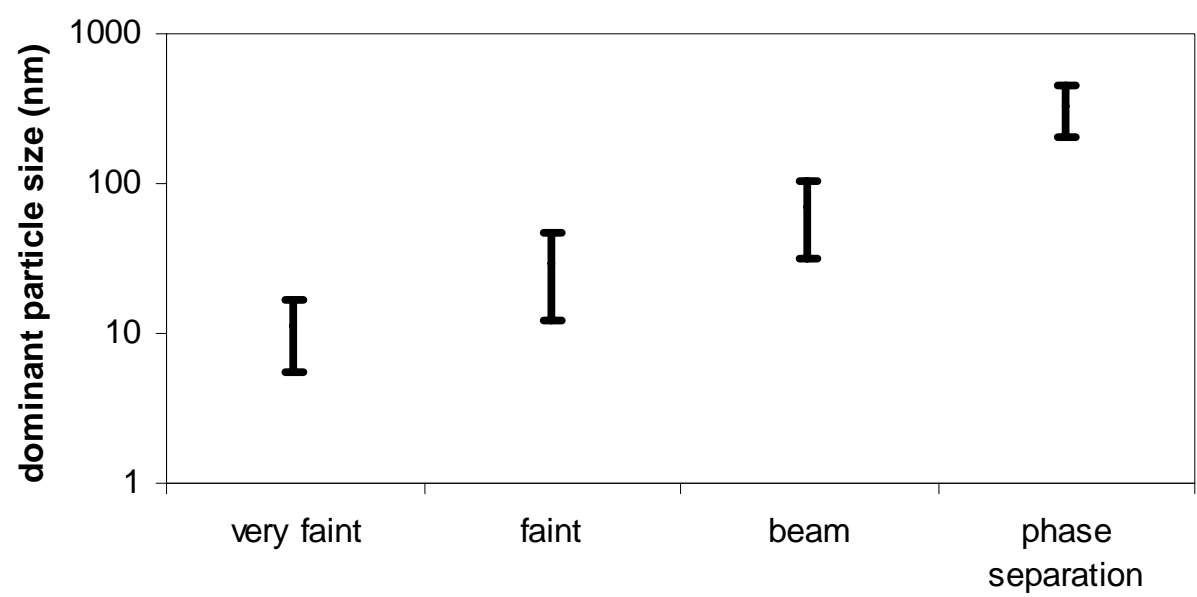

Figure 2.1-5 Relationship between appearance of scatter beam and dominant peak particle size

In order to propagate the surfactant, we need a suitable surfactant with appropriate alkali concentration to avoid the phase separation.

\section{Surfactant adsorption on porous media with different surface area}

Surface area of the porous media has remarkable effect on the surfactant adsorption. We tested two dolomite samples with different surface area. One is powdered dolomite, whose surface area is $1.7 \mathrm{~m}^{2} / \mathrm{gram}$; the other is dolomite sand, whose surface area is $0.3 \mathrm{~m}^{2} / \mathrm{gram}$. Figure 2.1-6 shows that the adsorptions between the two samples are comparable if we calculate the adsorption by using $\mathrm{mg}$ per surface area. If we calculate the adsorption by using mg per weight as in figure 2.1-7, we can find the adsorption on sand without alkali is about one sixth of the adsorption on powder. These results imply that we should use the surface area, not the weight, of the porous media to compare the adsorption. 
Adsorption of CS330 \&TDA-4PO (1:1) blend on dolomite

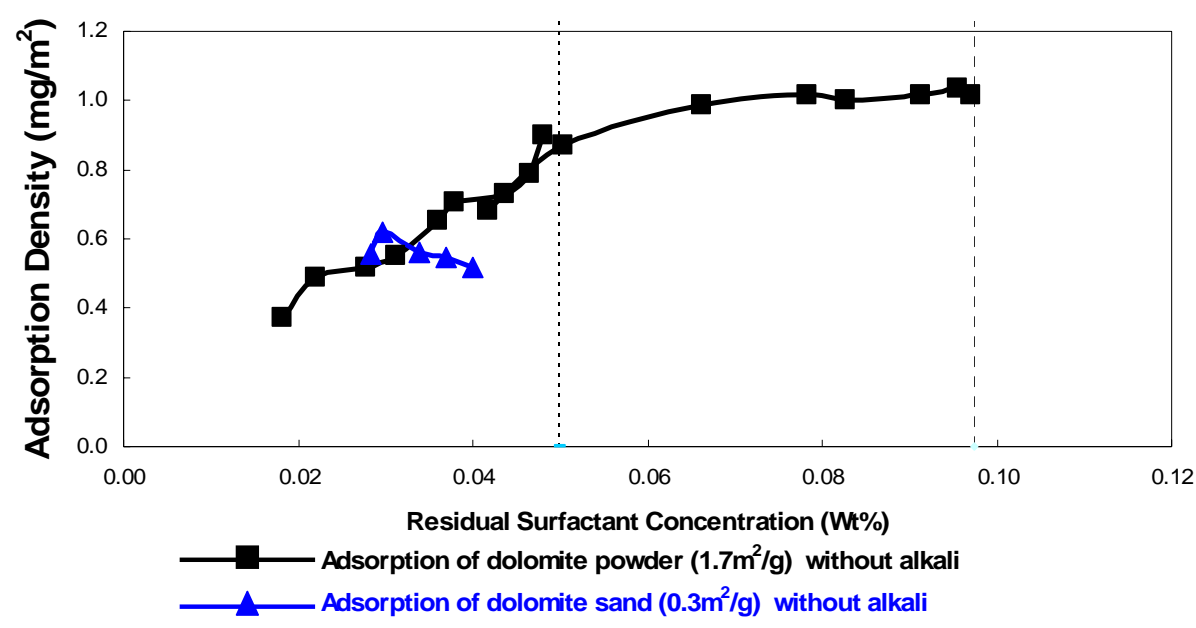

Figure 2.1-6 Adsorption of CS330: TDA-4PO (1:1) on dolomite with different surface area (I)

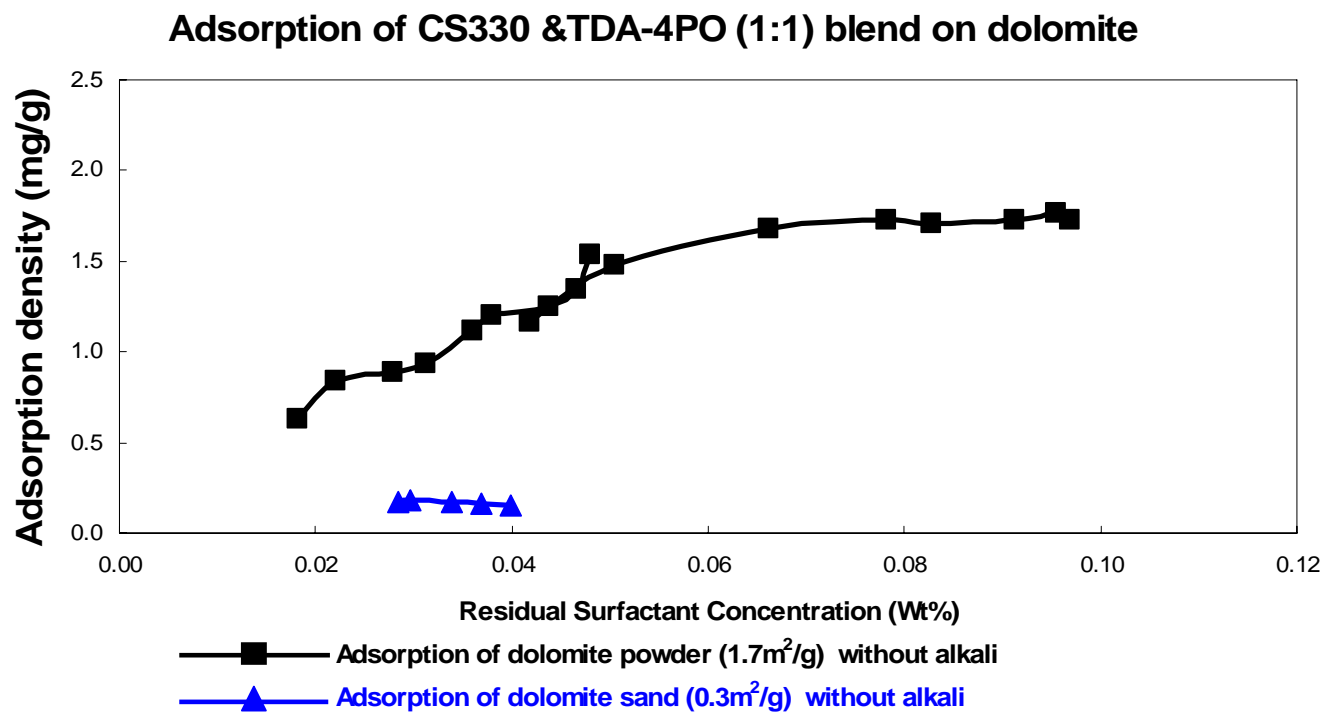

Figure 2.1-7 Adsorption of CS330: TDA-4PO (1:1) on dolomite with different surface area (II)

Adsorption isotherms for NEODOL-67-7PO:IOS (4:1) and threshold of $\mathrm{Na}_{2} \mathrm{CO}_{3}$

We found the previous surfactant formulation (CS330\&TDA-4PO) could generate viscous phases and its optimal salinity is very high (12 13\%) so that it is not our choice anymore. We tested our new surfactant formulation (NEODOL-67-7PO: IOS 4:1) adsorption on the calcite surface as figure 2.1-8 shows. This new formulation is selected because both surfactants in the new 
mixture have branched hydrophobic chain while one surfactant in earlier mixture is straight chain. We find that adsorption isotherms of this formulation are similar in shape to the previous blend. These results at 0 and $1 \% \mathrm{Na}_{2} \mathrm{CO}_{3}$ are consistent with Fig. 2.3-12 of this report. From figure 2.1-8, it is seen that adsorption increases only slightly when $\mathrm{Na}_{2} \mathrm{CO}_{3}$ concentration is reduced to $0.08 \%$.

We also tested the threshold of $\mathrm{Na}_{2} \mathrm{CO}_{3}$ concentration at which the adsorption reduction effect occurs as shown in figure 2.1-9. We used same amount of surfactant solution mixed with same amount calcite powder. We fixed the initial surfactant concentration but changed $\mathrm{Na}_{2} \mathrm{CO}_{3}$ concentration. And we found that the adsorption reduction effect seemed the same when the $\mathrm{Na}_{2} \mathrm{CO}_{3}$ concentration was higher than $0.1 \%$, i.e., enhancing the $\mathrm{Na}_{2} \mathrm{CO}_{3}$ concentration would not decrease the surfactant adsorption when $\mathrm{Na}_{2} \mathrm{CO}_{3}$ concentration was higher than $0.1 \%$. However, the adsorption will increase as the $\mathrm{Na}_{2} \mathrm{CO}_{3}$ concentration deceases below $0.1 \%$. From this result, the lowest $\mathrm{Na}_{2} \mathrm{CO}_{3}$ concentration for ASP process should be higher than $0.1 \%$.

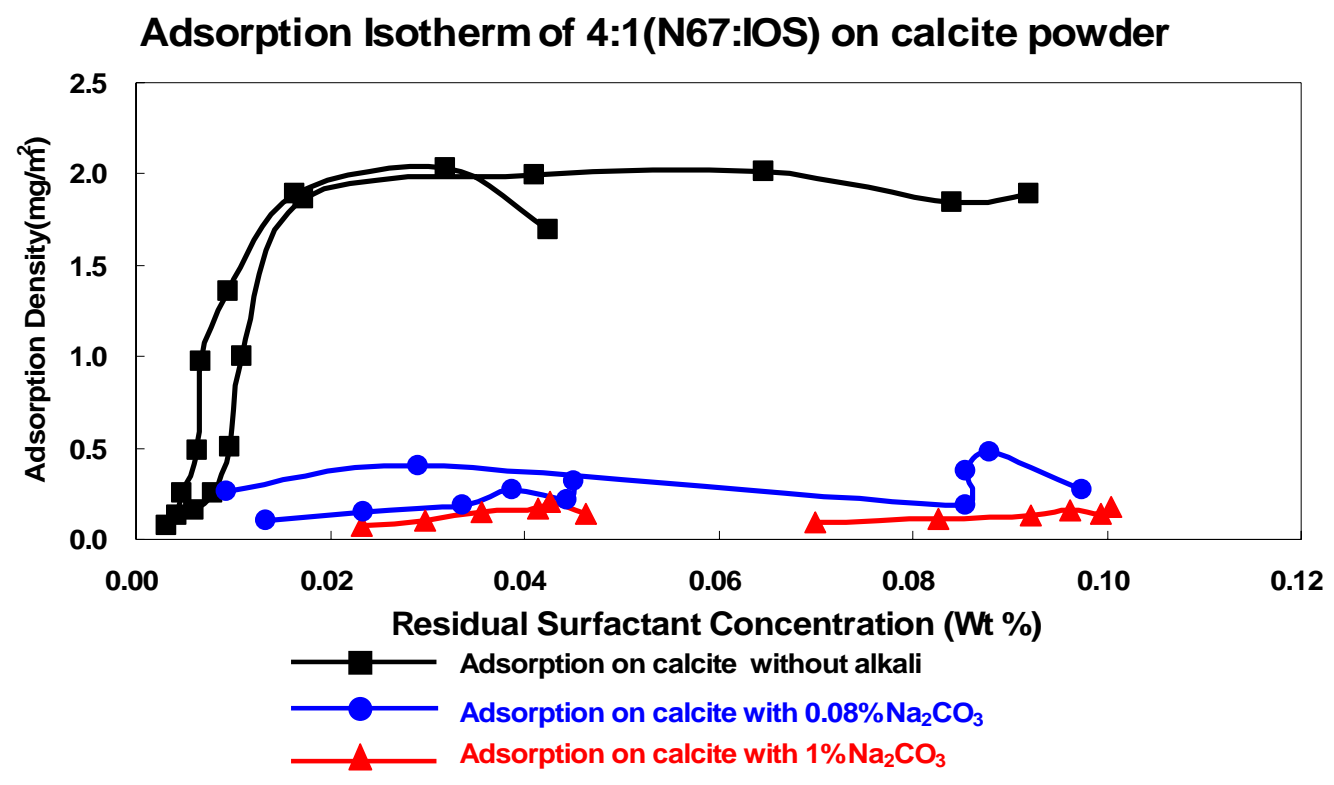

Figure 2.1-8 Adsorption on powdered calcite of $\mathrm{N} 67: \mathrm{IOS}(1: 1)$ with different $\mathrm{Na}_{2} \mathrm{CO}_{3}$ concentration 


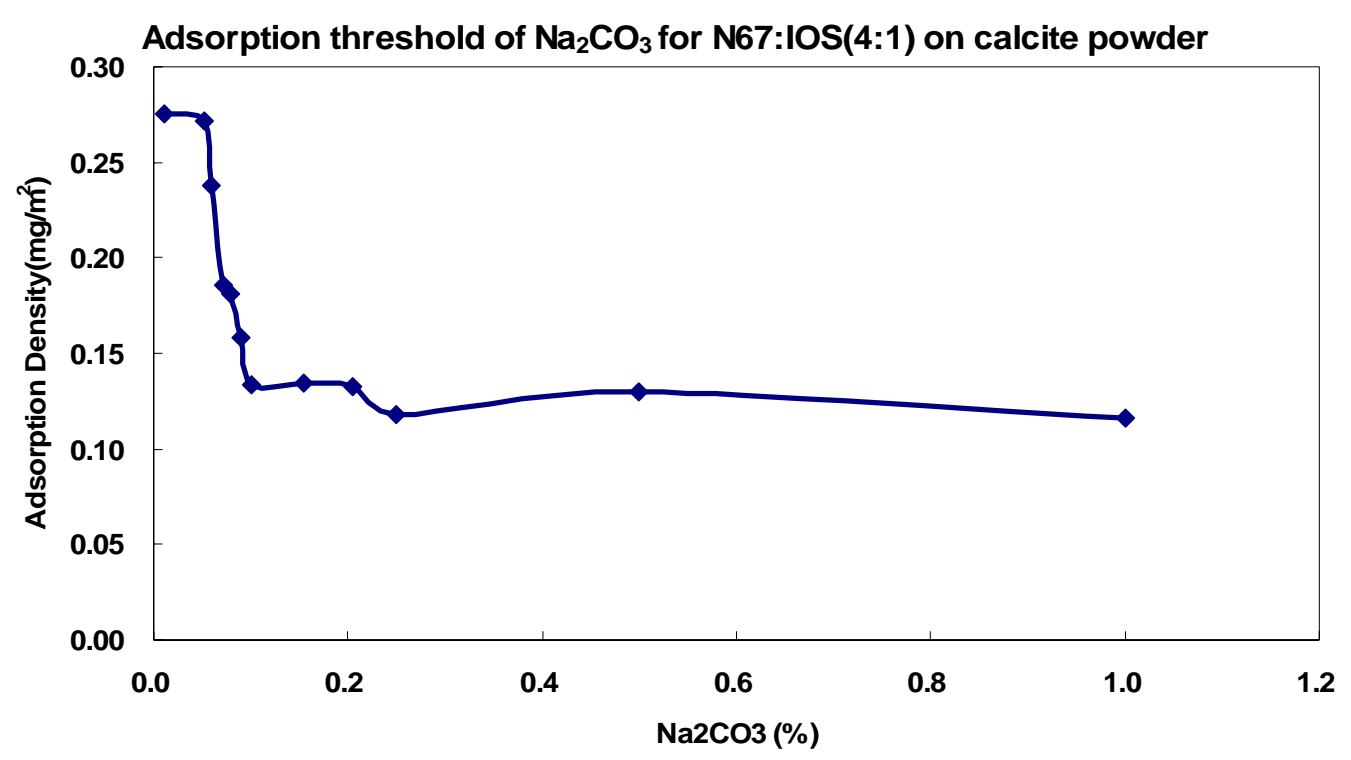

Figure 2.1-9 Test of threshold concentration of $\mathrm{Na}_{2} \mathrm{CO}_{3}$ for the adsorption

\section{Conclusions}

1. For alkaline surfactant process, the maximum adsorption amount is the determining factor for the surfactant propagation.

2. $\mathrm{NaOH}$ with $\mathrm{Na}_{2} \mathrm{SO}_{4}$ could be our next candidate for the reservoir containing $\mathrm{CaSO}_{4}$ if excessive precipitation occurs when $\mathrm{Na}_{2} \mathrm{CO}_{3}$ is injected.

3. Only the carbonate ion can reduce the surfactant adsorption on carbonate formation. Other potential determining ions (sulfate ion and hydroxyl ion) could not decrease the surfactant adsorption.

4. We can use lamp light scatter to estimate the surfactant aggregates' size, and we need to avoid large surfactant aggregates when we make the surfactant solution.

5. It is the surface area, not the weight, of the porous media that determine the surfactant adsorption.

6. The threshold $\mathrm{Na}_{2} \mathrm{CO}_{3}$ concentration for adsorption reduction is around $0.1 \% \mathrm{Wt}$.

Task 2 Phase behavior, adsorption, and composition changes during displacement

Subtask 2.2 Composition route for alkali-surfactant flooding

In order to understand and describe the ASP process, a one-dimensional, two phase, multi-componential simulator was developed to calculate the profiles and oil recovery as a function of process variables. In this simulator, 
the main relationships are: phase behavior and interfacial tension are the functions of electrolyte $(\mathrm{NaCl})$ concentration, surfactant and natural soap concentration; fractional flow is a function of interfacial tension, aqueous phase saturation and viscosity; surfactant adsorption is a function of surfactant concentration in aqueous phase and alkali concentration; natural soap is generated by the naphthenic acid contacted by the alkali; physical dispersion is described by convective dispersion; aqueous phase viscosity is a function of electrolyte $(\mathrm{NaCl})$ and polymer concentration; alkali consumption is due to the precipitation reactions between $\mathrm{Na}_{2} \mathrm{CO}_{3}$ that we inject and the $\mathrm{CaSO}_{4}$ that resides in the reservoir and the calcium ions in the formation brine, and to the reaction between alkali and clays.

\section{Assumptions and Models}

The basic assumptions of the model are as follow.

1. The system is one-dimensional and homogeneous in permeability and porosity.

2. Local equilibrium exists everywhere.

3. Capillary pressure is negligible.

4. The system is one-dimensional and horizontal. Thus there is no gravity effect.

5. The system has eight components. They are water(1), oil(2), synthetic surfactant or surfactant(3), natural soap(4), electrolyte( $\mathrm{NaCl})(5)$, alkali(6), polymer(7), naphthenic Acid(8). The numbers behind the chemicals are the index we will use for our future discussion.

6. Two mobile phases are: Aqueous(1), Oleic(2).

7. All the chemicals except water and oil are assumed to occupy negligible volume and are treated as tracers.

Additional assumptions also required for our model are discussed below.

\section{Partition}

Since our model is a two-phase model, the partitioning of the chemicals is very important. The partition coefficient of the component $i$ is defined as equation (1);

$$
K_{C i}=\frac{C_{i 2}}{C_{i 1}}
$$

where $c_{i 1}$ is the concentration in aqueous phase for component $\mathrm{i}$

$c_{i 2}$ is the concentration in oleic phase for component $\mathrm{i}$

We assume that electrolyte $(\mathrm{NaCl})$, alkali and polymer are totally in the aqueous phase, i.e. $K_{C 5}=0, K_{C 6}=0$ and $K_{C 7}=0$; while the naphthenic acid is entirely in the oleic phase, i.e. $K_{c 8} \rightarrow \infty$.

However, the partitioning for the surfactant and soap is not that simple and depends on the salinity (concentration of electrolyte) and the mole ratio 
between the soap and surfactant. The basis of this partition assumption comes from the phase behavior experiments of Leslie Zhang as in discussed in section 2.3. According to her discovery, the optimal salinity of the brine/crude oil system with soap and surfactant is as in figure 2.2-1. From this curve, we know that the optimal salinity is equal to that of soap when soap is dominant, and vice versa. And we assume that at the optimal condition, the average partition of soap and surfactant are unity. The average partition of soap and surfactant $K_{\text {aver }}$ is defined as equation (2). Figure 2.2-2 shows the $K_{\text {aver }}$ contour. For a specific salinity, surfactant concentration and soap concentration, we can obtain the average partition.

$$
K_{\text {aver }}=K_{C 3}\left(\frac{C_{3}}{C_{3}+C_{4}}\right)+K_{C 4}\left(\frac{C_{4}}{C_{3}+C_{4}}\right)
$$

where $C_{3}$ is the overall concentration of surfactant,

$C_{4}$ is the overall concentration of soap

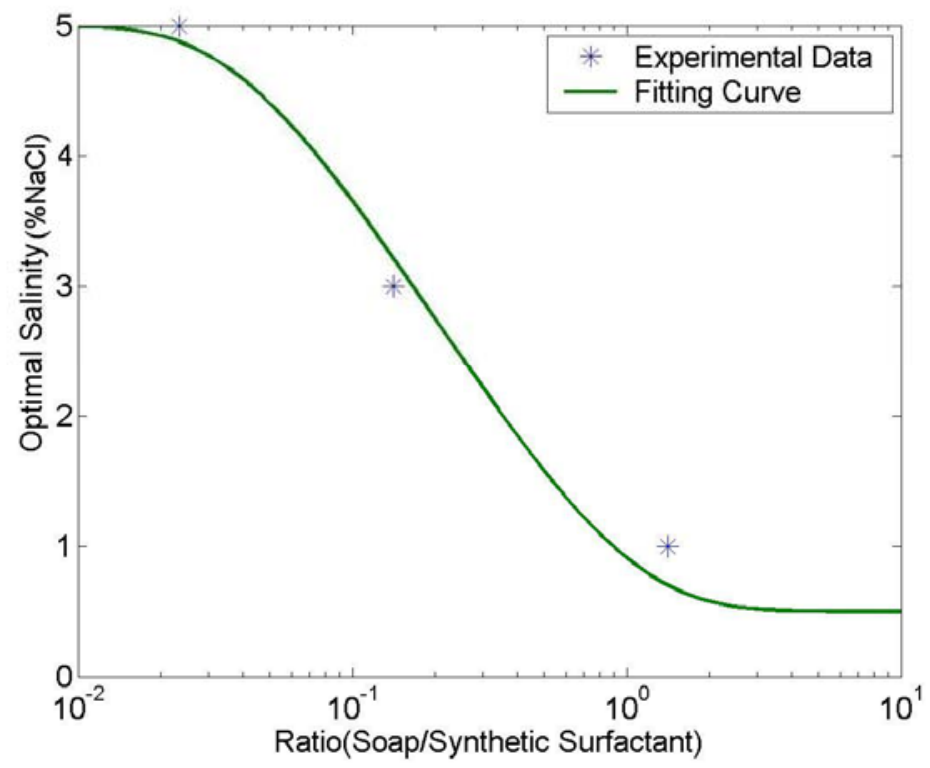

Figure 2.2-1 Optimal Salinity vs. Soap-Synthetic Surfactant Ratio Curve for N67:IOS (4:1) 


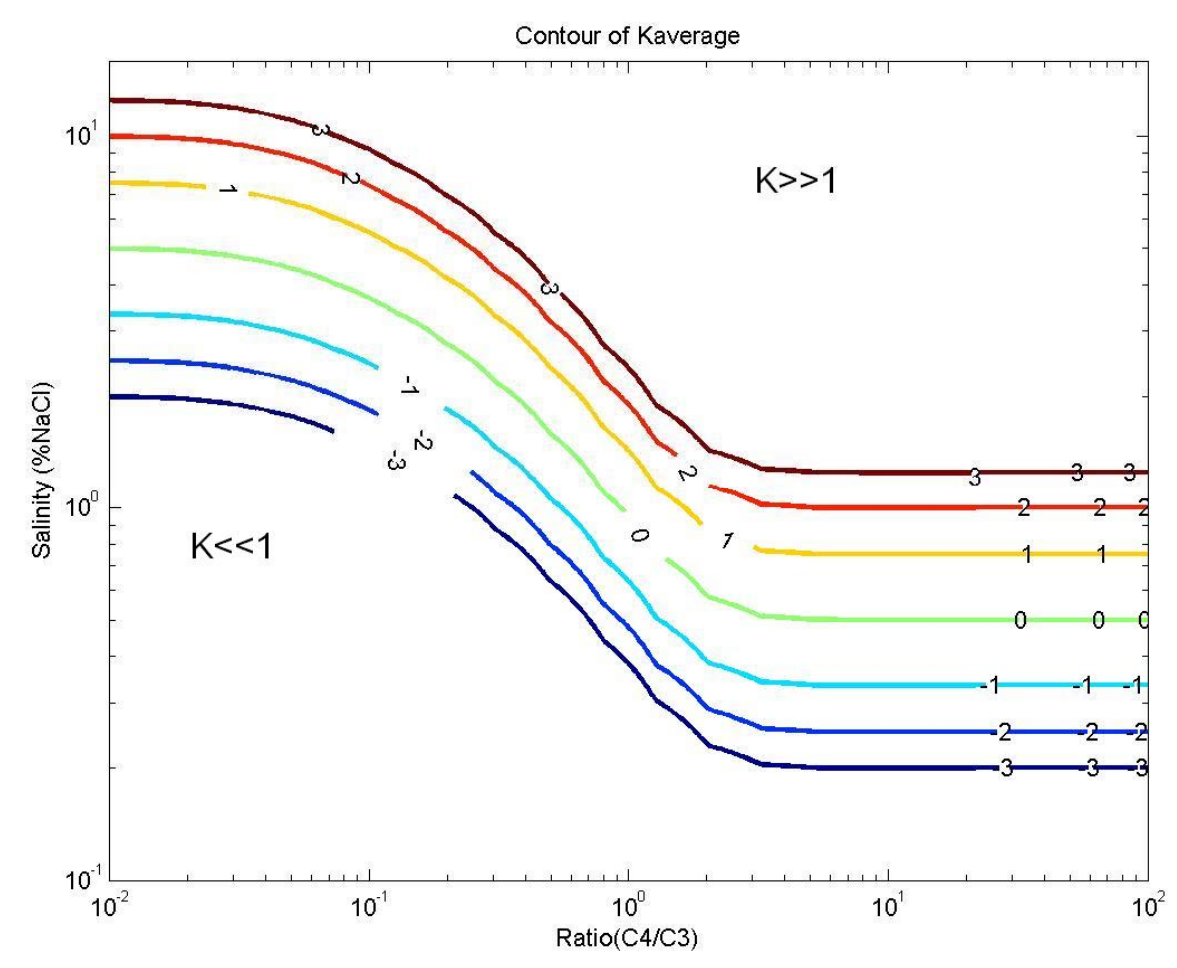

Figure 2.2-2 Contour of Average Partition Coefficient $\left(\log _{10}\left(\mathrm{~K}_{\mathrm{aver}}\right)\right)$

From figure 2.2-2, we can only find $K_{a v e r}$, not $K_{c 3}$ and $K_{C 4}$. To find $K_{C 3}$ and $K_{C 4}$, we introduce another parameter $k 4 k 3$ which is defined as:

$$
k 4 k 3=\frac{K_{C 4}}{K_{C 3}}
$$

In most cases, we assume that $k 4 k 3=1$, i.e., the surfactant and the soap have same partition coefficients. Such joint partitioning is not unreasonable for ionic surfactants, which have low solubility as monomers in the oil phase. If necessary, we can change the value of $k 4 k 3$ to represent the difference between surfactant and soap. By following these steps, we can calculate partitioning of all the components.

\section{Interfacial tensions}

The interfacial tension is a crucial factor for ASP process. Without low tension, the ASP process could not be a practical process. The basis of the interfacial tension also comes from experiments of Leslie Zhang's as figure 2.2-1. We assume that the interfacial tension could be as low as $10^{-3} \mathrm{dyne} / \mathrm{cm}$ at optimal condition. And the IFT contour is generated as figure 2.2-3. The difference between the optimal salinity and local salinity determine the IFT. When the salinity is far away from the optimal salinity, the IFT will be higher. Figure 2.2-4 displays how the IFT changes with salinity for soap surfactant ratio equal to unity. These calculations are for the condition that the soap and surfactant total concentration is greater than the CMC (Critical Micelle 
Concentration). And when the soap and surfactant total concentration is less than CMC, we calculate IFT by interpolation between the IFT calculated by figure 2.2-3 and the IFT of crude oil and brine without any surface active materials.

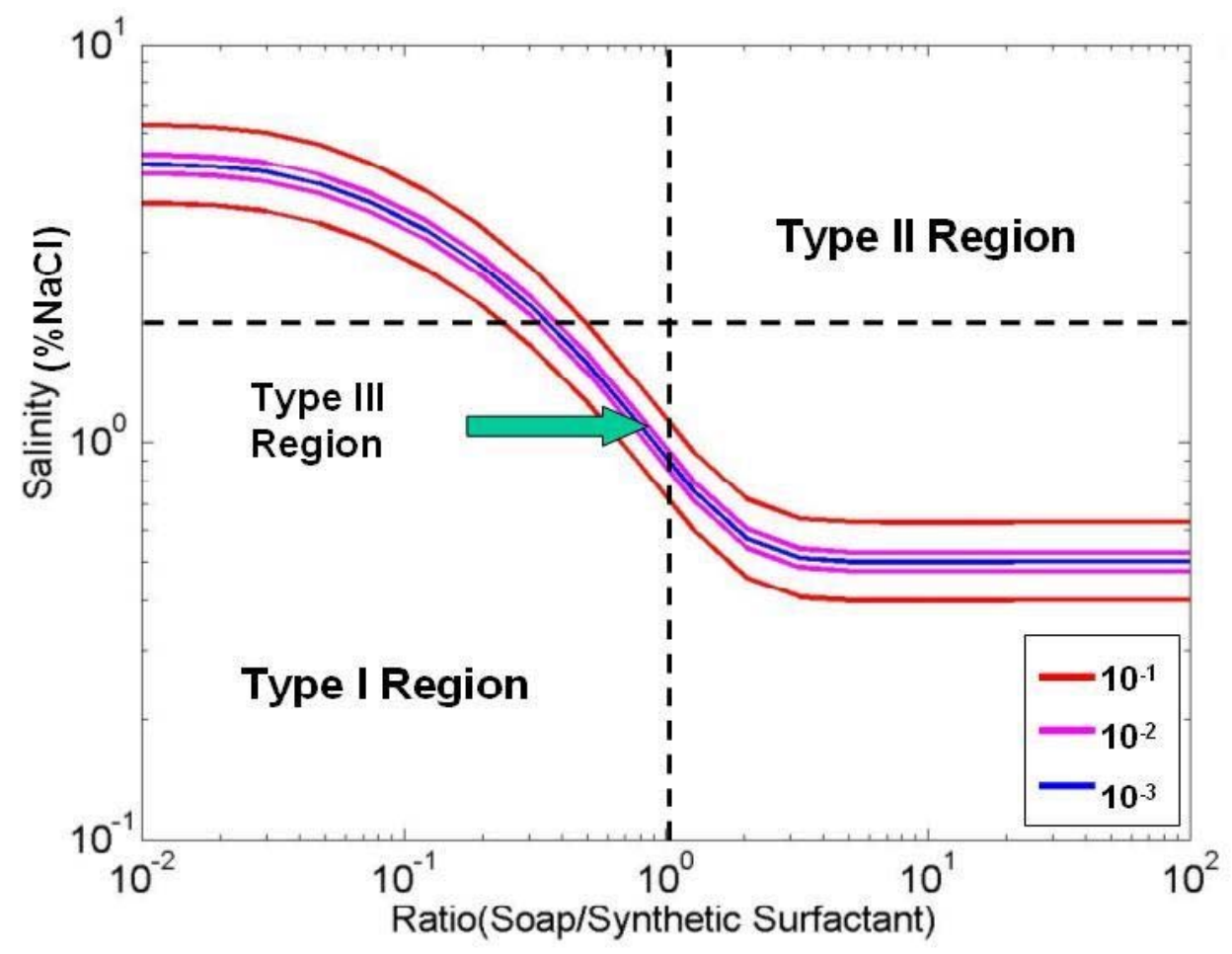

Figure 2.2-3 Contour of interfacial tension $\left(\log _{10}(\mathrm{IFT})\right)($ IFT: dyne/cm)

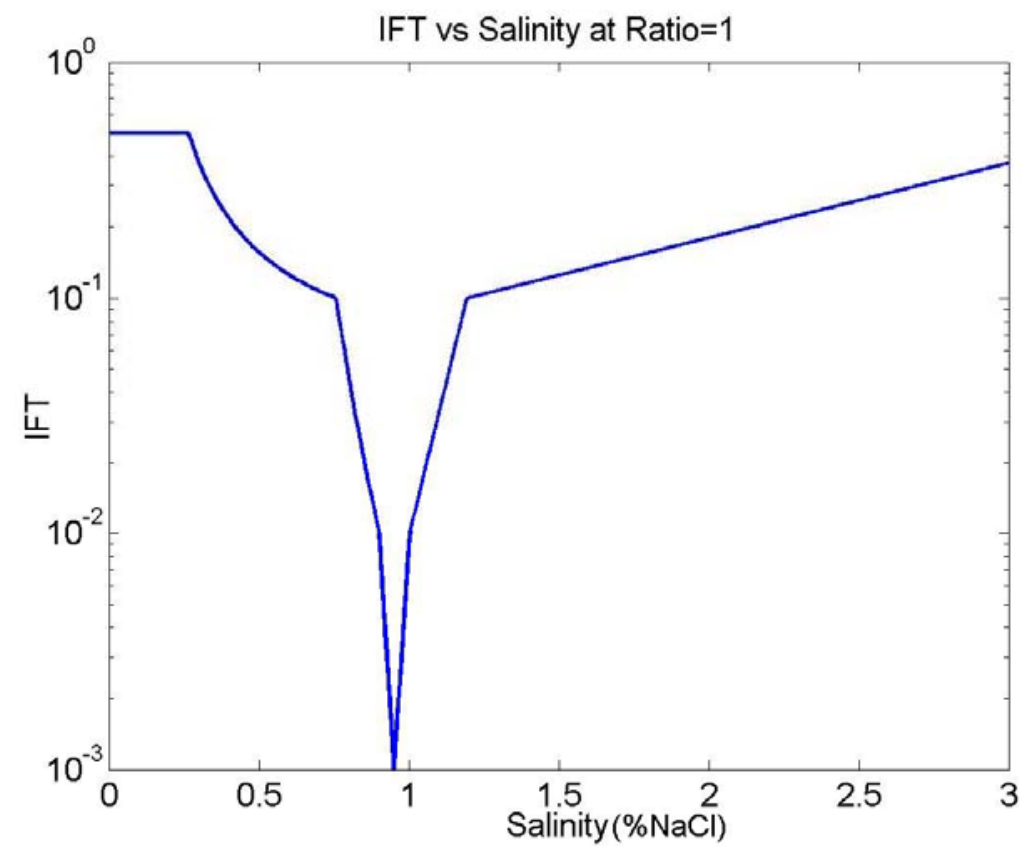

Figure 2.2-4 IFT (dyne/cm) vs Salinity for Soap Surfactant Ratio = 1 (According to Leslie Zhang's experiment, the optimal IFT can be as low as $10^{-3} \mathrm{dyne} / \mathrm{cm}$. The width of low IFT region is base on reference [1]) 


\section{Aqueous Phase Viscosity}

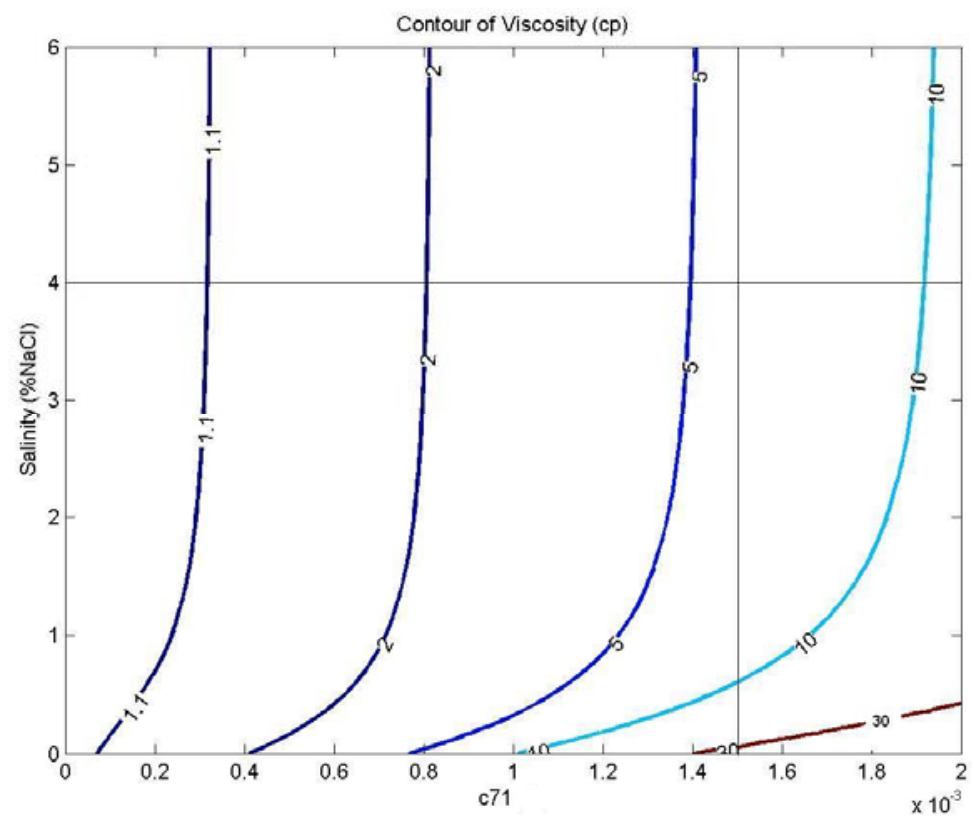

Figure 2.2-5 Contour of Viscosity (cp)

The viscosity of aqueous phase is very important for ASP process and is a function of polymer concentration and salinity. According to experimental data for Flopaam, the aqueous phase viscosity is shown as figure 2.2-5. In this figure, $c_{71}$ represent the concentration of polymer. We find that the viscosity increases as polymer concentration increases. When the salinity is less than $1 \%$, lower salinity would lead to high viscosity; but when the salinity is larger than $1 \%$, there is not much change on the viscosity by changing salinity. The lines that salinity equals $4 \%$ and polymer concentration equals $1500 \mathrm{ppm}$ in figure 2.2-5 are consistent with experimental data of figure 1.2-6 and 1.2-7. Currently, we do not count the permeability reduction by adding the polymer. But the permeability reduction due to the polymer is very important and we will calculate it in our future work.

\section{Fractional flow}

The fractional flow curve is a function of residual saturations and relative permeabilities, which are determined by IFT. For residual saturations, we calculate them as equation (4).

$$
\begin{array}{lcc}
S_{1 r}=0, S_{2 r}=0 & \text { when } & I F T<0.005 \text { dyne } / \mathrm{cm} \\
S_{1 r}=0.3 *\left[1+\left(\log _{10}(I F T) / 2.3\right)\right] & \text { when } & 0.005 \text { dyne } / \mathrm{cm}<I F T<1 \text { dyne } / \mathrm{cm}(4) \\
S_{2 r}=0.3 *\left[1+\left(\log _{10}(I F T) / 2.3\right)\right] & & \\
S_{1 r}=0.3, S_{2 r}=0.3 & \text { when } \quad I F T>1 \text { dyne/cm }
\end{array}
$$

where $S_{1 r}$ is the residual saturation of aqueous phase.

$S_{2 r}$ is the residual saturation of oleic phase. 
For the relative permeability, we calculate as follow:

$$
\begin{array}{ll}
S_{j R}=\frac{\left(S_{j}-S_{j r}\right)}{\left(1-S_{1 r}-S_{2 r}\right)} & j=1,2 \\
k_{r j}=k_{r j}^{o} S_{j R}^{E j} & j=1,2
\end{array}
$$

$k_{r 1}^{o}=k_{r w}^{o}+\left(1-k_{r w}^{o}\right)\left(0.3-S_{2 r}\right) / 0.3 \quad k_{r w}^{o}$ is end point permeability of water

$k_{r 2}^{o}=k_{r o}^{o}+\left(1-k_{r o}^{o}\right)\left(0.3-S_{1 r}\right) / 0.3 \quad k_{r o}^{o}$ is end point permeability of oil

$E j=1.0$

$E j=1.5+1 / 6 * \log _{10}(I F T)$

$E j=1.5$ when $\quad$ IFT<0.005dyne/cm

when 0.005 dyne/cm $<I F T<1$ dyne $/ \mathrm{cm}$

when IFT>1dyne/cm

At high IFT, the data we used come from the water-wet system.

Figure 2.2-6 shows the fractional flow changes with saturation at different IFT by assuming aqueous phase and oleic phase have same viscosity.

Fractional flow vs. Saturation at different IFT

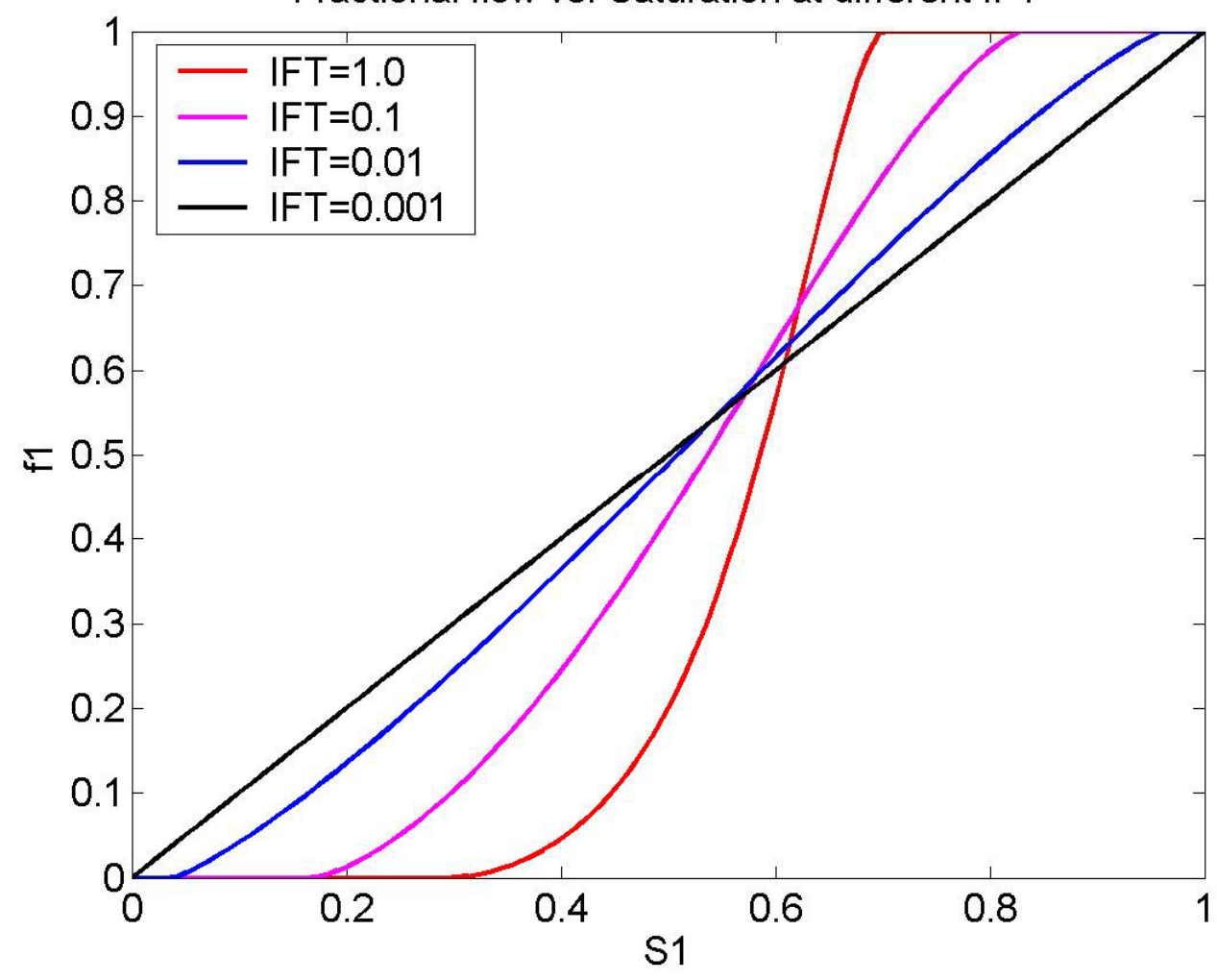

Figure 2.2-6 fractional flow changes with saturation at different IFT (Aqueous phase viscosity = Oleic phase viscosity)

\section{Surfactant adsorption}

The assumption for surfactant adsorption is Langmuir-type adsorption with two 
parameters $\left(c_{\max }, K\right)$ as equation (10).

$$
C_{3 a d s}=\frac{C_{\max } C_{31}}{\frac{C_{\max }}{K}+C_{31}}
$$

where $c_{\max }$ is the maximal adsorption amount, $K$ is the initial slope of the isotherm.

Since the adsorption amount can be significant reduced with the present of $\mathrm{Na}_{2} \mathrm{CO}_{3}$, we let $c_{\text {max }}$ be a function of $\mathrm{Na}_{2} \mathrm{CO}_{3}$. When the $\mathrm{Na}_{2} \mathrm{CO}_{3}$ concentration is larger than $0.1 \%$, the value of $c_{\max }$ is one tenth of $c_{\max }$ in the absence of $\mathrm{Na}_{2} \mathrm{CO}_{3}$.

\section{Equations and calculation procedure}

Given the above assumptions, the continuity equations for each component $i$ are

$$
\frac{\partial\left(C_{i}+C_{i a d s}\right)}{\partial t}+\frac{q}{A \phi} \frac{\partial F_{i}}{\partial x}=K_{l} \frac{\partial^{2} C_{i}}{\partial x^{2}}
$$

By using the following dimensionless variables, we can make the equation dimensionless.

$$
\begin{aligned}
& x_{D}=\frac{x}{L} \\
& t_{D}=\frac{q}{A \phi L} t \\
& P e=\frac{L q}{K_{l} A \phi} \quad \text { Peclet Number }
\end{aligned}
$$

Equation (11) becomes

$$
\frac{\partial\left(C_{i}+C_{i a d s}\right)}{\partial t_{D}}+\frac{\partial F_{i}}{\partial x_{D}}=\frac{1}{P e} \frac{\partial^{2} C_{i}}{\partial x_{D}{ }^{2}}
$$

where $C_{i}$ is the overall concentration of component $i . C_{i}=c_{i 1} * S_{1}+c_{i 2} * S_{2}$

$C_{\text {iads }}$ is the adsorbed concentration of component $i$

$F_{i}$ is the overall fractional flow of component $i . F i=c_{i 1} * f_{1}+c_{i 2} * f_{2}$

These equations are solved numerically by explicit finite difference in both $t_{D}$ and $x_{D}$. The computational procedure is as follows:

1. For a given $C_{i}$, we can calculate the $c_{i j}$ in each grid block by partition calculation if the component $i$ can not be adsorbed. For adsorbing component, it should be solved by Newton-Raphson iteration with the relationships of partition and adsorption. For the first time step, we start with initial conditions. 
2. With $c_{i j}$ calculated in step 1 , we can calculate IFT of each grid block.

3. With IFT, the residual saturation and relative permeability are solved. Thus the overall fractional flow can be calculated.

4. With $F_{i}$, we can use equation (15) to calculate the concentration in the next time step.

5. Steps 1 to 5 are repeated.

\section{Calculation example}

We will present one example of ASP process by using this simulator to show what an ASP process will be and what operating parameters we could use for an optimal strategy. The example shown here is an illustration of oil recovery by injecting chemical (alkali, surfactant and polymer) slugs. The initial condition of the example is that the reservoir has already been water flooded, i.e., the oil saturation is the residual oil saturation after water flooding.

Table 2.2-1 shows the operating parameters. A surfactant slug of 0.4 PV consisting of $0.1 \%$ (4:1NEODOL67:IOS), $0.5 \% \mathrm{Na}_{2} \mathrm{CO}_{3}, 1800 \mathrm{ppm}$ Flopaam, $5 \%$ $\mathrm{NaCl}$ is injected. This is followed by $0.2 \mathrm{PV}$ polymer drive consisting of 1800ppm Flopaam and 5\% $\mathrm{NaCl}$. After that, a $0.4 \mathrm{PV}$ brine drive $(5 \% \mathrm{NaCl})$ continues to be injected. Finally, we inject the formation brine $(1 \% \mathrm{NaCl})$.

The other major parameters for the calculation are listed in table 2.2-2. NX presents the number of grid block in the simulation; $\mathrm{dt} / \mathrm{dx}$ presents ration of the time step and grid block size. For example, if $\mathrm{NX}$ equals 100 , and $\mathrm{dt} / \mathrm{dx}$ equals 0.05 , the time step $d t$ will be $0.0005\left(=1 / N X^{*} d t / d x=1 / 100 * 0.05=0.0005\right)$. And the Peclet number presents the longitudinal dispersion. Equation (14) indicates small Peclet number implies large longitudinal dispersion.

\begin{tabular}{|c|c|c|}
\hline Chemicals & Concentration & Total Slug Size (PV) \\
\hline Alkali $\left(\mathrm{Na}_{2} \mathrm{CO}_{3}\right)$ & $0.5 \%$ & 0.4 \\
\hline Surfactant (4:1 NEODOL 67:IOS ) & $0.1 \%$ & 0.4 \\
\hline Polymer (Flopaam 3330S) & $1800 \mathrm{ppm}$ & 0.6 \\
\hline $\mathrm{NaCl}$ & $5 \%$ & $1.0^{*}$ \\
\hline
\end{tabular}

*After 1.0 PV, NaCl injecting concentration is 1.0\%

Table 2.2-1 Operating Parameters for the example

\begin{tabular}{|c|c|c|c|c|}
\hline $\begin{array}{c}\text { Initial Oil } \\
\text { Saturation }\end{array}$ & $\begin{array}{c}\text { Formation } \\
\text { Brine }\end{array}$ & Acid No. of Crude oil & NX (Grid block No.) & $\mathrm{dt} / \mathrm{dx}$ \\
\hline 0.3 & $1.0 \%$ & $0.2 \mathrm{~g} \mathrm{KOH} / \mathrm{g}$ & 100 & 0.05 \\
\hline Peclet No & $\begin{array}{c}\text { Polymer } \\
\text { adsorption }\end{array}$ & $\begin{array}{c}\text { Surfactant } \\
\text { Adsorption }\end{array}$ & Alkali consumption & Oil viscosity \\
\hline 500 & $20 \mu \mathrm{g} / \mathrm{g}$ & $0.2 \mathrm{mg} / \mathrm{g}$ & $1.4 \mathrm{mg} / \mathrm{g}$ & $8 \mathrm{cp}$ \\
\hline
\end{tabular}

Table 2.2-2 Other major parameters for the example

Figure 2.2-7 shows the profiles of surfactant and soap at 0.5 PV. Figure 2.2-8 displays the profiles of IFT and soap-synthetic surfactant ratio at 0.5 PV. 
Figure 2.2-9 presents the profile of oil at 0.5 PV.

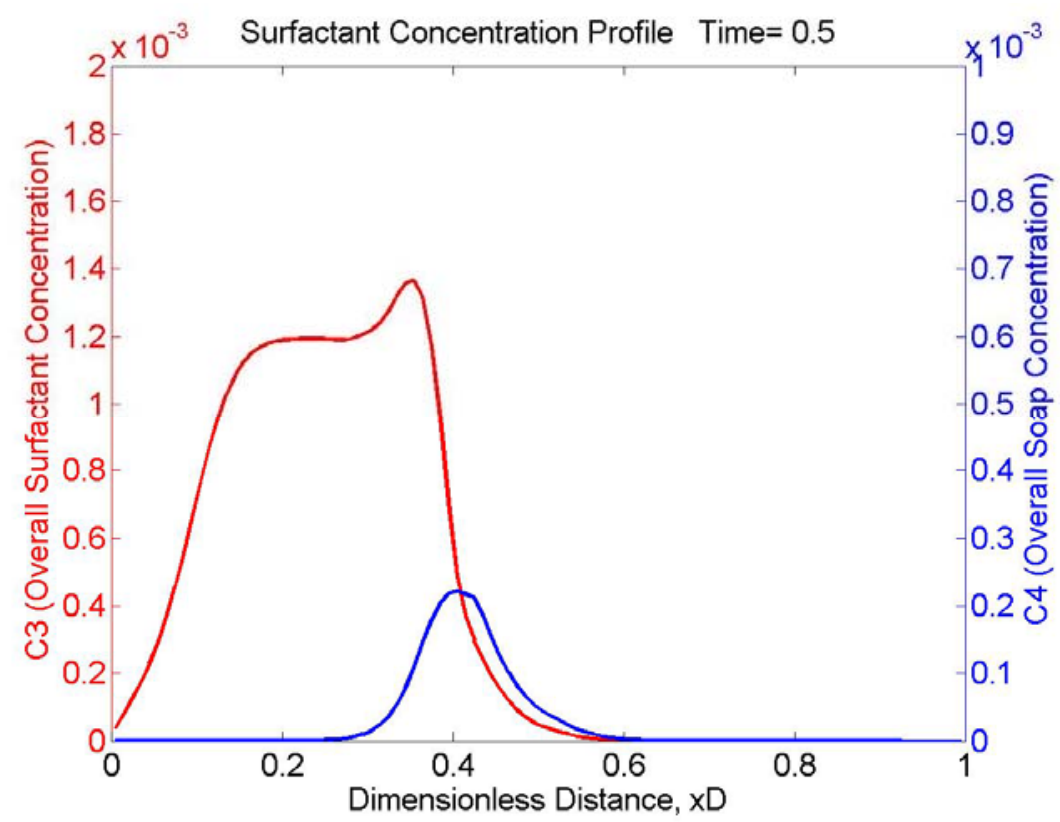

Figure 2.2-7 Profiles of surfactant and soap at 0.5PV

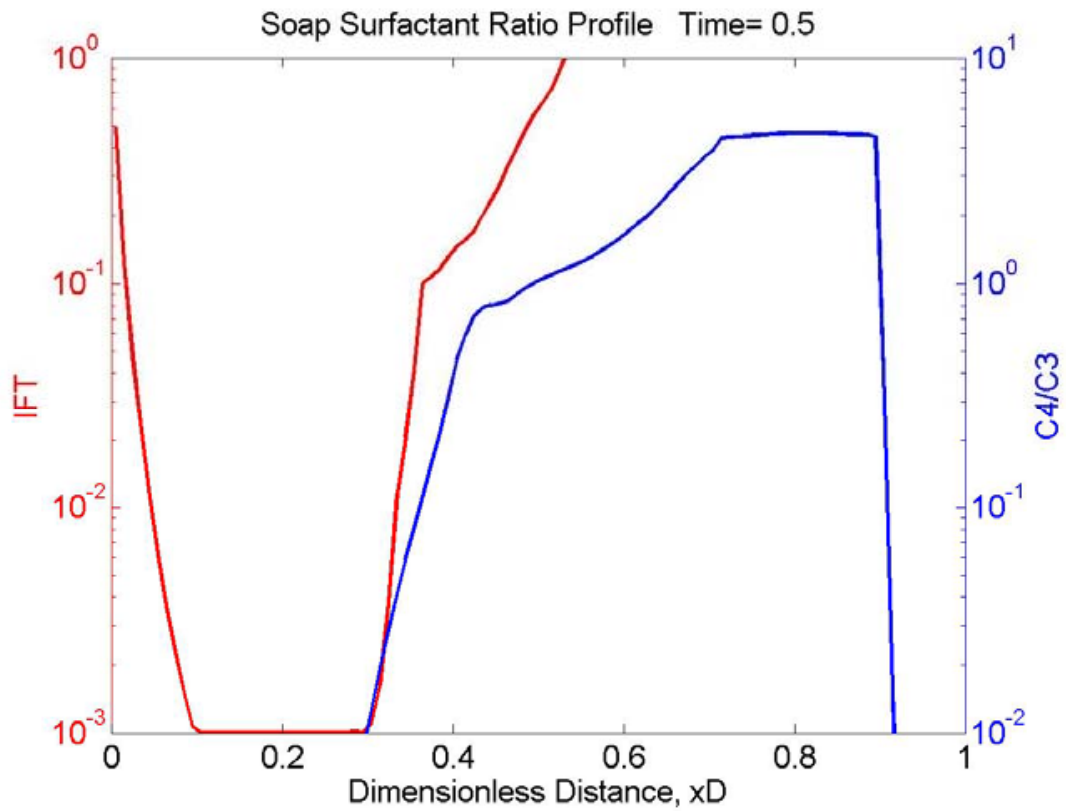

Figure 2.2-8 Profiles of IFT and soap-synthetic surfactant ratio at 0.5PV

From figure 2.2-7, we can find that alkali front is ahead of the surfactant front so that the soap front is ahead of the surfactant front. Thus, there is the type II (over-optimal region) ahead of the surfactant front because soap is dominant here. There is the type I (under-optimal region) far behind the surfactant front because surfactant is dominant and the drive salinity is only $1.0 \%$. And an optimal region is between type II and type I. This ASP process will have following merits: (1) it must pass through the optimal region; (2) it can retard surfactant that moves fast into the soap-dominant region ahead of the major surfactant bank, (3) it does not trap surfactant behind the surfactant 
bank since the surfactant is in the aqueous phase. This process design will make surfactant accumulate and oppose the dispersion effect. We can even see the surfactant concentration is a little bit larger than what we inject due to the accumulation of surfactants in figure 2.2-7. Figure 2.2-8 shows the ultra-low tension region locates at the place where soap-synthetic ratio less than 0.01 . This is because we inject at the optimal salinity of the surfactant. And figure 2.2-9 tells us that nearly all the oil has been recovered after the low-tension region.

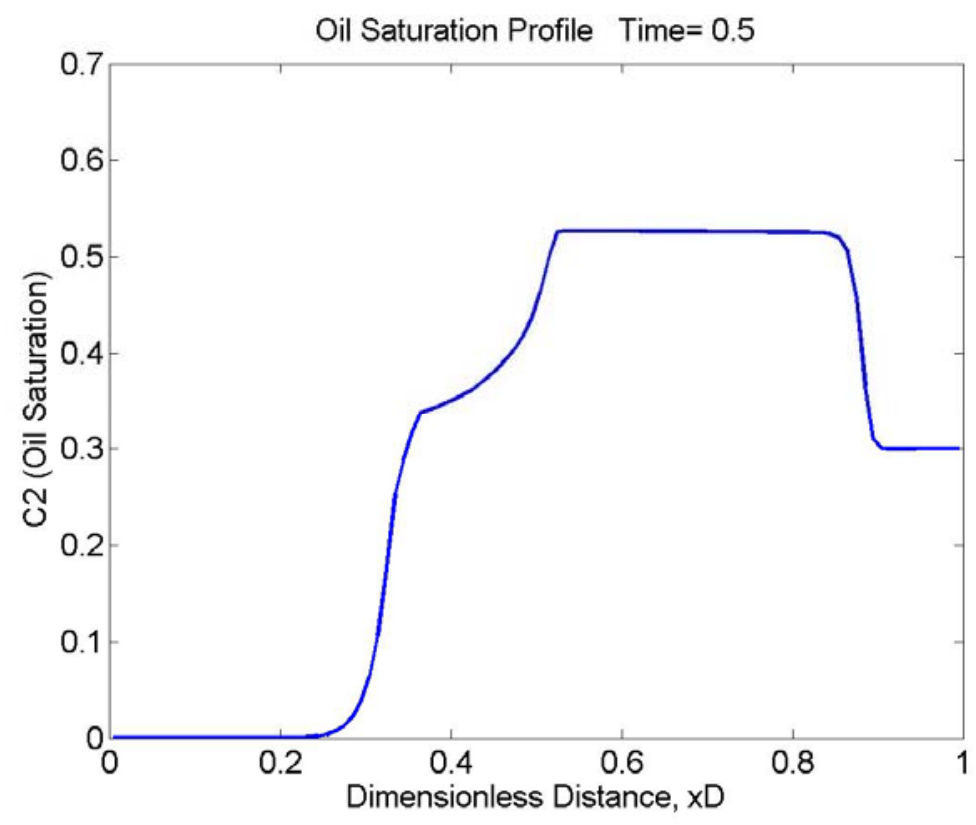

Figure2.2-9 Profile of oil saturation at 0.5PV

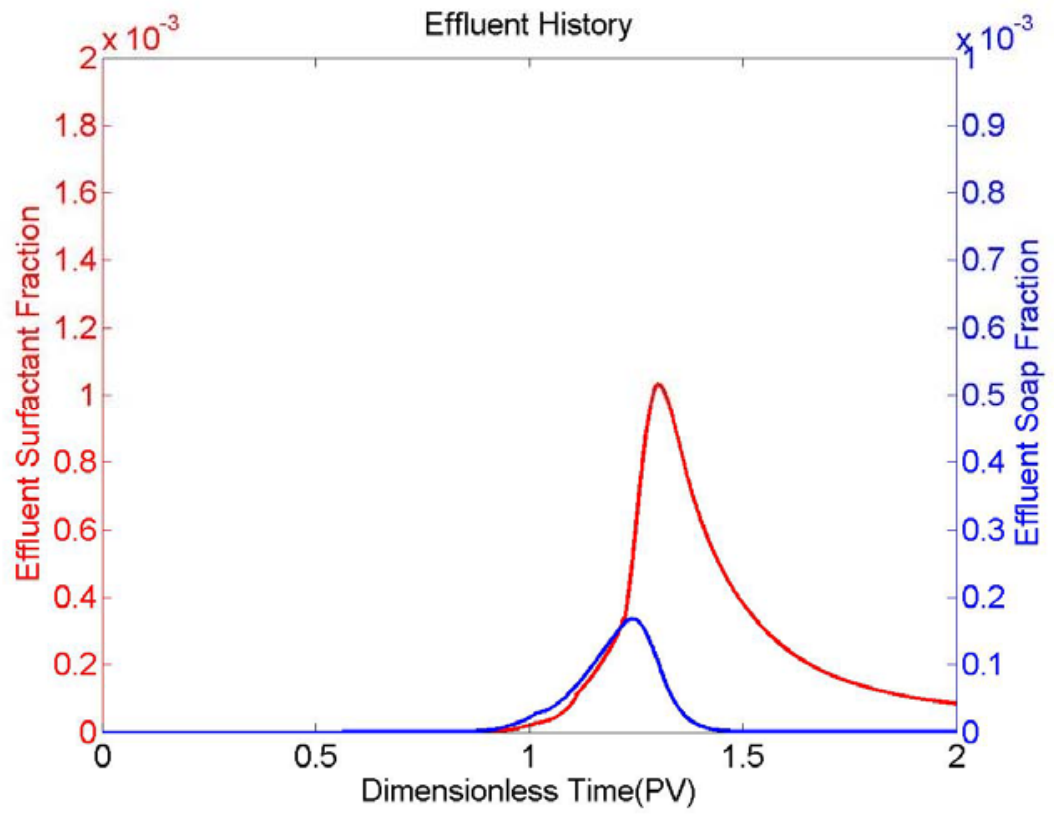

Figure 2.2-10 Effluent History of Synthetic surfactant and Soap 


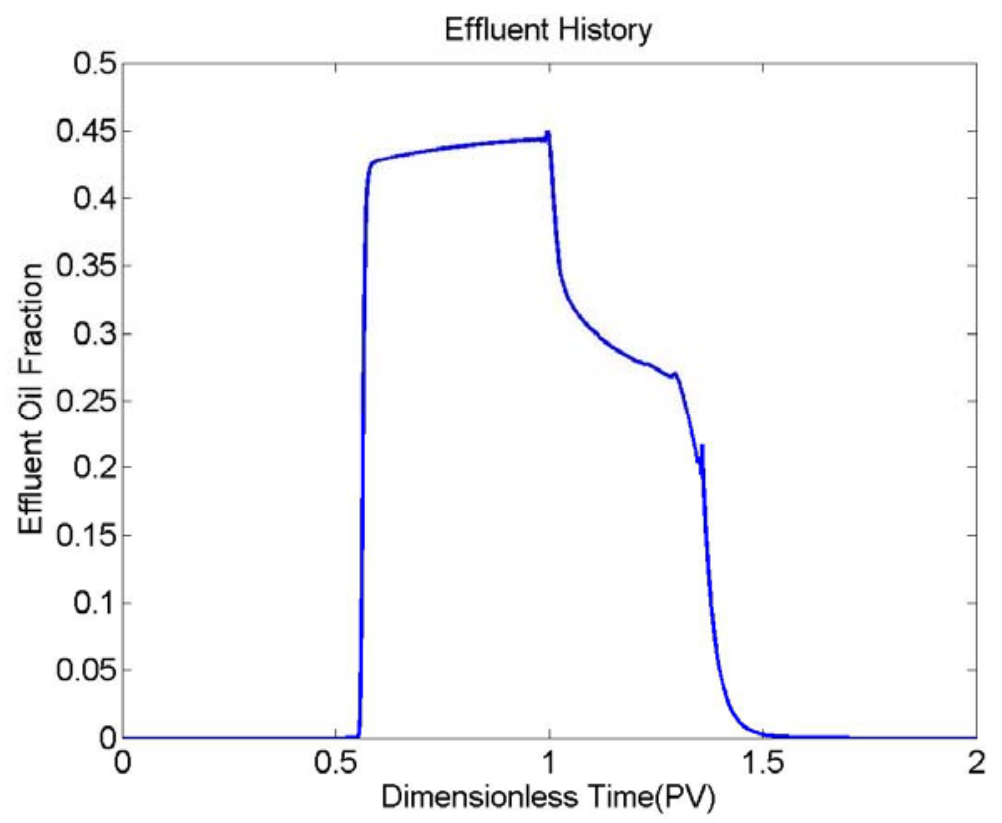

Figure 2.2-11 Effluent History of Oil

Figure 2.2-10 and 2.2-11 show the effluent history of surfactant, soap and oil. We can find most oil comes out before the surfactant breaks through. And the recovery efficiency of oil is $99.99 \%$, i.e., nearly all the oil has been recovered at time $2 \mathrm{PV}$. Since the soap and surfactant break through at 1.0 $\mathrm{PV}$, the oil will be in the emulsion after 1.0 PV. And the clean oil recovery efficiency is $74.6 \%$.

This base case seems similar to the surfactant flooding. What are the advantages that introducing the soap in the ASP process? Figure 2.2-12, 2.2-13 show one benefit that soap brings. Figure 2.2-12 is the surfactant flooding process without soap. We find that the oil recovery is sensitive to the injected brine salinity. At optimal condition (5\% salinity), the total recovery efficiency can be as high as $100 \%$. However, the total recovery drops to $70 \%$ when the salinity goes to $4.5 \%$. At $1 \%$ salinity, no oil is recovered. For the ASP process, we can recovery $35 \%$ total oil and $32 \%$ clean oil even at $1 \%$ salinity. This result implies the ASP process is more flexible and robust than the surfactant flooding.

If we increase the polymer concentration, i.e. increase the injecting aqueous phase viscosity, this effect will be more significant. The conditions in figure 2.2-14 are almost the same as the figure 2.2-12. The only difference of the two plots is the polymer concentration. The results show that, in the absence of soap, increasing polymer concentration without soap will not increase the total oil recovery but will increase the clean oil recovery a little bit. At $1 \%$ salinity, the total oil recovery will still be zero. But for ASP process, increasing polymer concentration will significantly enhance the total oil recovery and clean oil recovery. At $1 \%$ salinity, the total recovery and clean oil recovery will be $51 \%$ and $49.5 \%$ respectively. At $5 \%$ salinity, the total 
recoveries are $100 \%$ for both 1800 ppm and $2500 p p m$. However, the clean oil recovery increases from $70 \%$ to $85 \%$.

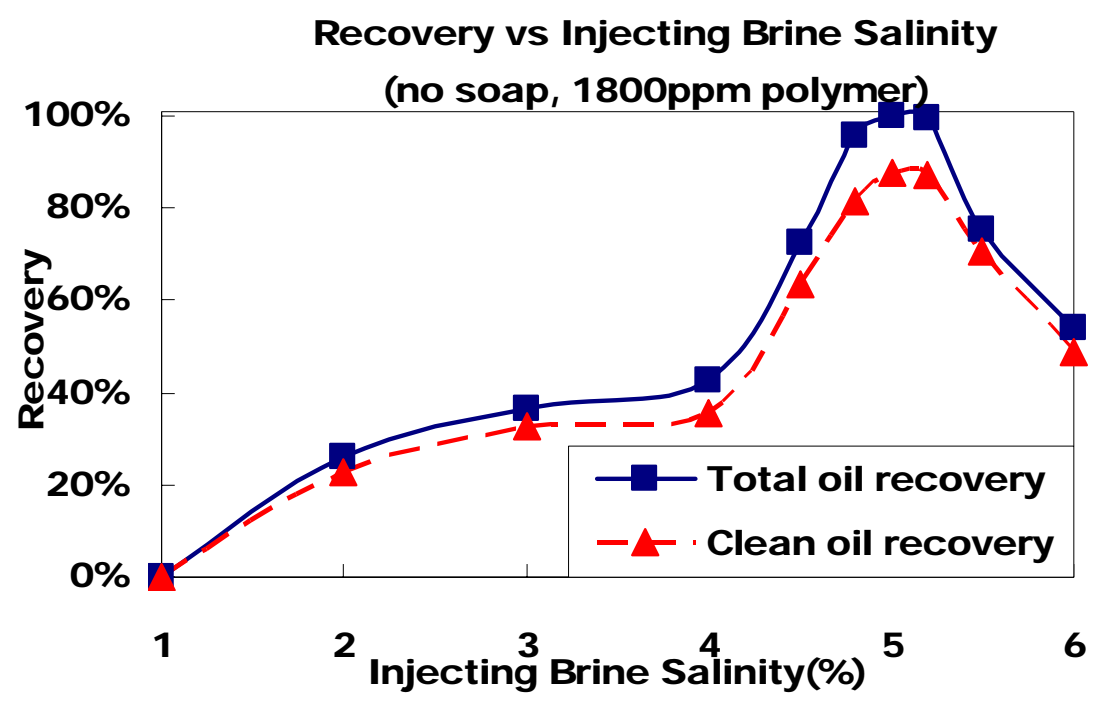

Figure 2.2-12 Oil recoveries vs. injecting brine salinities (no soap, 1800ppm polymer)

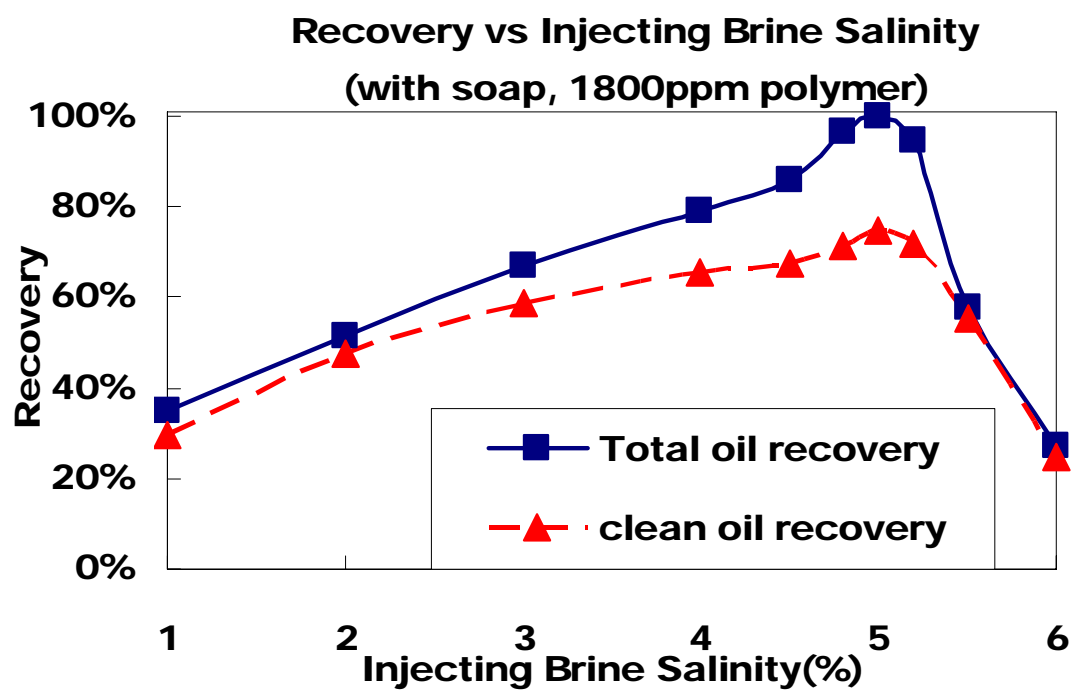

Figure 2.2-13 Oil recoveries vs. injecting brine salinities (with soap, 1800ppm polymer) 


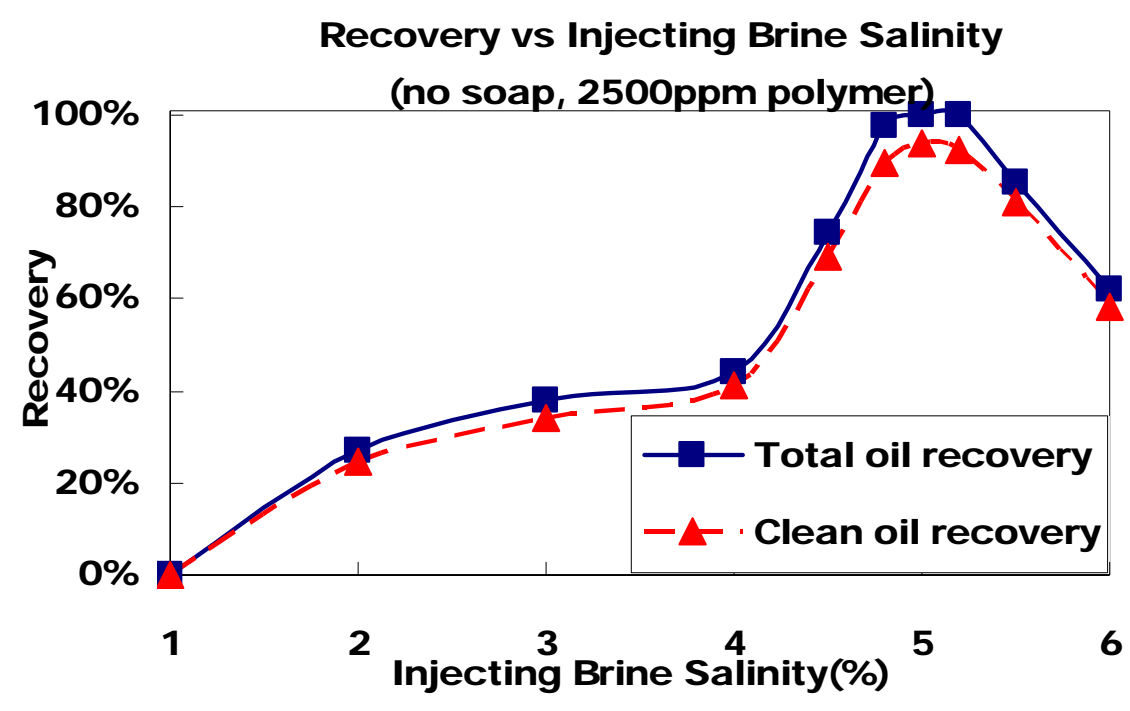

Figure 2.2-14 Oil recoveries vs. injecting brine salinities (no soap, 2500ppm polymer)

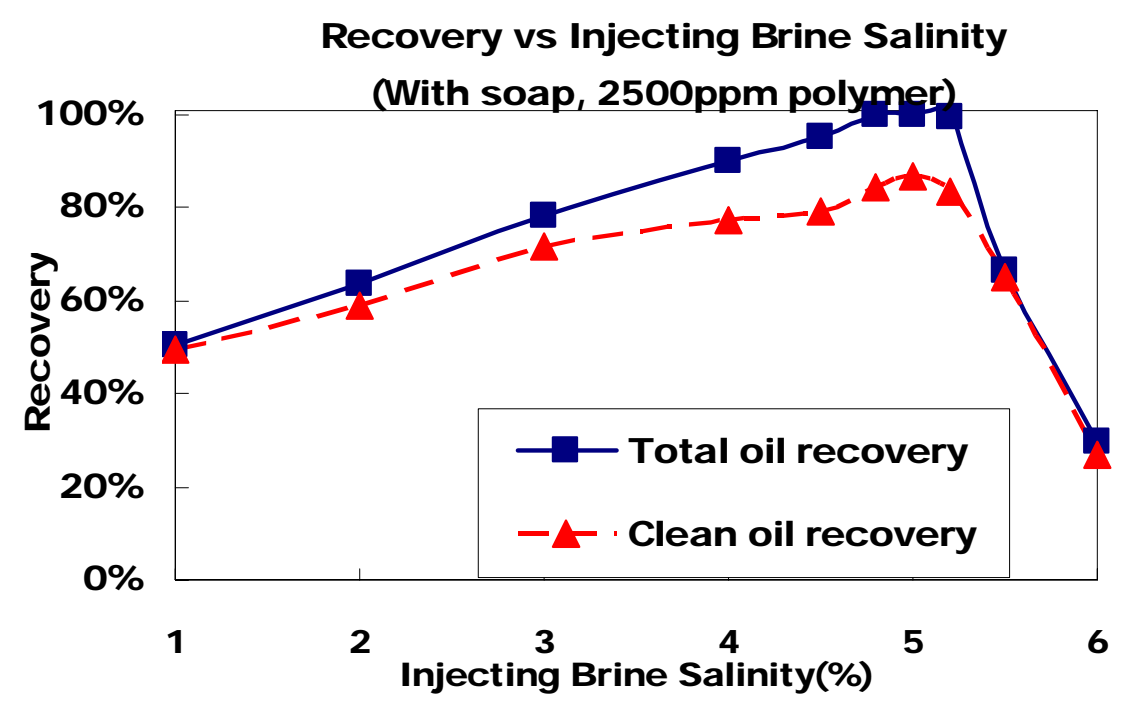

Figure 2.2-15 Oil recoveries vs. injecting brine salinities (with soap, 2500ppm polymer)

The other advantage of soap is the possibility that the presence of soap may decrease the surfactant adsorption. Because soap is also negatively charged and the carboxylate group desires to attach with alkali earth porous media, the soap may occupy the surface that can be used for adsorbing the surfactant. If so, the soap could be a sacrificial agent to save surfactant usage as the soap will travel ahead of the surfactant. Current simulator just assumes that surfactant adsorption is related only with the surfactant concentration. If the soap has effect on the surfactant adsorption, we need to change this assumption. This will be clarified in our future work. 


\section{Conclusions}

1. A one-dimensional, two phase, multi-componential simulator was developed. It can provide the profiles of all the components at any time and predict the oil recovery.

2. All of the oil can be recovered with salinity near optimum and adequate aqueous phase viscosity.

3. Soap generated by the alkali results in the ASP process being more robust to salinity changes than a conventional surfactant process. In particular oil recovery is substantially greater at salinities slightly below optimal for the injected surfactant in alkaline processes where soap forms as a second surfactant

4. The polymer concentration will significantly increase the total and clean oil recovery in ASP process

\section{Reference:}

[1] C. A. Miller and P. Neogi, in Interfacial Phenomena, Marcel Dekker, New York,1985 


\section{Subtask 2.5 Surfactant-enhanced spontaneous imbibition experiments}

While the TC blend consisting of equal weight amount of TDA-4PO and CS330 showed promising results, as discussed in the first annual report, it also has some drawbacks, such as optimal salinity increasing significantly with soap / synthetic surfactant ratio, and the formation of viscous phases, possibly due to liquid crystals. Therefore, this year's work has been dedicated to finding a much less hydrophilic surfactant or surfactant blend without viscous emulsions. N673PO sulfate and N67-7PO sulfate were tested alone or with co-surfactants/cosolvents.

\subsubsection{Surfactant Identification}

The surfactants and co-surfactants evaluated are identified in Table 2.5-1.

Table 2.5-1 Surfactant and co-surfactant identification

\begin{tabular}{|c|c|c|}
\hline$\frac{\text { Surfactant }}{\text { Type }}$ & $\underline{\text { Trade Name }}$ & $\underline{\text { Structure Name }}$ \\
\hline \multirow{11}{*}{$\begin{array}{l}\text { Anionic } \\
\text { Surfactant }\end{array}$} & CS-330 & Sodium dodecyl 3EO sulfate \\
\hline & TDA-4PO S & Ammonium iso-tridecyl $4 \mathrm{PO}$ sulfate \\
\hline & TC Blend & Blend of equal weight amount of TDA-4PO S and CS-330 \\
\hline & N67-3PO S & Ammonium NEODOL 67-3PO sulfate \\
\hline & N67-3EO S & Sodium NEODOL 67-3EO sulfate \\
\hline & N67-7 POS & Ammonium NEODOL 67-7PO sulfate \\
\hline & IOS 1518 & Sodium C15-18 internal olefin sulfonate \\
\hline & NI Blend & Blend of 4:1 weight ratio of N67-7PO sulfate and IOS 1518 \\
\hline & AOS C1618 & Sodium C16-18 alpha olefin sulfonate \\
\hline & AOS C2024 & Sodium C20-24 alpha olefin sulfonate \\
\hline & Oil-Chem 4-22 & C14-16 alkylsulfonate of phenol with 7EO \\
\hline \multirow{2}{*}{ Non-ionic } & Triton $\mathrm{X}-100$ & Octyl phenol ethoxylate \\
\hline & Tergitol 15-S-7 & C11-15-7EO secondary alcohol \\
\hline
\end{tabular}




\subsubsection{Problems with the TC Blend}

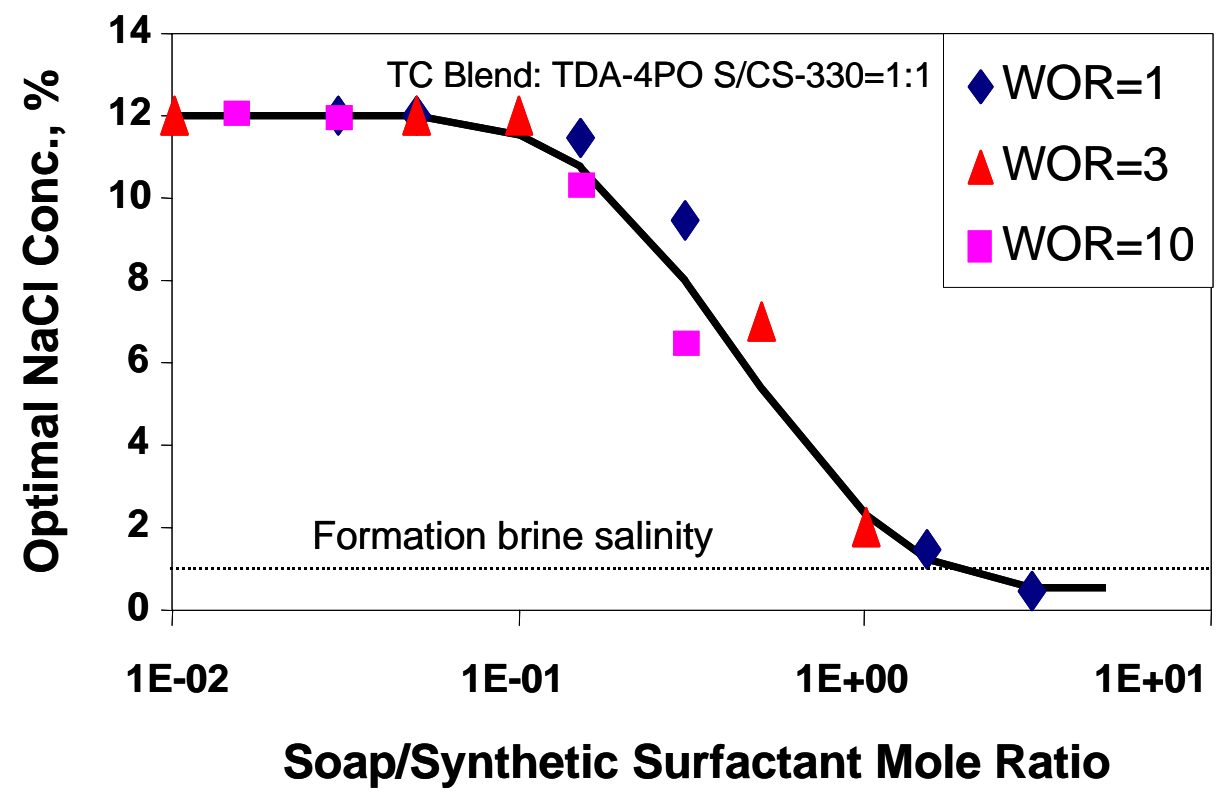

Fig 2.5-1 Dependence of optimal salinity on soap/synthetic surfactant ratio

Fig. 2.5-1 shows the dependence of the optimal salinity of the TC Blend on the soap / synthetic surfactant ratio. The optimal salinity at high surfactant concentration is about $12 \% \mathrm{NaCl}$ (with $1 \% \mathrm{Na}_{2} \mathrm{CO}_{3}$ ), while the reservoir salinity is only $1 \% \mathrm{NaCl}$. The drawback of optimal salinity increasing significantly with soap I synthetic surfactant ratio is that it will result in the large dependence of IFT on WOR.
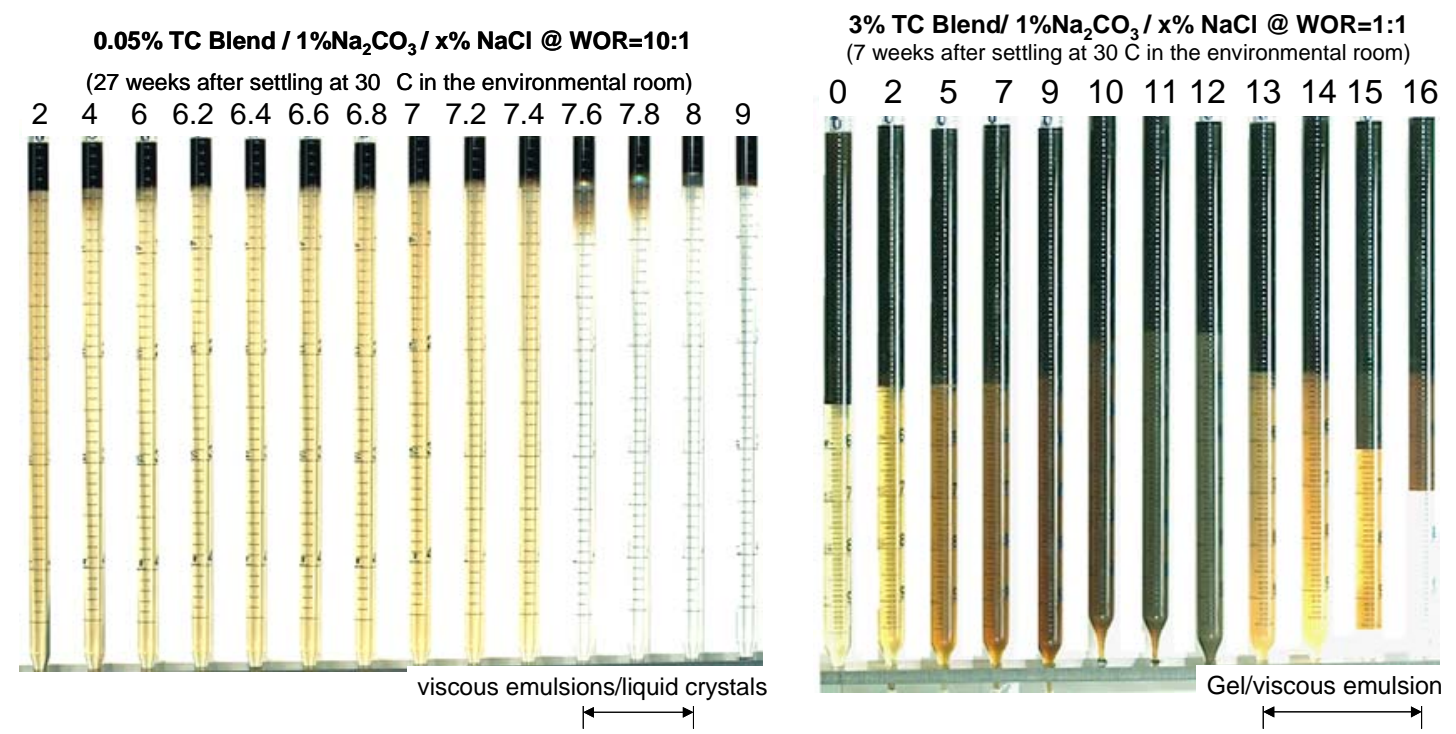

Fig 2.5-2 TC Blend surfactant forms viscous emulsions 
Another problem of the TC Blend surfactant is that it coalesces slowly at low surfactant concentration and forms viscous emulsions and gels at high surfactant concentrations (see Fig 2.5-2). The reason is that one component in the blend, CS-330, has a linear hydrophobe, which is known to form viscous phases such as liquid crystals at high salinity and low temperature.

Therefore, a surfactant or surfactant blend is needed which has a lower optimal salinity at high surfactant concentration, and does not form viscous phases. N67-3PO sulfate and N67-7PO sulfate were tested alone or with cosurfactants/co-solvent.

\subsubsection{N67-3PO S and Blends}

N67-3PO $S$ used at both 0.05 and $3 \%$, along with $1 \% \mathrm{Na}_{2} \mathrm{CO}_{3}$ / $\mathrm{NaCl}$, was mixed with crude oil MY3 at different WORs. The optimal $\mathrm{NaCl}$ concentration was estimated from phase behavior after a month, and plotted against soap/synthetic surfactant mole ratio (Fig. 2.5-3). The optimal salinity plateaus at around $3 \% \mathrm{NaCl}$ plus $1 \% \mathrm{Na}_{2} \mathrm{CO}_{3}$. Without $1 \% \mathrm{Na}_{2} \mathrm{CO}_{3}$, i.e., with $\mathrm{NaCl}$ as the only electrolyte, the optimal salinity is around $4 \% \mathrm{NaCl}$. When the oil is

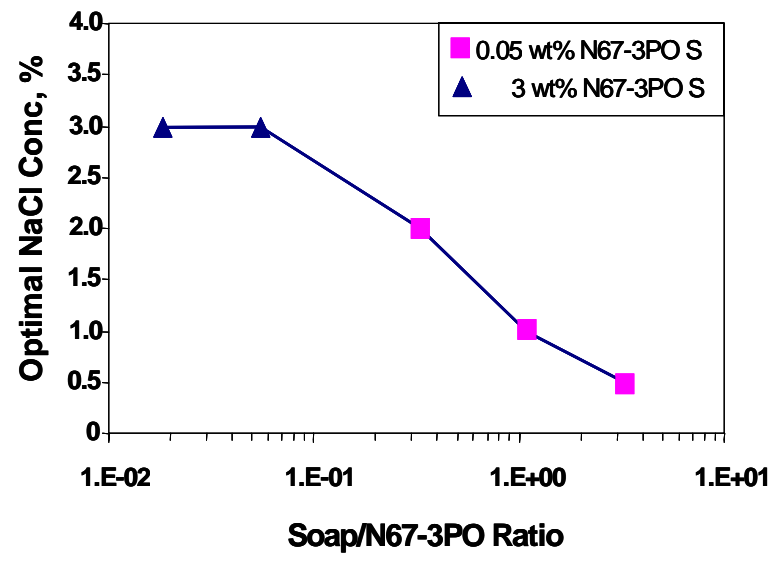

Fig. 2.5-3 Optimal salinity of N67-3PO S I $1 \% \mathrm{Na}_{2} \mathrm{CO}_{3}$ I $\mathrm{x} \% \mathrm{NaCl}$ changed to alkanes, the optimal

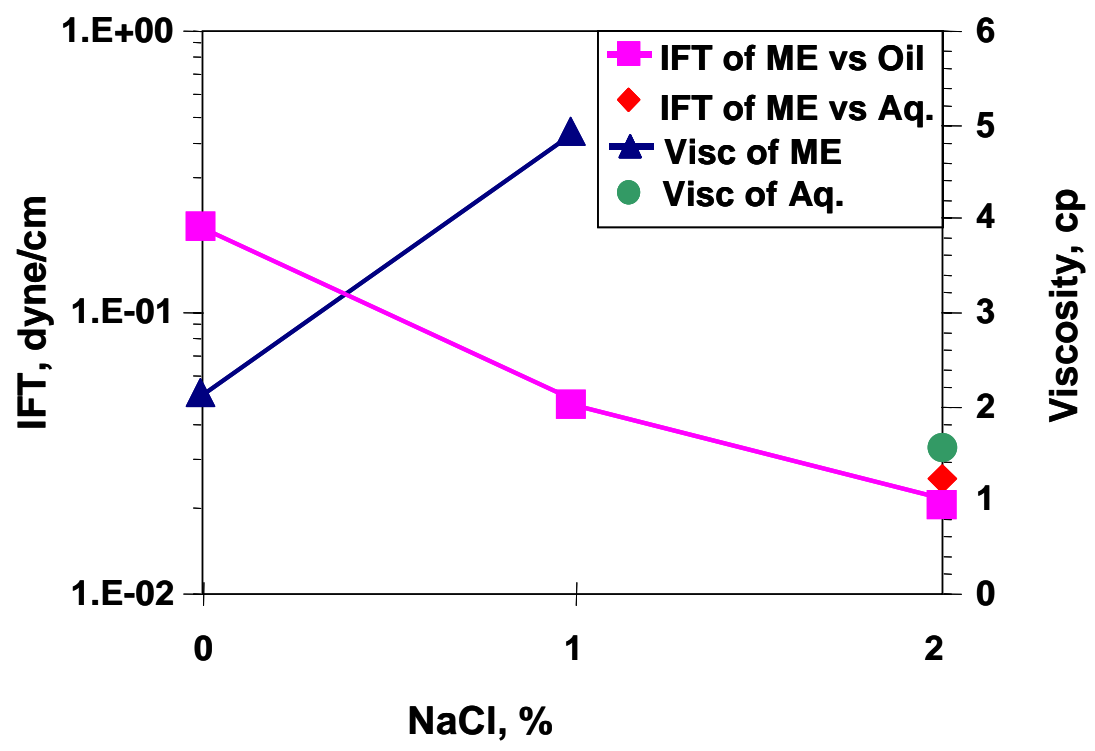

Fig 2.5-4 IFT and viscosity of 3\% N67-3PO S / 1\%AOS C2024 / 8\%SBA / 1\% $\mathrm{Na}_{2} \mathrm{CO}_{3} / \mathrm{NaCl}$ 
salinity with $\mathrm{n}-\mathrm{C} 5$ is around $2 \% \mathrm{NaCl}$ plus $1 \% \mathrm{Na}_{2} \mathrm{CO}_{3}$; and with $\mathrm{n}-\mathrm{C} 7$ the optimal salinity increased to about $3 \% \mathrm{NaCl}$ plus $1 \% \mathrm{Na}_{2} \mathrm{CO}_{3}$. That the optimal salinity is lower with $\mathrm{n}-\mathrm{C} 5$ than with $\mathrm{n}-\mathrm{C} 7$, i.e.,with lower alkane number, is consistent with existing literature on microemulsions and EOR.

When N67-3PO $S$ is used by itself, slow coalescence of emulsions in the aqueous phase occurs. Therefore, several co-surfactants - N67-3EO S, AOS C1618, AOS C2024, Oil-Chem 4-22, Triton X-100, Tergitol 15-S-7, or alcohol second butyl alcohol (SBA) were used with the N67-3PO $S$ to test their ability to enhance emulsion coalescence rate. It was found that at high N67-3PO S concentration (3\%), the addition of $8 \%$ SBA enhanced emulsion coalescence behavior, but nothing else had significant effect. However, at low N67-3PO S concentration (0.05\%), up to $1 \%$ SBA does not help emulsion coalescence.

IFT and viscosity of 3\% N67-3PO S / 1\%AOS C2024 / 8\%SBA / 1\% $\mathrm{Na}_{2} \mathrm{CO}_{3} / \mathrm{NaCl}$ were measured (Fig 2.5-4). Tensions were found to all be above $0.01 \mathrm{dyne} / \mathrm{cm}$, and viscosity below $5 \mathrm{cp}$. The high tension was caused by the addition of alcohol. But alcohol prevented the formation of viscous emulsion. N67-3PO S was not further researched because N67-7PO S has lower optimal salinity and higher solubility parameter at optimal condition, obtained at $3 \%$ surfactant with n-C10 (normal decane) as shown in Fig 2.5-5. The work in the rest of this report is done with N67-7PO S.

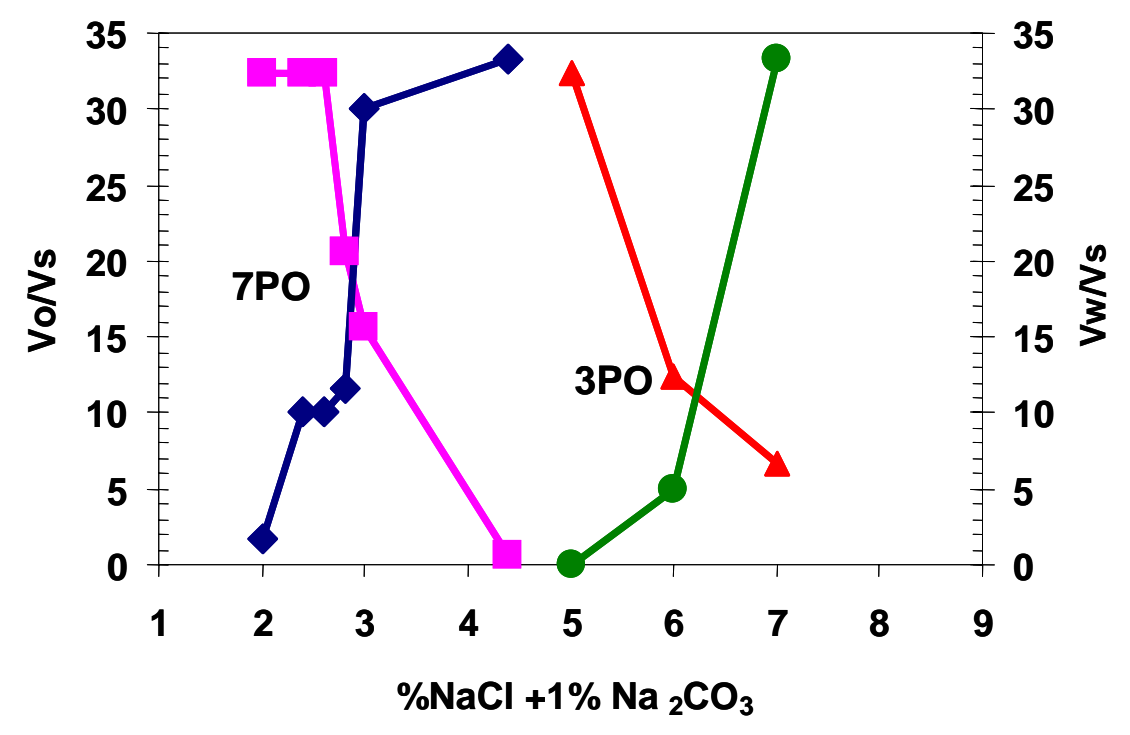

Fig 2.5-5 Solubility parameters of 3\% N67-3PO S and N67-7PO S, with n-C10 at WOR=1:1, $78{ }^{\circ} \mathrm{F}$ 


\subsubsection{N67-7PO Sulfate and Blends}

Phase behavior of $3 \%$ N67-7PO S with crude oil MY3 at WOR=3:1 is shown in Fig 2.5-6. The optimal salinity at this condition is around $2.2 \% \mathrm{NaCl}$, which indicates that N67-7PO $S$ is a much less hydrophilic surfactant than most surfactants tested so far. The picture also shows that it forms liquid crystals around the optimal condition (e.g. the iridescent region at $2.2 \% \mathrm{NaCl}$ ).

3\%N67-7PO S / 1\% $\mathrm{Na}_{2} \mathrm{CO}_{3} /$ x\% NaCl @ WOR=3:1

170 days after settling at room temperature

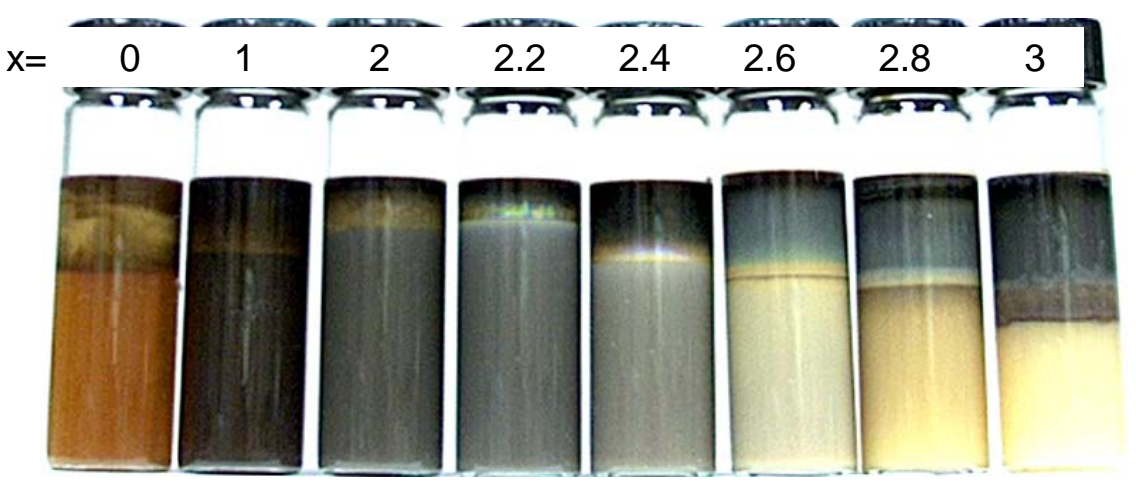

Fig 2.5-6 Phase behavior of $3 \%$ N67-7PO S with $1 \% \mathrm{Na}_{2} \mathrm{CO}_{3}$ as a function of $\mathrm{NaCl}$ concentration.

One way to prevent the formation of liquid crystals is to add alcohol. So $8 \%$ SBA was added to $3 \%$ N67-7PO S, and the phase behavior is shown in Fig 2.57. A middle phase was formed at $0.6-1.0 \% \mathrm{NaCl}$ (with $1 \% \mathrm{Na}_{2} \mathrm{CO}_{3}$ ). Compared with 3\% N67-7PO $\mathrm{S}$ by itself, the optimal salinity after adding SBA has been reduced from $2.2 \%$ to lower than $1.5 \% \mathrm{NaCl}$ (To actually decide the optimal salinity, a few more phase behavior tubes should be prepared between 1.0 and $1.5 \%)$

3\%N67-7PO S / 8\%SBA / 1\% $\mathrm{Na}_{2} \mathrm{CO}_{3} /$ x\% $\mathrm{NaCl} @$ WOR=3:1

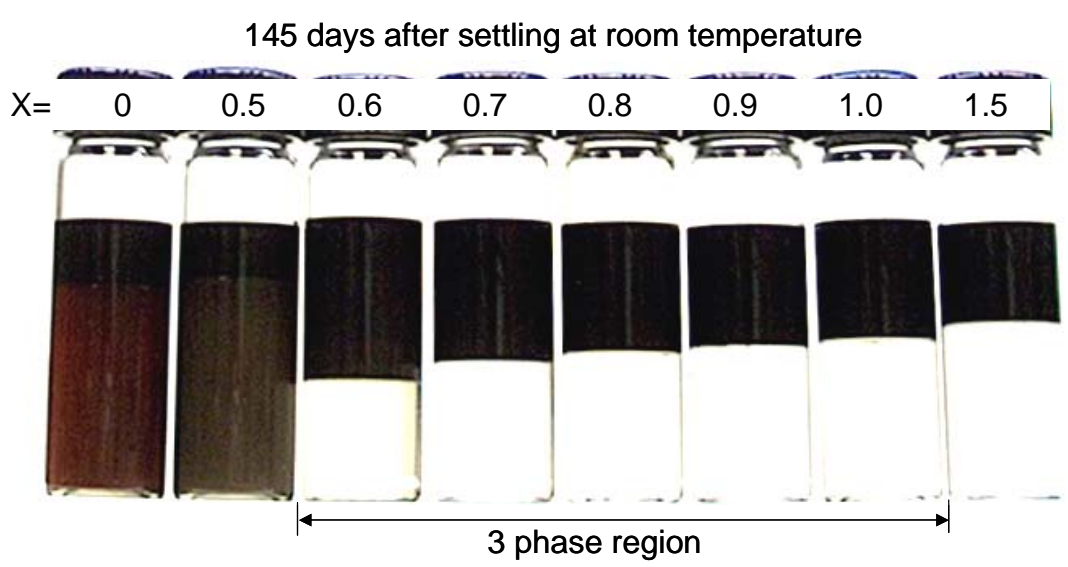

Fig 2.5-7 Phase behavior of 3\% N67-7PO S I 8\% secondary butyl alcohol, with $1 \% \mathrm{Na}_{2} \mathrm{CO}_{3}$ as a function of $\mathrm{NaCl}$ concentration. 


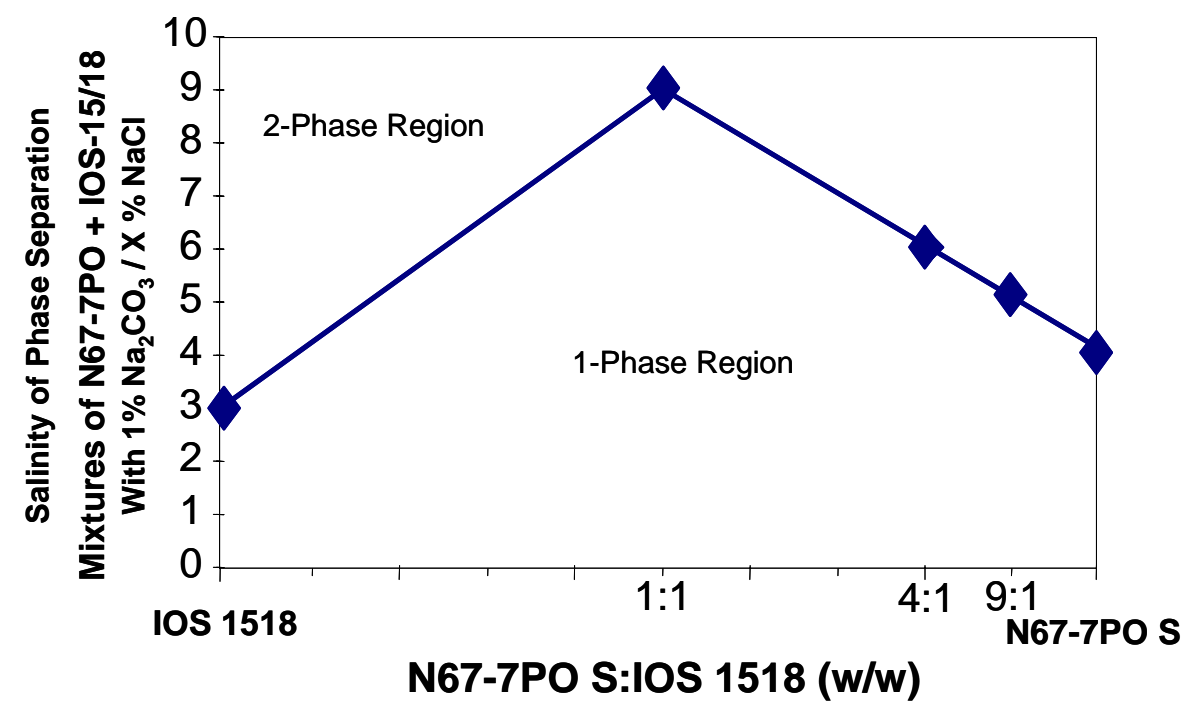

Fig 2.5-8 Salinity of phase separation increases when N67-7PO S and IOS 1518 are blended compared with used alone.

As shown in the last section, adding alcohol will increase IFT, which is not desired in the low tension induced, gravity dominated process. The alternative is to add a branched surfactant. Abe et al (Abe et al, 1986) found when a linear surfactant was used aloneat room temperature, a large amount of alcohol was needed to have microemulsion free of liquid crystals; but when twin-tailed surfactants were used, less, or even no alcohol was needed, depending on the location of the hydrophilic group. Based on this finding, IOS 1518, which is a twin-tailed surfactant with the sulfonate group distributed along the hydrocarbon chain, was blended with N67-7PO S.

When N67-7PO $S$ or IOS 1518 are used separately, the salinity of phase separation occured at 4 and $3 \% \mathrm{NaCl}$ (with $1 \% \quad \mathrm{Na}_{2} \mathrm{CO}_{3}$ ) respectively, as shown in Fig 2.5-8. But when they are mixed at $1: 1,4: 1$, and 9:1 weight ratio, they stay in the single-phase region over a much wider salinity range.

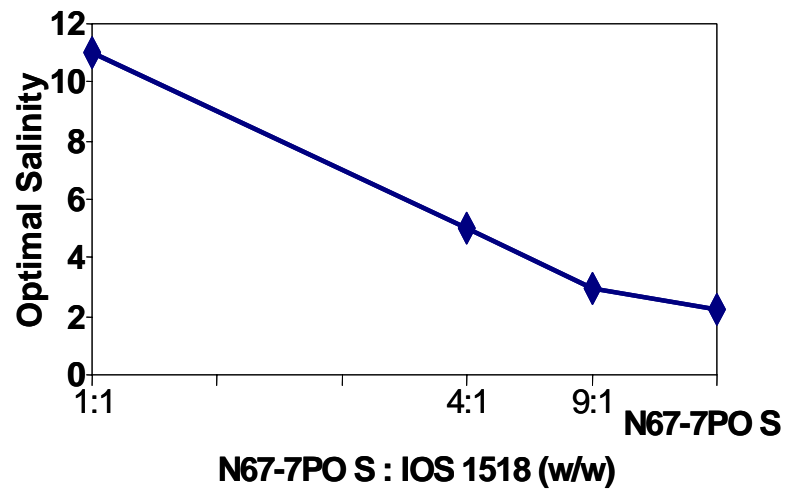

Fig 2.5-9 Optimal salinity of $3 \%$ total surfactant at different N67-7PO $S$ and IOS 1518 ratio. 
2.4\% N67-7PO S / 0.6\% IOS-15/18 / 1\% $\mathrm{Na}_{2} \mathrm{CO}_{3} /$ x\% $\mathrm{NaCl} @$ WOR=3:1

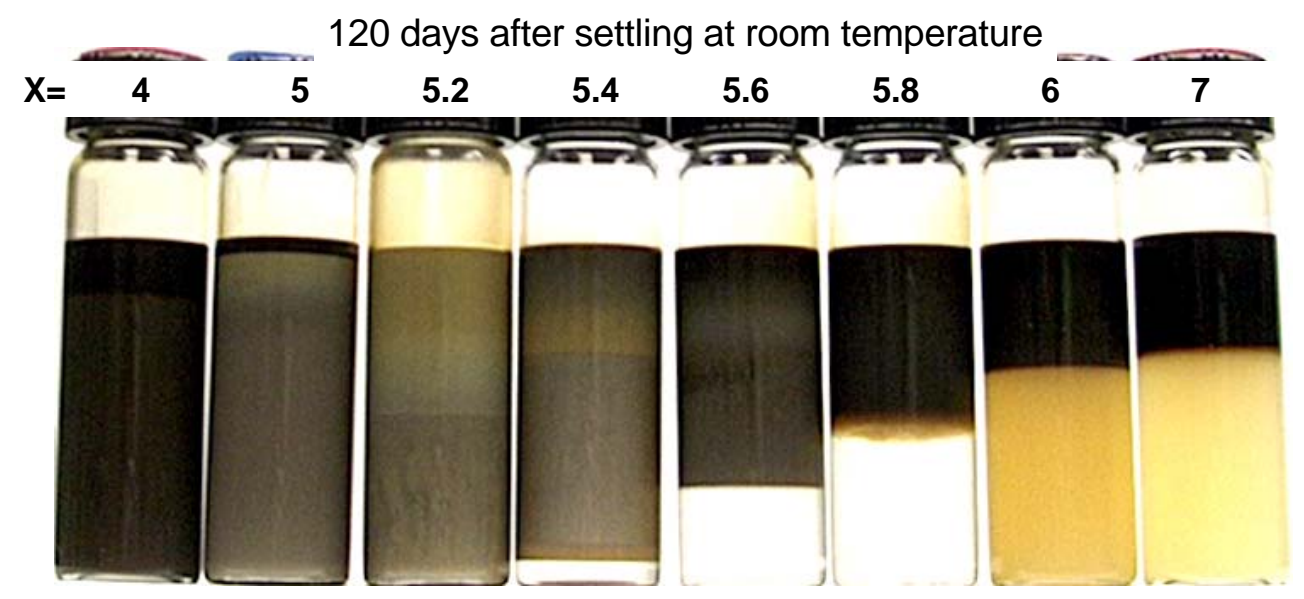

Fig 2.5-10 Phase behavior of 2.4\% N67-7PO S / 0.6\% IOS 1518 with $1 \% \mathrm{Na}_{2} \mathrm{CO}_{3}$ as a function of $\mathrm{NaCl}$ concentration.

Optimal salinities at 3\% total surfactant concentration of N67-7PO S and IOS 1518 mixed at the three different weight ratios mentioned above are summarized in Fig 2.5-9. The optimal salinity at $1: 1$ ratio is too high to be acceptable, and the emulsion coalescence rate at 9:1 ratio is not acceptable. At the $4: 1$ ratio (Fig 2.5-10), when the vials were tilted, all interfaces moved smoothly with no evidence of viscous phases. At this ratio, the optimal salinity is closer to that of the formation brine (Fig 2.5-11). Therefore the 4:1 ratio was chosen to test its ability to lower IFT and improve oil recovery.

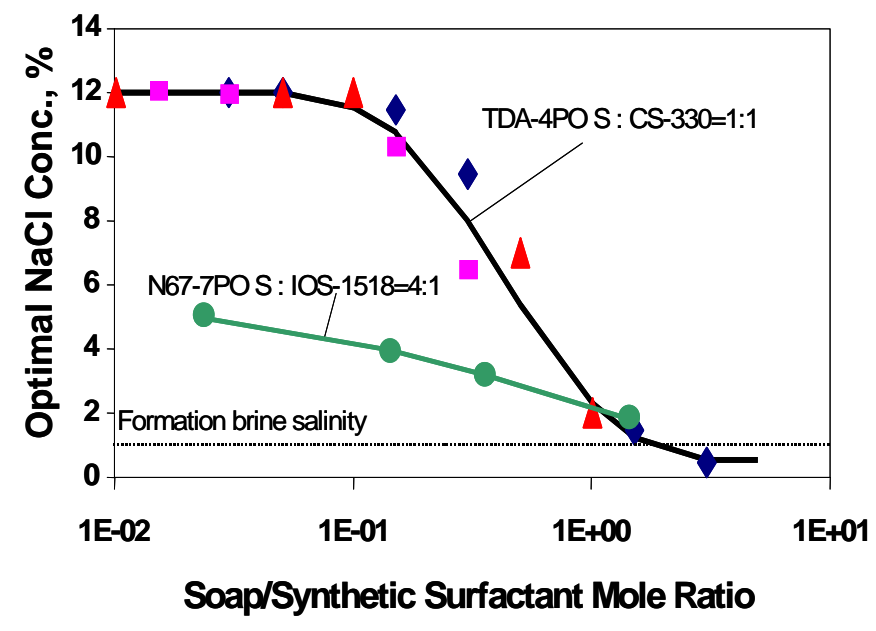

Fig 2.5-11 Soap/Synthetic Surfactant Mole Ratio Correlation

\subsubsection{N67-7PO S: IOS $1518=4: 1$ (wt)}

The mixture of 4:1 weight ratio of N67-7PO S and IOS 1518 (NI Blend) with $1 \% \mathrm{Na}_{2} \mathrm{CO}_{3}$ was examined as to its adsorption on calcite powder, and its ability to lower IFT and improve oil recovery. 


\subsubsection{Adsorption}

Surfactant adsorption was determined by potentiometric titration with hyamine. The initial surfactant concentration was fixed, while surfactant solution and calcite powder were mixed at varied weight ratios. The equilibrium surfactant concentration was determined by titration, while the calcite powder surface area determined by BET adsorption. With thus information, surfactant adsorption density was calculated.

The adsorption of $\mathrm{NI}$ Blend without or with sodium carbonate is shown in Fig 2.5-12. Two initial surfactant concentrations were used: $0.05 \mathrm{wt} \%(0.76 \mathrm{mmol} / \mathrm{l})$ and $0.1 \mathrm{wt} \%(1.52 \mathrm{mmol} / \mathrm{l})$. The equilibrium adsorption density of the surfactant without sodium carbonate is $1.5-2 \mathrm{mg} / \mathrm{m}^{2}$. But after adding $1 \% \mathrm{Na}_{2} \mathrm{CO}_{3}$, the adsorption is reduced several fold to about $0.1 \mathrm{mg} / \mathrm{m}^{2}$.
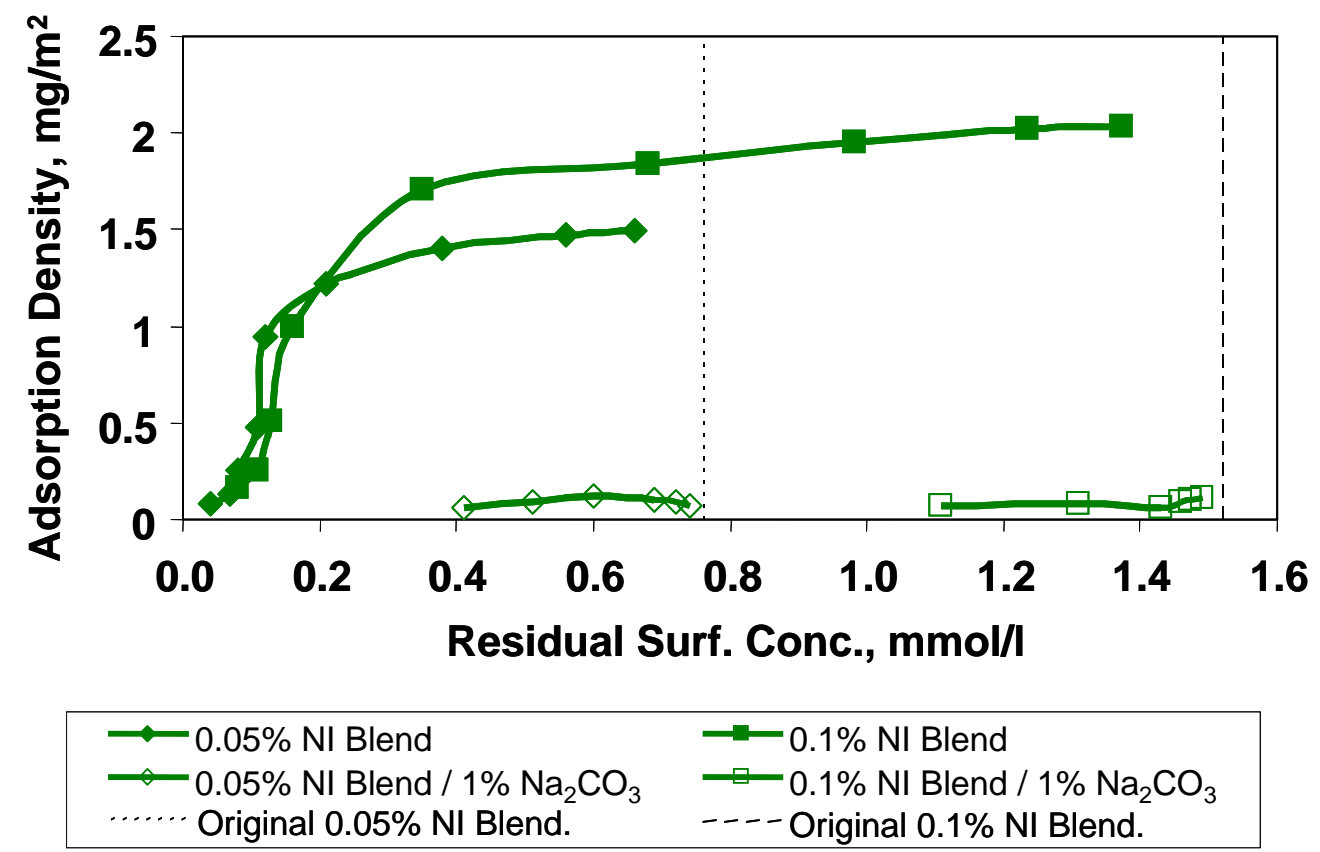

Fig 2.5-12 Adsorption of NI Blend on calcite powder

\subsubsection{Phase Behavior and IFT}

Phase behavior at low surfactant concentration, $0.05 \% \mathrm{NI}$ Blend / $1 \% \mathrm{Na}_{2} \mathrm{CO}_{3}$ I $\mathrm{x} \% \mathrm{NaCl}$, is shown in Fig 2.5-13. Traditionally, IFT was measured between microemulsion and excess brine or microemulsion and excess oil phases. But at very low surfactant concentration, there is not enough surfactant to form a large enough microemulsion phase for IFT measurements. In these cases it is often difficult to get reproducible measurements of IFT as discussed in last year's report. A new procedure has been developed to overcome this problem.

Most obvious difference between samples at 7 days and 1 month is that as brine phase at $2.0 \% \mathrm{NaCl}$ cleared up, IFT also changed with time, as shown in Fig 2.5-14, because the surfactant rich microemulsion phase has settled to the 
$0.05 \% \mathrm{NI}$ Blend / 1\% $\mathrm{Na}_{2} \mathrm{CO}_{3} / \mathrm{x} \% \mathrm{NaCl} @$ WOR=3:1, Room Temperature

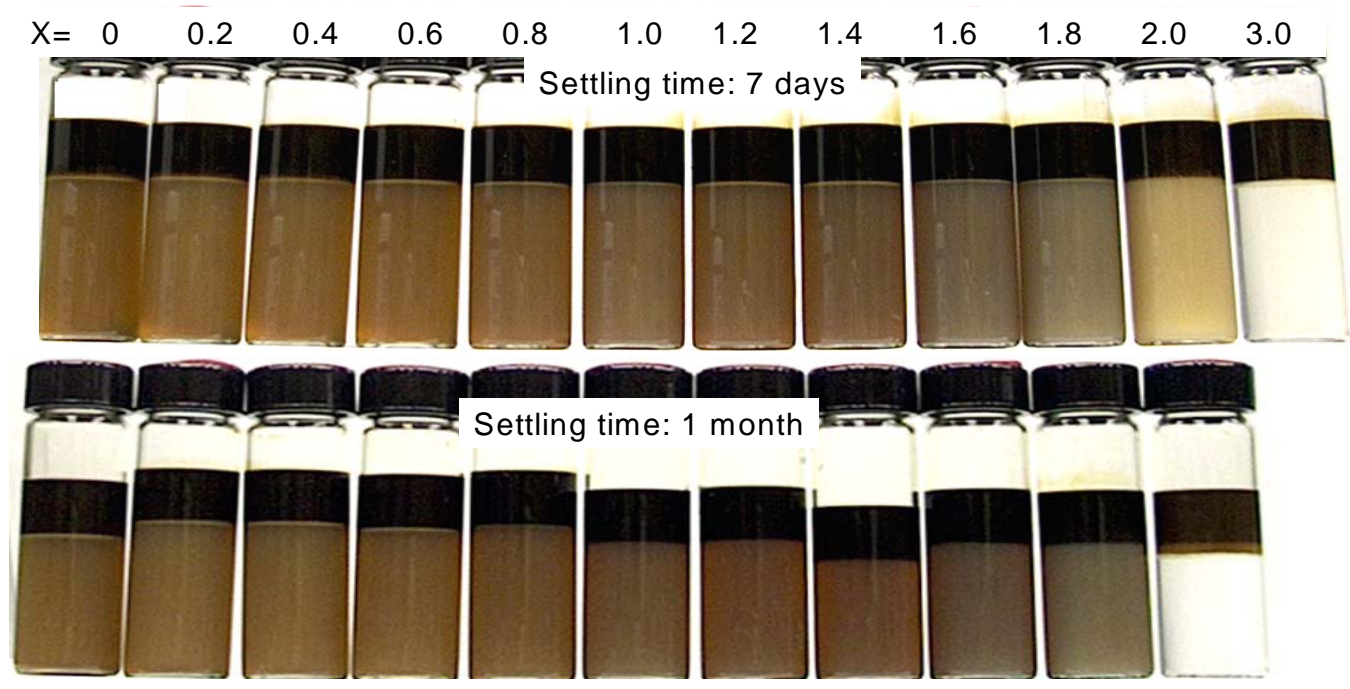

Fig 2.5-13 Phase Behavior of $0.05 \% \mathrm{NI}$ Blend $/ 1 \% \mathrm{Na}_{2} \mathrm{CO}_{3} / \times \% \mathrm{NaCl}$

interface. This phenomenon was observed with CS-330, TDA-4PO S, and their blend, and reported previously (Zhang et al, 2004). It was found that if a small amount of the middle layer was added, IFT could be lowered to ultra-low values again. But because the microemulsion layer was so thin, the result was difficult to reproduce.

A new sample of 1.8\% NaCl was prepared. After settling for 6 days, excess brine and oil phases were taken for IFT measurements, but the aqueous phase was too dark to see the oil phase in the spinning drop apparatus. Therefore the lower phase was separated from the oil phase, and centrifuged at 6,000 RPM for

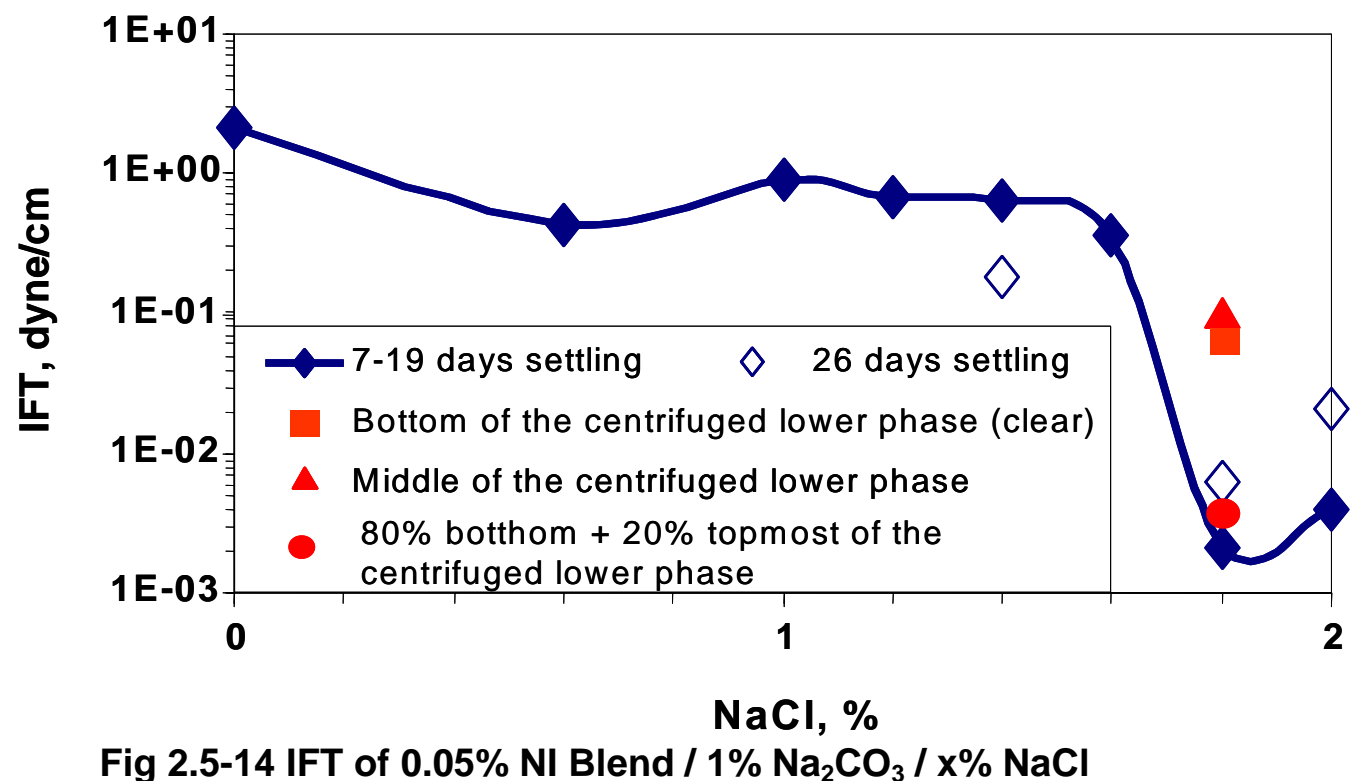


30 minutes. There was a turbidity gradient in the centrifuged solution - the bottom is clear while the top is the most turbid. IFT was measured between the equilibrated oil phase and aqueous phase sampled from different position of the centrifuged lower phase. When sampled from the bottom where it was clear, IFT was close to $0.1 \mathrm{dyne} / \mathrm{cm}$. When sampled from the middle, where it was turbid, IFT was still high - close to 0.1 dyne/cm. But when mixing $80 \%$ bottom clear solution with $20 \%$ topmost turbid layer (about top $2 \%$ of the centrifuged lower phase), the IFT was low $-0.003 \mathrm{dyne} / \mathrm{cm}$. This indicates that turbidity of the lower phase is a necessary but not sufficient condition for low IFT.

This last result also suggests an effective way of measuring IFT: A system should be settled only until enough oil coalesces for IFT measurement. Then IFT should be measured. If the lower phase is too dark to see the oil drop, the solution should be centrifuged. The clear bottom and upmost turbid layer should be mixed at a certain ratio, e.g. 4:1, as the aqueous phase for the spinning drop IFT measurements.

\subsubsection{Oil recovery by centrifuge imbibition}

Centrifuge imbibition experiments were conducted instead of spontaneous imbibition experiments because imbibition in centrifuge took much less time and allowed multiple experiments -6 cores can be processed at the same time.

1" diameter by 1" length Texas Cream limestone cores were used in the

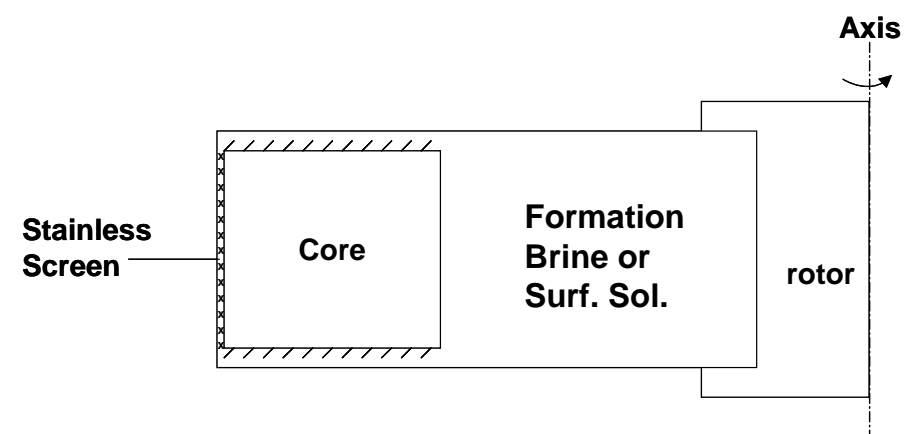

Fig 2.5-15 Schematic set-up of centrifuge imbibition with formation brine of surfactant solution.

centrifuge imbibition experiments. The cores jacketed with heat shrinkable Teflon sleeve were first subjected to vacuum for over 8 hours, then brine vacuum-saturated for 8 hours before being pressure-saturated for another 8 hours. The brine saturated cores were centrifuged in crude oil at 15,000 RPM, which corresponds to about $80 \mathrm{psi}$, for 12 hours, then the cores were turned upside down to centrifuge at the same speed for another 12 hours. After the oil-saturated cores were aged

Table 2.5-2 Bond number at 6,000 RPM, Perm=6 md

\begin{tabular}{|c|c|}
\hline IFT, $\mathrm{mN} / \mathrm{m}$ & $\mathrm{N}_{\mathrm{B}}$ \\
\hline 30 & $1.6^{\star} 10^{-6}$ \\
\hline 1 & $4.7^{\star} 10^{-5}$ \\
\hline 0.1 & $4.7^{\star} 10^{-4}$ \\
\hline 0.01 & $4.7^{\star} 10^{-3}$ \\
\hline 0.001 & $4.7^{\star} 10^{-2}$ \\
\hline
\end{tabular}




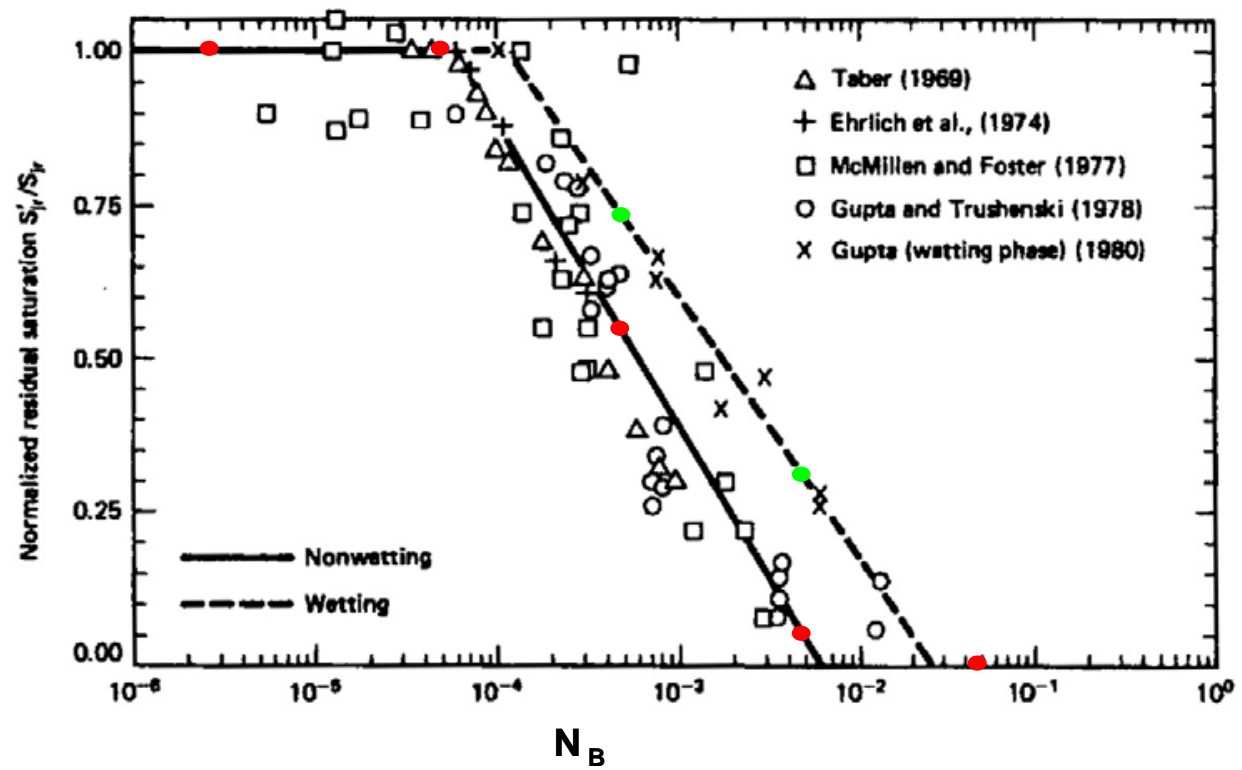

Fig 2.5-16 Correlation between residual oil saturation and Bond number. Dots are marked according to Table 2.5-2

at $80{ }^{\circ} \mathrm{C}$ for 48 hours, they were centrifuged at 6,000 RPM, which corresponds to about $27 \mathrm{psi}$, in either formation brine or surfactant solution. The schematic setup is shown in Fig 2.5-15. The stainless steel screen was used to allow the aqueous phase to be present at the end of the core and co-current flow allowed to occur.

Alkaline-surfactant solution improves oil recovery by altering wettability and lowering interfacial tension. Bond number at 6,000 RPM is calculated as a function of IFT (Table 2.5-2), and marked as red (water-wet) and green (oil-wet) dots on the correlation between residual oil saturation and Bond number (Fig 2.5-16). The figure suggests that if IFT can be lowered to $10^{-3}$ dyne $/ \mathrm{cm}$ $(\mathrm{mN} / \mathrm{m})$, ideally, all oil can be recovered.

The oil recovery with $0.05 \% \mathrm{NI}$ Blend is only marginally better than with formation brine, because $0.05 \%$ is close to the CMC of the blend surfactant, and when the surfactant solutions entered cores and mixed with formation brine, they were diluted and their concentrations dropped below CMC which may cause the system not to have low tension any more. Therefore, $0.2 \% \mathrm{NI}$ Blend was used instead.

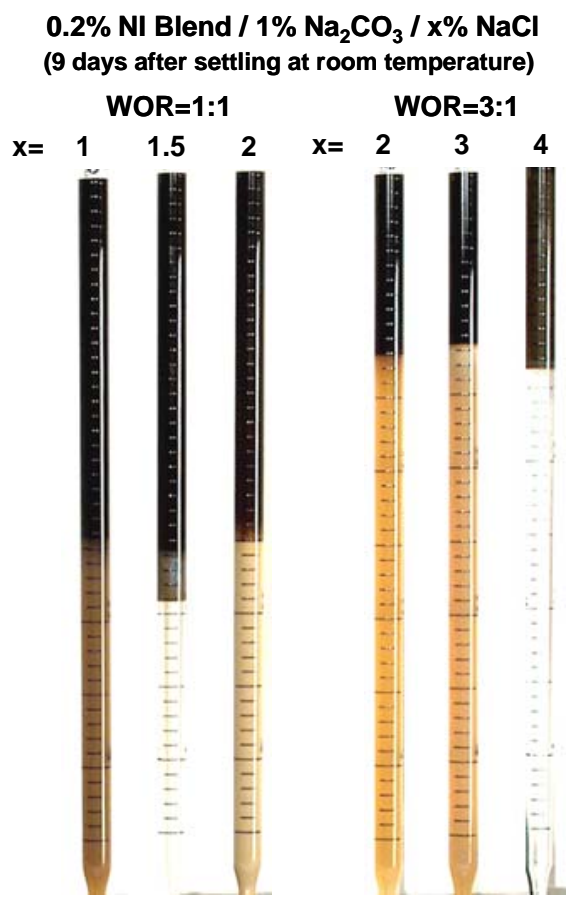

Fig 2.5-17 Phase behavior of $0.2 \% \mathrm{NI}$ Blend at WOR $=1$ and 3 
Table 2.5-3 Core properties, experimental conditions and results

\begin{tabular}{|c|c|c|c|c|c|c|c|c|c|c|}
\hline & $\begin{array}{c}\mathrm{NaCl}, \\
\%\end{array}$ & $\begin{array}{l}\text { kair, } \\
\text { md }\end{array}$ & $\begin{array}{c}\text { Porosity } \\
\text {, \% }\end{array}$ & PV, ml & $\begin{array}{c}\text { OOIP, } \\
\text { ml }\end{array}$ & So & $\begin{array}{l}\text { Centrifuge } \\
\text { time, days }\end{array}$ & $\begin{array}{l}\text { OR, } \\
\text { ml }\end{array}$ & Sor & $\begin{array}{c}\text { Rec., } \\
\text { OOIP\% }\end{array}$ \\
\hline \multirow{3}{*}{$\begin{array}{c}\text { Forma- } \\
\text { tion } \\
\text { brine }\end{array}$} & \multirow{3}{*}{$\sim 1$} & 4.933 & 21.2 & 2.661 & 2.11 & 0.79 & 4 & 1.45 & 0.25 & 69 \\
\hline & & 6.821 & 22.4 & 2.897 & 2.36 & 0.81 & 4 & 1.53 & 0.28 & 65 \\
\hline & & 8.873 & 24.2 & 2.972 & 2.35 & 0.79 & 3 & 1.60 & 0.25 & 68 \\
\hline \multirow{11}{*}{$\begin{array}{c}0.2 \% \\
\mathrm{NI} \\
\text { blend / } \\
1 \% \\
\mathrm{Na}_{2} \mathrm{CO} \\
{ }_{3} / \mathrm{x} \% \\
\mathrm{NaCl}\end{array}$} & 1 & 9.485 & 24.3 & 3.048 & 2.41 & 0.77 & 3 & 2.02 & 0.13 & 84 \\
\hline & 1.5 & 4.642 & 21.8 & 2.77 & 2.00 & 0.72 & 6 & 1.64 & 0.13 & 82 \\
\hline & 1.8 & 4.281 & 20.6 & 2.687 & 1.94 & 0.72 & 6 & 1.61 & 0.12 & 83 \\
\hline & 2 & 8.748 & 25.1 & 3.415 & 2.68 & 0.79 & 3 & 2.29 & 0.11 & 86 \\
\hline & 2.2 & 4.349 & 22.1 & 2.843 & 2.01 & 0.71 & 6 & 1.79 & 0.08 & 89 \\
\hline & 2.4 & 4.445 & 20.2 & 2.698 & 1.97 & 0.73 & 6 & 1.60 & 0.14 & 81 \\
\hline & 2.5 & 4.581 & 22.3 & 2.880 & 2.07 & 0.72 & 6 & 1.92 & 0.05 & 93 \\
\hline & 2.7 & 4.284 & 21.1 & 2.840 & 2.02 & 0.71 & 6 & 1.76 & 0.09 & 87 \\
\hline & 3 & 5.228 & 21.6 & 2.853 & 2.22 & 0.77 & 5 & 1.79 & 0.15 & 81 \\
\hline & 4 & 7.705 & 24.3 & 3.108 & 2.48 & 0.79 & 3 & 2.02 & 0.15 & 81 \\
\hline & 5 & 9.210 & 24.4 & 3.231 & 2.59 & 0.8 & 3 & 1.96 & 0.19 & 76 \\
\hline
\end{tabular}

Phase behavior of $0.2 \% \mathrm{NI}$ Blend / $1 \% \mathrm{Na}_{2} \mathrm{CO}_{3} / \mathrm{x} \% \mathrm{NaCl}$ at WOR of one and three is shown in Fig 2.5-17. The optimal salinity at WOR $=1: 1$ is between 1 and $1.5 \% \mathrm{NaCl}$, while that at $\mathrm{WOR}=3: 1$ is between 3 and $4 \% \mathrm{NaCl}$.

The core info and experimental conditions and results are listed in Table 2.5-

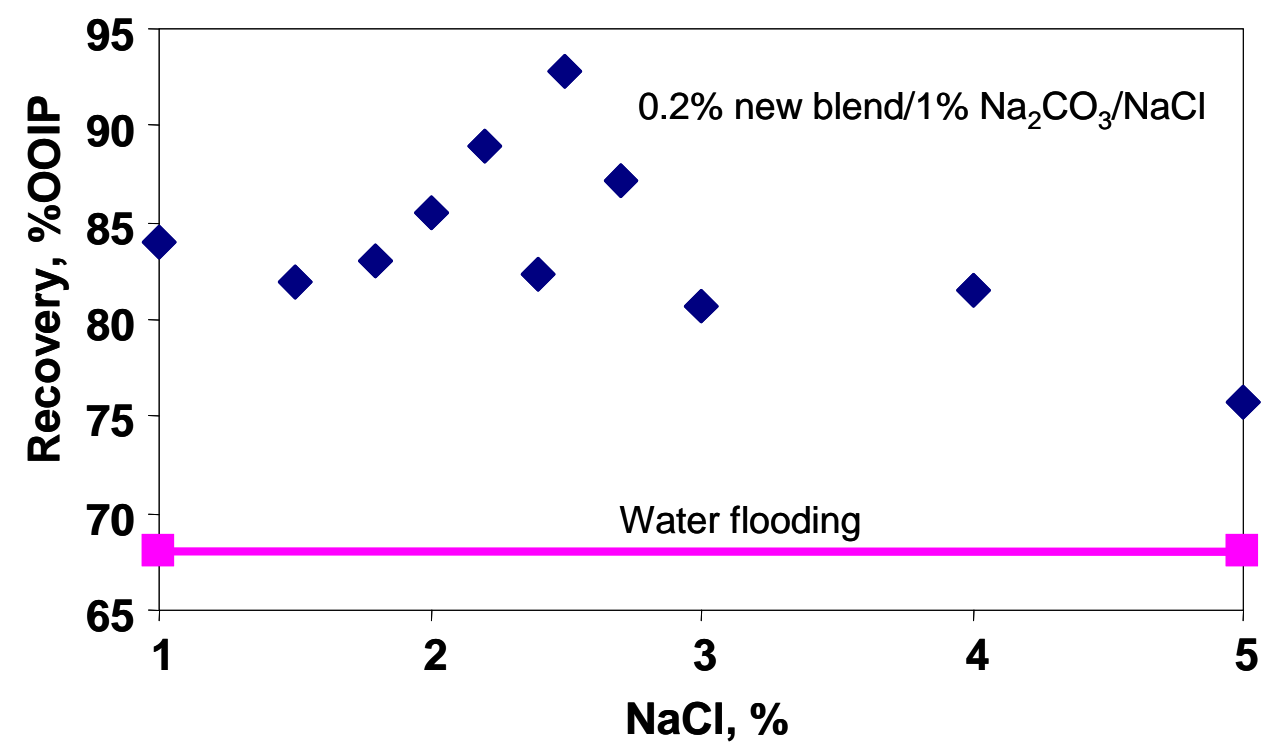

Fig 2.5-18 Oil Recovery by centrifuge imbibition in either formation brine (water flooding) or $0.2 \% \mathrm{NI}$ Blend / $1 \% \mathrm{Na}_{2} \mathrm{CO}_{3} /$ x\% NaCl. 
3. Centrifuge time is inversely proportional to permeability (Hirasaki et al, 1995), which is the reason for the difference in the centrifuge time

The recovery is plotted in Fig 2.5-18. The oil recovery by formation brine is $67 \%$ on average, while the oil recovery by $0.2 \% \mathrm{NI}$ Blend $/ 1 \% \mathrm{Na}_{2} \mathrm{CO}_{3} / \times \% \mathrm{NaCl}$ is much higher-76-93\%. Further experiments are planned at $\mathrm{NaCl}$ concentrations between 2 and $3 \%$ to establish whether higher recovery can be achieved there as suggested by some of the data points.

\section{Conclusions}

1. Blend of N67-7PO S and IOS 1518 at $4: 1$ weight ratio has phase behavior free of viscous phases and all interfaces can move smoothly. Its optimal salinity is closer to that of the formation brine than the previous TC blend.

2. Sodium carbonate reduces severalfold the adsorption of NI Blend on calcite.

3. When emulsions are present near optimal condition at low surfactant concentration, one sometimes observes a rather turbid lower phase that becomes clear with time. The IFT of the excess oil with the clear lower phase was always high. Turbidity of the lower phase is a necessary but not sufficient condition for ultra-low IFT. A procedure to capture enough microemulsion for low IFT is introduced.

4. $0.2 \% \mathrm{NI}$ Blend increases oil recovery from $67 \%$ of water flood to at least $85 \%$ and perhaps higher.

\section{Reference}

1. Abe, M, Schechter, D., Schechter, R.S., Wade, W.H., Weerasooriya, U., and Yiv, S., "Microemulsion Formation with Branched Tail Polyoxyethylene Sulfonate Surfactants", JCIS 114 (2), 1986

2. Hirasaki, G.J., Rohan, J.A., Dudley, J.W., "Interpretation of Oil-Water Relative Permeabilities from Centrifuge Experiments", SPE 24879 in SPE Advanced Technology Series, 3(1), 66-75, March 1995.

3. Zhang, D.L., Liu, S., Puerto, M., Miller, C., and Hirasaki, G.J., "Wettability Alteration and Spontaneous Imbibition in Oil-Wet Carbonate Formations", presented at the $8^{\text {th }}$ International Symposium on Evaluation of Wettability and Its Effect on Oil Recovery, Houston, TX, May 16-18, 2004. Accepted by J. Pet. Sci.\& Eng. 


\section{Task 3 Foam for Mobility Control}

\subsection{Foam diversion in fracture network model}

The main purpose of this research is to investigate the foam flow and foam diversion effect in heterogeneous fracture system. From our previous work [DOE annual report 2003-2004, OSTI ID: 829648], we found two contributions to the apparent viscosity when foam flows in homogeneous fracture. Here the theory was extended to heterogeneous fractures, and the parameters affecting the diversion by foam were studied.

\section{Experimental technique}

The fracture model has been established as in Fig. 3.1-1.The fracture model

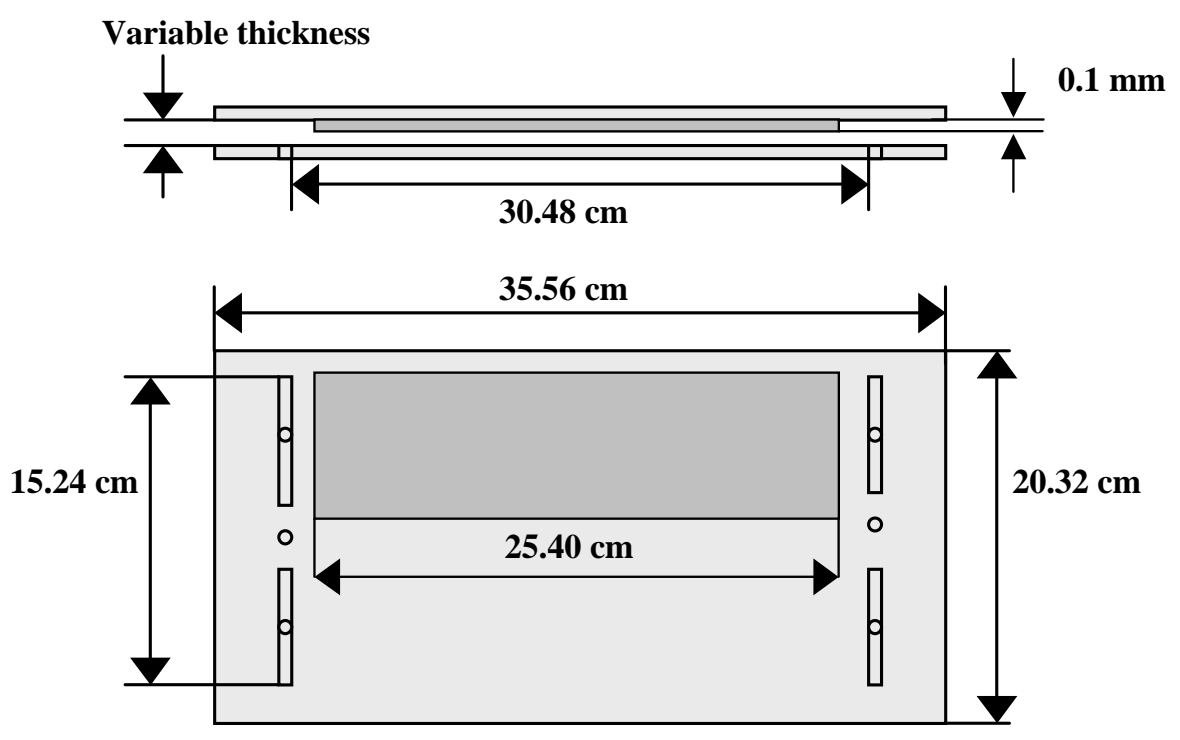

Fig. 3.1-1. Detailed diagram of heterogeneous fracture model

consists mainly of two parallel glass plates. Changing the gasket thickness between the two parallel plates can change the aperture of the fracture. The method of making the heterogeneous fracture is to adhere a $0.1 \mathrm{~mm}$ thickness glass to one of the glass plates (shaded region in Fig. 3.1-1). The procedure is: 1 . Adhere the $0.1 \mathrm{~mm}$ glass to the thick glass by Norland optical adhesive; 2 . Roll the thin glass on the thick glass to squeeze out any air and excess adhesive between them; 3. Cure the adhesive by a high intensity ultraviolet lamp (Model Spectroline SB-100P) for over 48 hours. Two spacers are put at the two ends of 
the model between the different apertures to ensure the uniform aperture at each side.

Surfactant solution

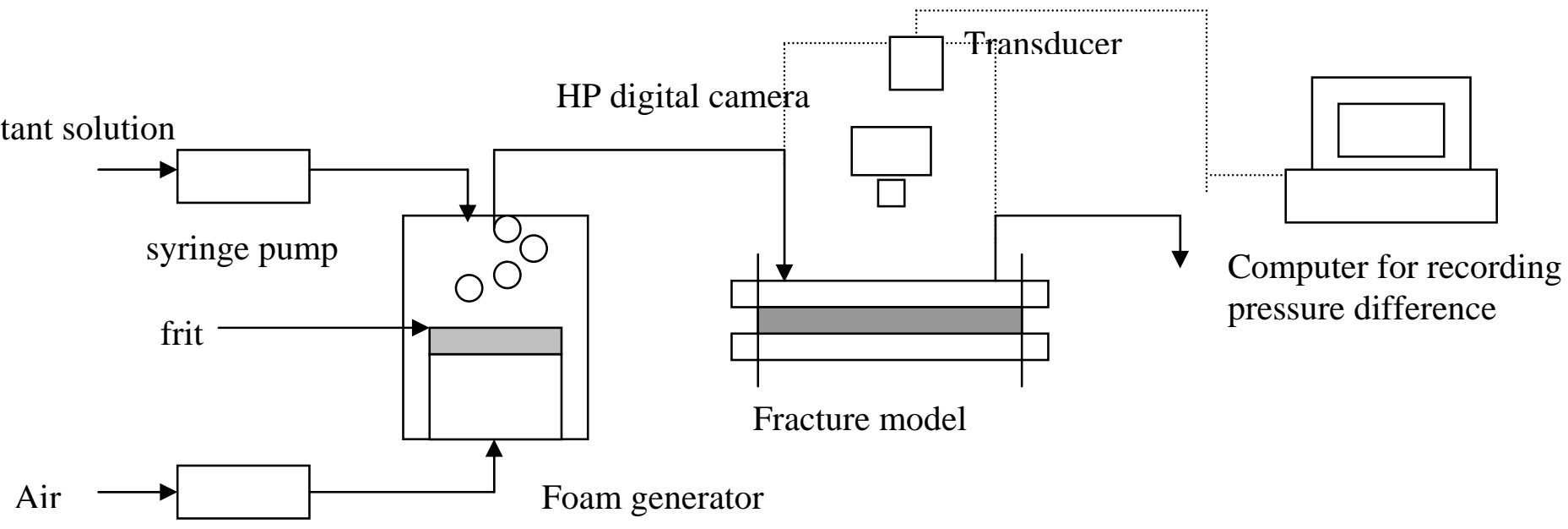

Air mass flow controller

Fig. 3.1-2. Set -up diagram for foam mobility control experiment in fracture model

The set-up diagram of the equipment for the foam experiments is shown in Fig. 3.1-2. A Harvard syringe infusion pump (Model 22) is used to inject surfactant solution and a Matheson mass flow controller (Model 8270) is used to inject air into the foam generator. Relatively uniform size bubbles can be generated only when the air and surfactant solution are introduced on opposite sides of the frit in the foam generator. Choosing frits with different pore sizes can generate different sizes of bubbles. Two grooves were made along the inlet and outlet of the fracture model to assure uniform pressures at the inlet and outlet.

The surfactant solution in the experiments was 0.5\% C13-4PO and 0.5\% CS330. STEOL C13-4PO is from Harcros Company and its chemical description is propoxylated C13 alcohol ether sulfate, ammonium salt. STEOL CS330 is from Stepan Company and its chemical description is C12-3EO sulfate. The salinity was $0.23 \% \mathrm{NaCl}, 0.07 \% \mathrm{CaCl}_{2}$ and $0.04 \% \mathrm{MgCl}_{2}$. The bubble diameters in the experiment were from 0.4 to $1.0 \mathrm{~mm}$. The aperture is $0.1 \mathrm{~mm}$ or $0.2 \mathrm{~mm}$ for homogeneous fracture experiments and the combinations of $0.1 \mathrm{~mm} / 0.2 \mathrm{~mm}$ or $0.05 \mathrm{~mm} / 0.15 \mathrm{~mm}$ for heterogeneous fracture experiments. The gas fractional flow range was from 0.0 to 0.9 . The values used for the viscosity of solution and surface tension were $1.0 \mathrm{mPa}$ 's and $28 \mathrm{mN} / \mathrm{m}$ from measurement. 


\section{Theory}

\section{Apparent viscosity}

The theory has been described in our DOE annual report 2003-2004 [OSTI ID: 829648]. But we repeat it here because it is applied to explain our new experimental results. From our previous research, the most important variable affecting foam apparent viscosity in uniform, smooth capillaries is foam texture. The principal factors affecting apparent viscosity of foam in uniform fracture are dynamic changes at gas/liquid interfaces. The apparent viscosity is the sum of two contributions as in Fig. 3.1-3:

1. Slugs of liquid between gas bubbles resist flow.

2. Viscous and capillary forces result in interface deformation against the restoring force of surface tension.

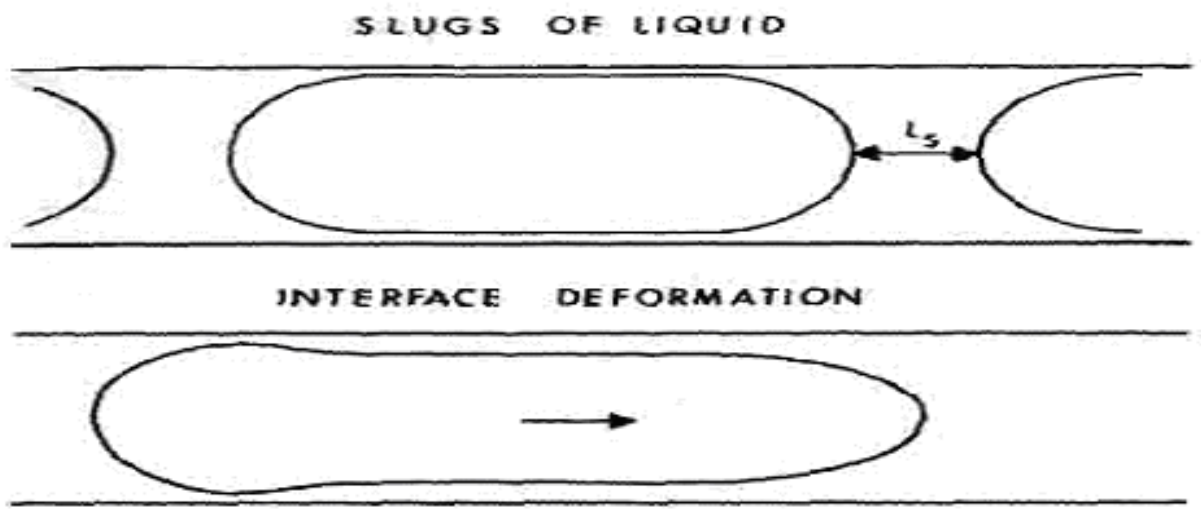

Fig. 3.1- 3. Mechanism of affecting apparent viscosity in fracture system

The apparent viscosity from the contribution of foam bubble deformation in uniform fracture can be predicted from the Plane-Poiseuille flow:

$$
\mu_{\text {app }}^{\text {shape }}=n_{L} \Delta p b^{2} /(12 U)=0.57\left(\mu^{\text {liq }} n_{L} b\right)\left(3 \mu^{\text {liq }} U / \sigma\right)^{-1 / 3} /\left(r_{c} / b\right)(1)
$$

where $n_{L}$ is the number of equivalent lamellae per unit length and $b$ is the aperture.

$n_{L}$ and $r_{c}$ are important parameters in determining the value of apparent viscosity. By assuming that individual bubbles are distributed uniformly in the fracture, the number of lamellae per unit length can be expressed in terms of the aperture and the equivalent bubble radius:

$$
n_{L}=\left[3 f_{g} b /\left(4 \pi r_{B}{ }^{3}\right)\right]^{1 / 2}
$$


where $f_{g}$ is fractional flow, $b$ is the fracture aperture and $r_{B}$ is the equivalent bubble radius. The equivalent bubble diameter is bigger than the fracture thickness. By assuming the bubbles are normally not in contact, the radius of curvature, $r_{c}$, is equal to the half aperture of the fracture.

The contribution to apparent viscosity from liquid slugs in uniform fracture can be predicted from the contribution of liquid viscosity in the total fluid. That is:

$$
\mu_{a p p}^{l i q}=\left(1-f_{g}\right) \mu^{l i q}
$$

where $\mu^{\text {liq }}$ is the viscosity of pure liquid and $f_{g}$ is the gas fractional flow.

The total apparent viscosity from theory when foam bubbles flow in uniform fracture is the sun of the two above contributions.

$$
\mu_{\text {app }}=\mu_{\text {app }}^{\text {liq }}+\mu_{\text {app }}^{\text {shape }}
$$

The total apparent viscosity can be obtained from measuring the pressure difference across the model. That is from Plane-Poiseuille law:

$$
\mu_{\text {app }}=b^{2} \nabla p /(12 U)
$$

where $\nabla p$ is the pressure gradient.

The velocities in both aperture regions of the heterogeneous fracture need to be determined to get the apparent viscosity either by theory or measurement. If only water or surfactant solution is injected, the apparent viscosity is around $1.0 \mathrm{cp}$. By assuming the pressure gradient is the same, the velocity ratio in different aperture regions can be derived from equation (5) as below.

$$
U_{1} / U_{2}=\left(b_{1} / b_{2}\right)^{2}
$$

For foam case, when contribution to apparent viscosity from bubble deformation dominates, by setting equation (1) equal to equation (5), assuming that bubble size and fractional flow are equal and that the pressure gradient is the same, the velocity ratio in different aperture portions of fracture can be derived as a function of the ratio of apertures as in equation (7).

$$
U_{1} / U_{2}=\left(b_{1} / b_{2}\right)^{3 / 4}
$$

Then from overall material balance, the velocities in different aperture regions of fracture can be estimated. 
Combining equation (1) with equation (7), the apparent viscosity from deformation contribution increases with the 5/4 power of aperture ratio, when the other conditions are the same. This result predicts liquid diversion into thinner fracture region because the flow encounters more resistance in higher thickness region.

\section{Experimental results}

All the experiments were done at Reynolds number less than 1.0, and the average bubble diameters were bigger than the aperture to meet the conditions of our theory from previous research. The Reynolds numbers were $\mathrm{Re}=0.22$ and $\mathrm{Re}=0.44$. The bubble diameters were $0.4 \mathrm{~mm}$ and $0.6 \mathrm{~mm}$. Gas fractional flow, $f_{g}$ was $0.0,0.15,0.25,0.33,0.67$ and 0.9 . Two different aperture ratios were used in the experiments: $0.10 \mathrm{~mm} / 0.20 \mathrm{~mm}$ and $0.05 \mathrm{~mm} / 0.15 \mathrm{~mm}$ or $1: 2$ and 1:3.

\section{Apparent viscosity}

The apparent viscosity in each region can be calculated using either equation (4) or equation (5). It is restricted to the case in which both regions of fracture are fully filled with foam so that there are minimal lateral pressure gradients and no cross flow. Also, we assume the fractional flow is the same in thinner and thicker apertures of the heterogeneous fracture. But by either method, the flow velocity in each layer is needed. They can be obtained from equation (7) and material balance.

The results of apparent viscosity from theory and measurement of pressure difference are shown in the Fig. 3.1-4 3.1-7. The apparent viscosity from theory is from equation (4), which includes the contributions from both bubble deformation and liquid slugs between bubbles. In the scope of our experiments, at aperture ratios $0.05 \mathrm{~mm} / 0.15 \mathrm{~mm}$ and $0.1 \mathrm{~mm} / 0.2 \mathrm{~mm}$, bubble size $0.4 \mathrm{~mm}$ and $0.6 \mathrm{~mm}$, Reynolds number 0.22 and 0.44 , the apparent viscosity from measurement of pressure difference fits well with that from theory prediction. This agreement between theory and experiment confirms the assumption of same fractional flow in both apertures.

Another assumption is that the contribution from foam bubble deformation dominates in the apparent viscosity. This assumption is valid for medium to high gas fractional flow. For example, at $f_{g}=0.9$, the contribution from liquid slug is only $0.1 \mathrm{cp}$ and the contribution from foam bubble deformation is above $3 \mathrm{cp}$ in the scope of all our experiments. At low gas fractional flow, because the contribution from liquid slug to apparent viscosity can't be neglected, equation (7) may not reflect the real velocity ratio in different layers. The reason may be that at low apparent viscosity, for example $f_{g}=$ 0.15 , the contribution from liquid slug is $0.85 \mathrm{cp}$. If the contribution from foam bubble deformation is $2.0 \mathrm{cp}$, the liquid slug contribution can be about $30 \%$ of the apparent viscosity. So one might expect deviation of the data from 
experiment from theory prediction at low gas fractional flow and indeed some deviation is seen in the plot.

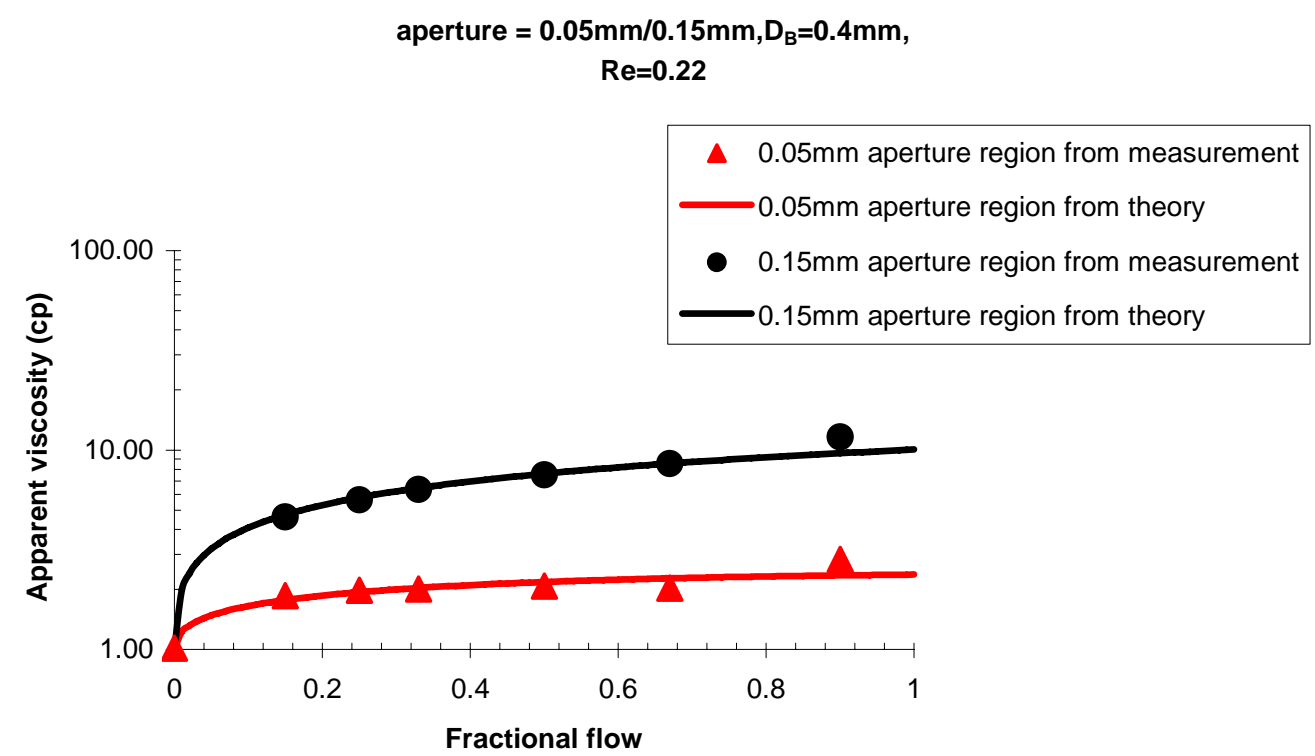

Fig. 3.1- 4. Apparent viscosity for aperture ratio of $0.05 \mathrm{~mm} / 0.15 \mathrm{~mm}$, bubble size $=0.4 \mathrm{~mm}$, and $\mathrm{Re}=0.22$

aperture $=0.1 \mathrm{~mm} / 0.2 \mathrm{~mm}, D_{B}=0.4 \mathrm{~mm}$

$\mathrm{Re}=0.22$

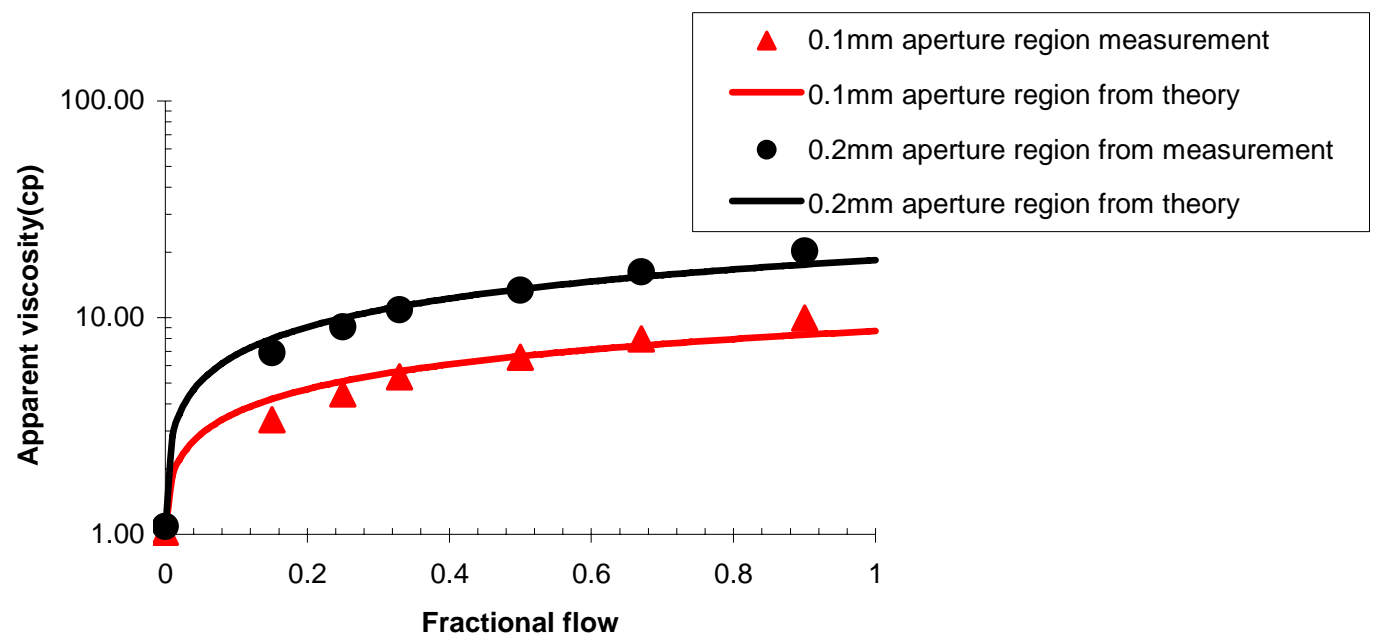

Fig. 3.1- 5. Apparent viscosity for aperture ratio of $0.1 \mathrm{~mm} / 0.2 \mathrm{~mm}$, bubble size $=0.4 \mathrm{~mm}$ and $\mathrm{Re}=0.22$ 


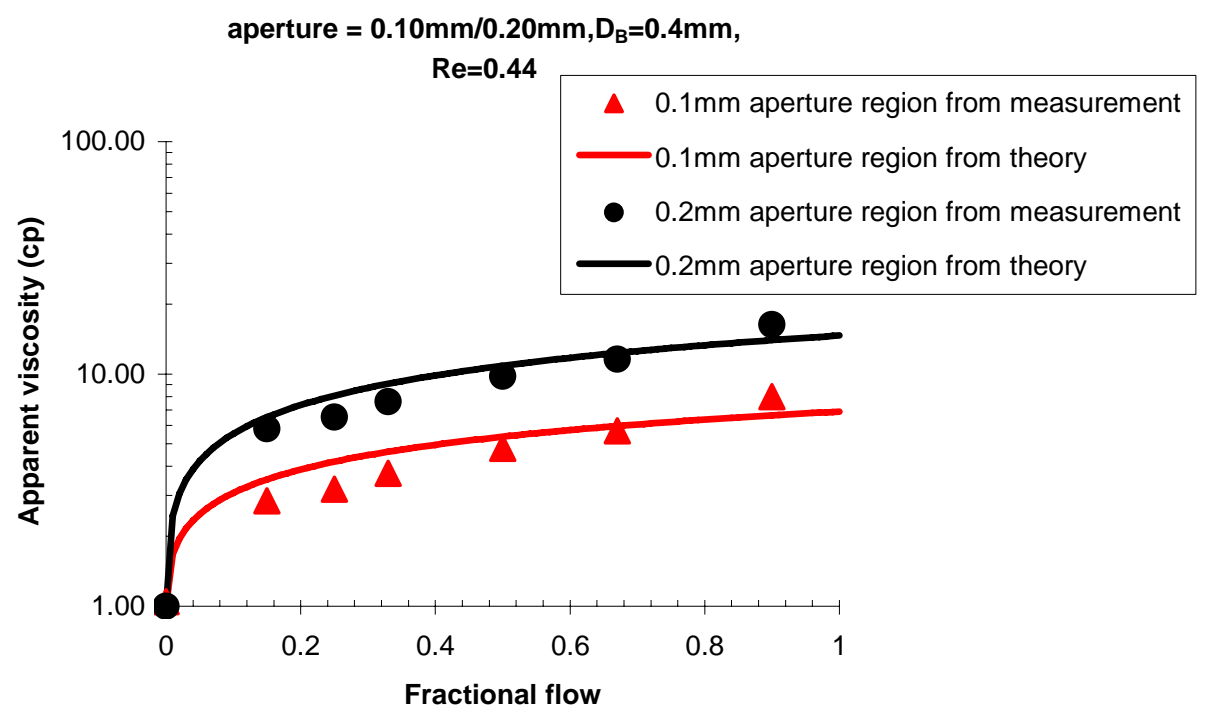

Fig. 3.1- 6. Apparent viscosity for aperture ratio of $0.1 \mathrm{~mm} / 0.2 \mathrm{~mm}$, bubble size $=0.4 \mathrm{~mm}$ and $\mathrm{Re}=0.44$

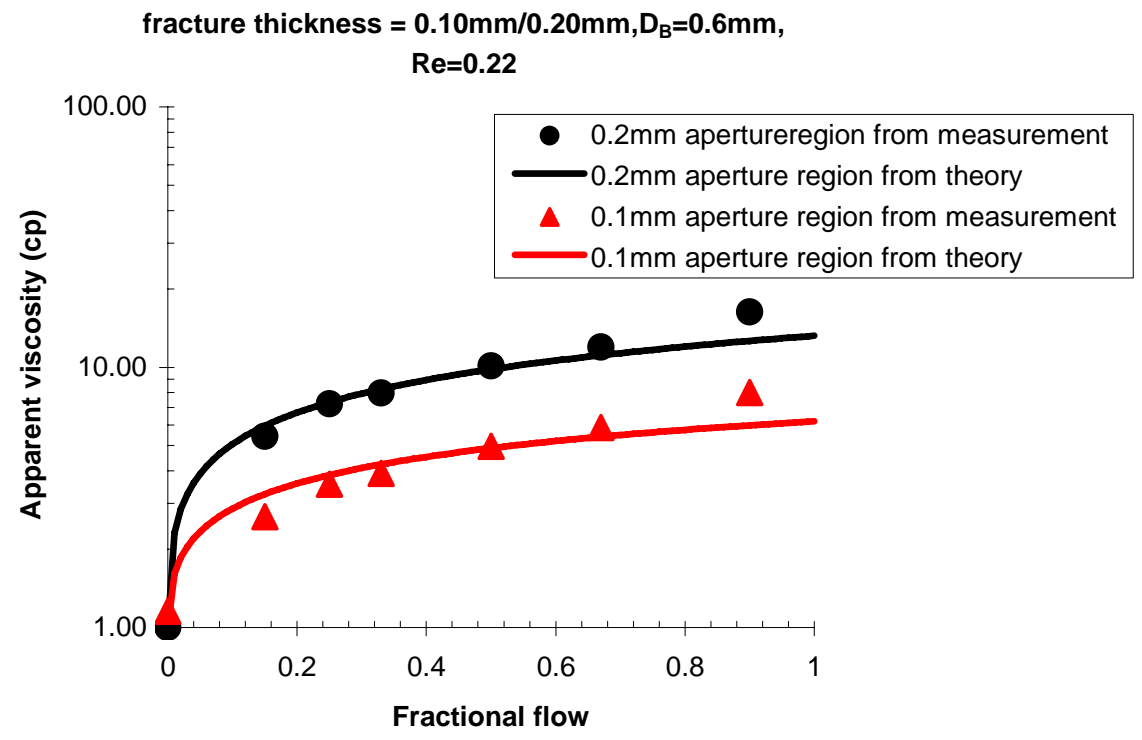

Fig. 3.1- 7. Apparent viscosity for aperture ratio of $0.1 \mathrm{~mm} / 0.2 \mathrm{~mm}$, bubble size $=0.6 \mathrm{~mm}$ and $\mathrm{Re}=0.22$

From Fig. 3.1-4 7, it is obvious that the gas fractional flow is an important factor in determining the apparent viscosity of foam flow. By comparing Fig. 3.1-4 and Fig 3.1-5, the difference of apparent viscosity between the thin and thick layers is bigger for the aperture ratio $0.05 \mathrm{~mm} / 0.15 \mathrm{~mm}$ or $1: 3$ than for aperture ratio $0.1 \mathrm{~mm} / 0.2 \mathrm{~mm}$ or 1:2. But from Fig 3.1-5, Fig 3.1-6 and Fig 3.1-7, the different bubble size $(0.4 \mathrm{~mm}$ and $0.6 \mathrm{~mm})$ and different velocity (Re $=0.22$ and 0.44 ) doesn't affect much the difference of apparent viscosity between the thin and thick layers. So we may expect distinct diversion effect 
or sweep efficiency improvement for high aperture ratio by high gas fractional flow foam sweep.

\section{Sweep efficiency}

Pictures were taken during experiments to investigate the sweep by foam and surfactant solution in heterogeneous fracture. An example of foam/surfactant solution sweep is shown in Fig. 3.1-9. For comparison, the picture of sweep by surfactant solution alone is shown in Fig. 3.1-8.

The injection of foam bubbles together with surfactant solution improves the sweep over the injection of surfactant solution only. From Fig. 3.1-8 for $0.05 \mathrm{~mm} / 0.15 \mathrm{~mm}$ fracture, at Reynolds number 0.22 , it takes about 6.6 pore volumes of surfactant solution to sweep the $0.05 \mathrm{~mm}$ aperture region, while from theory prediction 7.0 pore volume is needed. With gas fractional flow 0.9 and bubble size at $0.4 \mathrm{~mm}$ in diameter, only 0.15 pore volume of surfactant solution is needed, which is shown in Fig. 3.1-9. The amount of surfactant solution needed to sweep both regions is reduced by a factor of more than 40.

By using the similar derivation as Lake [Enhanced Oil Recovery, Prentice Hall, 1989, Page 201-205], the volume of surfactant solution required for sweep or dimensionless time can be obtained. The derivation is based on the assumptions:

1. No crossflow;

2. Equal pressure difference across different layers along the flow direction;

3. Plug flow;

4. The foam apparent viscosity is determined by the velocity of foam flow at steady state, i.e., the velocity after both layers have been swept.

The foam front position in each layer may be determined from Darcy's law

$$
\frac{d x_{l}}{d t}=v_{l}=-\left(\frac{k}{\Delta S}\right)_{l} \lambda_{\text {rel }} \frac{\Delta p}{L}, \quad l=1,2
$$

where $\Delta S$ is the water saturation change, $v_{l}$ is the interstitial velocity in layer $l$, and $\lambda_{\text {rel }}$ is the relative mobility in layer $l$ defined by

$$
\begin{array}{ll}
\lambda_{\text {rel }}=\left[\frac{x_{l}}{\lambda_{r 1}^{0}}+\frac{\left(1-x_{l)}\right.}{\lambda_{r 2}^{0}}\right]^{-1} & \text { for } x_{l}<1 \\
\text { or } \quad \lambda_{\text {rel }}=\lambda_{r 1}^{0} & \text { for } x_{l}>1
\end{array}
$$




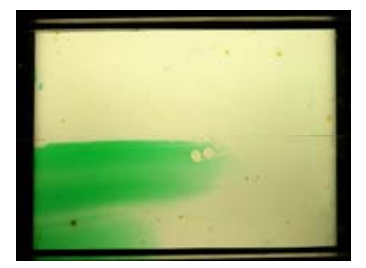

$0.41 \mathrm{PV}$

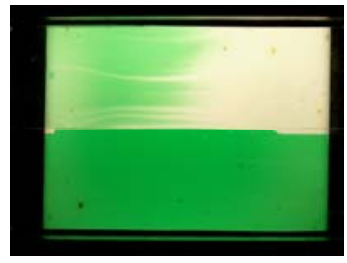

2.05PV

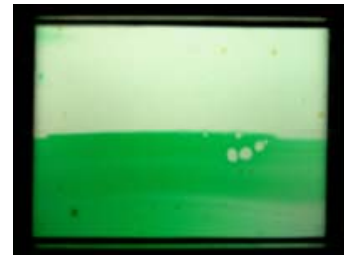

$0.82 \mathrm{PV}$

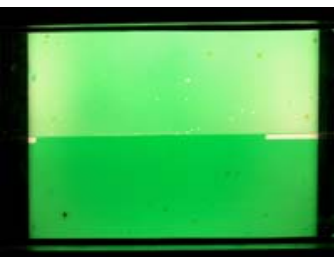

6.56 PV

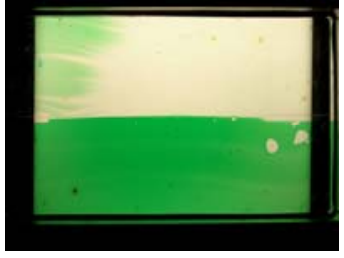

1.23 PV

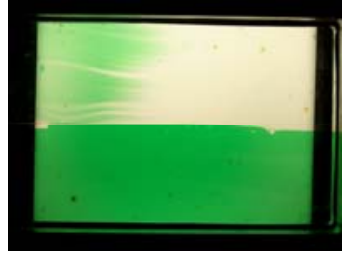

1.64 PV

Fig. 3.1-8. Surfactant solution sweeping heterogeneous fracture, $\operatorname{Re}=\mathbf{0 . 2 2}$, aperture ratio $=0.05 \mathrm{~mm}$ (top) $/ 0.15 \mathrm{~mm}$ (bottom) (Note: PV refers to pore volume of the entire heterogeneous fractures)

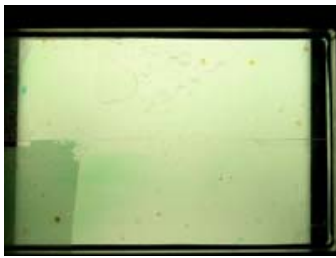

$0.04 \mathrm{PV}$

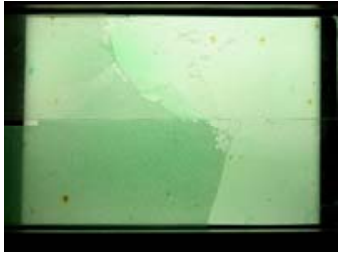

$0.08 \mathrm{PV}$

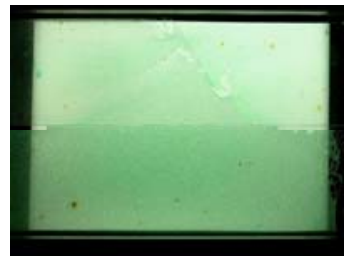

$0.12 \mathrm{PV}$

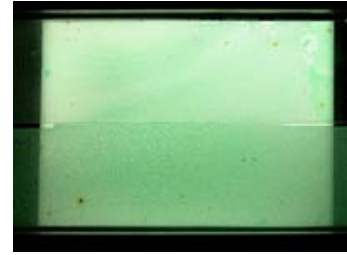

$0.16 \mathrm{PV}$

Fig. 3.1-9. Foam/surfactant solution sweeping heterogeneous fracture, $\operatorname{Re}=$ $0.22, f_{g}=0.9$, aperture ratio $=0.05 \mathrm{~mm} / 0.15 \mathrm{~mm}, \mathrm{~d}_{\mathrm{B}}=0.4 \mathrm{~mm}$ (Note: $\mathrm{PV}$ is the injected liquid pore volumes)

Taking the ratio of the interstitial velocities in the two layers will eliminate time and the pressure drop since both layers experience the same $\Delta p$. Thus before breakthrough $\left(x_{l}<1\right)$, we have

$$
\frac{d x_{1}}{d x_{2}}=\frac{k_{1}}{k_{2}} \frac{\mu_{12}}{\mu_{11}} \frac{x_{2}+\left(1-x_{2}\right) M_{2}}{x_{1}+\left(1-x_{1}\right) M_{1}}
$$

where $M_{1}, M_{2}$ are the mobility ratios, e.g. $M=\lambda_{r 1}^{0} / \lambda_{r 2}^{0}, k_{1}, k_{2}$ are the permeabilities, $k=b^{2} / 12$ in fractures where $b$ is the aperture, and $M_{1}=\mu^{0} / \mu_{11}$, $\mu_{12}$ are the foam apparent viscosities in thinner and thicker layers respectively, $M_{1}=\mu^{0} / \mu_{11}$ and $M_{2}=\mu^{0} / \mu_{12}$ where $\mu^{0}$ is the viscosity of water.

$$
\int_{0}^{x_{1}} k_{2} \mu_{11}\left[x_{1}+\left(1-x_{1}\right) M_{1}\right] d x_{1}=\int_{0}^{x_{2}} k_{1} \mu_{12}\left[x_{2}+\left(1-x_{2}\right) M_{2}\right] d x_{2}
$$




$$
\frac{\left(1-M_{1}\right)}{2} x_{1}^{2}+M_{1} X_{1}=\frac{k_{1} \mu_{12}}{k_{2} \mu_{i 1}}\left[\frac{\left(1-M_{2}\right)}{2} x_{2}^{2}+M_{2} X_{2}\right]
$$

When the foam front reaches the outlet of the thicker layer $\left(x_{2}=1.0\right)$, the dimensionless front position at the thinner layer is

$$
x_{1}=\frac{\left\{M_{1}^{2}+\frac{\left(1-M_{1}\right)\left(1+M_{2}\right)}{\left(\frac{k_{2} \mu_{11}}{k_{1} \mu_{12}}\right)}\right\}^{1 / 2}-M_{1}}{1-M_{1}}
$$

Then the dimensionless time in the liquid pore volume needed for the sweep of thicker region is

$$
\text { Dimensionless time }=\frac{x_{1} b_{1}+b_{2}}{b_{1}+b_{2}}\left(1-f_{g}\right)
$$

When the thinner layer was swept, the dimensionless front at the thicker layer (outside the fracture) can be obtained from

$$
\begin{aligned}
& \frac{d x_{2}}{d x_{1}}=\frac{k_{2}}{k_{1}} \frac{\mu_{11}}{\mu_{12}}\left[x_{1}+\left(1-x_{1}\right) M_{1}\right] \\
& \int_{1}^{x_{2}} d x_{2}=\int_{x_{1}^{0}}^{x_{1}} \frac{k_{2}}{k_{1}} \frac{\mu_{11}}{\mu_{12}}\left[x_{1}+\left(1-x_{1}\right) M_{1}\right] d x_{1} \\
& x_{2}=1+\frac{k_{2}}{k_{1}} \frac{\mu_{11}}{\mu_{12}}\left[\frac{\left(1-M_{1}\right)}{2}\left(x_{1}^{2}-\left(x_{1}^{0}\right)^{2}\right)+M_{1}\left(x_{1}-x_{1}^{0}\right)\right]
\end{aligned}
$$

Setting $x_{1}=1.0$, and $x_{1}^{0}=\frac{\left\{M_{1}^{2}+\frac{\left(1-M_{1}\right)\left(1+M_{2}\right)}{\left(\frac{k_{2} \mu_{11}}{k_{1} \mu_{12}}\right\}^{1 / 2}-M_{1}}\right.}{1-M_{1}}$ 


$$
x_{2}=1+\frac{k_{2}}{k_{1}} \frac{\mu_{11}}{\mu_{12}}\left[\frac{\left(1+M_{1}\right)}{2}-\frac{\left(1+M_{2}\right)}{2\left(\frac{k_{2} \mu_{11}}{k_{1} \mu_{12}}\right)}\right]
$$

And the dimensionless time or the liquid pore volume needed to sweep the thinner layer is

$$
\text { Dimensionless time }=\frac{x_{2} b_{2}+b_{1}}{b_{2}+b_{1}}\left(1-f_{g}\right)
$$

Fig. 3.1-10 shows the comparison between the theory prediction and experiment results. The theory prediction well matches the data from experiment. This validates our assumptions for the theory calculation. Also, it demonstrates the value of foam in greatly reducing the amount of surfactant required to sweep a heterogeneous fracture.

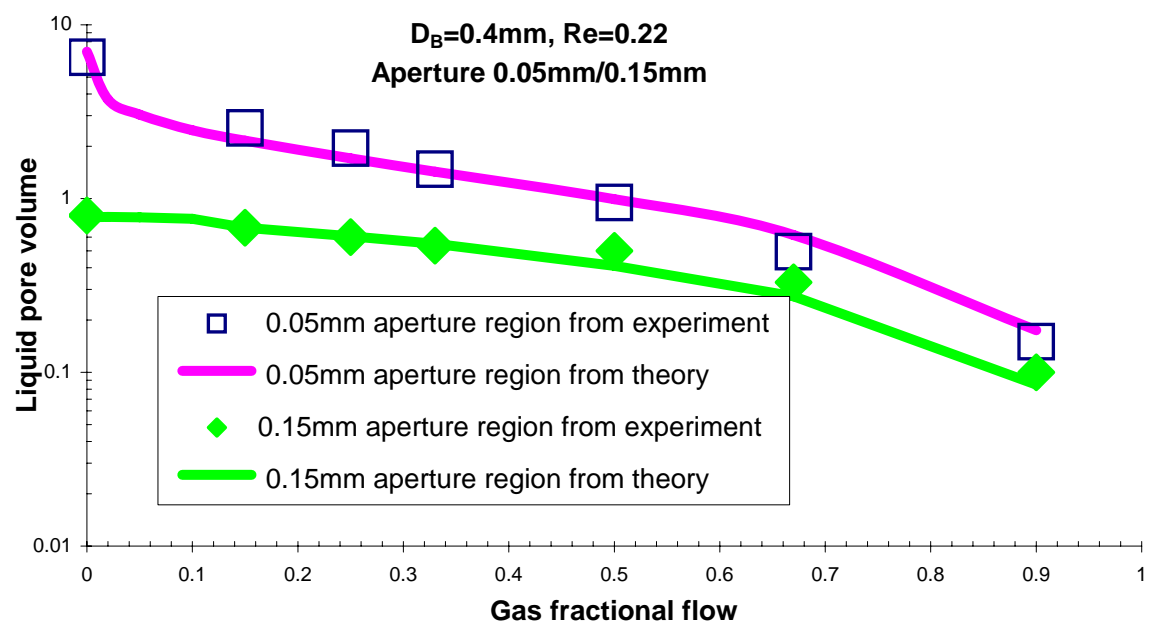

Fig. 3.1- 10. Comparison between the calculation and the experimental results for foam/surfactant sween in heternoenenus fractures with 1:3 anerture ratio

\section{Conclusions}

We investigated different factors' effects on sweep efficiency by foam in heterogeneous fracture and applied our theory for different contributions to foam apparent viscosity. Some conclusions can be made accordingly.

1. The foam apparent viscosity in heterogeneous fracture is from two contributions-bubble deformation and liquid slugs between bubbles, which is the same as in homogeneous fracture. 
2. The amount of surfactant required to sweep both regions of a heterogeneous fracture can be decreased by more than a order of magnitude.

3. Gas fractional flow, aperture ratio and bubble size can greatly affect the sweep efficiency.

4. Predictions based on assuming the same fractional flow in each layer of a heterogeneous fracture yield results in good agreement with experimental results for the conditions studied here.

\subsection{Test of surfactant's ability in generating foam}

From previous description, foam can greatly improve the sweep efficiency in fracture network. But the success of the foam sweep depends strongly on the strength and stability of foam, which is related to the surfactant composition and salinity. The surfactant composition and salinity in the above research are from an aquifer remediation project and were used in the fracture study because they had been demonstrated to form strong foam in sand packs. The surfactant used in the EOR process needs to be tested near its optimal salinity. We tested the strength of foam by coinjection of surfactant solution and air into a horizontal sand pack to generate foam and check the pressure difference across the sand pack to get the apparent viscosity of foam. The experimental device is shown schematically in Fig. 3.2-1. The surfactant tested is various mixtures of N677POS and IOS 1518 for total surfactant concentration of $0.5 \mathrm{wt} \%$ at the salinity $1 \% \mathrm{Na}_{2} \mathrm{CO}_{3}$ and $2 \% \mathrm{NaCl}$. The sand pack is 1 foot long and its permeability is 40 darcy.

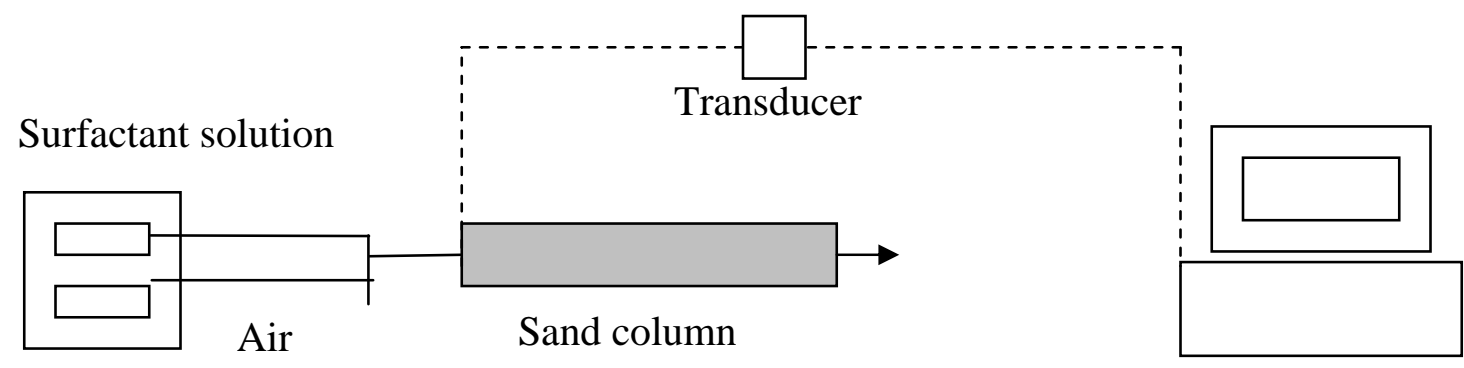

Syringe pump

Computer for recording pressure difference

Fig. 3.2-1. Set -up diagram for foam strength test

Fig. 3.2-2 shows the results of foam strength tests for different surfactant compositions and different velocities at the same salinity. With total surfactant concentration $0.5 \%$, at mixing ratio N67-7POS with IOS1518 at 1:1 to $4: 1$, the foam apparent viscosity is almost the same as N67-7POS itself at concentration $0.5 \%$. The foam strength by the blend of N67-7POS\&IOS1518 is weaker than that by the old blend C13-4PO\&CS330 at the same salinity. The other finding is that IOS1518 alone is a strong foamer. At the superficial velocity around $1 \mathrm{ft} /$ day, 
the apparent viscosity of foam by IOS1518 can be close to $900 \mathrm{cp}$. One reason may be that IOS1518 is hydrophilic, i.e., well below its optimal salinity with most oils at the conditions studied, such surfactants are generally good foamers. Fig. 3.2-3 indicates for the mixture of N67-7POS and IOS1518, the foaming ability is not affected by different salinity. So the conclusion is that the foaming ability of the mixture of N67-7POS and IOS1518 is limited by the foaming ability of N677POS. From our experience in 1-D to 3-D sand pack experiments in the aquifer remediation project, the foam strength in 3-D sand pack by the same surfactant and salinity can be 50 times weaker than in 1-D sand pack. But from the preliminary experiments, at least for the few conditions studied so far, behavior of new mixture of surfactants in fractures performs almost the same as for previous mixture. Other possible surfactant mixtures for EOR will be tested in the future. And the other future work is to test the foam stability at the presence of residual oil.

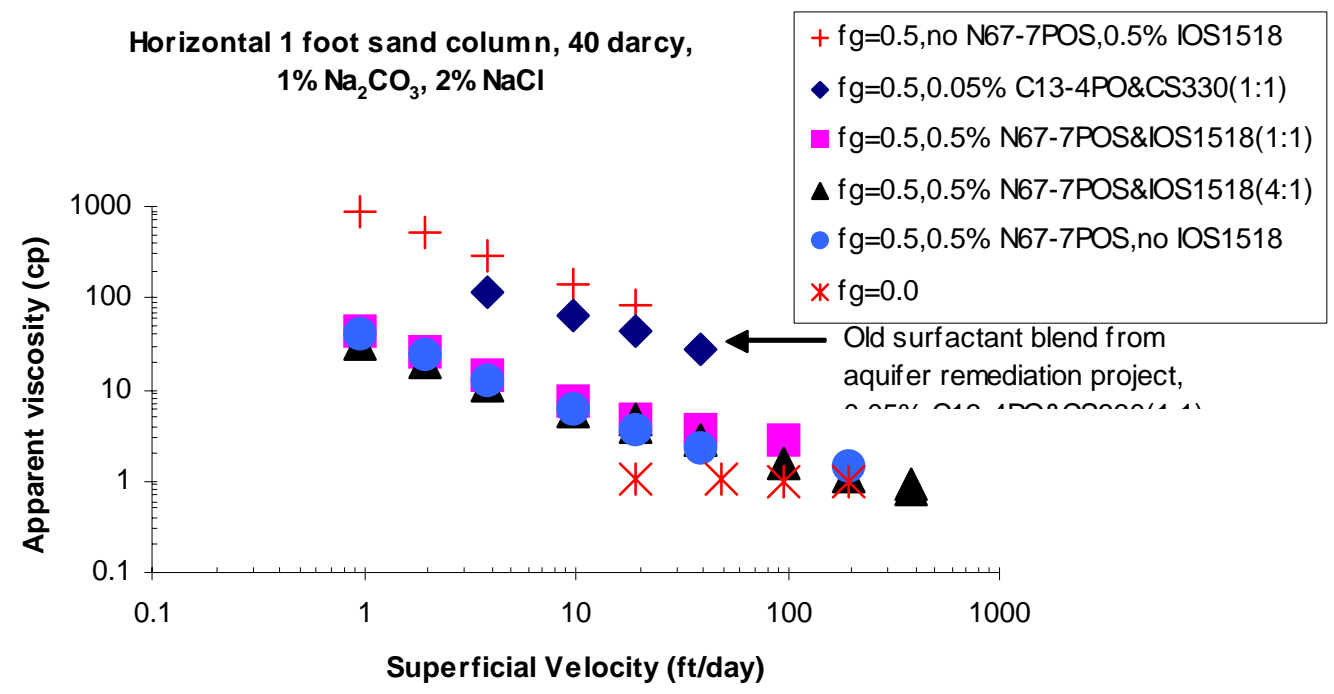

Fig. 3.2- 2. Foam strength at different surfactant composition

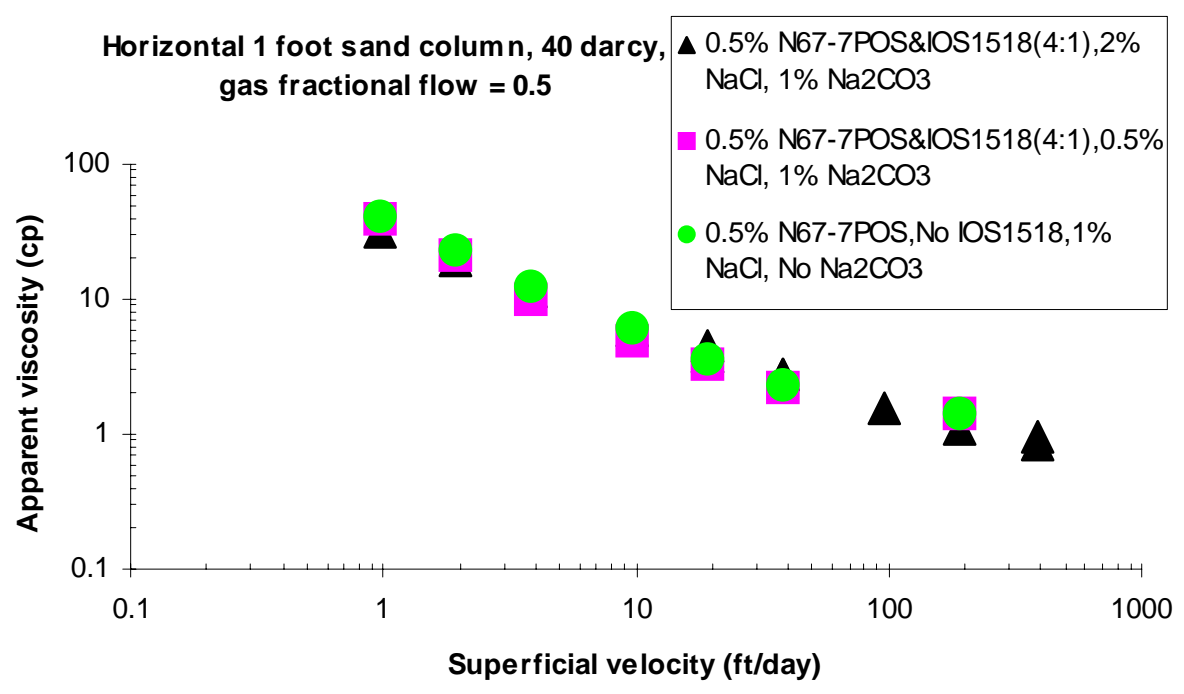

Fig. 3.2- 3. Foam strength at different surfactant composition and salinity 


\section{Task 4: Simulation of Field-Scale Processes}

\section{Subtask 4.2: Wettability alterations in naturally fractured reservoirs}

The objective of this task was to adapt the existing chemical reservoir simulator UTCHEM to model wettability alteration in oil reservoirs due to surfactant injection. An extensive literature search to gather data for residual oil saturation, relative permeability curves, and capillary desaturation curves for different wetting conditions has been performed. Based on these data, a procedure was developed to compute the capillary desaturation and relative permeability curves as a function of wettability. The next step is to implement the procedure in UTCHEM.

\section{Effect of Wettability on Residual Oil Saturation, Relative Permeability, and Capillary Desaturation Curves}

The wettability is the measure of the preference that a rock has for a particular fluid. If a rock is water-wet, the water phase will occupy the small pores and coat the remaining rock surfaces. The location of the fluids in an oilwet rock will reverse from the water-wet case. In some instances, a rock will not have a strong preference for any fluid and is thought to have a neutral wettability. In other cases, a rock will have a varying wettability throughout and is defined as having mixed wettability (Anderson, 1986). Presently, three methods (USBM, Amott-Harvey, and contact angle measurements) are used to calculate the wettability of a rock. For this work, data obtained from the Amott-Harvey method was used. The Amott-Harvey wettability test utilizes a series of spontaneous imbibition and forced displacement processes to calculate the change in fluid volumes expelled from the core as described in Amott, 1959. The Amott-Harvey wettability index $\left(\mathrm{I}_{\mathrm{w}}\right)$ can range from 1 (strongly water-wet) to -1 (strongly oil-wet). The wettability of a rock is important because it controls the residual oil saturation, relative permeability curves, and the capillary desaturation curves $(\mathrm{CDC})$.

The effect of wettability on the residual saturation is based on the location and distribution of the fluids within the rock pores. The wetting phase, occupying the small pores and coating the walls of the larger pores, is immobile due to high capillary forces. The non-wetting phase, which is present as globules in the large pores or across several pores, is held immobile by the interfacial tension between the two phases. Several papers have documented the change in residual oil saturation with changes in the Amott-Harvey Wettability Index (Figure 4.2.1). The common conclusion is that the residual oil saturation is lowest under neutral-wet conditions. Data provided by Jerauld, 1997 indicates that the residual water saturation also follows a similar tend. Another interesting finding is the trend of the residual oil saturation under oil-wet conditions, which mirrors the trend under water-wet conditions (Figure 4.2.1). 
The water/oil relative permeability curves are also dependent upon the wettability state of a rock. The primary changes to the relative permeability curves are the location of the crossover point and the movement of the endpoint relative permeabilities for water and oil. For a strongly water-wet rock, the crossover point of the water/oil relative permeability curves will occur at a water saturation greater than 0.5 . This effect is due to the low water endpoint relative permeability $(\sim 0.1$ to 0.3$)$ and high oil endpoint relative permeability $(\sim 1)$. For a strongly oil-wet rock, the crossover point will occur at a water saturation less than 0.5 . This is due to the higher water endpoint relative permeability $(\sim 0.4$ to 0.7$)$ and reduced oil endpoint relative permeability. To a lesser extent, the relative permeability curves are shifted due to the changes in residual phase saturations of differing wettability conditions. An example of the change in relative permeability with changes in wettability was obtained from Morrow, 1973 and curve fit using Corey type parameters as shown in Figure 4.2.2. It is apparent from this example that the primary effects of changes in wettability are the increase in the water relative permeability curve and the decrease in the oil relative permeability curve when shifting from water-wet to oil-wet. This effect is shifting the crossover point to lower water saturations. The minor effects of changes in residual oil saturation can also be seen.

The effect of wettability on capillary desaturation is also apparent. Local phase trapping occurs until the viscous forces overcome the capillary forces. A dimensionless constant to relate the viscous and capillary forces known as the capillary number was first introduced by Brownell and Katz, 1949. A common usage of the capillary number is to relate it to the residual phase saturations using a CDC. An example CDC for a water-wet sandstone is shown in Figure 4.2.3. As expected, the wetting phase (water) requires a higher critical capillary number $\left(\mathrm{N}_{\mathrm{cc}}\right)$ to begin desaturation compared to the non-wetting phase (oil). The effect of changes in wettability on the CDC of a Berea sandstone is shown in Figure 4.2.4. This plot shows the variation of the oil $\mathrm{N}_{c c}$ and the residual oil saturation at low capillary number for different wettability conditions. Changes in the CDC for weakly oil-wet and neutral-wet carbonate rocks are shown in Figure 4.2.5. The key observation of this plot is the extremely low values of $\mathrm{N}_{\mathrm{cc}}$ for each CDC. The $\mathrm{N}_{\mathrm{cc}}$ for the carbonate rocks in Figure 4.2.5 is three orders of magnitude lower than the mixed-wet and oil-wet sandstone values shown in Figure 4.2.4. A few possible explanations can explain the behavior of a carbonate compared to a sandstone: differences in pore-size distribution, permeability, porosity, and fluid distributions.

\section{Simulations with Differing Wettability}

In order to understand the effects of different wettabilities on surfactant/polymer flooding, four test simulations were conducted. Each of the four cases utilized the same reservoir model and well conditions, but had differing relative permeability curves, CDCs, and capillary pressure curves to mimic different wettability conditions. The model is based on physical and 
chemical properties for a dolomite reservoir within the Midland Farms Unit in West Texas (Table 4.2.1a). The permeability field for this model is shown in Figures 4.2.6. The permeability field was generated with an average permeability of $80 \mathrm{md}$ and Dykstra Parsons coefficient of 0.75 and the $x$ and $y$ correlation length of $20 \mathrm{ft}$ and the vertical correlation length of $4 \mathrm{ft}$. The relative permeability curves and CDCs for each case were developed using the data presented in the previous section. Since the majority of the available data are for sandstone rocks, all data were used for these test simulations regardless of rock type. Typical capillary pressure curves for each wettability condition were used. Table 4.2.2 provides the varying input parameters for each case. For comparison purposes of each test case, a waterflood simulation was performed in addition to a surfactant/polymer flood. The waterflood simulations were stopped when a $98 \%$ water cut was being produced. Immediately after the waterflood period a 0.25 pore volume surfactant slug of 2 vol\% surfactant and $1000 \mathrm{ppm}$ polymer was injected. This followed by $1 \mathrm{PV}$ of $1000 \mathrm{ppm}$ polymer drive and one PV water post flush. Therefore, the only difference in the flood design between each test case is the length in pore volumes of the initial waterflood period. The surfactant was injected at an optimum salinity of 0.445 $\mathrm{meq} / \mathrm{ml}$ as indicated in Table 4.2.1b. The surfactant/polymer flood simulations were performed as a salinity gradient design where the initial salinity at the end of the water injection is in Type $\mathrm{II}(+)$ as $1.026 \mathrm{meq} / \mathrm{ml}$ and the chemical slug at an optimum salinity of $0.445 \mathrm{meq} / \mathrm{ml}$ in Type III and followed by polymer drive at a salinity of $0.34 \mathrm{meq} / \mathrm{ml}$ in Type II(-). The surfactant phase behavior and properties used in our simulations were based on 1.5\% Neodol N67 -7 POS and $0.5 \%$ C2024 Alpha Olefin Sulfonate and 4\% SBA and $1 \% \mathrm{Na}_{2} \mathrm{CO}_{3}$ as described in Task I of this report. Polymer solution properties were based on HPAM (Alcomer $60 \mathrm{RD}$ ) described earlier in Task I.

\section{Case \#1: Strongly water-wet}

The first test case is representative of a strongly water-wet system. The relative permeability curves, CDCs, and capillary pressure for case \#1 are shown in Figures 4.2.7, 4.2.8, and 4.2.12, respectively. The first step was to conduct a waterflood simulation for this test case. The waterflood ran for 0.9 pore volumes until a $98 \%$ water cut was established. The production histories of this simulation are shown in Figures 4.2.13 through 4.2.16. In addition, oil saturation and pressure profiles are shown in Figures 4.2.24 through 4.2.31. The waterflood cumulative oil recovery reached a plateau relatively quickly and terminated at $38 \%$ (Figure 4.2.13). The water breakthrough time for this case was relatively fast. Figure 4.2.17 shows the hypothetical 1-D fractional flow curve for this wettability condition. The slope of the water fractional flow curve between the initial water saturation and the water frontal saturation is relatively high, which explains the fast water breakthrough time. It is also important to note the high average reservoir pressure at the end of the waterflood due to capillary pressure and relative permeability effects (Figure 4.2.14). The final average oil saturation was $39 \%$, which is $2 \%$ higher than the waterflood residual oil saturation. 
Next, a surfactant/polymer simulation was performed immediately after the $0.9 \mathrm{PV}$ waterflood period. The production histories of this simulation are shown in Figures 4.2.20 through 4.2.23. Oil saturation, pressure, microemulsion saturation, polymer concentration, surfactant concentration, and interfacial tension profiles are shown in Figures 4.2.32 through 4.2.67. The effectiveness of surfactant in mobilizing remaining oil saturation is apparent in Figures 4.2.32 through 4.2.34. Oil saturation distributions are also shown for a vertical slice through the middle layer as given in Figures 4.2.38 though 4.2.40. The profiles of surfactant concentration and corresponding interfacial tension values are given in Figures 4.256 through 4.2.61. The interfacial tension is reduced by several orders of magnitude.

The effects of fractional flow in a water-wet system were supported by the relatively early oil breakthrough as shown in Figure 4.2.17. The estimated breakthrough time can be determined by computing the inverse slope of a line connecting the initial waterflooded oil saturation and the expected chemical flood oil bank saturation. As shown in Figure 4.2.17, the slope of this line is very high indicating a very early oil breakthrough time. The final incremental oil recovery was $43 \%$ (Figure 4.2.20) leaving an average oil saturation of about 0.22 .

\section{Case \#2: Neutral-wet}

The second test case is representative of a neutral-wet condition. The relative permeability curves, CDCs, and capillary pressure curve for case \#2 are shown in Figures 4.2.7, 4.2.9, and 4.2.12, respectively. The first step was to conduct a waterflood simulation for this test case. The waterflood ran for 3.5 pore volumes until a $98 \%$ water cut was established. The production histories of this simulation are shown in Figures 4.2.13 through 4.2.16. In addition, oil saturation and pressure profiles are shown in Figures 4.2.68 through 4.2.75. The waterflood cumulative oil recovery increases slowly and terminates at a high value of $62 \%$ (Figure 4.2.13).

It is also important to note the effect of low residual phase saturations, relative permeabilities, and fractional flow on the length of time it took to achieve a $98 \%$ water cut. The hypothetical neutral-wet 1-D fractional flow curve shown in Figure 4.2.18 has a steadily decreasing slope at high water saturations. This is the primary reason for the required waterflood period to reach $98 \%$ water cut. The final average oil saturation was 0.32 , which is $14 \%$ higher than the waterflood residual oil saturation.

Next, a surfactant/polymer simulation with similar conditions as before was performed immediately after the 3.5 pore volume waterflood period. The production histories of this simulation are shown in Figures 4.2.20 through 4.2.23. Oil saturation, pressure, microemulsion saturation, polymer concentration, surfactant concentration, and interfacial tension profiles are shown in Figures 4.2.76 through 4.2.111. The oil breakthrough for this case occurred 
later than water-wet case but had a slightly higher incremental oil recovery in the end (Figure 4.2.20). The formation of oil bank due to the chemical injection and it movement towards the producer is demonstrated in the vertical slices in layer 3 as a function of time in Figures 4.2.82 through 4.2.84. Polymer concentration profiles in layer 3 (Figures 4.2.97 through 4.2.99) and surfactant concentration profiles given in Figures 4.2.100 through 4.2.102 indicate the in sync movement of surfactant and polymer in the chemical slug.

The late breakthrough time can be explained similar to the water-wet case. The chemical flood fractional flow curve is shown in Figure 4.2.18. The inverse slope of a line connecting the initial waterflooded oil saturation and the expected chemical flood oil bank saturation is significantly lower than the waterwet case. Therefore, a later oil breakthrough time is expected. The final incremental waterflood oil recovery was $44 \%$ (Figure 4.2.20) leaving an average oil saturation of 0.18 .

\section{Case \#3: Neutral-wet with a different CDC}

The third case is very similar to Case \#2. The only difference between the two test cases is the CDC. This case uses a CDC that allows an easier mobilization of both water and oil phases than in Case \#2. The relative permeability curves, CDCs, and capillary pressure curve for case \#3 are shown in Figures 4.2.27, 4.2.10, and 4.2.12, respectively. The only difference in the waterflood results between Case \#2 and Case \#3 is the reduction in average reservoir pressure (Figure 4.2.14). This is primarily the effect of capillary desaturation near the wellbore, which is causing larger negative capillary pressures than Case \#2. This effect did not cause differences in the cumulative oil recovery and production rates because the desaturation near the wellbore only slightly reduced the residual oil saturation. The final average oil saturation was 0.32 , which is $14 \%$ higher than the waterflood residual oil saturation.

The surfactant/polymer simulation was performed after the 3.5 pore volume waterflood period. The production histories of this simulation are shown in Figures 4.2.20 through 4.2.23. Oil saturation, pressure, microemulsion saturation, polymer concentration, surfactant concentration, and interfacial tension profiles are shown in Figures 4.2.112 through 4.2.147. The oil breakthrough for this case occurred later than water-wet case for the same reason as in Case \#2 but had a significantly higher incremental waterflood oil recovery of $58 \%$ (Figure 4.2 .20 ) leaving an average oil saturation of 0.13 . The increase in incremental recovery from Case \#2 was solely due to difference in the CDCs. The residual oil saturation was reduced by a greater amount for any given value of interfacial tension (capillary number). 


\section{Case \#4: Oil-wet}

The fourth test case is representative of an oil-wet system. The relative permeability curves, CDCs, and capillary pressure curve for this case are shown in Figures 4.2.7, 4.2.11, and 4.2.12, respectively. The first step was to conduct a waterflood simulation for this test case. The waterflood ran for 1.9 PV until a $98 \%$ water cut was established. The production histories of this simulation are shown in Figures 4.2.13 through 4.2.16. In addition, oil saturation and pressure profiles are shown in Figures 4.2.148 through 4.2.155. The waterflood cumulative oil recovery plateaus relatively slowly and terminates at $34 \%$ (Figure 4.2.13).

The water breakthrough time for this case was faster than all previous cases. Figure 4.2.19 shows the hypothetical 1-D fractional flow curve for this wettability condition. The slope of the water fractional flow curve between the initial water saturation and the water frontal saturation is significantly higher than the water- and neutral-wet cases, which explains the faster water breakthrough time. It is also important to note the low average reservoir pressure at the end of the waterflood due to capillary pressure and relative permeability effects (Figure 4.2.14). The final average oil saturation was 0.43 , which is $8 \%$ higher than the waterflood residual oil saturation.

Next, a surfactant/polymer simulation was performed immediately after the $0.9 \mathrm{PV}$ waterflood period. The production histories of this simulation are shown in Figures 4.2.20 through 4.2.23. Oil saturation, pressure, microemulsion saturation, polymer concentration, surfactant concentration, and interfacial tension profiles are shown in Figures 4.2.156 through 4.2.192. An oil bank forms ahead of the chemical slug and is produced from the production well as shown in Figures 4.2.156 through 4.2.158.

The effects of fractional flow in an oil-wet system were supported by the later oil breakthrough compared to the water-wet case (Figure 4.2.19). The inverse slope of a line connecting the initial waterflooded oil saturation and the expected chemical flood oil bank saturation is lower than the water-wet case but higher than the neutral-wet case. Therefore, a later oil breakthrough time is expected compared to water-wet case. The final incremental waterflood oil recovery was $37 \%$ (Figure 4.2.20) leaving an average oil saturation of 0.27 .

\section{Discussion}

The results of the four test cases provide a good understanding of recovering oil from reservoirs of different wettability during waterflood and surfactant/polymer flooding. The residual phase saturations, relative permeabilities, and fractional flow are the primary causes of differences in waterflooded oil recovery for each test case. The oil-wet case has the most unfavorable mobility ratio and has the fastest water breakthrough as expected. 
The mobility ratio becomes more favorable and the breakthrough time increases as the wettability condition is changed from oil-wet to neutral- and water-wet. The waterflood oil recovery is the highest for the neutral-wet condition (Cases \#2 and \#3) due to the low residual oil saturation. However, the neutral-wet case took the longest amount of time to reach $98 \%$ water cut. This is due primarily to the fractional flow to water. As shown in Figure 4.2.18, the waterflood fractional flow curve shows a steadily decreasing slope at higher water fractional flow values. For the water- and oil-wet cases (Figures 4.2.17 and 4.2.19, respectively), the slope of the fractional flow curve at high fractional flow does not steadily decline.

For the surfactant/polymer flood, the oil breakthrough time for each test case was affected by the relative permeabilities and fractional flow similar to the waterflood simulations. The water-wet case had the fastest oil breakthrough time and the neutral-wet cases had the slowest breakthrough time. This phenomenon can be explained by comparing the expected fractional flow curves for each wetting condition. However, the actual values on the fractional flow curves presented cannot be used literally because fractional flow theory is valid only for one dimensional flow. The following equation can be used to approximate the oil breakthrough time for a surfactant/polymer flood:

$$
t_{d}^{b . t .}=\frac{S_{O B}-S_{o I}}{f_{o B}-f_{o I}}
$$

The values used to approximate the breakthrough times of each test case are shown in Figure 4.2.17, 4.2.18, and 4.2.19. The water-wet case was expected to have an oil breakthrough time of 0.3 pore volumes. Whereas, the oil-wet and neutral-wet cases were expected to have oil breakthrough at 0.33 and 0.6 pore volumes, respectively. These values supported the actual breakthrough times of each simulation by comparing their relative values.

The incremental waterflood oil recovery results are most dependent upon the CDC. Case \#3 has the most favorable CDC because it has the lowest critical capillary number. In addition, Case \#3 had the highest incremental waterflood oil recovery. As expected, the oil-wet case (Case \#4), which had the least favorable $\mathrm{CDC}$, had the lowest incremental waterflood oil recovery.

Based on the results of these test simulations, a series of events is expected to occur during the wettability alteration process. If a rock is initially oilwet, waterflood and chemical flood oil recovery is affected significantly by unfavorable mobility and CDCs. If the rock is changed to neutral wettability by means of chemical alteration, several processes will take place. First, the relative permeability curves will change giving a more favorable mobility ratio and lower phase saturations. This change in relative permeability will alter the fractional flow curve. For the fractional flow range of interest (high water saturation), a less favorable fractional flow will occur in neutral wet conditions 
and the chemical flood oil bank will "slow down". Second, the CDC will change based on changes in low capillary number residual phase saturations and wettability dependent trapping parameter. The CDC for a neutral-wet condition is more favorable for displacing oil at high capillary numbers. If the rock is further altered to a water-wet state, these processes will continue. The relative permeability curves will change due to increases in the residual phase saturations and changes in the endpoint relative permeabilities. The chemical flood fractional flow and CDC will also become more favorable for oil recovery.

\section{Computing the Relative Permeability Curves as a Function of Wettability}

As a result of the extensive literature survey and test simulations, the effects of wettability on residual oil saturation, relative permeability curves, and CDCs are clear. However, a mathematical relationship to link the changes of each property with changes in wettability due to surfactant injection is unclear. A preliminary method has been established in an attempt to fulfill this complex task. Prior to running a simulation the following tasks should be completed.

1) Establish relative permeability curves and CDCs for the initial wettability condition and curves for the expected final condition.

2) Determine the changes in wettability index $\left(I_{w}\right)$ due to surfactant injection. It is possible that the amount of surfactant adsorbed to the pore wall or the concentration of surfactant within a pore can be related to wettability alteration. This relationship has not been completely studied at this time, but is expected to provide promising results.

3) Develop a relationship between residual phase saturation $\left(S_{j r}\right)$ and $I_{w}$. This relationship was discussed previously.

The next step is to modify UTCHEM to model the wettability alteration based on changes to the relative permeability, capillary pressure and capillary desaturation curves. During the simulation, the surfactant adsorption (or concentration) and capillary number is known for each gridblock during every timestep. Using these data, UTCHEM can perform the wettability alteration by following these next steps:

4) Determine $I_{w}$ based on the relationship developed in Step 2.

5) Determine the low capillary number residual saturation for water and oil $\left(S_{\mathrm{j} r}\right)$ from the relationship developed in Step 3.

6) Develop a new capillary desaturation curve for the altered wettability. The equation that UTCHEM uses to generate the CDC is as follows:

$$
S_{j r}=\min \left(S_{j}, S_{j r}^{\text {high }}+\frac{S_{j r}^{\text {low }}-S_{j r}^{\text {high }}}{1+T_{j} N_{c j}^{\tau_{j}}}\right)
$$

Where, $\mathrm{S}_{\mathrm{jr}}^{\text {high }}=$ Residual saturation of phase $\mathrm{j}$ at high capillary number (Typically 0 ) 
$\mathrm{S}_{\mathrm{jr}}^{\text {low }}=$ Residual saturation of phase $\mathrm{j}$ at low capillary number (Step 5)

$\mathrm{T}_{\mathrm{j}}=$ Trapping parameter for phase $\mathrm{j}$

$\mathrm{N}_{\mathrm{cj}}=$ Capillary number for phase $\mathrm{j}$

$\tau_{\mathrm{j}}=$ Trapping parameter exponent for phase $\mathrm{j}$

The trapping parameter exponent $\left(\tau_{\mathrm{j}}\right)$ is typically 1 and therefore, the only unknown in this equation is $T_{j}$. The trapping parameter $\left(T_{j}\right)$ is important because it determines the shape of the CDC and the value of the critical capillary number $\left(\mathrm{N}_{\mathrm{cC}}\right)$. A CDC obtained using a high trapping parameter $\left(\sim 10^{5}\right.$ to $\left.10^{6}\right)$ will have a lower $\mathrm{N}_{\mathrm{cc}}$ compared to a CDC with a low trapping parameter $\left(\sim 10^{2}\right.$ to $\left.10^{3}\right)$. The literature search was extended to attempt to determine a relationship between $T_{j}$ and $I_{w}$. CDC data were obtained from various sources and curve fit using Equation 2. A summary of the results of this literature search is provided in Table 4.2.3. In some instances, the wettability index was provided along with the CDC for the given rock sample. In other cases, the wettability index was obtained based on data provided by other sources that had consistent core preparation techniques (i.e. core firing, cleaning, etc.), initial water saturation, and brine properties. It is apparent that a clear correlation does not exist. However, the lack of data for oil-wet and neutral-wet conditions is important. Additionally, the laboratory experiments that were used to obtain each data set were conducted differently. Three main differences arose from each experiment: the use of wettability altering chemicals, differing flow rates to obtain the CDC, and differing interfacial tensions to obtain the CDC.

Using a correlation between $T_{j}$ and $I_{w}$, the modified trapping parameter can be obtained and a new CDC can be generated.

7) Determine the current $S_{\mathrm{j}}$ for each gridblock based on the modified CDC (Step 6) and the capillary number $\left(\mathrm{N}_{\mathrm{cj}}\right)$.

8) Develop a new set of water/oil relative permeability curves using the current $S_{\mathrm{jr}}$ from Step 7. Currently UTCHEM uses the following equations to modify the Corey type relative permeability parameters such as endpoint $\left(\mathrm{k}_{\mathrm{rj}}^{0}\right)$ and exponent $\left(n_{\mathrm{j}}\right)$ :

$$
\begin{aligned}
& \mathrm{k}_{\mathrm{rj}}^{\mathrm{o}}=\mathrm{k}_{\mathrm{rj}}^{\mathrm{o}^{\text {low }}}+\frac{\mathrm{S}_{\mathrm{jr}}^{\text {low }}-\mathrm{S}_{\mathrm{jr}}}{\mathrm{S}_{\mathrm{jr}}^{\text {low }}-\mathrm{S}_{\mathrm{jr}}^{\text {high }}} *\left(\mathrm{k}_{\mathrm{rj}}^{\mathrm{o}^{\text {high }}}-\mathrm{k}_{\mathrm{rj}}^{\mathrm{o}^{\text {low }}}\right) \\
& \mathrm{n}_{\mathrm{j}}=\mathrm{n}_{\mathrm{j}}^{\text {low }}+\frac{\mathrm{S}_{\mathrm{jr}}^{\text {low }}-S_{\mathrm{jr}}}{\mathrm{S}_{\mathrm{jr}}^{\text {low }}-\mathrm{S}_{\mathrm{jr}}^{\text {high }}} *\left(\mathrm{n}_{\mathrm{j}}^{\text {high }}-\mathrm{n}_{\mathrm{j}}^{\text {low }}\right)
\end{aligned}
$$

Where, $\mathrm{k}_{\mathrm{jr}}^{\text {high }}=$ Endpoint relative permeability of phase $\mathrm{j}$ at high capillary number $\mathrm{k}_{\mathrm{jr}}^{\text {low }}=$ Endpoint relative permeability of phase $\mathrm{j}$ at low capillary number 
$\mathrm{n}_{\mathrm{jr}}^{\text {high }}=$ Relative permeability exponent of phase $\mathrm{j}$ at high capillary number

$\mathrm{n}_{\mathrm{jr}}^{\text {low }}=$ Relative permeability exponent of phase $\mathrm{j}$ at low capillary number 
Table 4.2.1a. Reservoir Properties and Simulated Well Conditions

\begin{tabular}{|l|l|}
\hline $\mathrm{LxWxH}$ & $660 \times 660 \times 30 \mathrm{ft}$ \\
\hline Grid Blocks & $11 \times 11 \times 5$ \\
\hline Depth to Pay & $4700 \mathrm{ft}$ \\
\hline Initial Pressure & $1975 \mathrm{psi}$ \\
\hline Reservoir Temperature & $103^{\circ} \mathrm{F}$ \\
\hline Average Permeability $\left(\mathrm{k}_{\mathrm{x}}, \mathrm{k}_{\mathrm{y}}\right)$ & $80 \mathrm{md}$ \\
\hline $\mathrm{K}_{\mathrm{z}} / \mathrm{k}_{\mathrm{x}}$ & 0.1 \\
\hline Porosity & 0.16 \\
\hline Water Compressibility & $3 \times 10^{-6} \mathrm{psi}^{-1}$ \\
\hline Oil Compressibility & $1 \times 10^{-5} \mathrm{psi}^{-1}$ \\
\hline Water Density & $62.43 \mathrm{lb} / \mathrm{ft}^{3}$ \\
\hline Oil Density & $54.33 \mathrm{lb} / \mathrm{ft}^{3}$ \\
\hline Water Viscosity & $0.7 \mathrm{cp}$ \\
\hline Oil Viscosity & $5 \mathrm{cp}$ \\
\hline Water/Oil IFT & $20 \mathrm{dynes} / \mathrm{cm}$ \\
\hline Constant Injection Rate & $250 \mathrm{bbl} / \mathrm{day}$ \\
\hline Constant Production Pressure & $300 \mathrm{psi}$ \\
\hline
\end{tabular}

Table 4.2.1ba. Fluid Properties

\begin{tabular}{|l|c|}
\hline Initial formation salinity, $\mathrm{meq} / \mathrm{ml}$ & 1.026 \\
\hline Surfactant adsorption, $\mathrm{mg} / \mathrm{g}$ & 0.3 \\
\hline Polymer adsorption, $\mu \mathrm{g} / \mathrm{g}$ & 10 \\
\hline Surfactant slug size $(2 \mathrm{vol} \%)$ & 0.25 \\
\hline $\begin{array}{l}\text { Polymer concentration in slug, } \\
\text { wt\% }\end{array}$ & 0.1 \\
\hline Slug salinity, meq/ml & 0.445 \\
\hline Polymer drive, PV & 1 \\
\hline $\begin{array}{l}\text { Polymer concentration in drive, } \\
\text { wt\% }\end{array}$ & 0.1 \\
\hline Drive salinity, meq/ml & 0.34 \\
\hline $\begin{array}{l}\text { Salinity in water post flush, } \\
\text { meq/ml }\end{array}$ & 0.34 \\
\hline
\end{tabular}

Table 4.2.2. Input Parameters for Each Test Case

\begin{tabular}{|l|l|l|l|l|l|l|l|l|l|l|}
\hline $\begin{array}{l}\text { Cas } \\
\mathbf{e}\end{array}$ & $\mathbf{I}_{\mathbf{w}}$ & $\mathbf{S}_{\text {or }}{ }^{\text {low (1) }}$ & $\mathbf{S}_{\mathbf{w r}}{ }^{\text {low }}$ & $\mathbf{T}_{\mathbf{o}}$ & $\mathbf{T}_{\mathbf{w}}$ & $\mathbf{k}_{\text {or }}{ }^{\circ}$ & $\mathbf{k}_{\mathbf{w r}}{ }^{\circ}$ & $\mathbf{n}_{\mathbf{o}}$ & $\mathbf{n}_{\mathbf{w}}$ & $\mathbf{M}^{\mathbf{0}}$ \\
\hline$\# 1$ & 1 & 0.37 & 0.37 & $\begin{array}{l}1000 \\
0\end{array}$ & 500 & 1 & 0.1 & 2 & 2 & 0.7 \\
\hline$\# 2$ & 0 & 0.18 & 0.18 & 2000 & 2000 & 0.5 & 0.5 & 2 & 2 & 7.1 \\
\hline$\# 3$ & 0 & 0.18 & 0.18 & $\begin{array}{l}4000 \\
00\end{array}$ & $\begin{array}{l}40000 \\
0\end{array}$ & 0.5 & 0.5 & 2 & 2 & 7.1 \\
\hline$\# 4$ & -0.5 & 0.35 & 0.35 & 500 & 10000 & 0.4 & 0.7 & 2 & 2 & 12.5 \\
\hline
\end{tabular}

1: From the Jadhunandan and Morrow curve in Figure 1 
Table 4.2.3. Summary of Literature Search to Obtain Trapping Parameter Data

\begin{tabular}{|c|c|c|c|c|c|c|}
\hline Source & Rock Type & $I_{w}$ & $\mathrm{~S}_{\text {or }}^{\text {low }}$ & $S_{w r}^{\text {low }}$ & $T_{0}$ & $T_{w}$ \\
\hline Bhuyan, 1986 & Berea Sandstone & 0.57 & 0.33 & 0.39 & 17791 & 781 \\
\hline Bhuyan, 1986 & Berea Sandstone & -0.65 & 0.35 & 0.38 & 53452 & 3206 \\
\hline Bhuyan, 1986 & Berea Sandstone & -0.7 & 0.26 & 0.34 & 35000 & 55999 \\
\hline Kamath, 2001 & Oolitic Limestone & -0.25 & 0.6 & NA & 1000000 & NA \\
\hline Kamath, 2001 & Limestone & -0.19 & 0.5 & NA & 200000 & NA \\
\hline Kamath, 2001 & Micritic Limestone & -0.04 & 0.32 & NA & 400000 & NA \\
\hline Abrams, 1975 & Gallup Sandstone & NA & 0.34 & NA & 1500 & NA \\
\hline Abrams, 1975 & Dalton Sandstone & NA & 0.3 & NA & 1000 & NA \\
\hline Abrams, 1975 & Dalton Sandstone & NA & 0.29 & NA & 2000 & $\mathrm{NA}$ \\
\hline Abrams, 1975 & Paluxy Sandstone & NA & 0.28 & NA & 2500 & NA \\
\hline Abrams, 1975 & Bandera Sandstone & NA & 0.37 & NA & 1500 & $\mathrm{NA}$ \\
\hline Abrams, 1975 & Berea Sandstone & NA & 0.37 & NA & 3000 & NA \\
\hline Abrams, 1975 & Indiana Limestone & NA & 0.34 & NA & 500 & NA \\
\hline Gupta, 1979 & Berea Sandstone & $0.95^{1}$ & 0.25 & 0.42 & 8000 & 2500 \\
\hline Chatzis, 1981 & Berea Sandstone & $0.92^{1}$ & 0.34 & NA & 2000 & NA \\
\hline Chatzis, 1981 & Berea Sandstone & $0.92^{1}$ & 0.35 & NA & 4000 & NA \\
\hline Chatzis, 1981 & Berea Sandstone & $0.92^{1}$ & 0.34 & NA & 1000 & $\mathrm{NA}$ \\
\hline Chatzis, 1981 & Berea Sandstone & $0.92^{1}$ & 0.39 & NA & 1300 & NA \\
\hline Chatzis, 1981 & Berea Sandstone & $0.92^{1}$ & 0.3 & $\mathrm{NA}$ & 2400 & NA \\
\hline Chatzis, 1981 & $\begin{array}{l}\text { Cottage Grove } \\
\text { Sandstone }\end{array}$ & NA & 0.37 & NA & 2000 & NA \\
\hline Chatzis, 1981 & Boise Sandstone & $1^{1}$ & 0.27 & NA & 3000 & $\mathrm{NA}$ \\
\hline Chatzis, 1981 & $\begin{array}{l}\text { Fountainbleau } \\
\text { Sandstone }\end{array}$ & NA & 0.34 & NA & 3200 & NA \\
\hline Stegemeier, 1974 & Berea Sandstone & $0.84^{1}$ & 0.4 & NA & 3000 & $\mathrm{NA}$ \\
\hline Amaefule, 1982 & Berea Sandstone & $0.91^{1}$ & 0.2 & 0.4 & 1500 & 200 \\
\hline Mohanty, 1983 & Berea Sandstone & $0.79^{1}$ & 0.36 & $\mathrm{NA}$ & 4000 & NA \\
\hline Mohanty, 1983 & Berea Sandstone & $-0.75^{1}$ & 0.48 & $\mathrm{NA}$ & 1000 & NA \\
\hline Mohanty, 1983 & Berea Sandstone & $0.07^{1}$ & 0.26 & $\mathrm{NA}$ & 1000 & $\mathrm{NA}$ \\
\hline Bardon, 1980 & $\begin{array}{l}\text { Fountainbleau } \\
\text { Sandstone }\end{array}$ & NA & 0.4 & NA & 3000 & NA \\
\hline Boom, 1995 & Reservoir Sandstone & $\mathrm{NA}$ & 0.09 & 0.29 & 500 & 79 \\
\hline Boom, 1996 & Reservoir Sandstone & $\mathrm{NA}$ & 0.26 & $\mathrm{NA}$ & 315 & NA \\
\hline Delshad, 1990 & Berea Sandstone & NA & 0.4 & NA & 35000 & NA \\
\hline Henderson, 1998 & Berea Sandstone & $\mathrm{NA}$ & 0.29 & NA & 100000 & NA \\
\hline Henderson, 1998 & Berea Sandstone & NA & 0.27 & NA & 14854 & NA \\
\hline Garnes, 1990 & Berea Sandstone & $0.77^{1}$ & 0.49 & NA & 5000 & NA \\
\hline Garnes, 1990 & Berea Sandstone & $0.77^{1}$ & 0.6 & NA & 9000 & NA \\
\hline Garnes, 1990 & Berea Sandstone & $0.77^{1}$ & 0.45 & NA & 6000 & NA \\
\hline Garnes, 1990 & Tarbet Sandstone & 0.3 & 0.27 & NA & 1600 & NA \\
\hline Garnes, 1990 & Oregon Sandstone & NA & 0.45 & NA & 15000 & NA \\
\hline Garnes, 1990 & Oregon Sandstone & NA & 0.32 & NA & 8000 & NA \\
\hline
\end{tabular}

NA - Not Available

1: $I_{w}$ was obtained from a different source based on the core treatment process, initial water saturation, and brine. 


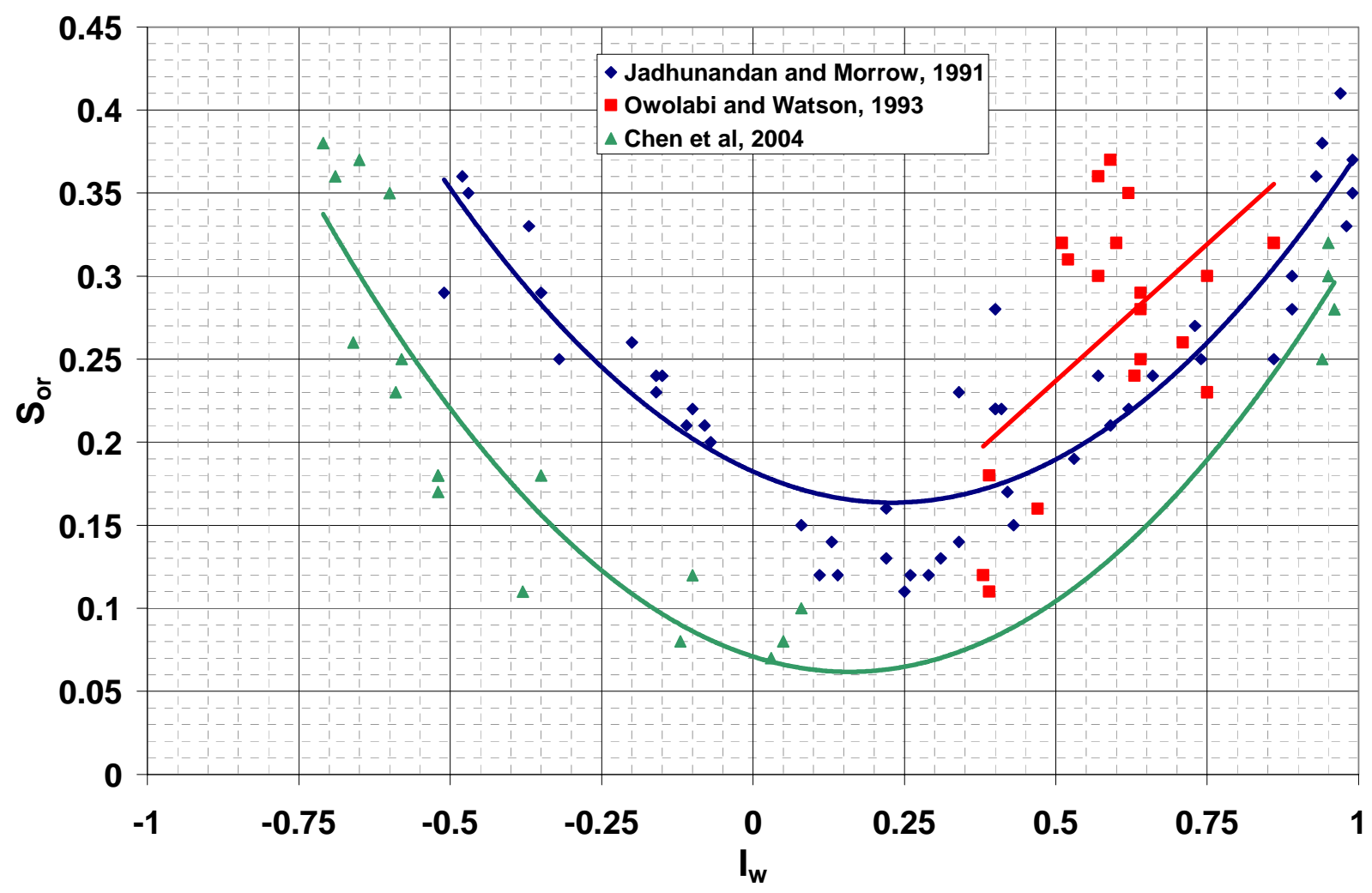

Figure 4.2.1. Effect of Amott-Harvey Wettability Index on Residual Oil Saturation in Berea Sandstone

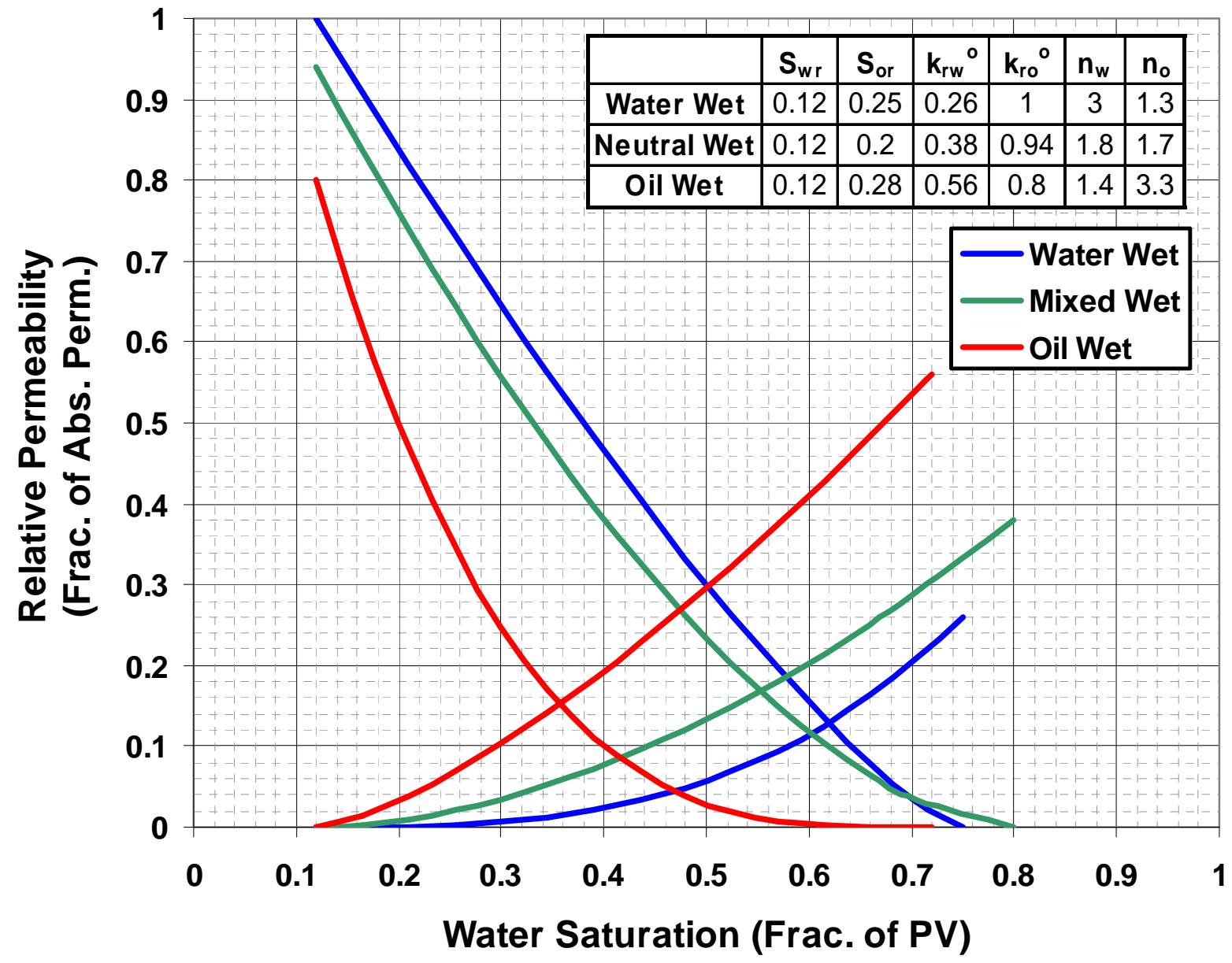

Figure 4.2.2. Effect of Wettability on Oil/Water Relative Permeability Curves (Morrow et. al. 1973) 


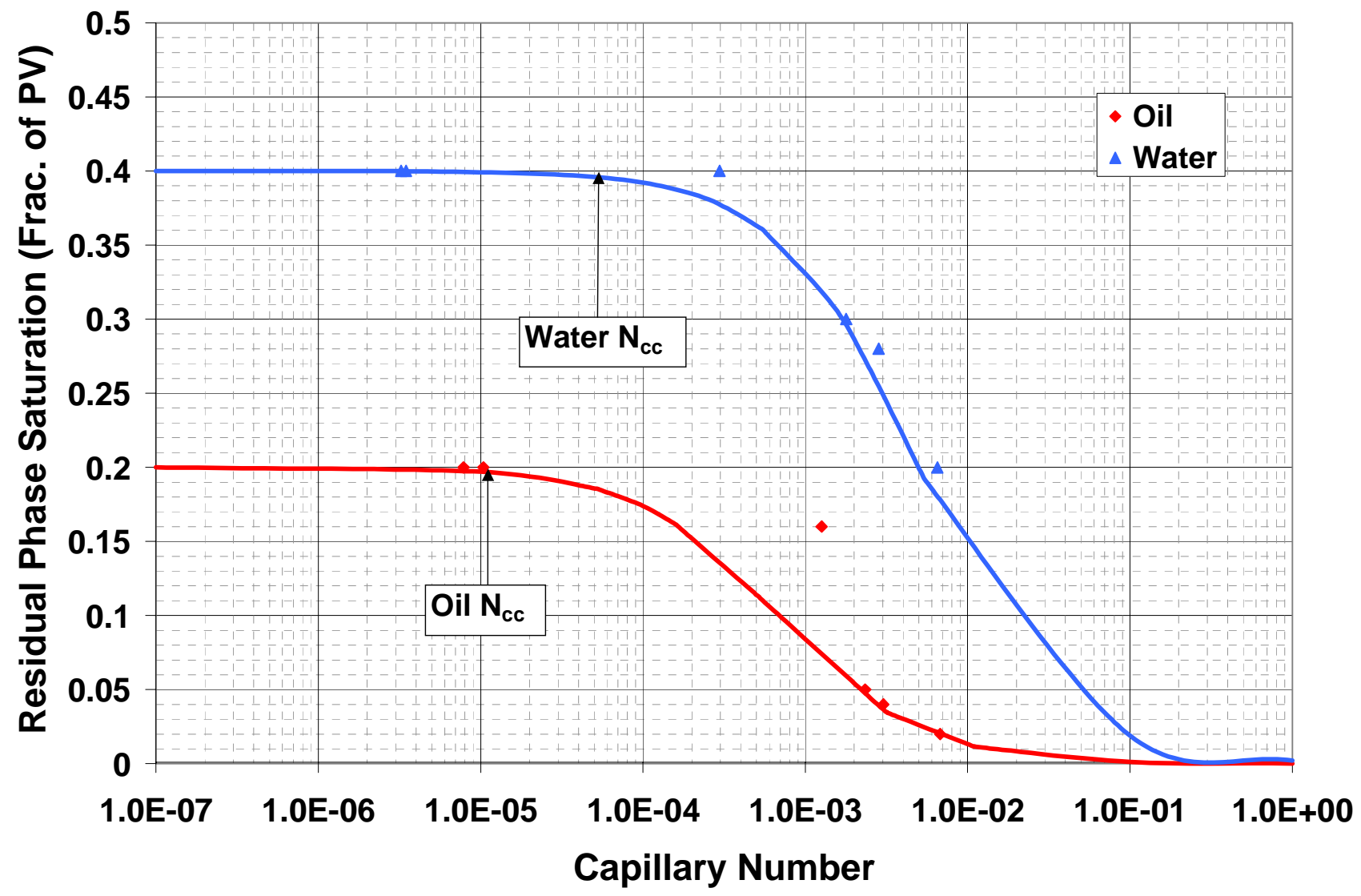

Figure 4.2.3. Example Water/Oil CDC for a Water Wet Berea Sandstone (Amaefule, 1982) 


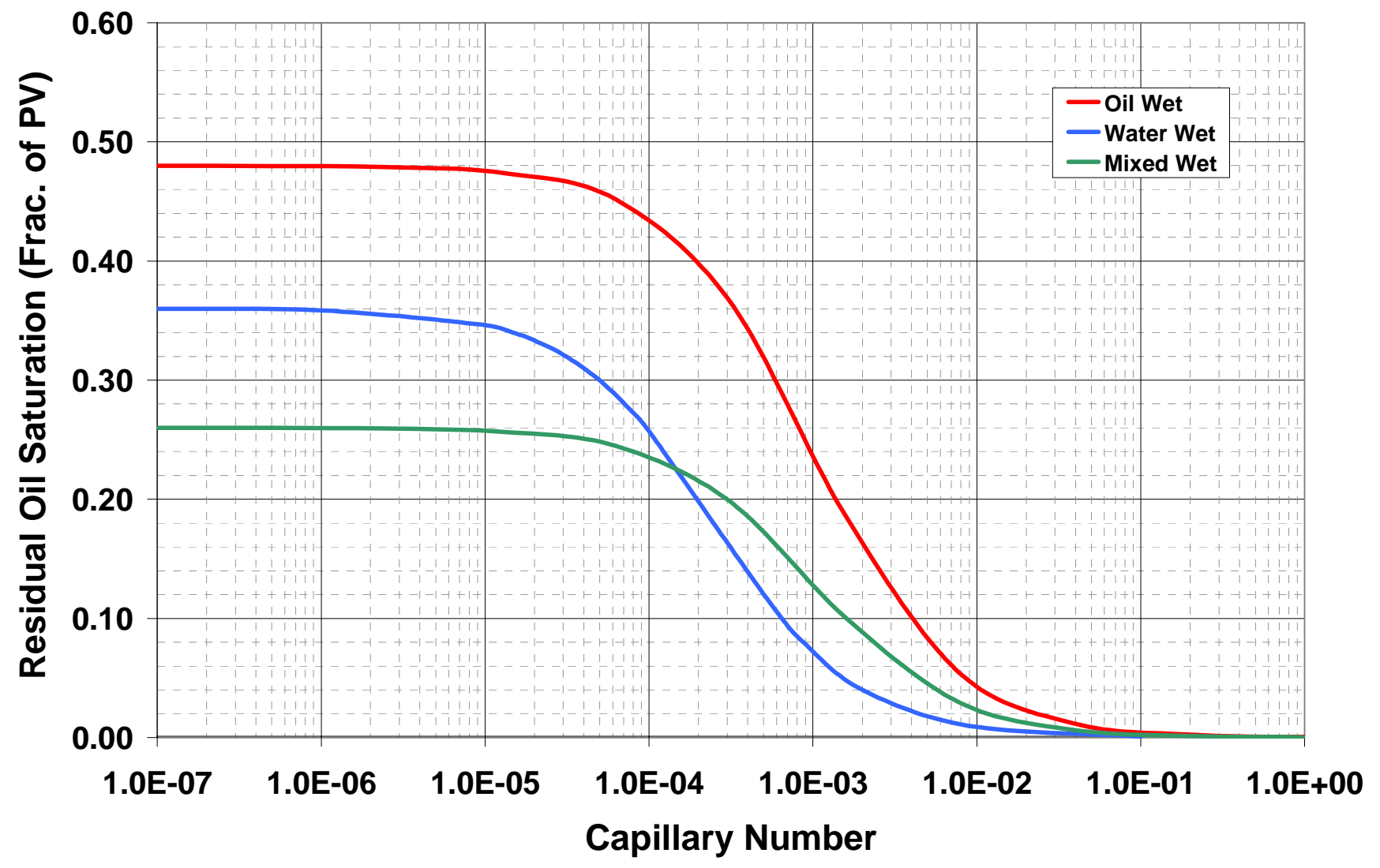

Figure 4.2.4. Effect of Wettability on the CDC for a Berea Sandstone (Mohanty, 1983)

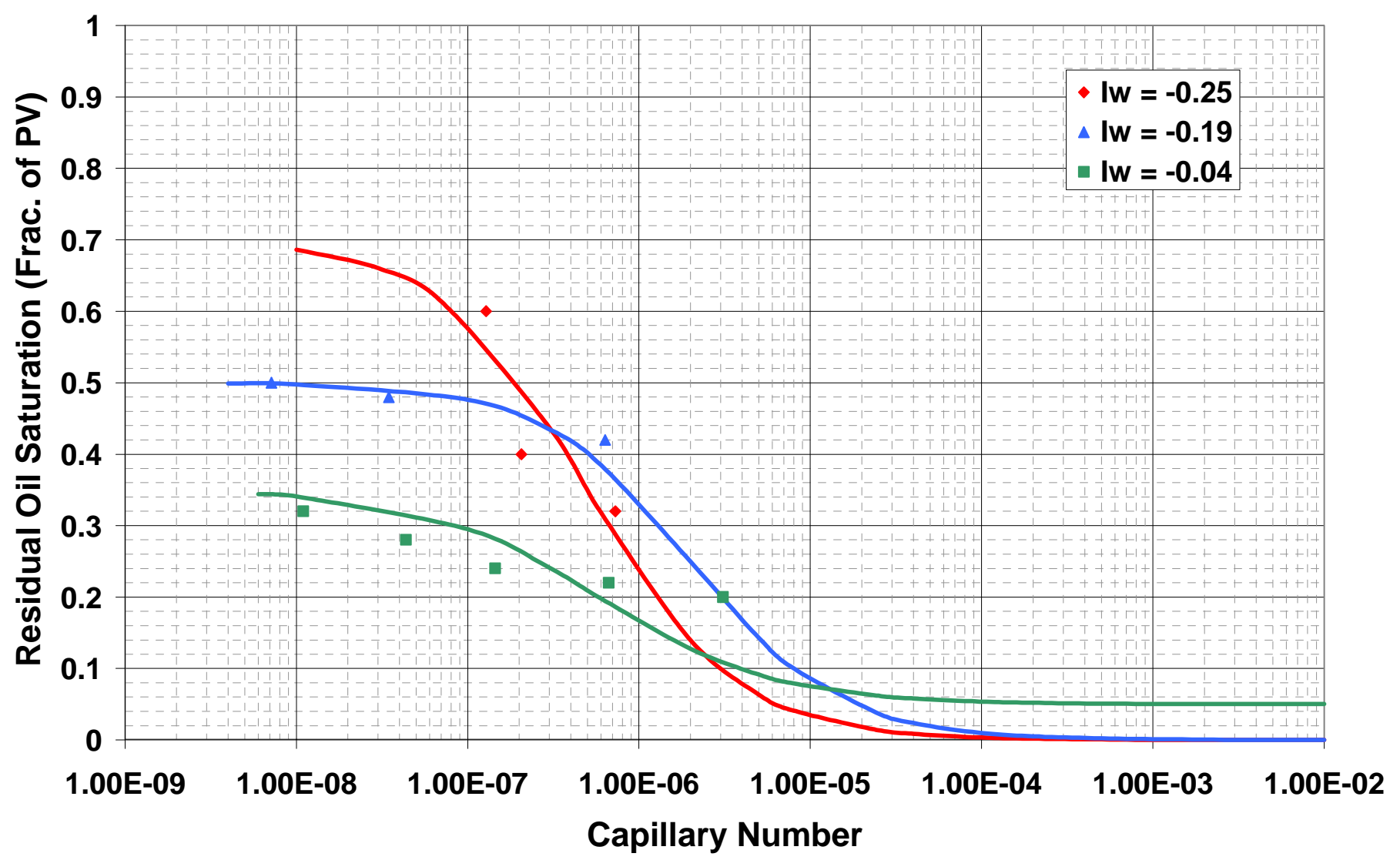

Figure 4.2.5. Effect of Wettability on the CDC for Three Weakly Oil-Wet to Neutral-Wet Carbonate Rocks (Kamath, 2001). *Based on the available data, $\mathrm{S}_{\text {or }}{ }^{\text {low }}$ values are not shown. 


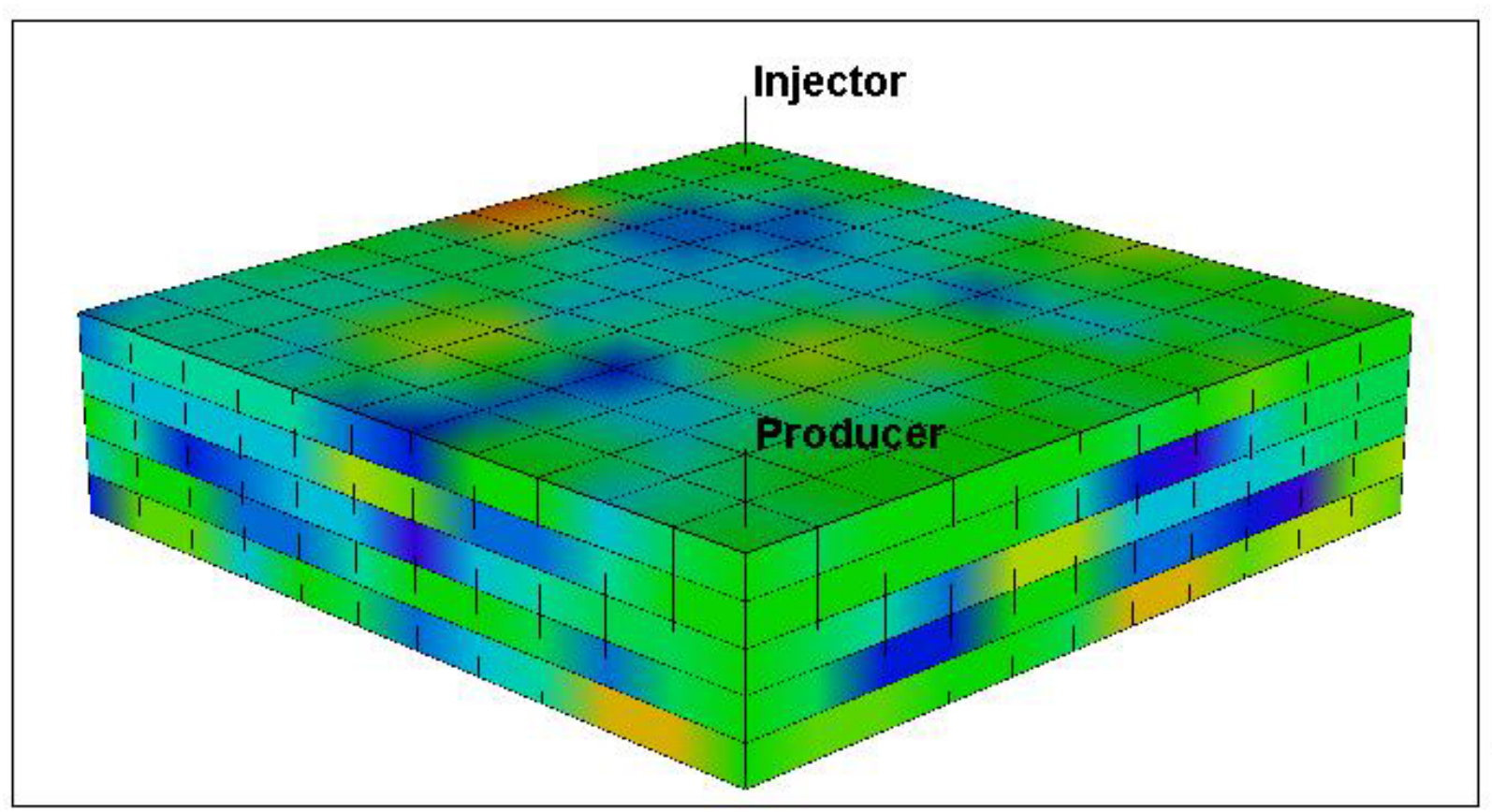

$1.00 \mathrm{e}+3$
$6.31 \mathrm{e}+2$

$3.98 \mathrm{e}+2$

$2.51 \mathrm{e}+2$

$1.58 \mathrm{e}+2$

$1.00 \mathrm{e}+2$

$6.31 \mathrm{e}+1$

$3.98 \mathrm{e}+1$

$2.51 \mathrm{e}+1$

$1.58 \mathrm{e}+1$

$1.00 \mathrm{e}+1$

$6.31 \mathrm{e}+0$

$3.98 \mathrm{e}+0$

$2.51 \mathrm{e}+0$

$1.58 \mathrm{e}+0$

Figure 4.2.6. Permeability Field (md) Used in All Test Simulations

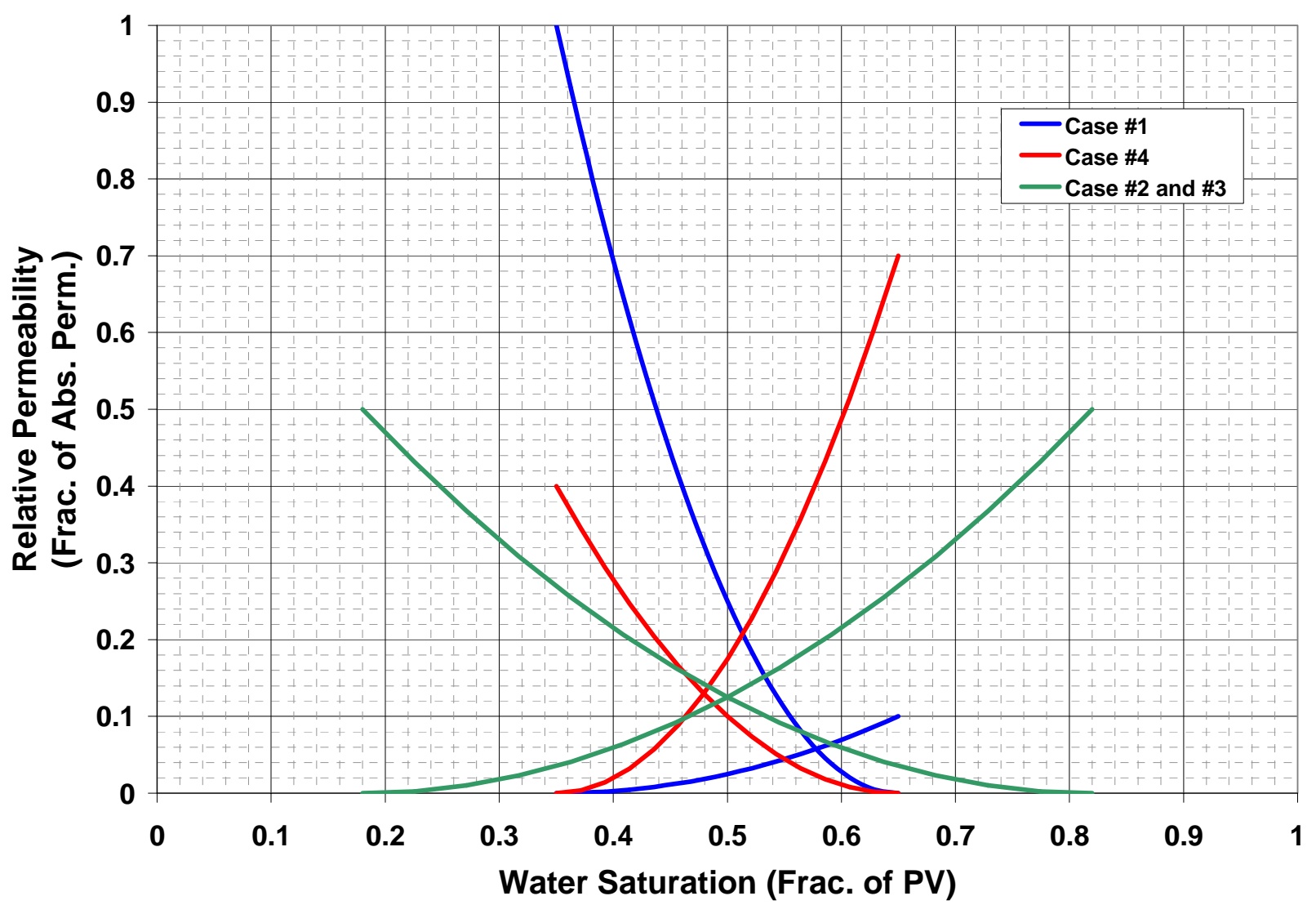

Figure 4.2.7. Relative Permeability Curves used in the Test Simulations 


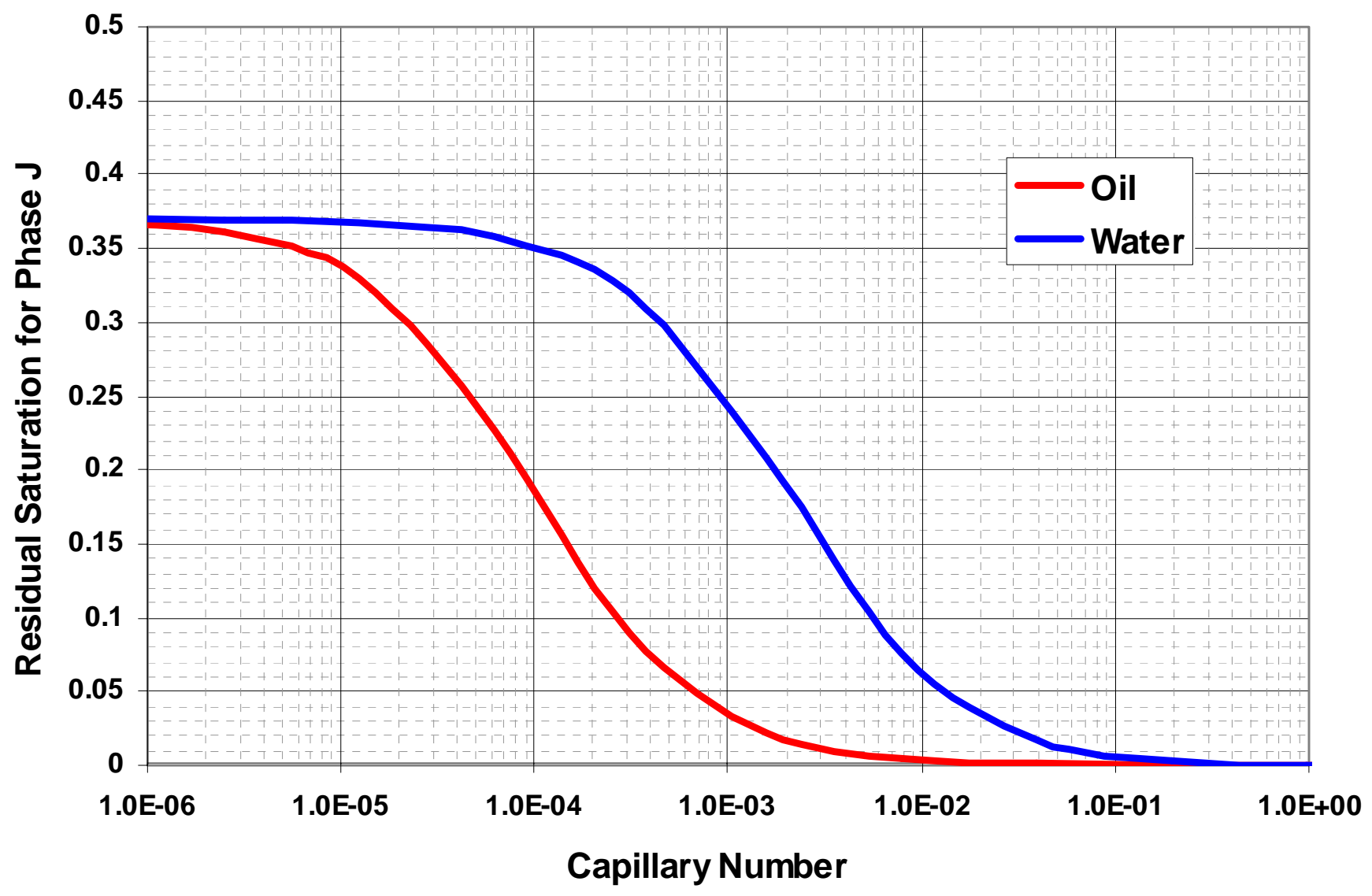

Figure 4.2.8. Water and Oil CDC for Case \#1

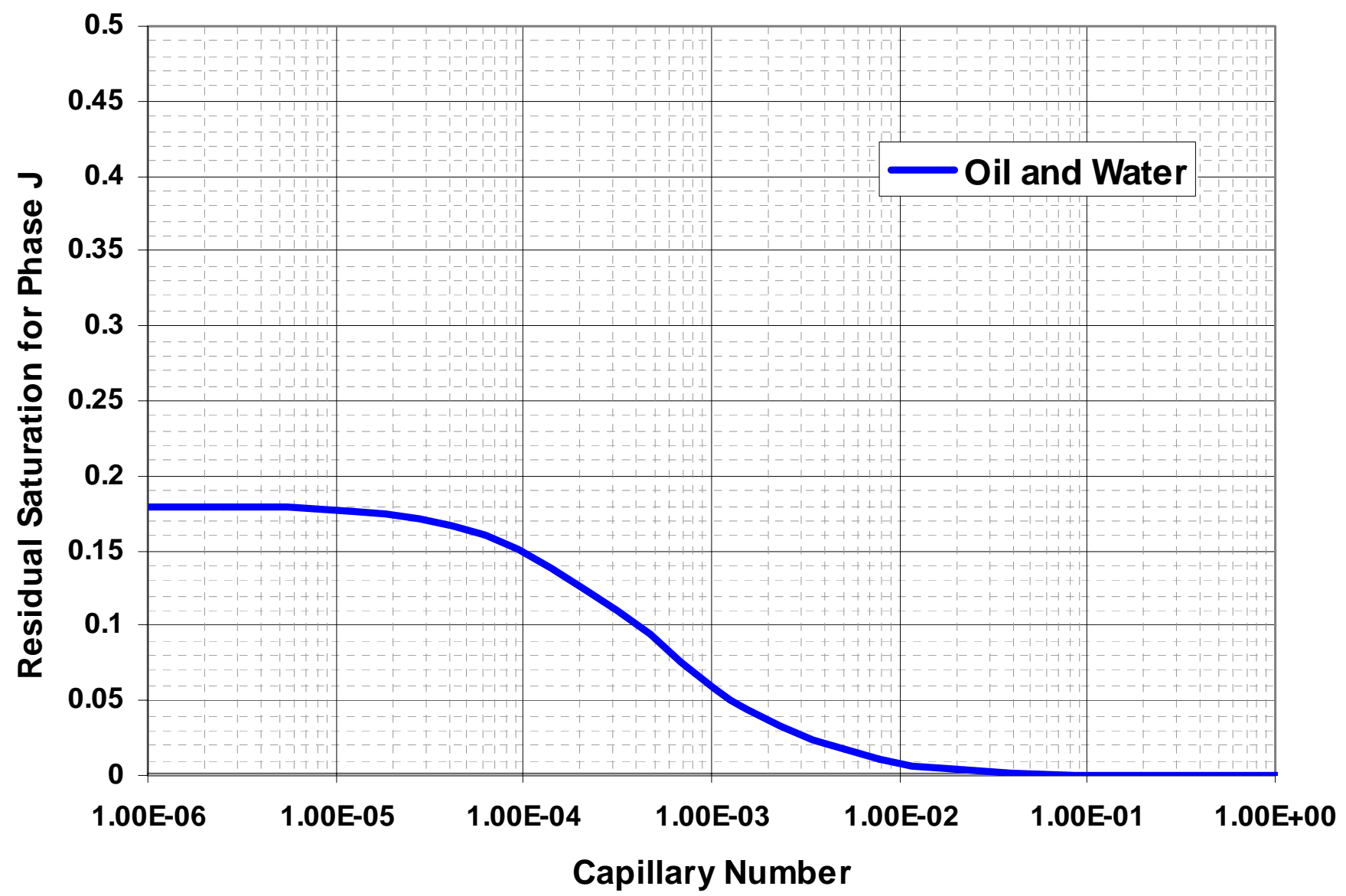

Figure 4.2.9. Water and Oil CDC for Case \#2 


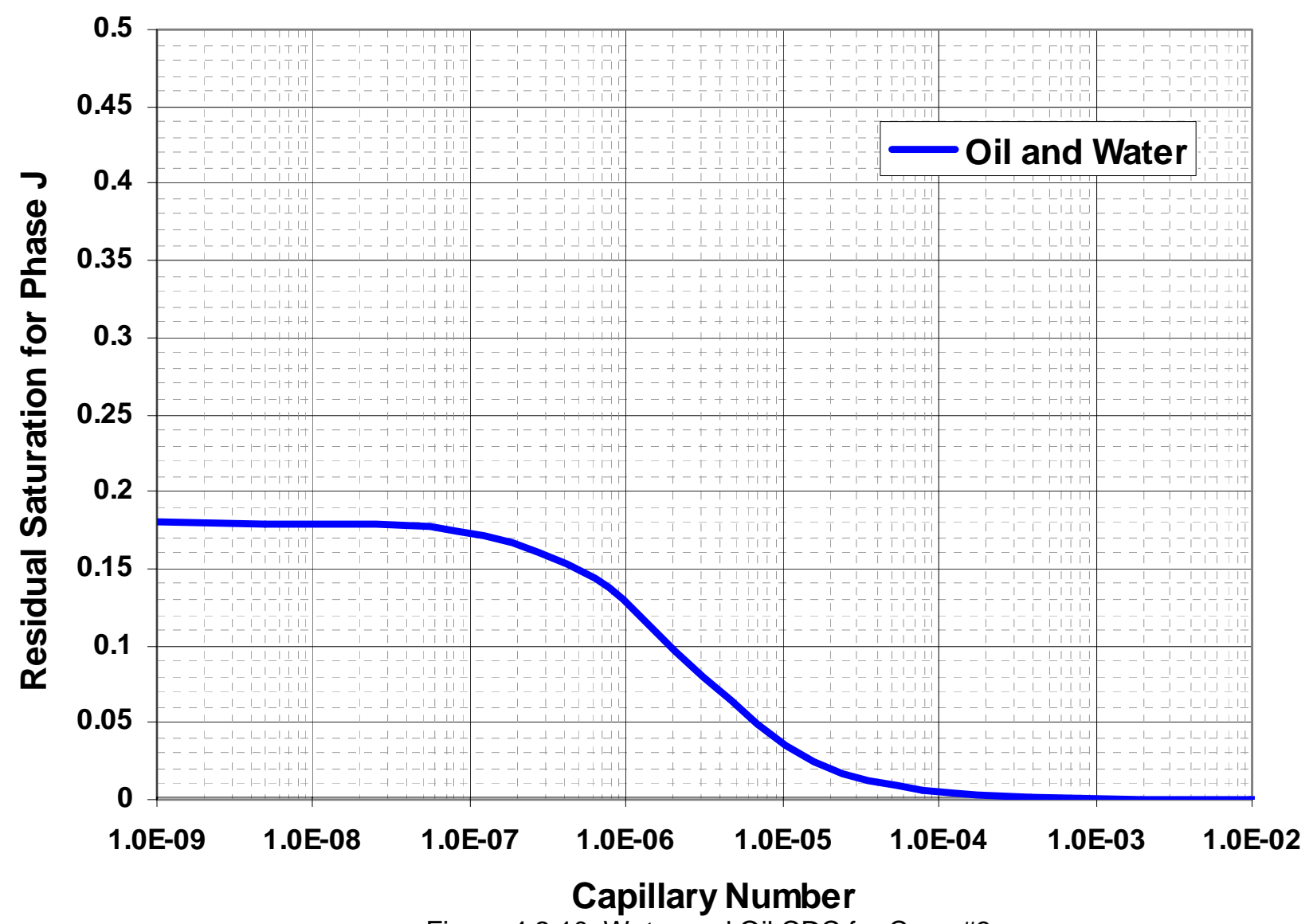

Figure 4.2.10. Water and Oil CDC for Case \#3

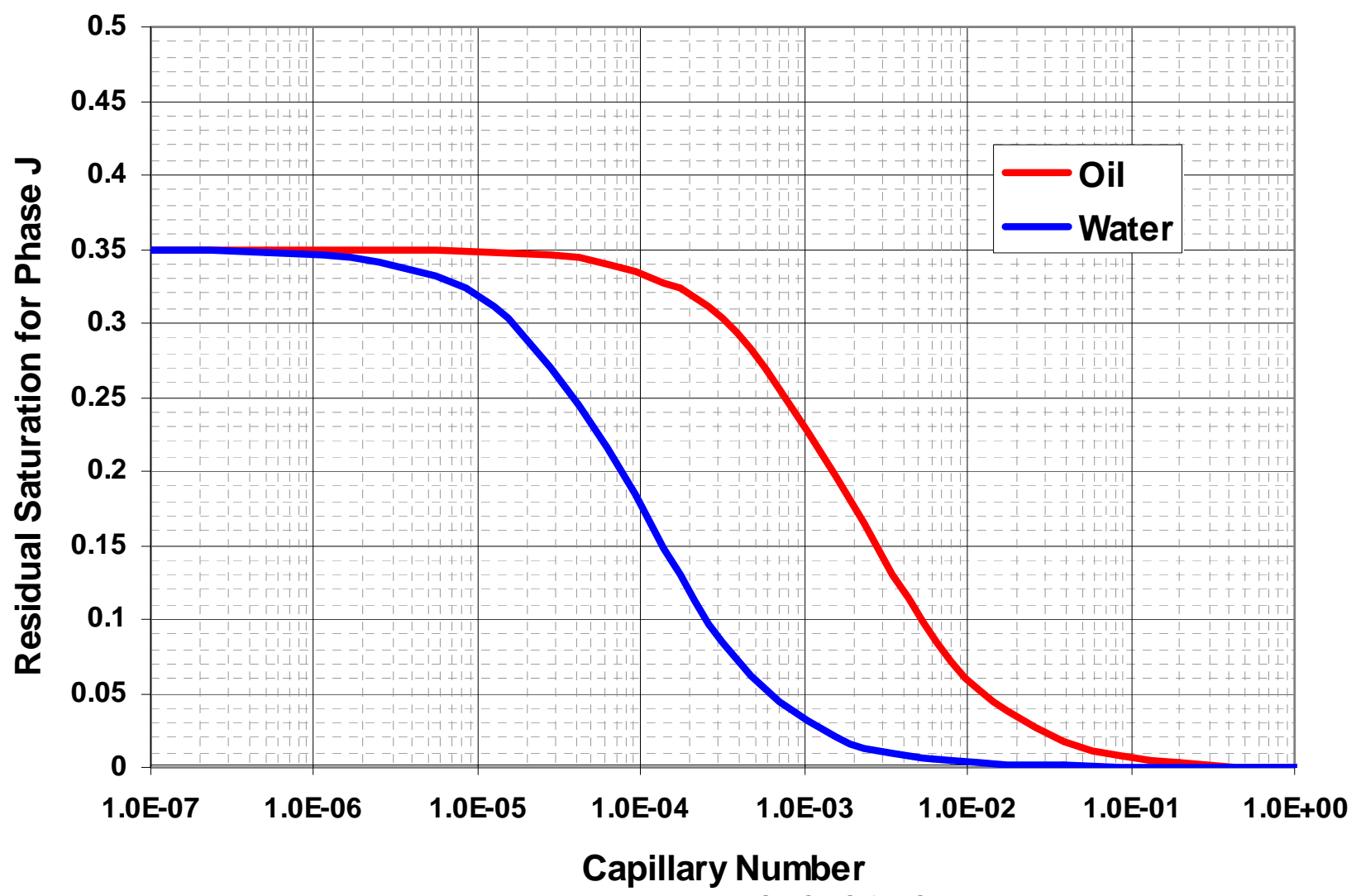

Figure 4.2.11. Water and Oil CDC for Case \#4 


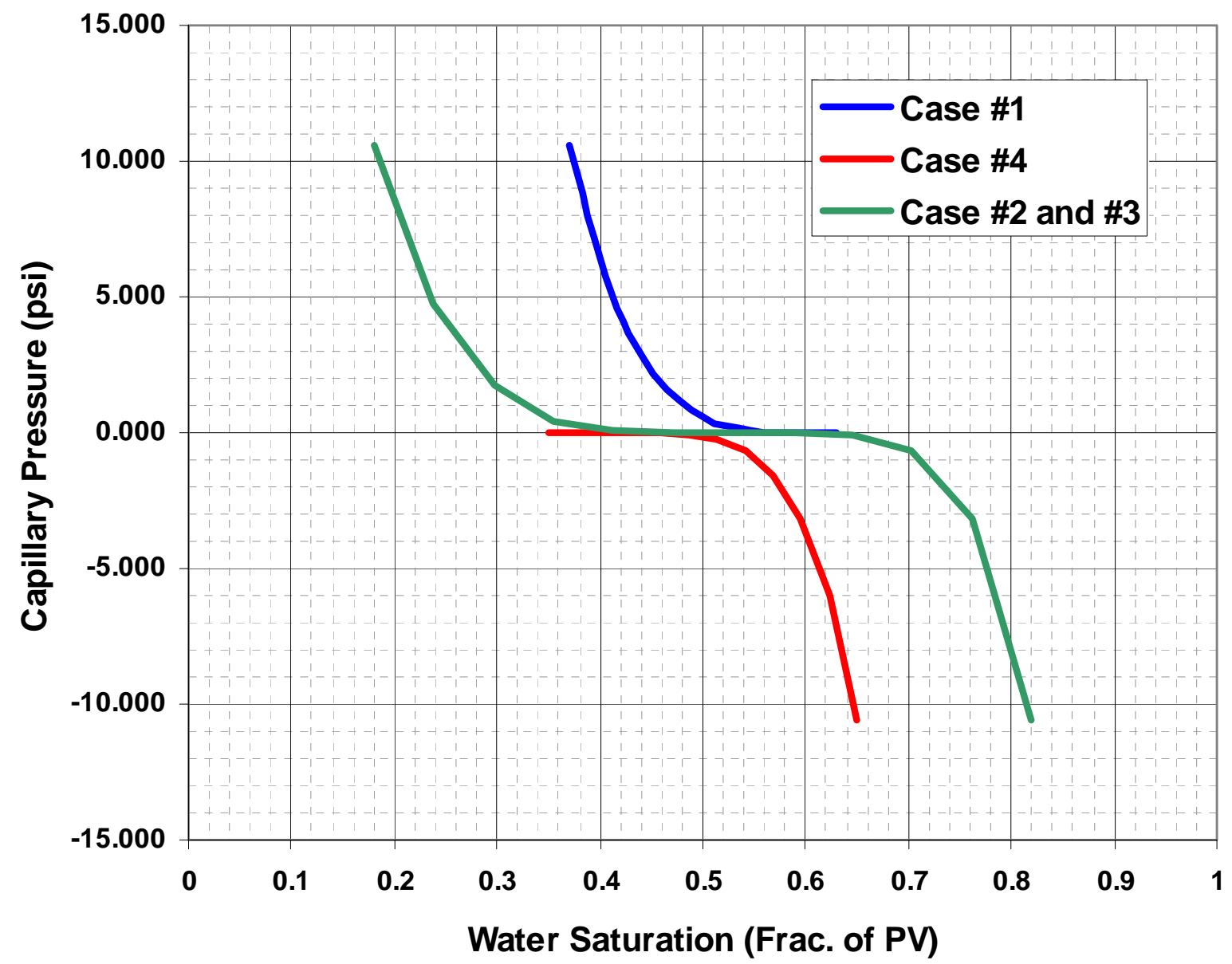

Figure 4.2.12. Capillary Pressure Curves for Each Test Simulation

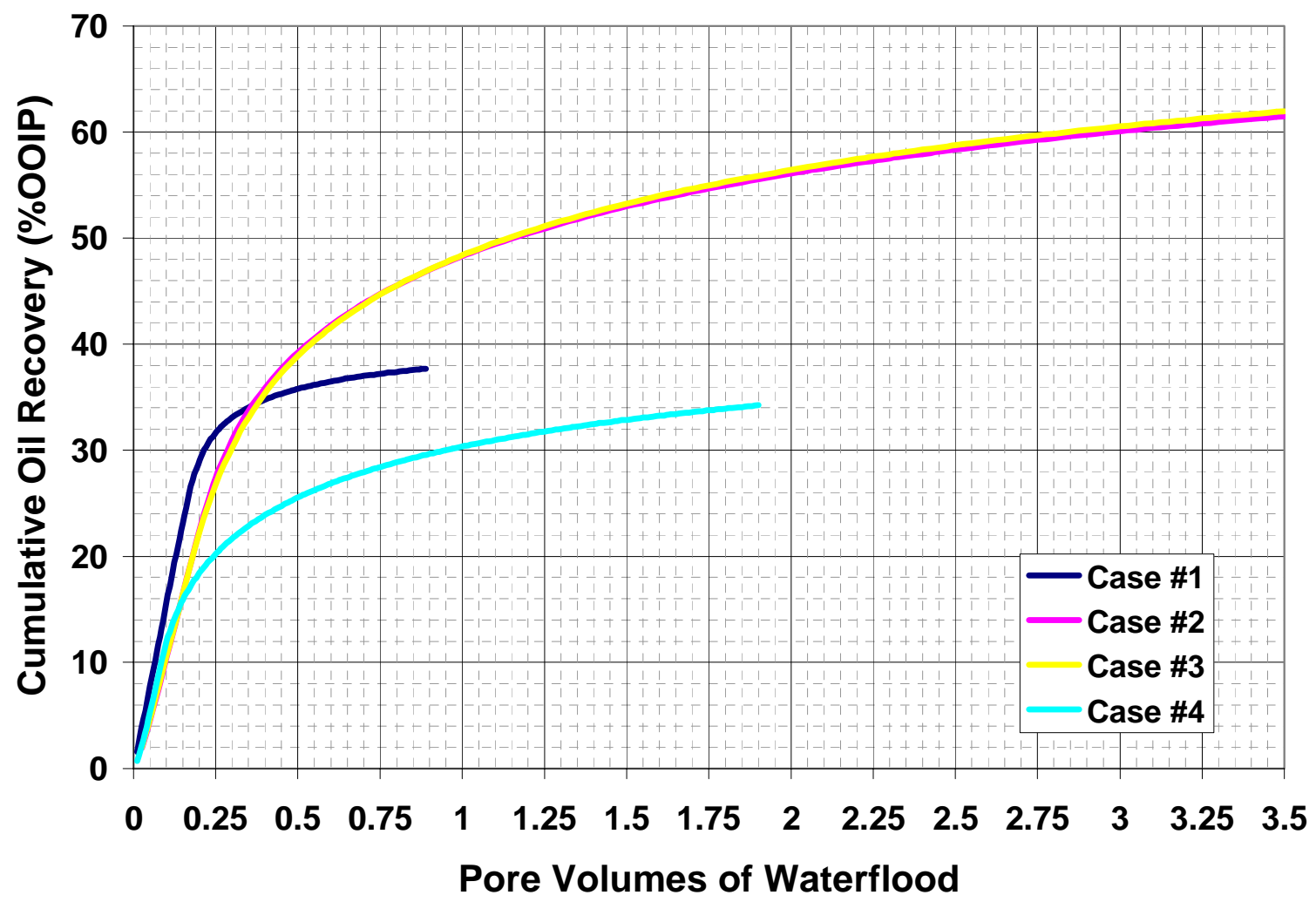

Figure 4.2.13. Waterflood - Cumulative Oil Recovery for Each Test Simulation 


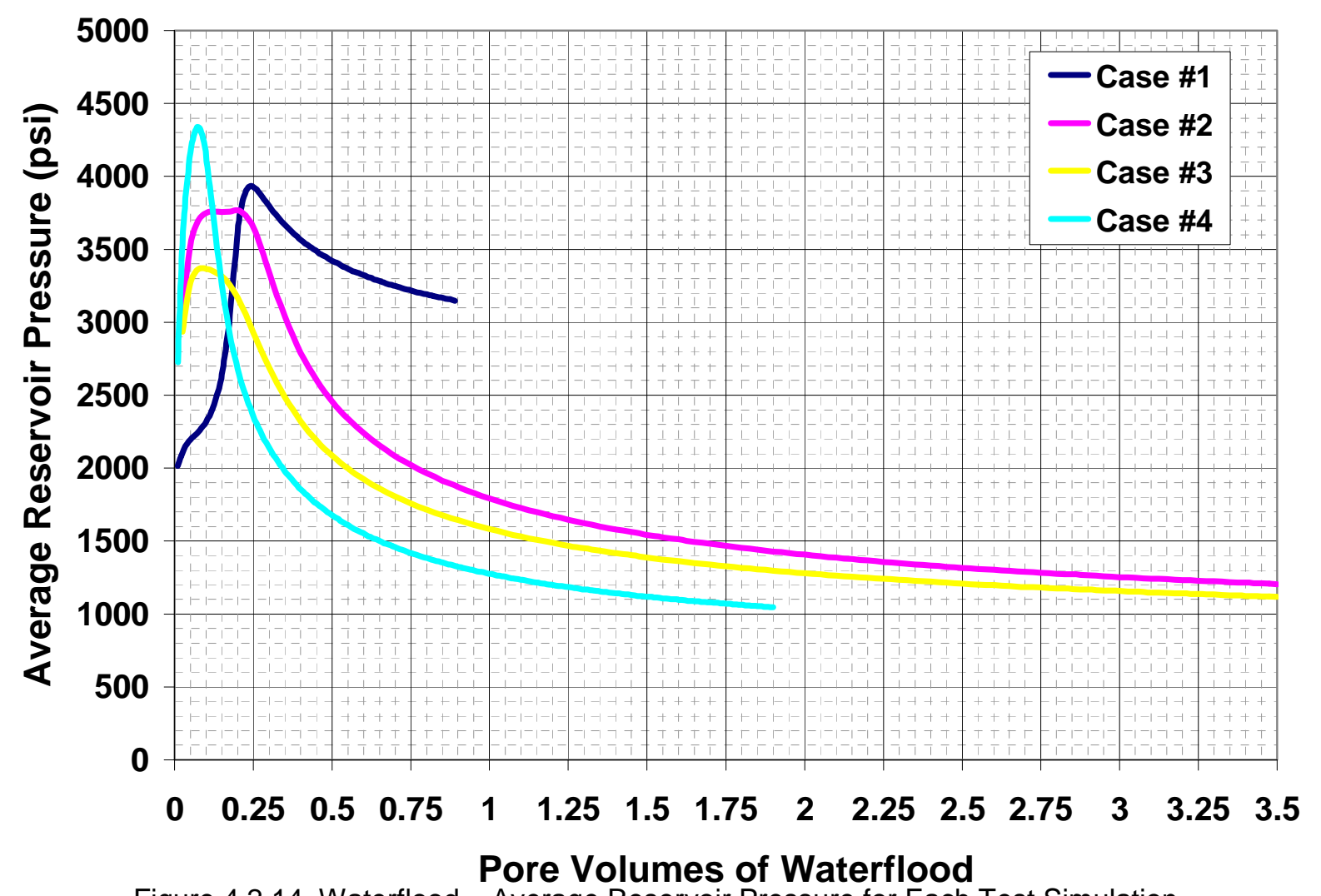

Figure 4.2.14. Waterflood - Average Reservoir Pressure for Each Test Simulation

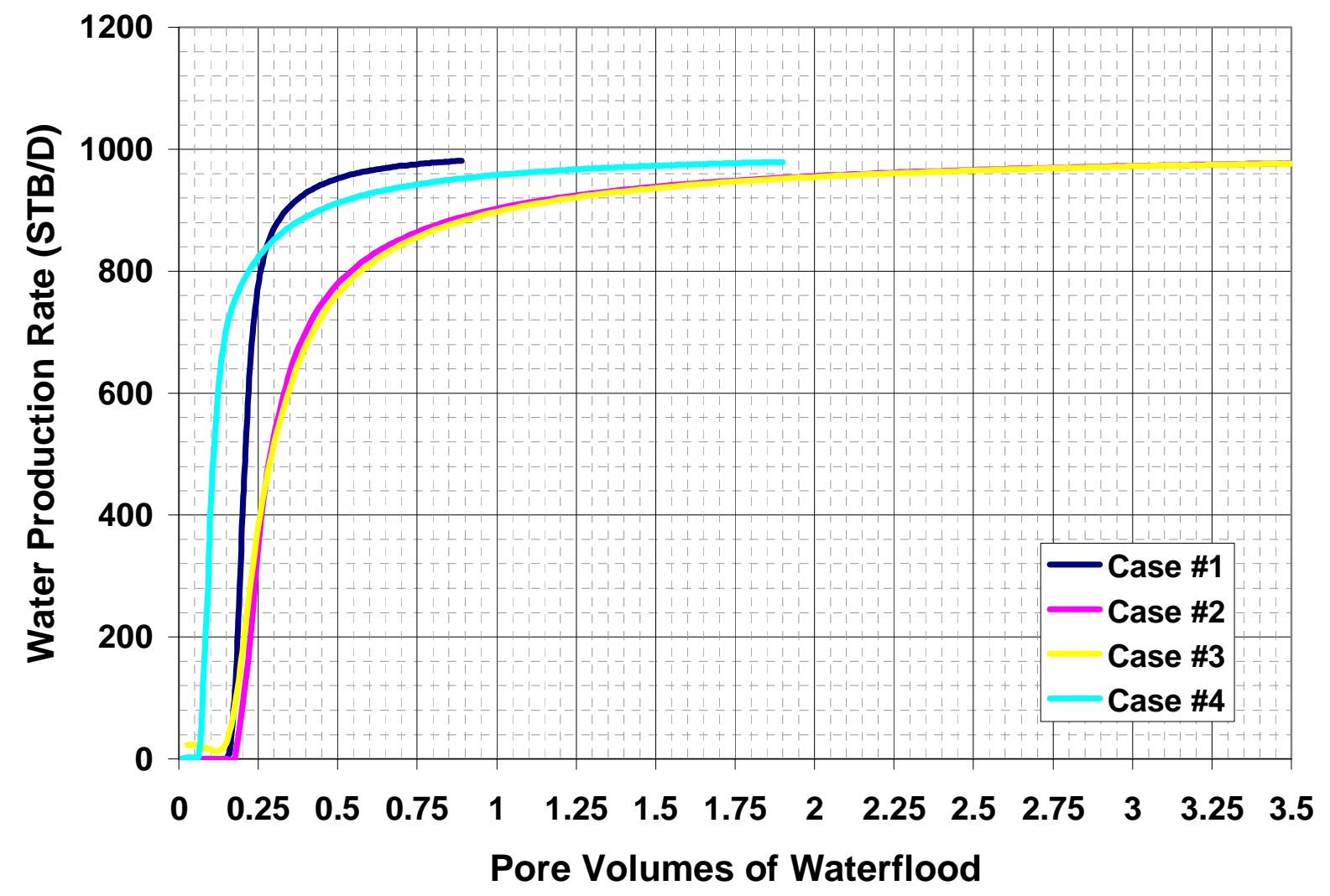

Figure 4.2.15. - Waterflood - Water Production Rate for Each Test Simulation 


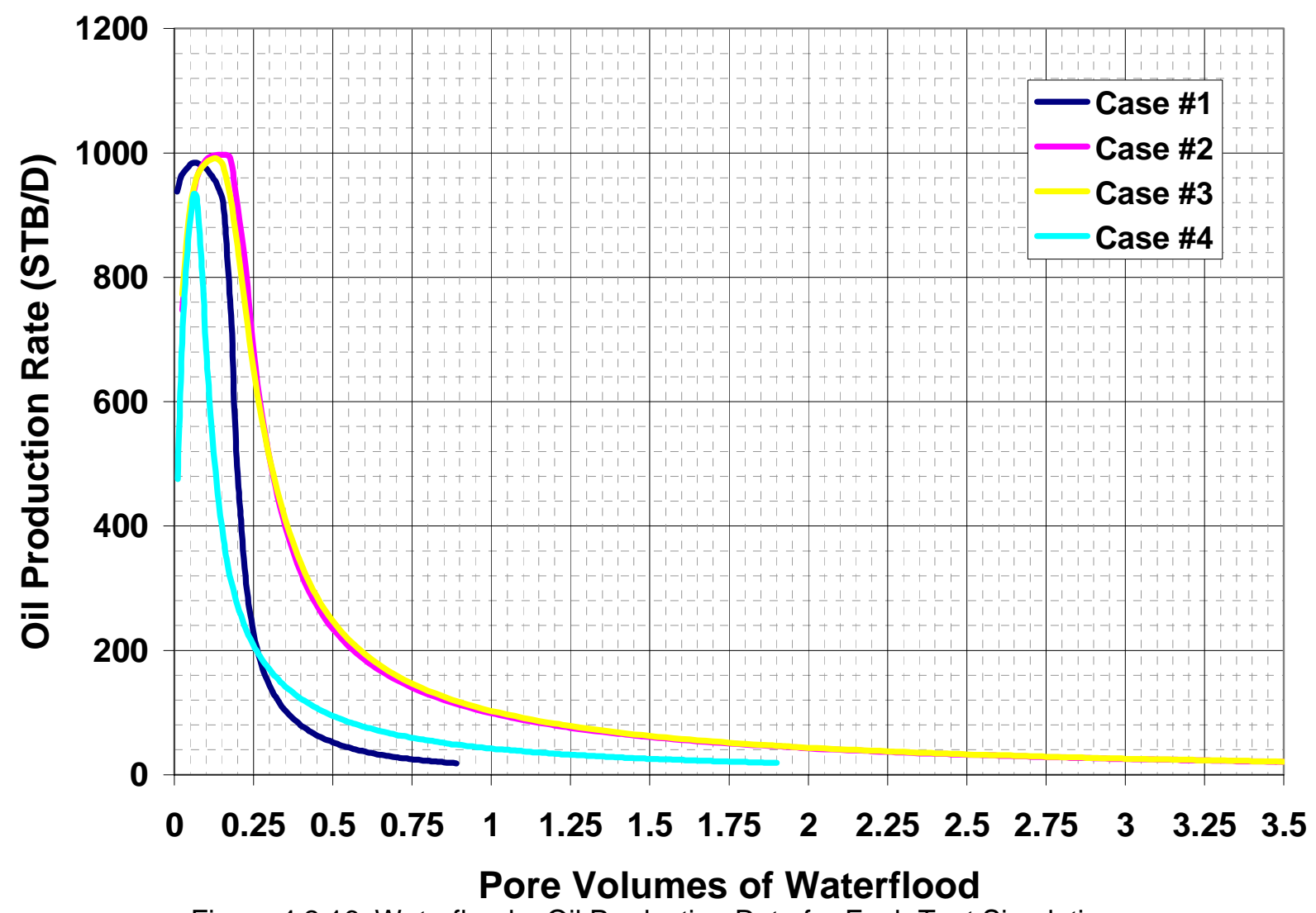

Figure 4.2.16. Waterflood - Oil Production Rate for Each Test Simulation

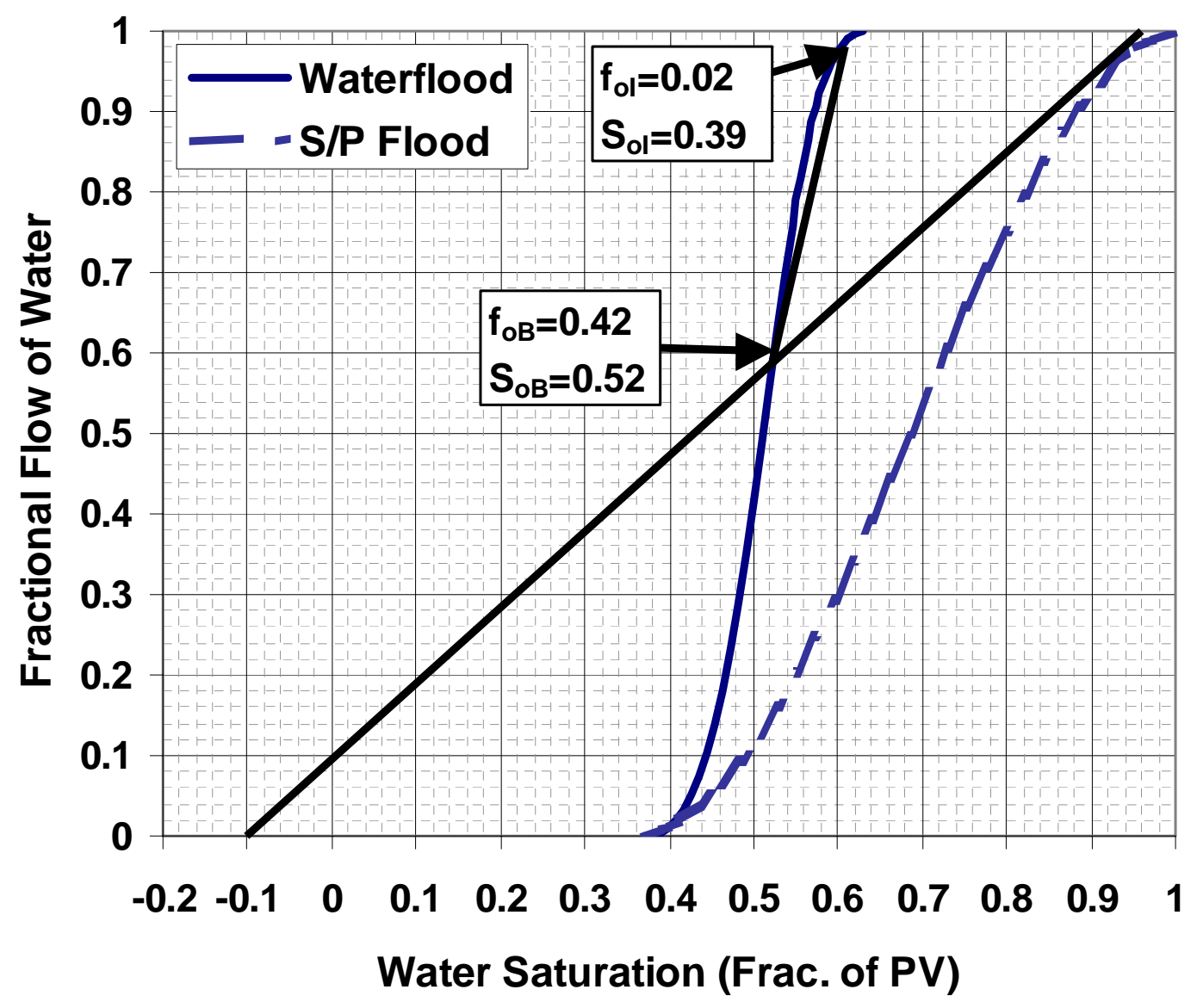

Figure 4.2.17. Hypothetical 1-D Fractional Flow Curves for Case \#1 


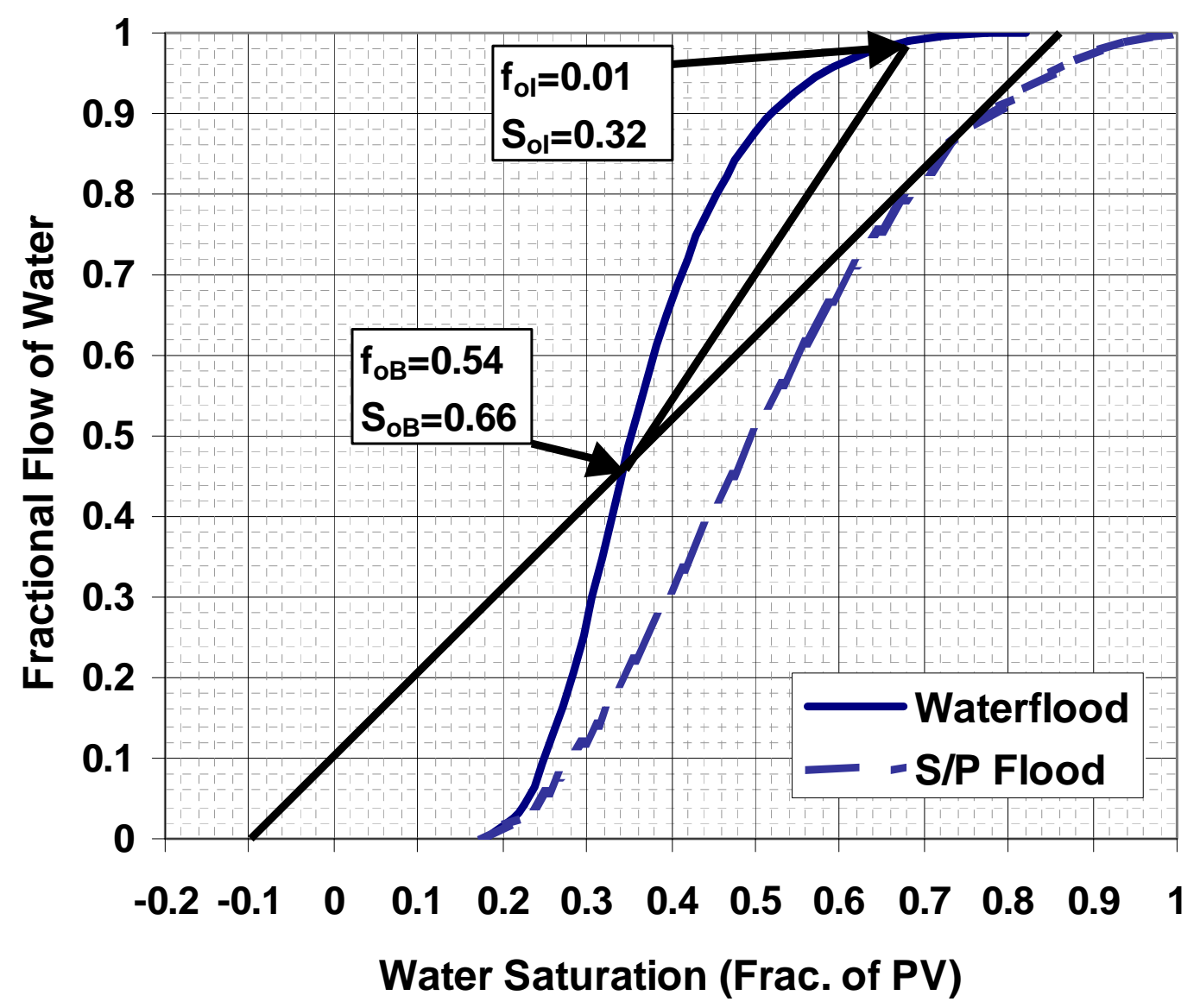

Figure 4.2.18. Hypothetical 1-D Fractional Flow Curves for Cases \#2 and \#3

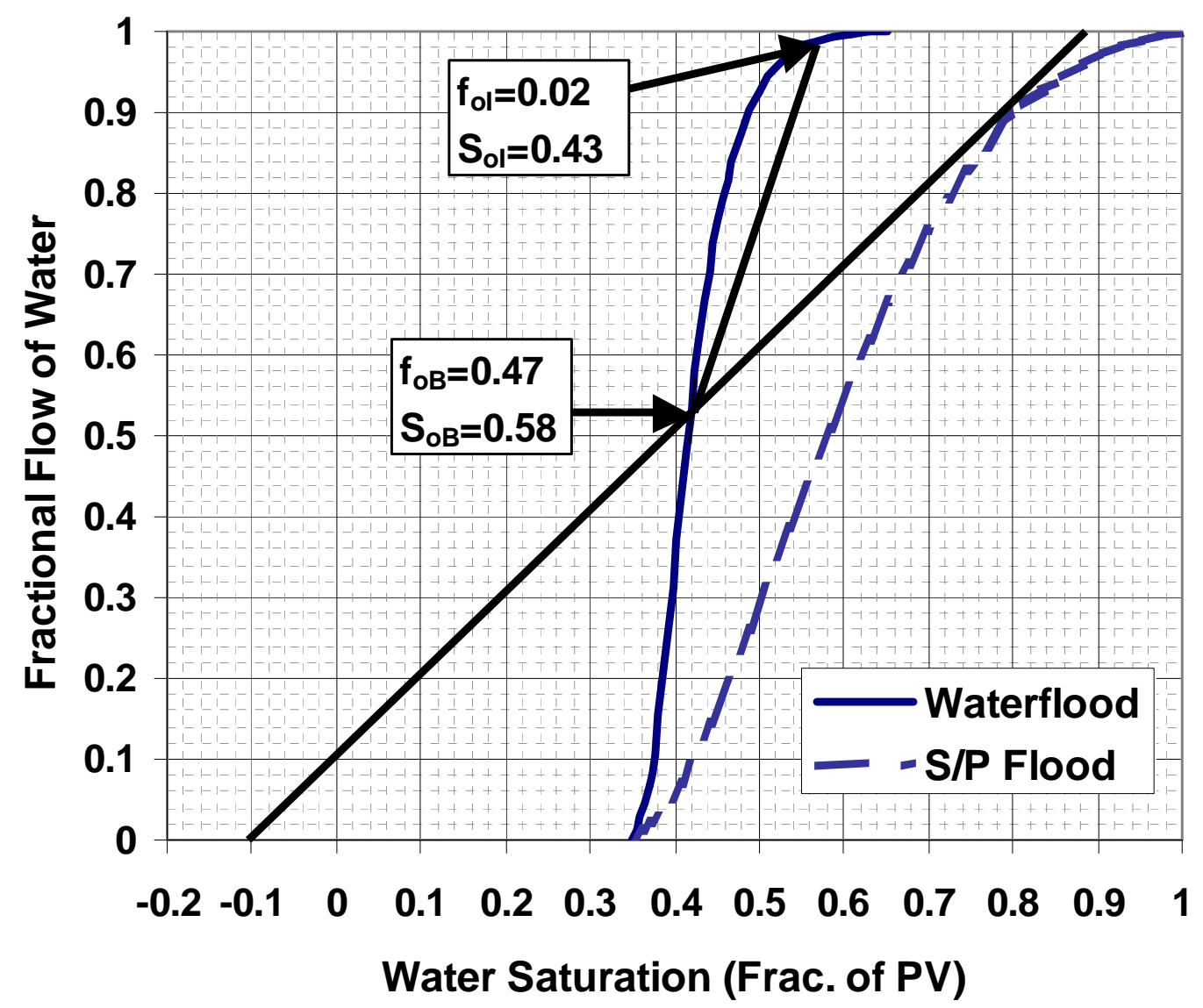

Figure 4.2.19. Hypothetical 1-D Fractional Flow Curves for Case \#4 


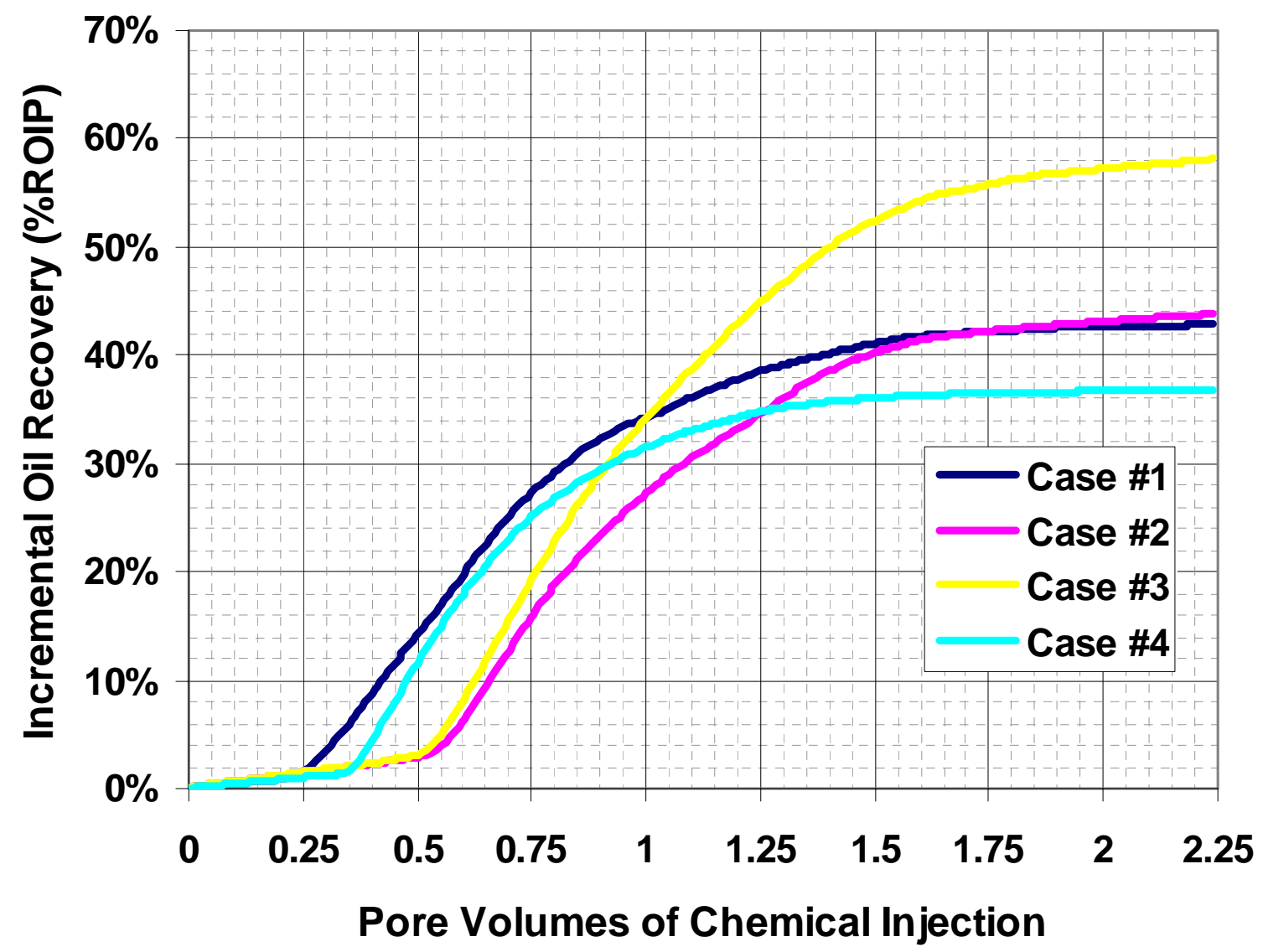

Figure 4.2.20. S/P Flood - Incremental Waterflood Oil Recovery for Each Test Simulation 


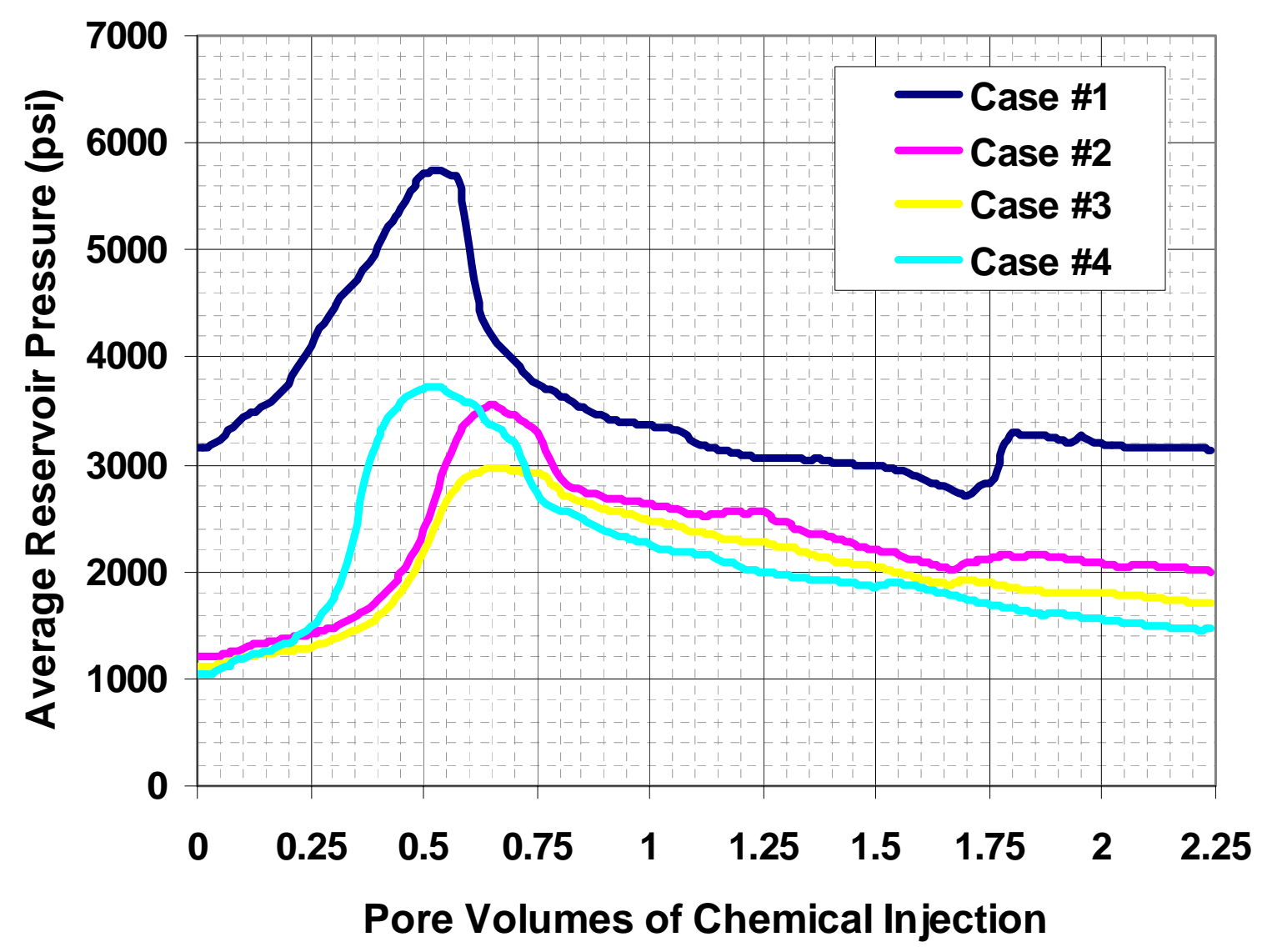

Figure 4.2.21. S/P Flood - Average Reservoir Pressure for Each Test Simulation

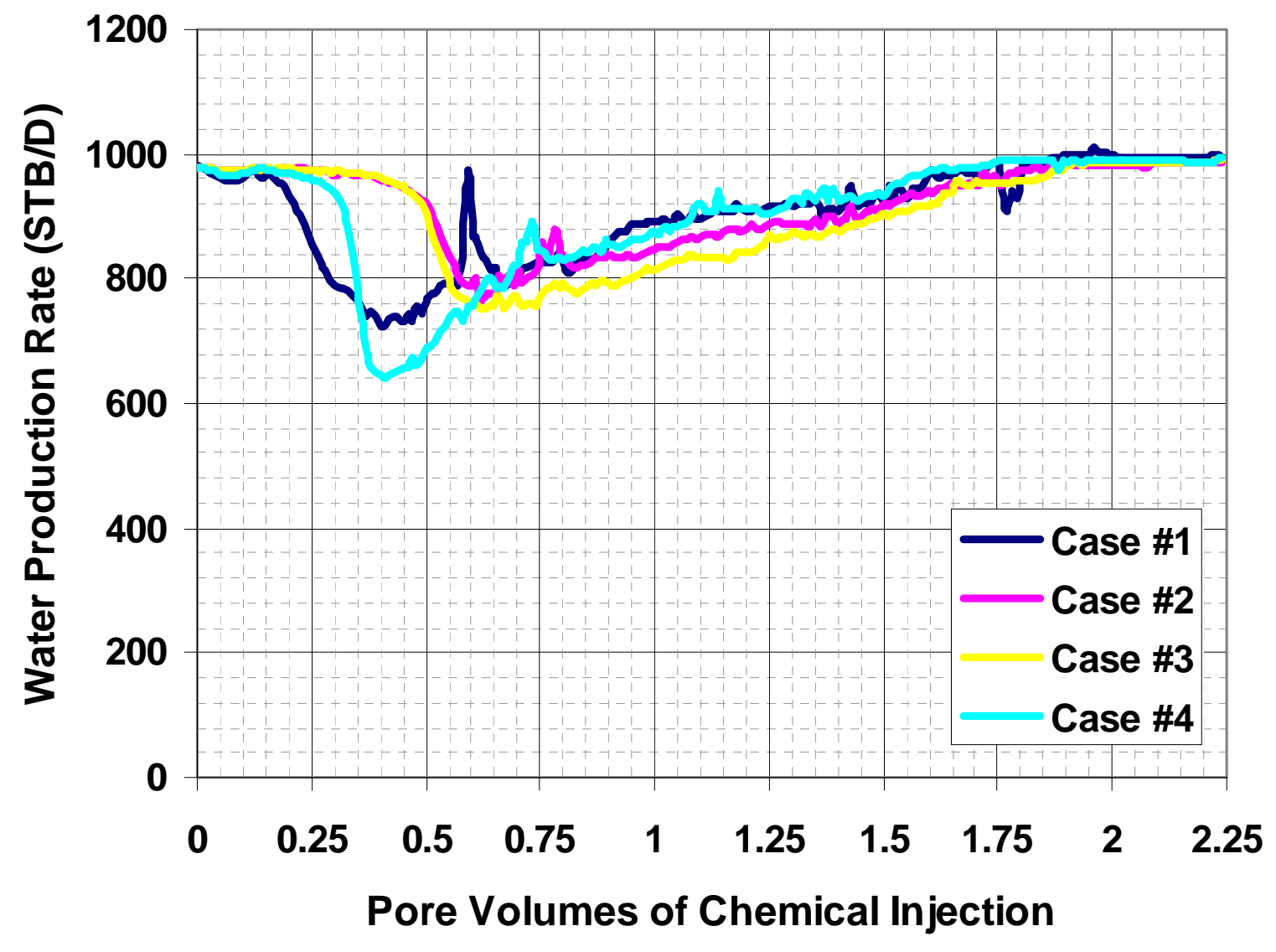

Figure 4.2.22. S/P Flood - Water Production Rate for Each Test Simulation 


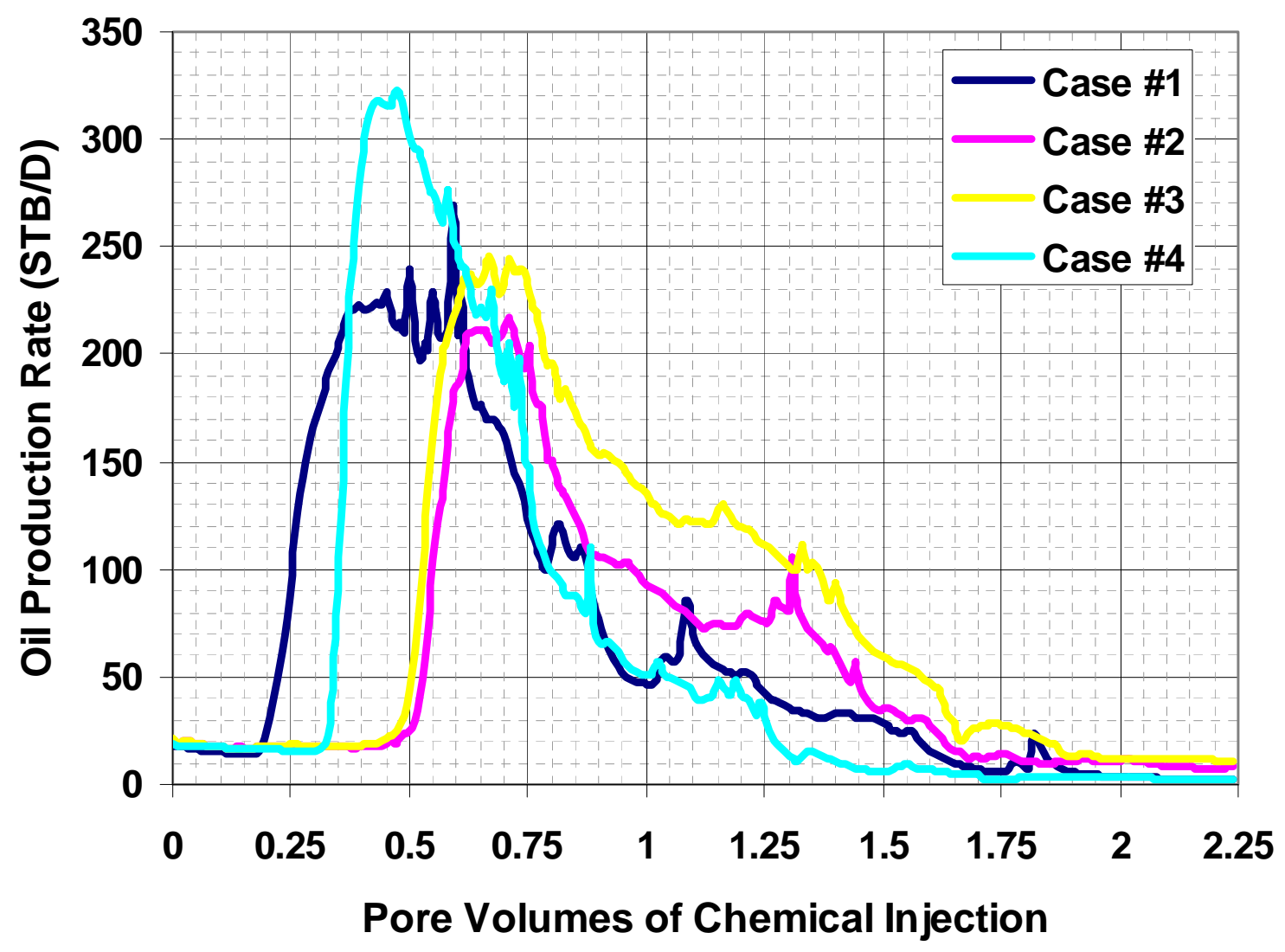

Figure 4.2.23. S/P Flood - Oil Production Rate for Each Test Simulation 


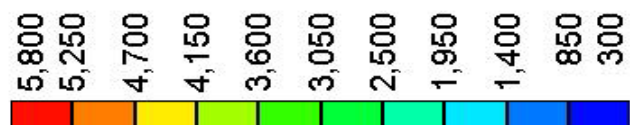

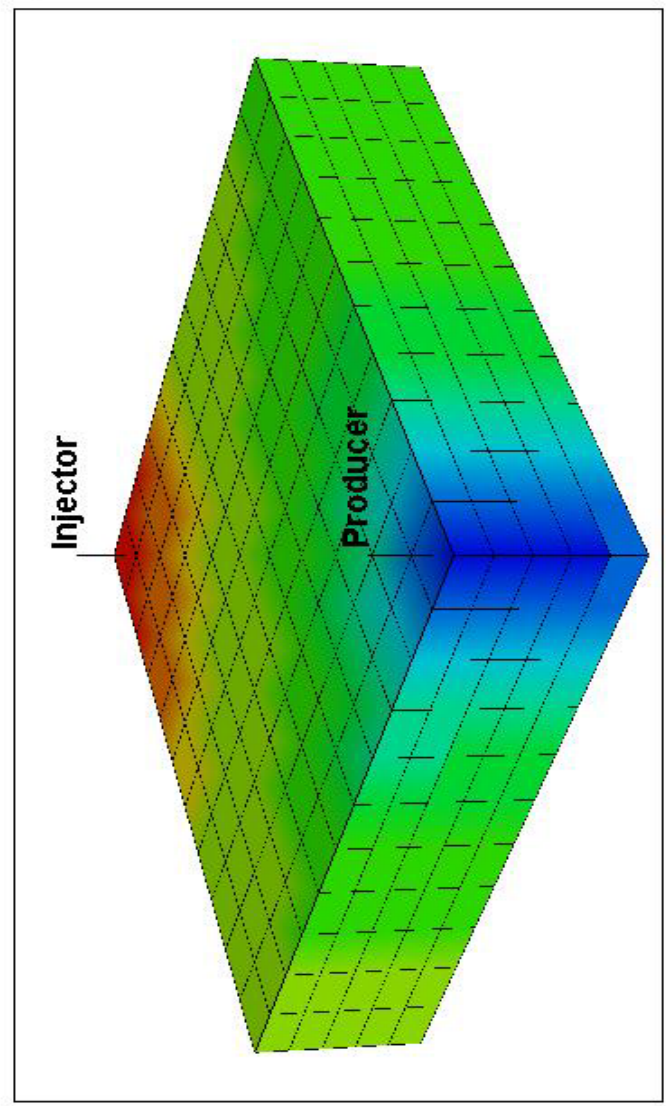

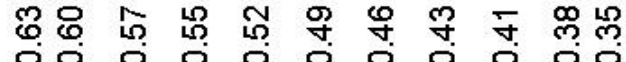

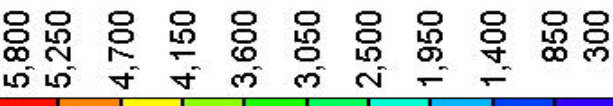
\begin{tabular}{l|l|l|l|l|l|l|l|l|}
\hline & & & & & & & & \\
\hline
\end{tabular}

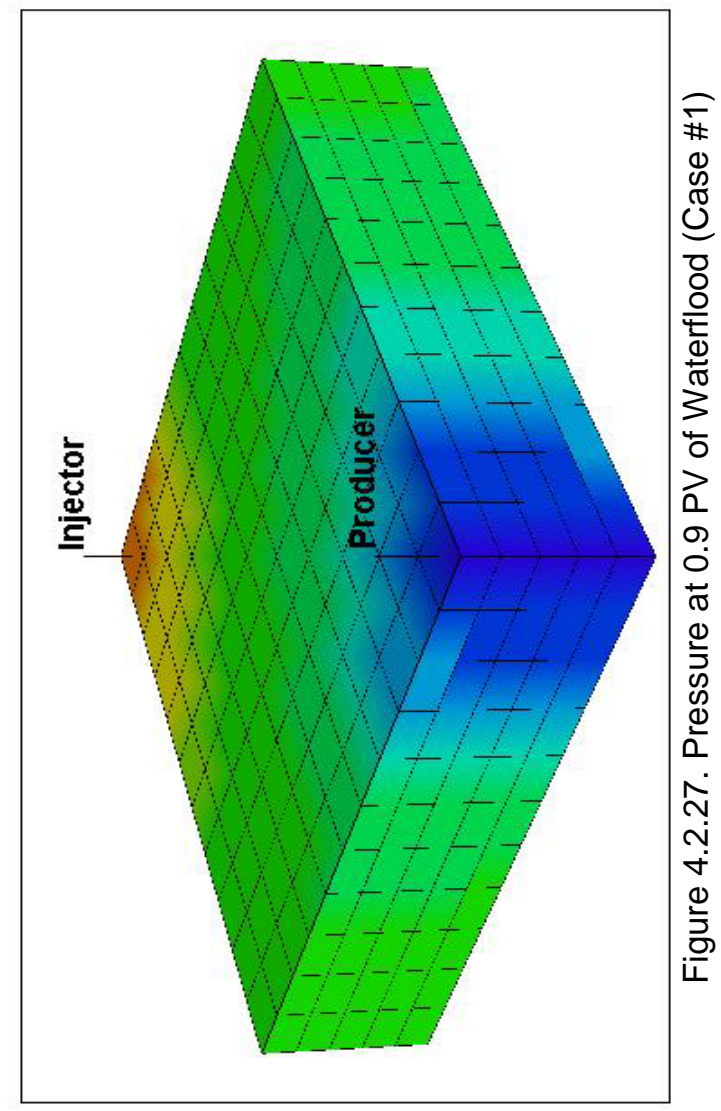

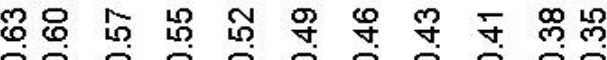
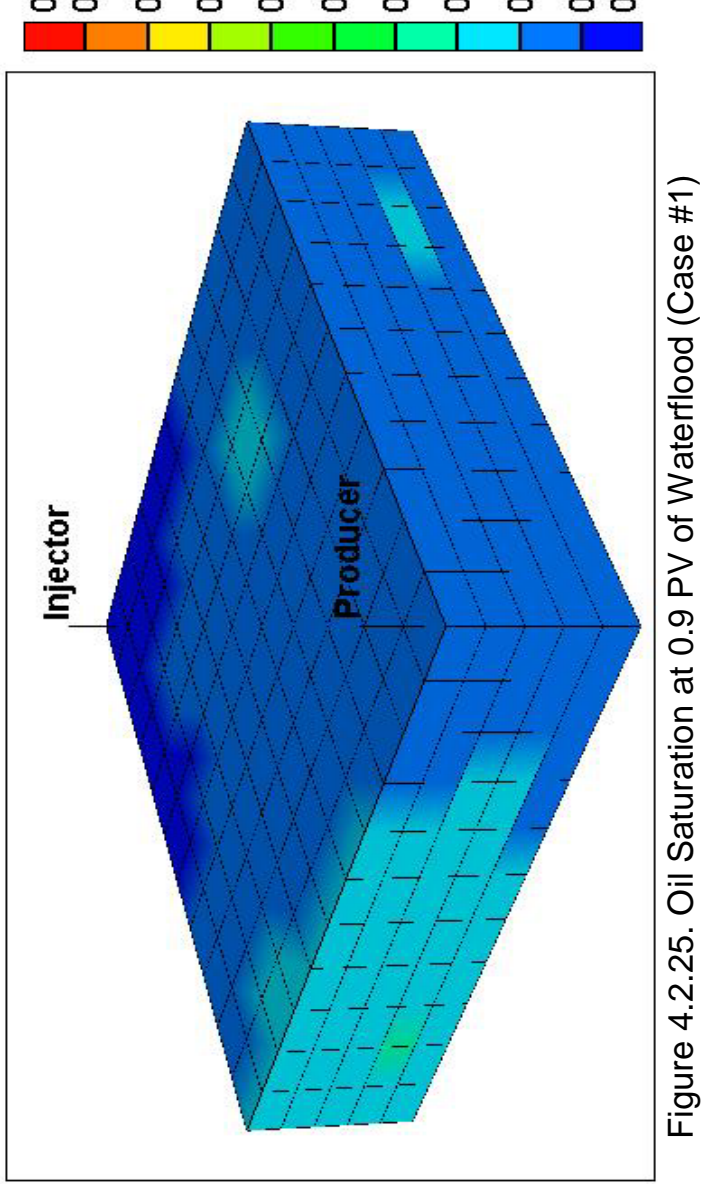

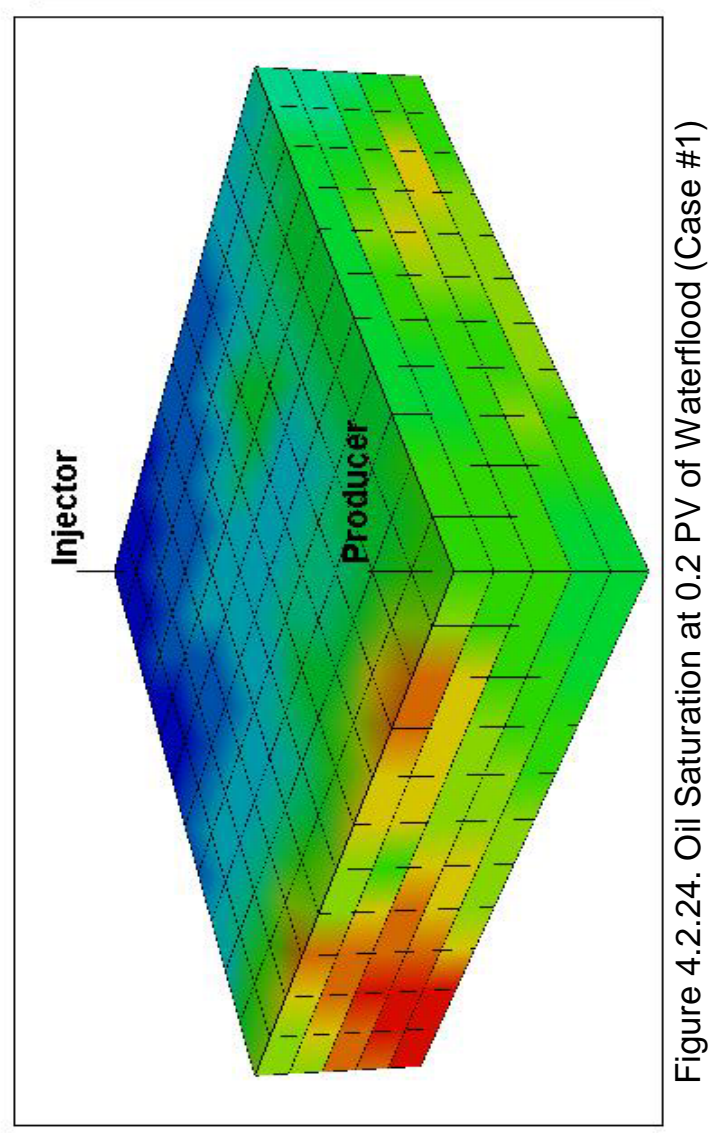




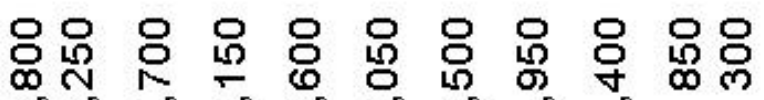
म

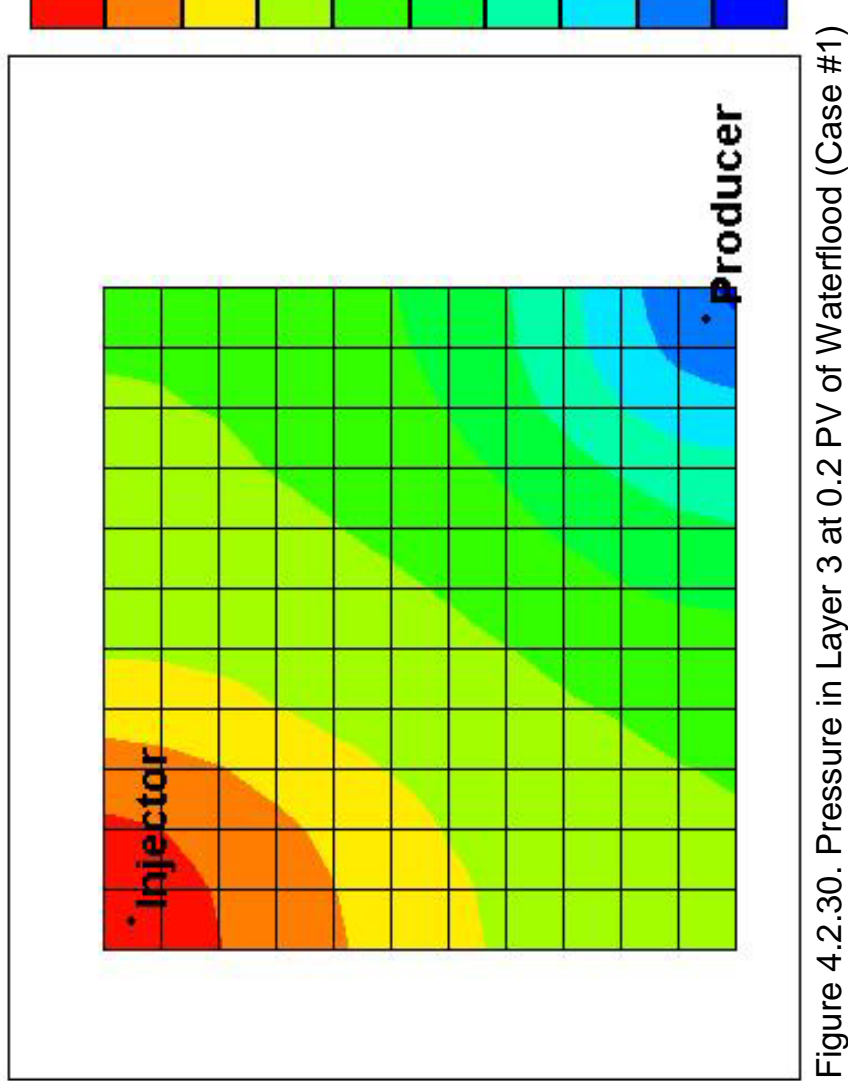

ल

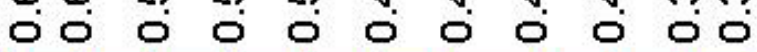

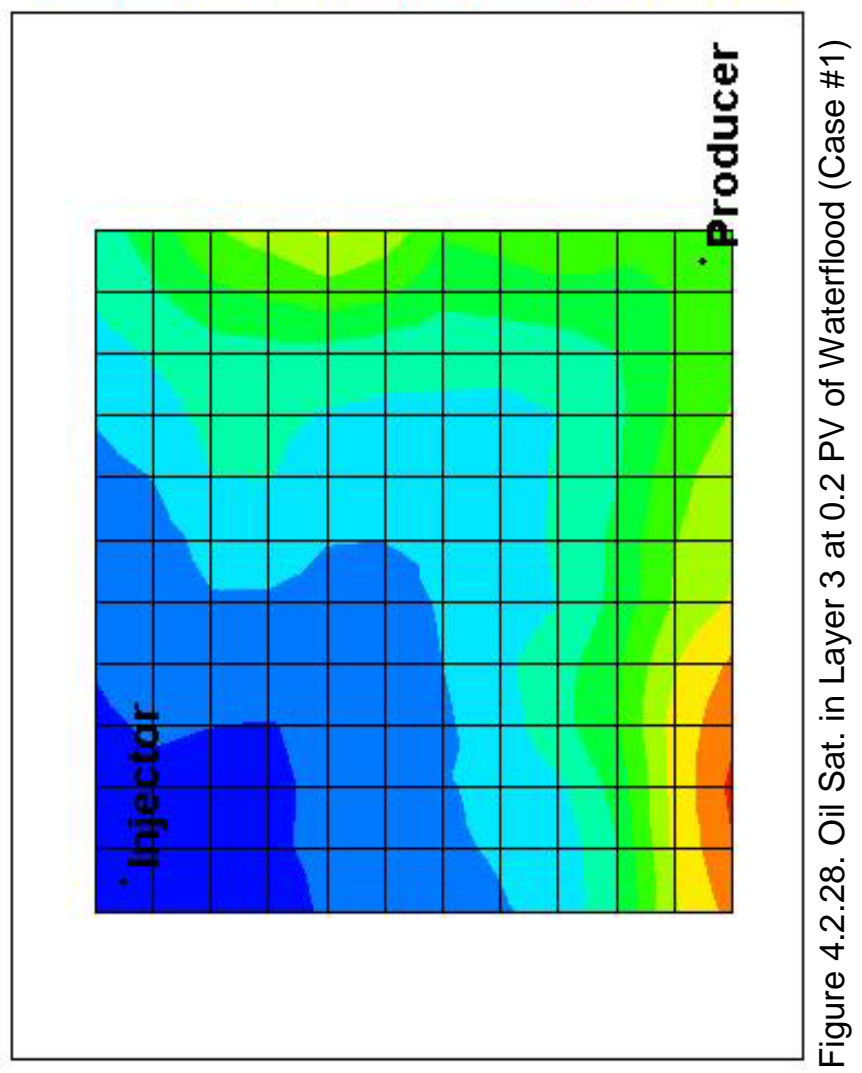

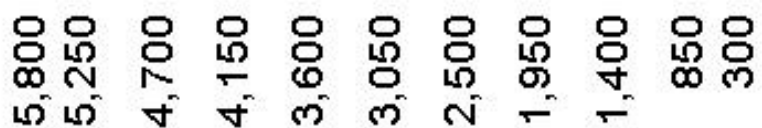

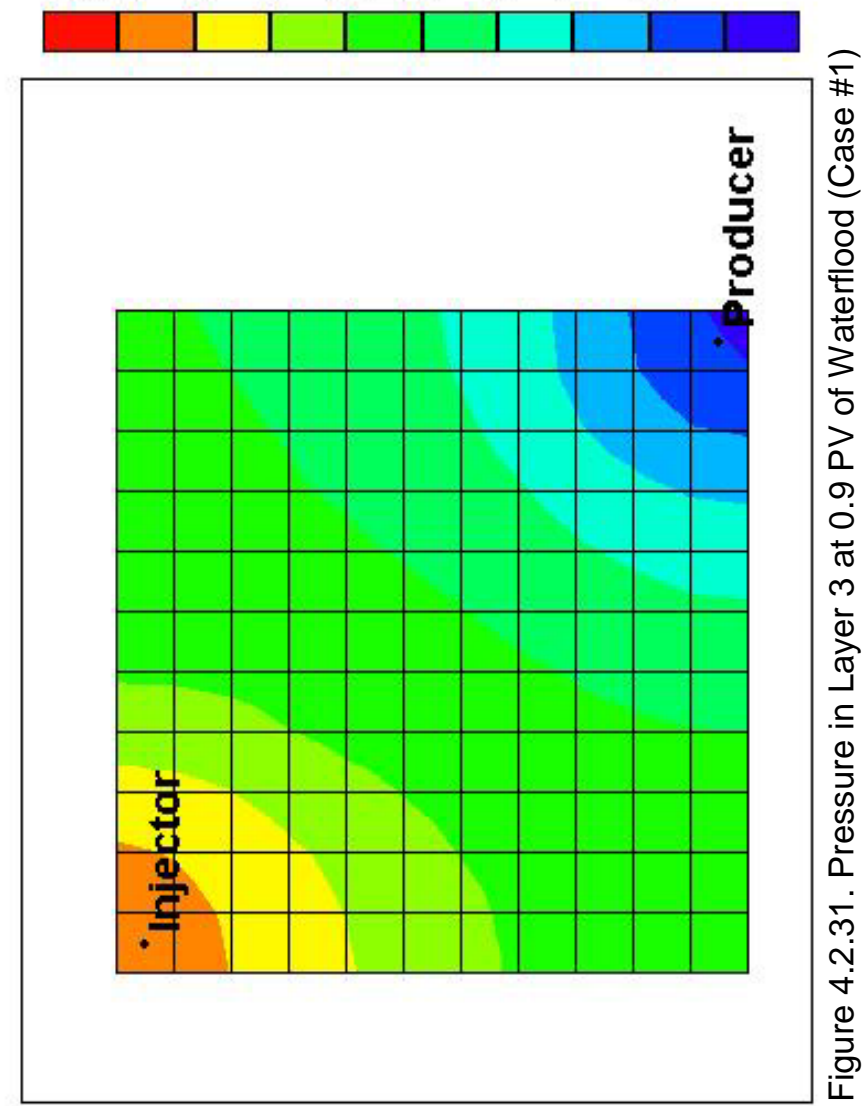

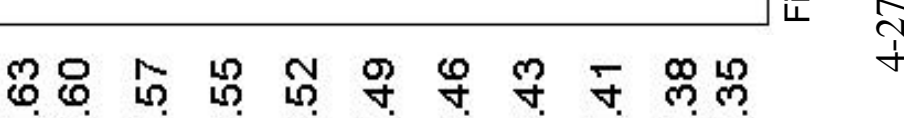
응으응ㅇㅇㅇㅇㅇㅇㅇㅇㅇ응

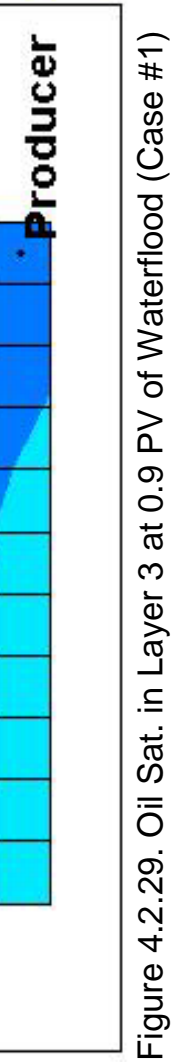




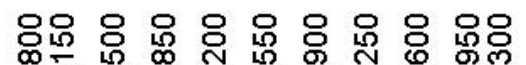

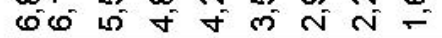

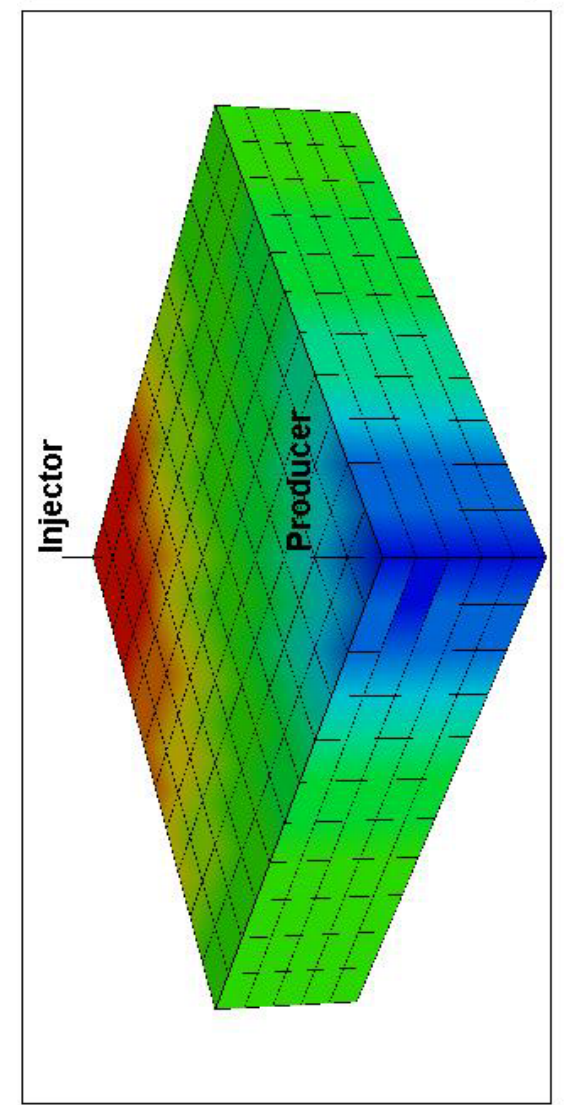

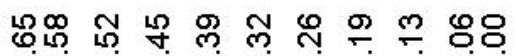
io 0 o 0 o o o o

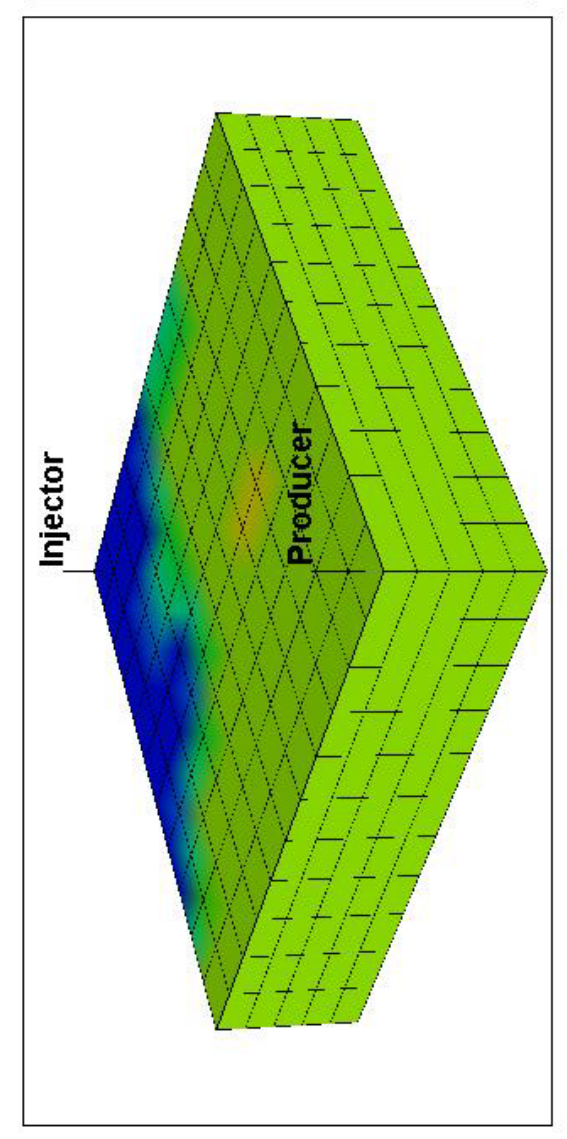

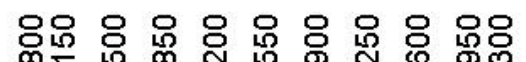

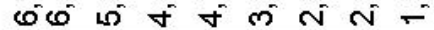

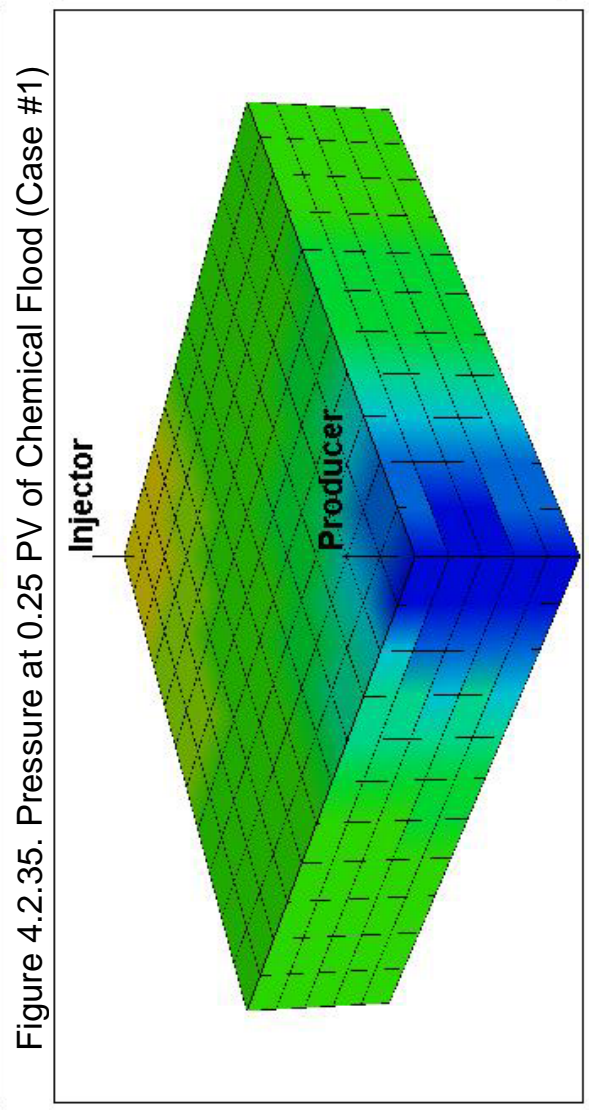

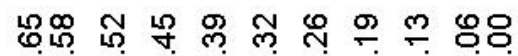

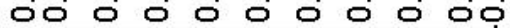

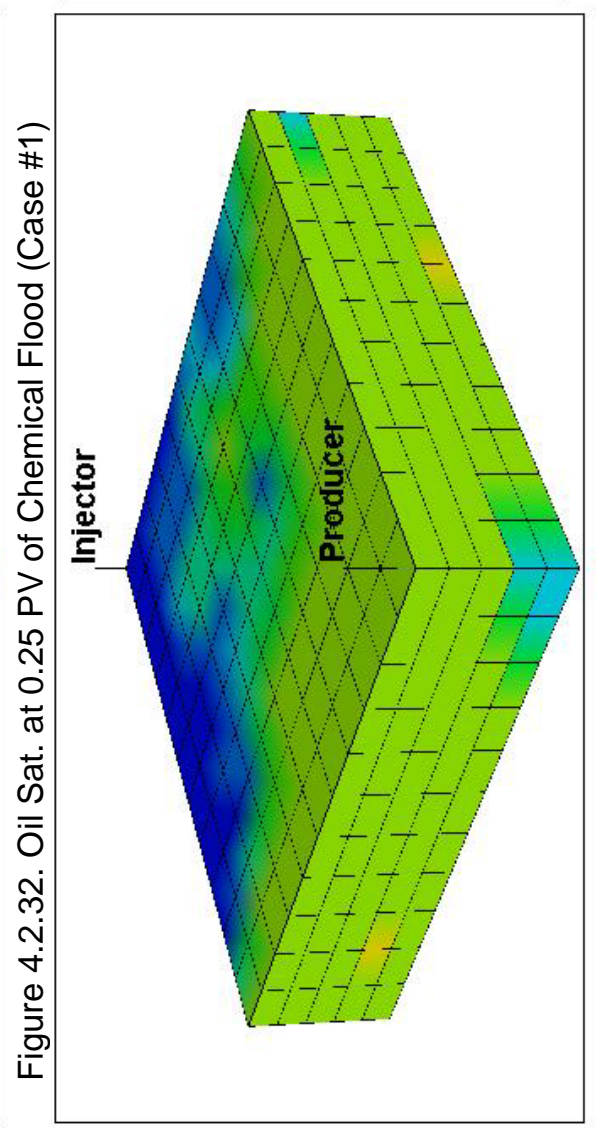

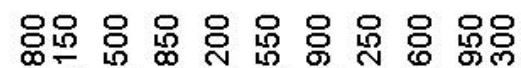
का मी वे वं ले ते -

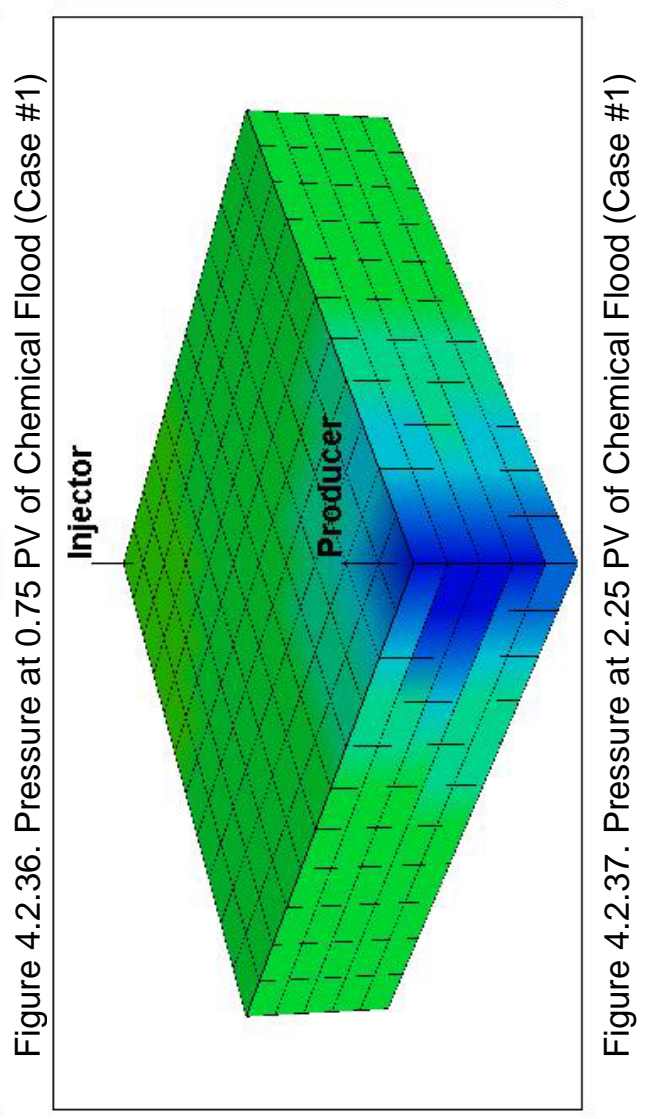

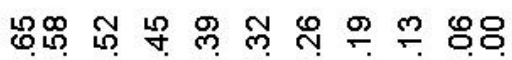
o 0 o 0 o 0000

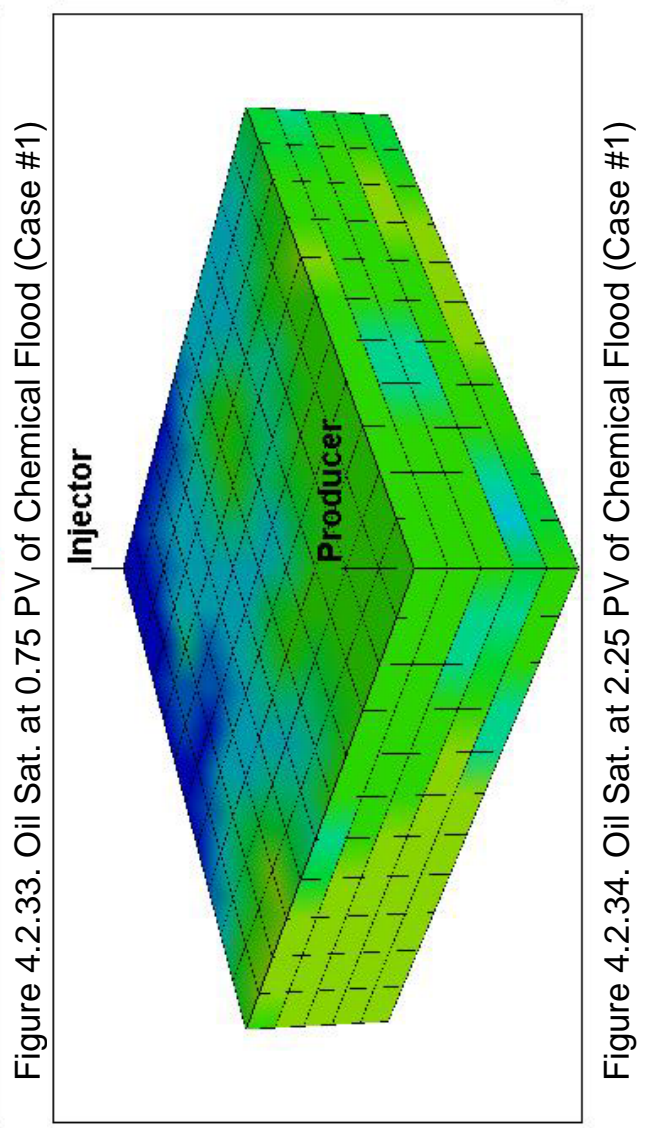




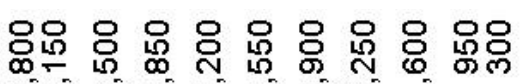
का मा +
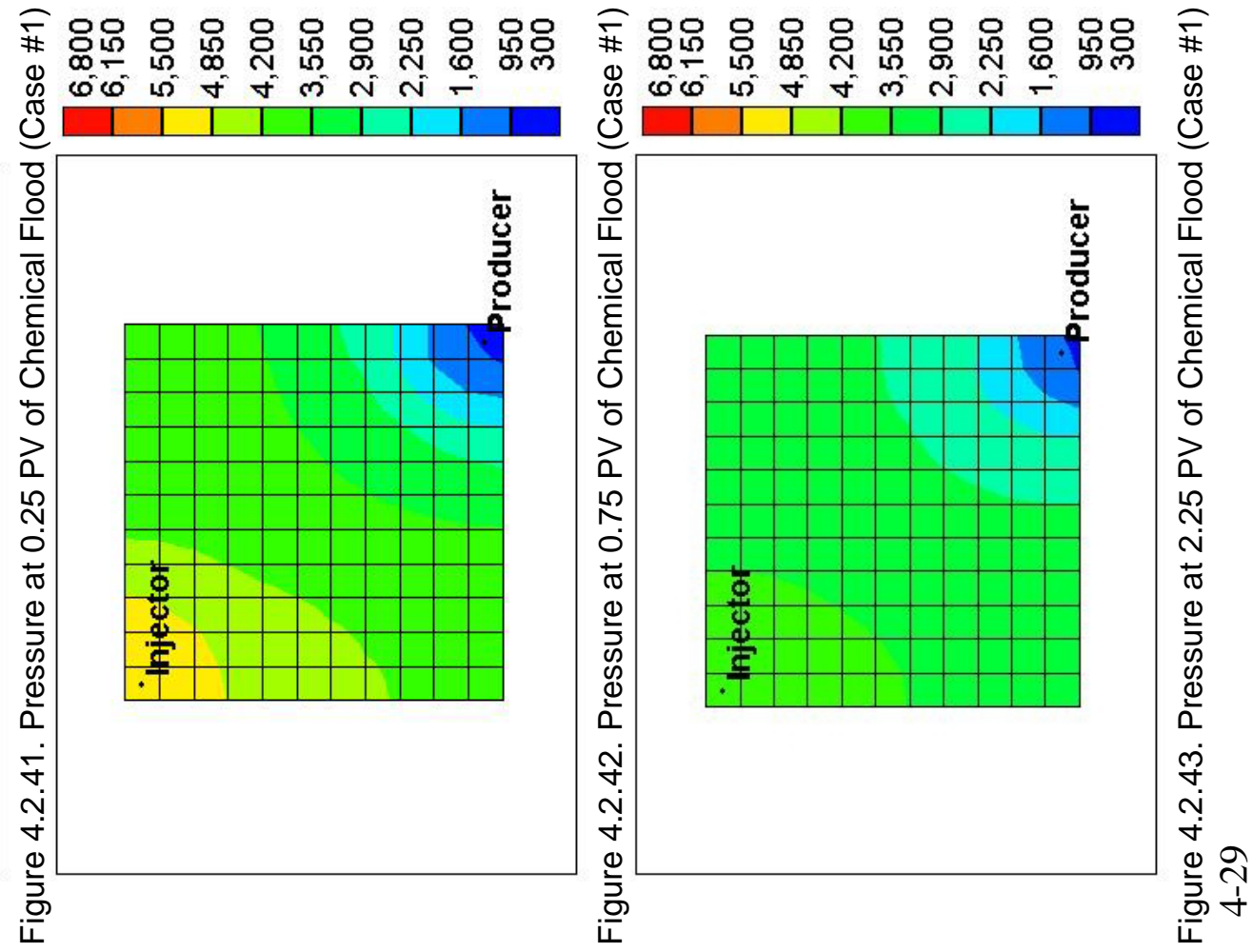

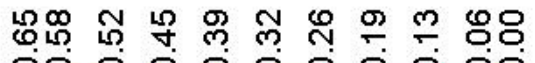
00000000000
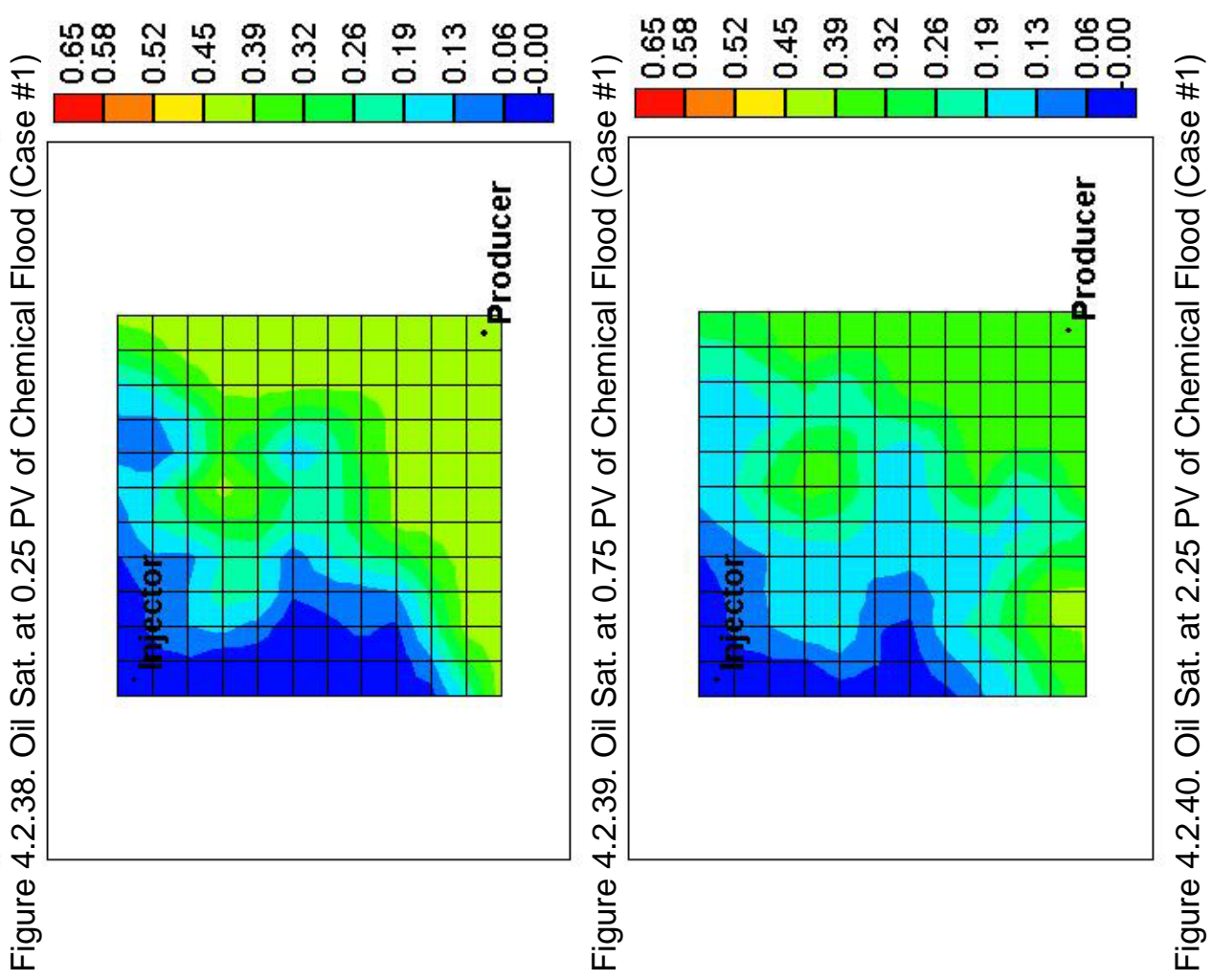


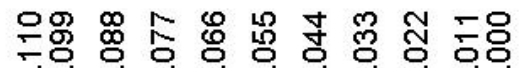
ะดำ

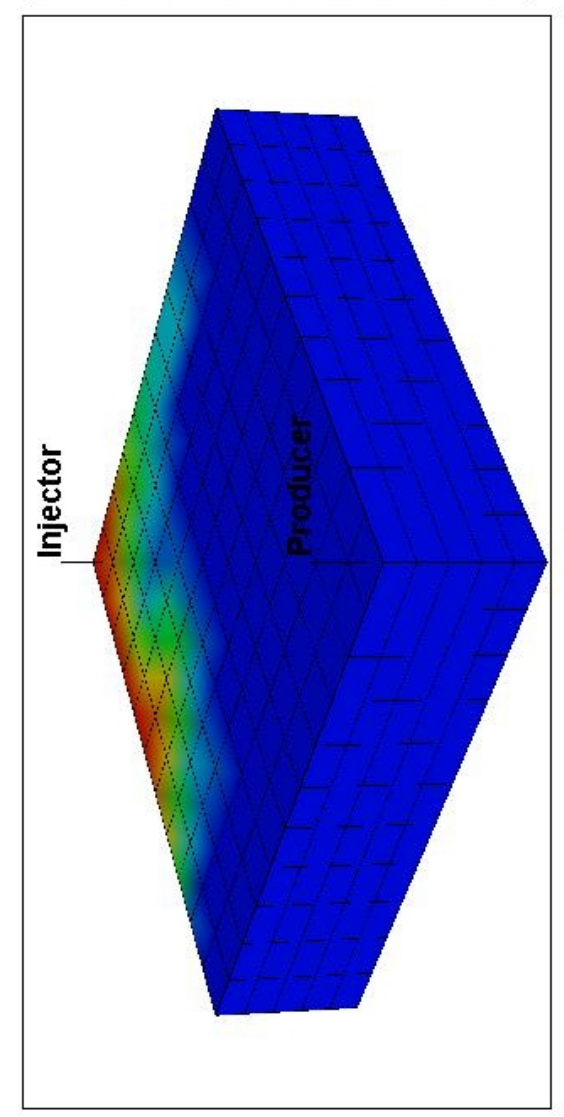

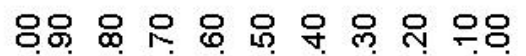
-o 0 i o o o o o

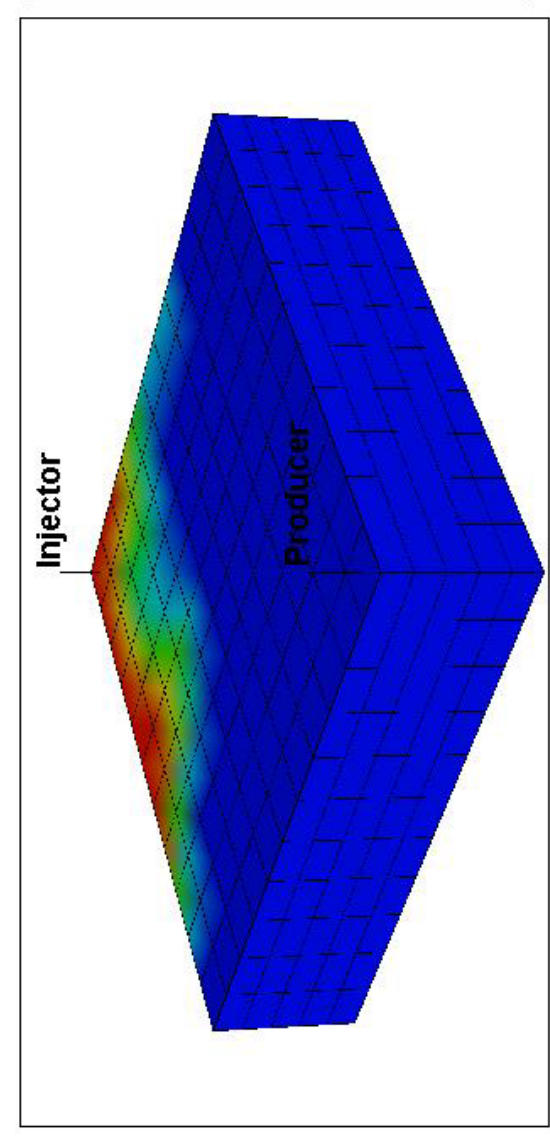

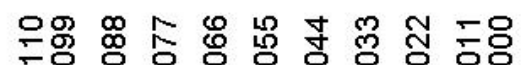
。ำ

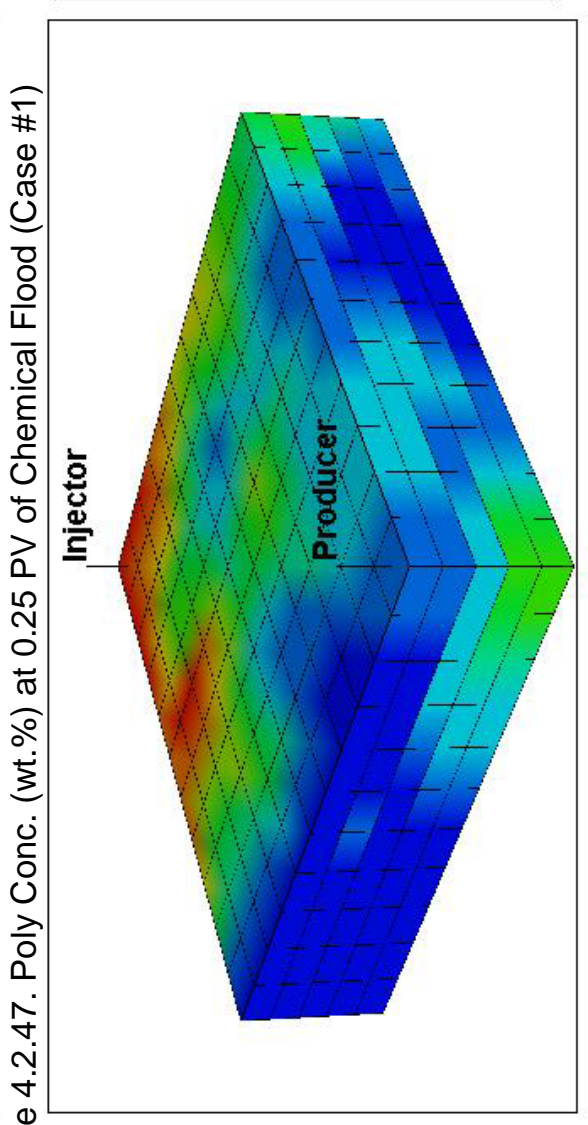

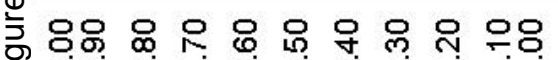
프

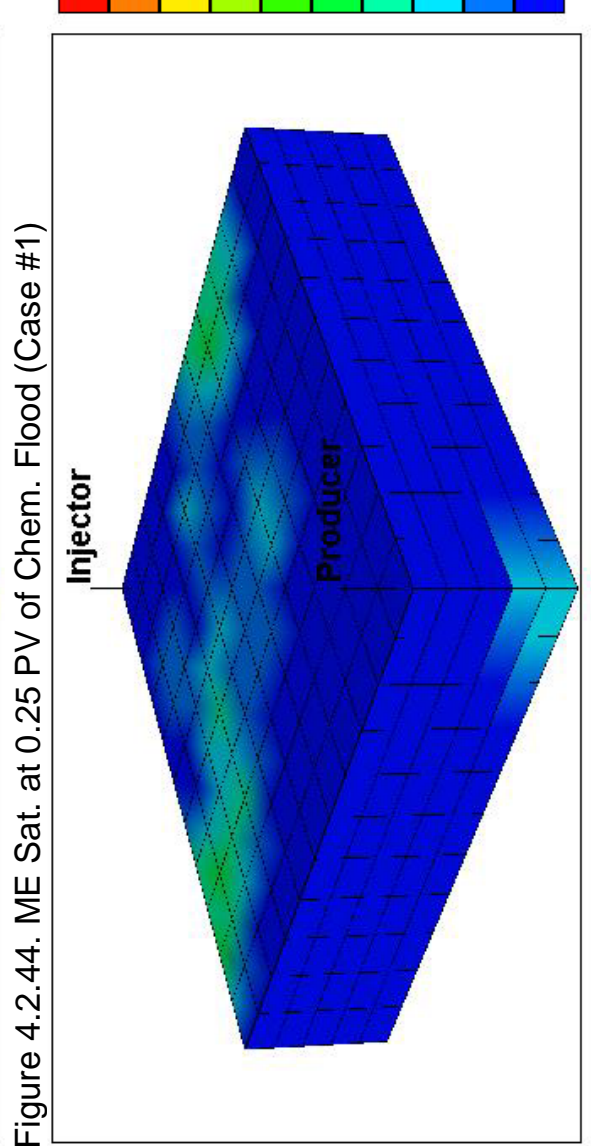

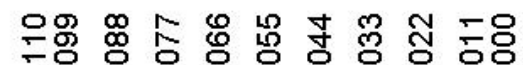

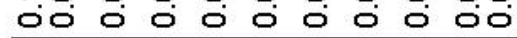

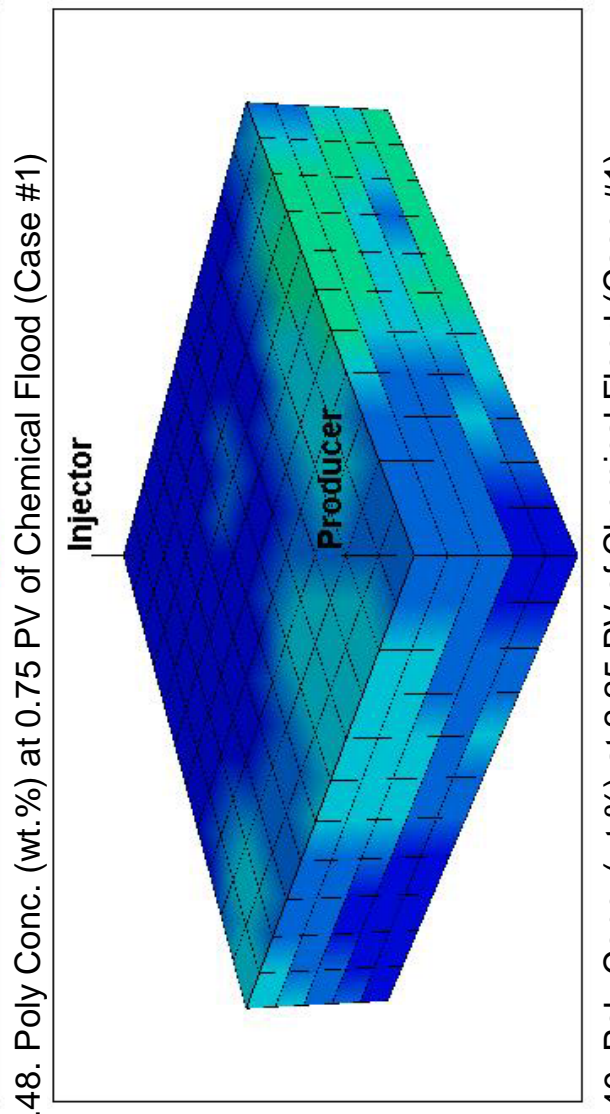

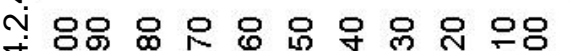

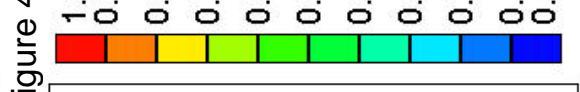

흔

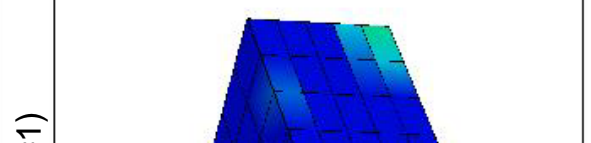




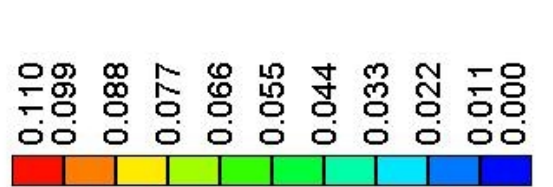

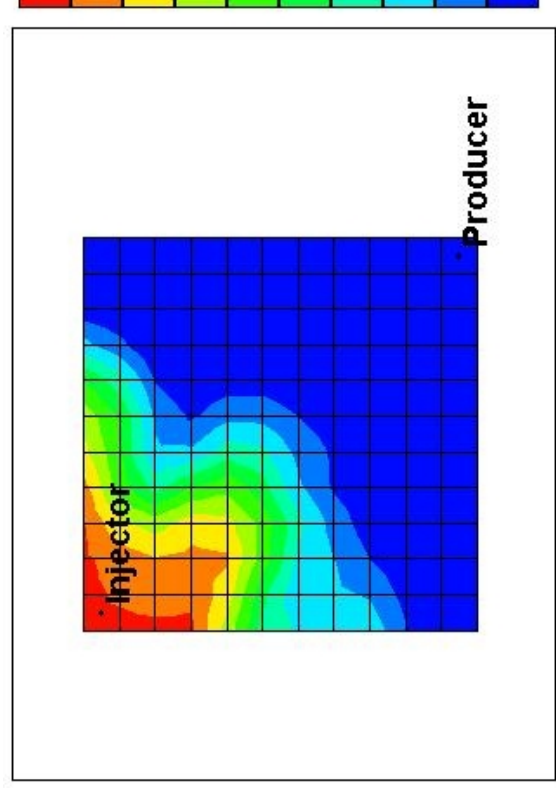

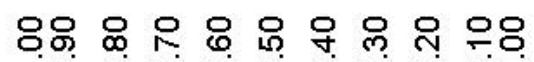
-0。0

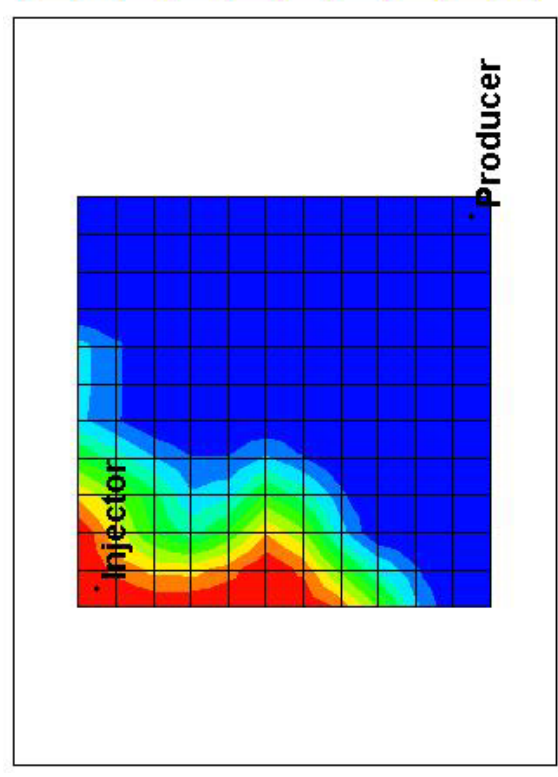

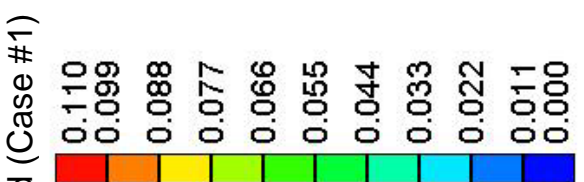

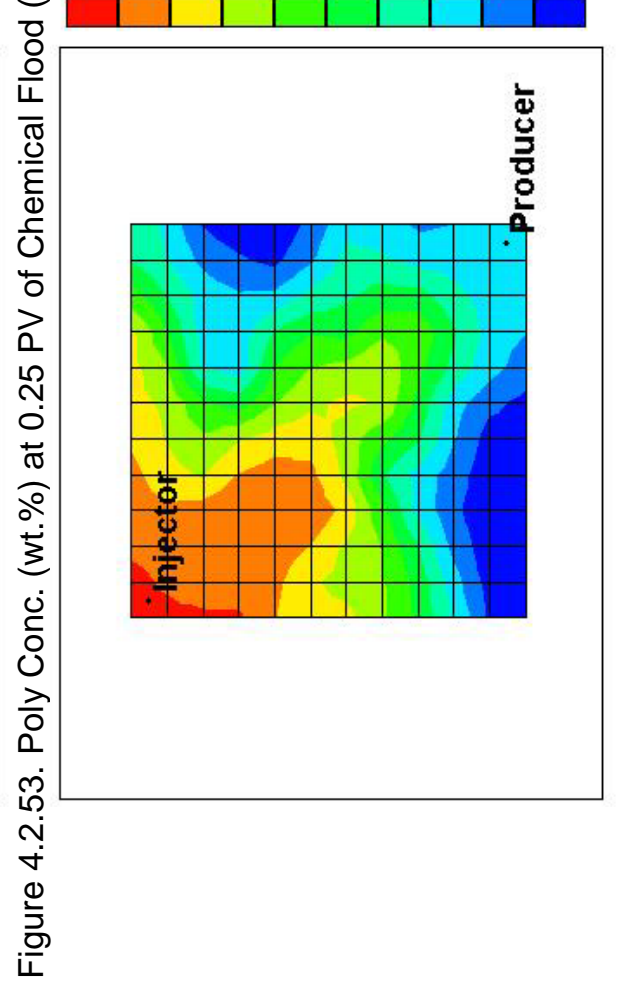

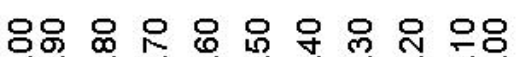
-0 0
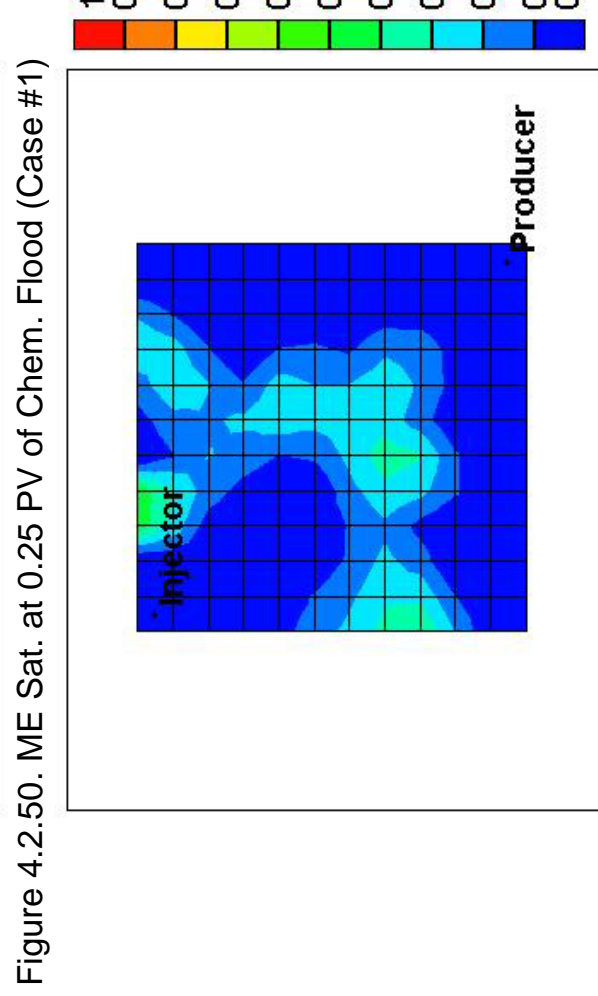

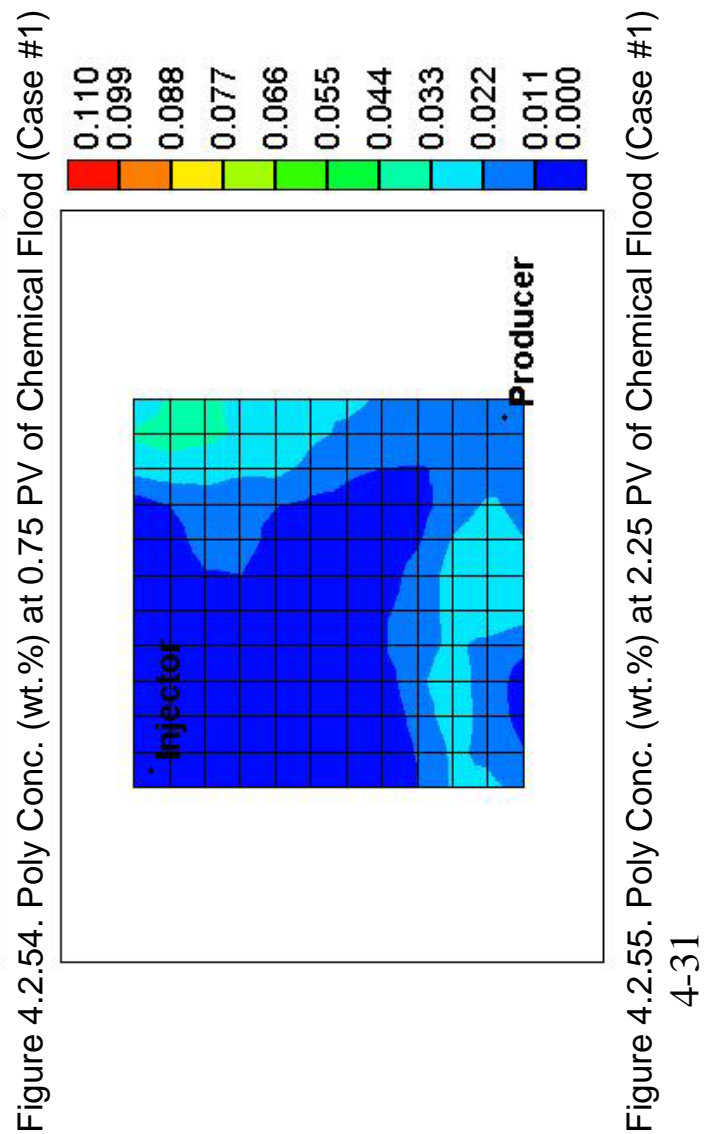

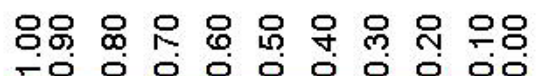
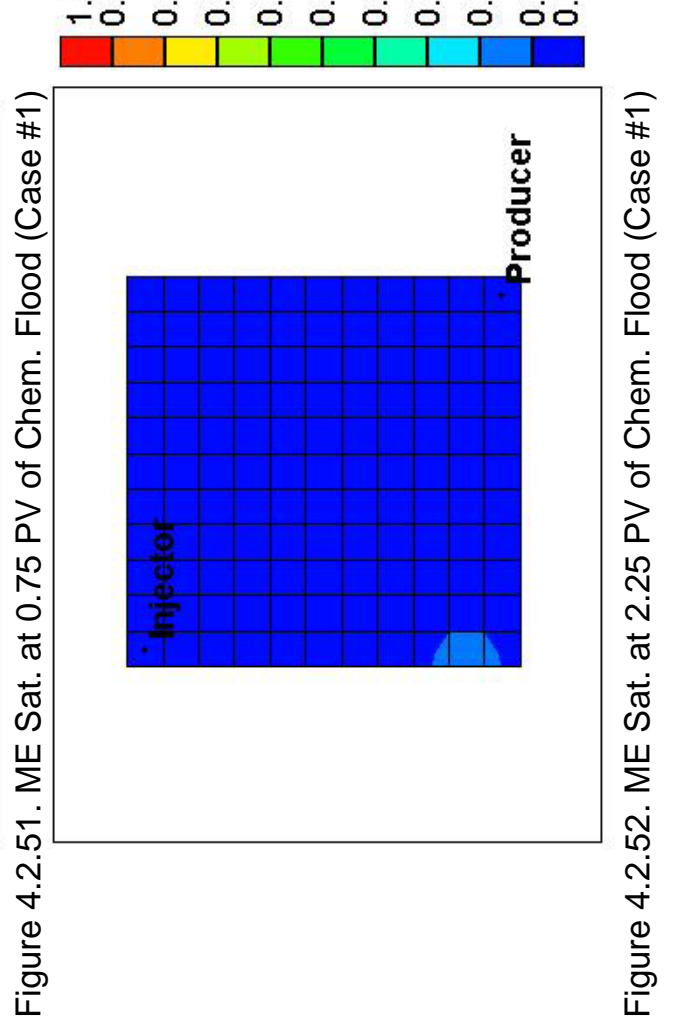


\section{ஈீ}
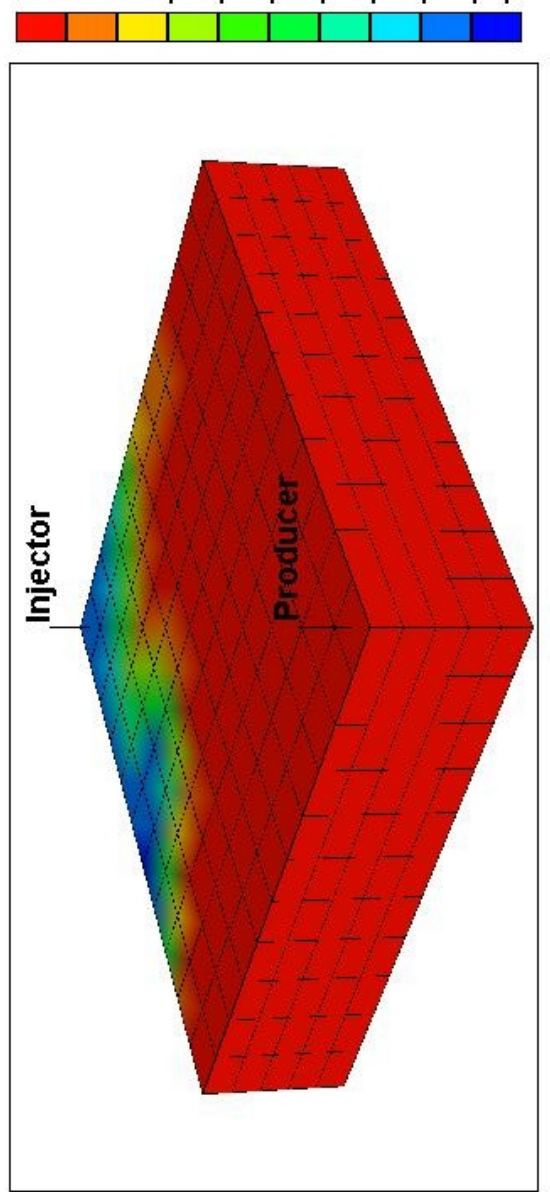

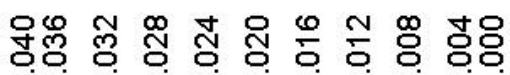

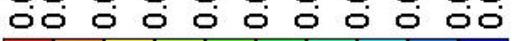

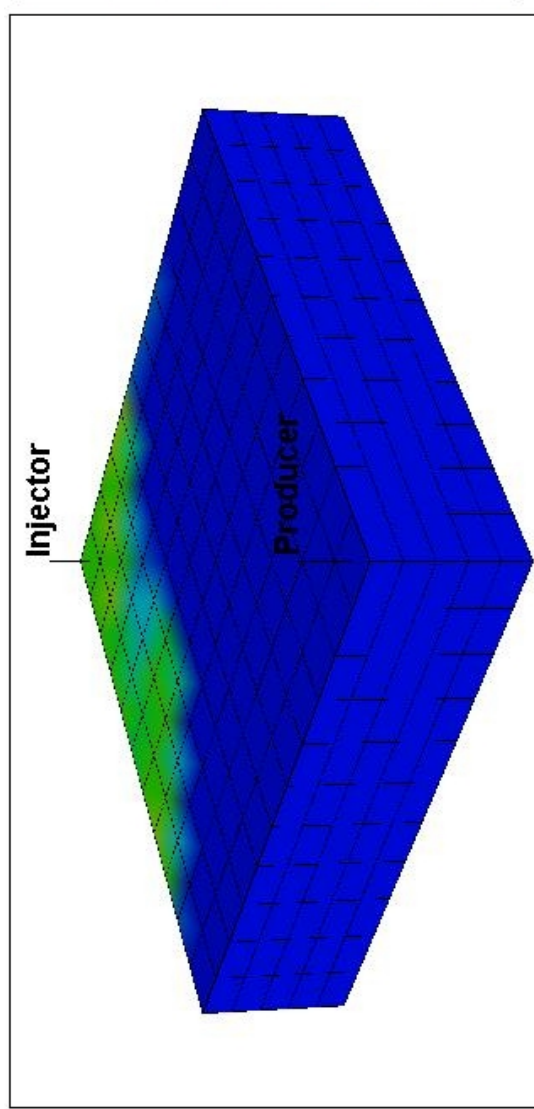

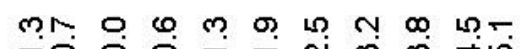

- 0 0

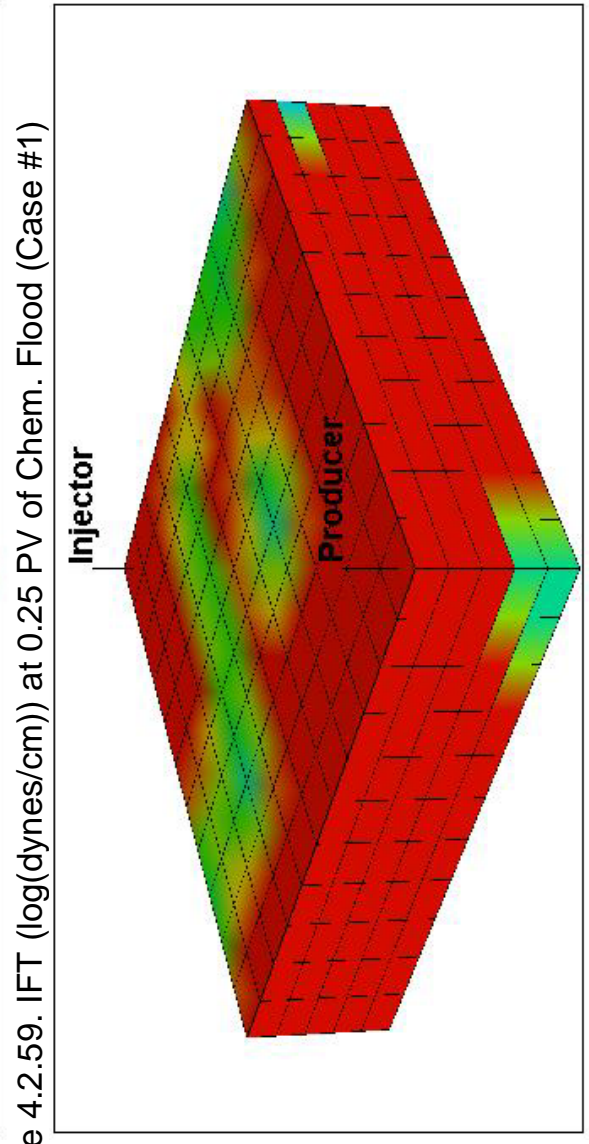

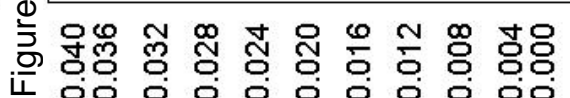
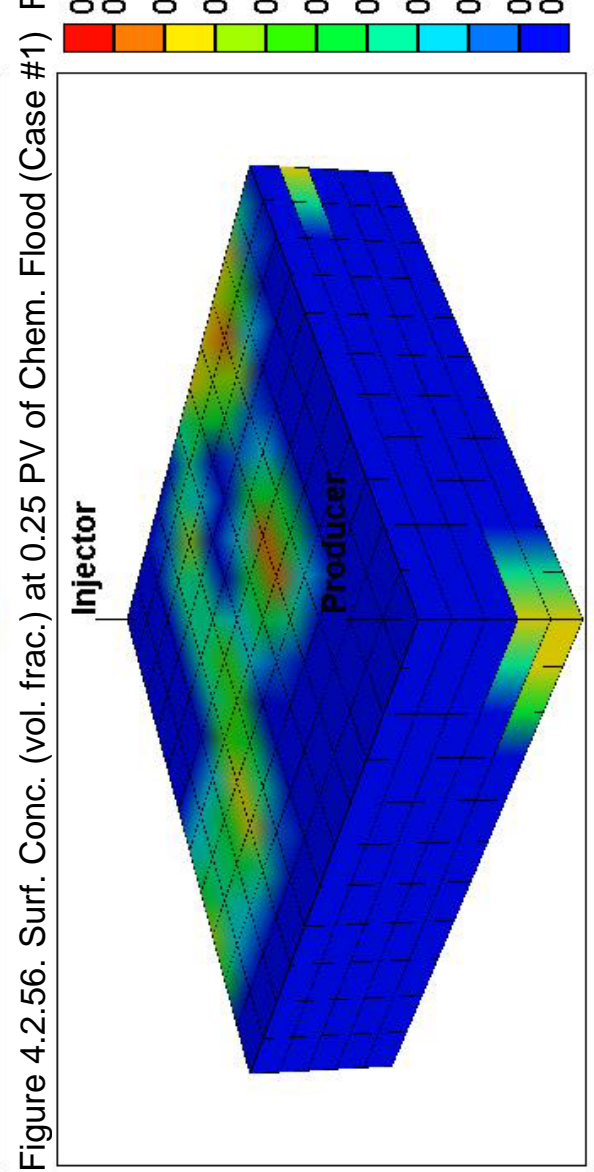

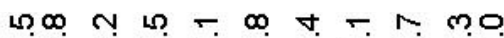

-0 ○

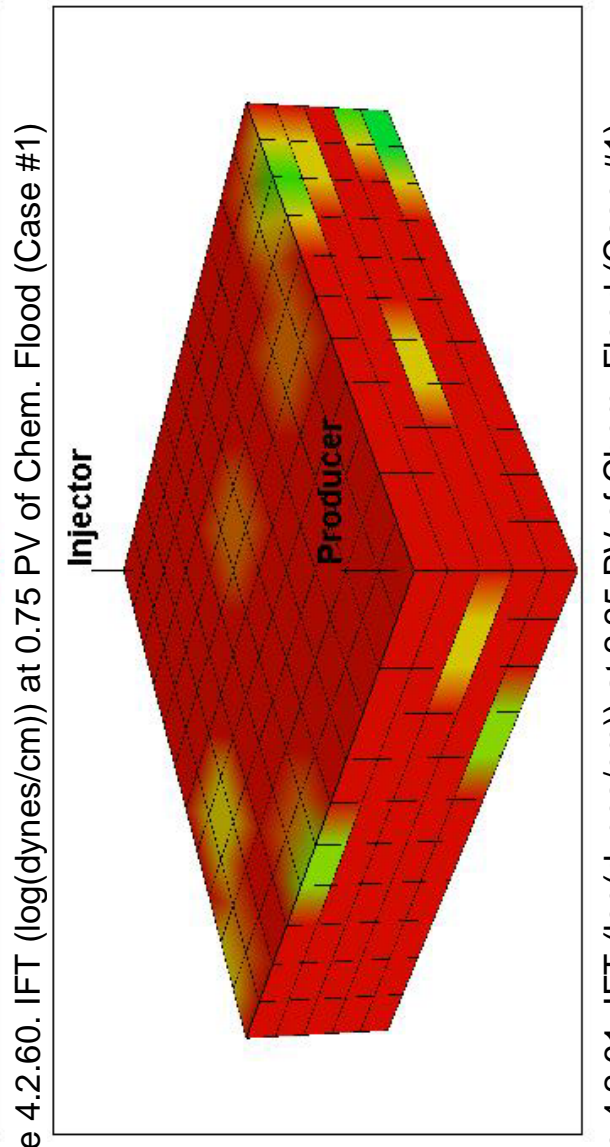

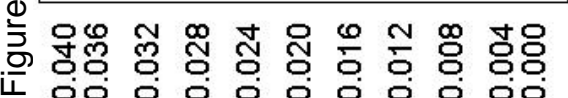
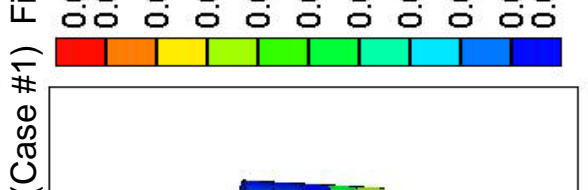


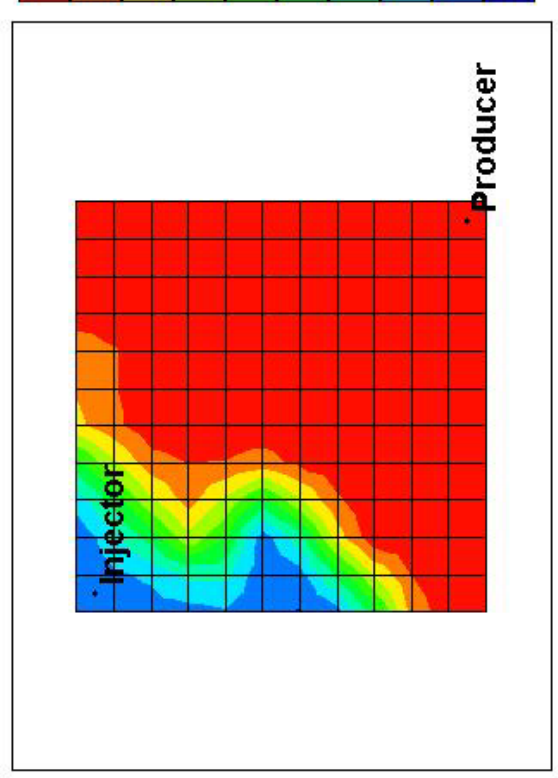

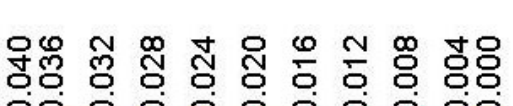
00 o o o o o o o

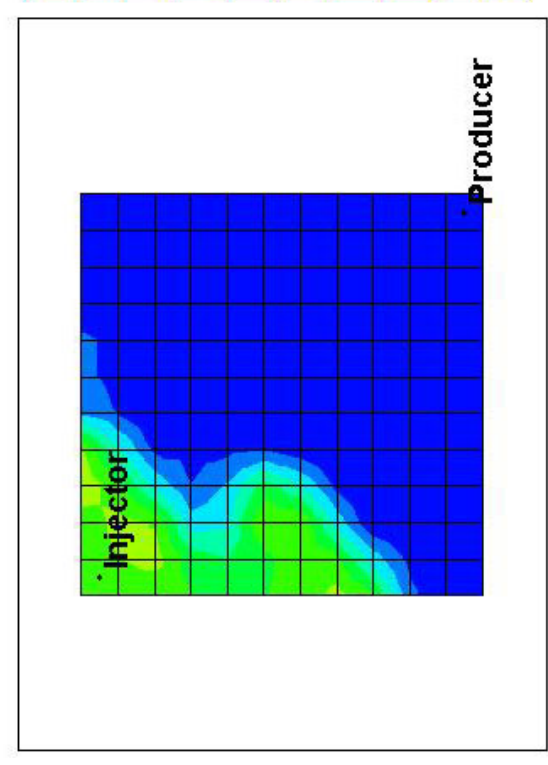

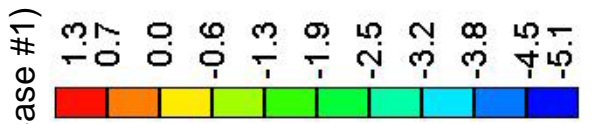

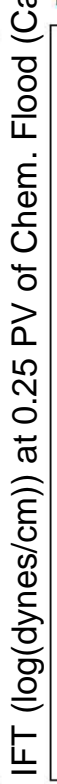

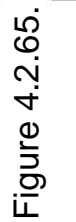

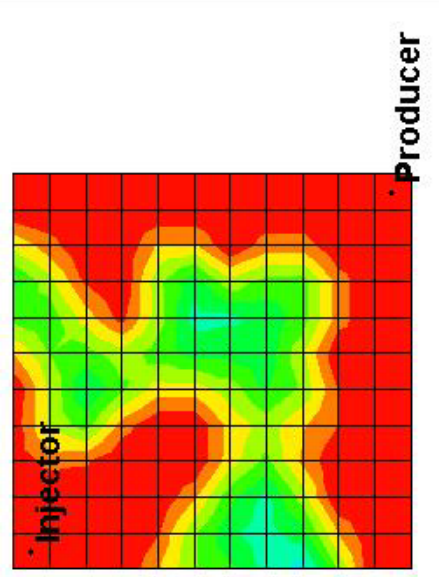

䆑

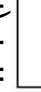

\#

承
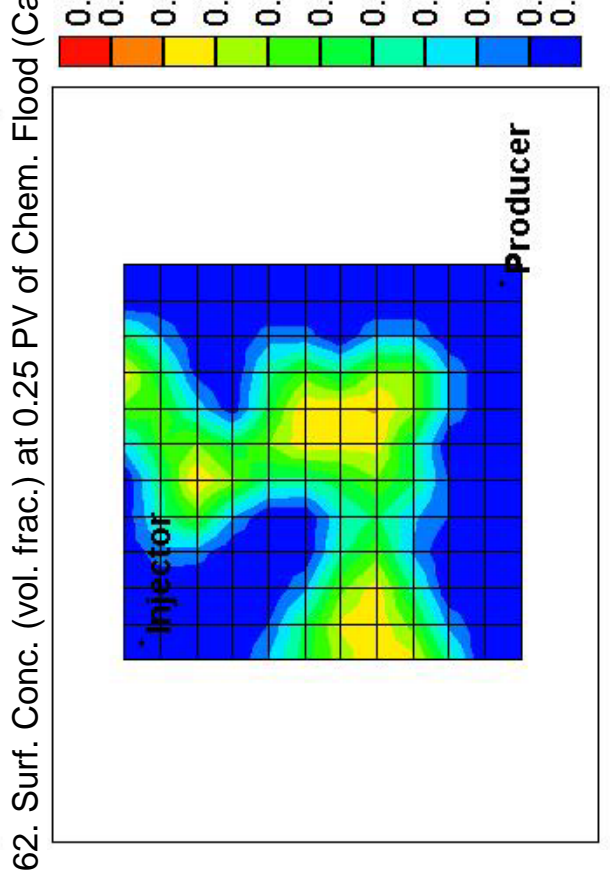

\#

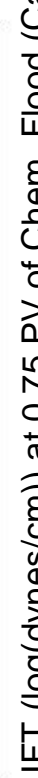

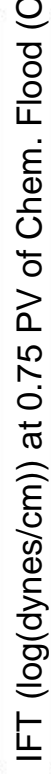

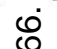

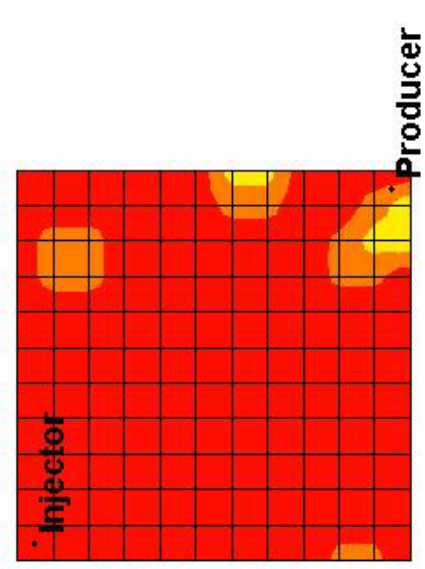

$\stackrel{\text { i }}{\stackrel{9}{+}}$

产

m

F

푼

\#

윤

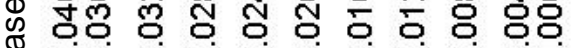

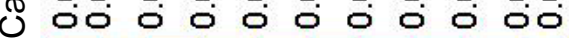

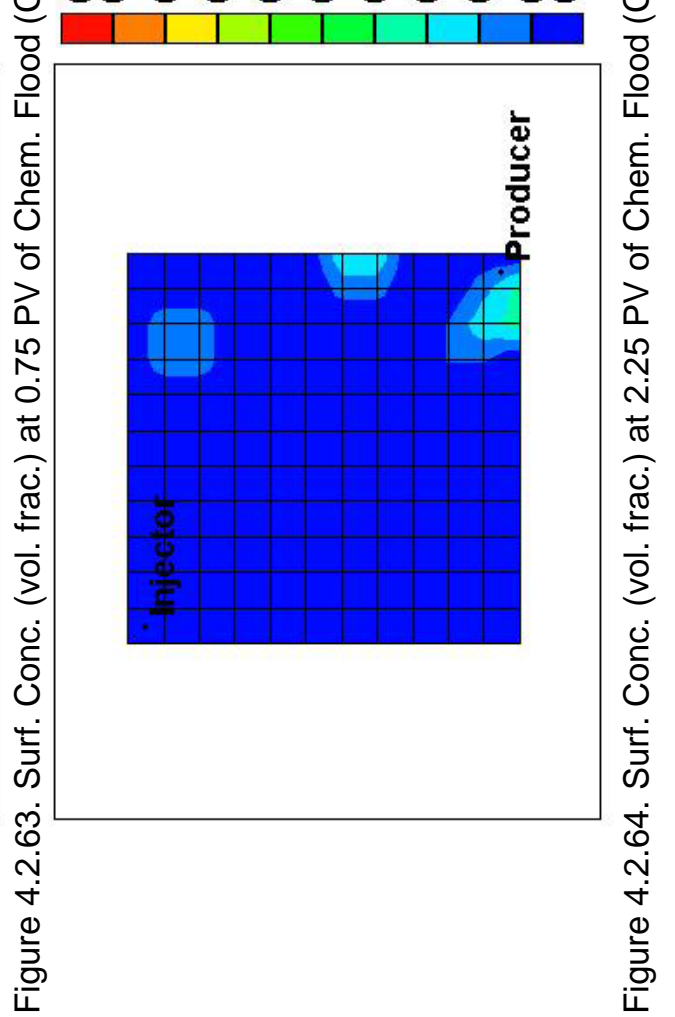




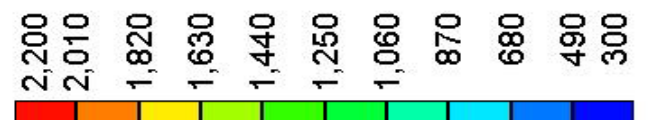

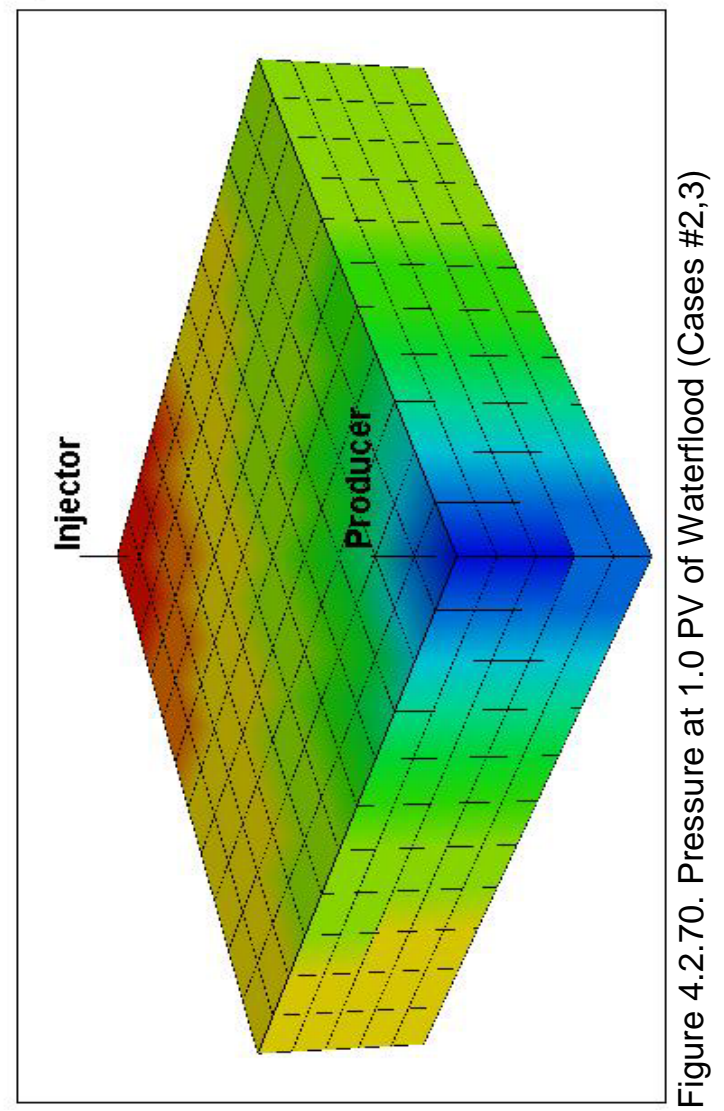

ஸ

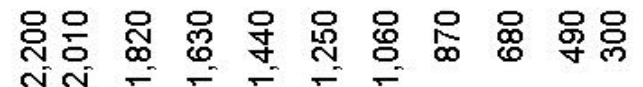
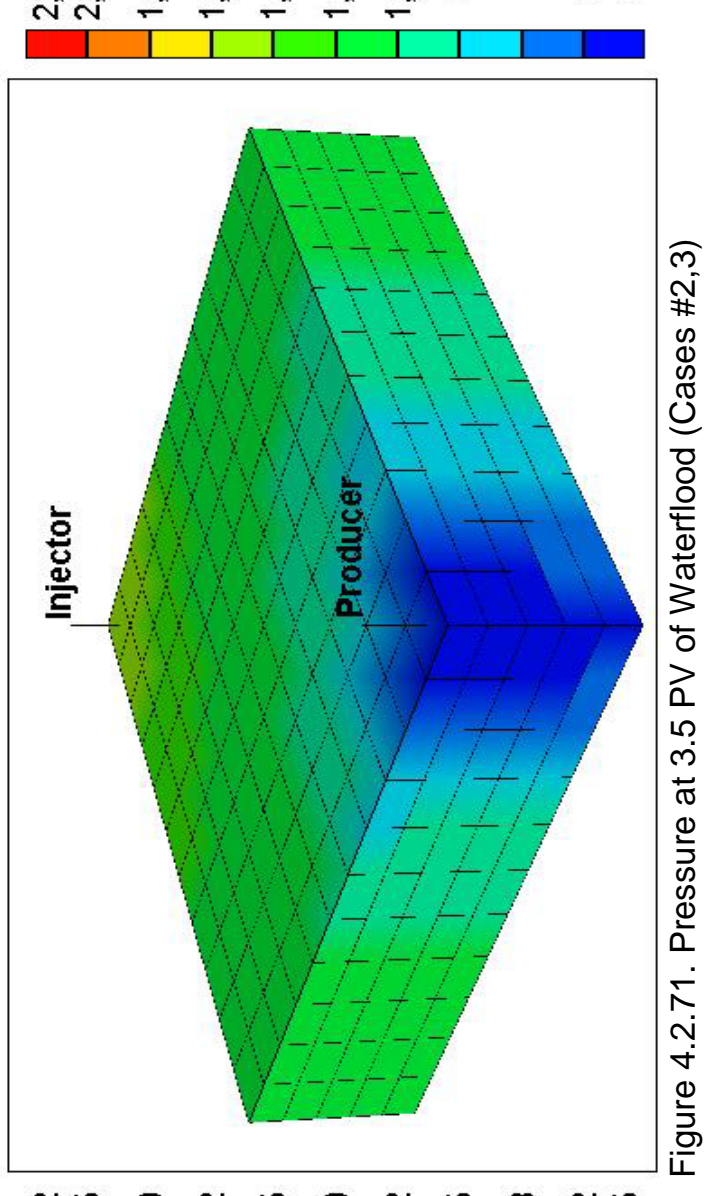

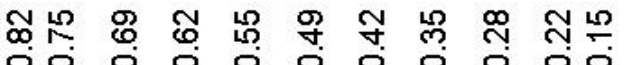
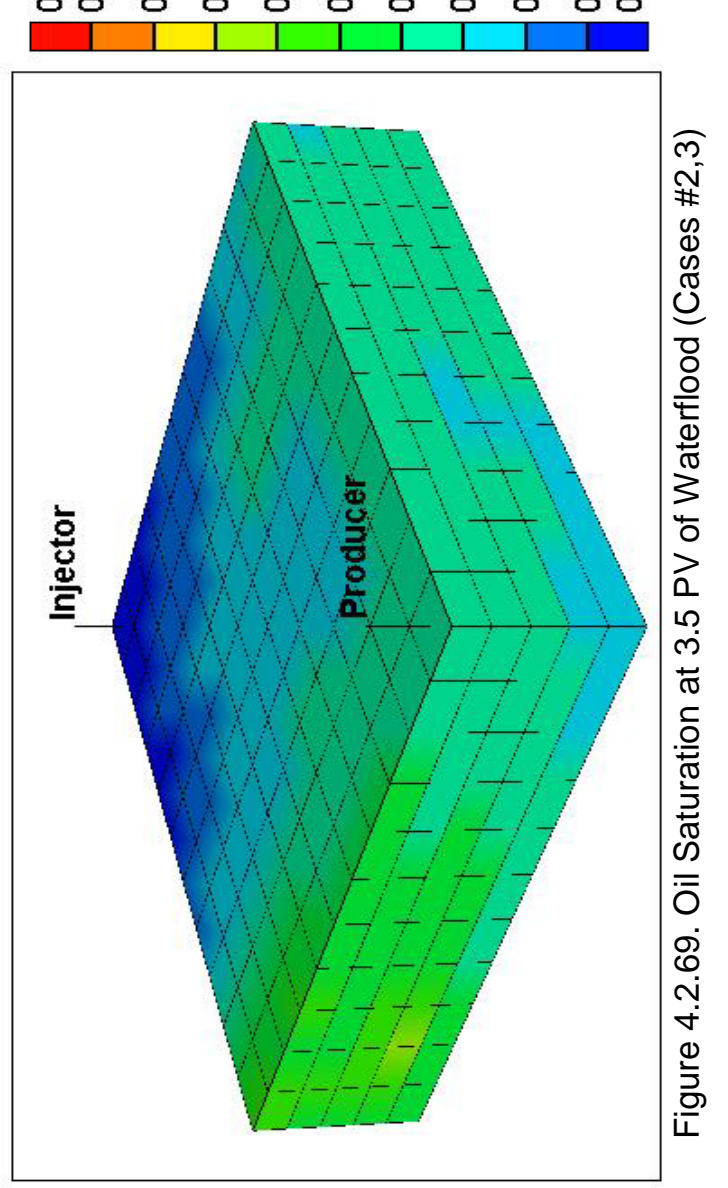

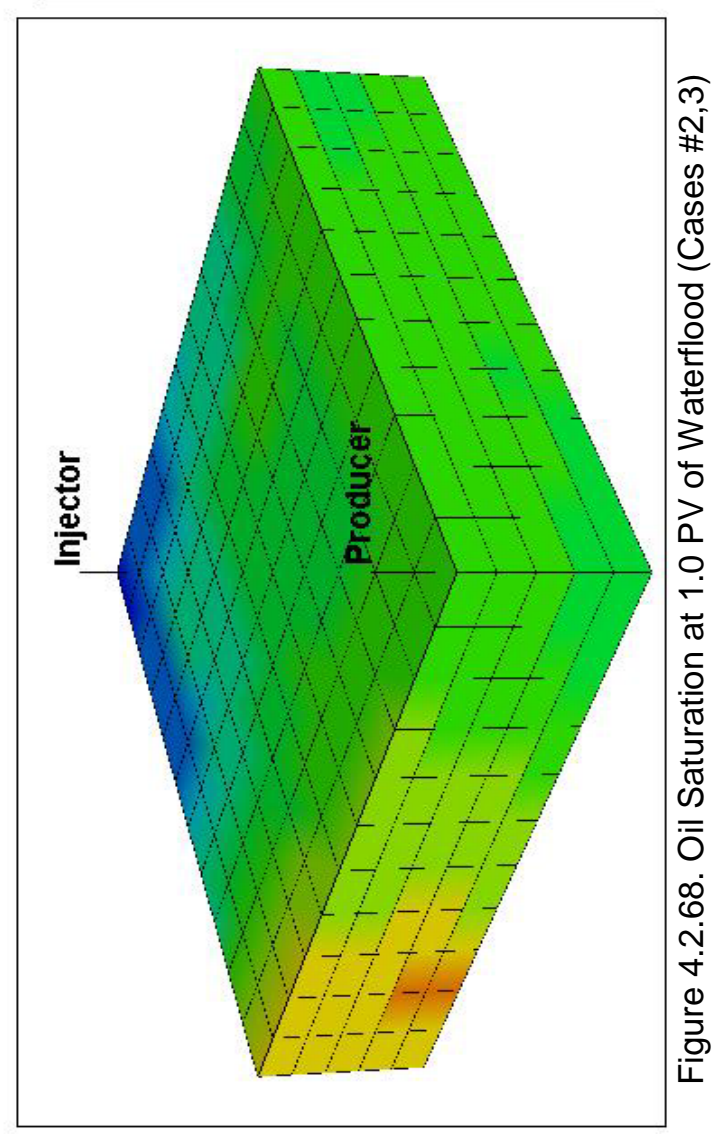




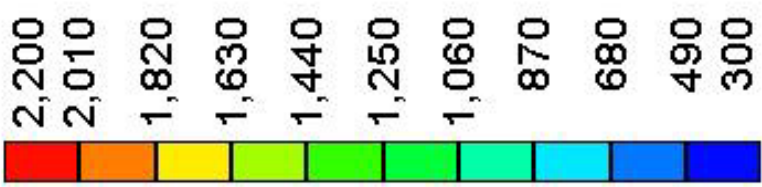

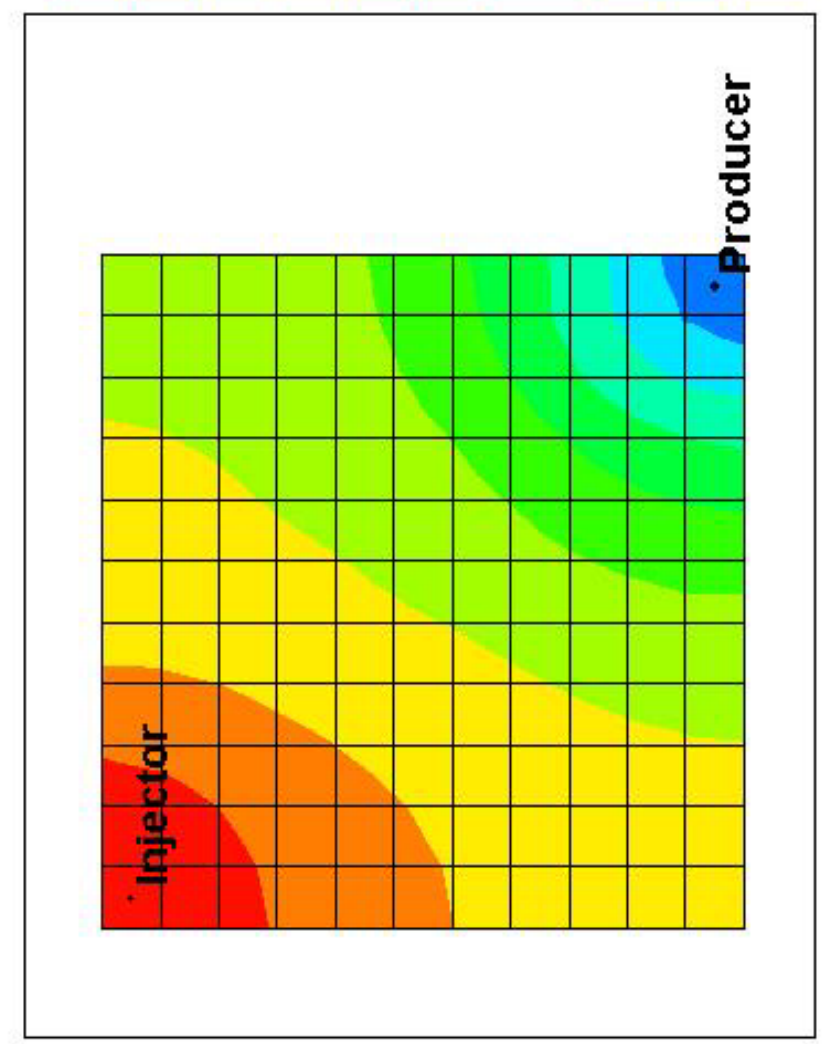

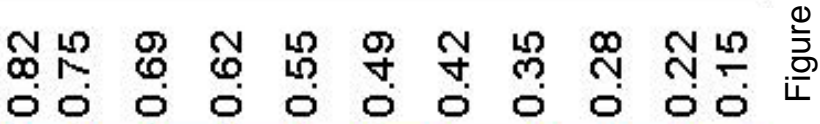

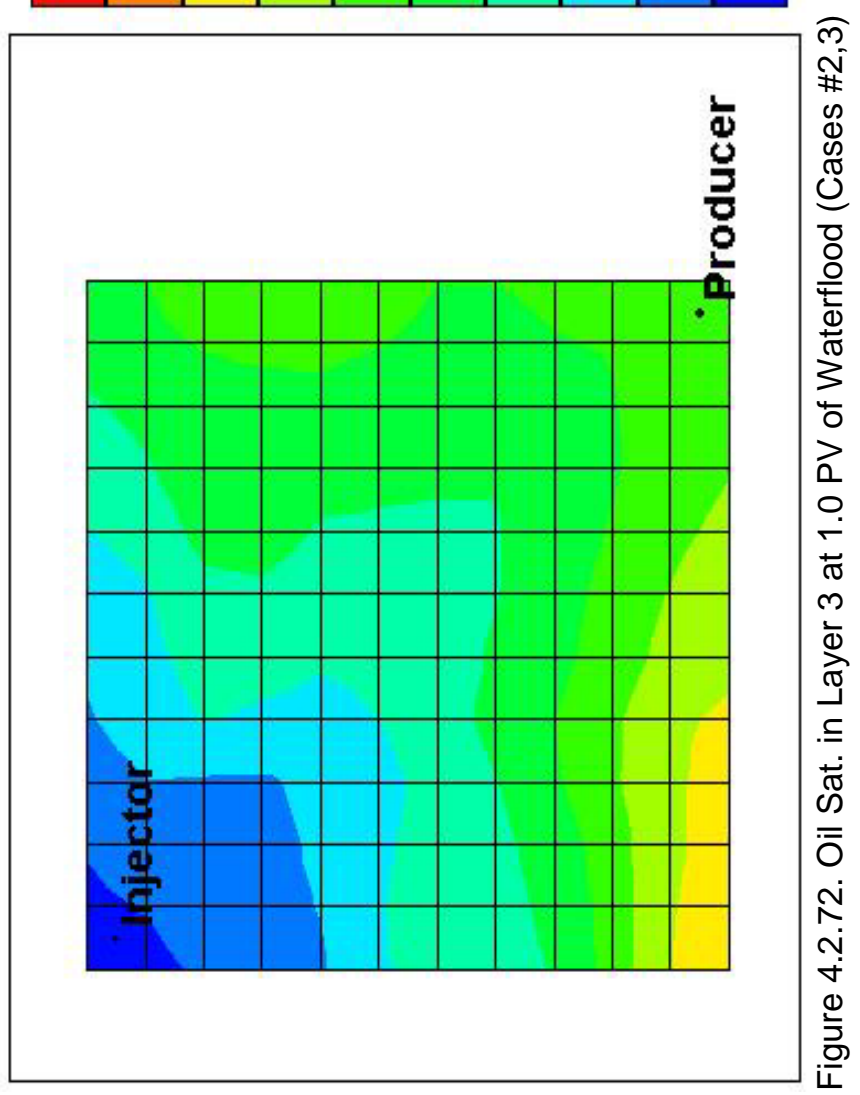

응응 융

$N A-T-T$

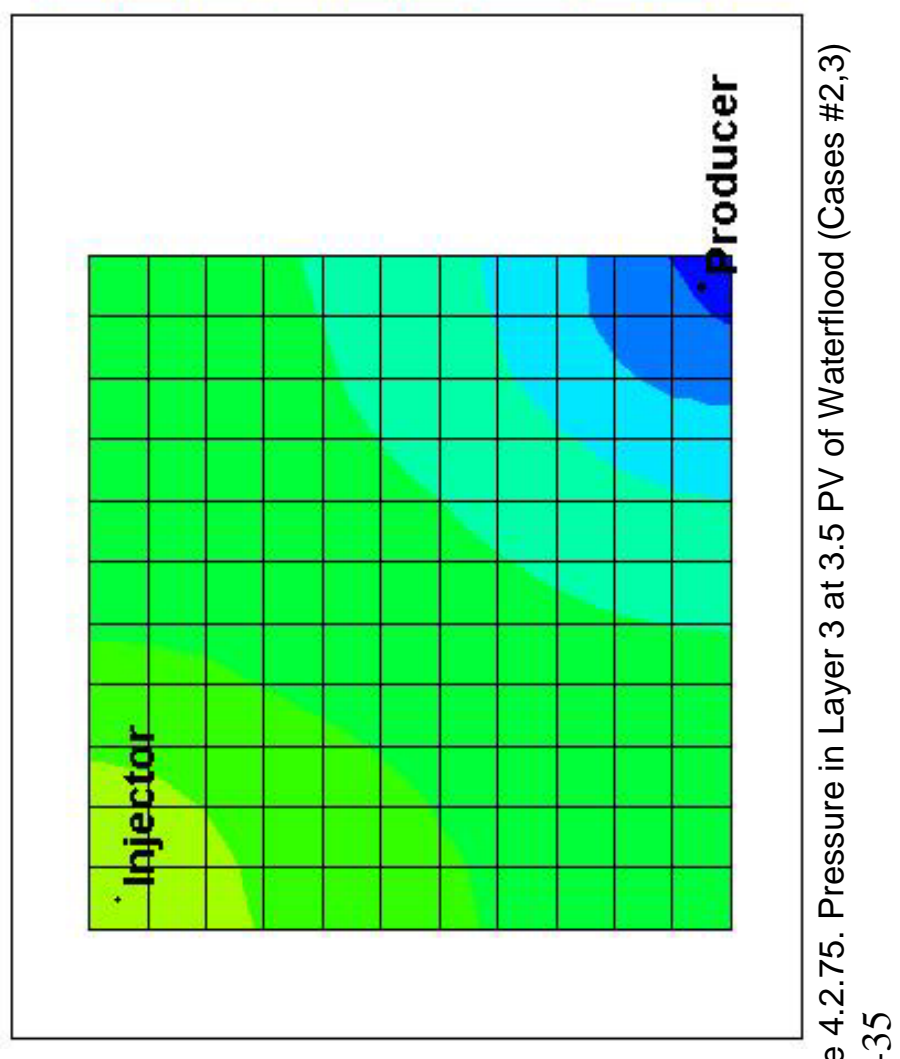

ஸ

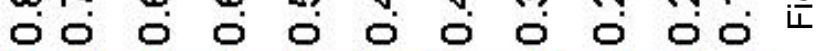

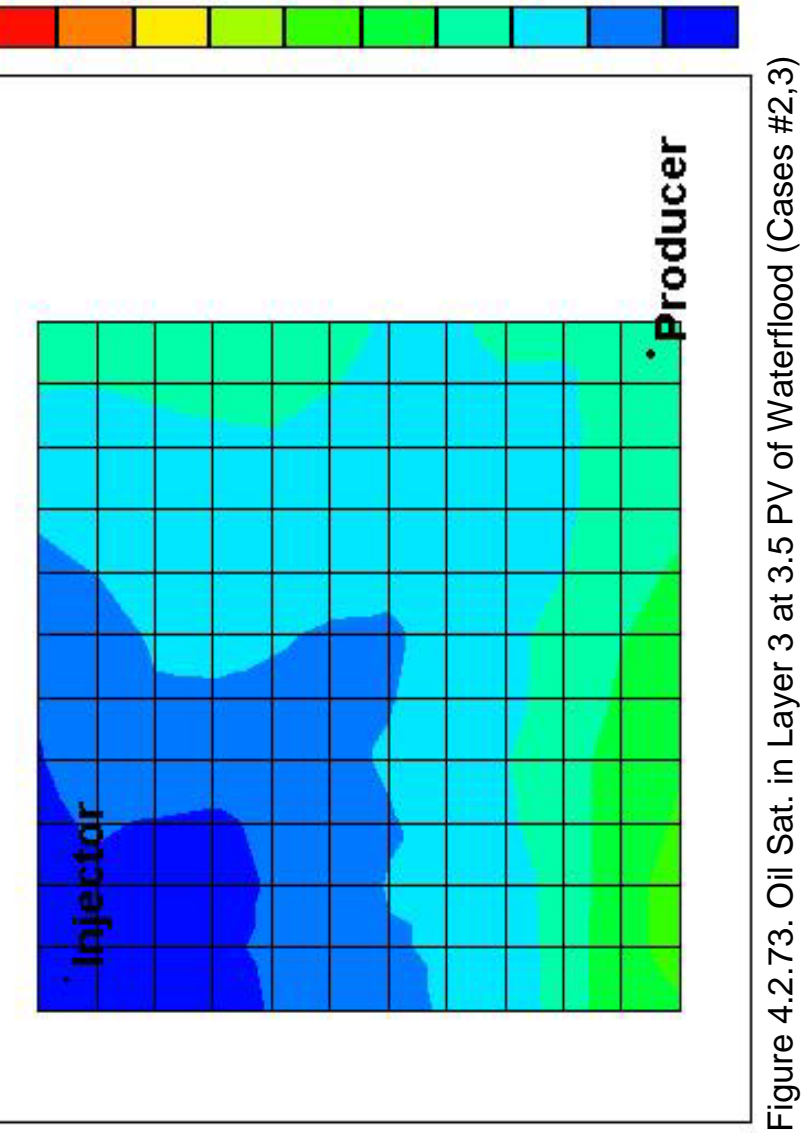




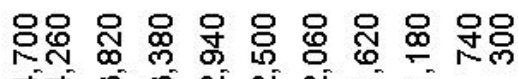
चं ल m N N N

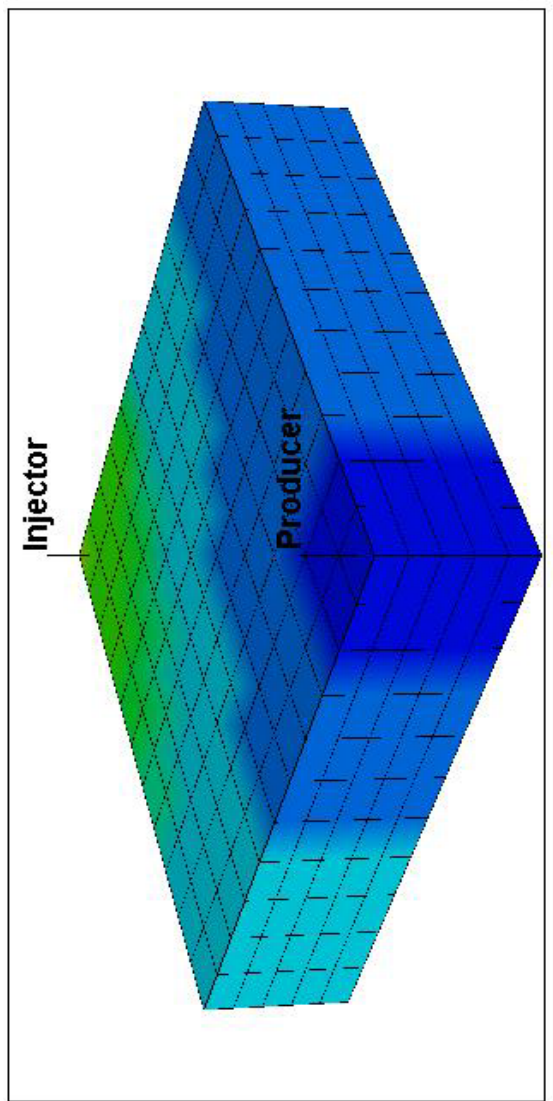

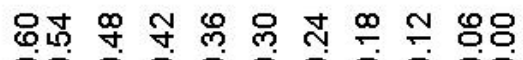

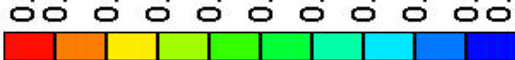

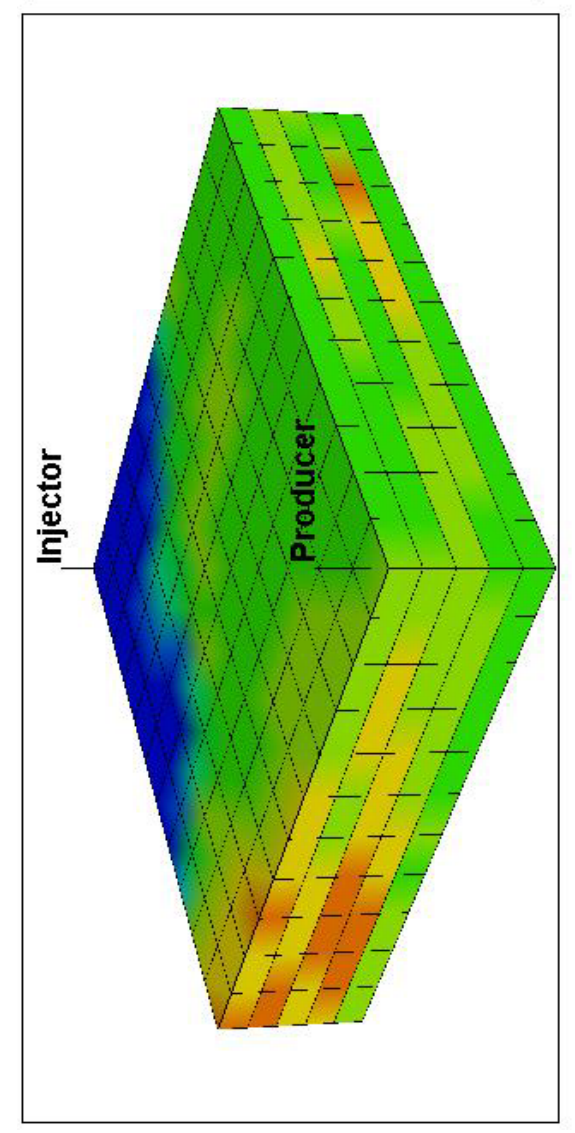

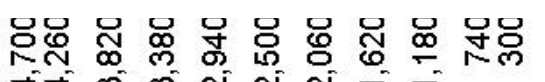
ปे m m N N N - -

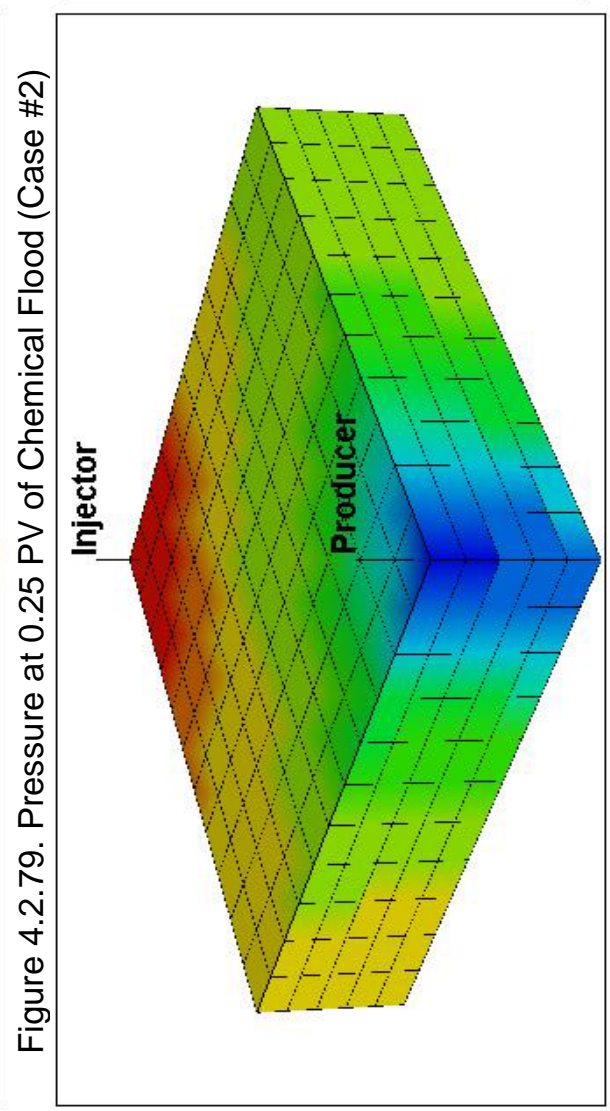

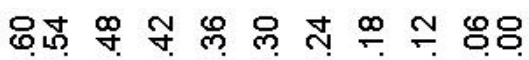
00 0 0 0 0 0 0 0 00

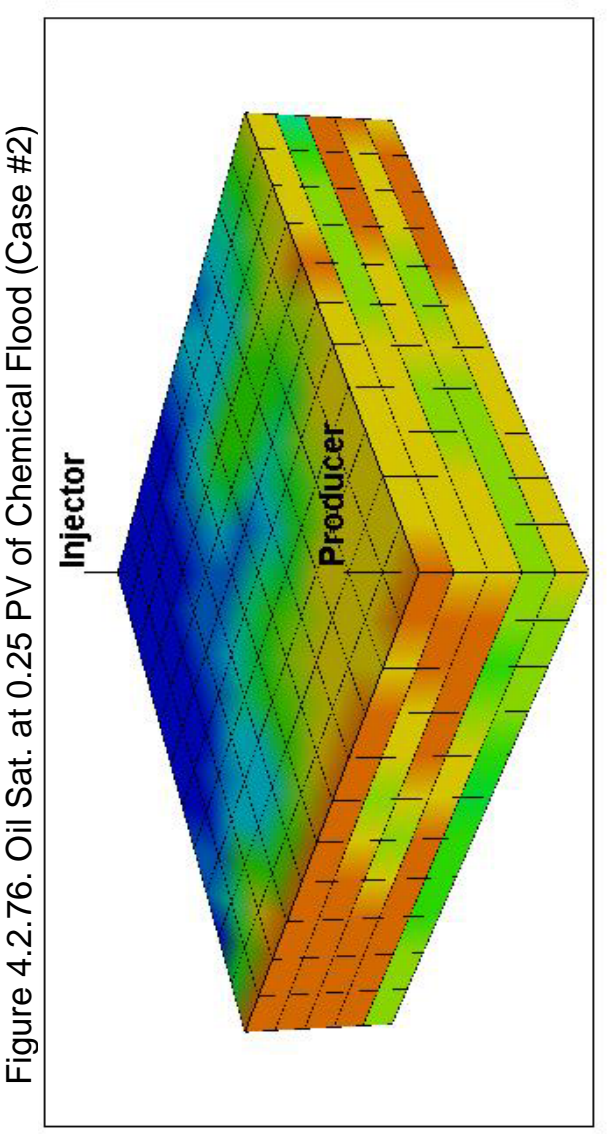

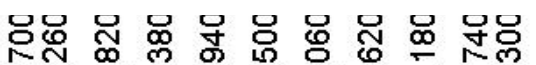
से ल m N N N =

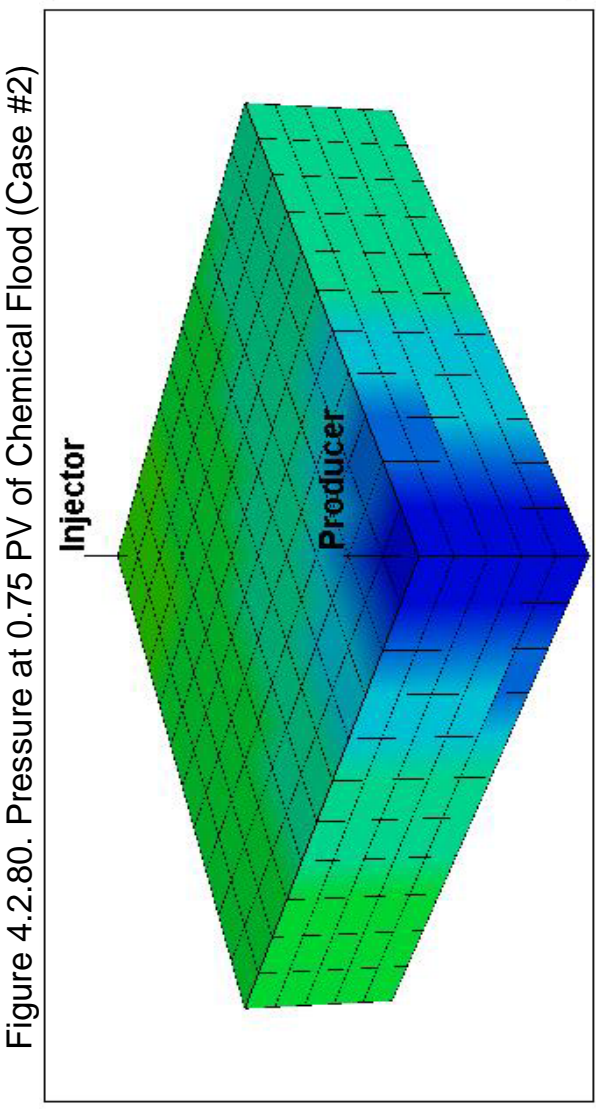

居 莳

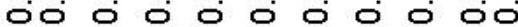

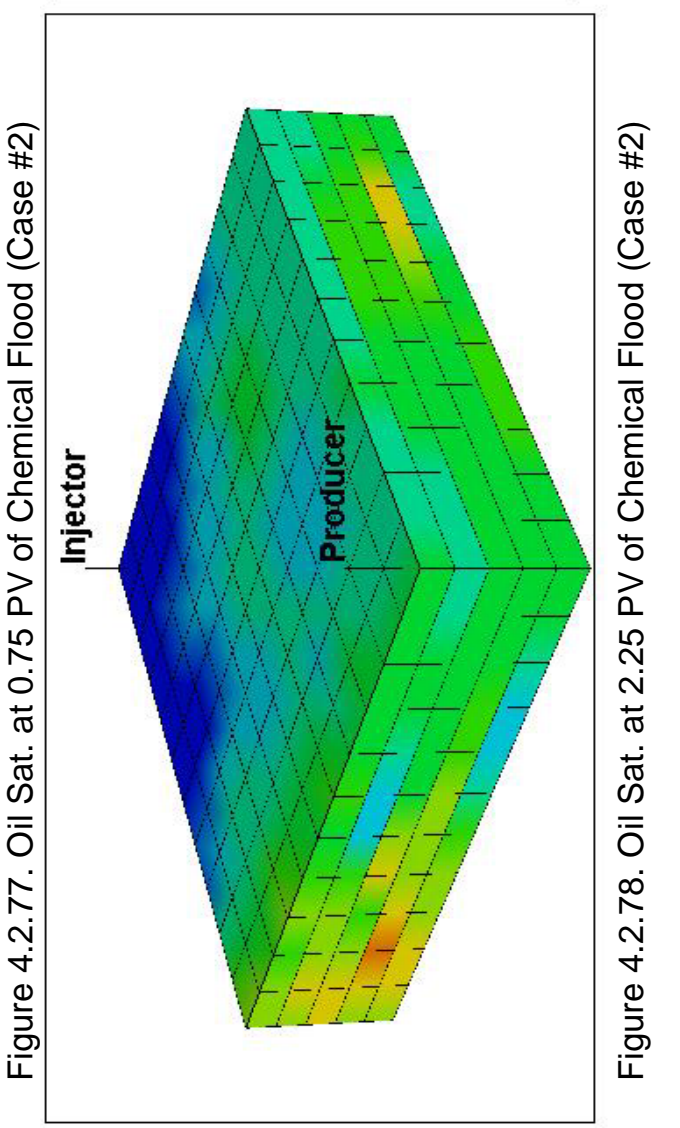




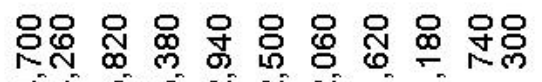

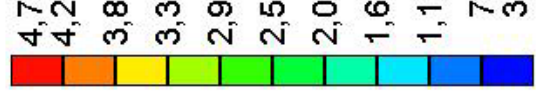

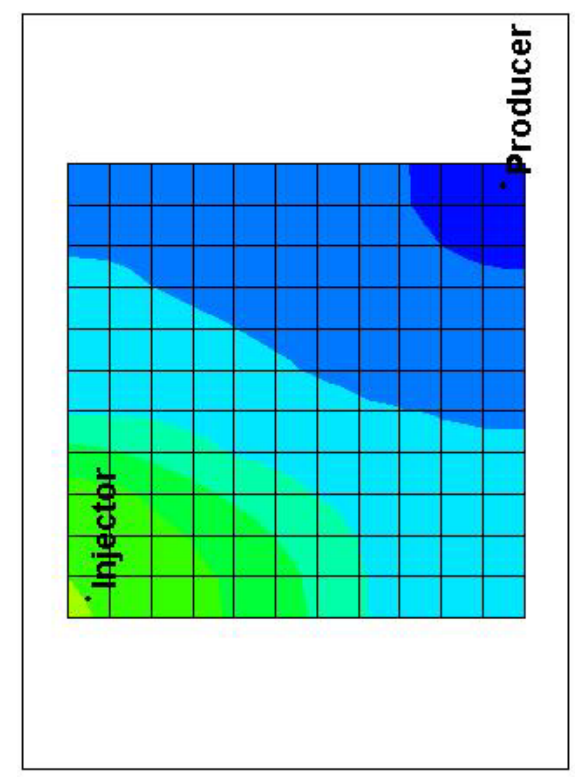

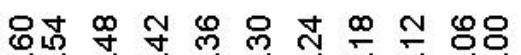

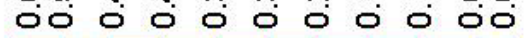

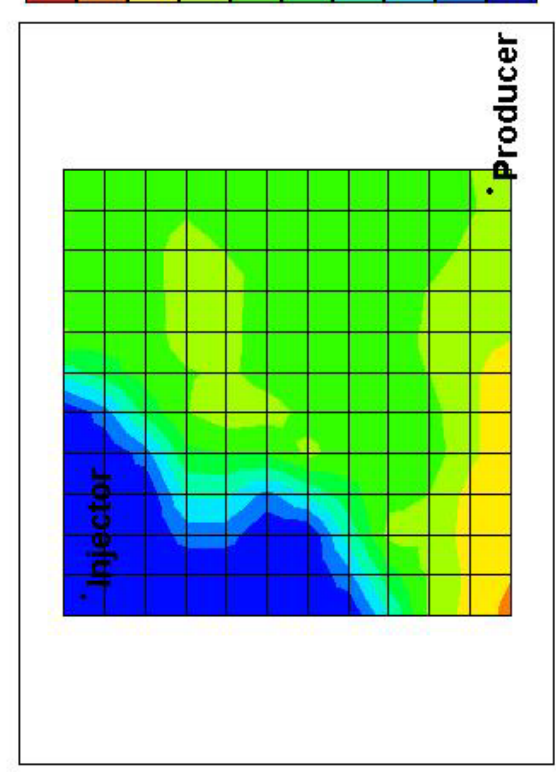

웅 응 웅 응 융 웅 웅
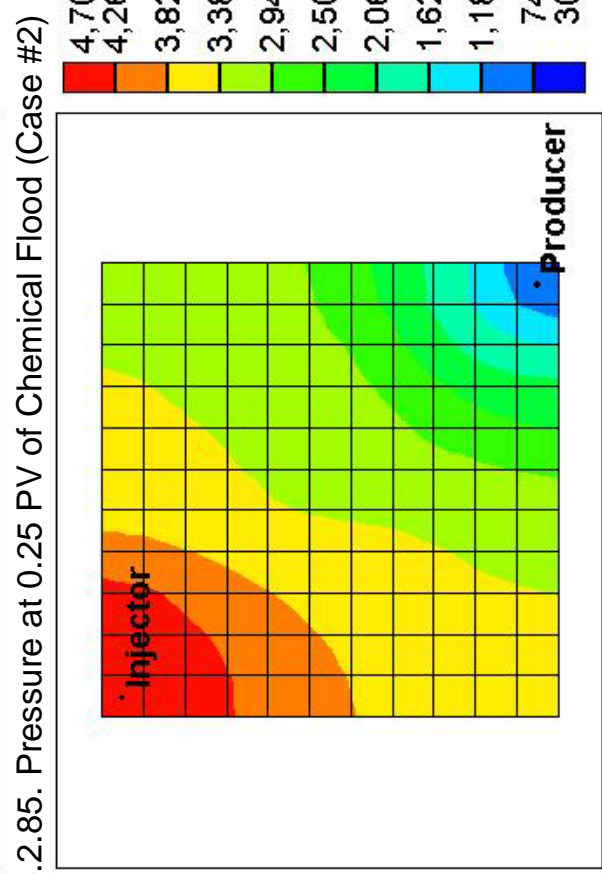

ㅎํㅁำ

ล

\# 유 ㅇำ

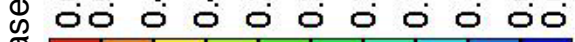
0

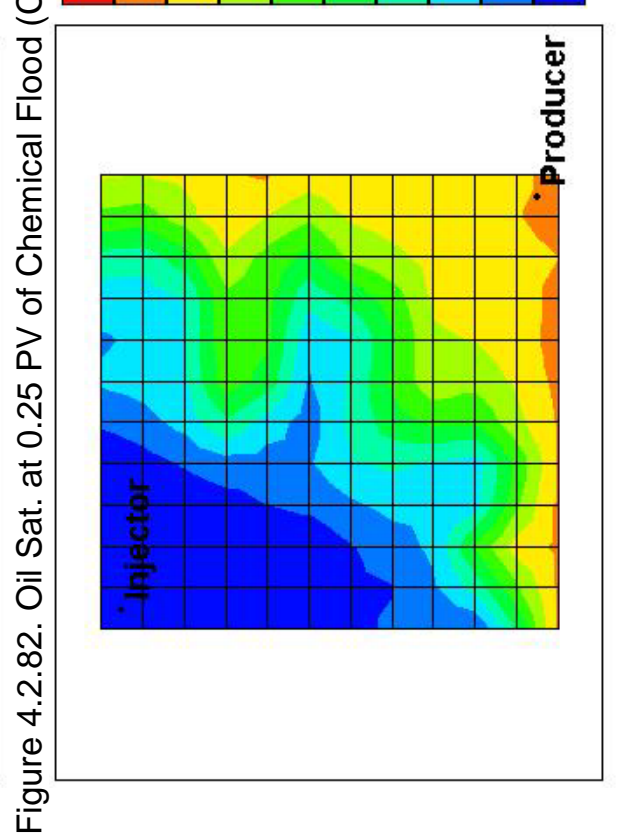

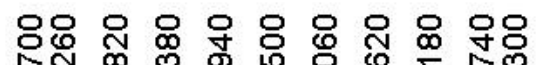
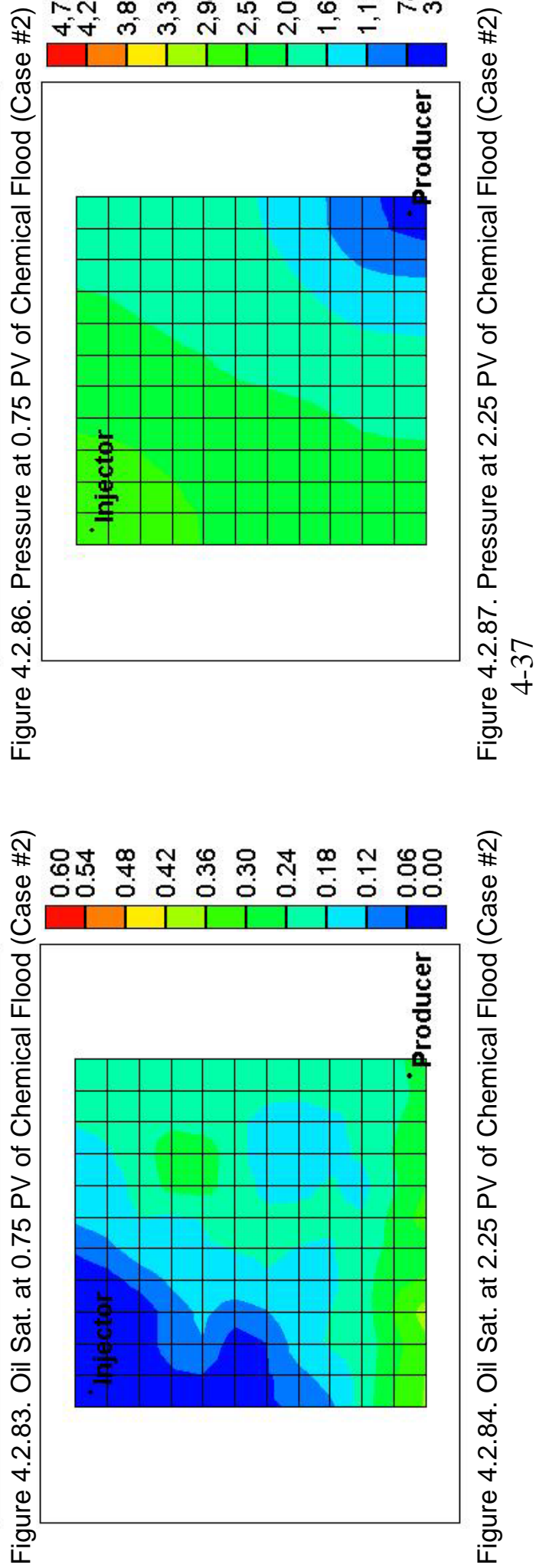


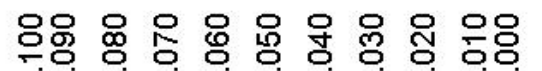

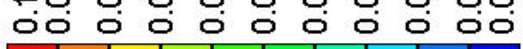

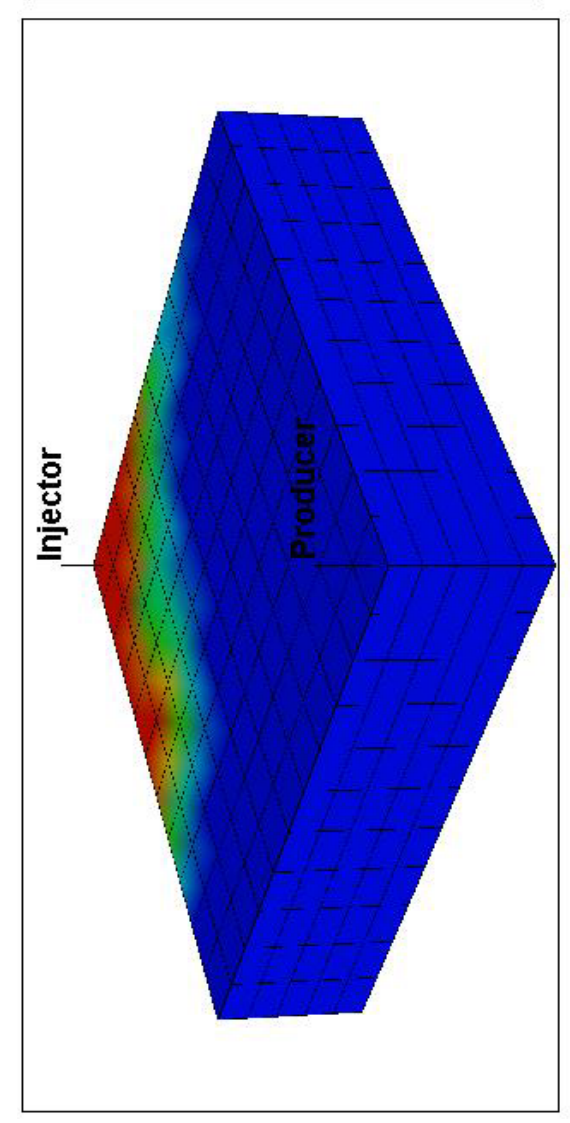

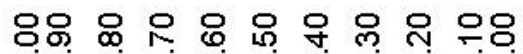

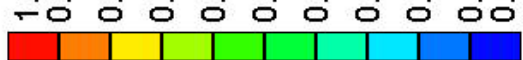

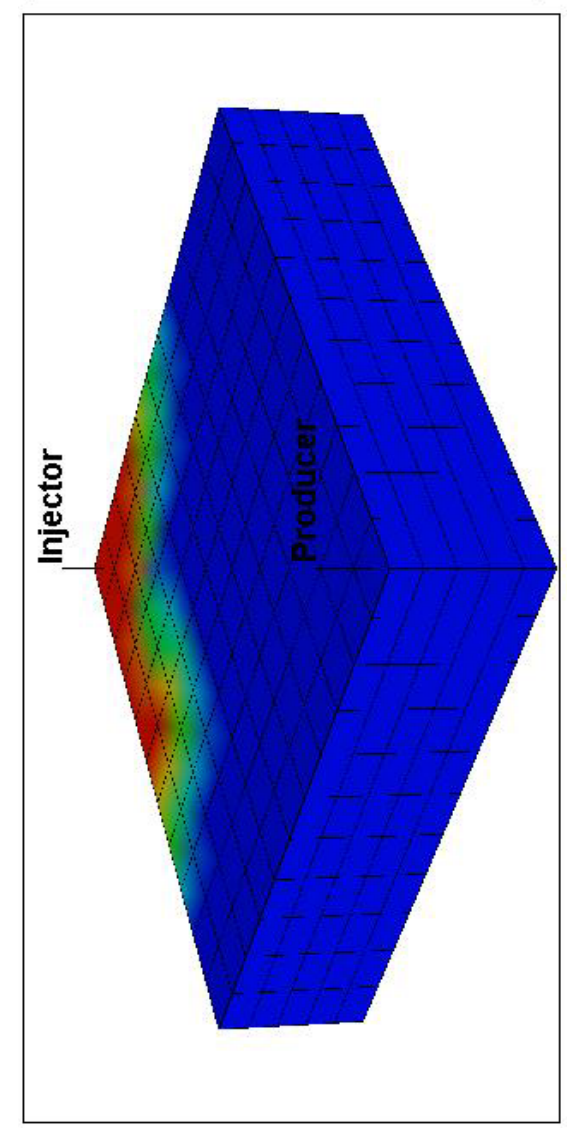

응용 \%

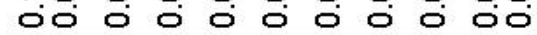

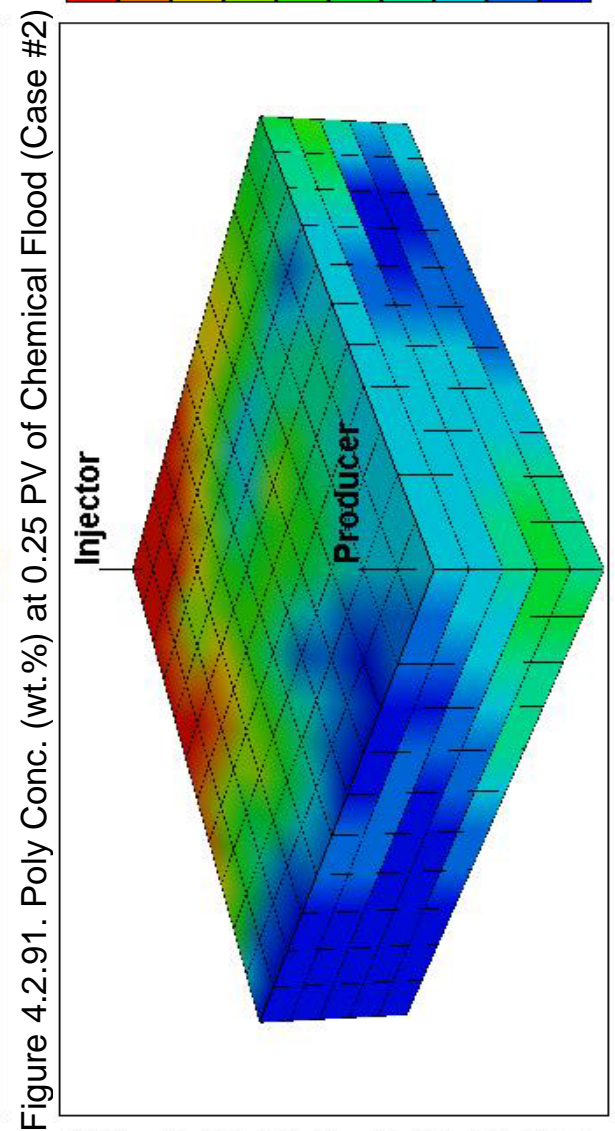

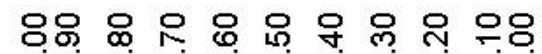
- $\dot{0} 0$ 0 0 0 0 0 0 0

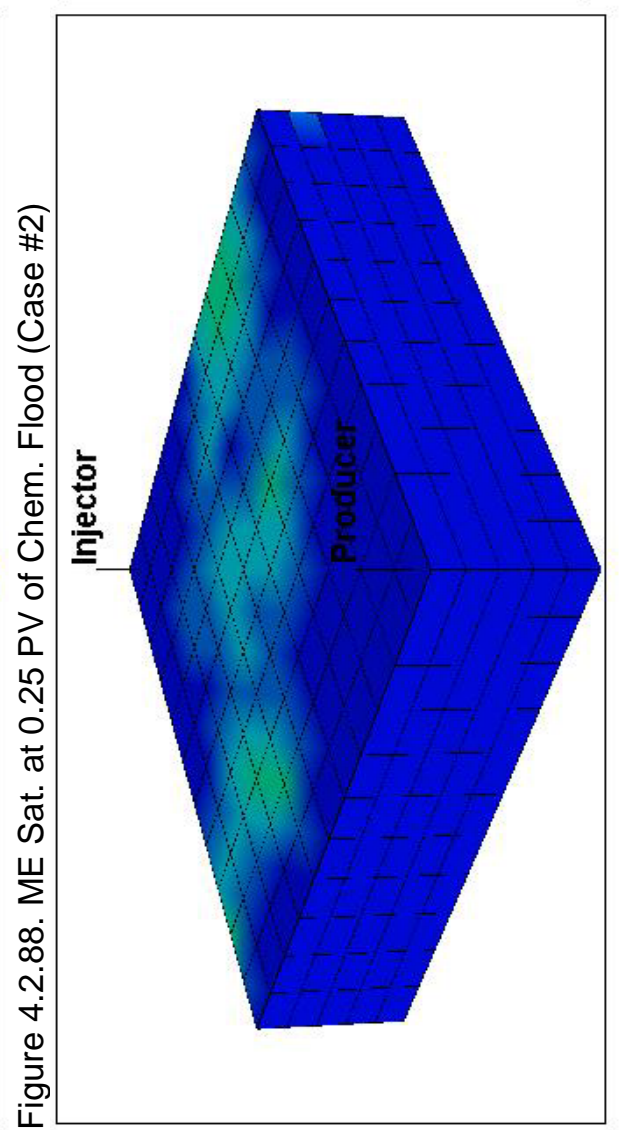

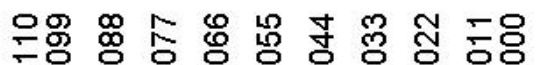
هi

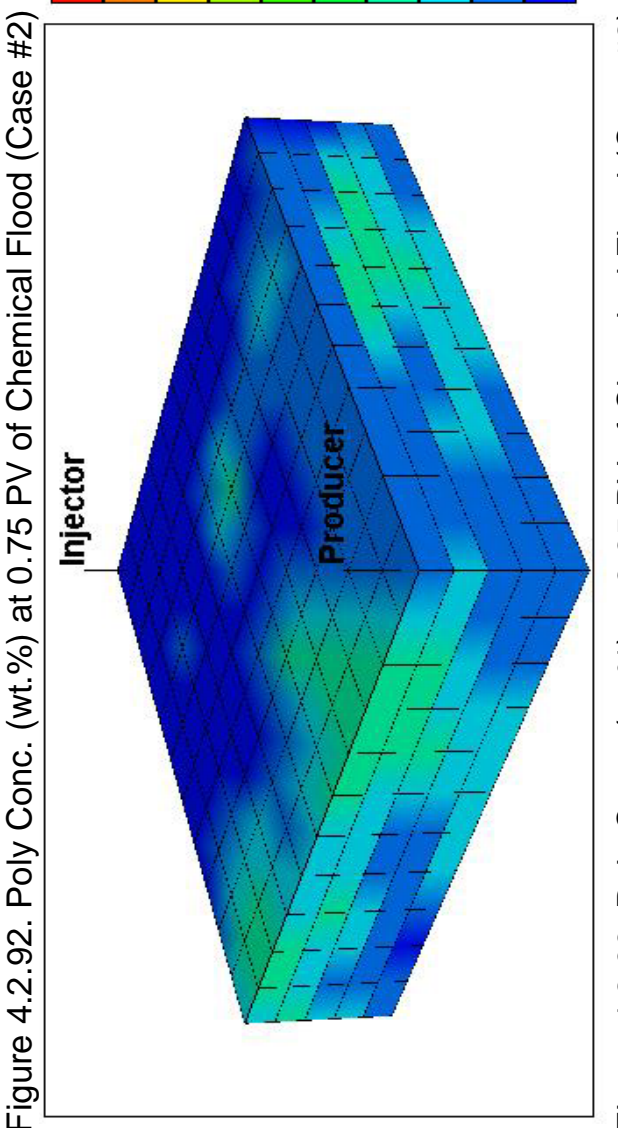

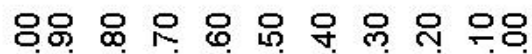
-0 0 0 0 0 0 0 0 0

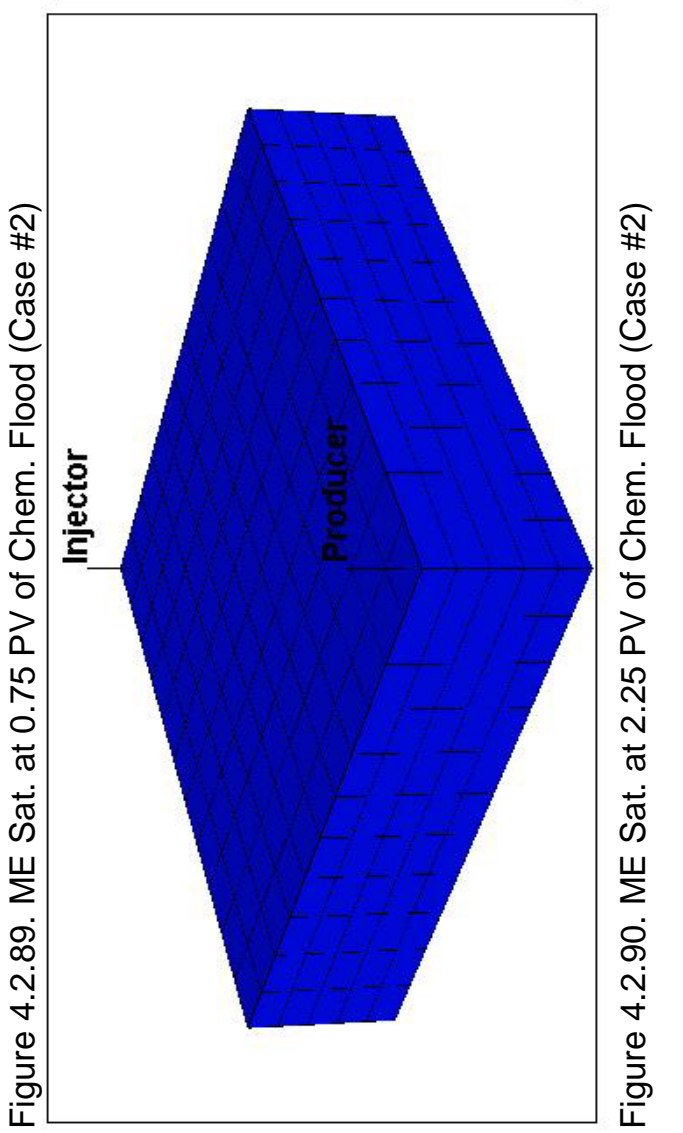




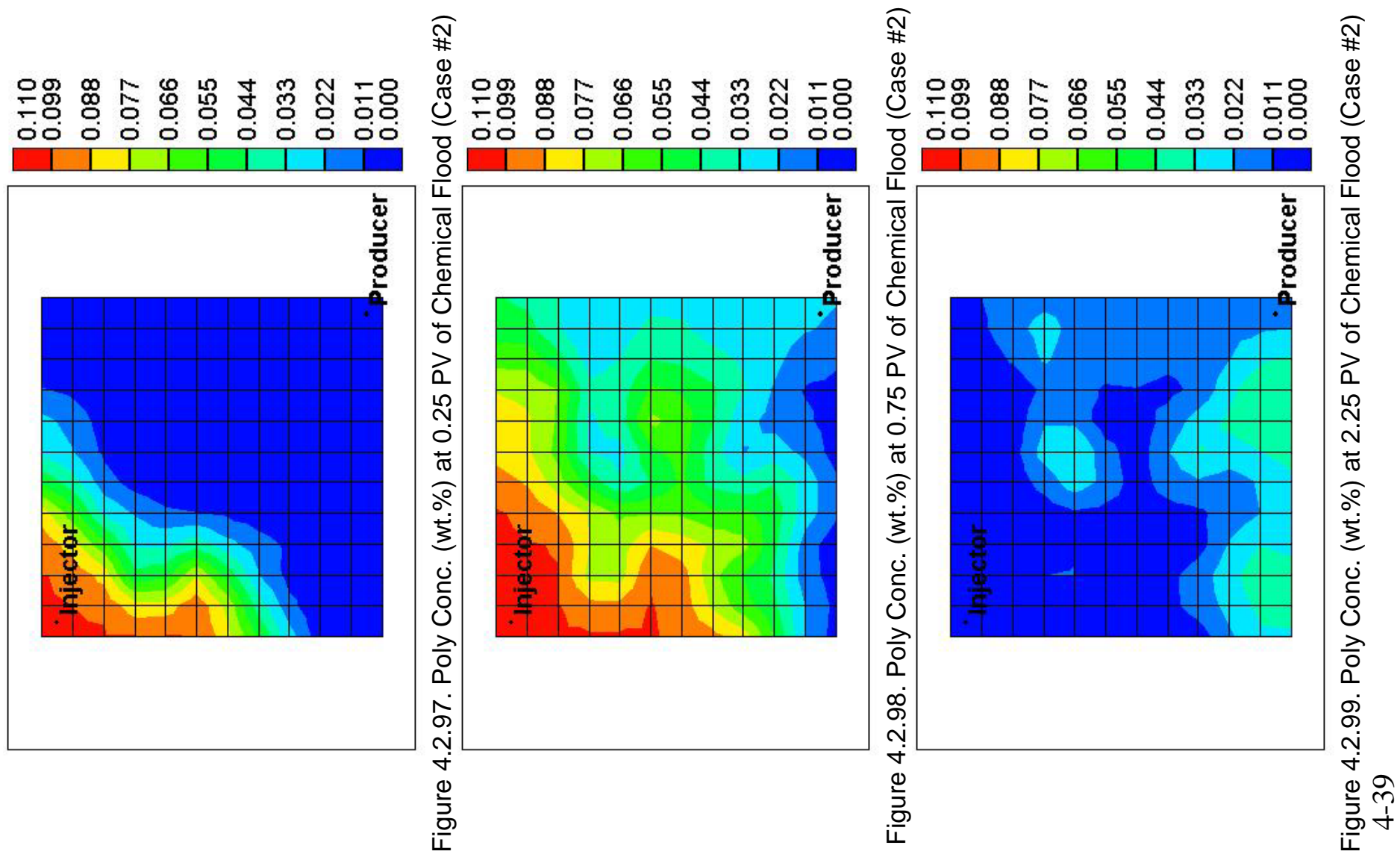

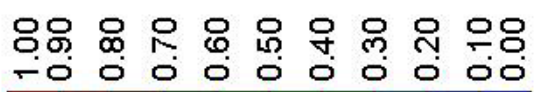

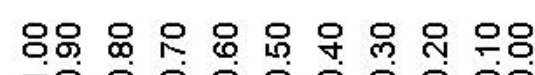
-o 0 o 0 o 0 o 0 io

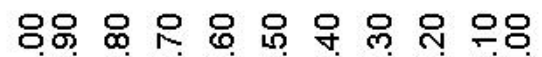
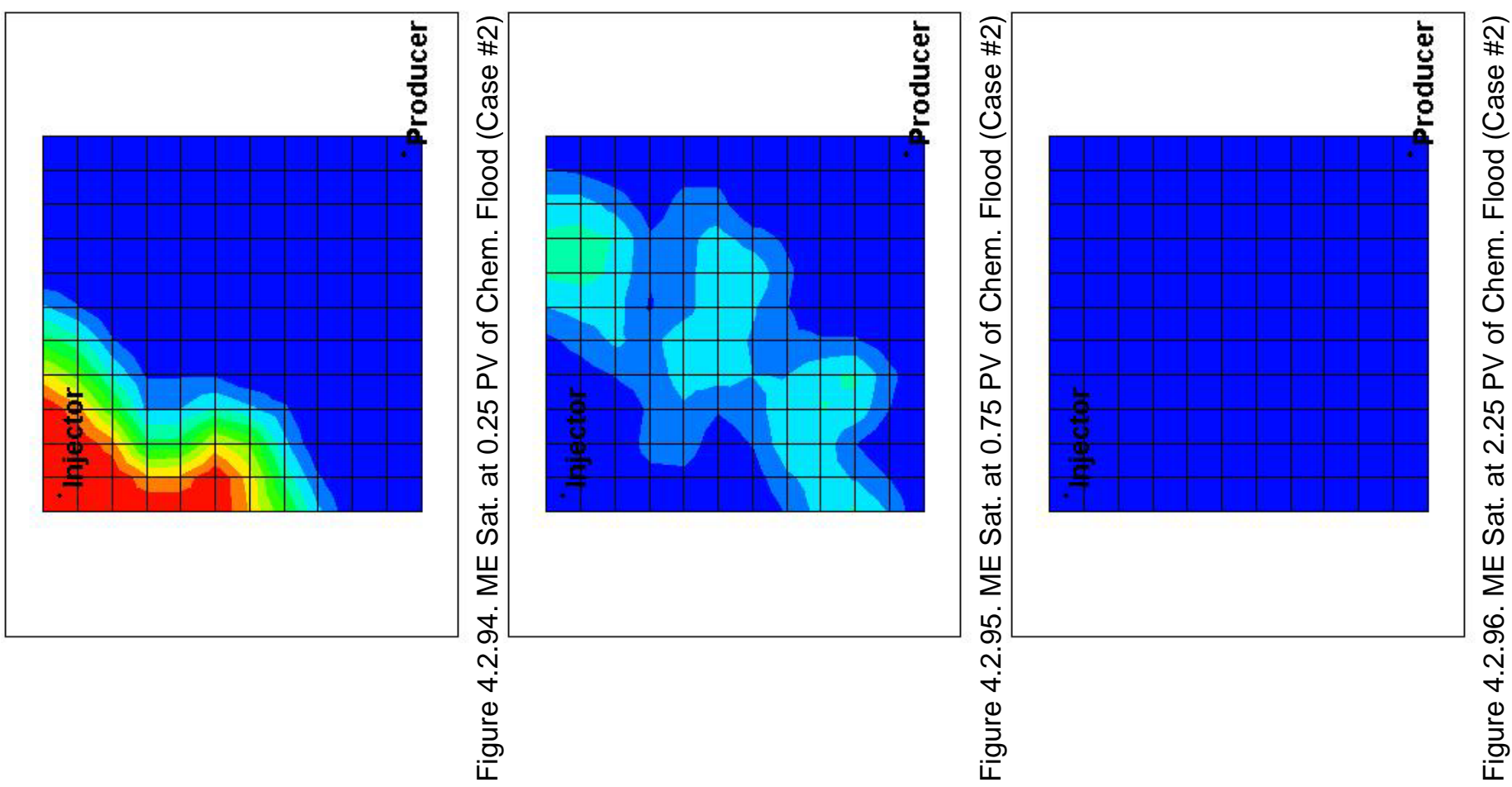

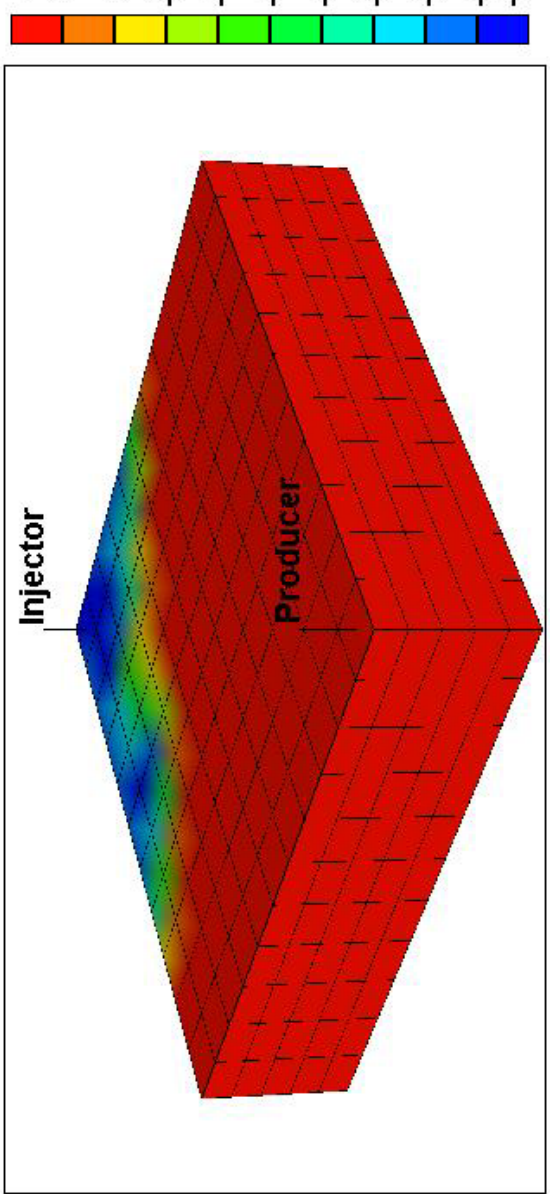

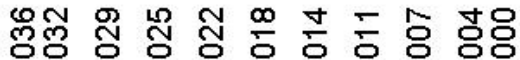

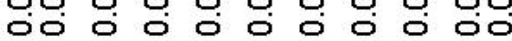

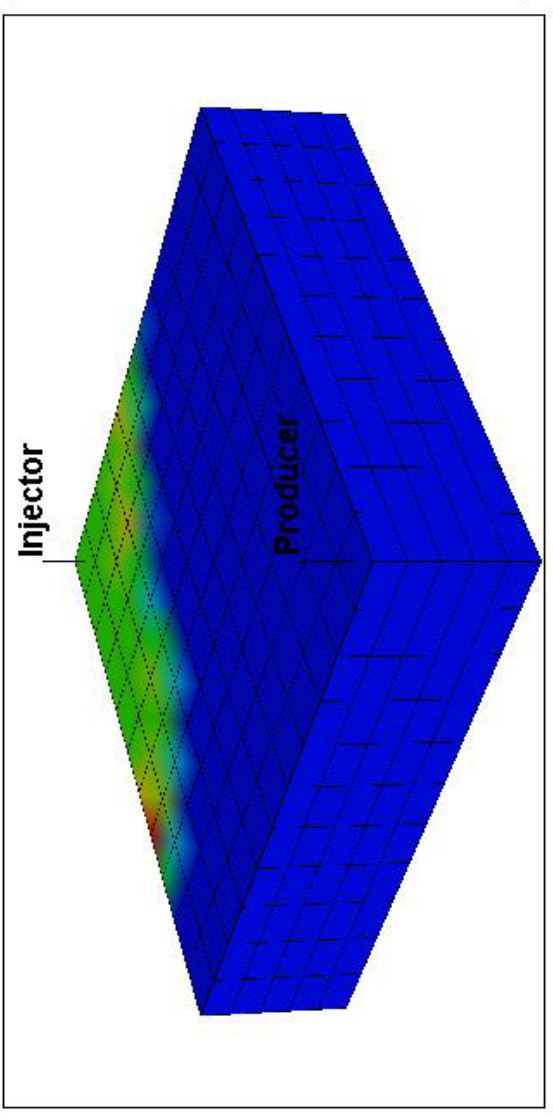

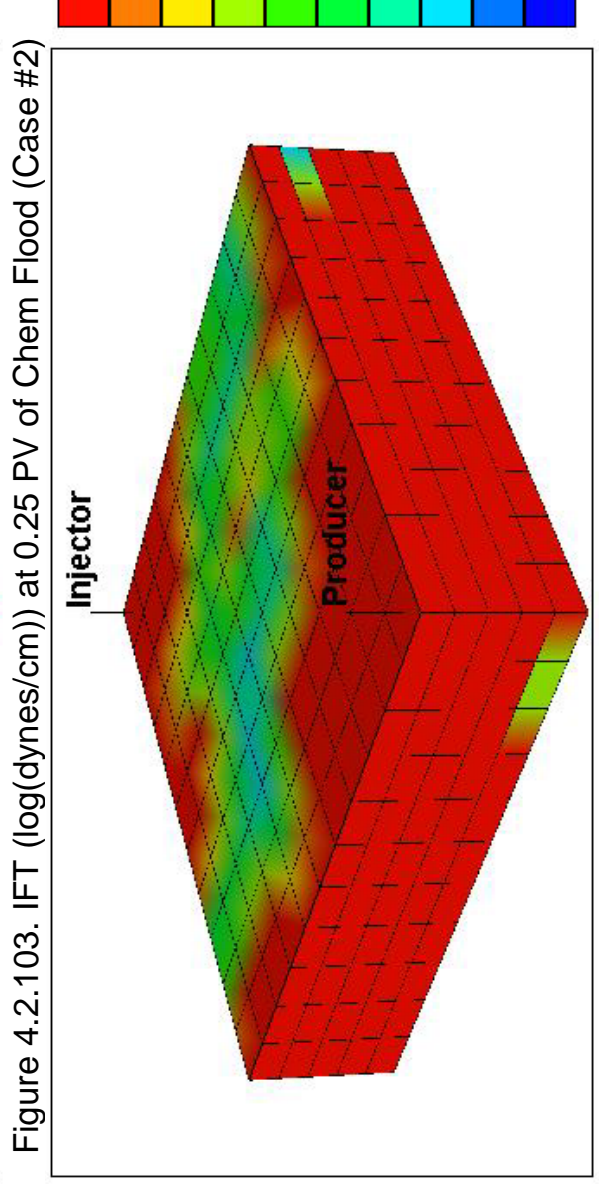

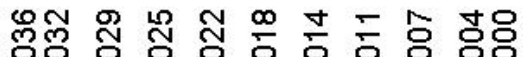
○̊․․

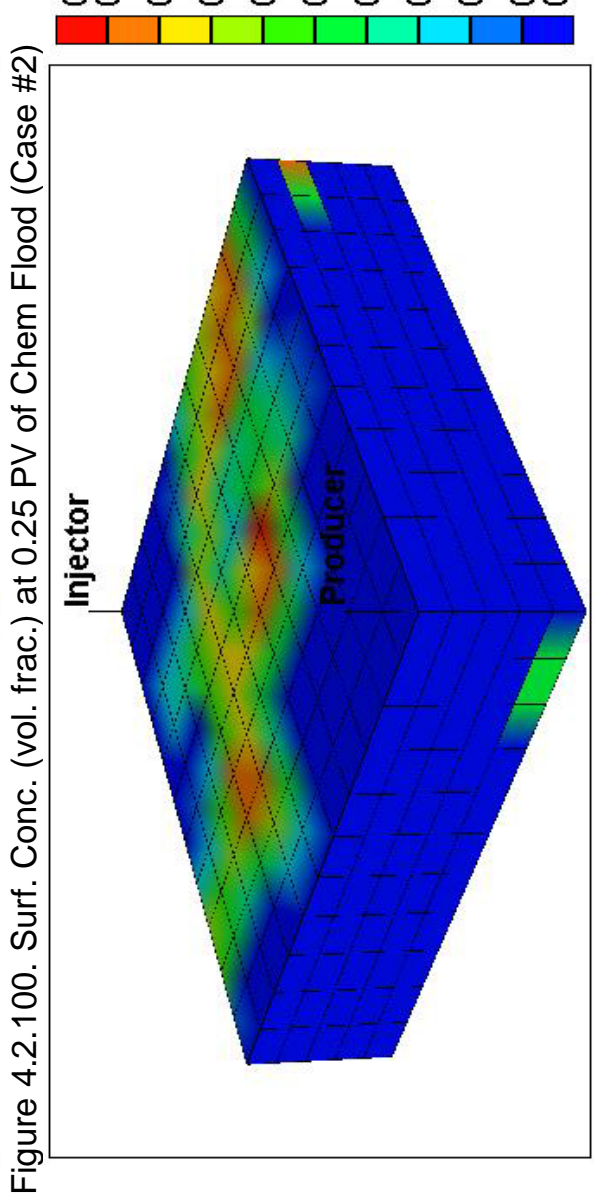

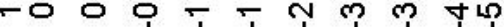

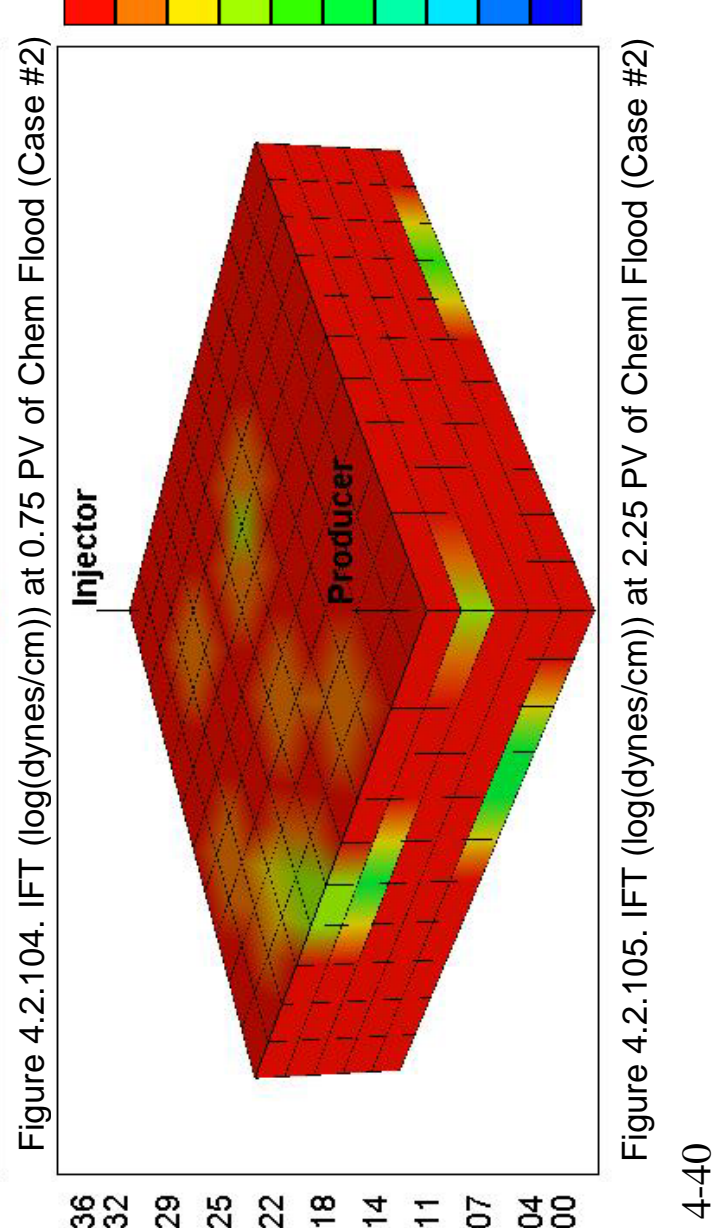

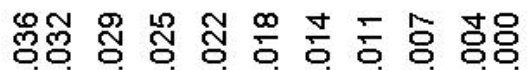
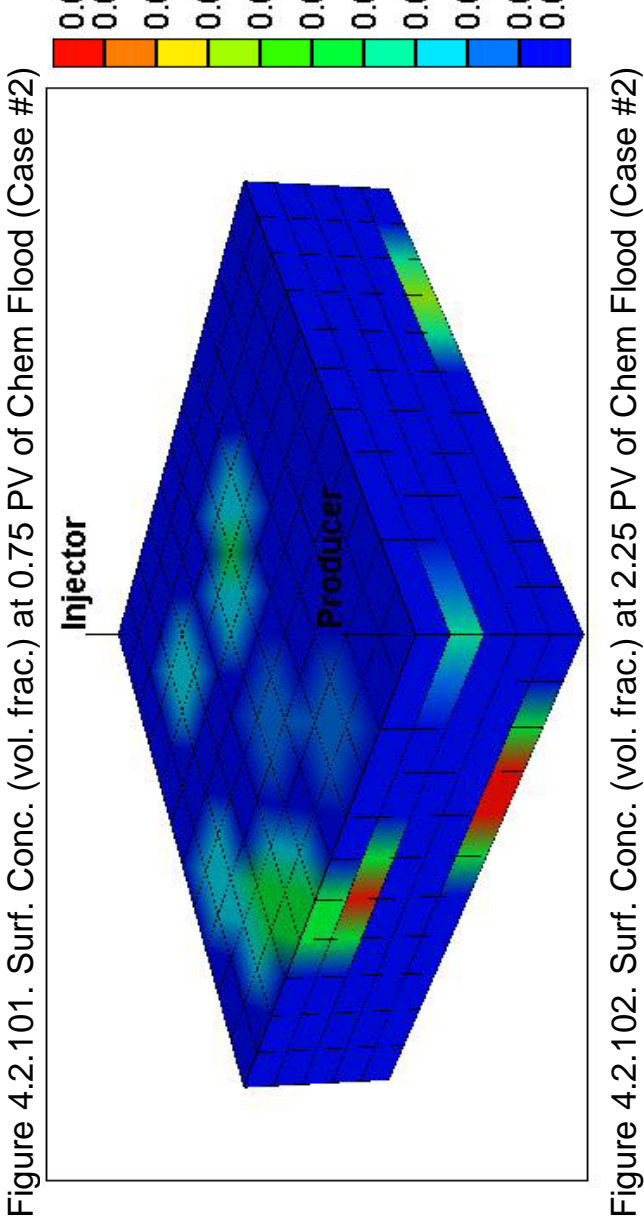

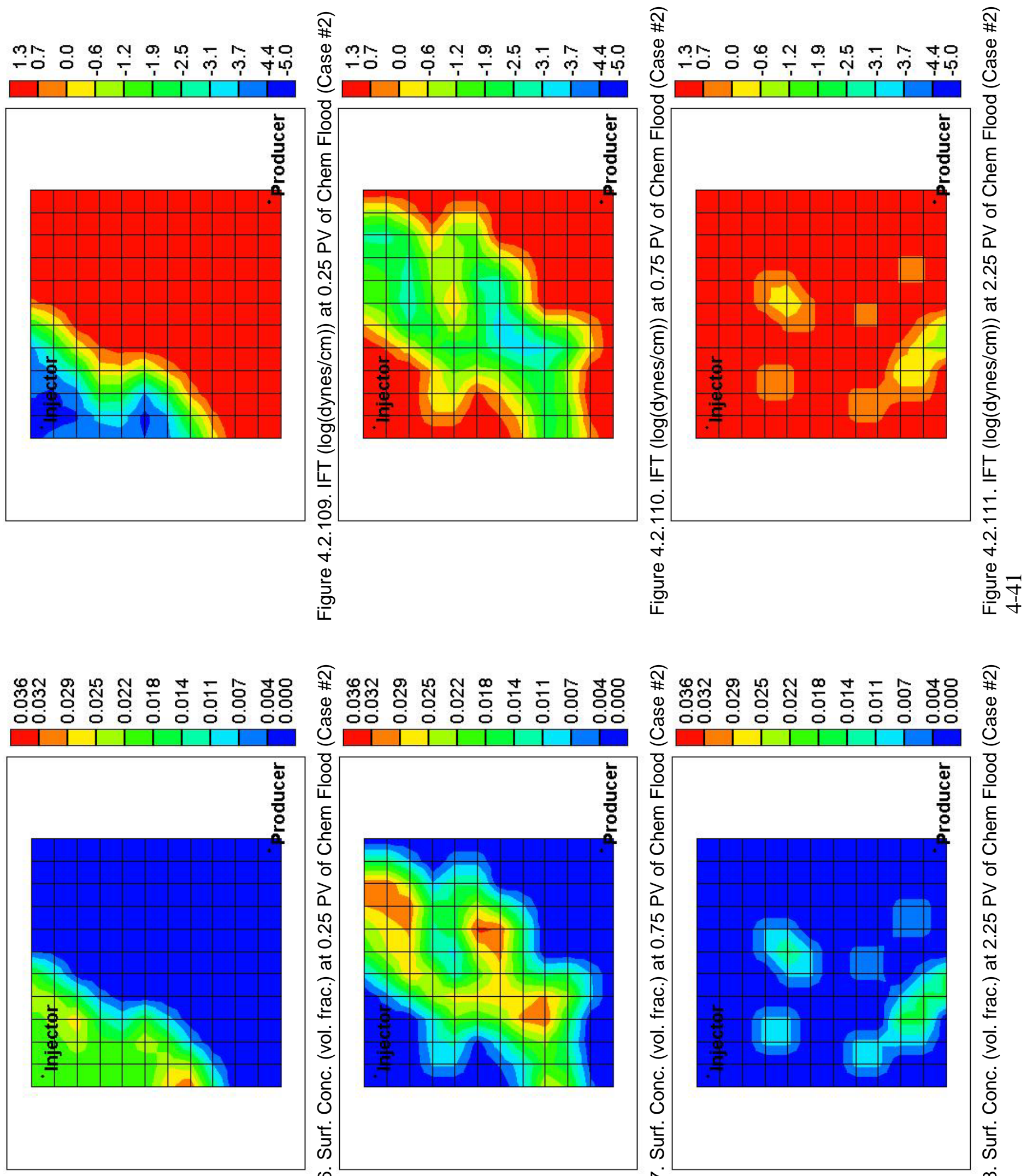

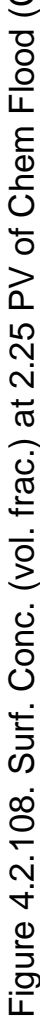




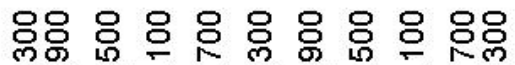
चल m m N N -

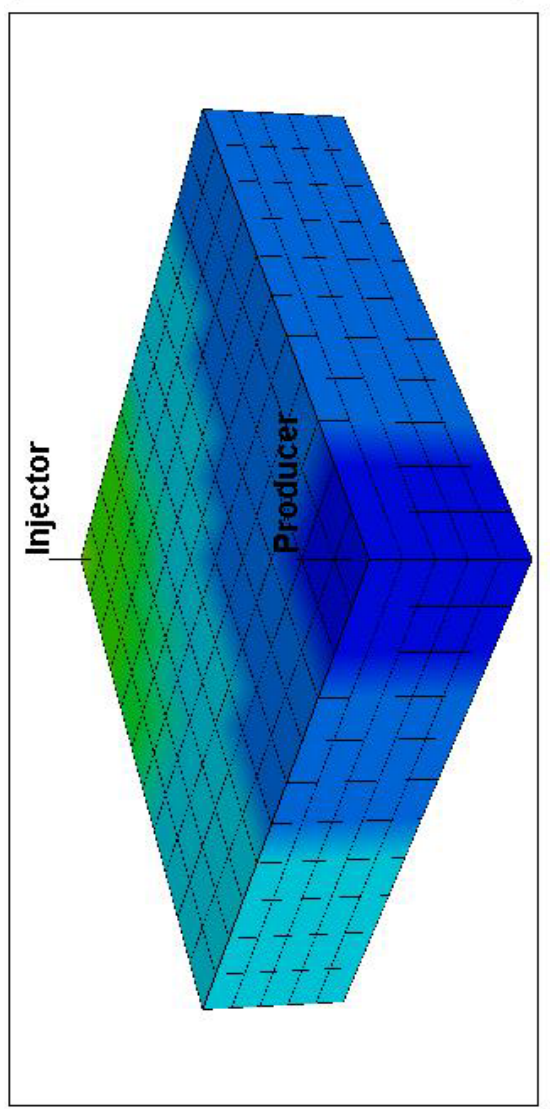

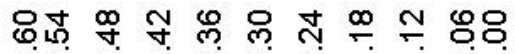

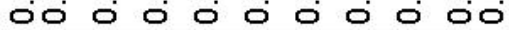

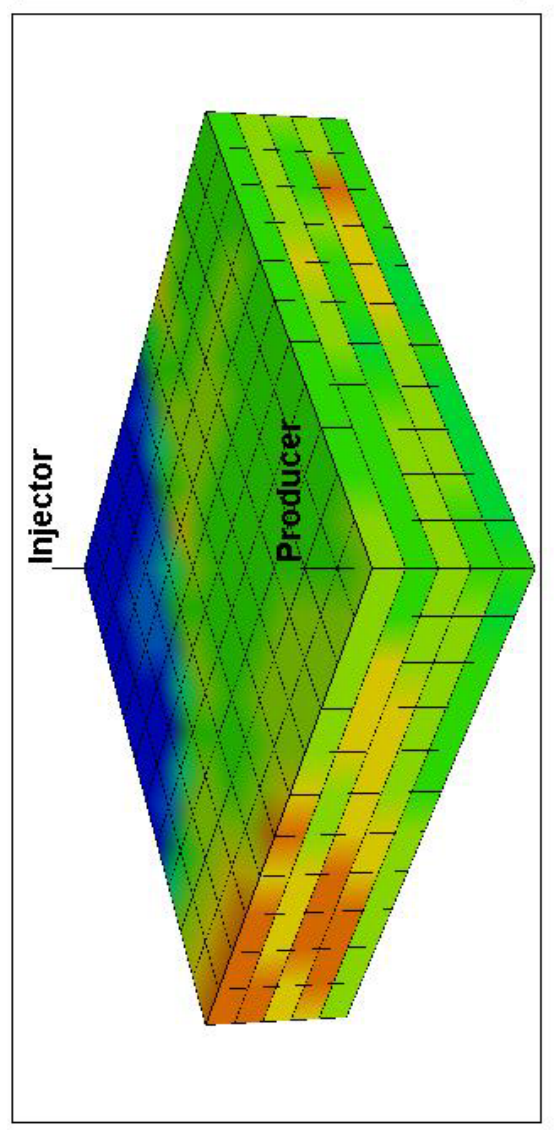

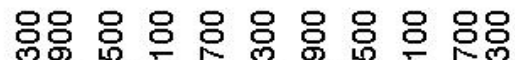
चल m ल N $=-$

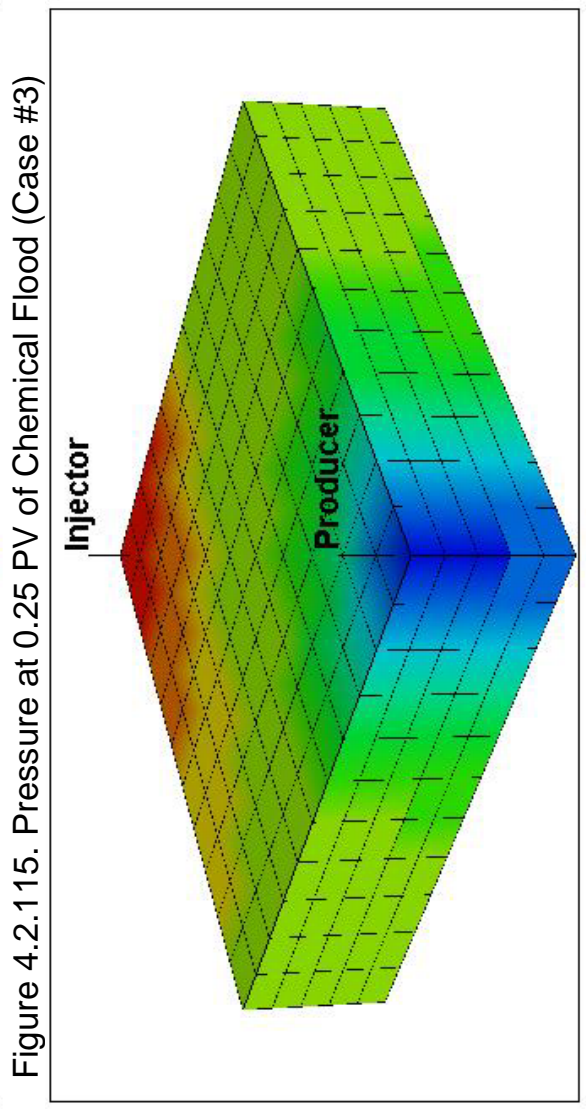

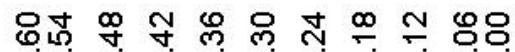
000000000
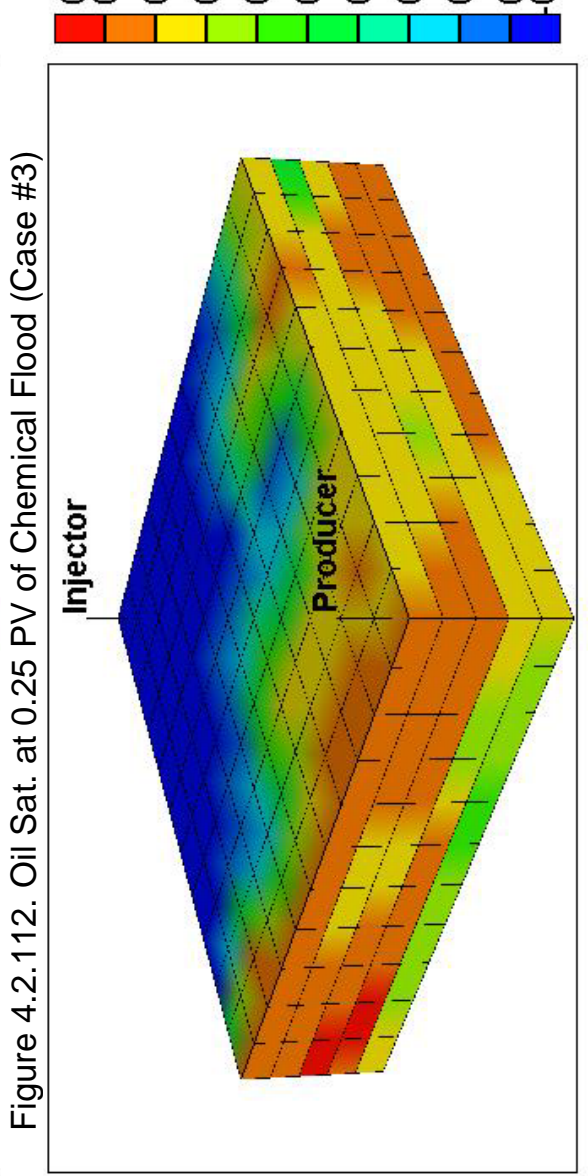

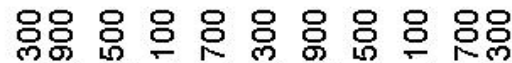

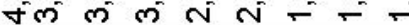

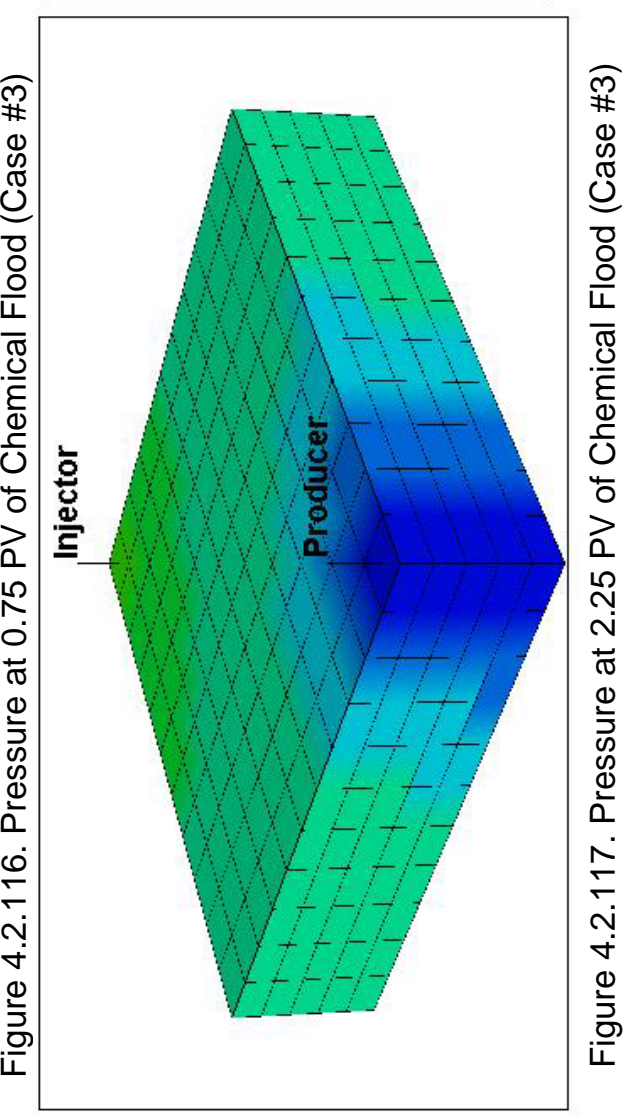

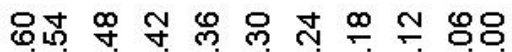
00 o 0 o 0 o 0000

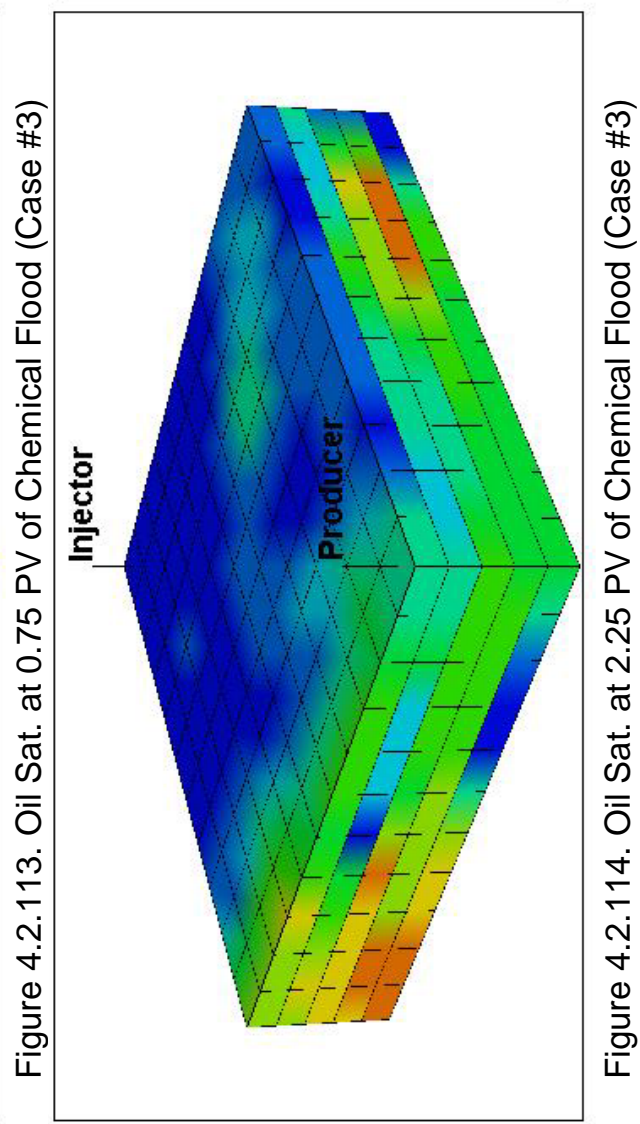




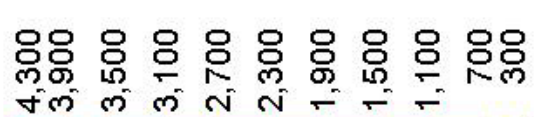
वलm

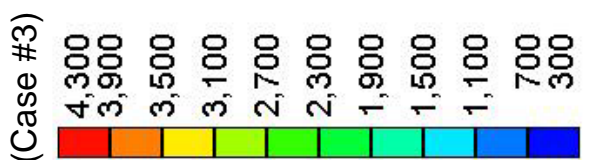

$\widehat{T}$
0
0
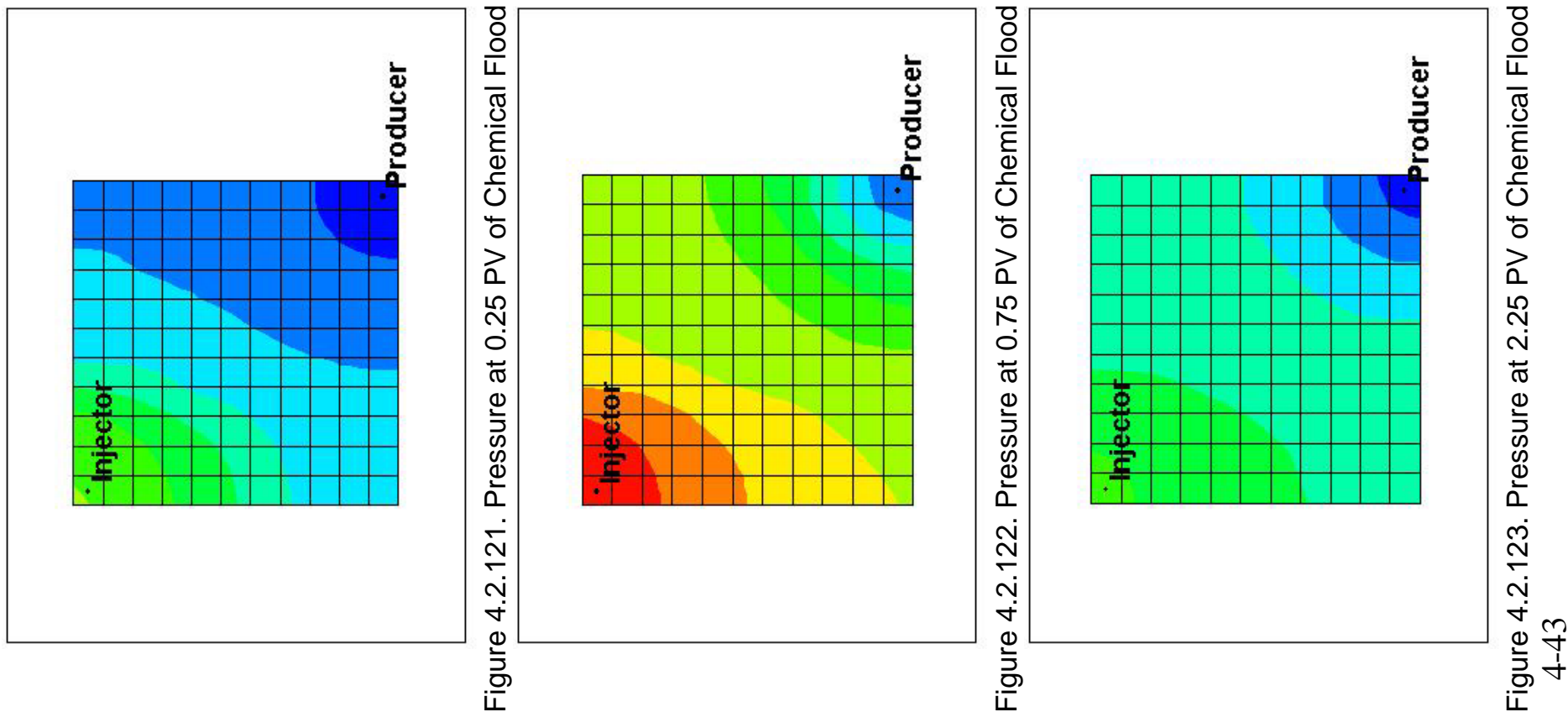

ஜீரீ
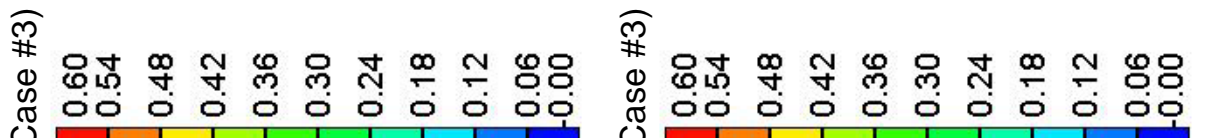

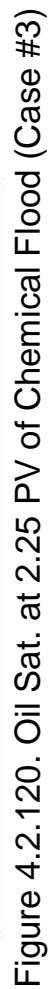
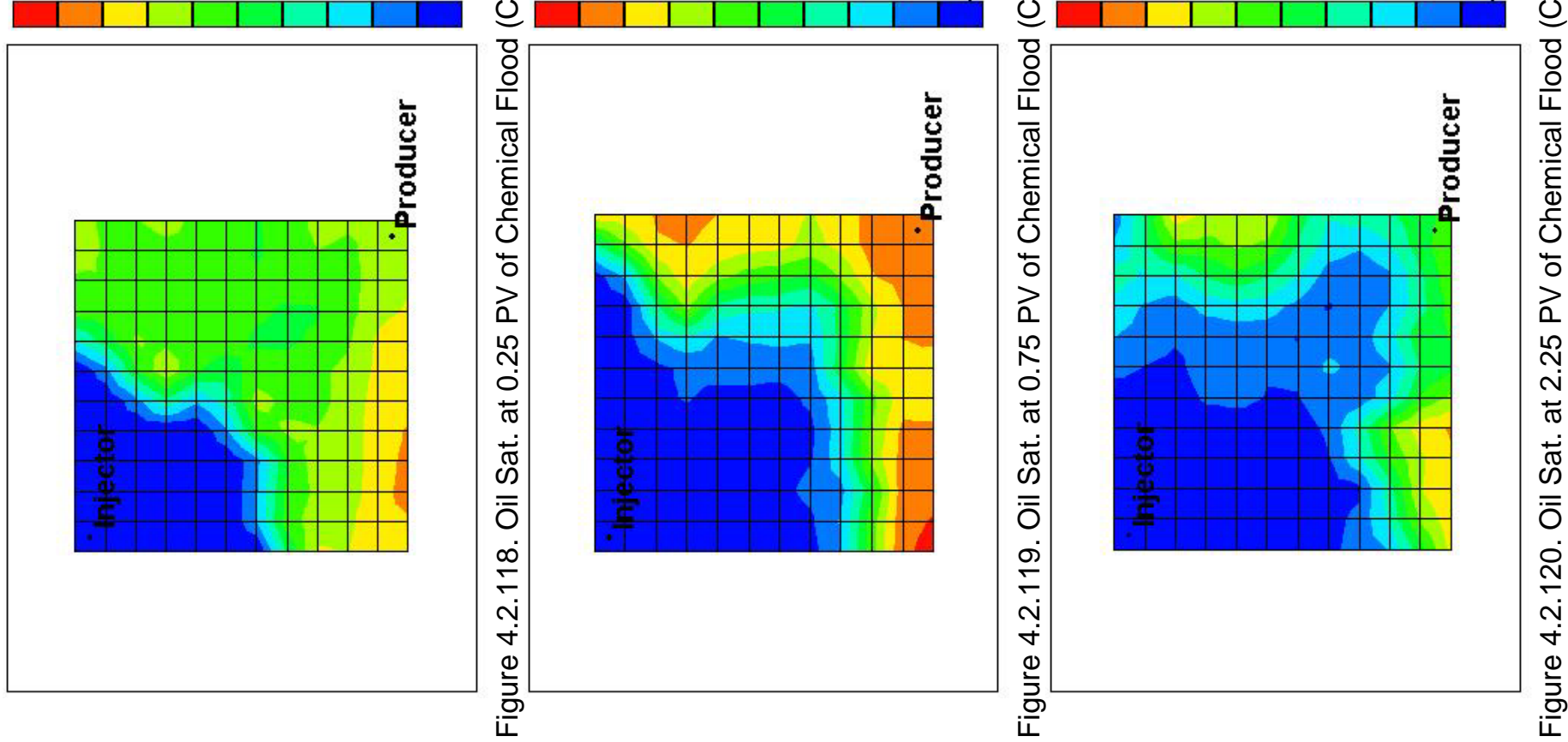


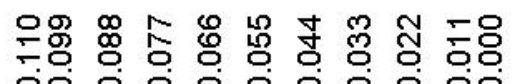
oiliiiiiva

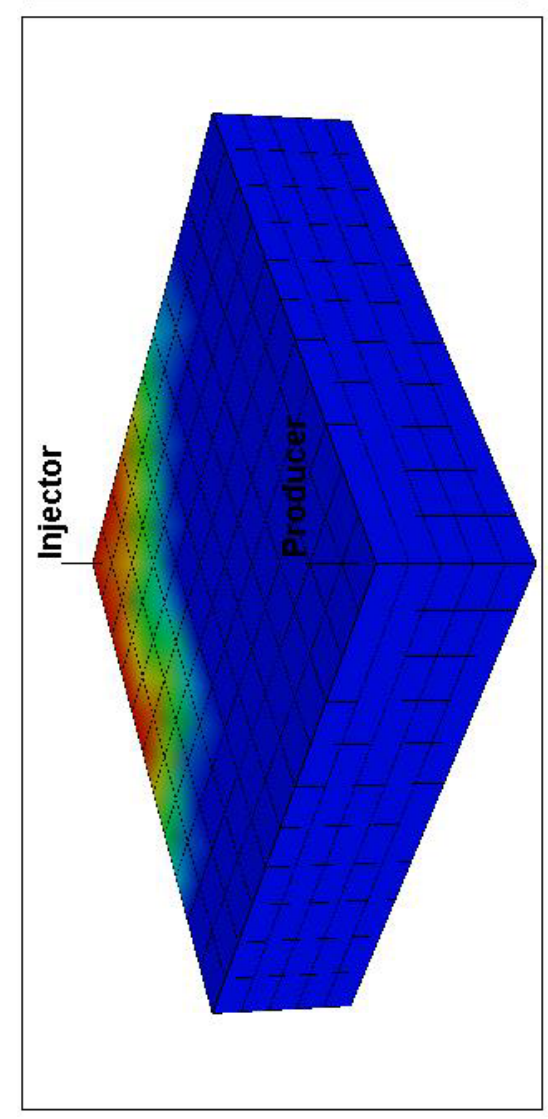

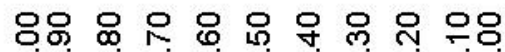
-o 0 o o o o o o o

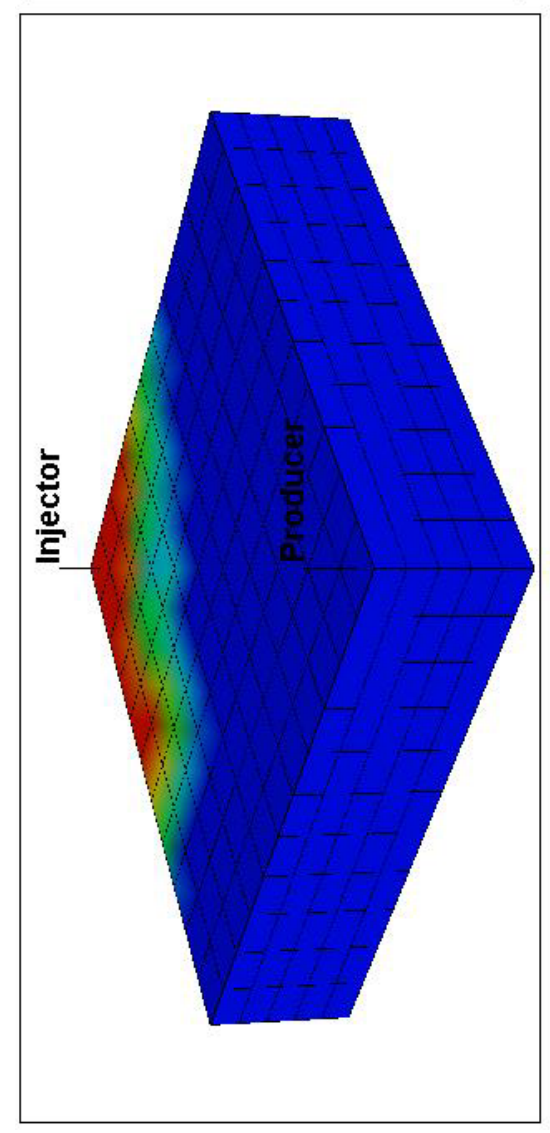

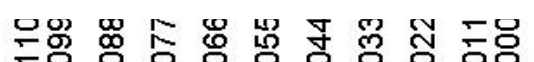

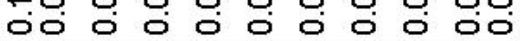

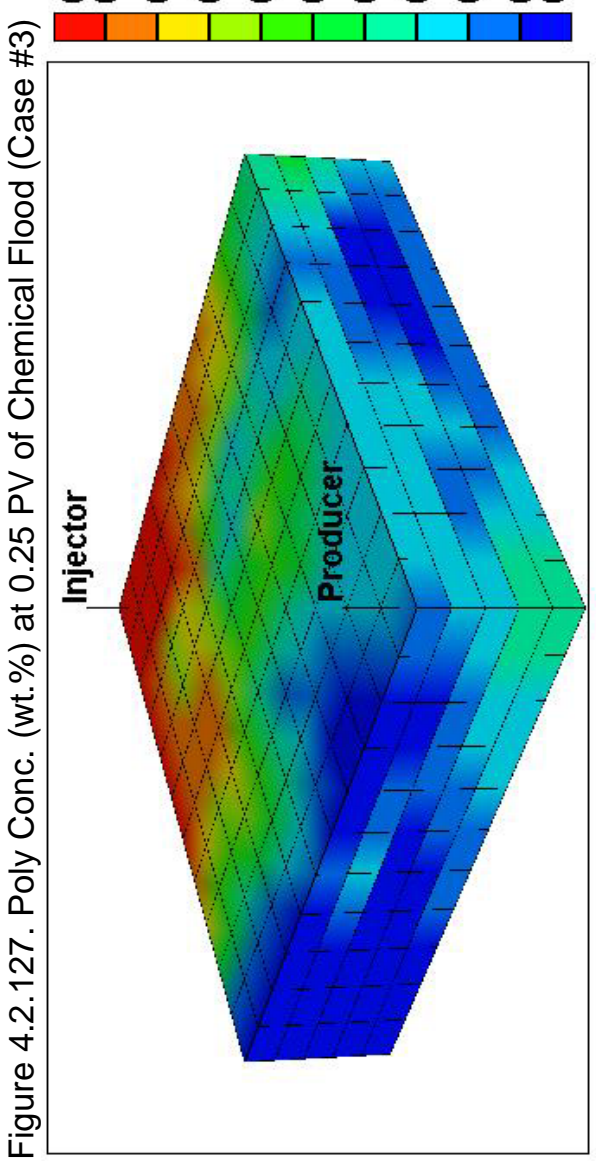

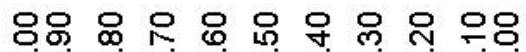
-o 000000000

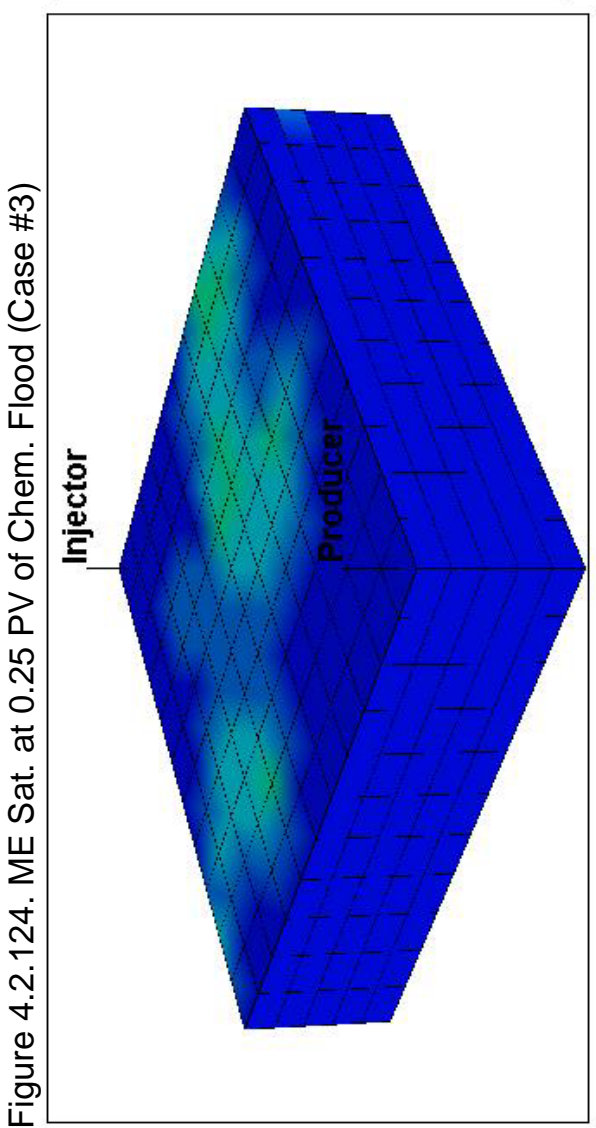

으 9 용 テૅ0.

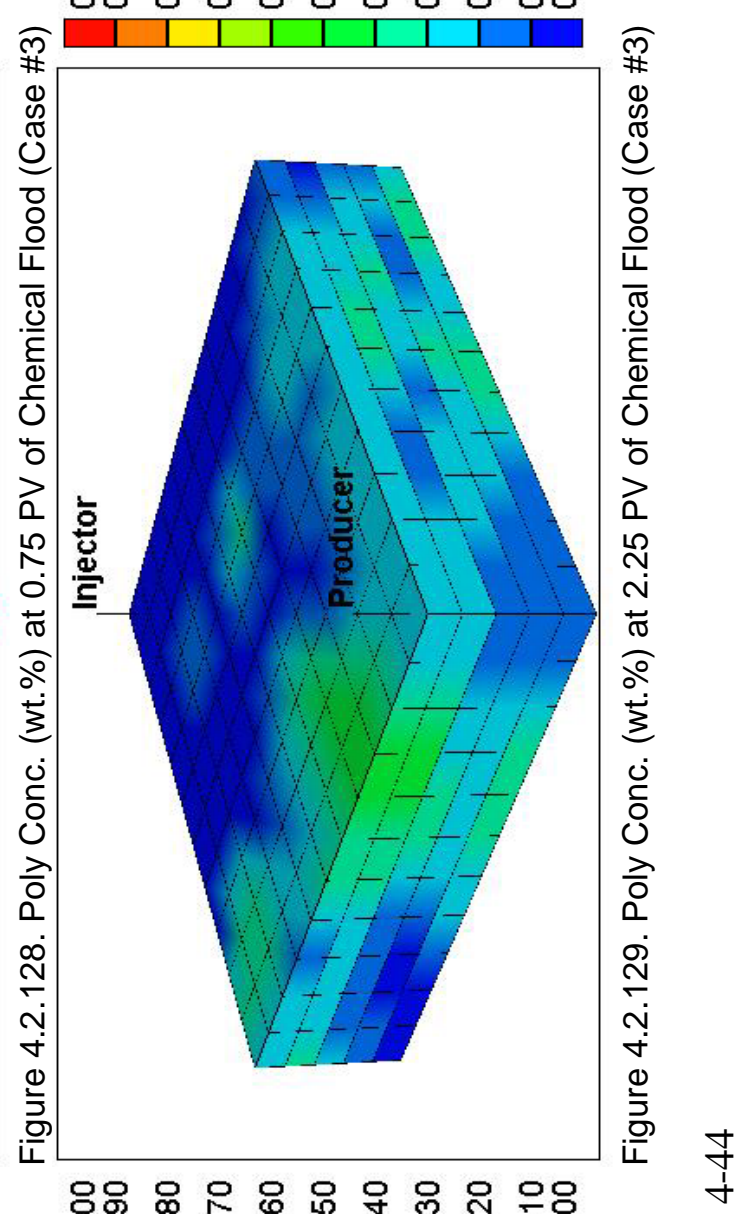
- 0 0 0 o 0 o 0 o 00

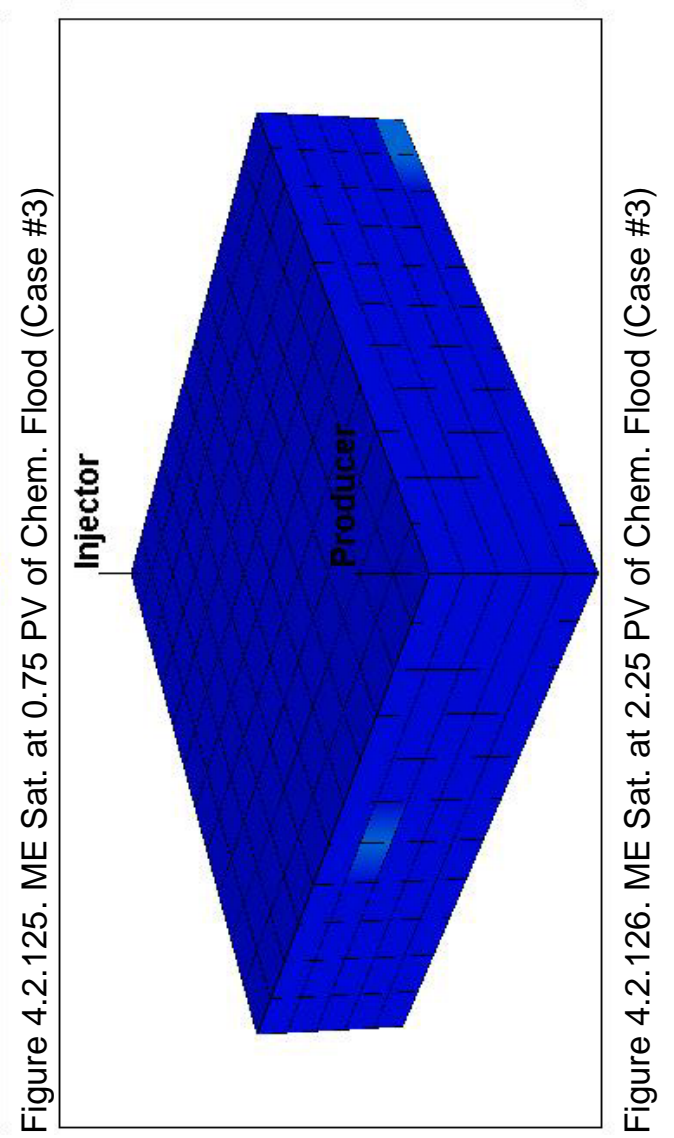




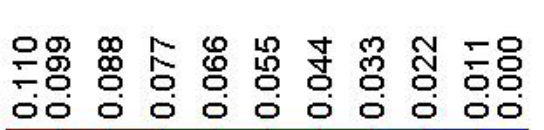

๓ึ

응

 刃 ㄷㅇㅇ
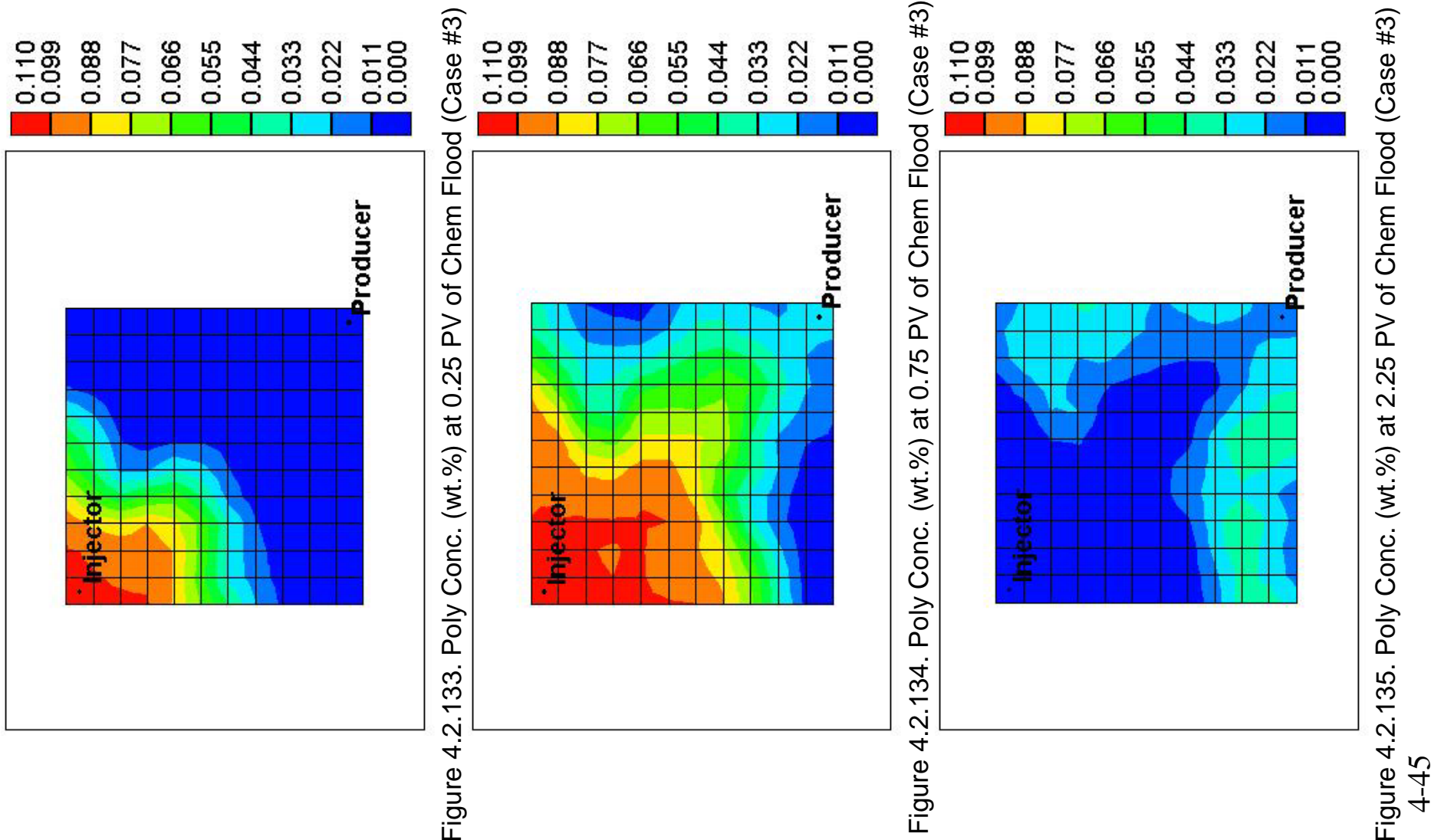

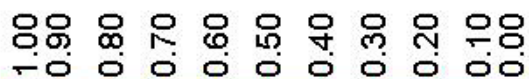
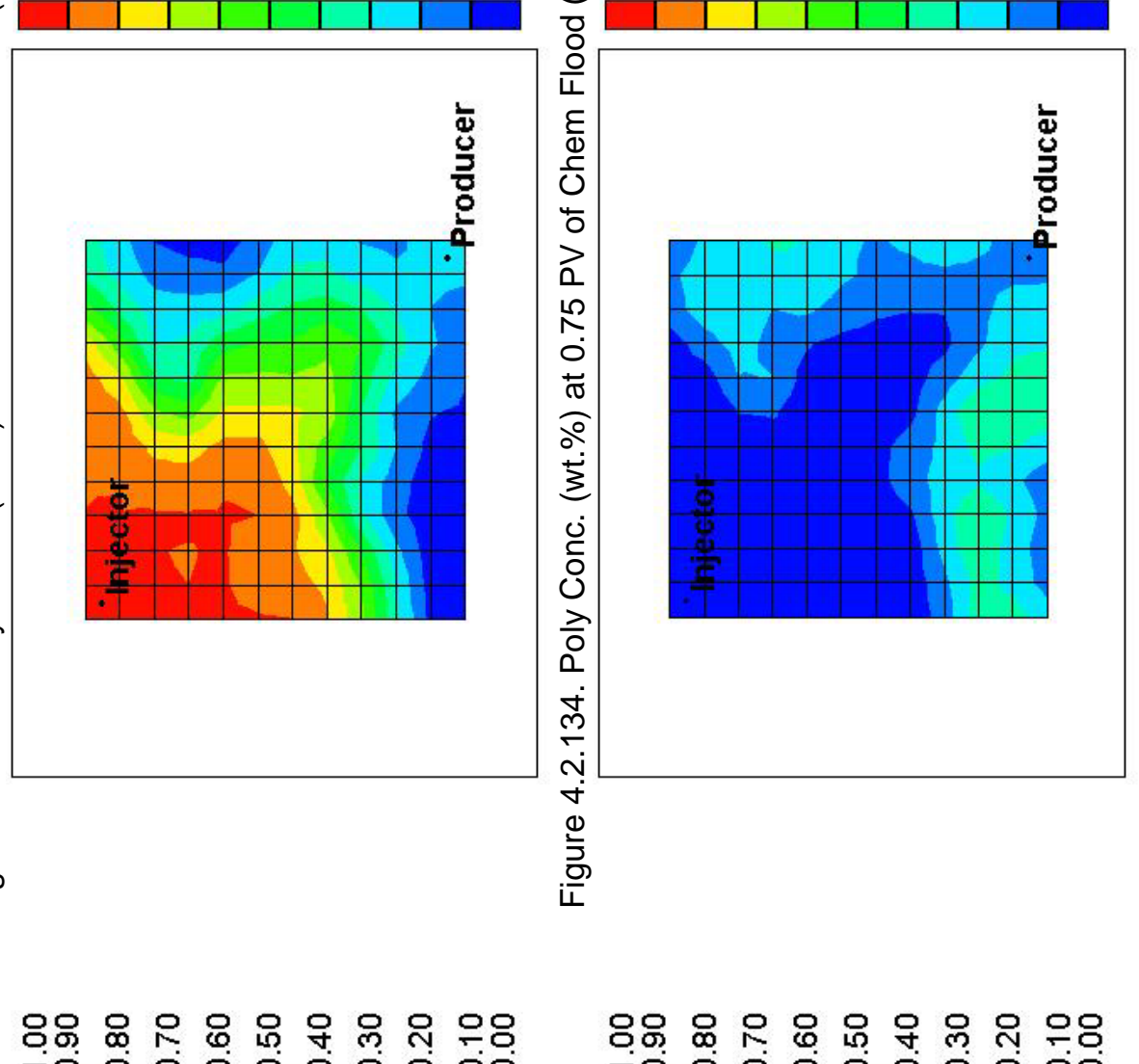

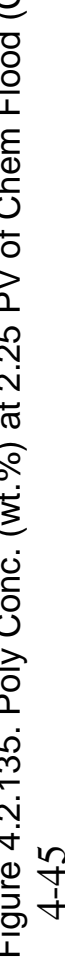
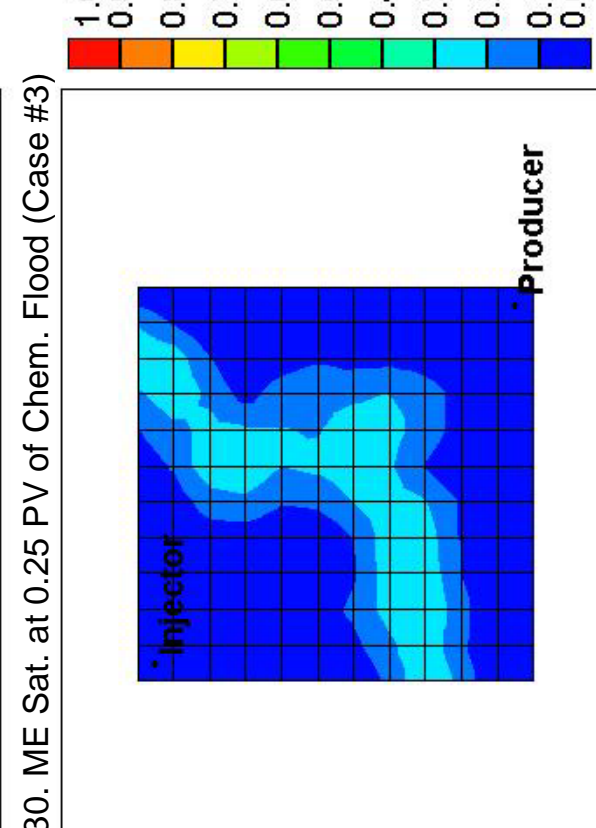

응유 웅 웅 융 웅 융 웅 응응 $\leftarrow 0$ o 0 o 0 o 0 o 00

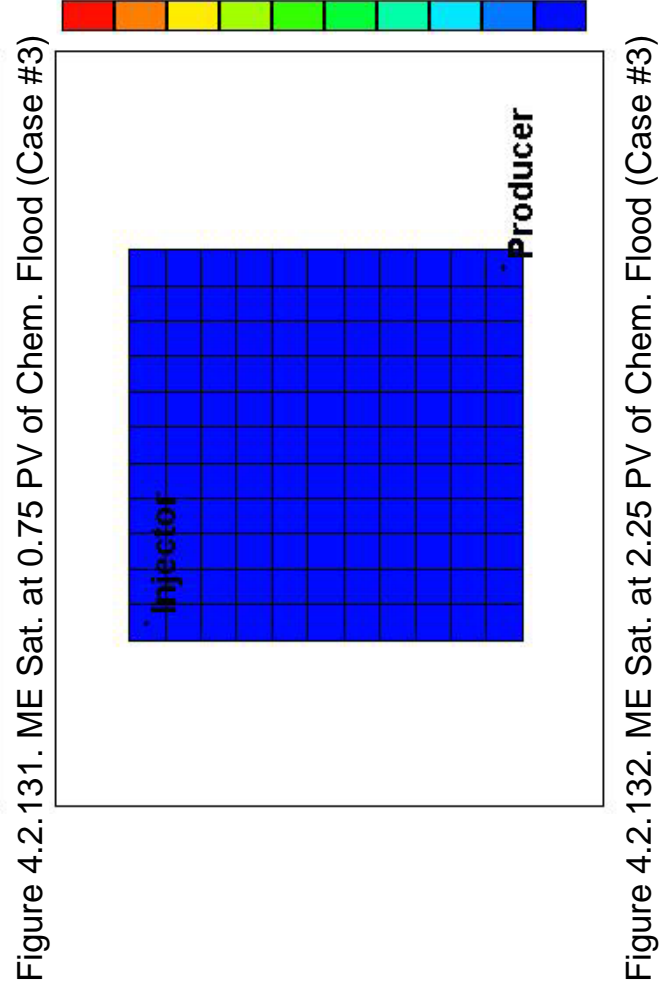



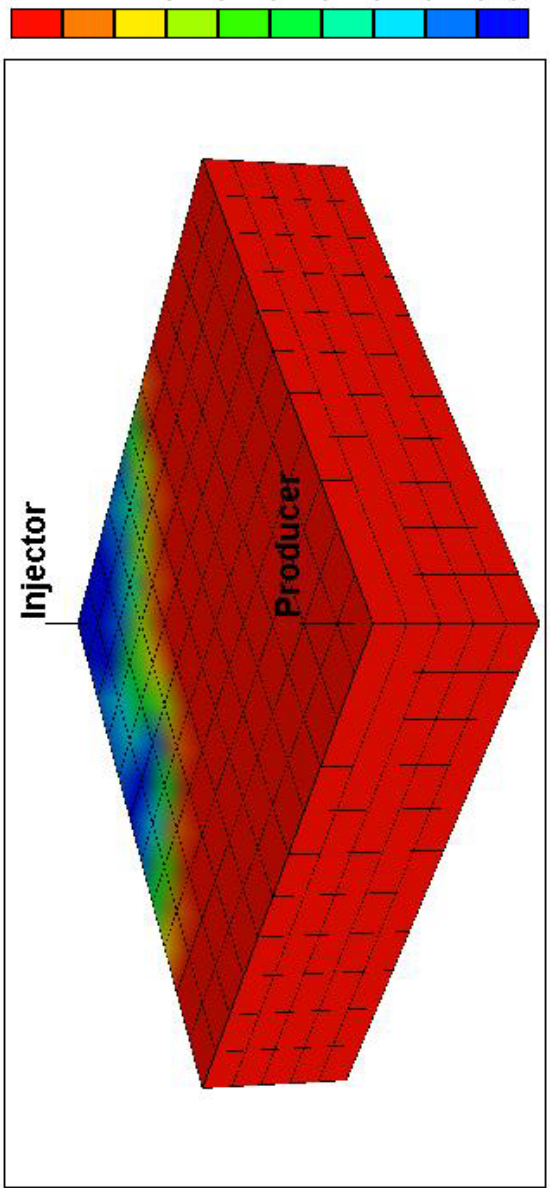

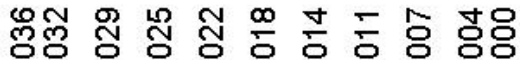

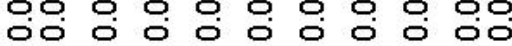

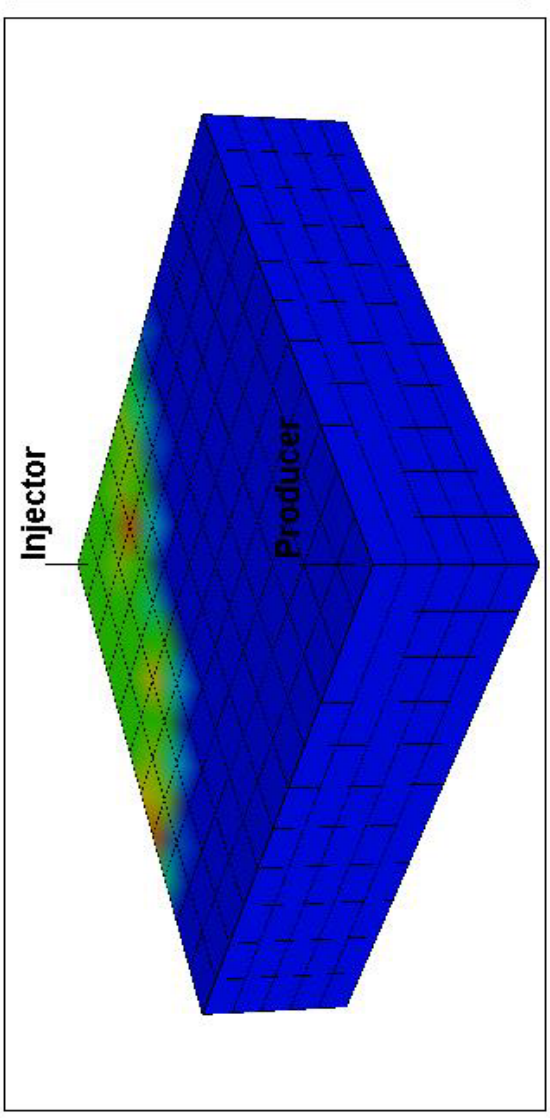

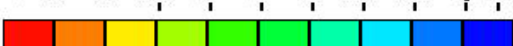

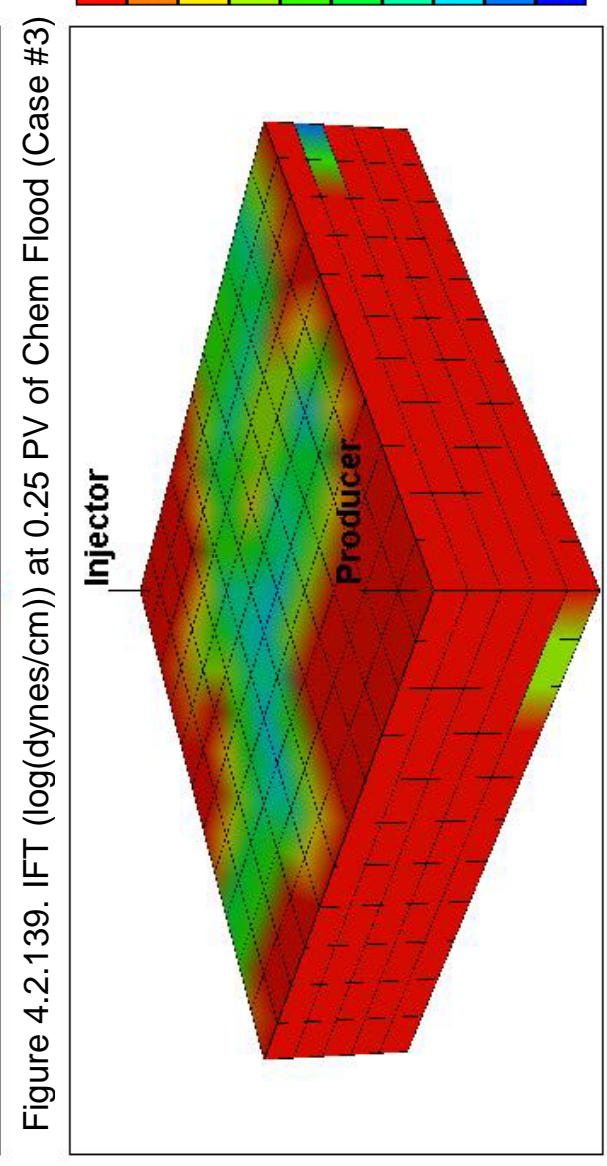

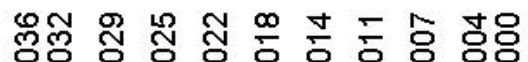

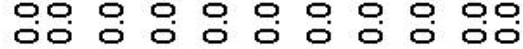

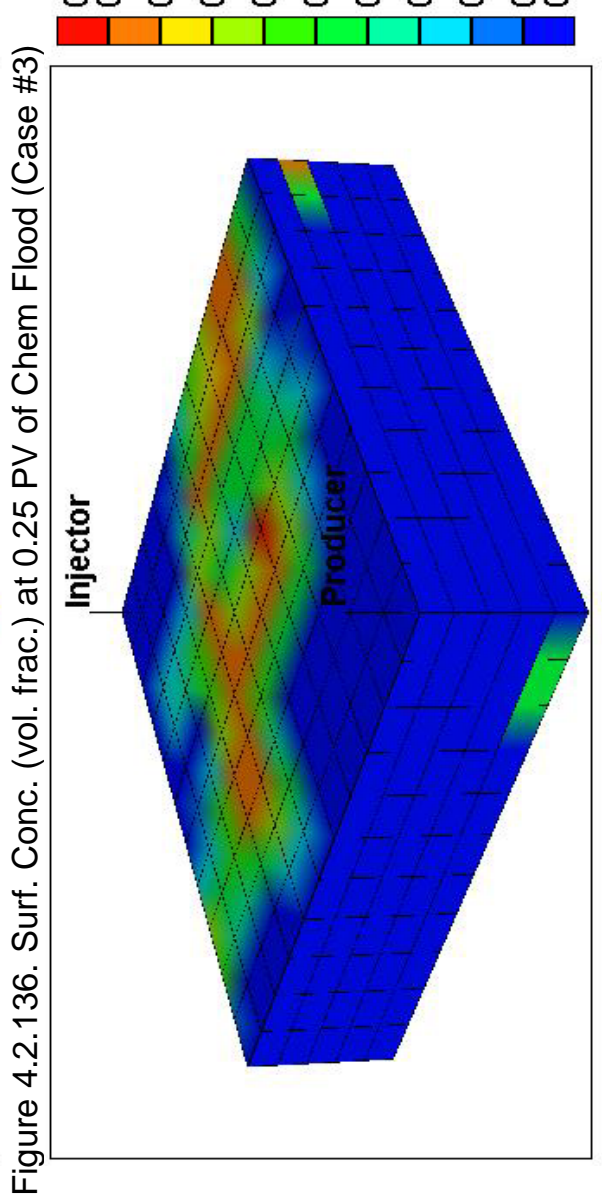

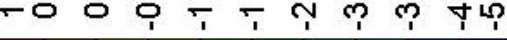

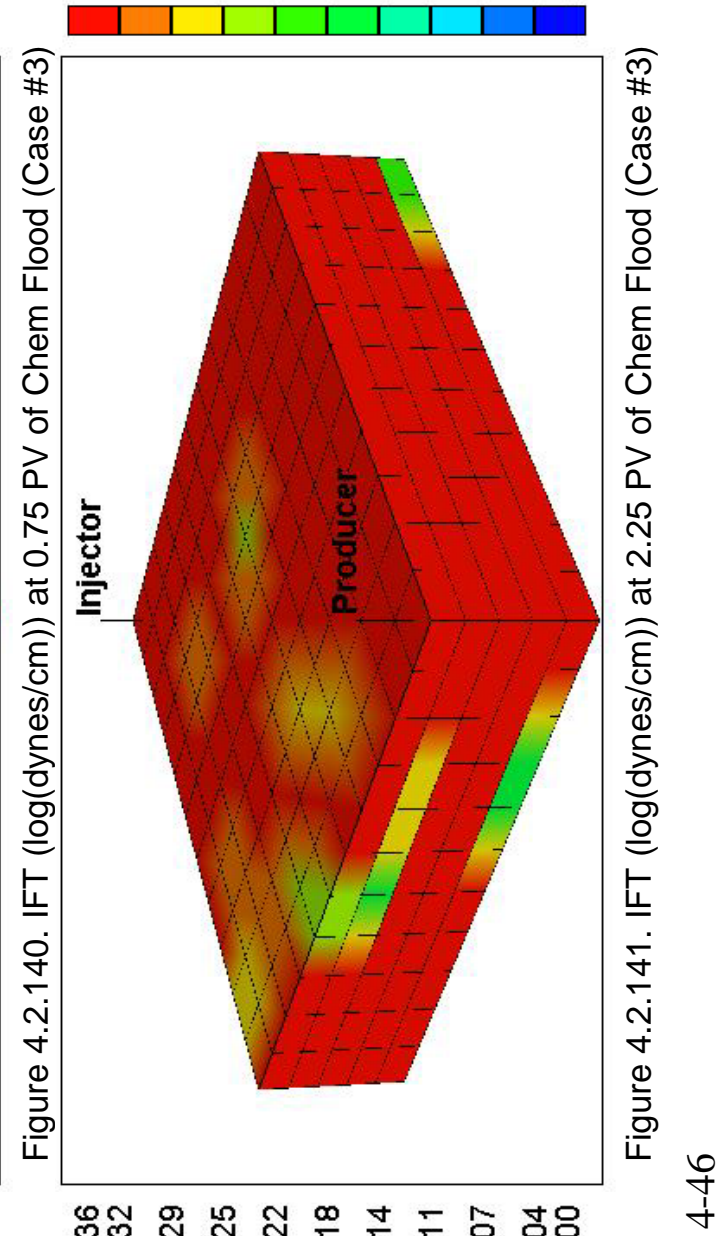

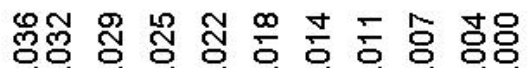
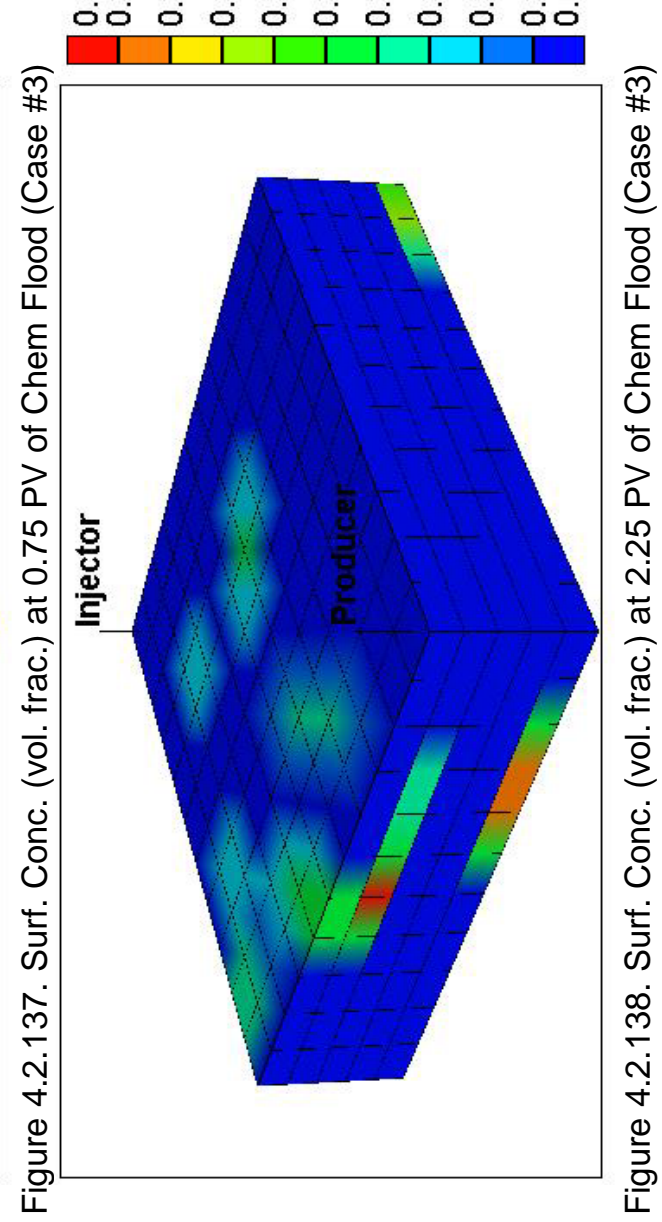
भ人o

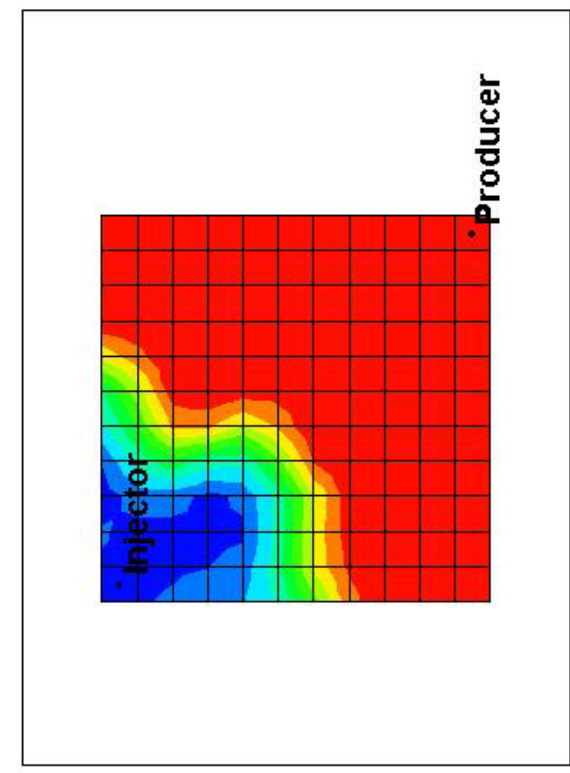

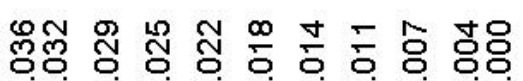

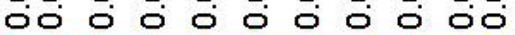

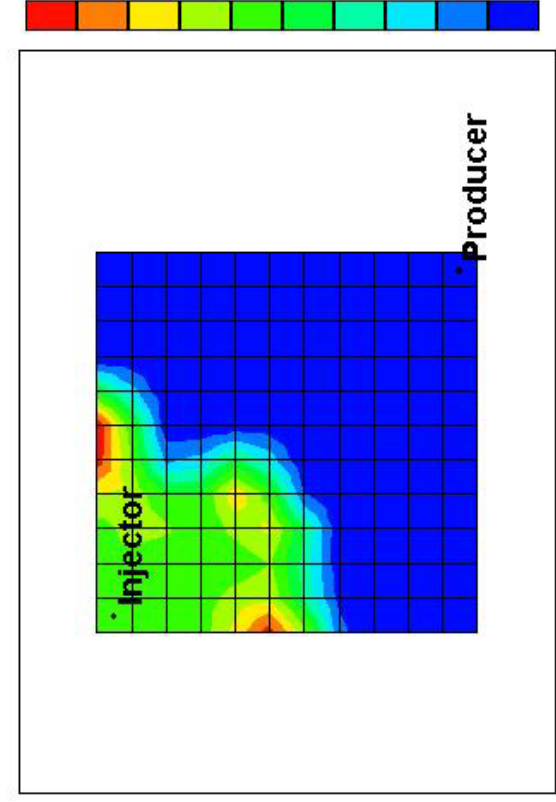

0
$\#$
0
0
0
0

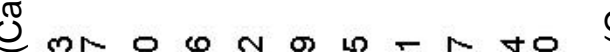
ठํㅇำ

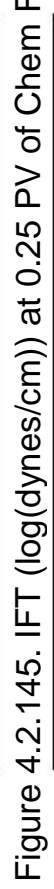

$\widehat{\text { \# }}$

里

mM 0 \%

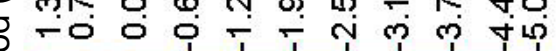

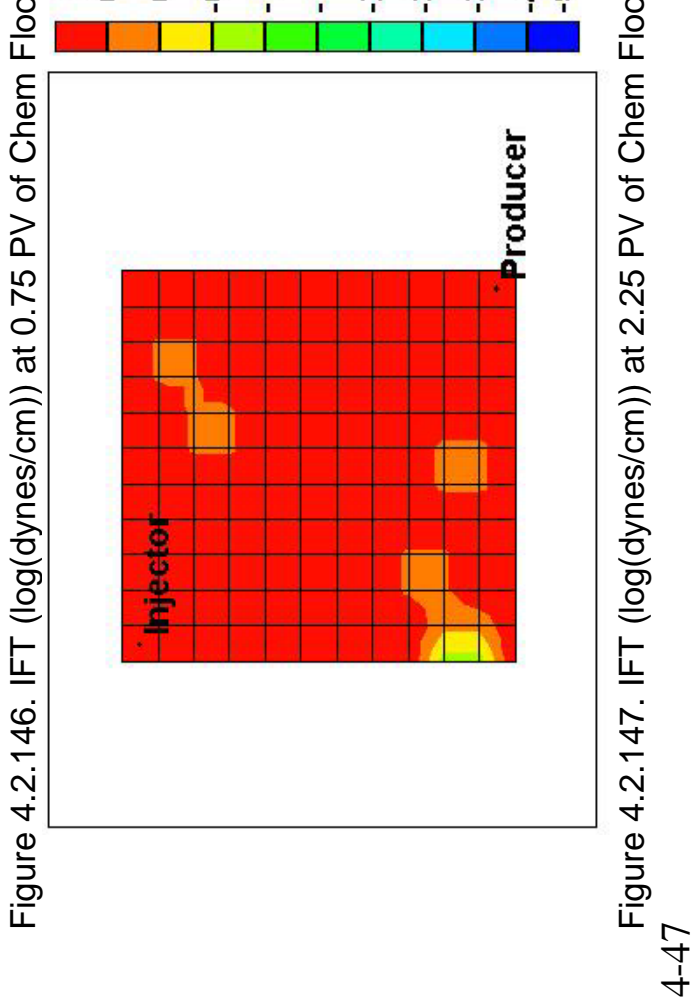

ตั

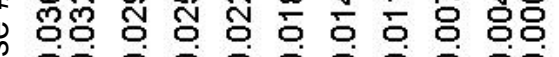

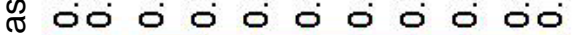

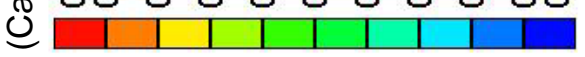

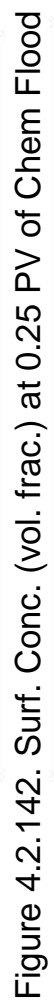

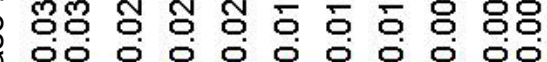

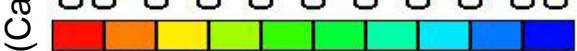

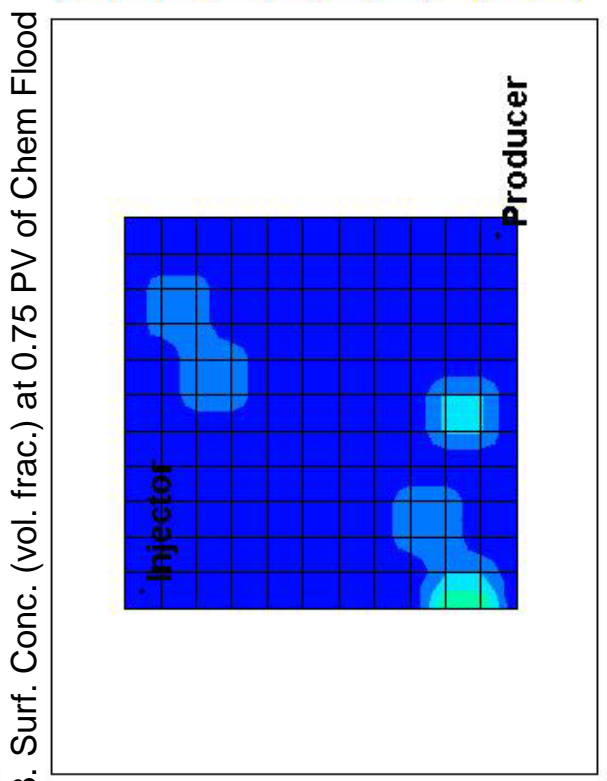

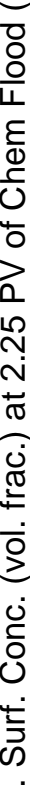




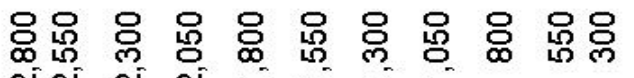
ก ก N N

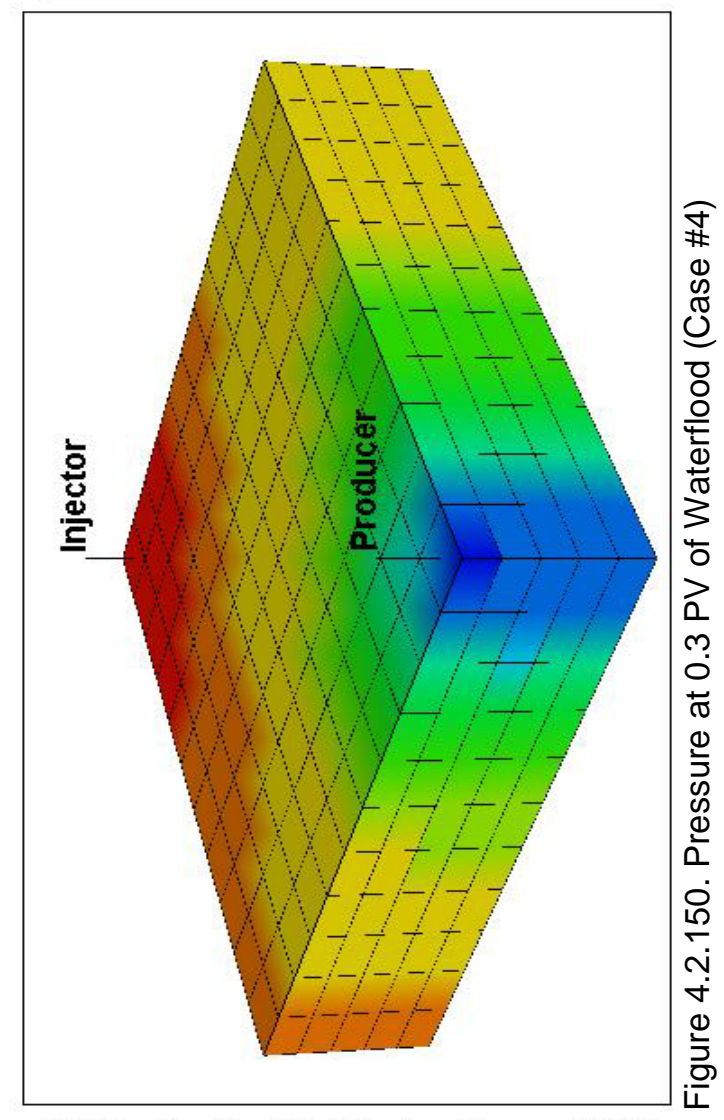

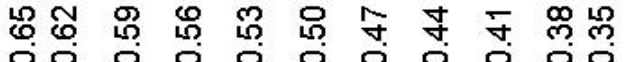
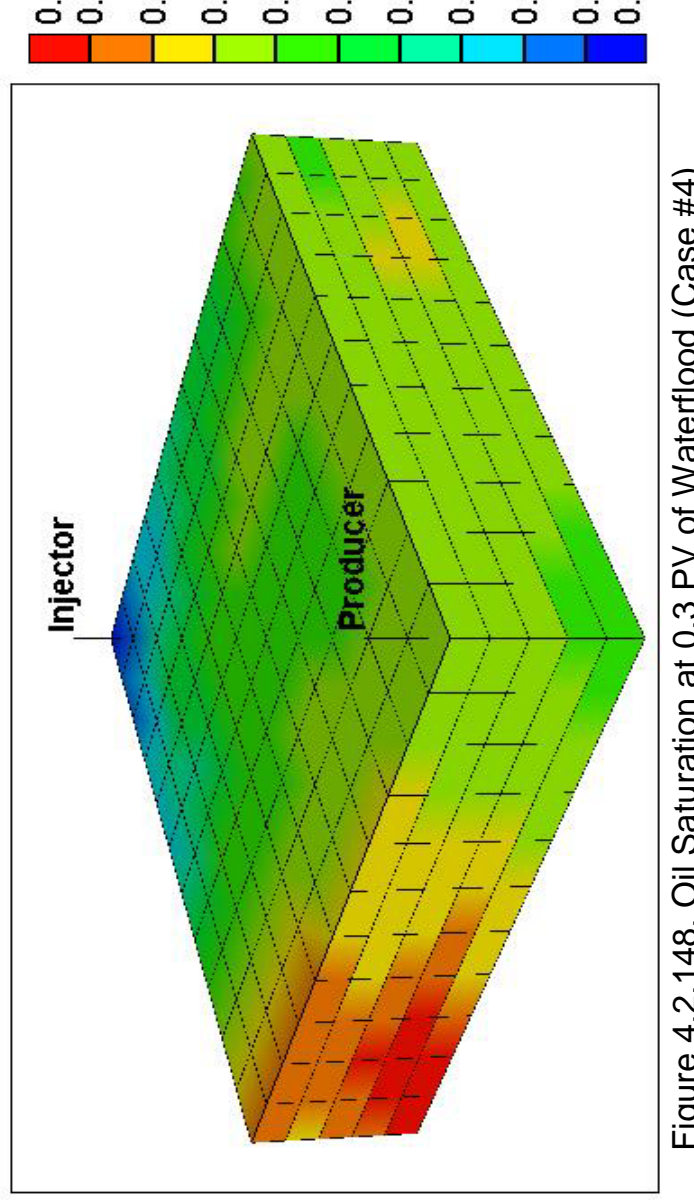

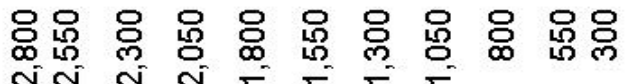
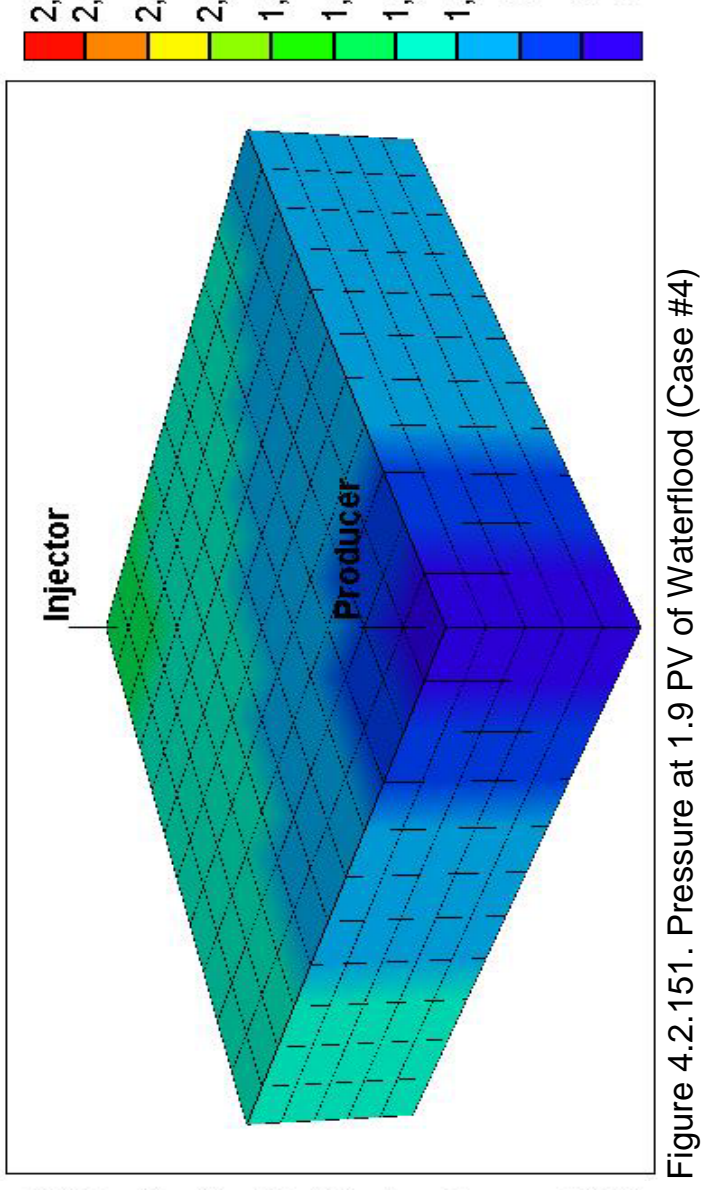

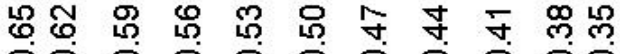

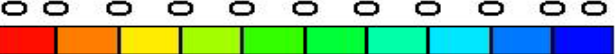




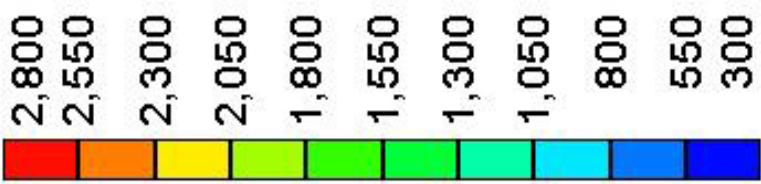

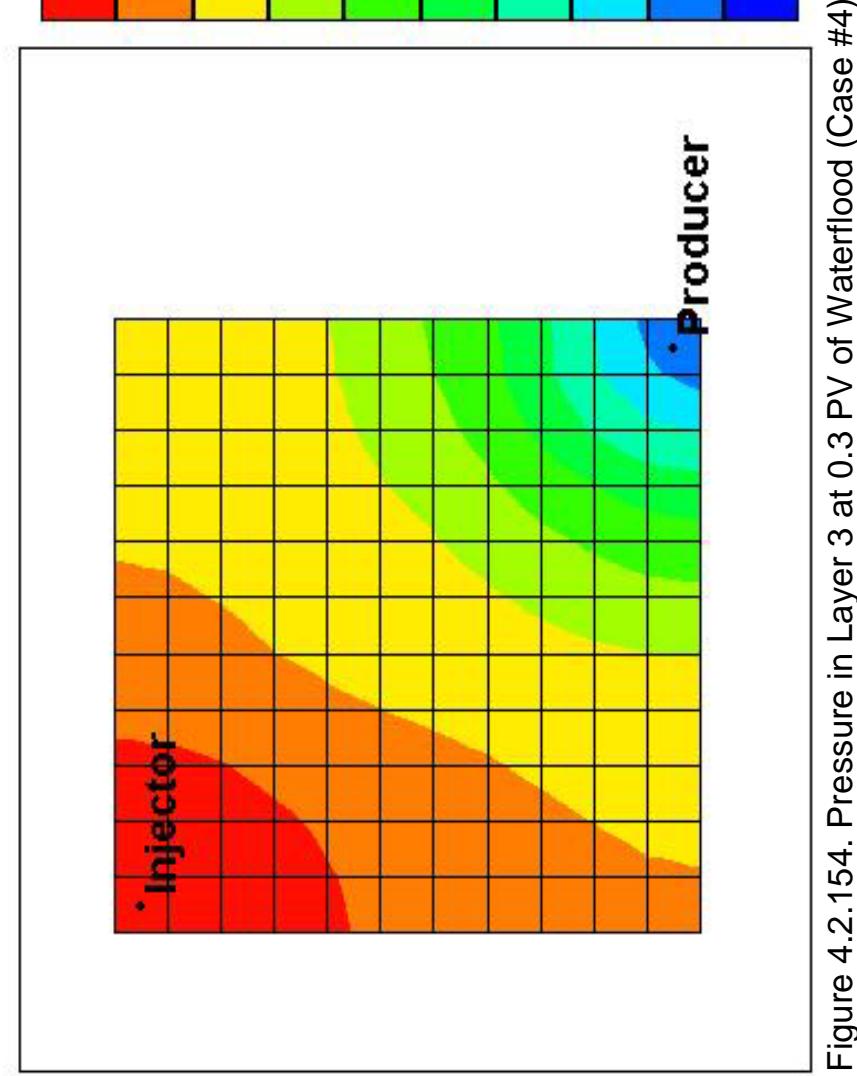

แ

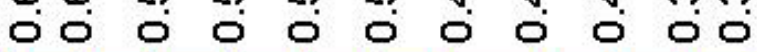

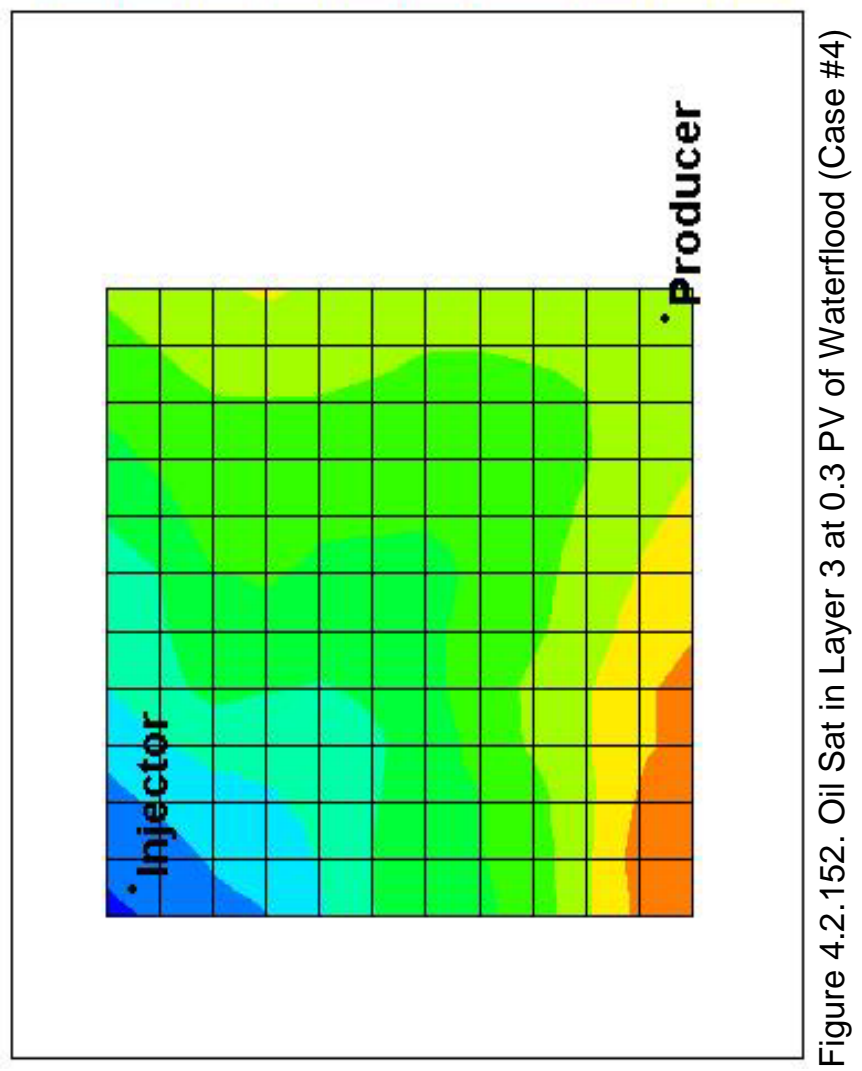

응ํํ 응 융

กั ก N

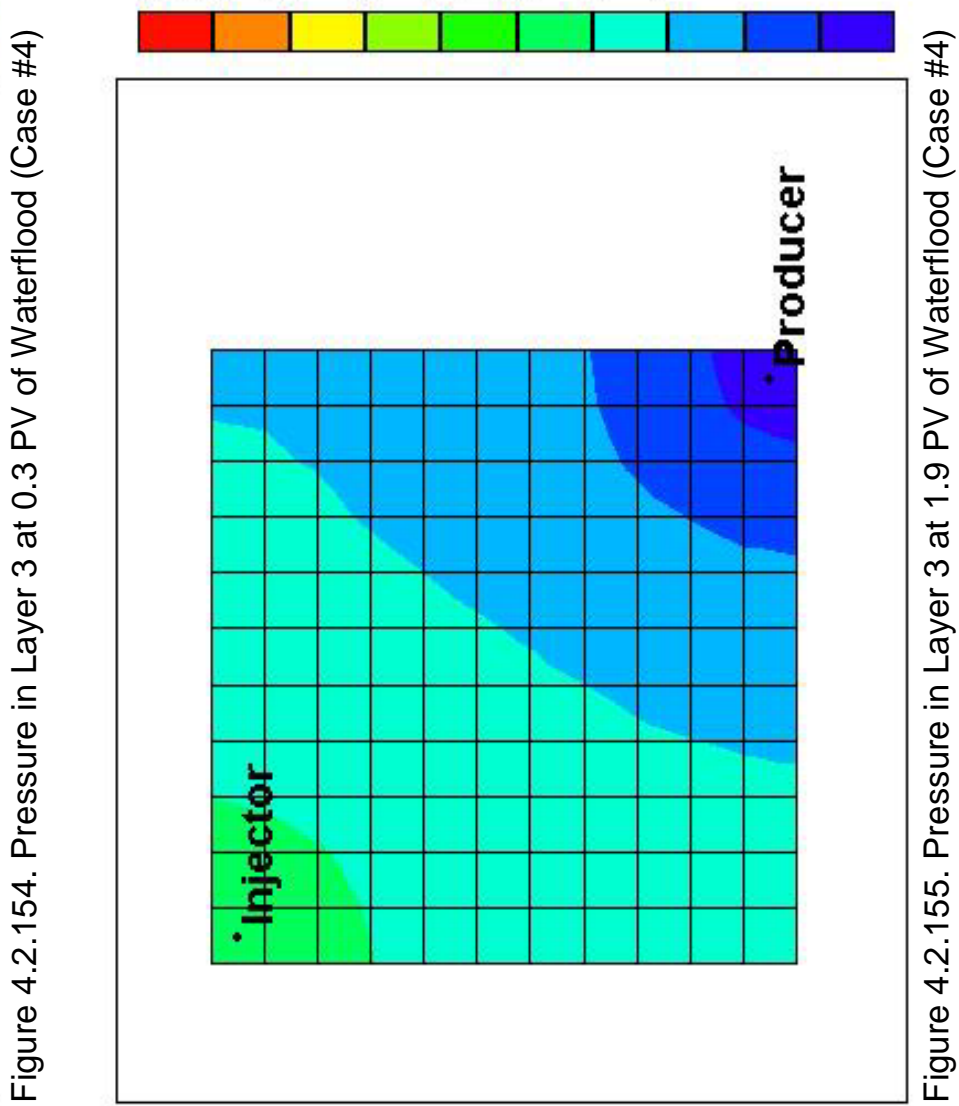

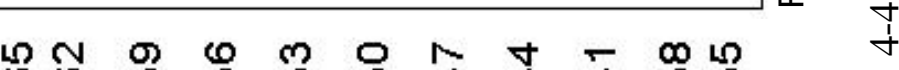

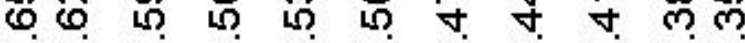
응으응응ㅇㅇㅇ응

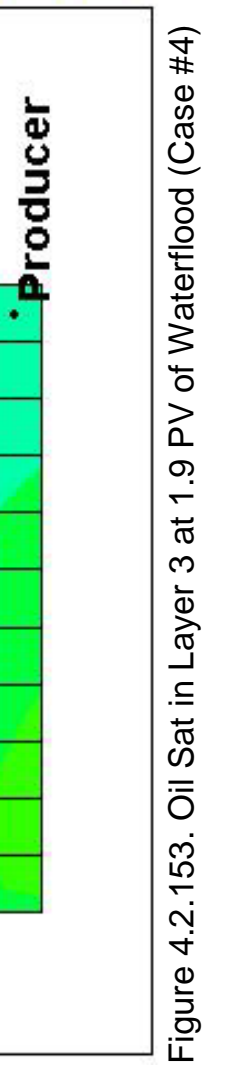




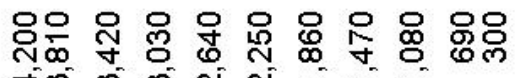
पे लो लं ते $=-$

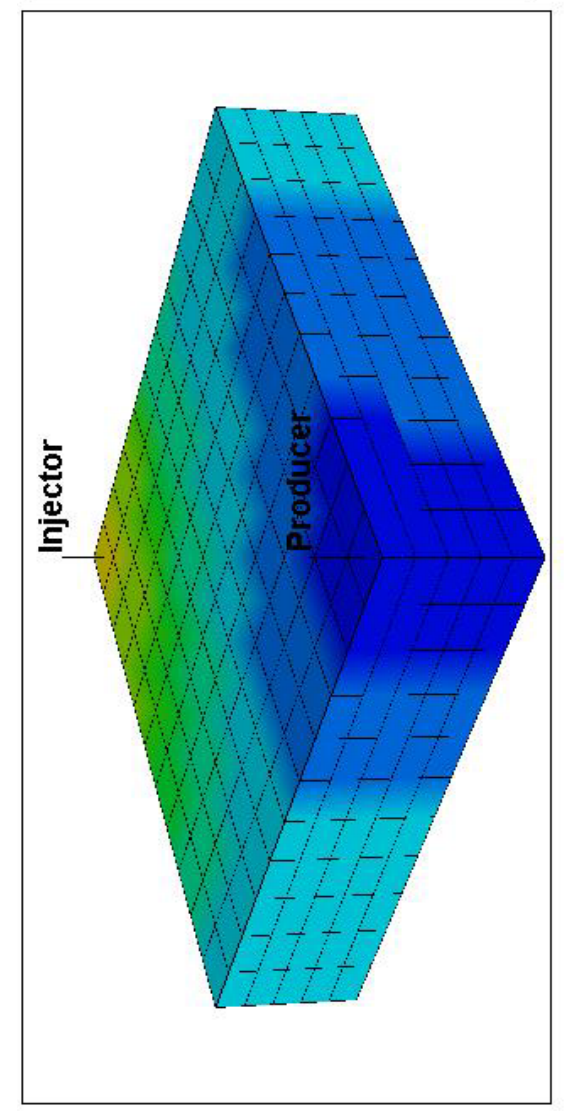

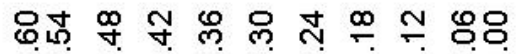

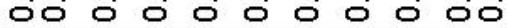

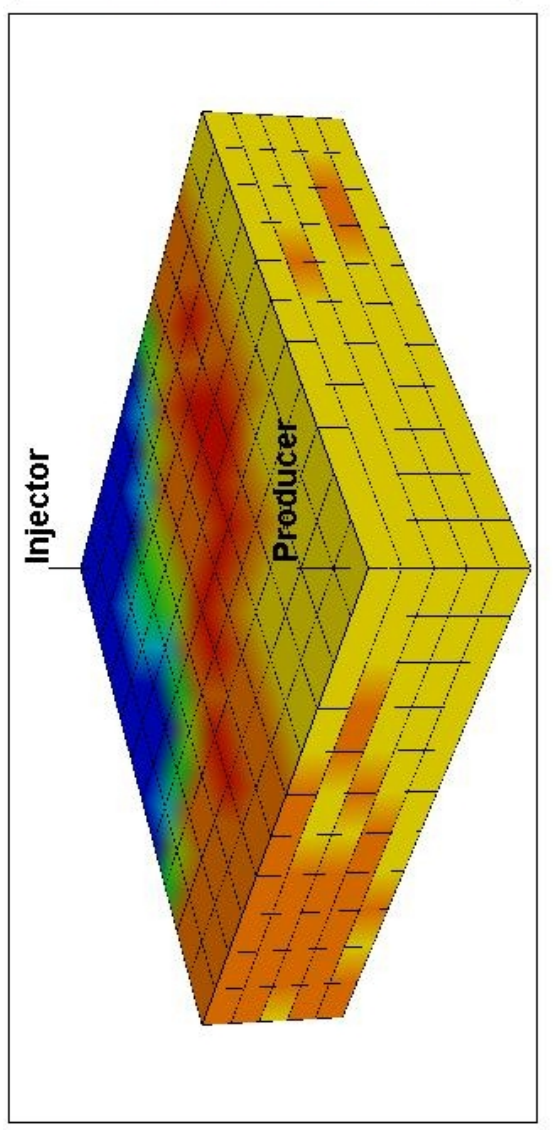

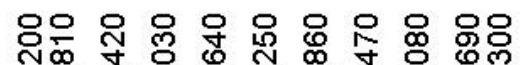
चल लं लं N - - -

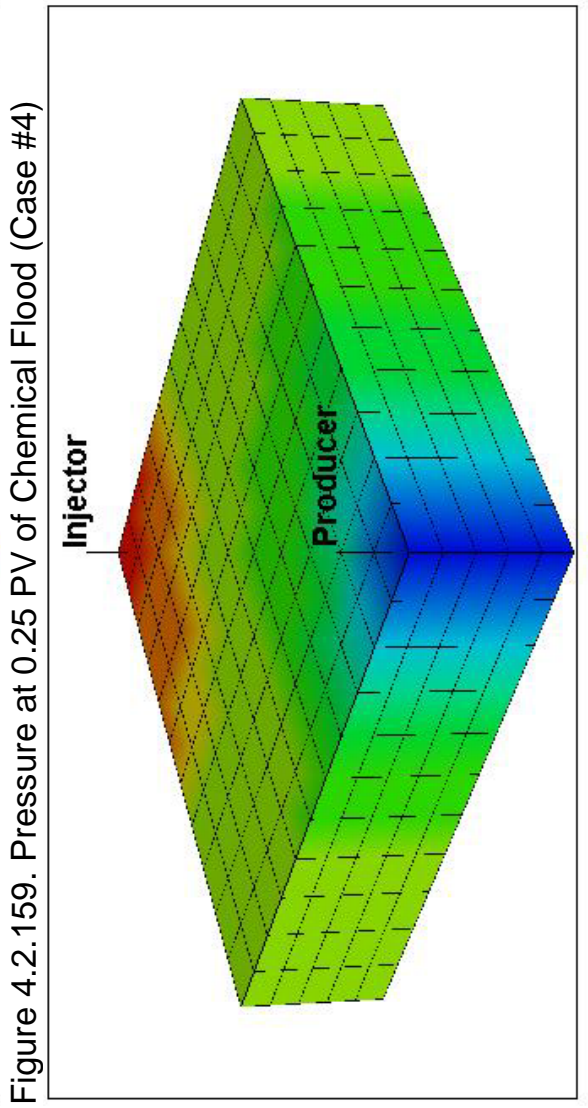

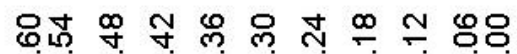
- 00000000

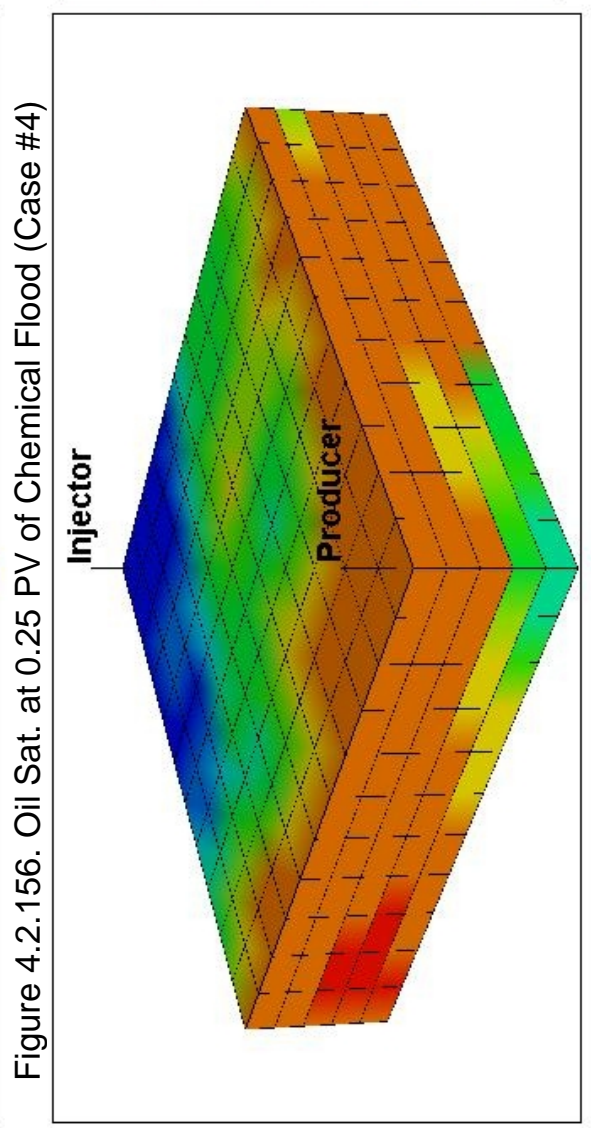

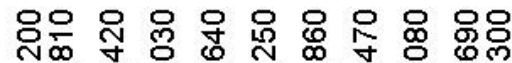
ปm ल लं $N$ N $=-$

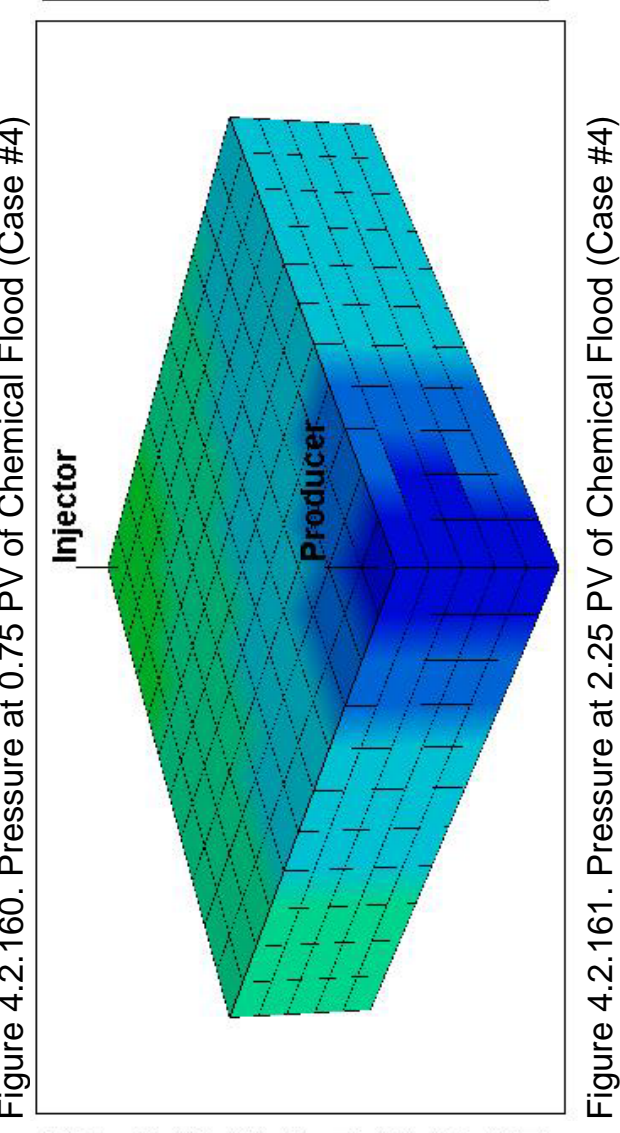

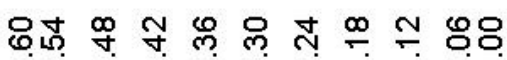

o 0 o 00 o 00 o

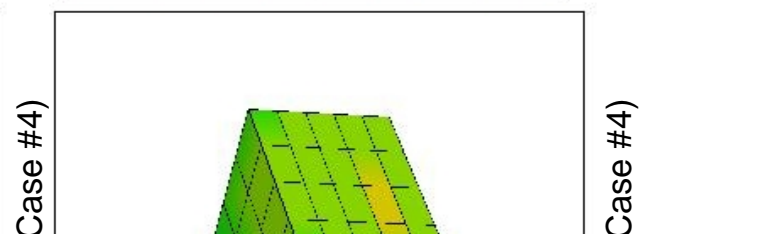




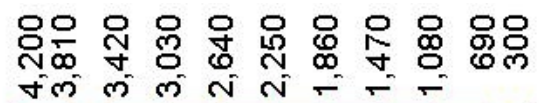
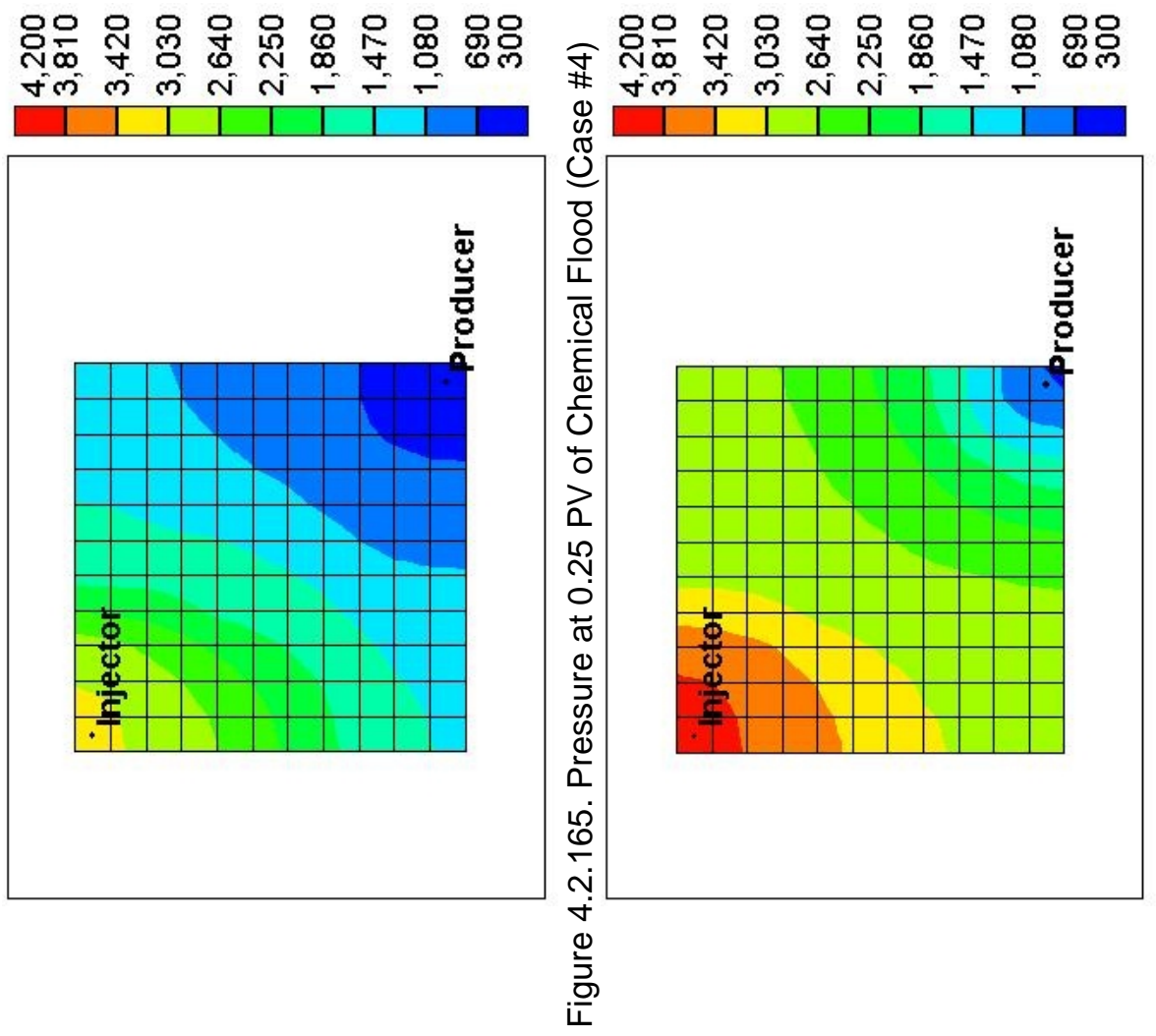

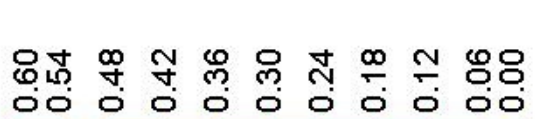
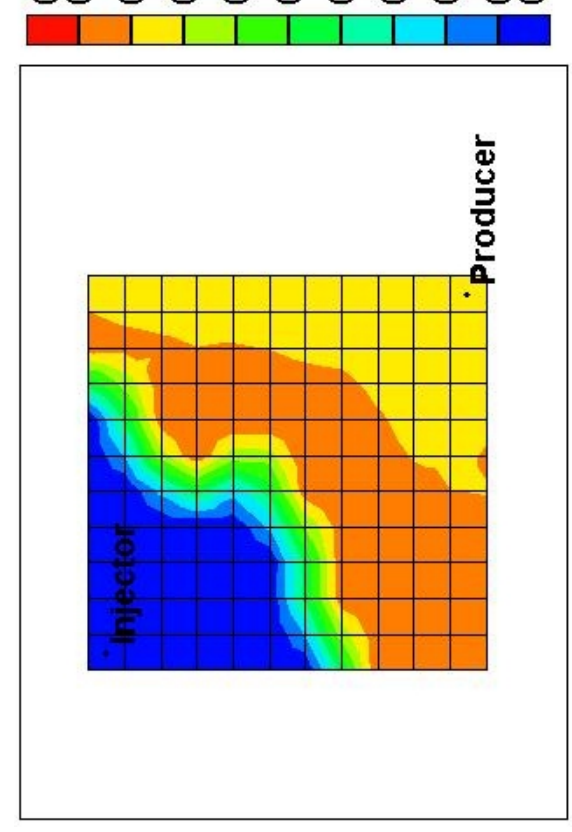

\#

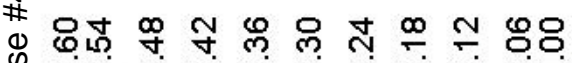
\& 00 O

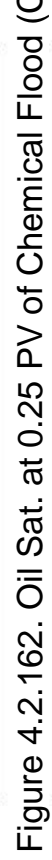

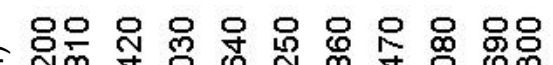

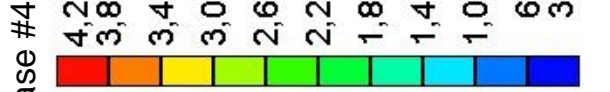

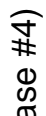

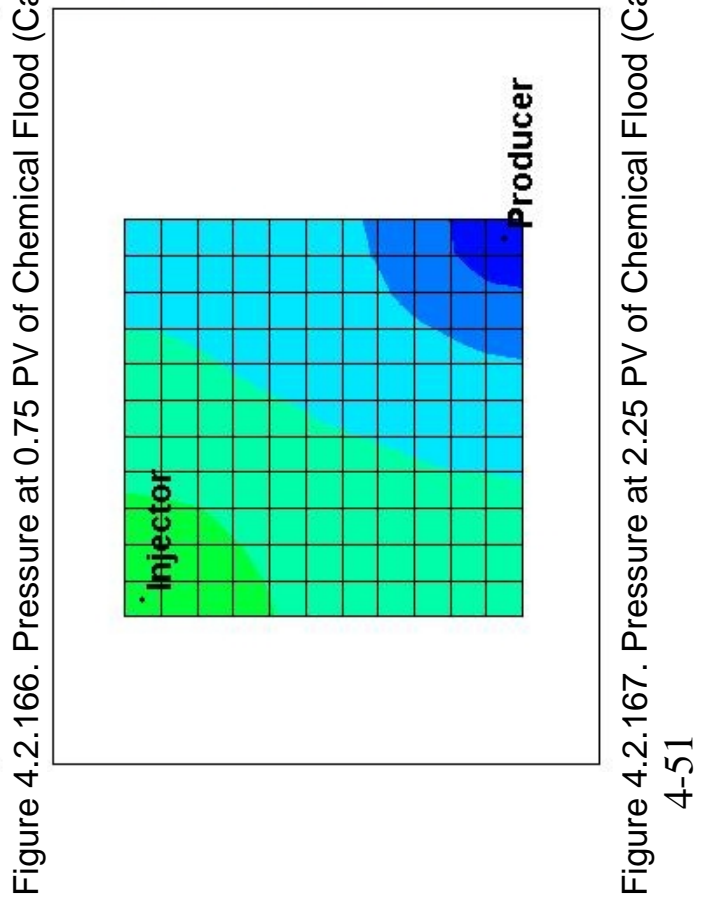

훈 $\underset{\$}{\#}$ ๒ํํำ ๆ ช

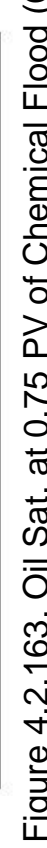




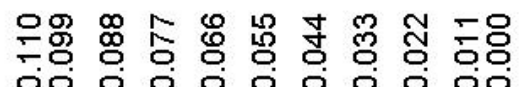
年i

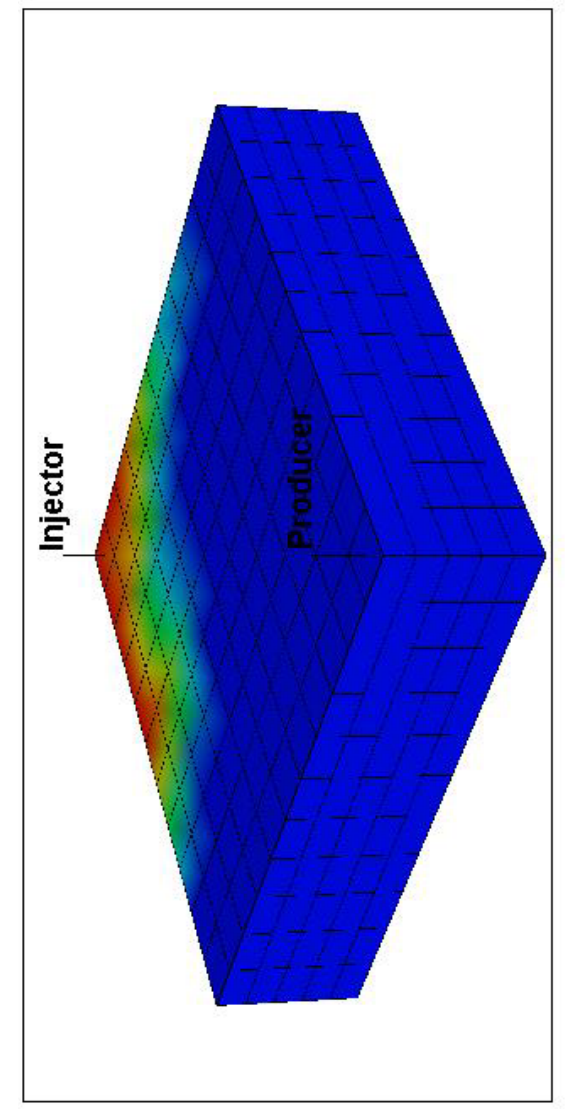

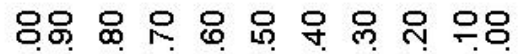
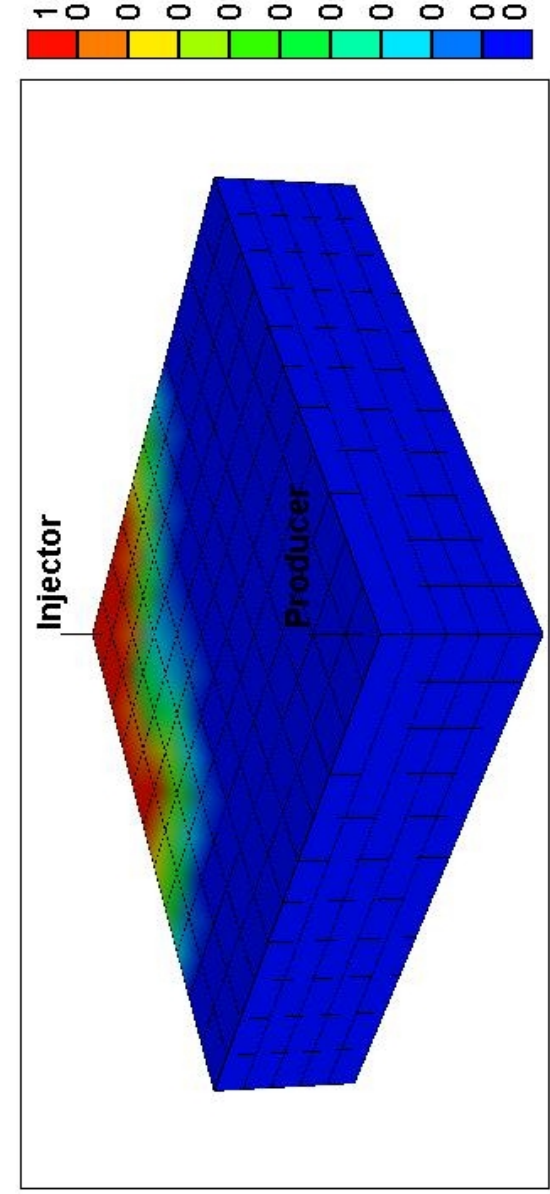

윽융 \&

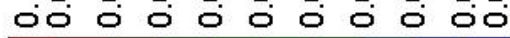

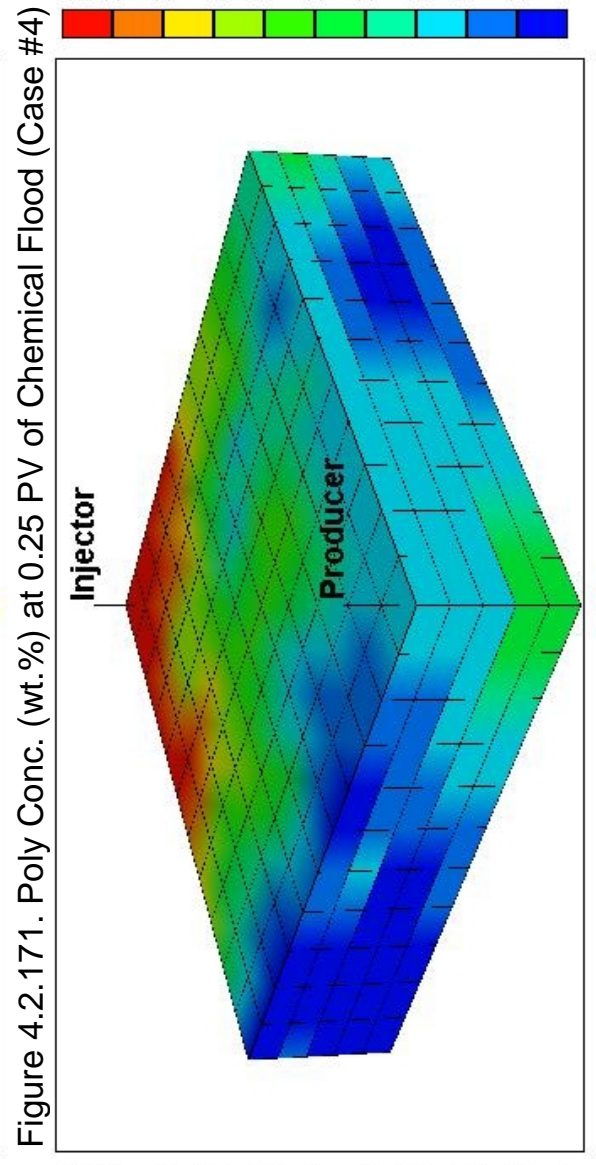

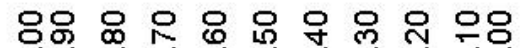
-0 000000000

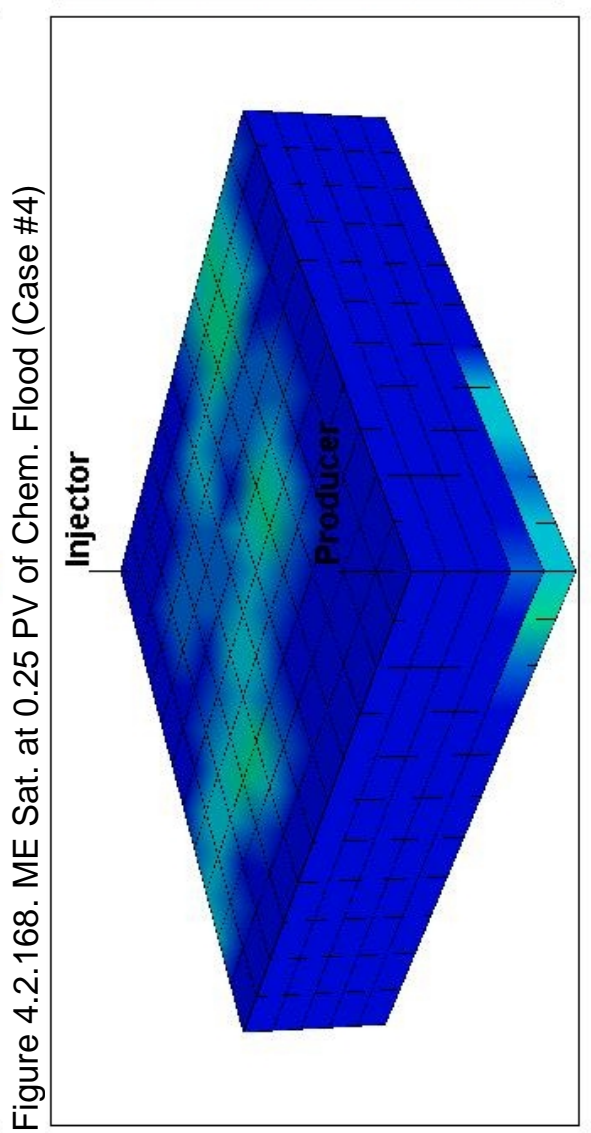

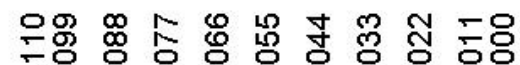
ió 0 O

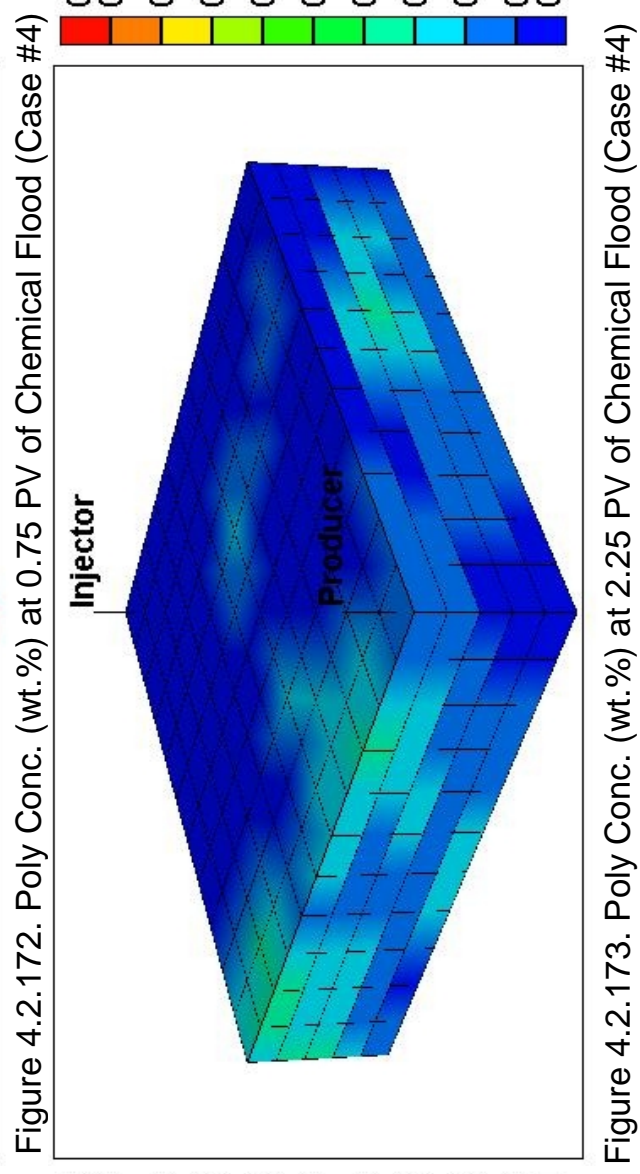

응용ㅇㅇㅇㅇㅇㅇㅇㅇㅇㅇㅇ응 -0 0 o 0 o 0 o 000

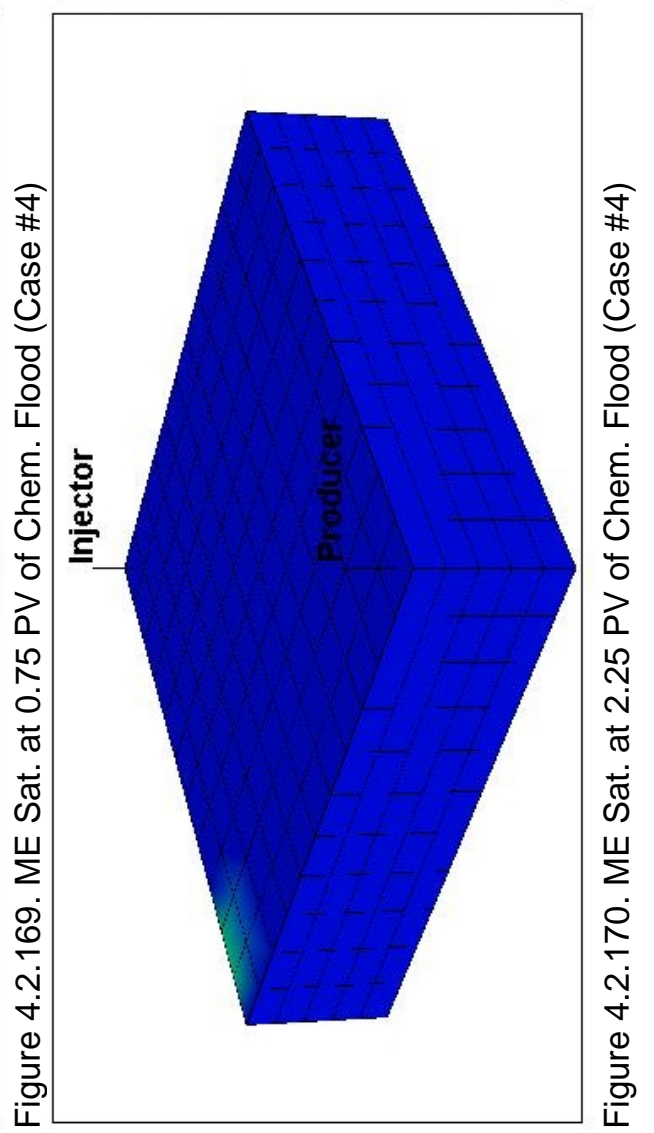




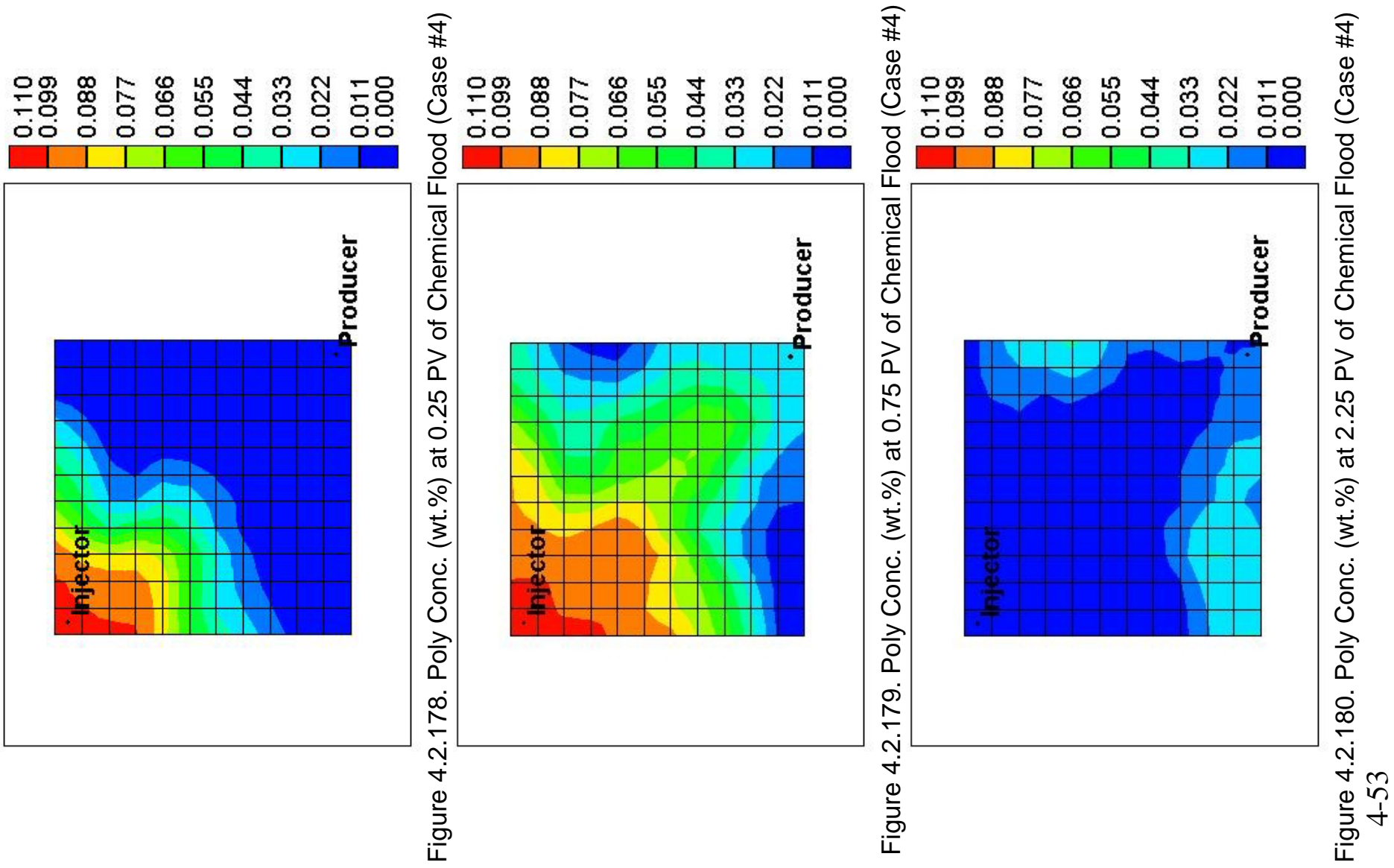

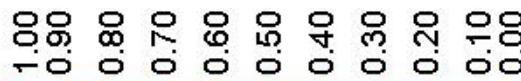

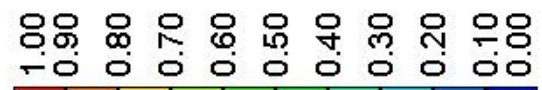

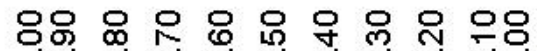
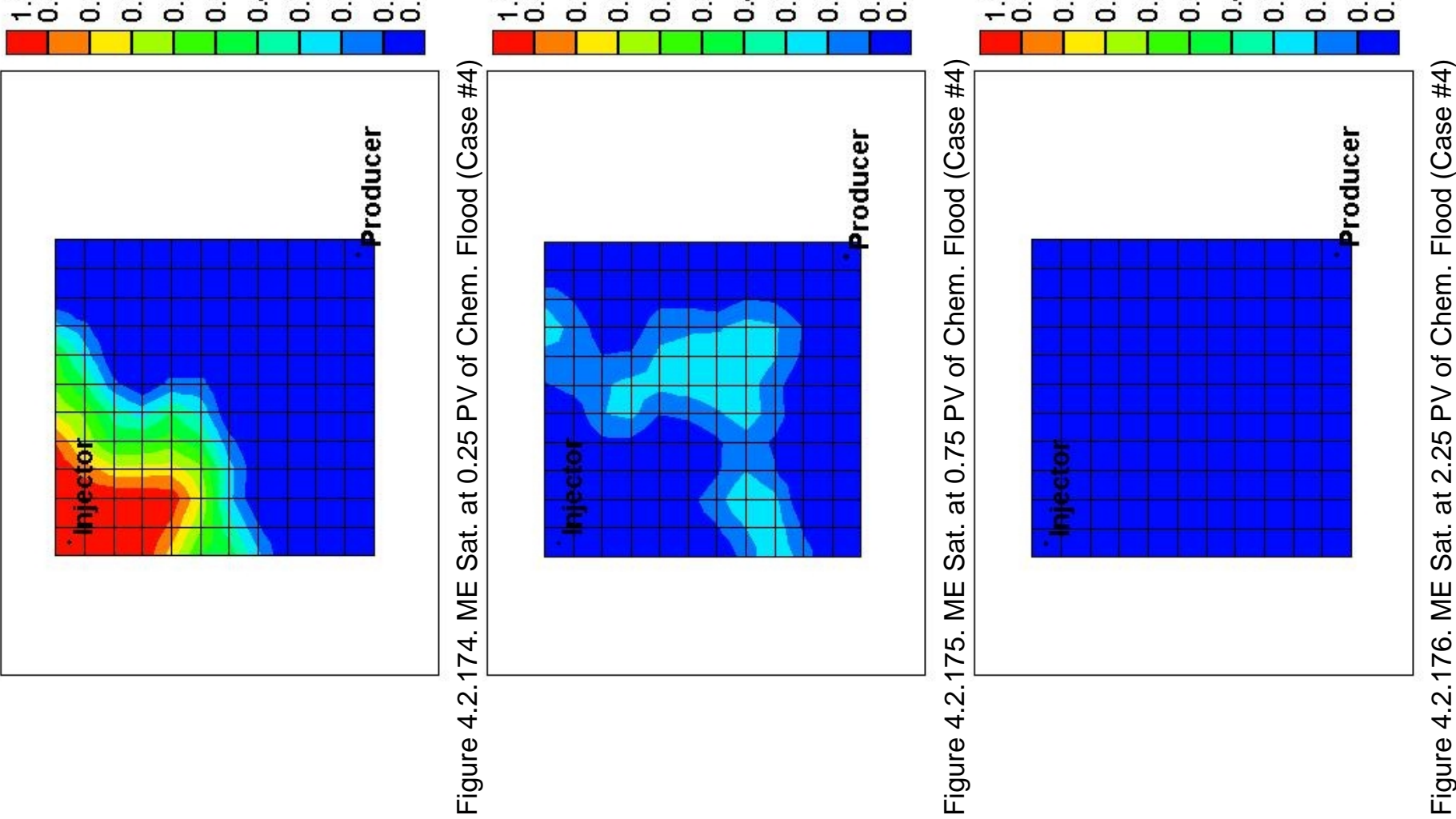

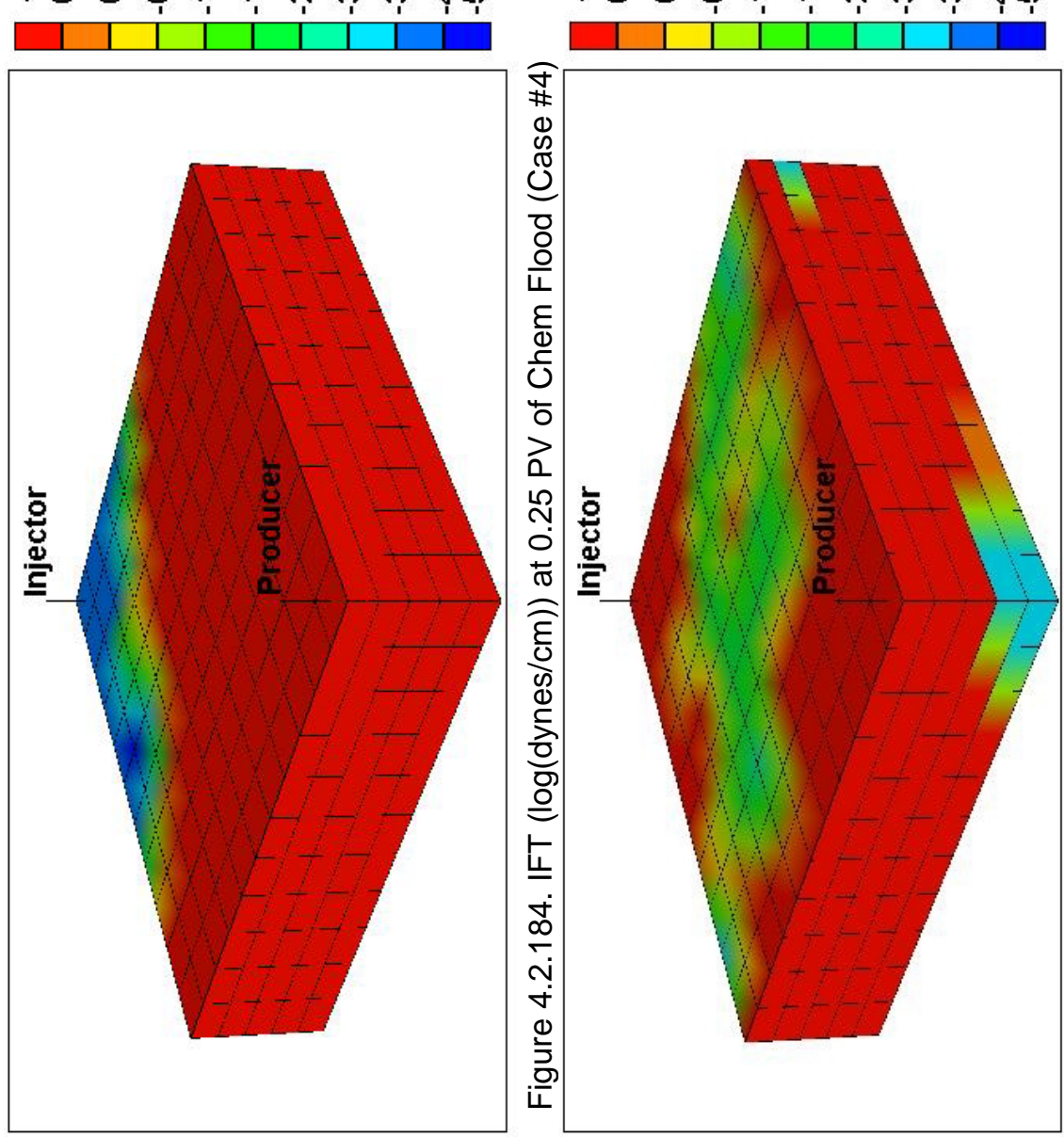

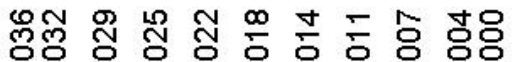
○ூ̊
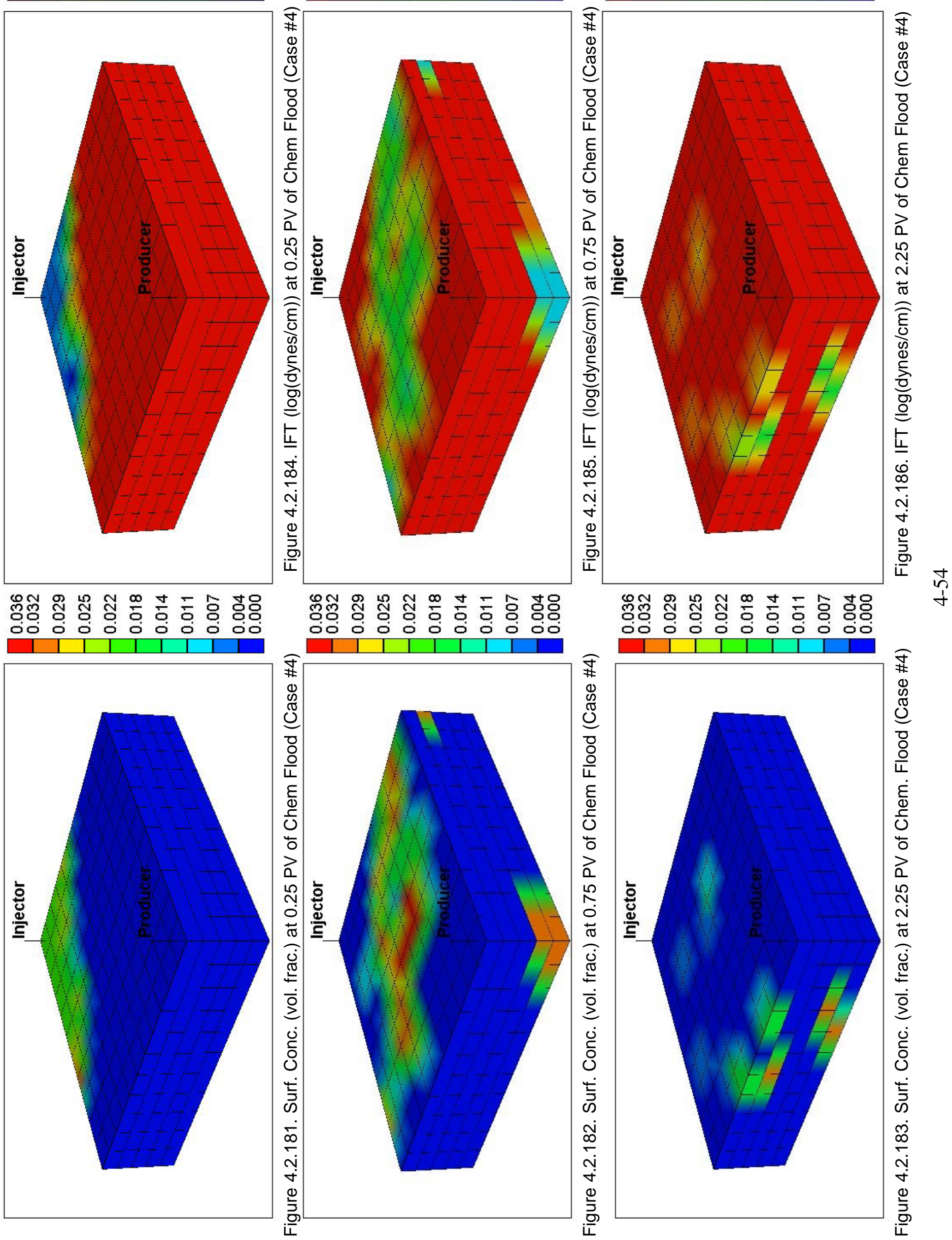

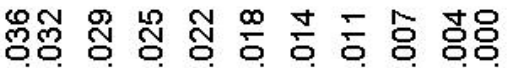

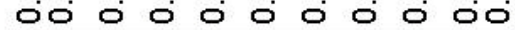

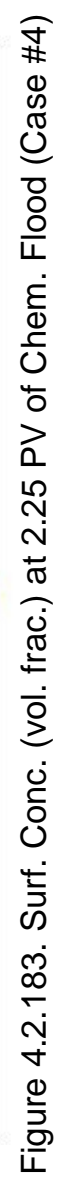




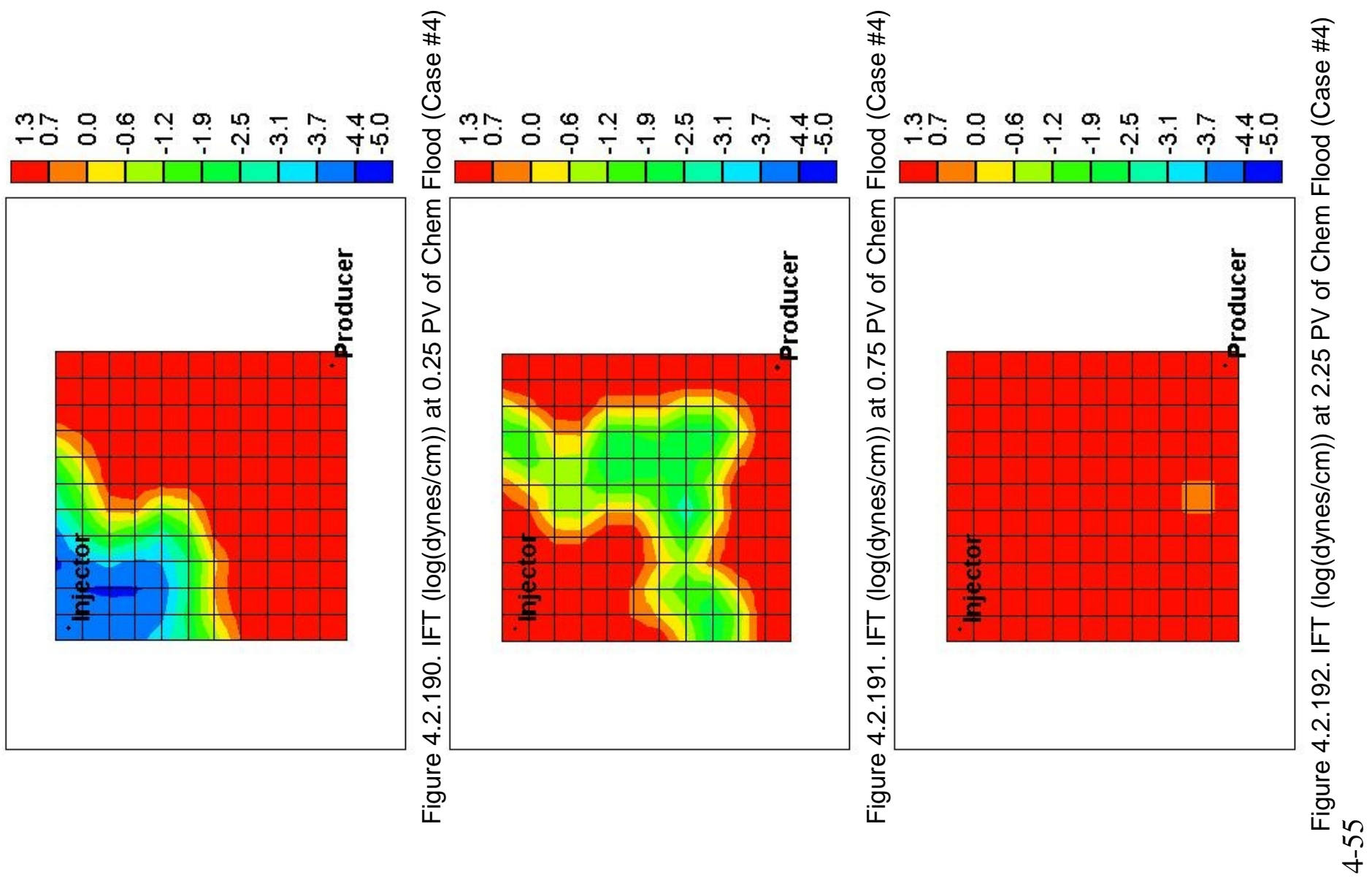

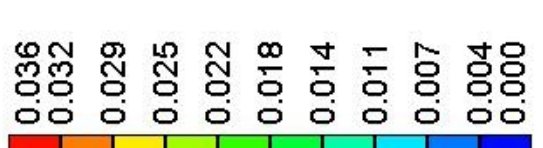
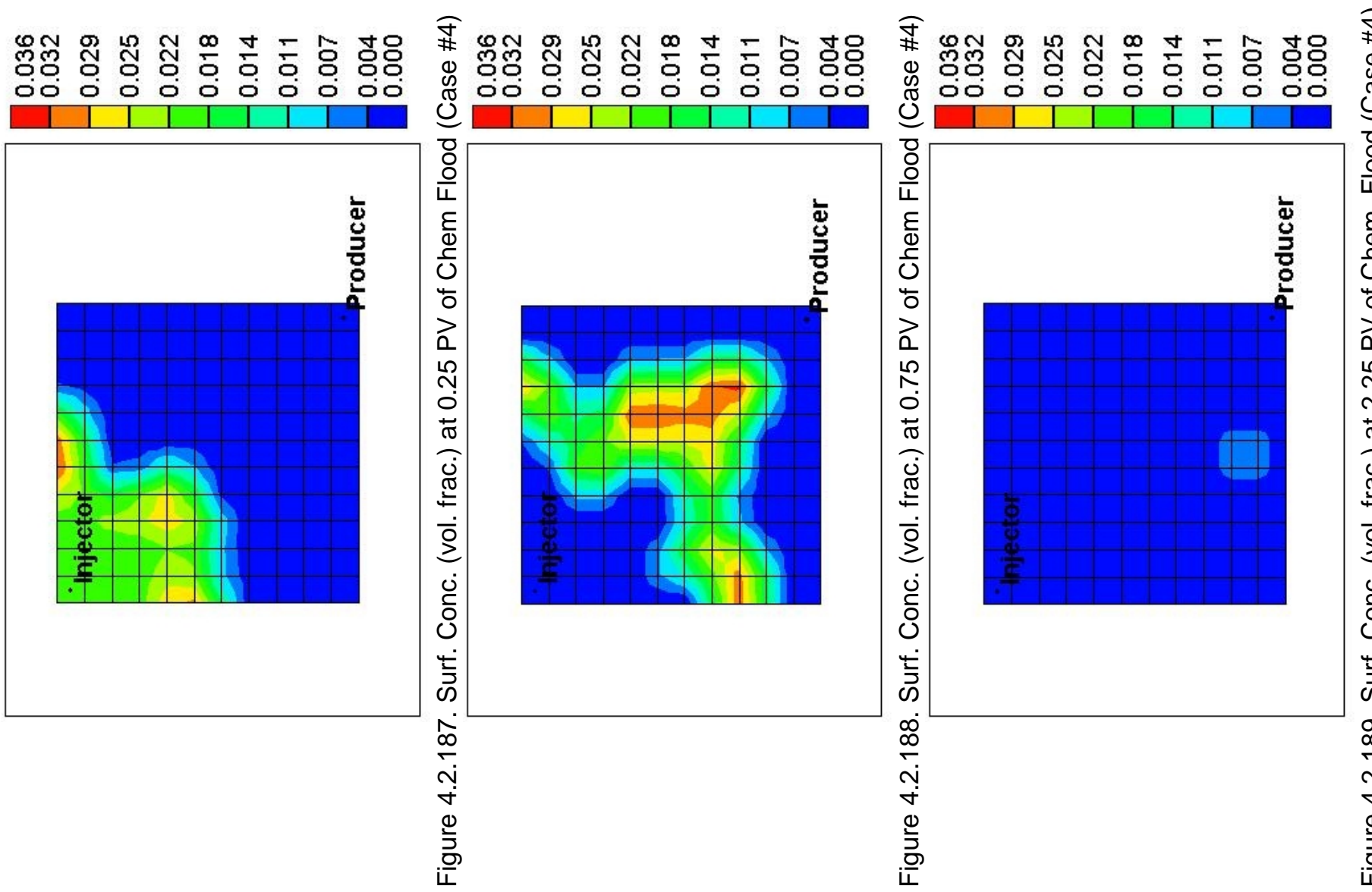

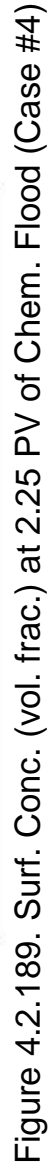




\section{References}

Abrams, A. 1975 "The Influence of Fluid Viscosity, Interfacial Tension, and Flow Velocity on Residual Oil Saturation Left by Waterflood". SPE 5050.

Amaefule, Jude O. and Handy, Lyman L. 1982. "The Effect of Interfacial Tensions on Relative OilWater Permeabilities of Consolidated Porous Media". SPE 9783.

Amott, E. 1959. "Observations Relating to the Wettability of Porous Rock". Trans. AIME 216.

Anderson, William G. 1986. "Wettability Literature Survey - Part 1: Rock/Oil/Brine Interactions and the Effects of Core Handling on Wettability". SPE 13932.

Bardon, Charles and Longeron, G.G. 1980. "Influence of Very Low Interfacial Tensions on Relative Permeability". SPE 7609.

Bhujan, Debojit 1986. "Effect of Wettability on Capillary Desaturation Curves". Masters Thesis.

Boom, W. et. al. 1995. "Experimental Evidence for Improved Condensate Mobility at Near-Wellbore Flow Conditions". SPE 30766.

Boom, W. et. al. 1996. "On the Use of Model Experiments for Assessing Improved Gas-Condensate Mobility Under Near-Wellbore Flow Conditions". SPE 36714.

Brownell, L. E and D. L. Katz. 1949. "Flow of Fluids Through Porous Media, Part II," Chemical Engineering Process, 43, 601-612.

Chatzis, loannis and Morrow, Norman R. 1984. "Correlation of Capillary Number Relationships for Sandstone". SPE 10114.

Chen, Jiansheng et. al.2004. "Study of Wettability Alteration From NMR: Effect of OBM on Wettability and NMR Responses". 8th International Symposium on Reservoir Wettability.

Delshad, M. 1990. "Trapping of Micellar Fluids in Berea Sandstone," PhD dissertation, The U. of Texas, Austin, Texas.

Gupta, Surendra P. and Trushenski, Scott P. 1979. "Micellar Flooding Compositional Effects on Oil Displacement". SPE 7063.

Henderson, G.D. et al. 1998 "Measurement and Correlation of Gas Condensate Relative Permeability by the Steady-State Method," SPERE April 1998.

Jadhunandan, P.P. and Morrow, N.R. 1991. "Effect of Wettability on Waterflood Recovery for Crude-Oil/Brine/Rock Systems". SPE 22597.

Jerauld, G.R. and Rathmell, J.J. 1997. "Wettability and Relative Permeability of Prudhoe Bay: A Case Study in Mixed-Wet Reservoirs". SPE 28576.

Kamath, Jairam and Meyer, Robert F. 2001. "Understanding Waterflood Residual Oil Saturation of Four Carbonate Rock Types". SPE 71505. 
Mohanty, Kishore K. and Salter, Stephen J. 1983. "Multiphase Flow in Porous Media: III. Oil Mobilization, Transverse Dispersion, and Wettability". SPE 12127.

Morrow, N.R. et. al. 1973. "Displacement Studies in Dolomite with Wettability Control by Octanoic Acid". SPE 3993.

Owolabi, O.O. and Watson, R.W. 1993. "Effects of Rock-Pore Characteristics on Oil Recovery at Breakthrough and Ultimate Oil Recovery in Water-Wet Sandstones". SPE 26935.

Stegemeier, George L. 1974. "Relationship of Trapped Oil Saturation to Petrophysical Properties of Porous Media" American Institute of Mining, Metallurgical, and Petroleum Engineers, Inc. SPE 4754. 